\title{
Classificação automática de textos por meio de aprendizado de máquina baseado em redes
}





\title{
Rafael Geraldeli Rossi
}

\section{Classificação automática de textos por meio de aprendizado de máquina baseado em redes}

\begin{abstract}
Tese apresentada ao Instituto de Ciências Matemáticas e de Computação - ICMC-USP, como parte dos requisitos para obtenção do título de Doutor em Ciências - Ciências de Computação e Matemática Computacional. VERSÃO REVISADA

Área de Concentração: Ciências de Computação e Matemática Computacional

Orientadora: Profa. Dra. Solange Oliveira Rezende
\end{abstract}


Ficha catalográfica elaborada pela Biblioteca Prof. Achille Bassi e Seção Técnica de Informática, ICMC/USP, com os dados fornecidos pelo(a) autor(a)

$\mathrm{R} 831 \mathrm{C}$

Rossi, Rafael Geraldeli

Classificação automática de textos por meio de aprendizado de máquina baseado em redes / Rafael Geraldeli Rossi; orientador Solange Oliveira Rezende. -- São Carlos, 2015. $285 \mathrm{p}$.

Tese (Doutorado - Programa de Pós-Graduação em Ciências de Computação e Matemática Computacional) Instituto de Ciências Matemáticas e de Computação, Universidade de São Paulo, 2015.

1. Classificação de Textos. 2. Aprendizado de Máquina. 3. Redes Heterogêneas. 4. Propagação de Rótulos. I. Rezende, Solange Oliveira, orient. II. Título. 


\section{Rafael Geraldeli Rossi}

\section{Text automatic classification through machine learning based on networks}

Doctoral dissertation submitted to the Instituto de Ciências Matemáticas e de Computação - ICMCUSP, in partial fulfillment of the requirements for the degree of the Doctorate Program in Computer Science and Computational Mathematics. FINAL VERSION

Concentration Area: Computer Science and Computational Mathematics

Advisor: Profa. Dra. Solange Oliveira Rezende 



\section{Agradecimentos}

aos meus pais Nestor e Maria Teresa pela educação que me deram e por terem me apoiado em todas as etapas da minha vida;

à minha namorada Aldrea pela enorme, gigantesca, colossal, etc., paciência e compreensão com minhas ausências nos últimos anos por conta do desenvolvimento deste projeto. Obrigado por compreender e me apoiar enquanto me esforcei ao máximo para atingir meus objetivos;

à minha orientadora Prof $^{\mathrm{a}}$. Dr ${ }^{\mathrm{a}}$. Solange Oliveira Rezende por me orientar e suportar desde o $3^{\circ}$ semestre do Bacharelado em Informática até os dias atuais. Toda minha formação acadêmica e base para me tornar um futuro professor e pesquisador foram norteados pelos ensinamentos dela. Tenho que agradecer também ao Anandsing

Dwarkasing pelas várias correções de inglês e, consequentemente, pela melhora na interpretação dos artigos;

ao meu coorientador Prof. Dr. Alneu de Andrade Lopes, que apesar de não poder ter sido oficializado como coorientador, me ajudou muito desde o início com frases do tipo "tem que mostrar a diferença na matemática" ou "tem que provar matematicamente que funciona", as quais nortearam o desenvolvimento deste trabalho. Além disso, suas contribuições na escrita dos artigos ajudaram muito a melhorar as descrições das nossas propostas;

aos companheiros que passaram nesses últimos 9 anos pelo Laboratório de Inteligência

Computacional (LABIC) pela esplendorosa e incomparável convivência. Não tenho palavras para descrever o quão bom foi passar todo esse tempo com vocês. Em especial aos amigos do Grupo de Mineração de Textos, Merley, Bruno, Fernanda, e aos atuais orientados da Prof ${ }^{\text {a }}$ Solange, Renan, Roberta, Camila e Ivone. Um agradecimento especial também ao amigo e companheiro desde a graduação Ricardo Marcacini, com o qual até hoje tenho discussões "científicas" acaloradas;

à todos os amigos e amigas que estiveram ao meu lado, e pessoas especiais que passaram pela minha vida. É graças a eles também que me tornei a pessoa que sou hoje;

à todos do ICMC-USP que contribuíram direta ou indiretamente para a conclusão do doutorado;

à FAPESP (Processo no 2011/12823-6) pelo apoio financeiro, que me possibilitou não só a dedicação exclusiva ao desenvolvimento deste projeto de doutorado como também atravessar o mundo para participar de conferências científicas. 



\section{Resumo}

Nos dias atuais há uma quantidade massiva de dados textuais sendo produzida e armazenada diariamente na forma de e-mails, relatórios, artigos e postagens em redes sociais ou blogs. Processar, organizar ou gerenciar essa grande quantidade de dados textuais manualmente exige um grande esforço humano, sendo muitas vezes impossível de ser realizado. Além disso, há conhecimento embutido nos dados textuais, e analisar e extrair conhecimento de forma manual também torna-se inviável devido à grande quantidade de textos. Com isso, técnicas computacionais que requerem pouca intervenção humana e que permitem a organização, gerenciamento e extração de conhecimento de grandes quantidades de textos têm ganhado destaque nos últimos anos e vêm sendo aplicadas tanto na academia quanto em empresas e organizações. Dentre as técnicas, destaca-se a classificação automática de textos, cujo objetivo é atribuir rótulos (identificadores de categorias pré-definidos) à documentos textuais ou porções de texto. Uma forma viável de realizar a classificação automática de textos é por meio de algoritmos de aprendizado de máquina, que são capazes de "aprender", generalizar, ou ainda extrair padrões das classes das coleções com base no conteúdo e rótulos de documentos textuais. O aprendizado de máquina para a tarefa de classificação automática pode ser de 3 tipos: (i) indutivo supervisionado, que considera apenas documentos rotulados para induzir um modelo de classificação e classificar novos documentos; (ii) transdutivo semissupervisionado, que classifica documentos não rotulados de uma coleção com base em documentos rotulados; e (iii) indutivo semissupervisionado, que considera documentos rotulados e não rotulados para induzir um modelo de classificação e utiliza esse modelo para classificar novos documentos. Independente do tipo, é necessário que as coleções de documentos textuais estejam representadas em um formato estruturado para os algoritmos de aprendizado de máquina. Normalmente os documentos são representados em um modelo espaço-vetorial, no qual cada documento é representado por um vetor, e cada posição desse vetor corresponde a um termo ou atributo da coleção de documentos. Algoritmos baseados no modelo espaço-vetorial consideram que tanto os documentos quanto os termos ou atributos são independentes, o que pode degradar a qualidade da classificação. Uma alternativa à representação no modelo espaço-vetorial é a representação em redes, que permite modelar relações entre entidades de uma coleção de textos, como documento e termos. Esse tipo de representação permite extrair padrões das classes que dificilmente são extraídos por algoritmos baseados no modelo espaço-vetorial, permitindo assim aumentar a performance de classificação. Além disso, a representação em redes permite representar coleções de textos utilizando diferentes tipos de objetos bem como diferentes tipos de relações, o que permite capturar diferentes características das coleções. Entretanto, observa-se na literatura alguns desafios para que se possam combinar algoritmos de aprendizado de máquina e representações de coleções de textos em redes para realizar efetivamente a classificação automática de textos. Os principais desafios abordados neste projeto de doutorado são (i) o desenvolvimento de representações em redes que possam ser geradas 
eficientemente e que também permitam realizar um aprendizado de maneira eficiente; (ii) redes que considerem diferentes tipos de objetos e relações; (iii) representações em redes de coleções de textos de diferentes línguas e domínios; e (iv) algoritmos de aprendizado de máquina eficientes e que façam um melhor uso das representações em redes para aumentar a qualidade da classificação automática. Neste projeto de doutorado foram propostos e desenvolvidos métodos para gerar redes que representem coleções de textos, independente de domínio e idioma, considerando diferentes tipos de objetos e relações entre esses objetos. Também foram propostos e desenvolvidos algoritmos de aprendizado de máquina indutivo supervisionado, indutivo semissupervisionado e transdutivo semissupervisionado, uma vez que não foram encontrados na literatura algoritmos para lidar com determinados tipos de relações, além de sanar a deficiência dos algoritmos existentes em relação à performance e/ou tempo de classificação. É apresentado nesta tese (i) uma extensa avaliação empírica demonstrando o benefício do uso das representações em redes para a classificação de textos em relação ao modelo espaço-vetorial, (ii) o impacto da combinação de diferentes tipos de relações em uma única rede e (iii) que os algoritmos propostos baseados em redes são capazes de superar a performance de classificação de algoritmos tradicionais e estado da arte tanto considerando algoritmos de aprendizado supervisionado quanto semissupervisionado. As soluções propostas nesta tese demonstraram ser úteis e aconselháveis para serem utilizadas em diversas aplicações que envolvam classificação de textos de diferentes domínios, diferentes características ou para diferentes quantidades de documentos rotulados.

Palavras-chave: Classificação de Textos, Aprendizado de Máquina, Redes Heterogêneas, Propagação de Rótulos. 


\section{Abstract}

A massive amount of textual data, such as e-mails, reports, articles and posts in social networks or blogs, has been generated and stored on a daily basis. The manual processing, organization and management of this huge amount of texts require a considerable human effort and sometimes these tasks are impossible to carry out in practice. Besides, the manual extraction of knowledge embedded in textual data is also unfeasible due to the large amount of texts. Thus, computational techniques which require little human intervention and allow the organization, management and knowledge extraction from large amounts of texts have gained attention in the last years and have been applied in academia, companies and organizations. The tasks mentioned above can be carried out through text automatic classification, in which labels (identifiers of predefined categories) are assigned to texts or portions of texts. A viable way to perform text automatic classification is through machine learning algorithms, which are able to "learn", generalize or extract patterns from classes of text collections based on the content and labels of the texts. There are three types of machine learning algorithms for automatic classification: (i) inductive supervised, in which only labeled documents are considered to induce a classification model and this model are used to classify new documents; (ii) transductive semi-supervised, in which all known unlabeled documents are classified based on some labeled documents; and (iii) inductive semi-supervised, in which labeled and unlabeled documents are considered to induce a classification model in order to classify new documents. Regardless of the learning algorithm type, the texts of a collection must be represented in a structured format to be interpreted by the algorithms. Usually, the texts are represented in a vector space model, in which each text is represented by a vector and each dimension of the vector corresponds to a term or feature of the text collection. Algorithms based on vector space model consider that texts, terms or features are independent and this assumption can degrade the classification performance. Networks can be used as an alternative to vector space model representations. Networks allow the representations of relations among the entities of a text collection, such as documents and terms. This type of representation allows the extraction patterns which are not extracted by algorithms based on vector-space model. Moreover, text collections can be represented by networks composed of different types of entities and relations, which provide the extraction of different patterns from the texts. However, there are some challenges to be solved in order to allow the combination of machine learning algorithms and network-based representations to perform text automatic classification in an efficient way. The main challenges addressed in this doctoral project are (i) the development of network-based representations efficiently generated which also allows an efficient learning; (ii) the development of networks which represent different types of entities and relations; (iii) the development of networks which can represent texts written in different languages and about different domains; and (iv) the development of efficient learning algorithms which make a better use of the network-based representations and increase the classification performance. In this doctoral project we proposed and developed 
methods to represent text collections into networks considering different types of entities and relations and also allowing the representation of texts written in any language or from any domain. We also proposed and developed supervised inductive, semi-supervised transductive and semi-supervised inductive learning algorithms to interpret and learn from the proposed network-based representations since there were no algorithms to handle certain types of relations considered in this thesis. Besides, the proposed algorithms also attempt to obtain a higher classification performance and a faster classification than the existing network-based algorithms. In this doctoral thesis we present (i) an extensive empirical evaluation demonstrating the benefits about the use of network-based representations for text classification, (ii) the impact of the combination of different types of relations in a single network and (iii) that the proposed network-based algorithms are able to surpass the classification performance of traditional and state-of-the-art algorithms considering both supervised and semi-supervised learning. The solutions proposed in this doctoral project have proved to be advisable to be used in many applications involving classification of texts from different domains, areas, characteristics or considering different numbers of labeled documents.

Keywords: Text Classification, Machine Learning, Heterogeneous Networks, Label Propagation. 


\section{Sumário}

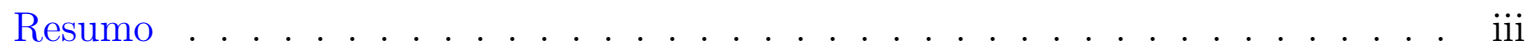

Abstract . . . . . . . . . . . . . . . . . . .

Sumário . . . . . . . . . . . . . . . . . . vii

Lista de Figuras . . . . . . . . . . . . . . . . . . . . . . . . xi

Lista de Tabelas . . . . . . . . . . . . . . . . . . . . . . xvii

Lista de Algoritmos . . . . . . . . . . . . . . . . . . . . . . xix

Lista de Abreviaturas . . . . . . . . . . . . . . . . . . xxi

1 Introdução 1

1.1 Contextualização . . . . . . . . . . . . . . . . . . . . 1

1.2 Desafios . . . . . . . . . . . . . . . . . . . 5

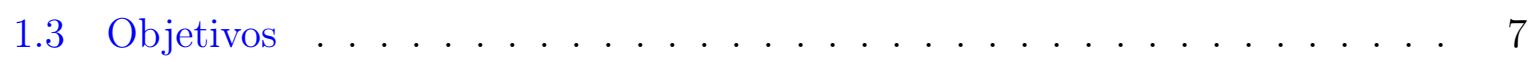

1.4 Principais Resultados . . . . . . . . . . . . . . . . . . 8

1.5 Organização do Texto . . . . . . . . . . . . . . . . . . 12

2 Representações de Textos e Estruturas Computacionais para Classificação de Textos $\quad 15$

2.1 Considerações Inicias . . . . . . . . . . . . . . . . . . . . . . . . . . . . . . . . . . . . . . . 15

2.2 Modelo Espaço-Vetorial . . . . . . . . . . . . . . . . . . . 17

2.2.1 Geração de Termos e Atributos . . . . . . . . . . . . . . . . . . 19

2.2.2 Definição dos Pesos dos Termos e Atributos . . . . . . . . . . . . . 22

2.2 .3 Seleção de Termos . . . . . . . . . . . . . . . . . . . . . . . . . . . . 22

2.2.4 Redução de Dimensionalidade . . . . . . . . . . . . . . . . . 26

2.3 Redes . . . . . . . . . . . . . . . . . . . . . . 29

2.3.1 Representações de Textos em Redes . . . . . . . . . . . . . . . 38

2.3.2 Representações Existentes Baseadas em Redes para Classificação de Textos .......................... 41

2.3.3 Representações em Redes Propostas e Utilizadas para Classificação de Textos . . . . . . . . . . . . . . . . . . 51

2.4 Estruturas Computacionais para a Classificação de Textos . . . . . . . . . 62

2.5 Considerações Finais . . . . . . . . . . . . . . . . . . 65

3 Classificação de Textos por Meio de Aprendizado Indutivo Supervisionado

3.1 Considerações Iniciais . . . . . . . . . . . . . . . . . . . . . 67

3.2 Trabalhos Relacionados . . . . . . . . . . . . . . . . . . 71

3.2.1 Aprendizado Indutivo Supervisionado Considerando Textos Representados no Modelo Espaço-Vetorial . . . . . . . . . . . . . . 71 
3.2.2 Aprendizado Indutivo Supervisionado Considerando Textos Representados em Redes . . . . . . . . . . . . . . . 87

3.3 Proposta para a Classificação de Textos por Meio de Aprendizado Indutivo Supervisionado Baseado em Redes . . . . . . . . . . . . . . . . . . . . . 92

3.3.1 Inductive Model using Heterogeneous Networks . . . . . . . . . . . . 94

3.3.2 Exemplo de Funcionamento do Algoritmo IMHN . . . . . . . . . . 98

3.3.3 Análise de Complexidade do Algoritmo IMHN . . . . . . . . . . . . 99

3.3.4 Extensão do Algoritmo IMHN para Outros Objetos e Domínios . . 99

3.4 Avaliação Experimental . . . . . . . . . . . . . . . . . . . . . 100

3.4.1 Configuração Experimental . . . . . . . . . . . . . . . . 100

3.4 .2 Resultados . . . . . . . . . . . . . . . . 103

3.5 Considerações Finais . . . . . . . . . . . . . . . . . . . . . . . . . . 114

4 Classificação de Textos por Meio de Aprendizado Transdutivo 115

4.1 Considerações Iniciais . . . . . . . . . . . . . . . . . . . . 115

4.2 Trabalhos Relacionados . . . . . . . . . . . . . . . . . 118

4.2.1 Aprendizado Transdutivo no Modelo Espaço-Vetorial . . . . . . . . 118

4.2 .2 Aprendizado Transdutivo em Redes . . . . . . . . . . . . . . . . 125

4.3 Propostas para a Classificação de Textos por Meio de Aprendizado Transdutivo Baseado em Redes . . . . . . . . . . . . . . . . . . . . . . 141

4.3.1 Transductive Classification through Term Networks . . . . . . . . . 142

4.3.2 Label Propagation through Heterogeneous Networks . . . . . . . . . 144

4.3.3 Transductive Categorization based on Heterogeneous Networks . . . 148

4.4 Avaliação Experimental . . . . . . . . . . . . . . . . . . 157

4.4.1 Configuração Experimental . . . . . . . . . . . . . . . . . . . 158

4.4 .2 Resultados . . . . . . . . . . . . . . . . . . 162

4.5 Considerações Finais . . . . . . . . . . . . . . . . . . . . . . . . . . . 191

5 Classificação de Textos por Meio de Aprendizado Indutivo Semissuper$\begin{array}{lr}\text { visionado } & 195\end{array}$

5.1 Considerações Iniciais . . . . . . . . . . . . . . . . . . . . . . . 195

5.2 Trabalhos Relacionados . . . . . . . . . . . . . . . . . . 197

5.2.1 Aprendizado Indutivo Semissupervisionado no Modelo Espaço-Vetorial197

5.2.2 Aprendizado Indutivo Semissupervisionado em Redes . . . . . . . . 198

5.3 Proposta para Classificação Classificação de Textos por Meio de Aprendizado

Indutivo Semissupervisionado Baseado em Redes . . . . . . . . . . . . 199

5.4 Avaliação Experimental . . . . . . . . . . . . . . . . . . . . 200

5.4 .1 Configuração Experimental . . . . . . . . . . . . . . . 200

5.4 .2 Resultados . . . . . . . . . . . . . . . . . . . 202

5.5 Considerações Finais . . . . . . . . . . . . . . . . . . 223

6 Conclusões $\quad 225$

6.1 Contribuições e Inovações Científicas . . . . . . . . . . . . . . . . . . . . . . . . . . . . . . . . . . . . . . . . . . . . .

6.2 Publicações . . . . . . . . . . . . . . . . . . . . . . . . . . 228

6.3 Limitações e Trabalhos Futuros . . . . . . . . . . . . . . . . . . . 230

$\begin{array}{ll}\text { Referências Bibliográficas } & 263\end{array}$ 
A Coleções de Textos e Características das Representações Utilizadas nas Avaliações Experimentais

A.1 Descrição das coleções de texto . . . . . . . . . . . . . . . . . . . . 265

A.2 Geração e Características das Representações no Modelo Espaço-Vetorial . 268

A.3 Geração e Características das Representações em Redes . . . . . . . . . . . 271

B Critérios de Avaliação de Performance de Classificação 283 



\section{Lista de Figuras}

2.1 Exemplos de redes: (a) homogênea e (b) heterogênea. . . . . . . . . . . . . 33

2.2 Exemplos de rede representadas em múltiplas camadas: (a) cada camada representa diferentes relações entre os mesmos objetos e (b) cada camada representa um tipo de objeto, podendo haver relações entre os mesmos tipos de objetos e relações entre objetos de tipos diferentes. . . . . . . . . . . . 34

2.3 Ilustrações de redes heterogêneas: (a) rede heterogênea bipartida; (b) rede heterogênea $k$-partida com $k=3$; (c) rede heterogênea estrela. . . . . . . . 35

2.4 Matriz de adjacências para redes heterogêneas. . . . . . . . . . . . . . . . 37

2.5 Lista de adjacências para redes homogêneas. . . . . . . . . . . . . . . . 38

2.6 Ilustração de uma rede de documentos baseada em similaridade. . . . . . . . 41

2.7 Ilustração de uma rede de termos extraída de uma página HTML (Schenker et al., 2003): (a) código fonte de uma página HTML e (b) rede extraída considerando o código fonte da Figura 2.7(a) . . . . . . . . . . . . . . 45

2.8 Exemplo de extração de uma rede semântica de um texto do domínio biomédico (figura adaptada de Mishra et al. (2012)): (a) texto biomédico com entidades nomeadas em negrito e (b) rede semântica considerando as entidades nomeadas extraídas do texto da Figura 2.8(a). . . . . . . . . . . 46

2.9 Exemplo de uma rede proposta em Jiang et al. (2010) para a sentença "A raposa marrom pulou o muro". . . . . . . . . . . . . . . . . . . . . . . 47

2.10 Exemplo de uma rede de distância proposta em Aggarwal e Zhao (2013): (a) texto de exemplo para geração de uma rede de distância; (b) rede de distância com $k=1$, rede de distância com $k=2$.

2.11 Ilustração de uma rede estrela extraída de uma página web (Aery e Chakravarthy, 2005): (a) código fonte de uma página HTML (b) rede estrela extraída considerando o código fonte da Figura 2.11(a) . . . . . . . . . . . . 50

2.12 Ilustração de uma rede semibipartida proposta em Aggarwal e Li (2011). 50

2.13 Ilustração de uma rede de informações bibliográficas. . . . . . . . . . . . . 51

2.14 Ilustração de uma rede de termos baseada similaridade. . . . . . . . . . . . 54

2.15 Ilustração de uma rede bipartida para representar coleções de textos. . . . 59

2.16 Ilustração de uma rede Doc-Doc-Doc-Termo. . . . . . . . . . . . . . . . . 60

2.17 Ilustração de uma rede Doc-Termo-Termo-Termo. . . . . . . . . . . . . . . 60

2.18 Ilustração de uma rede Doc-Doc-Doc-Termo-Termo-Termo. . . . . . . . . . . 61

2.19 Ilustração das estruturas computacionais para classificação em: (a) rede homogênea e (b) rede bipartida. . . . . . . . . . . . . . . . 64

3.1 Esquema ilustrativo da classificação automática de textos por meio de aprendizado indutivo supervisionado. . . . . . . . . . . . . . 
3.2 Ilustração de uma árvore de decisão. . . . . . . . . . . . . . . . . . . . . . 83

3.3 Exemplo de funcionamento do algoritmo IMBHN . . . . . . . . . . . . . . . 98

3.4 Diagrama de diferença crítica para a medida $F 1^{\text {Micro }} \ldots$. . . . . . . . . . 106

3.5 Diagrama de diferença crítica para a medida $F 1^{\text {Micro }}$ consideando apenas os algoritmos $I M H N^{C}(D T), I M H N^{C}(D T-T T), I M H N^{R}(D T)$ e $I M H N^{R}(D T-T T) .106$

3.6 Diagrama de diferença crítica para a medida $F 1^{\text {Macro }} \ldots$. . . . . . . . . 109

3.7 Diagrama de diferença crítica para a medida $F 1^{\text {Micro }}$ considerando representações documento-tópico para os algoritmos baseados no modelo espaço-vetorial. . . . . . . . . . . . . . . . . . . . 111

3.8 Diagrama de diferença crítica para a medida $F 1^{\text {Macro }}$ considerando representações documento-tópico para os algoritmos baseados no modelo espaço-vetorial.

4.1 Exemplo de uso de documentos não rotulados para auxiliar a classificação de textos. . . . . . . . . . . . . . . . . . 116

4.2 Esquema ilustrativo da classificação automática de textos por meio de aprendizado transdutivo. . . . . . . . . . . . . . . 116

4.3 Difereça entre SVM e TSVM (figura adaptada de Zhu e Goldberg (2009)). 124

4.4 Ilustração da classificação coletiva. . . . . . . . . . . . . . . . . . . 128

4.5 Ilustração da classificação transdutiva via propagação de rótulos. . . . . . . 135

4.6 Funcionamento do algoritmo TCBHN no exemplo ilustrativo. . . . . . . . 156

4.7 Valores $F 1^{\text {Micro }}$ do $1^{\mathrm{o}}$ grupo de experimentos (parte I) . . . . . . . . . . . . 164

4.8 Valores $F 1^{\text {Micro }}$ do $1^{\mathrm{o}}$ grupo de experimentos (parte II) . . . . . . . . . . . 165

4.9 Valores $F 1^{\text {Macro }}$ do $1^{\mathrm{o}}$ grupo de experimentos (parte I) . . . . . . . . . . 166

4.10 Valores $F 1^{\text {Macro }}$ do $1^{\circ}$ grupo de experimentos (parte II). . . . . . . . . . . 167

4.11 Diagramas de diferença crítica para o primeiro grupo de experimentos considerando a medida $F 1^{\text {Micro }}$. . . . . . . . . . . . . . . . . . . . . 168

4.12 Diagramas de diferença crítica para o primeiro grupo de experimentos considerando a medida $F 1^{\text {Macro }} \ldots \ldots \ldots$. . . . . . . . . . . 168

4.13 Valores $F 1^{\text {Micro }}$ do $2^{\circ}$ grupo de experimentos (parte I) . . . . . . . . . . . 169

4.14 Valores $F 1^{\text {Micro }}$ do $2^{\circ}$ grupo de experimentos (parte II) . . . . . . . . . . . 170

4.15 Valores $F 1^{\text {Macro }}$ para $2^{\circ}$ grupo de experimentos (parte I) . . . . . . . . . . 171

4.16 Valores $F 1^{\text {Macro }}$ para o $2^{\circ}$ grupo de experimentos (parte II). . . . . . . . . 172

4.17 Diagramas de diferença crítica para o segundo grupo de experimentos considerando a medida $F 1^{\text {Micro }} . \ldots \ldots$. . . . . . . . . . . . . 173

4.18 Diagramas de diferença crítica para o segundo grupo de experimentos considerando a medida $F 1^{\text {Macro }} \ldots$. . . . . . . . . . . . . . . . . . . . 174

4.19 Valores $F 1^{\text {Micro }}$ do $3^{\circ}$ grupo de experimentos (parte I) . . . . . . . . . . 175

4.20 Valores $F 1^{\text {Micro }}$ do $3^{\circ}$ grupo de experimentos (parte II) . . . . . . . . . . . 176

4.21 Valores $F 1^{\text {Macro }}$ do $3^{\circ}$ grupo de experimentos (parte I) . . . . . . . . . . 177

4.22 Valores $F 1^{\text {Macro }}$ do $3^{\text {o }}$ grupo de experimentos (parte II) . . . . . . . . . . 178

4.23 Diagramas de diferença crítica para o terceiro grupo de experimentos considerando a medida $F 1^{\text {Micro }} \ldots \ldots$. . . . . . . . . . . . . . . . . . . . . 179

4.24 Diagramas de diferença crítica para o terceiro grupo de experimentos considerando a medida $F 1^{\text {Macro }} \ldots \ldots$. . . . . . . . . . . . . . . . . . . 179

4.25 Valores $F 1^{\text {Micro }}$ do $4^{\mathrm{o}}$ grupo de experimentos (parte I) . . . . . . . . . . 180

4.26 Valores $F 1^{\text {Micro }}$ do $4^{\mathrm{o}}$ grupo de experimentos (parte II) . . . . . . . . . . 181

4.27 Valores $F 1^{\text {Macro }}$ do $4^{\mathrm{o}}$ grupo de experimentos (parte I) . . . . . . . . . . . 182

4.28 Valores $F 1^{\text {Macro }}$ do $4^{\mathrm{o}}$ grupo de experimentos (parte II) . . . . . . . . . 183 
4.29 Diagramas de diferença crítica para o quarto grupo de experimentos considerando a medida $F 1^{\text {Micro }} \ldots$. . . . . . . . . . . . . . . . . . . . . . 184

4.30 Diagramas de diferença crítica para o quarto grupo de experimentos considerando a medida $F 1^{\text {Macro }} \ldots \ldots \ldots \ldots$. . . . . . . . . . . 184

4.31 Valores $F 1^{\text {Micro }}$ do $5^{\mathrm{o}}$ grupo de experimentos (parte I). . . . . . . . . . . 185

4.32 Valores $F 1^{\text {Micro }}$ do $5^{\circ}$ grupo de experimentos (parte II) . . . . . . . . . . 186

4.33 Valores $F 1^{\text {Macro }}$ do $5^{\circ}$ grupo de experimentos (parte I) . . . . . . . . . . 187

4.34 Valores $F 1^{\text {Macro }}$ do $5^{\circ}$ grupo de experimentos (parte II). . . . . . . . . . . 188

4.35 Diagramas de diferença crítica para o quinto grupo de experimentos considerando a medida $F 1^{\text {Micro }} \ldots \ldots \ldots$. . . . . . . . . . . . . . . . . . 189

4.36 Diagramas de diferença crítica para o quinto grupo de experimentos considerando a medida $F 1^{\text {Macro }} \ldots \ldots \ldots$. . . . . . . . . . . . . 190

5.1 Esquema ilustrativo da classificação automática de textos por meio de aprendizado indutivo semissupervisionado. . . . . . . . . . . . . . 196

5.2 Valores $F 1^{\text {Micro }}$ do $1^{\mathrm{o}}$ grupo de experimentos (parte I) . . . . . . . . . . . 203

5.3 Valores $F 1^{\text {Micro }}$ do $1^{\mathrm{o}}$ grupo de experimentos (parte II). . . . . . . . . . . 204

5.4 Valores $F 1^{\text {Macro }}$ do $1^{\circ}$ grupo de experimentos (parte I) . . . . . . . . . . 205

5.5 Valores $F 1^{\text {Macro }}$ do $1^{\mathrm{o}}$ grupo de experimentos (parte II). . . . . . . . . . 206

5.6 Diagramas de diferença crítica para o primeiro grupo de experimentos considerando a medida $F 1^{\text {Micro }}$. . . . . . . . . . . . . . . . 207

5.7 Diagramas de diferença crítica para o primeiro grupo de experimentos considerando a medida $F 1^{\text {Macro }} \ldots$. . . . . . . . . . . . . . . . 207

5.8 Valores $F 1^{\text {Micro }}$ do $2^{\mathrm{o}}$ grupo de experimentos (parte I). . . . . . . . . . 208

5.9 Valores $F 1^{\text {Micro }}$ do $2^{\mathrm{o}}$ grupo de experimentos (parte II) . . . . . . . . . . . 209

5.10 Valores $F 1^{\text {Macro }}$ do $2^{\circ}$ grupo de experimentos (parte I) . . . . . . . . . . . 210

5.11 Valores $F 1^{\text {Macro }}$ do $2^{\circ}$ grupo de experimentos (parte II). . . . . . . . . . . 211

5.12 Diagramas de diferença crítica para o segundo grupo de experimentos considerando a medida $F 1^{\text {Micro }}$. . . . . . . . . . . . . . . . . . . 212

5.13 Diagramas de diferença crítica para o segundo grupo de experimentos considerando a medida $F 1^{\text {Macro }} \ldots \ldots$. . . . . . . . . . . . . . . 213

5.14 Valores $F 1^{\text {Micro }}$ do $3^{\text {o }}$ grupo de experimentos (parte I). . . . . . . . . . . . 213

5.15 Valores $F 1^{\text {Micro }}$ do $3^{\circ}$ grupo de experimentos (parte II). . . . . . . . . . . . 214

5.16 Valores $F 1^{\text {Macro }}$ do $3^{\circ}$ grupo de experimentos (parte I) . . . . . . . . . . . 215

5.17 Valores $F 1^{\text {Macro }}$ do $3^{\circ}$ grupo de experimentos (parte II). . . . . . . . . . 216

5.18 Diagramas de diferença crítica para o terceiro grupo de experimentos consi-

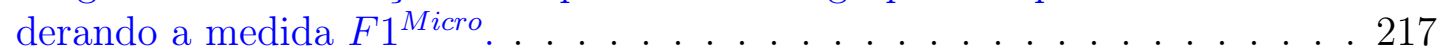

5.19 Diagramas de diferença crítica para o terceiro grupo de experimentos consi-

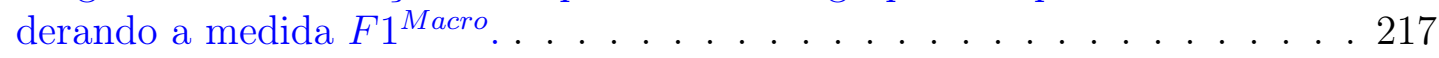

5.20 Valores $F 1^{\text {Micro }}$ do $4^{\mathrm{o}}$ grupo de experimentos (parte I). . . . . . . . . . . 218

5.21 Valores $F 1^{\text {Micro }}$ do $4^{\mathrm{o}}$ grupo de experimentos (parte II) . . . . . . . . . . . 219

5.22 Valores $F 1^{\text {Macro }}$ do $4^{\mathrm{o}}$ grupo de experimentos (parte I). . . . . . . . . . . 220

5.23 Valores $F 1^{\text {Macro }}$ do $4^{\mathrm{o}}$ grupo de experimentos (parte II). . . . . . . . . . . 221

5.24 Diagramas de diferença crítica para o quarto grupo de experimentos consi-

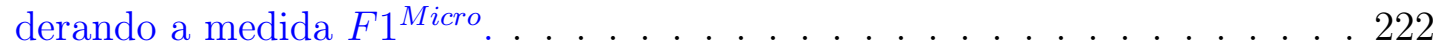

5.25 Diagramas de diferença crítica para o quarto grupo de experimentos considerando a medida $F 1^{\text {Macro }} \ldots \ldots \ldots$. . . . . . . . . . . . . . . 222 



\section{Lista de Tabelas}

2.1 Ilustração de uma matriz documento-termo representando uma coleção com $N$ documentos e $M$ termos. . . . . . . . . . . . . . . 18

2.2 Matriz de adjacências . . . . . . . . . . . . . . . . . 36

2.3 Matriz de contingência para os termos $t_{i}$ e $t_{j} \ldots \ldots \ldots \ldots$. . . . 55

2.4 Fórmulas das medidas de similaridade selecionadas (Geng e Hamilton, 2006; Blanchard et al., 2005; Tan et al., 2002b). . . . . . . . . . . . 58

2.5 Propriedades e intervalos de valores das medidas de similaridade selecionadas (Geng e Hamilton, 2006; Tan et al., 2002b). . . . . . . . . . . . . . . 58

2.6 Matriz de informações de classes dos objetos. . . . . . . . . . . . . . . . . 62

2.7 Matriz de informações de classes reais. . . . . . . . . . . . . . . . . 63

3.1 Valores da medida $F 1^{\text {Micro }}$ para classificação indutiva supervisionada. Foram consideradas representações bag-of-words para os algoritmos baseados no modelo espaço-vetorial. . . . . . . . . . . . . . . . . . . . . . . . . . 104

3.2 Número de vezes em que um algoritmo apresentado na linha superou o valor da medida $F 1^{\text {Micro }}$ de um algoritmo apresentado na coluna considerando os valores apresentados na Tabela 3.1. . . . . . . . . . . . . . . . . . 105

3.3 Valores da medida $F 1^{\text {Macro }}$ para classificação indutiva supervisionada. Foram consideradas representações bag-of-words para os algoritmos baseados no modelo espaço-vetorial. . . . . . . . . . . . . . . . . . . . . 107

3.4 Número de vezes em que um algoritmo apresentado na linha superou o valor da medida $F 1^{\text {Macro }}$ de um algoritmo apresentado na coluna considerando os valores apresentados na Tabela 3.3. . . . . . . . . . . . . . . . . . . . 108

3.5 Valores da medida $F 1^{\text {Micro }}$ para classificação indutiva supervisionada. Foram consideradas representações documento-tópico para os algoritmos baseados no modelo espaço-vetorial. . . . . . . . . . . . . . . . . . . . . 110

3.6 Número de vezes em que um algoritmo apresentado na linha superou o valor da medida $F 1^{\text {Micro }}$ de um algoritmo apresentado na coluna considerando os valores apresentados na Tabela 3.5 . . . . . . . . . . . . . . . . . . . 111

3.7 Valores da medida $F 1^{\text {Macro }}$ para classificação indutiva supervisionada. Foram consideradas representações documento-tópico para os algoritmos baseados no modelo espaço-vetorial.. . . . . . . . . . . . . . . . . . . . . . 112

3.8 Número de vezes em que um algoritmo apresentado na linha superou o valor da medida $F 1^{\text {Macro }}$ de um algoritmo apresentado na coluna considerando os valores apresentados na Tabela 3.7. . . . . . . . . . . . . . . . . 113 
4.1 Valores de informações de classe dos termos inferidas pelo algoritmo $I M H N^{\mathrm{R}}$, isto é, considerando apenas documentos rotulados, e inferidas pelo algoritmo TCHN, isto é, considerando documentos rotulados e não rotulados. . . . . . 158

4.2 Número de vitórias dos algoritmos indicados na linha em comparação com os algoritmos indicados na coluna para o primeiro grupo de experimentos considerando a medida $F 1^{\text {Micro }}$.

4.3 Número de vitórias dos algoritmos indicados na linha em comparação com os algoritmos indicados na coluna para o primeiro grupo de experimentos considerando a medida $F 1^{\text {Macro }}$.

4.4 Número de vitórias dos algoritmos indicados na linha em comparação com os algoritmos indicados na coluna para o segundo grupo de experimentos considerando a medida $F 1^{\text {Micro }}$.

4.5 Número de vitórias dos algoritmos indicados na linha em comparação com os algoritmos indicados na coluna para o segundo grupo de experimentos considerando a medida $F 1^{\text {Macro }}$.

4.6 Número de vitórias dos algoritmos indicados na linha em comparação com os algoritmos indicados na coluna para o terceiro grupo de experimentos considerando a medida $F 1^{\text {Micro }}$.

4.7 Número de vitórias dos algoritmos indicados na linha em comparação com os algoritmos indicados na coluna para o terceiro grupo de experimentos considerando a medida $F 1^{\text {Macro }}$.

4.8 Número de vitórias dos algoritmos indicados na linha em comparação com os algoritmos indicados na coluna para o quarto grupo de experimentos considerando a medida $F 1^{\text {Micro }}$.

4.9 Número de vitórias dos algoritmos indicados na linha em comparação com os algoritmos indicados na coluna para o quarto grupo de experimentos considerando a medida $F 1^{\text {Macro }}$.

4.10 Número de vitórias dos algoritmos indicados na linha em comparação com os algoritmos indicados na coluna para o quinto grupo de experimentos considerando a medida $F 1^{\text {Micro }}$.

4.11 Número de vitórias dos algoritmos indicados na linha em comparação com os algoritmos indicados na coluna para o quinto grupo de experimentos considerando a medida $F 1^{\text {Macro }}$.

5.1 Número de vitórias dos algoritmos indicados na linha em comparação com os algoritmos indicados na coluna para o primeiro grupo de experimentos considerando a medida $F 1^{\text {Micro }}$.

5.2 Número de vitórias dos algoritmos indicados na linha em comparação com os algoritmos indicados na coluna para o primeiro grupo de experimentos considerando a medida $F 1^{\text {Macro }}$.

5.3 Número de vitórias dos algoritmos indicados na linha em comparação com os algoritmos indicados na coluna para o segundo grupo de experimentos considerando a medida $F 1^{\text {Micro }}$. . . . . . . . . . . . . . . . . . . . . . . . 210

5.4 Número de vitórias dos algoritmos indicados na linha em comparação com os algoritmos indicados na coluna para o segundo grupo de experimentos considerando a medida $F 1^{\text {Macro }}$.

5.5 Número de vitórias dos algoritmos indicados na linha em comparação com os algoritmos indicados na coluna para o terceiro grupo de experimentos considerando a medida $F 1^{\text {Micro }}$. 
5.6 Número de vitórias dos algoritmos indicados na linha em comparação com os algoritmos indicados na coluna para o terceiro grupo de experimentos considerando a medida $F 1^{\text {Macro }} \ldots \ldots \ldots$. . . . . . . . . . . . . . 215

5.7 Número de vitórias dos algoritmos indicados na linha em comparação com os algoritmos indicados na coluna para o quarto grupo de experimentos considerando a medida $F 1^{\text {Micro }} \ldots \ldots \ldots \ldots \ldots$

5.8 Número de vitórias dos algoritmos indicados na linha em comparação com os algoritmos indicados na coluna para o quarto grupo de experimentos considerando a medida $F 1^{\text {Macro }} \ldots \ldots \ldots \ldots \ldots$. . . . . . . . . .

A.1 Características das representações bag-of-words das coleções utilizadas neste projeto de doutorado. . . . . . . . . . . . . . . . . . . . . . 274

A.2 Número de objetos do tipo documento e número médio de relações do tipo documento-documento para as abordagens $\operatorname{Exp}$ e $M k-N N$. . . . . . . . . 275

A.3 Número de objetos do tipo termo e número de objetos do tipo termo-termo para as abordagens Threshold e TopK utilizando a medida de similaridade Suporte.

A.4 Número de objetos do tipo termo e número de objetos do tipo termo-termo para as abordagens Threshold e TopK utilizando a medida de similaridade Informação Mútua. . . . . . . . . . . . . . . . . . . . . . . . 277

A.5 Número de objetos do tipo termo e número de objetos do tipo termo-termo para as abordagens Threshold e TopK utilizando a medida de similaridade Kappa. . . . . . . . . . . . . . . . . . . .

A.6 Número de objetos do tipo termo e número de objetos do tipo termo-termo para as abordagens Threshold e TopK utilizando a medida de similaridade Q de Yule. . . . . . . . . . . . . . . . . . . . . . 279

A.7 Número de objetos do tipo termo e número de objetos do tipo termo-termo para as abordagens Threshold e TopK utilizando a medida de similaridade Piatetsky-Shapiro. . . . . . . . . . . . . . . . . . . . . . 280

A.8 Número de objetos do tipo documento, número de objetos do tipo termo e número médio de relações do tipo documento-termo. . . . . . . . . . . . . 281 



\section{Lista de Algoritmos}

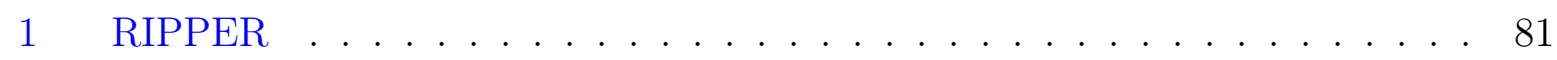

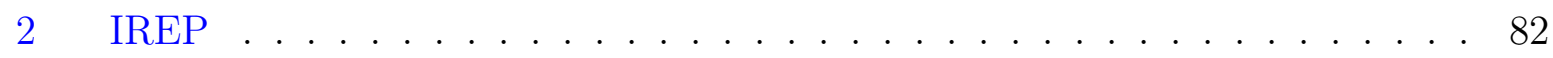

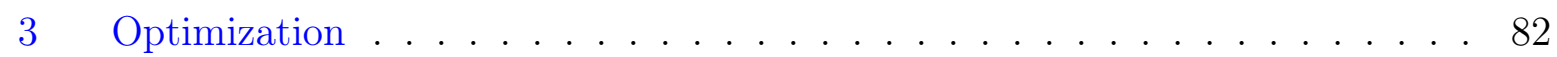

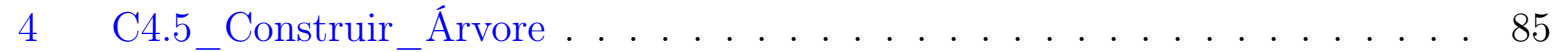

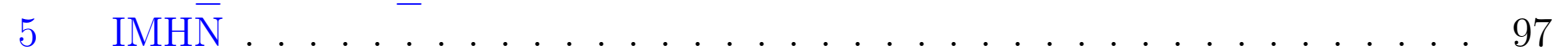

6 Self-Training . . . . . . . . . . . . . . . . . . 119

$7 \quad$ Co-Training . . . . . . . . . . . . . . . . . 120

8 Expectation Maximization. . . . . . . . . . . . . . . . . . . . 122

9 Transductive Support Vector Machines . . . . . . . . . . . . . . . . . . . 126

10 Iterative Classification . . . . . . . . . . . . . . . . . . . . . . 130

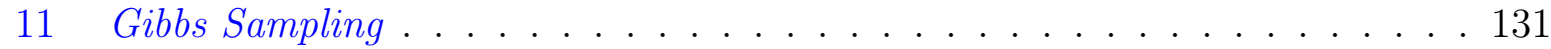

12 Relaxation Labeling . . . . . . . . . . . . . . . . . . . . . . . . 132

13 Iterative Reinforcement Categorization . . . . . . . . . . . . . . 133

14 Label Propagation . . . . . . . . . . . . . . . . . . . . . . . 138

15 Learning with Local and Global Consistency . . . . . . . . . . . . . . . . . . 139

16 Tag-based Model . . . . . . . . . . . . . . . . . . . . . . . 140

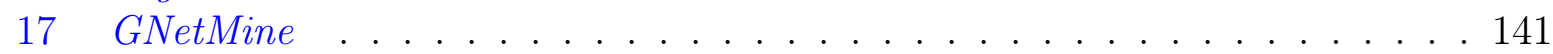

18 Label Propagation through Heterogeneous Networks . . . . . . . . . . . . . . 145

19 Transductive Categorization based on Heterogeneous Network . . . . . . . . 153 



\section{Lista de Abreviaturas}

BLR Bayesian Logistic Regression

CBC Centroid Based Classifier

CDRN Class Distribution Relational Neighbor

CMN Class Mass Normalization

DD Documento-Documento

DL Description Length

DF Document Frequency

DT Documento-Termo

EM Expectation Maximization

ER Entropy-based Ranking

GFHF Gaussian Fields and Harmonic Functions

GI Gini Index

GNM GNetMine

GS Gibbs Sampling

HTML HyperText Markup Language

IC Iterative Classification

IDF Inverted Document Frequency

IG Information Gain

IMBHN Inductive Model based on Bipartite Heterogeneous Networks

IMHN Inductive Model based on Heterogeneous Networks

IRC Iterative Reinforcement Categorization

IREP Incremental Reduced Error Pruning

kAC $k$-Associated Classifier 
kNN $k$-Nearest Neighbors

LDA Latent Dirichlet Allocation

LLGC Learning With Local and Global Consistency

LLSF Linear Least Squares Fit

LPBHN Label Propagation through Bipartite Heterogeneous Networks

LSI Latent Semantic Index

MEV Modelo Espaço-Vetorial

MkNN Mutual k-Nearest Neighbors

MDL Minimum Description Length

MNB Multinomial Naive Bayes

MSC Máximo Subgrafo Comum

NBC Network-only Bayes Classifier

NLB Network-only Link-based Classification

NMF Non-negative Matrix Factorization

PCA Principal Component Analysis

PLSI Probabilistic Latent Semantic Indexing

PMI Pointwise Mutual Information

RBF Radial Basis Function

RIPPER Repeated Incremental Pruning to Produce Error Reduction

RL Relaxation Labeling

RR Ridge Regression

TCBHN Transductive Classification based on Bipartite Heterogeneous Network

TCTN Transductive Classification through Term Networks

TCHN Transductive Classification based on Heterogeneous Network

LPHN Label Propagation through Heterogeneous Networks

SVD Singular Value Decomposition

SVM Support Vector Machines

TC Term Contribution

TF Term Frequency

TF-IDF Term Frequency - Inverted Document Frequency 
TM Tag-based Model

TGM Term Graph Model

TSVM Transductive Support Vector Machines

TT Termo-Termo

TV Term Variance

TVQ Term Variance Quality

WVRN Weighted Vote Relational Neighbor 

CAPÍTULO

1

\section{Introdução}

\subsection{Contextualização}

A quantidade de dados disponível em formato digital na rede mundial de computadores tem aumentado incessantemente. De acordo com estimativas realizadas em 2014, de 2013 a 2020 o universo digital irá aumentar de 4,4 trilhões de gigabytes para 44 trilhões de gigabytes (Turner et al., 2014). Parte dos dados no universo digital está no formato textual $^{1}$, como e-mails, relatórios, boletins, artigos, registros de pacientes e conteúdo de páginas web. Além disso, com o advento da Web 2.0, dados textuais tem sido utilizados como meio para disseminar informações, seja por postagens em redes sociais, wikis ou blogs (Fuchs et al., 2013; O'Reilly, 2009; Shelly e Frydenberg, 2009).

As informações contidas nos dados textuais podem ser úteis tanto na área acadêmica quanto na área empresarial para compreensão do comportamento humano, análise de opinião pública, organização de informações e extração de conhecimento. Devido à grande quantidade de informação textual produzida e disponibilizada nos dias atuais, torna-se humanamente impossível organizar, analisar, e extrair conhecimento embutido nas informações textuais. Consequentemente, mecanismos para realizar tais tarefas diminuindo a necessidade de intervenção humana têm ganhado importância nas últimas décadas (Biemann e Mehler, 2014; Aggarwal e Zhai, 2012; Berry e Kogan, 2010; Gupta e Lehal, 2009; Feldman e Sanger, 2006).

A classificação automática de textos é uma das áreas mais estudas e utilizadas para realizar as tarefas mencionadas anteriormente (Weiss et al., 2015; Aggarwal e Zhai, 2012; Manning et al., 2008; Nedjah et al., 2008; Berry e Castellanos, 2008; Feldman e Sanger, 2006; Sebastiani, 2002). A classificação automática de textos consiste em atribuir auto-

\footnotetext{
${ }^{1}$ De acordo com Ur-Rahman e Harding (2012) e (Kuechler, 2007), aproximadamente $80 \%$ das informações corporativas são compostas por dados textuais.
} 
maticamente um rótulo previamente definido à documentos textuais. Pode-se observar o uso da classificação de textos na (i) organização, por meio de roteamentos, filtragens e atribuições de metadados; (ii) análise, por meio das estatísticas dos rótulos atribuídos aos documentos ou por meio de análises descritivas e preditivas de WebSensors $^{2}$; e (iii) extração de conhecimento, por meio de um conjunto de regras ou valores que sumarizem os padrões presentes na coleção de documentos. Além disso, motores de recuperação de informação, que correspondem a grande parte do uso da internet para localização de informações e obtenção de conhecimento, fazem uso de algoritmos de classificação de textos para ranquear os documentos mais relevantes de acordo com a consulta de um usuário (Manning et al., 2008).

Para realizar a classificação automática de textos, podem ser utilizados sistemas especialistas ou de algoritmos de aprendizado de máquina. No primeiro caso, um ou mais especialistas de domínio criam um conjunto de regras (testes condicionais baseados na presença ou frequência de um conjunto de palavras) que definem a classe de um documento. Porém, regras geradas manualmente são difíceis de serem atualizadas ou mesmo de serem geradas para diferentes locais ou domínios de aplicação, além de serem dependentes da presença e esforço de especialistas de domínio ou engenheiros de conhecimento (Manning et al., 2008; Sebastiani, 2002; Dumais et al., 1998).

Uma alternativa aos sistemas especialistas é o uso de algoritmos de aprendizado de máquina para realizar a classificação automática de textos. O objetivo dos algoritmos de aprendizado de máquina é aprender, generalizar, ou ainda extrair padrões ou características das classes das coleções com base nos documentos textuais e rótulos (identificadores de classe) dos documentos informados por um usuário ou especialista de domínio. Apesar de ainda haver intervenção humana, a atividade de rotulação dos documentos é mais simples do que a definição de regras por especialista ou engenheiros de conhecimento. O uso de algoritmos de aprendizado de máquina para a classificação de textos demonstra ter uma performance de classificação comparável com as alcançadas por sistemas especialistas. Além disso, o uso de algoritmos de aprendizado de máquina exige um menor esforço humano e os modelos de classificação são mais rápidos de serem construídos (Benbrahim e Bramer, 2009), e portanto, são mais fáceis de serem utilizados em diferentes domínios e aplicações. Além disso, o uso de algoritmos de aprendizado de máquina permite facilmente a personalização da classificação automática de acordo com as necessidades dos usuários. Para tal, basta definir os rótulos dos documentos de acordo com seus objetivos. Por exemplo, em uma coleção de notícias, o usuário pode querer classificá-las em tópicos gerais, definindo rótulos como Cultura, Esporte e Economia, ou em tópicos mais específicos, como Moda, Comida e Horóscopo para textos sobre cultura, Basquete, Vôlei e Futebol para textos sobre esporte, ou Mercado, Empreendedorismo e Finanças Pessoais para textos sobre economia. O usuário pode ainda definir rótulos para as notícias como Interessante e Não Interessante, permitindo o sistema de classificação automática

\footnotetext{
${ }^{2}$ http://www.bv.fapesp.br/pt/auxilios/86135/aprendizado-de-maquina-para-websensors-algoritmos-eaplicacoes/
} 
filtrar novas notícias que são interessantes para o usuário.

Existem duas categorias de algoritmos de aprendizado de máquina para realizar a classificação automática: (i) aprendizado supervisionado e (ii) aprendizado semissupervisionado. O aprendizado supervisionado considera apenas documentos rotulados, isto é, documentos para os quais um usuário ou especialista definiu os rótulos, para induzir um modelo de classificação. Portanto, esse tipo de aprendizado também é conhecido por aprendizado indutivo supervisionado. Um modelo de classificação consiste em um conjunto de regras, hiperplanos de separação, documentos ou protótipos representantes de classes, probabilidades ou valores de relevância de termos para as classes, que são utilizados para predizer o rótulo de novos documentos. O aprendizado de máquina supervisionado vem sendo amplamente estudado e aplicado para as mais diversas finalidades envolvendo classificação de textos (Xia et al., 2014; Singhal e Bansal, 2013; Aggarwal e Zhai, 2012; Liu e Zhang, 2012; Yin et al., 2009a; Coussement e den Poel, 2008; Weiss et al., 2012; Melville et al., 2009; Chen e Hsieh, 2006a; Cubranic e Murphy, 2004; Sebastiani, 2002).

O objetivo do aprendizado semissupervisionado é fazer uso dos documentos não rotulados para melhorar a performance de classificação, isto é, a hipótese é que os documentos não rotulados possibilitam caracterizar melhor as classes e consequentemente melhorar a performance de classificação ${ }^{3}$. Com isso, pode-se ter uma performance de classificação superior a do aprendizado supervisionado considerando a mesma quantidade de exemplos rotulados, ou ainda uma performance equivalente considerando uma menor quantidade de exemplos rotulados (Zhu e Goldberg, 2009; Chapelle et al., 2006). Dada a facilidade de coleta e armazenamento de dados, e a grande quantidade de textos não rotulados disponível e produzida atualmente, esse tipo de aprendizado vêm ganhando interesse nos últimos anos (Xu e King, 2015; Subramanya e Talukdar, 2014; Søgaard, 2013; Breve et al., 2012; Culp e Michailidis, 2008).

Existem dois tipos de aprendizado semissupervisionado: (i) transdutivo e (ii) indutivo. No aprendizado transdutivo, dada toda a coleção de documentos que se deseja classificar e poucos documentos rotulados, o objetivo é classificar diretamente os documentos não rotulados sem a necessidade de induzir um modelo de classificação. Já no aprendizado indutivo semissupervisionado, documentos rotulados e não rotulados são utilizados para induzir um modelo de classificação, o qual será utilizado para classificar novos documentos.

Independente da categoria ou tipo de algoritmo de aprendizado, os documentos devem ser representados em um formato apropriado para a manipulação por parte dos algoritmos de aprendizado de máquina. A maioria dos trabalhos envolvendo classificação de textos considera que a coleção de documentos é representada em um modelo espaço-vetorial, no qual cada documento é representado por um vetor e cada posição desse vetor corresponde a uma dimensão (atributo ou termo) da coleção de documentos (Salton, 1989). Essa

\footnotetext{
${ }^{3}$ Performance de classificação refere-se à uma medida objetiva que quantifica a quantidade de classificação corretas geradas por uma processo de classificação automática, como Precisão, Revocação e $F^{1}$ (Sokolova e Lapalme, 2009).
} 
representação tem como principais características a alta dimensionalidade, na qual algumas centenas de documentos podem gerar milhares de dimensões, e a alta esparsidade, na qual cada documento contém poucos termos frente a todos os termos da coleção, e portanto, a maioria dos valores das dimensões é 0 . Essas características fazem com que vários algoritmos de aprendizado de máquina baseado no modelo espaço-vetorial consumam uma alta quantidade de memória e apresentem queda no desempenho. Além disso, algoritmos baseados no modelo espaço-vetorial consideram que as entidades que compõem uma coleção de textos, como documentos e termos, são independentes ou não relacionadas, o que pode levar a resultados espúrios (Lu e Getoor, 2003).

Tentativas de representar relações entre termos, por meio de $n$-gramas ou conjuntos de palavras, ou inserindo atributos correspondentes às relações entre documentos da coleção, aumentam ainda mais a dimensionalidade e esparsidade da representação, além de não melhorarem efetivamente a performance de classificação (Dang et al., 2014). A extração de tópicos, na qual todos os termos de um mesmo tópico são agrupados em um único atributo, pode ser utilizada para representar relações entre termos e diminuir a dimensionalidade e esparsidade das representações baseadas no modelo espaço-vetorial (Blei et al., 2003; Hofmann, 1999). Entretanto, apesar dos benefícios computacionais, esse tipo de representação também não melhora efetivamente a performance de classificação, como apresentado no Capítulo 3 desta tese.

Além do modelo espaço vetorial, coleções textuais também podem ser representadas como redes. As representações em redes permitem modelar relações entre entidades de um problema de maneira eficiente e em um formalismo matematicamente tratável (Blanco e Lioma, 2012). Esse tipo de representação tem surgido como uma excelente alternativa para representar conjuntos de dados e textos e nota-se que atualmente há um grande interesse do uso das representações em redes na área de Aprendizado de Máquina (Sun e Han, 2012; Han, 2012; Angelova et al., 2012; Newman, 2010; Aggarwal e Wang, 2010). As representações em redes permitem a extração de padrões de classes que dificilmente são capturados por algoritmos baseados no modelo espaço-vetorial, além de melhorarem a performance de classificação dos algoritmos de aprendizado de máquina (Breve et al., 2012).

Diversos tipos de objetos e relações podem ser utilizados para representar textos individuais ou coleções de textos. Pode-se considerar como objetos da rede, por exemplo, sílabas, termos, sentenças e documentos. Como relações, pode-se considerar, por exemplo, a precedência de sílabas, a coocorrência de termos, ou a similaridade de sentenças ou documentos. Alguns domínios específicos contendo informações textuais proporcionam mais possibilidades de tipos de objetos e relações. Por exemplo, em redes de informações bibliográficas pode-se ter objetos do tipo autor, conferência, artigo, e termo, e relações do tipo autor-escreve-artigo, artigo-publicado-em-conferência, dentre outras. Outro exemplo são redes de sistemas de busca, as quais são compostas por objetos do tipo usuário, página web e consulta, e relações do tipo usuário-realiza-consulta, 
consulta-leva-a-página-web, dentre outras.

As redes podem ser homogêneas, isto é, compostas por um único tipo de objeto e um único tipo de relação, ou heterogêneas, compostas por vários tipos de objetos e relações. Segundo Ji et al. (2010) e Long et al. (2010), diferentes tipos de objetos e relações são capazes de estruturar melhor os dados e consequentemente podem levar a uma extração de padrões de melhor qualidade. Além disso, segundo Sharm (2008) e Getoor e Diehl (2005), ter diferentes tipos de relações nos dados é crucial, uma vez que diferentes relações carregam diferentes tipos de informação, permitindo assim capturar padrões de melhor qualidade.

\subsection{Desafios}

Apesar dos benefícios das representações em redes, da existência de diversos métodos para geração de redes e algoritmos de classificação de textos baseados em redes, ainda existem desafios de pesquisa que limitam o uso, o desempenho e a performance de classificação das abordagens existentes. A seguir, são listados os desafios relacionados a classificação de textos representados em redes.

\section{Desafio 1 -Representações em redes eficientes para a classificação de textos:} existem diversas possibilidades para representar textos em redes (assunto abordado no Capítulo 2). Algumas delas geram uma rede para representar cada documento da coleção. Esse tipo de abordagem permite apenas que a classificação seja realizada por meio do cálculo das similaridades entre as redes (Schenker et al., 2003), extração de sub-redes frequentes (Jiang et al., 2010; Markov et al., 2006), ou ainda ou extração de diversas propriedades das redes (Amancio, 2015), ambas custosas computacionalmente. Além disso, há uma redundância de informações quando gerada uma rede para cada documento, uma vez que os mesmos objetos e relações podem se repetir em diferentes redes, aumentando assim o consumo de memória. Portanto, várias das propostas da literatura não são eficientes para classificação de textos, tanto em consumo de memória quanto em tempo de processamento, principalmente ao lidar com grandes coleções de textos. Dessa forma abordagens eficientes para geração, armazenamento, e que também permitam um processamento eficiente dos algoritmos de aprendizado de máquina são um desafio de pesquisa.

\section{Desafio 2- Representações em redes de coleções de textos para diferentes lín-} guas e domínios de aplicação: algumas formas de representações de textos em redes são baseadas em dicionários de domínio ou ontologias (Mishra et al., 2012; Jiang et al., 2010; Steyvers e Tenenbaum, 2005). Com isso, essas representações não podem ser utilizadas em outros domínios de aplicação. As relações de algumas redes da literatura também só podem ser geradas em domínios específicos (Aggarwal e Li, 2011; Ji et al., 2010; Sun et al., 2009a; Gao et al., 2005), e portanto, são limitadas 
a estes domínios. Além disso, algumas representações em redes requerem o uso de técnicas de part-of-speech tagging para extração das categorias léxicas dos termos. Isso aumenta o custo computacional da geração das redes, torna a performance de classificação dependente da qualidade da técnica de part-of-speech tagging, e torna a geração da rede dependente de idioma, uma vez que as técnicas part-of-speech tagging são específicas para cada idioma. Formas de representações em redes independentes de domínio e língua facilitam sua aplicação em situações práticas, aumentam o leque de possibilidades de utilização dessas redes e são menos custosas para serem geradas. Porém, nota-se na literatura que redes com tais características em geral não provêm performance de classificação superior a outros tipos de rede ou mesmo algoritmos baseados no modelo espaço-vetorial. Sendo assim, é um desafio relevante na área desta tese de doutorado o desenvolvimento redes independentes de conhecimento de domínio ou língua, que possibilitem uma performance de classificação superior ao modelo espaço-vetorial, e que ao mesmo tempo sejam capazes de representar diferentes objetos e relações que podem ser extraídas de qualquer coleção de textos.

\section{Desafio 3 - Diferentes tipos de objetos e relações estruturam os textos em dife-} rentes formas e consequentemente proporcionam diferentes performances de classificação: a maioria das pesquisas na literatura consideram apenas um tipo de objeto e(ou) um único tipo de relação (Amancio, 2015; Aggarwal e Zhao, 2013; Bertini et al., 2011; Zhou et al., 2004; Zhu et al., 2003a). Nessas pesquisas também não há comparações com redes contendo outros tipos de objetos e relações. Portanto, não fica claro qual tipo de relação ou mesmo quais combinações de relações são mais eficazes na performance de classificação. Alguns dos trabalhos que utilizam vários tipos de objetos e relações são de domínios específicos (Aggarwal e Li, 2011; Ji et al., 2010; Aery e Chakravarthy, 2005), e portanto, as análises a respeito das relações dos objetos são válidas apenas para o domínio em que a rede foi utilizada. Sendo assim, um dos desafios da literatura é definir quais tipos de objetos e relações, que podem ser extraídos de qualquer tipo de coleção de documentos, são capazes de prover as maiores performances de classificação.

\section{Desafio 4 - Diferentes medidas e abordagens podem ser usadas para definir} os pesos das relações entre os objetos da rede: uma das formas de se gerar relações na rede é por meio do cálculo da similaridades entre os objetos. Esse tipo de abordagem vem sendo muito utilizada na área de Aprendizado de Máquina, uma vez que vem apresentando bons resultados (Berton e Lopes, 2014; Tseng et al., 2012; Bertini et al., 2011; Kim et al., 2009; Subramanya e Bilmes, 2008; Palshikar, 2007; Angelova e Weikum, 2006; Belkin et al., 2006; Zhou et al., 2004; Zhu et al., 2003a; Jacobs, 2002), além de permitir a modelagem de qualquer coleção de textos em redes. Entretanto, para diferentes tipos de objetos, diferentes medidas de similaridade e diferentes estratégias para relacionar os objetos considerando similaridade podem ser utilizadas. Sendo assim, um dos desafios de pesquisa é definir quais tipos de 
medidas e estratégias para relacionar os objetos considerando a similaridade proveem as maiores performances de classificação e(ou) os menores tempos de processamento.

Desafio 5 - Algoritmos de aprendizado de máquina eficientes que façam um melhor uso das representações em redes e que consequentemente superem a performance de classificação dos algoritmos existentes: em geral, algoritmos baseados em redes com performance de classificação superior às obtidas pelo modelo espaço-vetorial são custosos computacionalmente (Markov et al., 2006; Aery e Chakravarthy, 2005; Schenker et al., 2003). Por outro lado, algoritmos mais eficientes computacionalmente obtém performance de classificação inferior a dos algoritmos baseados no modelo espaço-vetorial. Portanto, o desenvolvimento de algoritmos de classificação baseados em redes que sejam eficientes computacionalmente e que, ao mesmo tempo, superem a performance de algoritmos de classificação estado da arte, tanto baseados no modelo espaço-vetorial quanto em redes, é um desafio relevante.

\subsection{Objetivos}

Dados os benefícios e desafios do uso de representações de coleções de textos em redes para a classificação automática de textos apresentados na seção anterior, têm-se como principais objetivos desse projeto de doutorado:

1. Avaliar redes existentes e propor novas representações de coleções de textos em redes que sejam eficientes para classificação de textos, que permitam gerar as representações independente de língua e domínio, que permitam considerar diferentes tipos de objetos e relações, e que possibilitem aos algoritmos de aprendizado de máquina obter uma performance de classificação superior a de representações baseadas no modelo espaço-vetorial ou representações em redes.

2. Propor algoritmos de aprendizado de máquina supervisionados e semissupervisionados eficientes, que considerem as redes propostas nesta tese e que obtenham performance de classificação superior a de algoritmos baseados no modelo espaço-vetorial ou baseados em outras representações redes.

Vale ressaltar que os objetivos principais deste projeto de doutorado seguem 3 princípios de sistemas de classificação automática baseados em Hayes et al. (1990):

1. Performance de classificação: a proposta de novos algoritmos de classificação só é justificada se a performance de classificação dos mesmos é superior a de algoritmos existentes ou apresentam algum benefício ao usuário quanto à definição de parâmetros ou tempo computacional.

2. Velocidade de classificação: muitos sistemas que utilizam a classificação de textos requerem respostas rápidas ao usuário, como filtragem de e-mails e notícias, resposta 
automática de e-mails, roteamento de documentos a usuários, dentre outras, uma vez que podem ter grande impacto em decisões de negócios e satisfação do consumidor. Mesmo sistemas que não requerem respostas rápidas, como geração de metadados para indexação de documentos em sistemas de busca ou bibliotecas digitais, ou algumas aplicações de mineração de opinião, necessitam de algoritmos eficientes para gerar respostas em um tempo hábil, uma vez que esses sistemas normalmente têm que lidar com grandes volumes de textos.

3. Portabilidade: os algoritmos de aprendizado de máquina propostos devem ser capazes de aprender e classificar textos de diferentes domínios, estilos de escrita, quantidade de classes e língua.

Além dos objetivos principais deste projeto de doutorado, têm-se também os seguintes objetivos secundários que visam permitir o emprego das redes e algoritmos propostos em situações práticas:

1. Propor diferentes redes com diferentes custos de geração, diferentes números de objetos e relações, e avaliar o impacto dessas redes na performance de classificação, fornecendo assim uma análise de custo-benefício entre custo de geração, custo de processamento da rede e performance de classificação. Com isso o usuário adequar o consumo de memória, tempo de classificação e performance de classificação de acordo com suas necessidades.

2. Realizar uma extensa avaliação empírica para determinar em geral qual tipo de rede e algoritmo de aprendizado de máquina obtém a melhor performance de classificação para diferentes quantidades de exemplos rotulados.

3. Disponibilizar para a comunidade ferramentas computacionais e códigos fonte para pré-processamento de textos, geração das representações utilizadas e propostas, e algoritmos de aprendizado de máquina supervisionados e semissupervisionados, tanto os utilizados quanto os propostos, para aplicação em sistemas que envolvam classificação automática ou para replicação dos resultados.

\subsection{Principais Resultados}

Baseado nos desenvolvimentos das propostas para atingir os objetivos principais e secundários definidos neste projeto de doutorado, foram realizadas as seguintes contribuições científicas:

\section{Algoritmo para classificação indutiva supervisionada de textos utilizando redes}

bipartidas: foi proposto e desenvolvido o algoritmo Inductive Model based on Bipartite Heterogeneous Networks (IMBHN) (Rossi et al., 2014a, 2012) que induz um modelo de classificação considerando uma coleção de textos representada em 
uma rede bipartida, isto é, uma rede onde há relações somente entre objetos que representam os documentos e objetos que representam os termos. O modelo de classificação corresponde aos valores de relevância dos termos para as classes, que são obtidos por meio de um processo de otimização que minimiza a diferença entre o rótulo de um documento e valores de relevância dos termos fortemente relacionados ao documento. O algoritmo $I M B H N$ obtém performance de classificação superior aos algoritmos indutivos supervisionados e estado da arte para classificação de textos, como Support Vector Machines e k-Nearest Neighbors. Detalhes do algoritmo IMBHN são apresentados na Seção 3.3.

\section{Algoritmo para classificação indutiva supervisionada de textos utilizando redes} heterogêneas: foi proposto e desenvolvido o algoritmo Inductive Model based on Heterogeneous Networks (IMHN). O algoritmo induz valores de relevância dos termos para as classes por meio de um processo de otimização, minimizando as diferenças entre os rótulos dos documentos e valores de relevância dos termos fortemente relacionados aos documentos, e a minimização das diferenças entre os valores de relevâncias entre termos fortemente relacionados. Portanto, o algoritmo IMHN é uma extensão do algoritmo $I M B H N$ considerando relações entre termos. A inclusão das relações entre termos proporcionou um aumento da performance de classificação em comparação com o algoritmo IMBHN. Detalhes do algoritmo IMHN são apresentados na Seção 3.3.

\section{Dois algoritmos para classificação transdutiva de textos utilizando redes bipar-}

tidas: foram propostos e desenvolvidos nesta tese os algoritmos Label Propagation through Bipartite Heterogeneous Networks (LPBHN) (Rossi et al., 2014b) e Transductive Classification based on Bipartite Heterogeneous Network (TCBHN) (Rossi et al., 2015a), ambos considerando coleções de textos representadas em uma rede bipartida. O algoritmo $L P B H N$ realiza a classificação transdutiva por meio da propagação rótulos dos documentos para os termos e dos termos para os documentos iterativamente. O algoritmo $L P B H N$ não possui parâmetros, o que torna interessante sua aplicação em situações onde o usuário é leigo ou quando não se pode realizar uma grande quantidade de experimentos. Apesar de livre de parâmetros, o algoritmo $L P B H N$ apresentou resultados competitivos em relação a outros algoritmos. Já o algoritmo $T C B H N$ realiza um processo de otimização para obter valores de relevância dos termos para as classes considerando o rótulo dos documentos, e propaga esses valores de relevância para definir os rótulos de documentos não rotulados. O processo de otimização e propagação se repete até a convergência. O algoritmo TCBHN apresentou uma performance de classificação superior a de algoritmos baseados no modelo espaço-vetorial ou baseados em redes compostas por relações simples. Os detalhes do algoritmo $L P B H N$ são apresentados na Seção 4.3.2 e os detalhes do algoritmo TCBHN são apresentados na Seção 4.3.3. 


\section{Framework para classificação transdutiva de textos utilizando rede de termos:} foi proposto um framework denominado Transductive Classification through Term Networks (TCTN) para realizar a classificação transdutiva de textos representados em uma rede composta por relações entre termos (Rossi et al., 2015b). O objetivo do framework TCTN é propagar os valores de relevância dos termos para classe, considerando o peso das relações entre os termos, para definir os valores de relevância de todos os termos da coleção. As relevâncias dos termos são usadas para definir as classes dos documentos não rotulados. Como framework, cada etapa permite diferentes instanciações. Sendo assim, o usuário pode instanciar os componentes do framework conforme sua necessidade ou de acordo com as informações disponíveis no domínio de aplicação. Até a proposta do algoritmo TCTN, não havia na literatura algoritmos para realizar classificação transdutiva utilizando redes de termos. O uso das relações entre termos demostrou ser útil para a indução dos valores de relevância dos termos. Além disso, o desenvolvimento do TCTN permite comparar a performance de classificação obtida por redes de termos com outras redes compostas por relações simples e verificar se a união das relações entre termos com outros tipos de relação pode aumentar a performance de classificação. O artigo referente à proposta do TCTN recebeu o prêmio Best Paper Award - Second Place na $16^{\text {th }}$ International Conference on Intelligent Text Processing and Computational Linguistics. Os detalhes do framework TCTN são apresentados na Seção 4.3.1.

Algoritmos para classificação transdutiva utilizando redes heterogêneas: os algoritmos $L P B H N$ e $T C B H N$ foram estendidos para considerar diferentes tipos de relações e consequentemente permitir analisar se o uso de diferentes tipos de relações em conjunto aumenta a performance de classificação. As extensões dos algoritmos $L P B H N$ e TCBHN são denominadas respectivamente Label Propagation through Heterogeneous Networks (LPHN) e Transductive Classification based on Heterogeneous Network (TCHN). Os resultados demonstram que, em geral, o uso de diferentes tipos de relações em uma única rede aumenta a performance de classificação. Os detalhes do algoritmo $L P H N$ são apresentados na Seção 4.3 .2 e os detalhes do algoritmo TCHN são apresentados na Seção 4.3.3.

\section{Extensão dos algoritmos transdutivos propostos para realizar a classificação} indutiva semissupervisionada de textos: algoritmos indutivos semissupervisionados possuem duas etapas: (i) transdução, na qual são definidos rótulos aos documentos não rotulados, e (ii) indução ou extração de um modelo de classificação utilizando documentos rotulados e considerando os rótulos atribuídos aos documentos não rotulados. Devido aos bons resultados obtidos pelos algoritmos de classificação transdutiva propostos, estes foram considerados também para a classificação indutiva semissupervisionada. Foi proposto o uso dos valores de relevância dos pesos para as classes obtidos pelos algoritmos LPBHN, LPHN, TCTN, TCHN e TCBHN, como modelo de classificação. Essa proposta demostrou obter uma performance 
de classificação superior em relação aos algoritmos existentes baseados no modelo espaço-vetorial ou em redes. Além disso, a proposta para classificação indutiva semissupervisionada apresenta um custo computacional menor do que os algoritmos baseados em redes existentes. Os detalhes sobre a abordagem proposta para o aprendizado indutivo semissupervisionado são apresentados na Seção 5.3.

Análises de custo-benefício: neste projeto de doutorado são apresentadas análises sobre o impacto do esforço, tanto humano quanto computacional, na performance de classificação de textos. Para tal foram analisados (i) o impacto de diferentes tipos de redes, considerando custo de geração e número de objetos e relações, na performance de classificação; (ii) o impacto do número de textos rotulados na performance de classificação; (iii) o impacto do uso de textos não rotulados, que aumenta o custo computacional dos algoritmos de aprendizado de máquina semissupervisionados em relação aos supervisionados, na performance de classificação. O impacto do uso dos diferentes tipos de rede na performance de classificação é apresentado nas avaliações da classificação automática de textos por meio de aprendizado indutivo supervisionado (Seção 3.4), transdutivo semissupervisionado (Seção 4.4), e indutivo semissupervisionado (Seção 5.4). Já o impacto do número de textos rotulados e o impacto do uso de textos não rotulados na performance de classificação são apresentados nas avaliações experimentais referentes ao uso de aprendizado transdutivo e aprendizado indutivo semissupervisionado na classificação automática de textos.

Criação de um repositório de coleções de benchmarking: a grande maioria dos trabalhos sobre classificação de textos na literatura realizam uma avaliação experimental utilizando poucas coleções de textos, geralmente 2 ou 3. Com tal número de coleções é impossível afirmar que um método ou representação é melhor para coleções de um determinado domínio, melhor para coleções com determinadas características, ou ainda realizar um teste para determinar se a diferença de performance de classificação obtida por diferentes algoritmos ou representações é estatisticamente significante. Para as avaliações experimentais e análises realizadas nesta tese foram coletadas, estruturadas, extraídas características e disponibilizadas 45 coleções de documentos textuais de diferentes domínios. As coleções estão disponíveis gratuitamente na página web http://sites.labic.icmc.usp.br/text_collections/. Também foi publicado um relatório técnico (Rossi et al., 2013) apresentando maiores detalhes sobre as coleções, suas características, e também disponibilizados resultados obtidos por algoritmos tradicionais de classificação e agrupamento de textos de forma a servir como base para futuras pesquisas ou ainda evitar a reexecução de experimentos por parte da comunidade científica. Os detalhes das coleções de textos e das representações baseadas no modelo espaço-vetorial e em redes geradas a partir das coleções são apresentadas no Apêndice A. 
Aplicação das técnicas desenvolvidas e implementadas nesta tese em outros domínios de aplicação: os algoritmos desenvolvidos e implementados nesta tese foram aplicados a outros domínios de aplicação além da classificação de textos, como extração automática de termos de domínio (Conrado et al., 2005), classificação transdutiva de músicas (Silva et al., 2014), identificação de verbos causais (Drury et al., 2014), pós-processamento de regras de associação (de Padua et al., 2014) e extração de aspectos de produtos e serviços (Matsuno et al., 2015).

Implementação e disponibilização de métodos para pré-processamento de textos, representação de coleções de textos, e algoritmos de aprendizado de máquina supervisionados e semissupervisionados: neste projeto foi desenvolvida uma ferramenta computacional contendo (i) métodos para pré-processamento de textos, geração de representações no modelo espaço-vetorial e em redes; (ii) algoritmos de aprendizado supervisionado, transdutivos semissupervisionado e indutivo semissupervisionado; e (iii) mecanismos para execução de experimentos em lote considerando diferentes algoritmos, valores de parâmetros, número de exemplos rotulados e critérios de validação. A ferramenta computacional, denominada Text Categorization Tool, foi desenvolvida na linguagem Java, sendo portanto portável para diferentes sistemas operacionais, e está disponível em http://sites.labic.icmc.usp.br/ ragero/thesis/text_categorization_tool/. Também está disponível no mesmo endereço o código-fonte da ferramenta.

\subsection{Organização do Texto}

O restante desta tese está organizado da seguinte forma:

Capítulo 2 - Representações de Textos e Estruturas Computacionais para a Classificação de Textos: este capítulo trata sobre representações de textos baseadas no modelo espaço-vetorial, tentativas de representar relações entre objetos neste tipo de representação e suas desvantagens. Em seguida, são definidas as redes e são apresentadas as diversas maneiras de representar textos ou coleções de textos em redes. São detalhadas as propostas para geração de redes e combinação de diferentes tipos de relações. Também são detalhadas as notações e estruturas computacionais necessárias para realizar a classificação de textos tanto consideração representações baseadas no modelo espaço-vetorial quanto em redes.

\section{Capítulo 3 - Classificação de Textos por Meio de Aprendizado Indutivo Su-} pervisionado: primeiramente é apresentada uma conceituação sobre classificação indutiva supervisionada, e são apresentados algoritmos de aprendizados indutivos supervisionados baseados no modelo espaço-vetorial e baseados em redes mais adequados para a classificação de textos. Em seguida, são apresentadas as propostas para classificação indutiva supervisionada utilizando redes. Por fim, é apresentada a 
avaliação experimental, comparando os resultados obtidos por algoritmos indutivos supervisionados baseados no modelo espaço-vetorial e em redes existentes com os resultados obtidos pelas redes e algoritmos propostos, a análise dos resultados e as considerações finais.

\section{Capítulo 4 - Classificação de Textos por Meio de Aprendizado Transdutivo:} neste capítulo são apresentados os algoritmos baseados no modelo espaço-vetorial tradicionalmente utilizados e que servem como base para outros algoritmos, e algoritmos baseados em redes. Em seguida, são apresentadas as propostas para a classificação transdutiva utilizando redes. Também é apresentada a avaliação experimental, comparando os resultados obtidos por algoritmos transdutivos baseados no modelo espaço-vetorial e em redes existentes com os resultados obtidos pelas redes e algoritmos propostos. Por fim, são apresentadas as análises sobre os algoritmos e os diferentes tipos de relações e suas combinações, além das considerações finais.

\section{Capítulo 5 - Classificação de Textos por Meio de Aprendizado Indutivo Semis-} supervisionado: neste capítulo são apresentados algoritmos para a classificação indutiva semissupervisionada. Também são apresentadas as propostas para indução de um modelo de classificação de maneira semissupervisionada considerando as representações em redes propostas neste projeto de doutorado. Por fim, é realizada uma avaliação experimental, na qual as propostas para classificação indutiva semissupervisionada existentes são comparadas com as propostas deste projeto de doutorado. Também é analisado o impacto dos diferentes tipos de relações e suas combinações na performance de classificação. Por fim, são apresentadas as considerações finais.

Capítulo 6 - Conclusões: neste capítulo são apresentadas as contribuições científicas, as publicações relacionadas a este projeto de doutorado, as limitações ocorridas no desenvolvimento deste projeto, e por fim, os trabalhos futuros.

\section{Apêndice A - Coleções de Textos e Características das Representações Utiliza-} das nas Avaliações Experimentais: neste apêndice são apresentadas as descrições das coleções de textos utilizadas nas avaliações experimentais dos Capítulos 3, 4 e 5 , bem como as características das representações no modelo espaço-vetorial e em redes geradas para as coleções.

Apêndice B - Critérios de Avaliação de Performance de Classificação: neste apêndice são detalhadas as medidas de performance de avaliação que foram consideradas na avaliações experimentais realizadas nos Capítulos 3, 4 e 5. 



\section{Representações de Textos e Estruturas Computacionais para Classificação de Textos}

\subsection{Considerações Inicias}

A representação de textos é a base para o processamento de textos e consequentemente para a aplicação de algoritmos de aprendizado de máquina ${ }^{1}$. A qualidade dos resultados dos algoritmos de aprendizado de máquina é diretamente proporcional a qualidade da representação da coleção de textos.

Tipicamente o modelo espaço-vetorial tem sido utilizado para representar coleções de textos. Neste modelo, os documentos são representados por vetores e as dimensões correspondem à termos ou atributos da coleção de textos. A representação no modelo espaço-vetorial é simples e permite o uso de algoritmos de aprendizado de máquina tradicionais que lidam com vetores numéricos. Apesar de muito utilizado, o modelo espaço-vetorial é ineficiente ao representar importantes aspectos dos textos que podem ser relevantes para melhorar a performance de classificação, como relações entre termos (Zhang e Zhu, 2007; Bekkerman e Allan, 2004; Caropreso et al., 2001; Zhang e Yang, 2003; Beil et al., 2002; Fung et al., 2003) e relações entre documentos (Guo et al., 2010). Apenas para alguns algoritmos, tarefas ou coleções de textos específicas, a representação de relações entre as entidades de uma coleção, como termos ou documentos, no modelo espaço-vetorial demostrou aumentar a performance de classificação (Carvalho e Cohen, 2006; Tesar et al., 2006; Yang et al., 2003; Tan et al., 2002a). Além disso, essas propostas apresentam alta dimensionalidade e, em geral, impossibilitam o processamento por parte dos algoritmos de

\footnotetext{
${ }^{1}$ Além das representações apresentadas neste capítulo, existem outras formas de representações de textos como sequências de caracteres (Lodhi et al., 2002), árvores de sufixo (Zamir e Etzioni, 1998) e tensores (Liu et al., 2005b). Entretanto, esses tipos de representações não serão tratadas nesta tese devido ao seu baixo uso nas tarefas de classificação automática de textos.
} 
aprendizado de máquina, mesmo para pequenas coleções de documentos. Portanto, essas abordagens são sempre seguidas da aplicação de métodos de seleção de atributos, quando possível. Devido à alta dimensionalidade gerada, os custos computacionais embutidos para geração e seleção de termos e o baixo impacto na performance de classificação, as representações baseadas no modelo espaço-vetorial considerando apenas palavras simples como termos é ainda uma das mais utilizadas e efetivas na classificação automática de textos (Aggarwal, 2014; Aggarwal e Zhai, 2012; do Prado e Ferneda, 2008; Feldman e Sanger, 2006; Bekkerman et al., 2001).

Uma alternativa para as representações no modelo espaço-vetorial são as representações em redes, as quais têm ganhado atenção nas últimas décadas (Sun e Han, 2012; Silva e Zhao, 2012; Newman, 2010; Aggarwal e Wang, 2010). Esse tipo de representação se caracteriza por permitir a representação de diferentes tipos de relações entre os diferentes tipos de entidades dos textos (Rossi et al., 2015b, 2014b; Aggarwal e Zhao, 2013; Ferreira et al., 2013; Mishra et al., 2012; Ji et al., 2010; Solé et al., 2010; Gee e Cook, 2005; Hensman, 2004; Lu e Getoor, 2003) e vêm obtendo bons resultados em comparação com algoritmos baseados no modelo espaço-vetorial (Rossi et al., 2015a,b; Silva et al., 2014; Breve et al., 2012; Yin et al., 2009b; Belkin et al., 2006; Xue et al., 2004). Além disso, os diferentes tipos de relações que podem ser modelados em uma rede permitem capturar diferentes características das coleções de textos e considerar essas diferentes características em uma única rede possibilita a melhora da performance de classificação (Ji et al., 2010; Getoor e Diehl, 2005). Vale ressaltar que os algoritmos de aprendizado de máquina baseado em redes utilizam não somente as relações diretas entre os objetos da rede, mas também cadeias de relações para definir as classes, grupos ou importância dos objetos da rede. Isso possibilita a extração de padrões que não são extraídos ao representar textos no modelo espaço-vetorial (Breve et al., 2012; Mihalcea e Radev, 2011; Jiang et al., 2010).

Apesar dos diversos tipos de objetos e relações que podem ser usados para representar textos em redes, nota-se o uso de poucos tipos de objetos e relações nas redes utilizadas para classificação automática de textos. Além disso, muitas das representações de textos baseadas em redes foram propostas para domínios específicos, como páginas web, artigos científicos e patentes, ou ainda necessitam de dicionários e thesaurus específicos para um determinado domínio de aplicação, e portanto não podem ser aplicadas à qualquer tipo de coleções de textos. Nota-se também um alto custo computacional para a classificação automática de textos considerando várias das abordagens baseadas em redes existentes. Por outro lado, representações baseadas em redes que podem ser aplicadas à qualquer tipo de coleção de textos e que provêm uma baixo custo computacional na classificação de novos documentos, em geral, não apresentam performances de classificação satisfatórias.

Dados os benefícios da representação em redes, as lacunas envolvendo a utilização de representações de textos em redes mencionadas acima, e os princípios de classificação automática de textos apresentados no Capítulo 1, nesta tese foram propostas formas de representar coleções de textos em redes que atendam os seguintes requisitos: 
- Permitam gerar redes independentemente de língua e domínio;

- Permitam a representação de diferentes tipos de objetos e relações e possibilitem a utilização de algoritmos estado da arte baseados em redes, bem como a utilização dos algoritmos propostos nesta tese;

- Gerem uma classificação de novos documentos mais rápida que a de outros algoritmos baseados em redes;

- Possibilitem que os algoritmos obtenham uma performance de classificação superior à de algoritmos de aprendizado de máquina existentes baseados no modelo espaçovetorial ou baseados em redes.

Além disso, para avaliar e validar a hipótese que a combinação de diferentes tipos de relações entre diferentes tipos de objetos em uma única rede heterogênea é capaz de extrair padrões de melhor qualidade e consequentemente melhorar a performance de classificação, inicialmente são propostas e exploradas redes contendo um único tipo de relação e posteriormente as combinações das relações. Isso permite verificar o impacto na performance de classificação de diferentes tipos de relações e confirmar se de fato, a combinação de relações resulta no aumento da performance de classificação.

Nas próximas seções são apresentadas formas de representar textos no modelo espaçovetorial, incluindo procedimentos para gerar termos e atributos que representem relações entre entidades de uma coleção e suas desvantagens. Posteriormente são apresentadas as definições das redes, considerando seus diferentes tipos, e também são apresentadas formas de representar coleções de textos em redes para diversas tarefas de aprendizado de máquina, incluindo representações utilizadas para a classificação de textos. Também são apresentadas estruturas computacionais tanto para representações baseadas no modelo espaço-vetorial quanto para representações em redes. Em seguida são apresentadas as propostas para representação de coleções de textos em redes para a tarefa de classificação. Por fim, são detalhadas as estruturas computacionais para realizar a classificação automática de textos, além das notações que são utilizadas para descrever tanto os algoritmos propostos quanto os algoritmos utilizados nas avaliações experimentais realizadas nesta tese.

\subsection{Modelo Espaço-Vetorial}

Representações baseadas no modelo espaço-vetorial são as mais comuns na área de Aprendizado de Máquina (Aggarwal, 2014; Shalev-Shwartz e Ben-David, 2014; Sra et al., 2012) e portanto, uma grande gama de algoritmos foi desenvolvida considerando este tipo de representação. Neste modelo, cada exemplo ou instância do conjunto de dados é constituído por um vetor, sendo que cada dimensão do vetor corresponde à uma característica ou um atributo do conjunto de dados.

Representações baseadas no modelo espaço-vetorial também são umas das mais usadas na classificação automática de textos. Usualmente usa-se a palavra "termo" para denotar 
as dimensões geradas com base nas palavras de um texto, como uma palavras simples, sequências ou conjuntos de palavras, e atributo para denotar as dimensões não baseadas em termos, como um identificador de uma página web para o qual o documento aponta, presença de determinados autores em artigos, ou localização geográfica de um documento. Por simplicidade, nesta tese são consideradas que as dimensões das representações baseadas no modelo espaço-vetorial correspondem apenas aos termos, uma vez que essa é a forma mais utilizada na literatura. Quando necessário especificaremos a utilização de atributos neste tipo de representação.

Seja $\mathcal{D}=\left\{d_{1}, d_{2}, \ldots, d_{N}\right\}$ o conjunto de $N$ documentos e $\mathcal{T}=\left\{t_{1}, t_{2}, \ldots, t_{M}\right\}$ o conjunto de $M$ termos que compõem uma coleção de textos. Portanto, cada um dos $N$ vetores dos documentos de uma coleção é composto por $M$ dimensões. A união dos vetores das representações dos documentos de uma coleção é representada por uma matriz denominada matriz documento-termo (Tan et al., 2005) e será denotada por W nesta tese. Na Tabela 2.1 é apresentada uma ilustração da matriz documento-termo para representar uma coleção com $N$ documentos e $M$ termos. O valor de uma célula $w_{d_{i}, t_{j}}$ na matriz documento-termo representa um valor ou um peso de um termo $t_{j}$ em um documento $d_{i}$.

No caso da tarefa de classificação, há uma coluna adicional (última coluna) para representar a classe do documento. A classe de um documento $d_{i}$ é denotada por $c_{d_{i}}$. A coluna classe contém apenas valores nominais, que são descrições das classes dos documentos. Esses valores nominais são também denominados rótulos. O valor de $c_{d_{i}}$ é nulo caso não tenha sido definido um rótulo para um documento $d_{i}$. Os documentos que possuem valor para o atributo classe são denominados documentos rotulados, enquanto os que não possuem são denominados documentos não rotulados.

Tabela 2.1: Ilustração de uma matriz documento-termo representando uma coleção com $N$ documentos e $M$ termos.

\begin{tabular}{c|c|c|c|c|c|c|c||c}
\hline \hline & $\mathbf{t}_{\mathbf{1}}$ & $\mathbf{t}_{\mathbf{2}}$ & $\mathbf{t}_{\mathbf{3}}$ & $\ldots$ & $\mathbf{t}_{\mathbf{M}-\mathbf{2}}$ & $\mathbf{t}_{\mathbf{M}-\mathbf{2}}$ & $\mathbf{t}_{\mathbf{M}}$ & Classe \\
\hline \hline $\mathbf{d}_{\mathbf{1}}$ & $w_{d_{1}, t_{1}}$ & $w_{d_{1}, t_{2}}$ & & $\ldots$ & $w_{d_{1}, t_{M-2}}$ & $w_{d_{1}, t_{M-1}}$ & $w_{d_{1}, t_{M}}$ & $c_{d_{1}}$ \\
\hline $\mathbf{d}_{\mathbf{2}}$ & $w_{d_{2}, t_{1}}$ & $w_{d_{2}, t_{2}}$ & & $\ldots$ & $w_{d_{2}, t_{M-2}}$ & $w_{d_{2}, t_{M-1}}$ & $w_{d_{2}, t_{M}}$ & $c_{d_{2}}$ \\
\hline $\mathbf{d}_{\mathbf{3}}$ & $w_{d_{3}, t_{1}}$ & $w_{d_{3}, t_{2}}$ & & $\ldots$ & $w_{d_{3}, t_{M-2}}$ & $w_{d_{3}, t_{M-1}}$ & $w_{d_{3}, t_{M}}$ & $c_{d_{3}}$ \\
\hline$\vdots$ & $\vdots$ & $\vdots$ & $\vdots$ & $\ddots$ & $\vdots$ & $\vdots$ & $\vdots$ & $\vdots$ \\
\hline $\mathbf{d}_{\mathbf{N}-\mathbf{2}}$ & $w_{d_{N-2}, t_{1}}$ & $w_{d_{N-2}, t_{2}}$ & & $\ldots$ & $w_{d_{N-2}, t_{M-2}}$ & $w_{d_{N-2}, t_{M-1}}$ & $w_{d_{N-2}, t_{M}}$ & $c_{d_{N-2}}$ \\
\hline $\mathbf{d}_{\mathbf{N}-\mathbf{1}}$ & $w_{d_{N-1}, t_{1}}$ & $w_{d_{N-1}, t_{2}}$ & & $\ldots$ & $w_{d_{N-1}, t_{M-2}}$ & $w_{d_{N-1}, t_{M-1}}$ & $w_{d_{N-1}, t_{M}}$ & $c_{d_{N-1}}$ \\
\hline $\mathbf{d}_{\mathbf{N}}$ & $w_{d_{N}, t_{1}}$ & $w_{d_{N}, t_{2}}$ & & $\ldots$ & $w_{d_{N}, t_{M-2}}$ & $w_{d_{N}, t_{M-1}}$ & $w_{d_{N}, t_{M}}$ & $c_{d_{N}}$ \\
\hline \hline
\end{tabular}

Nas próximas subseções serão detalhadas (i) as formas de gerar os termos e atributos das representações de textos baseadas no modelo espaço-vetorial, acrescentando formas de adicionar dimensões para considerar relações entre entidades das coleções de textos; (ii) como definir os valores das dimensões, isto é, os pesos dos termos ou atributos nos documentos; e (iii) formas de diminuir o número de dimensões por meio de técnicas de seleção de atributos e redução de dimensionalidade. 


\subsubsection{Geração de Termos e Atributos}

A geração de termos e atributos para representações baseadas no modelo espaço-vetorial tem impacto direto na classificação automática de textos, tanto no quesito velocidade quanto performance de classificação. Normalmente utiliza-se palavras simples como termos da coleção de documentos, gerando a matriz documento-termo denominada bag-of-words. A representação bag-of-words tem como características principais a alta dimensionalidade e a alta esparsidade. A alta dimensionalidade é causada pelo grande número de palavras diferentes contidas em uma coleção de textos. Já a natureza esparsa da matriz é ocasionada pelo fato de que grande parte das palavras ocorre somente em uma pequena parte dos documentos. Esse tipo de representação apresenta bom custo benefício em relação ao número de termos, representação do conteúdo dos documentos para algoritmos de aprendizado de máquina e performance de classificação (Bekkerman e Allan, 2004). Entretanto, devido à alta dimensionalidade e esparsidade, em geral, algoritmos de aprendizado de máquina têm seu desemprenho negativamente afetado (Yu e Liu, 2004).

Outra característica da bag-of-words é que não são representadas relações entre as entidades das coleções de textos como relações entre termos (similaridades, ordem ou distâncias) ou relações entre documentos (similaridades ou hyperlinks), e os algoritmos de aprendizado de máquina que utilizam este tipo de representação não são capazes de inferir tais relações. Para tanto é preciso representar explicitamente as relações na forma de termos ou atributos na representação no modelo espaço-vetorial.

Para representar relações entre termos, pode-se adotar basicamente duas estratégias: (i) considerar frases como termos e (ii) considerar conjuntos de palavras como termos. Ambas as estratégias podem ser utilizadas em conjunto com a representação bag-of-words.

As frases podem ser de dois tipos:

- Frases estatísticas: qualquer sequência de $n$ palavras, após realizada a etapa de pré-processamento, com $n \geq 2$, que ocorrem em ao menos um documento da coleção. Portanto, o valor de $n$ define o número de palavras que irão compor o termo. As frases estatísticas também são conhecidas como n-gramas e são utilizadas para manter a relação de ordem entre as palavras;

- Frases sintáticas: qualquer conjunto de palavras que satisfaça determinadas relações sintáticas ou que constituem estruturas sintáticas específicas. Pode-se especificar, por exemplo, que uma frase pode ser constituída por um substantivo seguido por um adjetivo, por exemplo "performance eficiente".

Algumas pesquisas investigaram as diferenças obtidas pelo uso destes dois tipos de frases, como as apresentadas em Mitra et al. (1997) e Fagan (1989). Em ambos os trabalhos, as diferenças obtidas pelas abordagens foram insignificantes, além de haver uma grande sobreposição das frases em ambas as abordagens. Normalmente opta-se pelo uso de frases estatísticas, que apresentam custos computacionais menores para a geração de termos, além de serem robustas à variantes sintáticas, como exemplo de classificação e exemplo 
classificado. Além disso, observa-se um uso maior de $n$-gramas em relação ao uso de frases sintáticas na classificação de textos (Carvalho e Cohen, 2006; Zhang e Lee, 2003; Caropreso et al., 2001; Fürnkranz e Widmer, 1994). Porém, o número de diferentes termos que podem ser gerados aumenta monotonicamente com $n$. Além disso, o número de ocorrências da maioria dos $n$-gramas decai com o crescimento de $n$. Portanto, quanto maior o valor de $n$, maior a dimensionalidade e esparsidade da matriz, o que favorece o overfitting por parte dos algoritmos de aprendizado de máquina (Liu et al., 2008).

Segundo Dang et al. (2014) e Schneider (2005), a maioria dos trabalhos envolvendo $n$-gramas resulta em uma pequena melhora na performance de classificação. Além disso, os resultados sobre o uso de $n$-gramas não são conclusivos, uma vez que alguns trabalhos relatam um decrescimento na performance de classificação enquanto outros apresentam um aumento na performance de classificação.

Além de utilizar frases como termos, pode-se utilizar também conjuntos de palavras. Neste caso, as palavras que compõem um termo podem aparecer distantes uma das outras nos documentos (Rossi e Rezende, 2011a,b; Zhang e Zhu, 2007; Tesar et al., 2006; Yang et al., 2003; Ahonen-Myka et al., 1999). Normalmente este tipo de atributo visa representar relações de similaridade entre as palavras. Os termos que contém conjuntos de palavras são mais livres, mais descritivos, e podem ser reconhecidos como uma expansão do $n$-gramas. Porém, o mesmo problema que ocorre ao utilizar n-gramas como termos ocorre ao utilizar conjuntos de palavras: o número de diferentes termos que podem ser extraídos em uma coleção de documentos pode ser muito maior que o da representação bag-of-words e muitas vezes inviabiliza o uso de algoritmos de aprendizado de máquina.

Independente do número de palavras contidas nos termos, técnicas de pré-processamento de textos podem ser utilizadas para atenuar a dimensionalidade e/ou esparsidade de representações baseadas no modelo espaço-vetorial, e manter ou melhorar a qualidade dos resultados dos algoritmos de aprendizado de máquina (Uysal e Gunal, 2014; Nogueira et al., 2008). Dentre as técnicas de pré-processamento de textos destacam-se a padronização de caixas, remoção de palavras irrelevantes ou ruídos, agrupamento palavras contendo o mesmo significado em um único atributo, ou ainda seleção de palavras de acordo com uma determinada função sintática.

Um dos procedimentos que podem ser utilizados para remoção de palavras irrelevantes é a remoção de stopwords. As stopwords são palavras consideradas irrelevantes para os padrões aprendidos por algoritmos de aprendizado de máquina. Normalmente são consideradas como stopwords preposições, pronomes, artigos e interjeições. Além dessas palavras, pode haver palavras que não são úteis apenas para um domínio de aplicação, como a palavra "introdução" em uma coleção de artigos científicos. Essas palavras consideradas irrelevantes somente em um domínio específico são denominadas stopwords de domínio. Além disso, em muitas aplicações de classificação automática de textos, palavras compostas por caracteres alfanuméricos podem ser consideradas como ruídos e podem ser removidas da coleção de textos. 
A simplificação de palavras faz com que palavras que tenham o mesmo significado essencial mas que se diferenciam pelo tempo verbal, número ou gênero, representem a mesma informação. Isso faz com que palavras como agrupar, agrupamento, e agrupado correspondam a um único termo e consequentemente sejam representadas e contabilizadas de uma única maneira, por exemplo, agrup. A simplificação de palavras pode ser feita utilizando a radicalização, que reduz cada palavra do texto ao seu radical; a lematização, que agrupa as variantes de um termo em um único lema, ou seja, transforma verbos para sua forma no infinitivo, e substantivos e adjetivos para o masculino singular; ou a substantivação, na qual as palavras passam a exibir um comportamento sintático/semântico semelhante aquele próprio de um nome (Conrado et al., 2012; Uysal e Gunal, 2014). Notase na literatura o uso predominante de técnicas de radicalização na classificação de textos. De acordo com Joachims (1999), os termos gerados pela radicalização de palavras são capazes de gerar uma representação mais compacta sem perder muita informação.

O uso de thesaurus e dicionários de domínio também podem ser usados para diminuir o número de termos. No primeiro caso, um termo é usado para substituir outros termos que tenham significados semelhantes ou pertençam a um mesmo tema. Por exemplo, supondo um conjunto de documentos sobre notícias de esporte, ao invés de gerar termos como "futebol", "natação", "vôlei", pode-se gerar apenas o termo "esporte". No segundo, são considerados apenas os termos contidos em um dicionário como termos de uma representação no modelo espaço-vetorial.

Técnicas de Processamento de Língua Natural também podem ser usadas para filtrar termos que serão utilizados nas representações no modelo espaço-vetorial. Neste caso, pode-se considerar apenas termos de determinada função sintática na representação, por exemplo, considerar apenas substantivos.

Além das relações entre termos, outros tipos de relações também podem ser expressas no modelo espaço-vetorial, como relações entre documentos dadas por hyperlinks, citações ou coautoria, ou atributos que expressem a ocorrência do nomes próprios, nomes de organizações, marcas de produtos, localizações geográficas ou temporais, logs de comportamento de usuários, ou tags atribuídas por usuários (Sinoara et al., 2014; Aggarwal et al., 2014; Vargas et al., 2012; Aggarwal et al., 2012; Modha e Spangler, 2000). Aggarwal et al. (2012) e Aggarwal et al. (2014) tratam esse tipo de informação por side-information ou atributos auxiliares. Normalmente esses atributos são binários ou ao menos mantêm a característica esparsa das matrizes (Aggarwal e Zhai, 2012). Por exemplo, no caso da representação de hyperlinks, para cara página web da coleção é criado um atributo no espaço vetorial e é atribuído o valor 1 na dimensão correspondente ao hypelink das páginas e 0 nas demais dimensões. Vale ressaltar que a adição de atributos auxiliares aumenta ainda mais a dimensionalidade e esparsidade das representações, sofrendo portanto dos mesmos problemas apresentados ao modelar relações entre palavras no modelo espaço-vetorial. 


\subsubsection{Definição dos Pesos dos Termos e Atributos}

Os valores das células da matriz documento-termo, exceto os da coluna Classe, são numéricos. Esses valores representam o peso de um termo ou atributo em um documento. Os pesos dos termos para os documentos são medidas quantitativas baseadas na frequência de um termo $t_{j}$ em um documento $d_{i}\left(w_{d_{i}, t_{j}}\right)$. Em geral essas medidas são obtidas de maneira não supervisionada, isto é, não é considerado o rótulo dos documentos para gerar os pesos. Métodos não supervisionados mais comuns para definir valores para $w_{d_{i}, t_{j}}$ são (Manning et al., 2008; Feldman e Sanger, 2006): (i) binário, no qual $w_{d_{i}, t_{j}}$ é igual a 1 se $t_{j}$ ocorre em $d_{i}$ e 0 caso contrário; (ii) frequência do termo (do inglês term frequency - $t f$ ), no qual $w_{d_{i}, t_{j}}$ corresponde à frequência (número de repetições) de $t_{j}$ em $d_{i}$; e (iii) frequência do termo ponderada pelo inverso da frequência de documento (do inglês term frequency inverse document frequency - tf-idf), que pondera a frequência do termo pelo inverso do número de documentos da coleção em que o termo ocorre.

Outros métodos para definir os valores de $w_{d_{i}, t_{j}}$ foram propostos na literatura (Erenel e Altinçay, 2012; Altinçay e Erenel, 2010; Chisholm e Kolda, 1999; Lee, 1995), incluindo métodos supervisionados, isto é, métodos que consideram o rótulo dos documentos para a definição dos pesos dos termos nos documentos (Ren e Sohrab, 2013; Lan et al., 2009; Debole e Sebastiani, 2003). Entretanto, a contribuição dessas medidas para aumentar a performance de classificação é limitada à tarefas específicas, como classificação de questões (Quan et al., 2011), classificação com classes desbalanceadas (Liu et al., 2009b), análise de sentimentos (Deng et al., 2014; Maas et al., 2011), fluxo de dados (Reed et al., 2006), ou algoritmos específicos, como K-Nearest Neighbor e Support Vector Machines (Lan et al., 2009, 2006, 2005). Diferentes medidas para definir o peso de termos em documentos dificilmente provêm melhoras na performance de classificação para diferentes algoritmos e coleções de textos com diferentes características, tais como número de termos, termos redundantes, e distribuição de frequência dos termos (Erenel e Altinçay, 2012). Além disso, métodos supervisionados obtém resultados próximos aos métodos não supervisionados (Lan et al., 2009), além de serem ineficientes em cenários onde há poucos exemplos rotulados.

No caso dos atributos auxiliares, aqueles que representam relações entre documentos, como hyperlinks ou citações, os pesos são normalmente binários. Já atributos referentes à geolocalização ou tempo normalmente são discretizados, isto é, mapeados para atributos nominais e posteriormente convertidos para dados binários, isto é, é gerado um atributo para cada valor nominal e o valor 1 é atribuído ao atributo correspondente ao valor nominal e 0 nos demais atributos. Os atributos originalmente nominais, como tags, nome de autores, personalidades, ou locais, também são convertidos para atributos binários.

\subsubsection{Seleção de Termos}

Além das técnicas de pré-processamento de textos utilizadas para atenuar a dimensionalidade das representações baseadas no modelo espaço-vetorial, apresentadas na Seção 2.2.1, 
pode-se também utilizar técnicas de seleção de termos como complemento para tal finalidade. O objetivo dos métodos de seleção de termos é selecionar um subconjunto de termos de acordo com algum critério de avaliação. Técnicas de seleção de termos são úteis tanto para eliminar termos ruidosos, isto é, termos que não contribuem para a qualidade dos resultados, quanto para aumentar a velocidade do processamento das representações por parte dos algoritmos de aprendizado de máquina.

Os critérios de avaliação podem ser do tipo Wrapper, no qual um subconjunto de termos é avaliado considerando o resultado obtido por um algoritmo de aprendizado de máquina, ou do tipo filtro, no qual é utilizada uma medida de avaliação independente do algoritmo de aprendizado de máquina que será empregado. Normalmente utilizam-se técnicas do tipo filtro uma vez que estas geralmente apresentam custos computacionais inferiores as das abordagens do tipo Wrapper.

Dado um critério de avaliação, existem basicamente três formas de realizar a seleção de termos: (i) avaliação de subconjuntos, (ii) ranking e (iii) corte por limiares. No primeiro caso, avaliação de subconjuntos, um espaço de busca contendo todos os possíveis subconjuntos de termos é analisado e é considerado o subconjunto que apresentar o maior valor segundo algum critério, como a correlação (Hall, 1999). Como critérios de busca no espaço dos subconjuntos pode-se utilizar busca exaustiva ou heurísticas como best first ou algoritmos genéticos (Witten e Frank, 2005). Apesar do uso de heurísticas para diminuir o espaço de busca, métodos de avaliação de subconjuntos são pouco utilizados na literatura de classificação automática de textos por serem mais custos computacionalmente em relação aos métodos baseados em ranking ou corte por limiares (Rossi et al., 2014a; Nogueira et al., 2008; Liu et al., 2005a).

No ranking ou no corte por limiares, são gerados valores de importância para cada termo da coleção de documentos. No caso dos métodos baseados em ranking, os termos são ranqueados em ordem decrescente de acordo com o valor de importância e os $X$ termos mais bem ranqueados são selecionados como termos da representação no modelo espaço-vetorial. Já no caso dos cortes por limiares, normalmente são selecionados os termos cujos valores de importância estão acima de um limiar. Em algumas situações, também são selecionados termos cujo valor de importância está contido em um intervalo, isto é, os valores de importância dos termos devem estar acima de um limiar $a$ e abaixo de um limiar $b$. Esse tipo de corte é denominado corte de Luhn (Luhn, 1958; Nogueira, 2009) e é normalmente aplicado considerando métricas de seleção de termos não supervisionadas. Estratégias de seleção de termos baseados em ranking ou cortes por limiares são mais utilizadas na literatura de classificação de textos e todas as medidas para definir a importância dos termos apresentadas a seguir podem ser empregadas utilizando ambas as estratégias.

A seleção de termos pode ser supervisionada, isto é, considerando os rótulos dos documentos, ou não supervisionada, isto é, baseada apenas na distribuição dos termos ao longo da coleção de documentos. Um conjunto de medidas para seleção de termos não supervisionada define a importância de um termo de acordo com o somatório do peso do 
termo ao longo da coleção de documentos, ou seja, a importância de termo $t_{j}$ é dada por:

$$
I\left(t_{j}\right)=\sum_{d_{i} \in \mathcal{D}} w_{d_{i}, t_{j}}
$$

Normalmente os pesos definidos para os termos neste tipo de seleção são dados pelas medidas binária, $t f$ ou $t f$ - $i d f$. Quando utilizada a medida binária, $I\left(t_{j}\right)$ é denominada frequência de documento (do inglês document frequency - $d f$ ) do termo $t_{j}$. Essa medida é comumente utilizada na seleção de termos não supervisionada (Aggarwal e Zhai, 2012; Nogueira et al., 2008; Liu et al., 2005a)

Outro grupo de medidas para seleção de termos não supervisionada considera a contribuição dos termos no cálculo da similaridade entre documentos para definir sua importância. Exemplos de medidas com essa característica são Term Contribution (TC) (Liu et al., 2003) e Entropy-based Ranking (ER) (Aggarwal e Zhai, 2012).

A medida $T C$ refere-se a quanto um termo contribui para o cálculo da similaridade entre documentos. Considerando que comumente é utilizada a medida cosseno (Equação 2.23) para calcular a similaridade entre documentos, e esta é dada pelo produto dos vetores de dois documentos, o valor de $T C$ para o termo $t_{k}$ é dada por:

$$
T C\left(t_{k}\right)=\sum_{d_{i}, d_{j} \in \mathcal{D}, d_{i} \neq d_{j}} w_{d_{i}, t_{k}} \cdot w_{d_{j}, t_{k}}
$$

ou seja, quanto maior a repetição e frequência de um termo $t_{k}$ nos pares de documentos, maior sua importância na coleção de documentos. Já a medida $E R$ calcula a redução na entropia ao remover um termo da coleção (Aggarwal e Zhai, 2012), ou seja, o valor de ER de um termo $t_{k}$ é dada por:

$$
E R\left(t_{k}\right)=-\sum_{d_{i}, d_{j} \in \mathcal{D}, d_{i} \neq d_{j}}\left(S\left(d_{i}, d_{j}\right) \cdot \log \left(S\left(d_{i}, d_{j}\right)\right)+\left(1-S\left(d_{i}, d_{j}\right)\right) \cdot \log \left(1-S\left(d_{i}, d_{j}\right)\right)\right)
$$

na qual $S\left(d_{i}, d_{j}\right)$ é a similaridade entre os documentos $d_{i}$ e $d_{j}$ após a remoção do termo $t_{j}$, a qual é definida por

$$
S\left(d_{i}, d_{j}\right)=2^{-\frac{d i s t\left(d_{i}, d_{j}\right)}{\operatorname{dist}}}
$$

e $\operatorname{dist}\left(d_{i}, d_{j}\right)$ é a distância entre os documentos $d_{i}$ e $d_{j}$ após a remoção do termo $t_{k}$ e $\overline{d i s t}$ é a distância média entre todos os documentos após a remoção de $t_{k}$.

Outro conjunto de medidas não supervisionadas visa selecionar termos baseados em sua variância. Neste caso, quanto maior a variância do peso do termo na coleção de documentos maior a importância do termo. Os dois principais métodos baseados em variância são Term Variance (TV) e Term Variance Quality (TVQ) (Dhillon et al., 2003). A medida $T V$ considera que termos importantes são aqueles que mantêm uma distribuição não uniforme ao longo da coleção. Portanto, o valor da medida TV para um termo $t_{j}$ é 
dada por:

$$
T V\left(t_{j}\right)=\sum_{d_{i} \in \mathcal{D}}\left(w_{d_{i}, t_{j}}-\overline{\mathbf{w}_{t_{j}}}\right)^{2}
$$

na qual $\overline{\mathbf{w}_{t_{j}}}$ é a média das frequências do termo $t_{j}$ na coleção de documentos. Já a medida $T V Q$ corresponde à uma variação da medida $T V$. A medida $T V Q$ para um termo $t_{j}$ é dada por:

$$
T V Q\left(t_{j}\right)=\sum_{d_{i} \in \mathcal{D}}\left(w_{d_{i}, t_{j}}\right)^{2}-\frac{1}{|\mathcal{D}|}\left(\sum_{d_{i} \in \mathcal{D}} w_{d_{i}, t_{j}}\right)^{2}
$$

Já ao considerar os rótulos dos documentos para selecionar conjuntos de termos, em geral, quanto mais "exclusivos" são os termos para uma determinada classe, isto é, quanto maior o número de ocorrências em documentos de uma classe $c_{j}$ e maior o número de ausência em documentos de uma classe $c_{k}$, tal que $c_{j} \neq c_{k}$, maior será a importância do termo na coleção de documentos. As medidas de seleção de termos supervisionadas mais utilizadas são (Aggarwal e Zhai, 2012; Aghdam et al., 2009; Forman, 2003; Yang e Pedersen, 1997): (i) Gini Index, (ii) Information Gain, (iii) Pointwise Mutual Information, e (iv) $\chi^{2}$.

O valor da função Gini Index $(G I)$ para um termo $t_{i}$ é dada por:

$$
G I\left(t_{i}\right)=\sum_{c_{j} \in \mathcal{C}} p\left(t_{i} \mid c_{j}\right)^{2}
$$

na qual $p\left(t_{i} \mid c_{j}\right)$ é a probabilidade de coocorrência do termo $t_{i}$ e da classe $c_{j}$. Já o valor da medida Information Gain $(I G)$ para um termo $t_{i}$ é dada por:

$$
\begin{gathered}
G I\left(t_{i}\right)=-\sum_{c_{j} \in \mathcal{C}} p\left(c_{j}\right) \cdot \log \left(1-p\left(t_{i} \mid c_{j}\right)\right)+p\left(t_{i}\right) \cdot \sum_{c_{j} \in \mathcal{C}} p\left(t_{i} \mid c_{j}\right) \cdot \log \left(p\left(t_{i} \mid c_{j}\right)\right) \\
+\left(1-p_{t_{i}}\right) \cdot \sum_{c_{j} \in \mathcal{C}}\left(1-p\left(t_{i} \mid c_{j}\right)\right) \cdot \log \left(1-p\left(t_{i} \mid c_{j}\right)\right)
\end{gathered}
$$

na qual $p\left(c_{j}\right)$ é a probabilidade de ocorrer a classe $c_{j}$. O valor da medida Pointwise Mutual Information $(P M I)$ de um termo $t_{i}$ para uma classe $c_{j}$ é dada por:

$$
\operatorname{PMI}\left(t_{i}, c_{j}\right)=\log \frac{p\left(t_{i} \mid c_{j}\right)}{p\left(c_{j}\right)}
$$

O valor geral da medida $P M I$ para um termo $t_{i}$ pode ser obtido pela média dos valores de $P M I\left(t_{i}, c_{j}\right)$ considerando todas as classes (Equação 2.10), ou pelo valor máximo de $P M I\left(t_{i}, c_{j}\right)$ considerando todas as classes da coleção de documentos (Equação 2.11).

$$
P M I_{a v g}\left(t_{i}\right)=\sum_{c_{j} \in \mathcal{C}} p\left(c_{j}\right) \cdot P M I\left(t_{i}, c_{j}\right)
$$




$$
P M I_{\max }\left(t_{i}\right)=\max _{c_{j} \in \mathcal{C}}\left\{P M I\left(t_{i}, c_{j}\right)\right\}
$$

O valor de $\chi^{2}$ para um termo $t_{i}$ e uma classe $c_{j}$ é dada por:

$$
\chi^{2}\left(t_{i}, c_{j}\right)=\frac{|\mathcal{D}| \cdot p\left(t_{i}\right)^{2} \cdot\left(p\left(t_{i} \mid c_{j}\right)-p\left(c_{j}\right)\right)^{2}}{p\left(t_{i}\right) \cdot\left(1-p\left(t_{i}\right)\right) \cdot p\left(c_{j}\right) \cdot\left(1-p\left(c_{j}\right)\right)}
$$

Assim como na medida PMI, o valor de geral de $\chi^{2}\left(t_{i}, c_{j}\right)$ pode ser obtido considerando a média dos valores para todas as classes ou considerando o valor máximo.

De acordo com Benbrahim e Bramer (2009), a aplicação de métodos de seleção de termos deve ser cautelosa e nem sempre garante uma boa performance de classificação. Segundo os mesmo autores, a seleção de atributos pode levar a perda de informação e normalmente não há um pequeno conjunto de termos suficiente para descrever todos os documentos com respeito à tarefa de classificação.

\subsubsection{Redução de Dimensionalidade}

Além das técnicas de seleção de termos, apresentadas na seção anterior, técnicas de redução de dimensionalidade também podem ser utilizadas para reduzir o número de dimensões de representações baseadas no modelo espaço-vetorial. Essas técnicas normalmente são vistas como uma projeção de dados em um espaço semântico (Aggarwal e Zhai, 2012), na qual vários termos semanticamente relacionados, como sinônimos, são agrupados em um único atributo. Portanto, técnicas de redução de dimensionalidade também podem ser usadas para representar relações entre termos no modelo espaço-vetorial. Segundo Schneider (2005), as técnicas de redução de dimensionalidade apresentam maior sucesso do que as técnicas utilizando frases sintáticas ou estatísticas. Porém, vale ressaltar que a aplicação de técnicas de redução de dimensionalidade não implica na não utilização de técnicas de seleção de termos.

Técnicas de redução de dimensionalidade são normalmente aplicadas em uma representação bag-of-words. A representação com menor dimensionalidade extraída por técnicas de redução de dimensionalidade visa preservar as características do conjunto de dados original, ou seja, essas técnicas buscam obter representações compactas de forma que sejam capazes de reproduzir os dados originais (Aggarwal e Zhai, 2012).

As técnicas para redução de dimensionalidade pode ser dividias em duas categorias: extração de atributos e extração de tópicos. A extração de atributos utiliza técnicas de álgebra linear para projetar um conjunto de dados de alta dimensão para um novo conjunto de dados conjunto de dados de baixa dimensão . Os atributos gerados para a nova representação do conjunto de dados, denominados componentes principais, apresentam 3 propriedades: (i) são cominações lineares dos atributos do conjunto de dados original, (ii) são ortogonais uns aos outros, (iii) capturam a variação máxima do conjunto de dados (Tan et al., 2005). Duas das técnicas de extração de atributos mais utilizadas na literatura 
são Principal Component Analysis (PCA) (Jolliffe, 2002) e Latent Semantic Index (LSI) (Deerwester et al., 1990). Em ambas as técnicas são obtidos os autovetores e autovalores do conjunto de dados. Os maiores autovalores correspondem às dimensões que preservam a maior variância do conjunto de dados. Portanto, os autovalores extraídos são ordenados de forma decrescente e são selecionadas as dimensões correspondentes aos $k$ maiores autovalores caso o usuário deseje representar a coleção de documentos em $k$ dimensões.

O método $P C A$ extrai os autovetores e autovalores resolvendo a seguinte equação:

$$
\mathbf{C}=\mathbf{P} \cdot \mathbf{D} \cdot \mathbf{P}^{T}
$$

na qual C é a matriz de covariância de tamanho $|\mathcal{D}| \times|\mathcal{D}|$, positiva e semi-definida, extraída do conjunto de dados na qual $c_{i, j}$ correspondente à covariância entre as dimensões $i$ e $j, \mathbf{D}$ é uma matriz diagonal contendo os autovalores de $\mathbf{C}$, e $\mathbf{P}$ é uma matriz que representa os autovetores (base ortonormal).

A técnica $L S I$ é semelhante a técnica $P C A$, porém, é mais apropriada para dados com características textuais (Aggarwal e Zhai, 2012). Os autovetores bem como os autovalores no LSI são obtidos usando o método Singular Value Decomposition (SVD) (Berry, 1992). Dada a transposta da matriz documento-termo $\left(\mathbf{W}^{T}\right)$, a decomposição em valores singulares da matriz $\mathbf{W}^{T}$ é dada por

$$
\mathbf{W}^{T}=\mathbf{U} \cdot \mathbf{\Sigma} \cdot \mathbf{V}^{T}
$$

na qual as matrizes $\mathbf{U}$ e $\mathbf{V}$ são matrizes de bases ortonormais de tamanhos $|\mathcal{T}| \times|\mathcal{T}|$ e $|\mathcal{D}| \times|\mathcal{D}|$ respectivamente, e $\Sigma$ é uma matriz diagonal de tamanho $|\mathcal{T}| \times|\mathcal{D}|$. Os valores na diagonal da matriz $\boldsymbol{\Sigma}$ correspondem aos autovalores da matriz $\mathbf{W}^{T}$. As colunas das matrizes $\mathbf{U}$ e $\mathbf{V}$ são chamadas respectivamente de vetores singulares à esquerda e vetores singulares à direita.

Outra forma de redução de dimensionalidade é por meio da extração de tópicos. Tópico é entendido como um tema ou assunto da coleção de documentos e cada tópico é composto por um conjunto de termos relacionados a um determinado assunto. Seja $\mathcal{Z}=\left\{z_{1}, \ldots, z_{k}\right\}$ o conjunto dos $k$ tópicos de uma coleção de textos. A extração de tópicos consiste em transformar a matriz documento-termo $\mathbf{W}$ em duas matrizes: uma matriz documento-tópico e uma matriz termo-tópico. Portanto, dado que o usuário deseje representar a coleção de documentos em $k$ dimensões, a matriz documento-tópico tem tamanho $|\mathcal{D}| \times k$ e a matriz termo-tópico tem tamanho $|\mathcal{T}| \times k$. Os valores das linhas da matriz documento-tópico consistem nos pesos, importância, ou relevância de cada documento à cada tópico, enquanto que as linhas da matriz termo-tópico consistem nos pesos, importância ou relevância de cada termo aos tópicos. Esses valores podem ser utilizados para: (i) extrair os tópicos latentes, compostos por conjuntos de palavras relacionadas, isto é, palavras que pertençam ao mesmo tópico, e ainda utilizar os tópicos como atributos da nova representação; (ii) reduzir a dimensionalidade da coleção de termos, representando os documentos em um novo espaço $k$-dimensional; e (iii) obter diretamente 
os grupos de documentos e grupos de termos da coleção de textos.

Dentre os algoritmos existentes para extração de tópicos destacam-se os métodos Non-negative Matrix Factorization (NMF) (Xu et al., 2003), Probabilistic Latent Semantic Indexing (PLSI) (Hofmann, 1999), e Latent Dirichlet Allocation (LDA) (Blei et al., 2003). O objetivo do método $N M F$ é minimizar a seguinte função objetivo:

$$
N M F=\frac{1}{2}\left(\mathbf{W}-\mathbf{U} \cdot \mathbf{V}^{T}\right)
$$

na qual $\mathbf{U}$ e $\mathbf{V}$ são matrizes de valores não negativos e correspondem as matrizes documento-tópico e termo-tópico respectivamente. As matrizes $\mathbf{U}$ e V são obtidas de forma que os pesos são tais que o somatório da multiplicação do peso de um documento $d_{i}$ para cada tópico pelo peso de um termo $t_{j}$ para cada tópico resulte em um valor próximo ao valor de $w_{d_{i}, t_{j}}$, ou seja $w_{d_{i}, t_{j}} \approx \sum_{z_{l} \in \mathcal{Z}} u_{d_{i}, z_{l}} \cdot v_{t_{j}, z_{l}}$. Diferente do PCA ou LSI, a técnica $N M F$ não gera um sistema de bases ortonormais. Outra característica do $N M F$ é que a não negatividade dos valores das matrizes $\mathbf{U}$ e $\mathbf{V}$ garante que os documentos correspondem à uma combinação não negativa dos tópicos de uma coleção (Aggarwal e Zhai, 2012).

Já os algoritmos PLSI e $L D A$ são algoritmos que utilizam modelos probabilísticos para encontrar padrões de coocorrência dos termos e extrair os tópicos da coleção de documentos. A técnica PLSI considera que os documentos de uma coleção são gerados por um modelo generativo. De acordo com o PLSI, a probabilidade conjunta de ocorrer um termo $t_{j}$ em um documento $d_{i}$ é dada por:

$$
p\left(t_{j}, d_{i}\right)=p\left(d_{i}\right) p\left(t_{j} \mid d_{i}\right)
$$

na qual

$$
p\left(t_{j} \mid d_{i}\right)=\sum_{z_{l} \in \mathcal{Z}} p\left(t_{j} \mid z_{i}\right) p\left(d_{i} \mid z_{l}\right)
$$

Pode-se utilizar a maximização da estimativa de máxima verossimilhança para obter as probabilidades dos termos e dos documentos aos tópicos. O logaritmo da estimativa de verossimilhança é dado por:

$$
\mathcal{L}=\sum_{d_{i} \in \mathcal{D}} \sum_{t_{j} \in \mathcal{T}} w_{d_{i}, t_{j}} \log p\left(t_{j}, d_{i}\right) .
$$

A Equação 2.18 é minimizada utilizando o algoritmo Expectation Maximization (Dempster et al., 1977). Vale ressaltar que a otimização da função da Equação 2.18 é sujeita às restrições de que os valores da probabilidade de cada documento para cada tópico e a probabilidade de cada termo para cada tópico devem somar 1.

No $L D A$, a distribuição dos termos para um tópico $z_{l}$ é dada por uma distribuição multinomial $\Phi_{z_{l}}$, que é amostrada por uma distribuição de Dirichlet com parâmetro $\beta$, isto é: 


$$
p\left(\boldsymbol{\Phi}_{z_{l}} \mid \beta\right)=\frac{\Gamma(|\mathcal{T}| \beta)}{[\Gamma(\beta)]^{|\mathcal{T}|}} \prod_{t_{j} \in \mathcal{T}} \phi_{z_{l}, t_{j}}^{\beta-1}
$$

na qual $\Gamma(.$.$) é uma extensão da função fatorial na qual há um decréscimo de 1, isto é,$ $\Gamma(n)=(n-1)$ !. Já a distribuição de tópicos para um documento $d_{i}$ é representada por uma distribuição multinomial $\Theta_{d_{i}}$, que é extraída de uma distribuição de Dirichlet com parâmetros $\alpha$, isto é:

$$
p\left(\boldsymbol{\Theta}_{d_{i}}\right)=\frac{\Gamma\left(\sum_{z_{l} \in \mathcal{Z}} \alpha_{z_{l}}\right)}{\prod_{z_{j} \in \mathcal{Z}} \Gamma\left(\alpha_{j}\right)} \prod_{z_{l} \in \mathcal{Z}} \theta_{d_{i}, z_{l}}^{\alpha_{z_{l}}-1}
$$

A estimativa dos parâmetros do $L D A$ é baseada na maximização da seguinte função de verossimilhança:

$$
L=\prod_{d_{i} \in \mathcal{D}} \prod_{t_{j} \in \mathcal{T}} p\left(w_{d_{i}, t_{j}} \mid z_{d_{i}, t_{j}}, \boldsymbol{\Phi}\right) p\left(z_{d_{i}, t_{j}} \mid \boldsymbol{\Theta}_{d_{i}}\right) p\left(\boldsymbol{\Theta}_{d_{i}} \mid \alpha\right) p(\mathbf{\Phi} \mid \beta)
$$

A função apresentada na Equação 2.21 só é otimizada por meio de aproximações, uma vez que os valores de $z_{d_{i}, t_{j}}$ não são observados. Normalmente utilizam-se algoritmos de inferência como o Gibbs Sampling (Griffiths e Steyvers, 2004) e Variational Expectation Maximization (Blei et al., 2003) para estimar os parâmetros do $L D A$. O LDA é visto como uma versão Bayesiana do algoritmo PLSI. Em Girolami e Kabán (2003) é demonstrado que o algoritmo $P L S I$ é equivalente ao $L D A$ quando aplicado com uma distribuição uniforme de Dirichlet.

Normalmente as técnicas para extração de tópicos são aplicadas em cenários onde não há rótulos dos documentos. Porém, os métodos para extração de tópicos podem ser modificados para considerar os rótulos dos documentos. Versões supervisionadas do $L D A$ são apresentadas em Lacoste-Julien et al. (2009); Ramage et al. (2009); Mcauliffe e Blei (2008) e do LSI são apresentadas em Chakraborti et al. (2007); Sun et al. (2004); Wiener (1995). Entretanto, vale ressaltar que essas técnicas não são eficientes em cenários com poucos exemplos rotulados.

\subsection{Redes}

Muitos problemas do mundo real podem ser modelados utilizando redes. Algumas definições para redes encontradas na literatura são:

- "Uma rede é um sistema de elementos que interagem ou regulam uns aos outros" ou um "conjunto de sistemas de coisas (objetos inanimados ou pessoas)" (Blanco e Lioma, 2012). 
- "Uma rede, em sua forma mais simples, é uma coleção de pontos, nos quais pares de pontos são conectados por uma linha" (Newman, 2010).

- "Uma rede é uma representação simplificada que reduz um sistema à uma representação abstrata" (Newman, 2010).

- "Muitos dos dados ou objetos informativos, agentes, grupos ou componentes são conectados ou interagem uns com os outros, formando redes numerosas, grandes, interconectadas e sofisticadas" (Sun e Han, 2012).

Dependendo da área do saber, os pontos ou elementos de um sistema, bem como suas ligações recebem diferentes nomes. Por exemplo, os pontos ou elementos, e suas ligações são denominados respectivamente nós e arestas na computação, sítios e ligações na física, atores e laços ou relações na sociologia (Newman, 2010). Também encontram-se em trabalhos de diferentes áreas o uso do termo "objetos" para denotar os elementos, e dos termos "relações", "conexões" e "links" para denotar as ligações entre os elementos. Nesta tese serão utilizados preferencialmente os termos "objetos" e "relações" para denotar os elementos e a ligações entre os elementos respectivamente, uma vez que essa terminologia é comum na literatura ao tratar os tipos de redes abordadas nesta tese (Sun e Han, 2013; Sun et al., 2010; Ji et al., 2010; Sun et al., 2009a; Gao et al., 2005). Porém, as outras nomenclaturas também serão utilizadas no decorrer desta tese de acordo com a conveniência.

Pode-se também encontrar na literatura os termos "redes" e "grafos" sendo usados indistintamente para denotar o mesmo conceito, principalmente na área de aprendizado de máquina. Alguns autores definem grafos como uma representação matemática das redes ou como uma representação visual das iterações entre os componentes (Newman, 2010). Outros autores utilizam redes para indicar representações naturais entre objetos e grafos para indicar relações geradas por um processo automático (Mihalcea e Radev, 2011). Ainda, alguns autores definem que redes tem uma estrutura mais complexa e com características específicas do que alguns tipos de grafos, como redes livre de escala e redes de pequeno mundo (Mihalcea e Radev, 2011; Newman, 2010).

A representação em redes vem sendo utilizada para representar diferentes sistemas. Alguns exemplos de sistemas representados em redes são (Newman, 2010):

Redes tecnológicas: nessas redes os objetos correspondem a equipamentos tecnológicos e as relações correspondem à conexão estabelecida por esses objetos. A característica entre essas redes são as ligações físicas. Exemplos de redes tecnológicas são: redes de computadores, redes de telefones e redes de energia elétrica.

Redes sociais: objetos correspondem, por exemplo, à pessoas, companhias, organizações e universidades, e as relações podem ser de diferentes tipos como amizade, familiar, comunicação e transação comercial. 
Redes biológicas: objetos correspondem à elementos biológicos e as relações correspondem à iterações entre esses elementos. Exemplos de redes biológicas são: redes metabólicas, redes de iteração de proteínas, redes neurais, e redes de cadeia alimentar.

Redes de informação: objetos correspondem a dados e as ligações correspondem à alguma forma de relacionamento ou de troca de informação entre esses dados. Esse tipo de rede é talvez um dos tipos de redes com maior número de aplicações dentro da área de aprendizado de máquina e é o tipo de rede utilizado nesta tese. Vale ressaltar que redes com aspectos sociais, como e-mails, e redes de compartilhamento de fotos, também envolvem trocas de informações, como conteúdos de e-mails e tags das imagens, caracterizando assim essas redes também como redes de informação. Outros exemplos de redes de informação são:

- Redes de páginas web (ou World Wide Web): objetos correspondem à páginas web e as relações representam os hyperlinks entre as páginas.

- Redes de citações: objetos correspondem à artigos ou patentes e as relações representam as citações entre eles. Esse tipo de rede também pode ser utilizado para gerar uma rede de cocitações, nas quais os objetos correspondem aos artigos ou patentes e estes são ligados se citam um mesmo artigo/patente em comum.

- Redes de coautoria: objetos correspondem à autores e dois autores são conectados se estes são coautores de um texto. Algumas pesquisas, como Barabási et al. (2002), tratam redes de coautoria como redes sociais.

- Redes de recomendação: objetos correspondem à pessoas, itens ou produtos, na qual uma pessoa é conectada à itens ou produtos de sua preferência ou que comprou.

- Redes de índices de palavras-chaves: objetos correspondem à documentos e termos, e termos são ligados aos documentos nos quais ocorrem.

Independente do tipo de rede, todas elas podem ser formalmente definidas como uma tripla $N=\langle\mathcal{O}, \mathcal{R}, \mathcal{W}\rangle$, na qual $\mathcal{O}$ representa o conjunto de objetos da rede, $\mathcal{R}$ representa o conjunto das relações entre os objetos e $\mathcal{W}$ representa o conjunto de pesos das relações entre os objetos.

Dados dois pares de objetos $o_{i}, o_{j} \in \mathcal{O}$, a relação entre esses objetos, caso exista, será representada por $r_{o_{i}, o_{j}}$. Nos casos em que o sentido da relação é importante, $r_{o_{i}, o_{j}}$ representa uma relação de $o_{i}$ para $o_{j}$, não significando que há uma relação de $o_{j}$ para $o_{i}$. Redes com esse tipo de relação são denominadas redes direcionadas. Redes de páginas web e redes de citações são normalmente representadas por redes direcionadas. Caso o sentido da relação não seja considerado, ou ainda sempre que existe uma relação $r_{o_{i}, o_{j}}$ também existe a relação $r_{o_{j}, o_{i}}$, a rede é denominada não direcionada. Exemplos de redes não direcionadas são as redes sociais, onde se um objeto $o_{i}$ é amigo de $o_{j}$ então $o_{j}$ 
também é amigo de $o_{i}$, ou em redes baseadas em medidas de similaridades simétricas, onde a similaridade entre um objeto $o_{i}$ e um objeto $o_{j}$ é igual a similaridade entre um objeto $o_{j}$ e um objeto $o_{i}$.

Também existe a possibilidade de um objeto ter uma aresta para ele mesmo (autoaresta), o que é incomum na área de aprendizado de máquina, ou utilizar arestas que relacionem mais de um objeto ao mesmo tempo. Este tipo de aresta é denominada hiperaresta e os grafos com esses tipos de arestas são denominados hipergrafos. Entretanto, esse tipo de grafo também é incomum no aprendizado de máquina, além do fato de que hipergrafos podem ser também representados por redes bipartidas (apresentadas a seguir).

O peso de uma relação $r_{o_{i}, o_{j}}$ será dada por $w_{o_{i}, o_{j}}$. Dependendo da aplicação ou do tipo de rede, todas as relações podem possuir o mesmo peso, isto é, para todo $o_{i}, o_{j} \in \mathcal{O}$, $w_{o_{i}, o_{j}}=1$ se $\exists r_{o_{i}, o_{j}} \in \mathcal{R}$. Redes com esse tipo de relação são denominadas redes não ponderadas (do inglês unweighted networks). Normalmente redes de páginas web, redes de citações e redes sociais são não ponderadas. Em outras aplicações ou tipos de redes, é necessário considerar o peso da relação, isto é, considerar a frequência de vezes com que os objetos se relacionam em um conjunto de dados ou o grau de associação entre os objetos. Neste caso, se $\exists r_{o_{i}, o_{j}} \in \mathcal{R}, w_{o_{i}, o_{j}}$ poderá ter como peso qualquer valor real. $\mathrm{Na}$ área Aprendizado de Máquina, normalmente utiliza-se valores reais positivos como pesos das arestas. Redes com esse tipo de relação são denominadas redes ponderadas (do inglês weighted networks). Exemplos de redes ponderadas são as redes de índices de palavras-chaves, redes de coautoria e redes tecnológicas.

Entretanto, pode-se considerar também que cada aresta contenha um vetor de atributos ao invés de um peso. Alguns exemplos de redes com atributos nas arestas são: (i) rede de e-mails, na qual é criada uma aresta se há uma comunicação entre duas pessoas e os atributos correspondem às palavras da comunicação (Qi et al., 2012); (ii) redes sociais, na qual os objetos correspondem às pessoas e imagens, e as arestas correspondem às palavraschave utilizadas como tags das imagens (Qi et al., 2012); e (iii) rede de coocorrência de termos, na qual objetos correspondem a termos e as arestas correspondem ao centroide obtido de todos os documentos cobertos pelos termos da relação (Marcacini e Rezende, 2010). Esse tipo de aresta, entretanto, é menos comum uma vez que os atributos das arestas podem ser mapeados como objetos da rede.

Quando $\mathcal{O}$ contém apenas um tipo de objeto, a rede é denominada homogênea. Também encontra-se na literatura as nomenclaturas "redes mono-dimensionais", "redes unimodais" ou "redes mono-tipo" referindo-se às redes homogêneas. Exemplos de redes homogêneas são as redes de páginas web, redes de citações, e redes de coautoria. Na Figura 2.1(a) é apresentada uma ilustração de uma rede homogênea.

Quando $\mathcal{O}$ é composto por $h$ diferentes tipos de objetos, isto é, $\mathcal{O}=\mathcal{O}_{1} \cup \mathcal{O}_{2} \cup \ldots \cup \mathcal{O}_{h}$, com $h \geq 2$, a rede é denominada heterogênea. Exemplos de redes heterogêneas são (i) redes sociais compostas por diferentes entidades, como pessoas, universidades e companhias, e os diferentes tipos de interações entre as entidades; e (ii) redes bibliográficas compostas 
por artigos, livros, autores, editoras, locais de publicações e seus diferentes tipos de relacionamentos. Na Figura 2.1(b) é apresentada uma ilustração de uma rede heterogênea.

Também encontra-se na literatura o uso dos termos "redes multitipo", "redes multidimensionais", "redes multimodais" ou redes "redes multirelacionais" (Magnani e Rossi, 2013; Berlingerio et al., 2013; Rodriguez e Shinavier, 2010; Tang et al., 2008; Wang et al., 2003). Alguns autores utilizam um conceito de redes multicamadas para representar diferentes objetos e relações entre os objetos. Por exemplo, em Bródka et al. (2011), cada tipo diferente de relação que pode existir entre os mesmos objetos são representadas em camadas diferentes, como ilustrado na Figura 2.2(a). Já em Wan et al. (2007); Wang et al. (2003), cada camada é utilizada para representar um tipo de objeto. São também modeladas relações entre objetos do mesmo tipo (relações que ocorrem na mesma camada) e relações entre objetos de diferentes tipos (relações entre objetos de camadas diferentes). Na Figura 2.2(b) é apresentada uma relação deste tipo de rede. Vale ressaltar que apesar das diferentes visões sobre a representação de diferentes objetos e relações, os diferentes tipos de relações e tipos de objetos representados pelas diferentes camadas podem ser representados por uma única rede heterogênea.

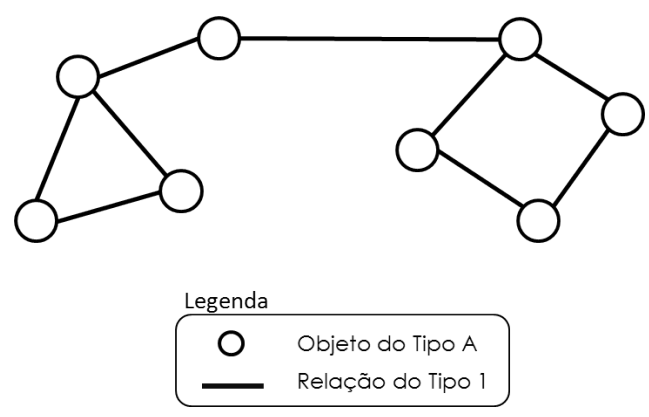

(a)

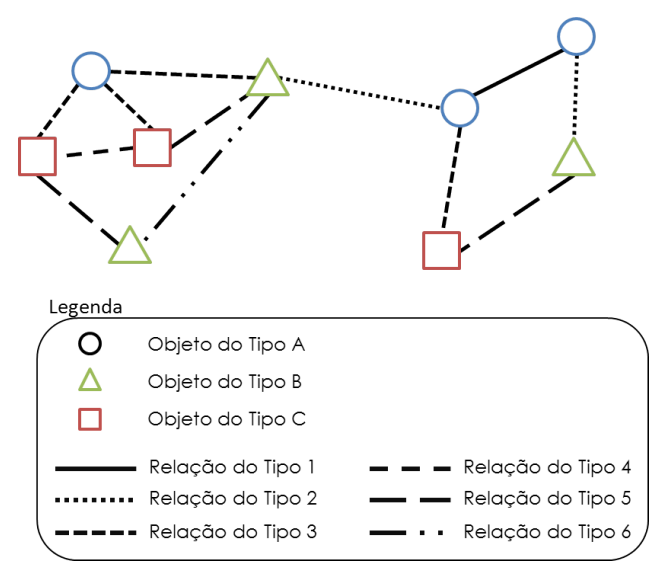

(b)

Figura 2.1: Exemplos de redes: (a) homogênea e (b) heterogênea.

Existem redes heterogêneas com características específicas como as redes bipartidas, redes $k$-partidas e redes estrela. As redes bipartidas são compostas por dois tipos de objetos sendo que um tipo de objeto somente se conecta com objetos do outro tipo. Na Figura 2.3(a) é apresentado uma ilustração de uma rede heterogênea bipartida.

Exemplos de redes bipartidas para representar coleções de textos são as redes de índices de palavras-chave, apresentadas anteriormente, na qual os objetos correspondem a documentos e termos, e os termos são conectados aos documentos em que ocorrem (Rossi et al., 2014b, 2012; Newman, 2010; Dhillon, 2001; Zha et al., 2001). Pode-se também gerar uma rede bipartida considerando sentenças e termos de um documento (Zha, 2002), conferências e autores ou artigos e autores para coleções de artigos científicos (Sun et al., 2009a), ou considerando consultas e páginas web (Xue et al., 2004). 


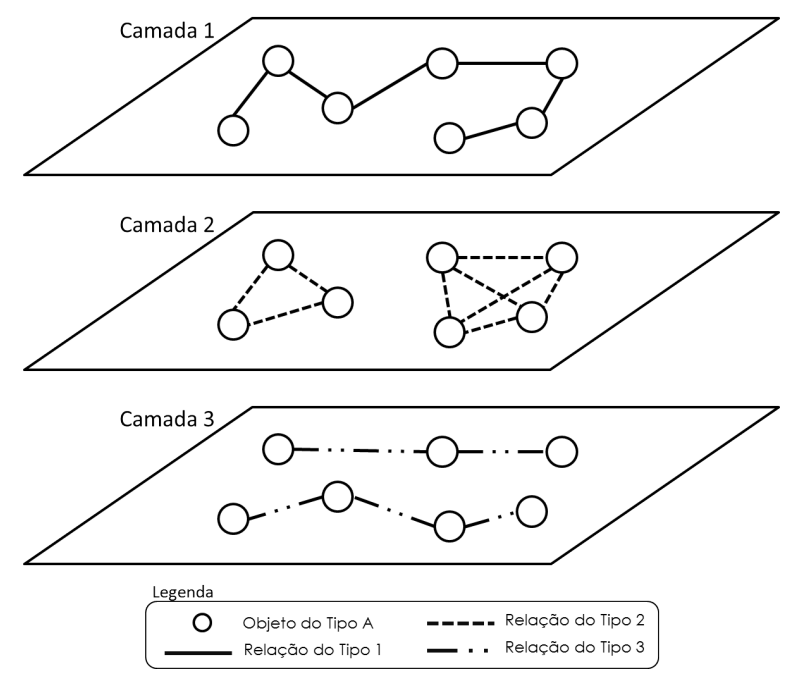

(a)

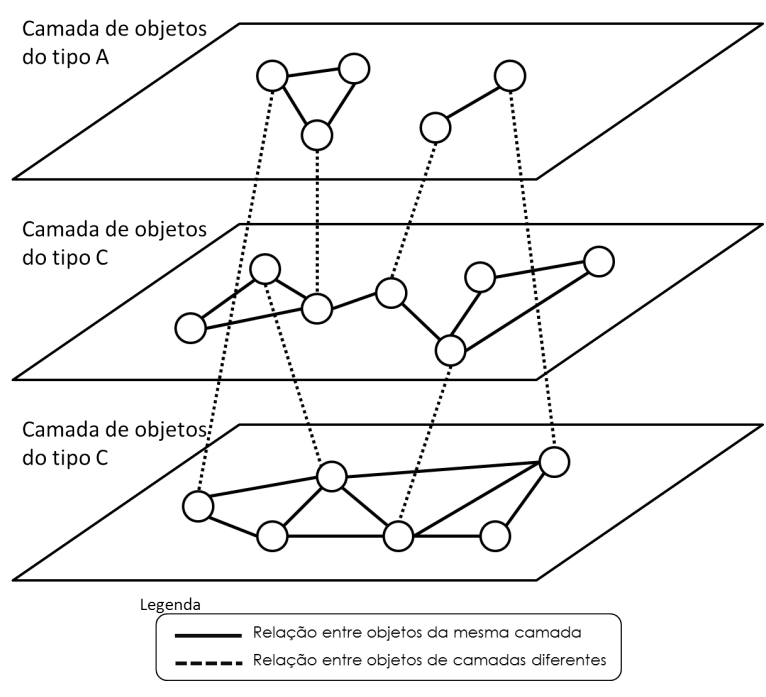

(b)

Figura 2.2: Exemplos de rede representadas em múltiplas camadas: (a) cada camada representa diferentes relações entre os mesmos objetos e (b) cada camada representa um tipo de objeto, podendo haver relações entre os mesmos tipos de objetos e relações entre objetos de tipos diferentes.

Nas redes $k$-partidas existem objetos de $k$ tipos diferentes, sendo que objetos de um mesmo tipo não são conectados entre sí (Gao et al., 2012; Liu e Murata, 2011; Long et al., 2006). Na Figura 2.3(b) é apresentada uma ilustração de uma rede heterogênea $k$-partida com $k=3$. Esse tipo de rede pode ser vista como uma extensão das redes bipartidas. Para $k=2$, a rede $k$-partida torna-se uma rede bipartida. Exemplos de redes $k$-partidas são redes compostas por (i) páginas web, consultas, usuários; (ii) artigos, palavras-chaves, autores e publicações; ou (iii) usuários, tags, e postagens.

Quando todos os tipos de objetos de uma rede se conectam à objetos de um determinado tipo (objeto central), a rede formada é denominada rede estrela (Sun et al., 2009b; Gao et al., 2006, 2005). Na Figura 2.3(c) é apresentada uma rede heterogênea estrela. Este tipo de rede pode ser vista como um caso particular das redes $k$ partidas em que $k-1$ tipos de objetos se conectam a um objeto central. Exemplos de redes que podem ser representadas por redes estrela são (i) redes compostas por usuários, consultas, e páginas web, tento as consultas como objeto central; e (ii) redes compostas por autores, conferências, artigos e palavras-chave, tendo o artigo como objeto central.

Independente do tipo de rede, as relações entre os objetos da rede podem ser geradas considerando informações "explícitas" ou informações "implícitas". Informações explícitas referem-se a relações naturais ou relações informadas explicitamente no conjunto de dados. Relações entre autores e artigos, entre documentos e termos, entre páginas web dada por hyperlinks, entre artigos científicos ou patentes dada por citações, são exemplos de relações geradas por meio de informações explícitas extraídas dos próprios conjuntos de dados.

Entretanto, alguns tipos de relações podem ser gerados por meio de informações implícitas, ou relações mineradas do conjunto de dados. Normalmente, as relações implícitas são extraídas por meio do cálculo da similaridade entre os objetos de uma rede. Para tanto, 


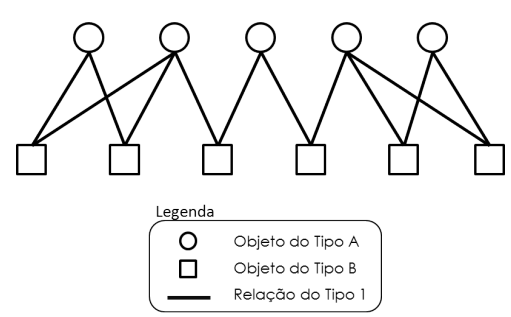

(a)

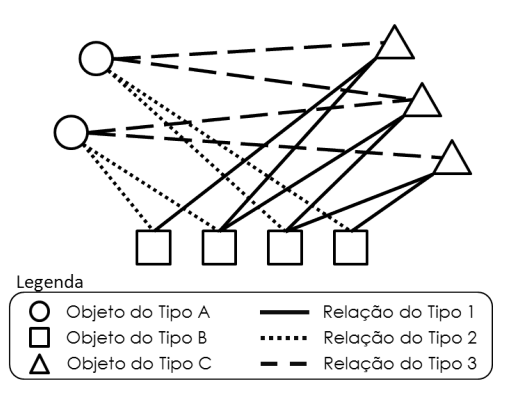

(b)

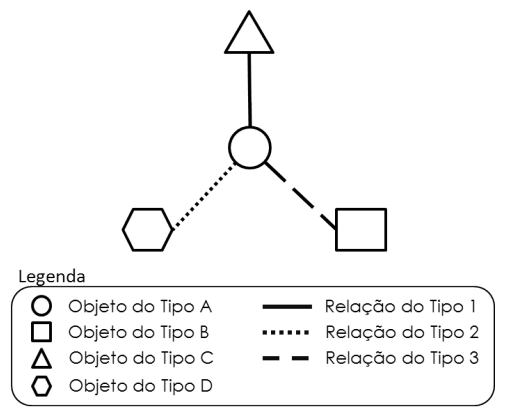

(c)

Figura 2.3: Ilustrações de redes heterogêneas: (a) rede heterogênea bipartida; (b) rede heterogênea $k$-partida com $k=3$; (c) rede heterogênea estrela.

cada objeto da rede deve conter um vetor de atributos ou alguma estrutura computacional que permita o cálculo da similaridade entre os objetos. No caso de textos, por exemplo, pode-se considerar cada documento como um objeto de rede e calcular a similaridade entre os objetos da rede considerando o vetor de termos dos documentos. Observa-se na literatura um grande uso de redes baseadas em similaridade para a representação de coleções de textos em diferentes tarefas como classificação (Tseng et al., 2012; Kim et al., 2009; Wang et al., 2005), agrupamento (Mihalcea e Radev, 2011; Marcacini e Rezende, 2010), extração de tópicos (Cai et al., 2008), sumarização de textos (Salton et al., 1997) e extração de palavras-chave (Palshikar, 2007).

A similaridade entre os objetos também pode ser utilizada para refinar ou reduzir o número de relações extraídas por meio de informações explícitas, o que reduz o consumo de memória, torna o processamento da rede mais rápido, e pode aumentar a qualidade dos resultados obtidos pela modelagem em redes (Angelova e Weikum, 2006). Pode-se também calcular a similaridade entre os documentos por meio de uma combinação das relações explícitas e o conteúdo dos documentos (Menczer, 2004; Modha e Spangler, 2000). Além disso, a combinação de relações explícitas e implícitas pode melhorar a qualidade dos resultados extraídos por meio da modelagem em redes (Macskassy, 2007).

As relações entre objetos modeladas em uma rede são úteis para inferir grupos ou classes uma vez que objetos relacionados tendem a pertencer ao mesmo grupo ou classe. Além disso, a modelagem em redes permite considerar uma cadeia de relações, isto é, pode-se utilizar as informações de vizinhos de vizinhos para definir os grupos ou classes dos objetos da rede. Dado isso, algoritmos de aprendizado de máquina baseado em redes, ou mineração de dados em redes, ou simplesmente mineração de redes, têm ganhado muita atenção nos últimos anos (Missaoui e Sarr, 2015; Wang et al., 2014; Kang et al., 2014; Sun e Han, 2013; Tsai et al., 2012; Sun e Han, 2012; Ting et al., 2011; Newman, 2010; Aggarwal e Wang, 2010; Yu et al., 2010; Ng, 2009).

Técnicas de visualização e medidas para extrair propriedades dos objetos (PageRank, HITS, closeness, betweenness, e coeficiente de agrupamento) e das características das redes (grau médio, caminho mínimo médio, diâmetro, e coeficiente de agrupamento médio) também podem ser utilizadas para extração de conhecimento (Mihalcea e Radev, 2011; 
Newman, 2010). Além disso, as redes permitem (i) a representação hierárquica do conjunto de dados uma vez que uma rede pode ser particionado em sub-redes; (ii) o aprendizado de grupos e classes em formatos arbitrários; e (iii) a combinação tanto estatísticas locais quanto globais do conjunto de dados (Bertini et al., 2011; Breve, 2010). Todas essas possibilidades geradas pela modelagem em redes podem melhorar a qualidade dos resultados das diferentes tarefas de aprendizado de máquina.

As representações em redes vêm sendo utilizadas em diversas tarefas como agrupamento de objetos (ou detecção de comunidades) (Valejo et al., 2014; Long et al., 2010; Sun et al., 2009a; Xu et al., 2007; Gao et al., 2005; Danon et al., 2005; Ding et al., 2001), predição de links (Valverde-Rebaza e de Andrade Lopes, 2013; Lü e Zhou, 2011; Miller et al., 2009), classificação de objetos da rede (Angelova et al., 2012; Ji et al., 2010; Yin et al., 2009b; Xue et al., 2004), e regressão (Wan et al., 2015; Ni et al., 2012; Wang et al., 2007).

\section{Estruturas Computacionais para a Representação de Redes}

Uma das estruturas computacionais mais utilizadas para a representação de redes é a matriz de adjacências. Cada célula da matriz de adjacências indica se existe relação entre objetos da rede e seus respectivos pesos. Em uma rede homogênea, a matriz de adjacências tem dimensões $|\mathcal{O}| \times|\mathcal{O}|$. Na Tabela 2.2 é apresentada uma matriz de adjacências para redes homogêneas. Nesta matriz, $w_{o_{i}, o_{j}}$ corresponde ao peso da relação entre os objetos $o_{i}$ e $o_{j}$. Nesta tese a matriz de adjacência será denotada por W.

Tabela 2.2: Matriz de adjacências

\begin{tabular}{c||c|c|c|c}
\hline \hline & $\mathbf{O}_{\mathbf{1}}$ & $\mathbf{O}_{\mathbf{2}}$ & $\ldots$ & $\mathbf{O}_{|\mathcal{O}|}$ \\
\hline \hline $\mathbf{O}_{1}$ & $w_{o_{1}, o_{1}}$ & $w_{o_{1}, o_{2}}$ & $\ldots$ & $w_{o_{1}, o_{|\mathcal{O}|}}$ \\
\hline $\mathbf{O}_{2}$ & $w_{o_{2}, o_{1}}$ & $w_{o_{2}, o_{2}}$ & $\ldots$ & $w_{o_{2}, o_{|\mathcal{O}|}}$ \\
\hline$\vdots$ & $\vdots$ & $\vdots$ & $\ddots$ & $\vdots$ \\
\hline $\mathbf{O}_{|\mathcal{O}|}$ & $w_{O_{|\mathcal{O}|}, o_{1}}$ & $w_{o_{|\mathcal{O}|}, o_{2}}$ & $\ldots$ & $w_{o_{|\mathcal{O}|}, o_{|\mathcal{O}|}}$ \\
\hline \hline
\end{tabular}

Essa mesma matriz de adjacência também pode ser usada para representar redes heterogêneas. Neste caso, existem duas possibilidades: (i) os objetos são ordenados de acordo com o tipo em uma única matriz, ou (ii) gera-se uma matriz para cada tipo diferente de relação entre objetos. Para ilustrar as duas possibilidades, considere uma rede heterogênea na qual $\mathcal{O}=\mathcal{O}_{1} \cup \mathcal{O}_{2} \cup \ldots \cup \mathcal{O}_{h}$. Na primeira possibilidade, os índices dos objetos do tipo $\mathcal{O}_{j}$ nesta matriz variam de $1+\sum_{\mathcal{O}_{i} \in \mathcal{O}, i<j}\left|\mathcal{O}_{i}\right|$ a $\sum_{\mathcal{O}_{i} \in \mathcal{O}, i \leq j}\left|\mathcal{O}_{i}\right|$. Uma ilustração deste tipo de matriz é apresentada na Figura 2.4. Na segunda possibilidade, gera-se uma matriz de adjacências de dimensões $\left|\mathcal{O}_{i}\right| \times\left|\mathcal{O}_{j}\right|$ para cada $\mathcal{O}_{i}, \mathcal{O}_{j} \in \mathcal{O}$, nas quais as células representam os pesos das relação entre objetos do tipo $\mathcal{O}_{i}$ e objetos do tipos $\mathcal{O}_{j}$. As matrizes geradas na segunda possibilidade correspondem à submatrizes da primeira possibilidade. Será utilizada a notação $\mathbf{W}\left(\mathcal{O}_{i}, \mathcal{O}_{j}\right)$ para representar uma matriz de adjacência refente às relações entre objetos do tipo $\mathcal{O}_{i}$ e objetos do tipo $\mathcal{O}_{j}$. 


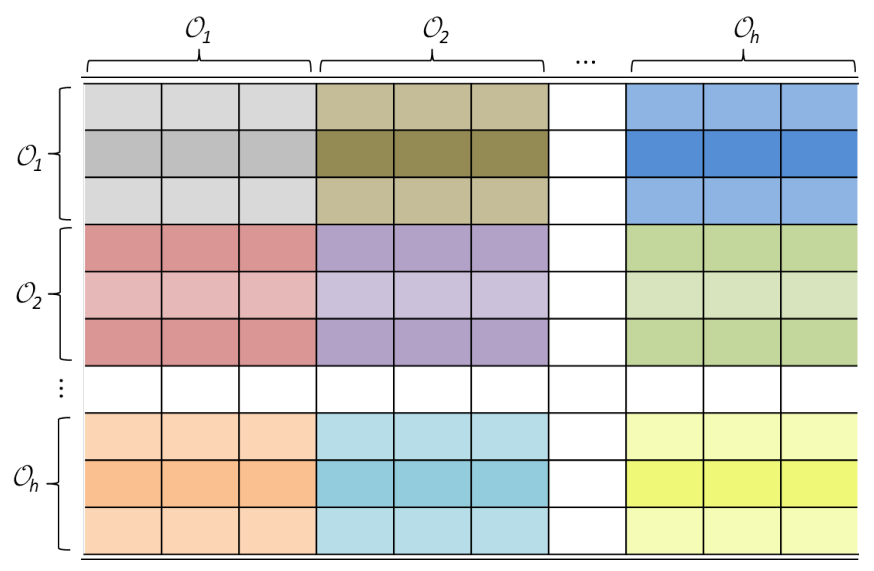

Figura 2.4: Matriz de adjacências para redes heterogêneas.

Vários cálculos de medidas e algoritmos de aprendizado baseados em redes são formulados considerando a representação em matrizes de adjacência. Portanto, este tipo de representação permite a aplicação direta da matriz nos cálculos e algoritmos. Entretanto, a matriz de adjacências é comumente esparsa, isto é, a maioria dos objetos apresenta um número de conexões muito inferior ao número de objetos da rede, gerando portanto um desperdício de memória. Inserir, remover ou mesmo verificar a existência de uma relação na matriz de adjacências tem complexidade $O(1)$. Entretanto, a enumeração, isto é, a listagem dos vizinhos de um nó, tem custo $O(|\mathcal{O}|$ ) (custo de percorrer toda a linha da matriz de adjacência). Uma vez que esse tipo de operação é comum nos algoritmos de aprendizado de máquina, torna-se inviável o uso de matrizes de adjacência para representar grandes redes esparsas, uma vez que a enumeração dos $|\mathcal{O}|$ objetos de uma rede terá custo $O\left(|\mathcal{O}|^{2}\right)$ além do desperdício de memória mencionado anteriormente. Entretanto, para redes não esparsas, a matriz de adjacência apresenta custo de enumeração equivalente a de outras alternativas para representação de redes. Vale ressaltar que no caso de redes não direcionadas, a matriz de adjacências é simétrica. Neste caso, pode-se considerar apenas a matriz diagonal inferior ou superior para diminuir o consumo de memória.

Uma alternativa à matriz de adjacência, e uma das estruturas mais utilizadas para representar redes (Newman, 2010), é a lista de adjacências. A lista de adjacência é constituída por um conjunto de listas, cada lista relacionada a um objeto. Para redes homogêneas, cada elemento da lista é composto por um índice, que se refere ao objeto no qual existe relação, e o peso da relação, como ilustrado na Figura 2.5. Para redes heterogêneas, pode-se criar listas de adjacência para cada tipo de relação, ou ainda, adicionar um índice em cada elemento da lista contendo informação sobre o tipo de relação. No caso de redes direcionadas, é criada uma lista de adjacência considerando apenas as arestas de entrada e outra considerando apenas as arestas de saída.

A inserção de novas relações da lista de adjacência tem custo $O(1)$, assim como na matriz de adjacências. Já o custo para verificar a existência de uma relação, remoção ou enumeração é $O(|\mathcal{R}| /|\mathcal{O}|)$. Essas três operações envolvem a verificação de todos os elementos de uma lista de adjacências, que em média corresponde ao grau médio da 


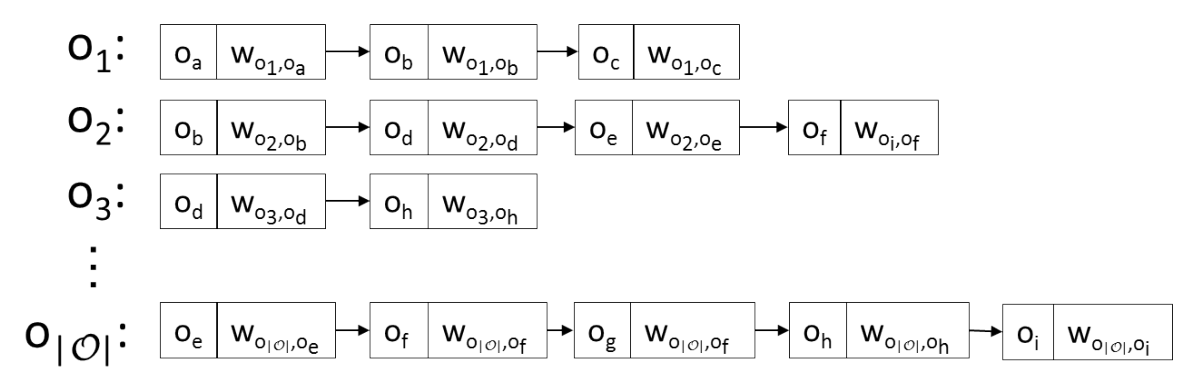

Figura 2.5: Lista de adjacências para redes homogêneas.

rede $(|\mathcal{R}| /|\mathcal{O}|)$. Esse tipo de estrutura apresenta vantagens em relação a matriz de adjacência para tarefas de aprendizado de máquina quando as redes são esparsas. A maior velocidade na enumeração torna o processo de aprendizado mais rápido. Também há um menor consumo de memória, uma vez que não se consome memória considerando relações inexistentes entre os objetos, permitindo a manipulação de redes com grande número de objetos e relações ${ }^{2}$. Já para redes não esparsas, o custo de enumeração é equivalente ao da matriz de adjacências, porém, o consumo de memória é maior devido ao fato de a lista de adjacência ter que armazenar o índice dos objetos da rede. Devido às vantagens de determinados tipos de estrutura computacional em determinadas situações, tanto a representação em matriz quanto a representação em listas de adjacência foram consideradas nas implementações dos algoritmos baseados em redes apresentados nos Capítulos 3, 4 e 5 .

Além de representar diretamente as informações das relações entre objetos da rede em uma matriz ou lista, pode-se derivar deste tipo de informação denominada matriz Laplaciana (Merris, 1994). A matriz Laplaciana é da por:

$$
\mathbf{L}=\mathbf{D}-\mathbf{W},
$$

na qual D é uma matriz na qual cada célula da diagonal contém o grau dos vértices das linhas correspondentes, isto é, $d_{o_{i}, o_{i}}=\sum_{o_{j} \in \mathcal{O}} w_{o_{i}, o_{j}}$, e os demais valores são 0 . A matriz Laplaciana é utilizada para extrair importantes aspectos da rede e é utilizada em soluções fechadas de algoritmos de aprendizado de máquina baseado em rede (Fritscher, 2011; Del-Vecchio et al., 2007). Entretanto, dado que nesta tese optou-se por algoritmos baseados em rede com soluções iterativas para atender aos requisitos de velocidade de classificação estabelecidos nesta tese, a matriz Laplaciana não foi utilizada.

\subsubsection{Representações de Textos em Redes}

No que se refere aos tipos de dados considerados nesta tese, encontra-se na literatura afirmações sobre as representações em redes serem uma forma natural e direta de representar

\footnotetext{
${ }^{2}$ Além das estruturas computacionais em formas de matrizes e listas de adjacências, existem outras estruturas como as representações em árvores de adjacência, representação híbrida matriz/lista, e heap (Newman, 2010). Entretanto, esses tipos de representações computacionais são menos comuns que a lista de adjacências, além dos custos de enumeração e consumo de memória não serem inferiores aos da lista de adjacências.
} 
dados textuais para diferentes tarefas (Blanco e Lioma, 2012; Mihalcea e Radev, 2011). Segundo Blanco e Lioma (2012), a representação em redes é poderosa, uma vez que permite integrar diferentes aspectos, como topológicos, estatísticos e gramaticais em um único modelo e em um formalismo matematicamente tratável.

As representações de textos em redes são usadas em diferentes tarefas nas diferentes áreas que envolvem processamento e análise textual. Por exemplo, na área de Mineração de Textos, observa-se o uso das representações em redes nas tarefas de classificação (Mishra et al., 2012; Ji et al., 2010; Kim et al., 2009; Subramanya e Bilmes, 2008; Macskassy e Provost, 2007; Angelova e Weikum, 2006; Aery e Chakravarthy, 2005; Gee e Cook, 2005; Schenker et al., 2003; Lu e Getoor, 2003; Oh et al., 2000; Chakrabarti et al., 1998), agrupamento (Dhillon, 2001; Zha et al., 2001), extração de tópicos (Wang et al., 2013; Weninger et al., 2012; Deng et al., 2011; Marcacini e Rezende, 2010; Cai et al., 2009; Mei et al., 2008a), e visualização e exploração de coleções de documentos (Tomita et al., 2004; Tseng et al., 2012). Na área de Recuperação de Informação, observa-se o uso de representações em redes tanto para realizar o ranqueamento de páginas web (Yang et al., 2006; Kleinberg, 1999; Page et al., 1999a; Lu, 1990) quanto para a recomendação de páginas, notícias e livros (Konstas et al., 2009; Wang et al., 2008; Huang et al., 2002). Já na área de Processamento de Linguagem Natural, representações de textos em redes têm-se sido usadas na extração de palavras-chave (Wan et al., 2007; Palshikar, 2007; Mihalcea e Tarau, 2004; Matsuo et al., 2001; Ohsawa et al., 1998), sumarização de textos (Samei et al., 2014; Ferreira et al., 2013; Mihalcea e Tarau, 2005; Erkan e Radev, 2004; Mihalcea e Tarau, 2004; Zha, 2002; Salton et al., 1997), segmentação de textos (Malioutov e Barzilay, 2006), resolução de correferência (Ng, 2009), tradução automática (Amancio et al., 2008; Monz e Dorr, 2005), disambiguação de palavras (Amancio et al., 2012a; Agirre e Soroa, 2009; Dorow e Widdows, 2003), disambuiguação de nomes (Amancio et al., 2012b), e definição de pesos dos termos no modelo espaço-vetorial (Hassan et al., 2007).

Diferentes tipos de objetos e diferentes tipos de relações podem ser utilizas para gerar representações de textos ${ }^{3}$. Alguns autores definem 3 tipos básicos de redes para representar textos (Mihalcea e Radev, 2011; Liu et al., 2008; Sole et al., 2005):

Redes semânticas: os nós representam conceitos ou palavras e as arestas representam as relações semânticas entre conceitos e/ou palavras. Três tipos de redes semânticas dentre as mais famosas são (i) Rede Associativa (Steyvers e Tenenbaum, 2005; Nelson et al., 1999), na qual dada uma palavra (sugestão), pessoas tinham que escrever a primeira palavra que vinha à mente relacionada à sugestão, criando um link entre a sugestão e a palavra associada; (ii) Roget's Thesaurus (Roget, 1966), a qual possui 29000 palavras relacionadas com 1000 categorias semânticas (ex. existência, quantidade, ordem, número, tempo, dimensão, forma e movimento) formando uma rede bipartida; e (iii) WordNet (Miller et al., 1990), que é uma base de dados léxicos

\footnotetext{
${ }^{3}$ Todas as técnicas de pré-processamento de textos apresentadas na Seção 2.2.2, como simplificação de termos, extração de termos simples e compostos, e remoção de stopwords, podem ser utilizadas na geração das redes para representar textos.
} 
contendo nomes, verbos, adjetivos, advérbios, e colocações, agrupados em conjuntos de sinônimos cognitivos (synsets), na qual cada synset representa conceitos distintos, e os synsets são conectados por meio de relações semânticas do tipo sinonímia, hiperonímia, hiponímia, meronímia, antonímia, ou relações do tipo "É-UM".

Redes de dependência: este tipo de rede é gerada de acordo com os formalismos da gramática. As dependências sintáticas conectam palavras denominadas "cabeças" com as palavras denominadas "modificadores". As redes são direcionadas e uma palavra do tipo modificador aponta para uma palavra do tipo cabeça.

Redes de coocorrência: neste tipo de rede, duas palavras são relacionadas se aparecem na mesma sentença, parágrafo ou janela de palavras. A representação de textos em redes de coocorrência é mais comum do que os dois primeiros tipos de rede. Esse tipo de rede pode ser tanto direcionada, isto é, se um termo $t_{i}$ ocorre antes de $t_{j}$ é gerada uma aresta direcionada de $t_{i}$ para $t_{j}$, ou não direcionada, na qual não é considerada a ordem que as palavras ocorrem. As arestas também podem ser não ponderadas quanto ponderadas. No último caso, pode-se considerar o número de vezes em que as palavras coocorrem ou ainda utilizar medidas como $\chi^{2}$ ou Pointwise Mutual Information para definir o peso das relações (Mihalcea e Radev, 2011; Gamon, 2006). Também pode-se eliminar arestas cujo peso não ultrapasse um limiar neste tipo de rede (Amancio et al., 2011). Segundo Liu et al. (2008), as relações de coocorrência refletem parcialmente as relações sintática e semânticas de um texto.

Várias das redes propostas na literatura, principalmente as redes de termos (apresentadas na Seção 2.3.2), são derivadas dos três tipos de rede apresentadas acima. Esses três tipos de redes consideram apenas palavras como objetos da rede. Além dessas, outros tipos de objetos e outros tipos de relações além das sintáticas, semânticas, e de coocorrência, podem ser utilizadas para modelar textos em redes. Por exemplo, pode-se gerar redes homogêneas nas quais os objetos e relações correspondem respectivamente à (i) sílabas (Soares et al., 2005), sendo que duas sílabas são conectadas se fazem parte da mesma palavra; (ii) sentenças, conectando sentenças similares entre sí (Mihalcea e Tarau, 2004; Salton et al., 1997), (iii) documentos, conectando documentos por meio de hyperlinks (Page et al., 1999a; Kleinberg, 1999), ou de acordo com a similaridade (Cai et al., 2009; Subramanya e Bilmes, 2008; Yang et al., 2006); ou mesmo (iv) termos, considerando a similaridade de termos em cada documento (Palshikar, 2007; Ohsawa et al., 1998), ou na coleção de documentos (Tseng et al., 2012; Marcacini e Rezende, 2010; Jacobs, 2002).

Pode-se também gerar redes heterogêneas compostas por diferentes tipos de objetos e relações para representar textos. Por exemplo, uma coleção de artigos científicos pode ser representada por uma rede heterogênea na qual os objetos correspondem a autores, termos, artigos, e conferências ou locais de publicação. Artigos e autores podem ser conectados com relações do tipo escrito por e escreve, artigos e locais podem ser conectados publicado 
em e publica, e artigos e termos podem ser conectados por relações do tipo contém e contido em (Wang et al., 2013; Deng et al., 2011; Ji et al., 2010).

\subsubsection{Representações Existentes Baseadas em Redes para Classificação de Textos}

Nesta seção são apresentadas as formas de geração e demais detalhes pertinentes das representações baseadas em redes que foram utilizadas na literatura para a classificação de textos. Dentre as inúmeras possibilidades para modelagem de textos em redes, observam-se dois tipos predominantes de redes para a tarefa de classificação: redes de documentos e redes de termos. Recentemente, observa-se com menor frequência o uso de redes heterogêneas na classificação de textos. Na próxima seção são apresentados mais detalhes sobre as representações baseadas em redes de documentos, redes de termos e redes heterogêneas.

\section{Rede de Documentos}

Em uma rede de documentos, $\mathcal{O}=\mathcal{D}$, na qual $\mathcal{D}=\left\{d_{1}, d_{2}, \ldots, d_{n}\right\}$ representa os documentos de uma coleção. As primeiras pesquisas envolvendo a modelagem de textos utilizando redes de documentos consideraram relações explícitas para gerar a rede, como hyperlinks e citações (Lu e Getoor, 2003; Oh et al., 2000; Chakrabarti et al., 1998). Porém, pesquisas posteriores demonstraram que considerar a similaridade ao invés das relações explícitas para gerar uma rede de documentos provê melhores resultados (Angelova e Weikum, 2006). Além disso, com o advento da área de aprendizado semissupervisionado, redes de documentos baseadas em similaridade têm sido mais utilizadas (Subramanya e Bilmes, 2008; Belkin et al., 2006; Zhou et al., 2004; Zhu et al., 2003a).

Nesta tese foram consideradas redes baseadas em similaridade, uma vez que este tipo de rede não depende de informações explicitas e pode ser utilizada para modelar qualquer coleção de documentos textuais em uma rede de termos, além de melhorar a performance de classificação. Na Figura 2.6 é apresentada uma ilustração sobre uma rede de documentos baseada em similaridade.
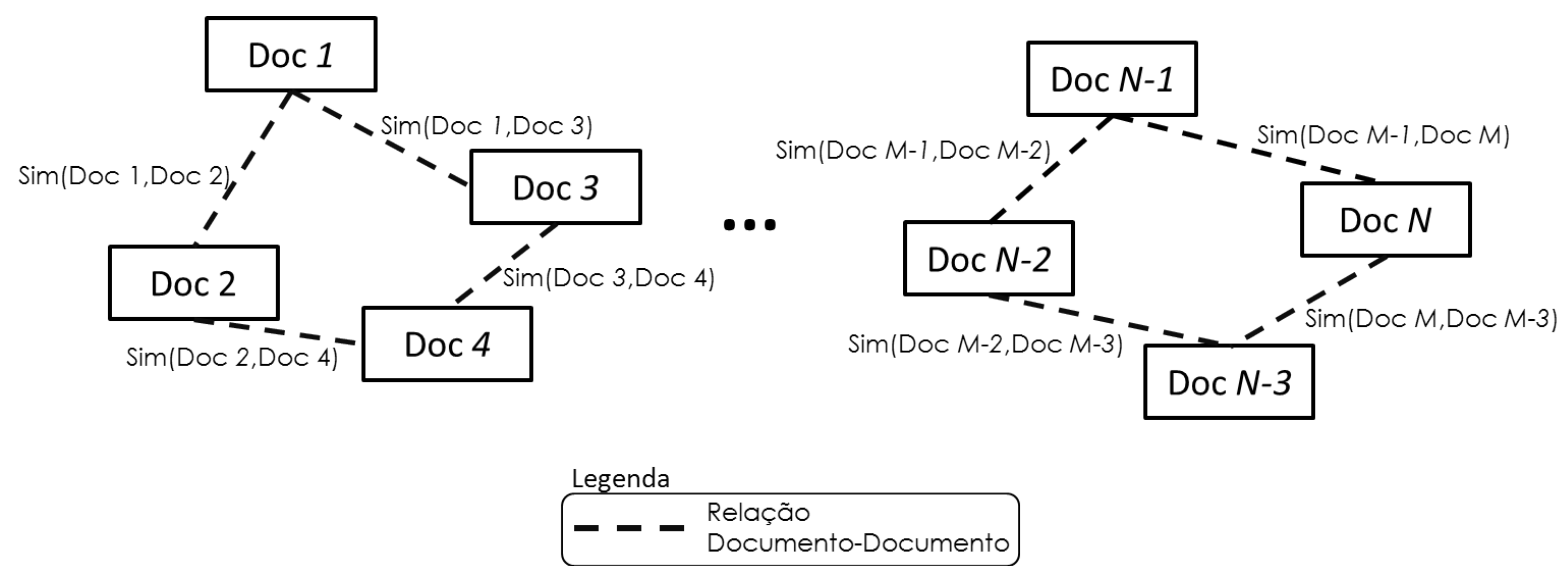

Figura 2.6: Ilustração de uma rede de documentos baseada em similaridade.

O primeiro passo para gerar uma rede de documentos baseada em similaridade é 
calcular a similaridade entre todos os documentos da coleção. As similaridades, na maioria dos trabalhos, são calculadas com base nos vetores de atributos dos objetos da rede, ou seja, assume-se que os objetos da coleção possuem uma representação no modelo espaço-vetorial. Em uma coleção de textos, normalmente assume-se que os documentos estão representados em uma bag-of-words. Em alguns domínios específicos, outros tipos de atributos podem ser gerados para o cálculo da similaridade. Por exemplo, em Kim et al. (2009), cada página web $d_{i}$ contém um vetor, na qual cada dimensão corresponde à uma consulta, e o valor de cada dimensão corresponde ao número de cliques de usuários na página $d_{i}$ dada a consulta correspondente ao atributo.

A medida cosseno é comumente utilizada para calcular similaridade entre documentos (Aggarwal, 2014; Manning et al., 2008; Tan et al., 2005). A similaridade cosseno entre um documento $d_{i}$ e um documento $d_{j}$ é dada por:

$$
\operatorname{Cosseno}\left(\mathbf{w}_{d_{i}}, \mathbf{w}_{d_{j}}\right)=\frac{\mathbf{w}_{d_{i}} \cdot \mathbf{w}_{d_{j}}}{\left\|\mathbf{w}_{d_{i}}\right\| \cdot\left\|\mathbf{w}_{d_{j}}\right\|}=\frac{\sum_{t_{k} \in \mathcal{T}} w_{d_{i}, t_{k}} \cdot w_{d_{j}, t_{k}}}{\sqrt{\sum_{t_{k} \in \mathcal{T}}\left(w_{d_{i}, t_{k}}\right)^{2}} \cdot \sqrt{\sum_{t_{k} \in \mathcal{T}}\left(w_{d_{j}, t_{k}}\right)^{2}}}
$$

na qual $\mathbf{w}_{d_{i}}$ e $\mathbf{w}_{d_{j}}$ são os vetores de atributos dos documentos $d_{i}$ e $d_{j}$ respectivamente.

Após computada a similaridade entre os documentos, algumas estratégias podem ser adotadas para gerar as redes baseadas em similaridade. As estratégias mais utilizadas são Zhu (2005b):

- Rede totalmente conectada: todos os pares de documentos $d_{i}, d_{j} \in \mathcal{D}$ são conectados se Cosseno $\left(\mathbf{w}_{d_{i}}, \mathbf{w}_{d_{j}}\right)>0$. As arestas da rede devem ser necessariamente ponderadas para que se possam identificar quais documentos são mais similares a outros e com isso melhorar a qualidade dos resultados. Normalmente usa-se uma função Gaussiana ou kernel Radial Basis Function (RBF) para ponderar a similaridade entre os elementos da rede. O intervalo de valores de similaridades utilizando uma função Gaussiana é $[0,1]$ seu valor descresse conforme aumente a distância entre dois objetos da rede. O peso da relação entre um documento $d_{i}$ e um documento $d_{j}$ utilizando uma função Gaussiana é dada por:

$$
w_{d_{i}, d_{j}}=\exp \left(\frac{-\left(1-\operatorname{Cosseno}\left(\mathbf{w}_{d_{i}}, \mathbf{w}_{d_{j}}\right)\right)^{2}}{\sigma^{2}}\right)
$$

na qual $\sigma$ controla a abertura da função gaussiana. Esse tipo de rede é comumente utilizada nos algoritmos de aprendizado semissupervisionados baseados em rede. Entretanto, esse tipo de rede tende a ser não esparsa devido ao alto número de conexões geradas, e consequentemente, o custo computacional dos algoritmos de classificação neste tipo de rede pode ser alto. Esse tipo de rede será tratada por Rede Gaussiana ou Rede Exp nesta tese. 
- Rede esparsa: ao contrário da rede totalmente conectada, neste tipo de rede cada documento está normalmente conectado a poucos documentos. As redes esparsas são processadas mais rapidamente do que as redes totalmente conectadas. As arestas não necessariamente precisam ter peso, uma vez que se um documento está conectado a outro em uma rede esparsa significa que existe uma forte relação entre os documentos. Entretanto, normalmente adota-se o valor da similaridade, podendo ser ponderada por função Gaussiana (Equações 2.24), para definir o peso das relações. As principais abordagens para gerar redes esparsas são:

- Rede $k$-Nearest Neighbors ( $k \mathbf{N N}$ ): um documento $d_{i}$ é conectado a um documento $d_{j}$ se $d_{j}$ é um dos $k$ vizinhos mais próximos de $d_{i}$. O parâmetro $k$ controla a densidade, isso é, o número de conexões da rede. Vale ressaltar que um valor de $k$ muito baixo pode resultar em redes desconexas, o que pode prejudicar os resultados dos algoritmos de aprendizado de máquina semissupervisionados. Uma variante da rede $k N N$ é a rede Mutual $k N N(M k N N)$, na qual um documento $d_{i}$ e um documento $d_{j}$ são conectados se $d_{j}$ é um dos $k$ vizinhos mais próximos de $d_{i}$ e $d_{i}$ é um dos $k$ vizinhos mais próximos de $d_{j}$. Empiricamente a rede $M k N N$ provê melhores resultados que a rede $k N N$ (Ozaki et al., 2011). Além disso, redes $M k N N$ tendem a gerar menos $h u b s^{4}$ que as redes $k N N$, além do número máximo de conexões de um objeto ser limitado pelo valor de $k$.

- Rede $\epsilon$-Nearest Neighbors $(\epsilon \mathbf{N N})$ : um documento $d_{i}$ é conectado ao documento $d_{j}$ se a similaridade entre os documentos $d_{i}$ e $d_{j}$ for maior ou igual a um limiar $\epsilon$. O parâmetro $\epsilon$ controla a densidade da rede.

Além dessas redes, observa-se também o uso, menos frequente, das redes b-matching (Jebara et al., 2009) no aprendizado semissupervisionado. Nesse tipo de rede, todo objeto tem grau igual à $b$. As redes são obtidas via processo de otimização. Porém, mesmo com aproximações, o custo é proibitivo para grandes redes. Além disso, para classificação de textos, as redes $M k N N$ podem prover uma performance de classificação de textos superior a das redes b-matching (Ozaki et al., 2011).

Vale ressaltar que as redes de similaridades detalhadas anteriormente não levam em consideração a classe dos objetos na geração das redes. Isso se deve ao fato de que essas redes são comumente aplicadas no aprendizado semissupervisionado, e neste tipo de cenário, assume-se que há poucos exemplos rotulados. Portanto, construir a rede se baseando nas informações dos rótulos dos documentos pode degradar a performance de classificação quando considerados poucos exemplos rotulados (Rohban e Rabiee, 2012). Entretanto, observa-se na literatura propostas de construção de redes utilizando informações sobre os rótulos de objetos da rede. A performance de classificação utilizando esse tipo de rede é variável em relação as redes não supervisionadas (Berton e Lopes, 2014; Rohban e Rabiee, 2012).

\footnotetext{
${ }^{4}$ Um hub é um objetos com um grande número de conexões. Segundo Ozaki et al. (2011), hubs tendem a deteriorar a performance de classificação de algoritmos de aprendizado de máquina semissupervisionados.
} 
No caso do aprendizado supervisionado, em que todos os exemplos de um conjunto de dados são rotulados, pode-se considerar os rótulos dos documentos para gerar uma rede de documentos. Nesse sentido, em Lopes et al. (2009) e Bertini et al. (2011) é apresentada a rede $k$-Associada, que visa gerar componentes cujos nós pertencem à mesma classe. Esses componentes são utilizados para definir a pertinência de um novo documento a cada um dos documentos e consequentemente a cada uma das classes.

Para construir uma rede $k$-Associada, são calculados os $k$ vizinhos mais próximos de cada documento $d_{i} \in|\mathcal{D}|$. Dos $k$ vizinhos de um documento $d_{i}$, é gerada uma aresta direcionada de $d_{i}$ para todos os vizinhos cuja classe é a mesma de $d_{i}$. Após a geração das arestas, a rede é composta por componentes (subredes conectadas), cada qual composto por objetos de apenas uma classe, ou seja, uma rede $N$ é dada por $N=N_{1} \cup N_{2} \cup \ldots \cup N_{l}$, na qual $N_{i}=\left\langle\mathcal{O}_{i}, \mathcal{R}_{i}, \mathcal{W}_{i}\right\rangle$, onde $\mathcal{O}_{i}, \mathcal{R}_{i}$ e $\mathcal{W}_{i}$ correspondem respectivamente aos objetos, relações e pesos das relações de um componente $N_{i}$, e $N_{i}$ é um componente da rede $N$, ou seja, $N_{i} \subseteq N$. O número de componentes é no mínimo igual ao número de classes. Quanto maior o valor de $k$, menor o número de componentes. Os componentes são usados para estimar a probabilidade de um novo documento pertencer a um dos componentes e consequentemente inferir a classe.

Em Lopes et al. (2009) e Bertini et al. (2011) também é apresentada uma solução para gerar uma rede $k$-Associada sem a necessidade de definir o valor de $k$, denominada rede $k$-Associada Ótima. Para isso, geram-se componentes da rede $k$-Associada variando o valor de $k$ a partir de 1 e com incremento 1 até um critério de parada. Compara-se a pureza de um componente considerando um valor $k$ com um componente gerado por $(k+z)$, para $z>=1$. A pureza mede a probabilidade de ocorrer conexões entre os vértices de um mesmo componente. A pureza de um componente $N_{i}$ é dada por:

$$
\Phi_{N_{i}}=\frac{D_{N_{i}}}{2 \cdot k}
$$

na qual $D_{N_{i}}$ é o grau médio do componente $N_{i}$, e é dado por:

$$
D_{N_{i}}=\frac{1}{\left|\mathcal{O}_{i}\right|} \sum_{d_{j} \in \mathcal{O}_{i}} \sum_{d_{k} \in \mathcal{O}_{i}}\left(w_{d_{j}, d_{k}}+w_{d_{k}, d_{j}}\right) .
$$

Quanto mais compacto for o componente, isto é, quanto maior a probabilidade de haver conexões entre os objetos do mesmo componente, maior será o valor da medida de pureza. Seja $N_{i}^{(k)}$ um componente gerado por um valor $k$ e seja $N_{j}^{(k+z)}$ um componente gerado por $(k+z)$, tal que $z \geq 1$. Se $N_{i}^{(k)} \subseteq N_{j}^{(k+z)}$ e $\Phi_{N_{j}} \geq \Phi_{N_{i}}, N_{j}^{(k+z)}$ é considerado como componente ótimo. No final do processo, a rede $k$-Associada ótima é formada por um conjunto de componentes ótimos.

\section{Rede de Termos}

Em uma rede de termos, $\mathcal{O}=\mathcal{T}$, na qual $\mathcal{T}=\left\{t_{1}, t_{2}, \ldots, t_{m}\right\}$ representa o conjunto de termos de uma coleção. Diferentes abordagens de gerar redes de termos foram apresentadas 
na Seção 2.3. Independente das abordagens utilizadas, existem basicamente 4 estratégias para utilizar redes de termos na classificação de textos: (i) extrair redes de termos de cada documento da coleção e calcular a similaridade entre as redes; (ii) minerar as redes de forma a extrair atributos para o modelo espaço-vetorial e aplicar qualquer algoritmo de classificação existente baseado no modelo espaço-vetorial; (iii) utilizar as redes para definir novos pesos para os atributos no modelo-espaço-vetorial; e (iv) extrair protótipos das classes e aplicar algoritmos de classificação baseados em protótipos.

Exemplos de estratégias que extraem redes de termos de cada documento da coleção e calculam a similaridade entre as redes são apresentadas em Schenker et al. (2003) e Mishra et al. (2012). Em Schenker et al. (2003) são geradas redes de termos para representar páginas HTML. Posteriormente, se um termo $t_{j}$ precede imediatamente um termo $t_{i}$ em uma página, é criada uma aresta direcionada de $t_{i}$ para $t_{j}$. As arestas são rotuladas de acordo com as seções da página HTML em que elas ocorrem (TITLE, TEXT, e LINK). Na Figura 2.7 é ilustrada esse tipo de rede. Os pesos das arestas correspondem ao número de vezes em que ocorrem as conexões. Apenas os termos mais frequentes podem ser selecionados para diminuir o tamanho da rede. Para classificar um novo documento é utilizado o algoritmo $k$-Nearest Neighbors (apresentado na Seção 3.2.1), considerando Maximum Common Subgraphs como medida de similaridade (Bunke e Shearer, 1998).

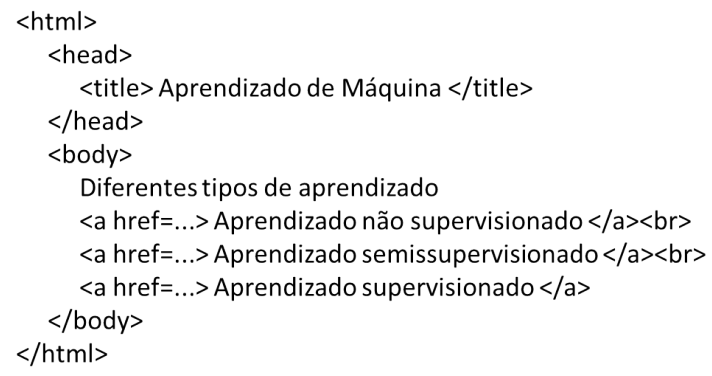

(a)

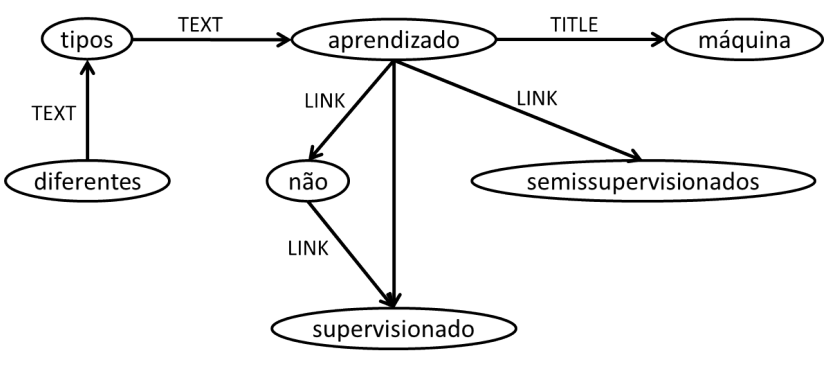

(b)

Figura 2.7: Ilustração de uma rede de termos extraída de uma página HTML (Schenker et al., 2003): (a) código fonte de uma página HTML e (b) rede extraída considerando o código fonte da Figura 2.7(a)

Em Mishra et al. (2012), são geradas redes de termos semânticas com base em um vocabulário controlado do domínio biomédico, que também contém termos, conceitos e relações entre termos e conceitos. É necessário utilizar algoritmos para reconhecimento de entidades nomeadas e conceitos. As entidades e conceitos são comparados com o vocabulário para validação e extração das relações. As relações são do tipo pai-filho, sinonímia, e irmão. Na Figura 2.8 é apresentada uma ilustração da rede proposta em Mishra et al. (2012). Após gerar a rede, uma matriz de kernel é construída contendo a similaridade entre as redes de termos geradas. As similaridades são calculadas utilizando kernels, que medem o número de termos e relações em comum entre as redes de termos dos documentos. Algoritmos baseados em uma matriz de kernel ou similaridades, como o k-Nearest Neighbors ou Support Vector Machines, podem ser empregados.

Exemplos de estratégias que extraem atributos para o modelo espaço-vetorial são 


\begin{abstract}
... A apresentação é fornecida, a respeito da histórico clínico, exame clínico, radiografia convencional, estereoradiografia, tomografia de superfície, ultrassons, tomografia computadorizada e imagem de ressonância magnética, concentrando-se nos pontos específicos para a patologia da escoliose idiopática. $O$ uso de um escoliômetro se tornou sistemático na avaliação clínica. Questionários de qualidade de vida, incluindo aqueles endossados pela Sociedade Ortopédica de Escoliose, Tratamento e Reabilitação, orientado para pacientes com escoliose, ganha popularidade e são extremamente úteis para avaliar objetivamente a deficiência relacionada com escoliose. A radiografia clássica serve como exame básico para determinar o tipo de curva e magnitude. Ultrassons, tomografia computadorizada e imagens de ressonância magnética são indicados em situação de prescrições clínicas precisas. Estereoradiografia e topografia da superfície parecem ser as técnicas mais promissoras, porém exigem padronização. Além de medições sofisticadas, a experiência de um médico não pode ser subestimada. Avaliação clínica alto padrão irá provavelmente continuar a servir como referência para outros métodos de avaliação de pacientes com escoliose...
\end{abstract}

(a)

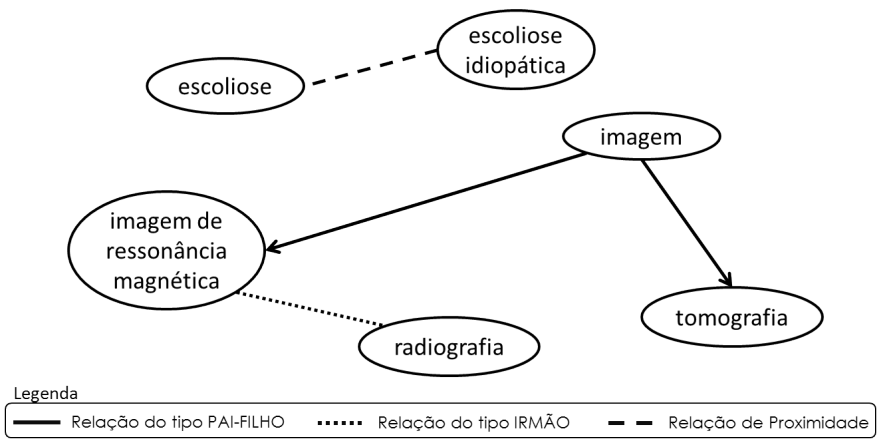

(b)

Figura 2.8: Exemplo de extração de uma rede semântica de um texto do domínio biomédico (figura adaptada de Mishra et al. (2012)): (a) texto biomédico com entidades nomeadas em negrito e (b) rede semântica considerando as entidades nomeadas extraídas do texto da Figura 2.8(a).

apresentadas em Markov et al. (2006); Jiang et al. (2010); Aery e Chakravarthy (2005); Aggarwal e Zhao (2013); Amancio (2015). Vale ressaltar que ao extrair atributos, qualquer algoritmo baseado no modelo espaço-vetorial pode ser utilizado.

Em Markov et al. (2006) são geradas redes de termos da mesma forma que as propostas por Schenker et al. (2003) (Figura 2.7). São então procuradas por sub-redes frequentes, isto é, conjuntos de nós e conexões que se repetem nas redes de termos dos documentos acima de um determinado número definido pelo usuário. As sub-redes são extraídas considerando documentos de cada uma das classes individualmente. As sub-redes frequentes são consideradas como atributos em uma representação baseada no modelo espaço-vetorial.

Em Jiang et al. (2010), são geradas redes que capturam diferentes aspectos do documento. Nas redes são representadas as palavras do texto, além de seus radicais, partof-speech, ordem de ocorrência, hiperonímias, além da estrutura, divisão e ordem das sentenças. Na Figura 2.9 é apresentada uma ilustração deste tipo de rede. Após gerar as redes, é aplicado um processo para a extração de sub-redes frequentes, que serão consideradas como atributos binários dos documentos.

Em Aggarwal e Zhao (2013), se um termo $t_{i}$ precede um termo $t_{j}$ no documento em até $k$ posições de diferença (janela), é criado um aresta direcionada de $t_{i}$ para $t_{j}$. Esse tipo de rede é denominado rede de distância. Os peso da aresta entre um termo $t_{i}$ e um termo $t_{j}$ corresponde ao número de vezes que o termo $t_{i}$ precede o termo $t_{j}$ em até $k$ posições. 


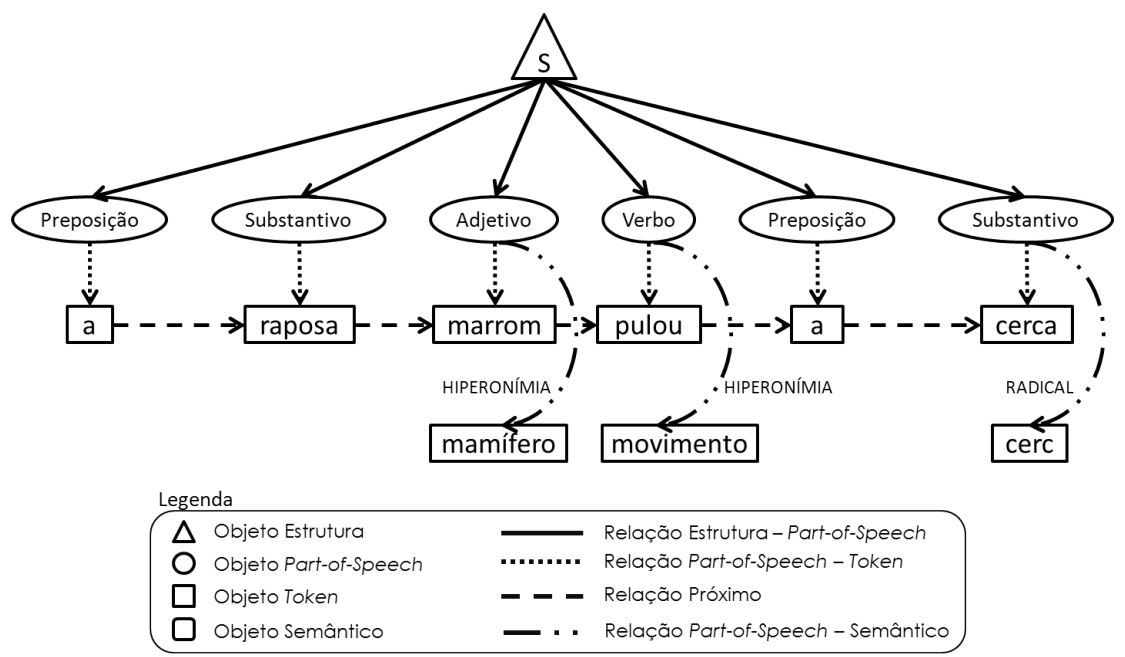

Figura 2.9: Exemplo de uma rede proposta em Jiang et al. (2010) para a sentença "A raposa marrom pulou o muro".

Cada objeto contém uma aresta para si mesmo. Neste caso, o peso da aresta corresponde à frequência do termo no documento. Na Figura 2.10 é apresentada uma ilustração deste tipo de rede. Depois de gerada a rede, para cada aresta é gerado um atributo correspondente no modelo espaço-vetorial, na qual o peso do atributo irá corresponder ao peso da aresta.

Em Amancio (2015), é gerada uma rede de termos para cada documento da coleção, na qual um termo $t_{i}$ é conectado a um termo $t_{j}$ se $t_{i}$ é adjacente a $t_{j}$ em algum documento da coleção de textos. Os objetos da rede não contém autoarestas como em Aggarwal e Zhao (2013), além das arestas serem não direcionadas. Esse tipo de rede pode ser vista portanto como uma simplificação da rede de distância com $k=1$. Após gerada a rede, são extraídas propriedades desta como coeficiente de agrupamento, grau médio, acessibilidade, betweenness, e intermitência. Essas características, com seus respectivos valores obtidos, são consideradas como atributos do documento no modelo espaço-vetorial.

Exemplos de estratégias que utilizar as redes para definir novos pesos para os atributos no modelo espaço-vetorial são apresentadas em Liu et al. (2008); Hassan et al. (2007). Em ambas as propostas é gerada uma rede coocorrência para cada documento da coleção. Um termo $t_{i}$ é conectado a um termo $t_{j}$ se $t_{i}$ e $t_{j}$ coocorrem em uma janela de palavras. Esse tipo de rede pode ser vista como uma combinação da rede de coocorrência apresentada em Amancio (2015) e da rede de distância apresentada em Aggarwal e Zhao (2013). O número de coocorrências entre $t_{i}$ e $t_{j}$ determina o peso da conexão. Para cada rede de termos é executado o algoritmo PageRank para definir um valor de importância de cada termo para cada rede. Os valores de importância são usados como pesos dos atributos no modelo espaço-vetorial.

Exemplos de estratégias que extraem protótipos para as classes da coleção de documentos são apresentadas em Wang et al. (2005), na qual é gerada uma rede de termos para cada documento da coleção. Um termo $t_{i}$ é conectado a um termo $t_{j}$ se $t_{i}$ e $t_{j}$ coocorrem frequentemente nos documentos de uma determinada classe. As redes são não direcionadas e peso da relação é dado pelo número de coocorrência dos termos. Após geradas as redes 
A classificação automática de textos pode ser realizada por meio do uso de sistemas especialistas ou algoritmos de aprendizado de máquina.

Algoritmos de aprendizado de máquina exigem menor esforço humano e maior portabilidade em comparação com sistemas especialistas.

(a)

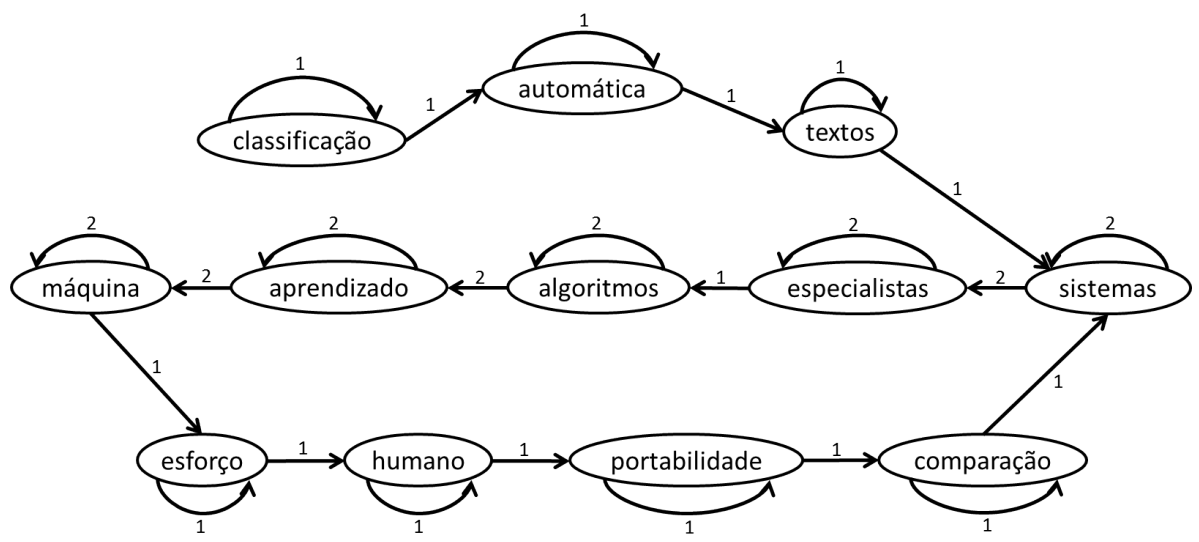

(b)

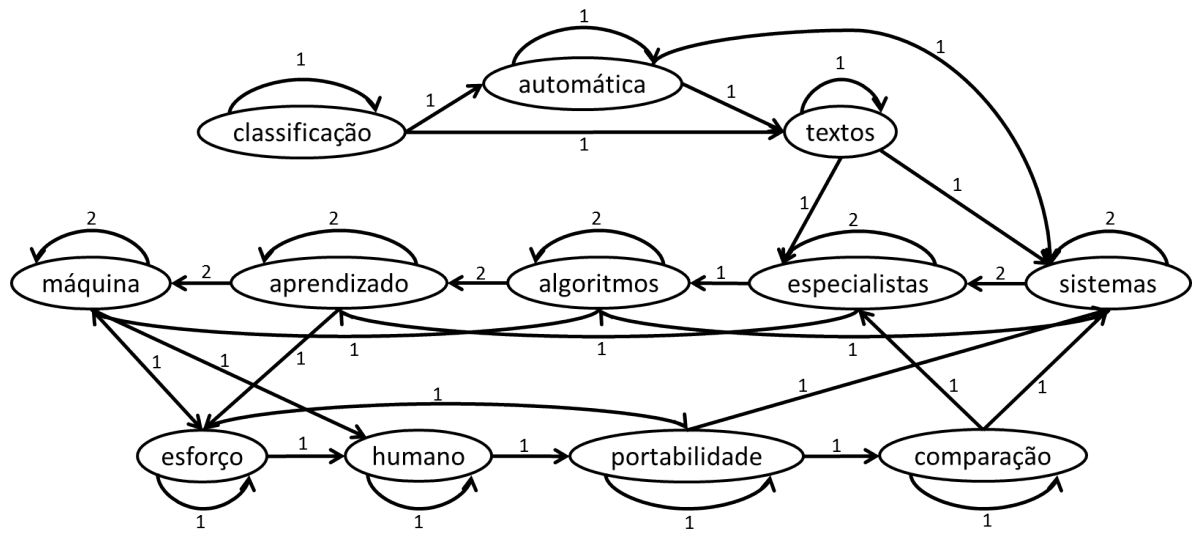

(c)

Figura 2.10: Exemplo de uma rede de distância proposta em Aggarwal e Zhao (2013): (a) texto de exemplo para geração de uma rede de distância; (b) rede de distância com $k=1$, rede de distância com $k=2$.

de termos para cada classe, é executado o algoritmo PageRank para definir a importância dos pesos para cada classe. Os valores das importâncias são usados para criar um ranking para cada termo da coleção. O valor do ranking é usado como peso do atributo no modelo espaço-vetorial. Portanto, para cada classe é gerado um vetor de atributos, também denominado protótipo.

As redes de termos existentes e utilizadas para a classificação de textos apresentam uma série de desvantagens que podem tornar a utilização dessas redes inviáveis ou mesmo impossíveis em situações práticas. Por exemplo, gerar redes de termos para cada documento da coleção pode implicar em um alto consumo ou desperdício de memória. Isso se deve ao fato que vários termos e relações entre termos se repetem ao longo da coleção de textos, e ao invés de representá-los como objetos únicos em uma única rede, estes são replicados nas 
várias redes de textos da coleção. Já a computação de similaridade entre redes, seja ela para classificação dos documentos ou para a extração de sub-redes frequentes, apresenta um alto custo computacional, sendo proibitivo para grandes coleções de documentos.

O uso de vocabulário controlado, ou a necessidade de estruturas específicas nos textos de uma coleção, como o caso das páginas $H T M L$, limita a utilização da modelagem desses tipos de redes a domínios específicos, tornando as propostas não portáveis para outras coleções ou outras aplicações. Além disso, ao se utilizar arestas das redes, ou mesmo extrair sub-redes frequentes como atributos, pode-se gerar uma dimensionalidade muitos maior que da representação bag-of-words, tendo assim um impacto negativo no tempo gasto pelo processo de classificação de textos.

Utilizar informações sintáticas na rede também aumentam o custo computacional devido à execução de $P O S$ tagging, tornam a abordagem dependente de língua, além da qualidade de classificação da rede ser dependente da qualidade dos resultados dos algoritmos de POS tagging. Já os resultados referentes à extração das propriedades das redes como atributos não são claros, uma vez que nos trabalhos em que foram propostas, não há comparações com representações baseadas no modelo espaço-vetorial, ou mesmo outras abordagens baseadas em redes. Nas poucas comparações realizadas, esse tipo de abordagem mostrou resultados inferiores a outros resultados encontrados na literatura. Além disso, há o custo computacional de se extrair diversas medidas das redes, muitas das quais são custosas computacionalmente.

\section{Redes Heterogêneas}

Recentemente observa-se o uso de redes heterogêneas para representação de coleções textos. Em Aery e Chakravarthy (2005), é utilizado uma rede estrela, na qual um objeto central representa um documento e as demais palavras do documento estão ligadas ao objeto central. As arestas são rotuladas de acordo com a seção do documento em que elas ocorrem, por exemplo, título ou corpo em páginas web ou links. Na Figura 2.11 é apresentada uma ilustração deste tipo de rede. São então extraídas sub-redes frequentes considerando os documentos de cada classe. A extração de sub-redes frequentes considerase o casamento inexato de redes, isto é, duas redes podem ser similares mesmo que elas possuam vértices ou arestas diferentes. Também é definido um valor de importância para cada sub-rede de acordo com sua representatividade para cada classe. As sub-redes são comparadas com a rede de um novo documento, e a classe é definida de acordo com a importância das sub-redes encontradas.

Em Aggarwal e Li (2011), o conjunto de objetos da rede é composto por documentos e termos. Há relações entre documentos dada por hyperlinks, chamada pelos autores de informação estrutural, e entre documentos e termos dada pela ocorrência de um termo em um documento, chamada pelos autores de informação de conteúdo. A rede gerada é denominada rede semibipartida. Na Figura 2.12 é apresentada uma ilustração de um rede semibipartida. A classificação é realizada por meio de caminhadas aleatórias considerando 


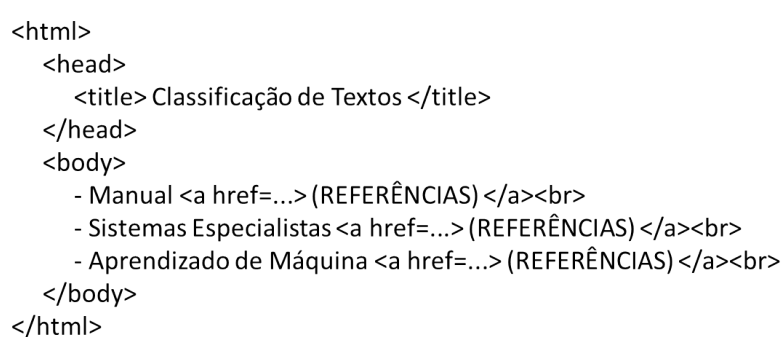

(a)

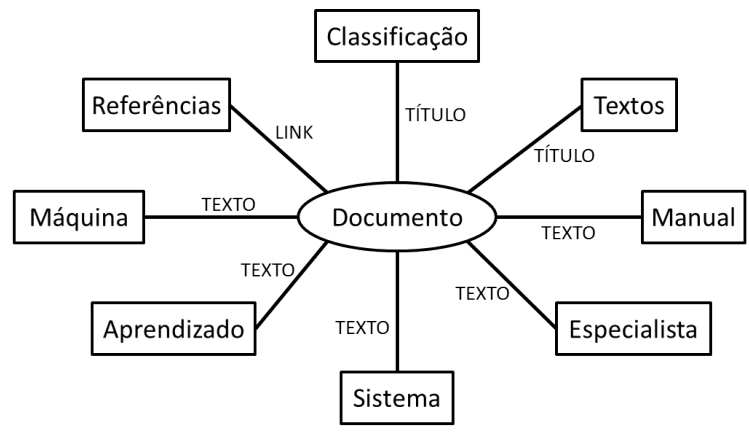

(b)

Figura 2.11: Ilustração de uma rede estrela extraída de uma página web (Aery e Chakravarthy, 2005): (a) código fonte de uma página HTML (b) rede estrela extraída considerando o código fonte da Figura 2.11(a).

tanto as relações entre documentos quanto as relações entre termos e documentos.
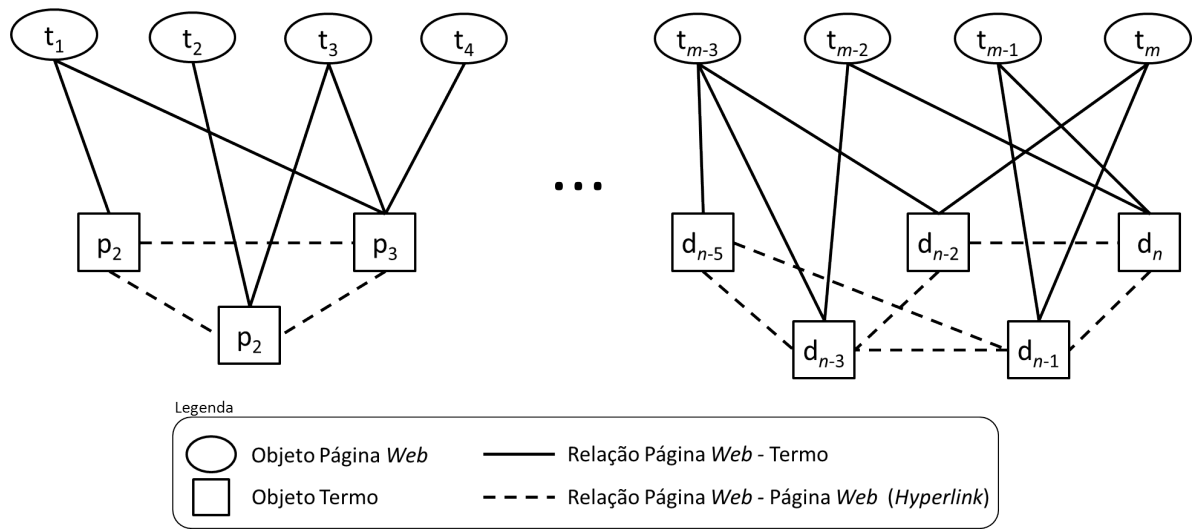

Figura 2.12: Ilustração de uma rede semibipartida proposta em Aggarwal e Li (2011).

Em Ji et al. (2010) é construída uma rede de informações bibliográficas. A rede é composta por objetos do tipo artigo, autores, local de publicação, e termos. Artigos e autores são conectados por meio de relações do tipo escrito por e escreve. Artigos e locais são conectados por meio de relações publicado em e publica. Artigos e termos são conectados por meio de relações do tipo contém e contido em. Na Figura 2.13 é apresentada uma ilustração de uma rede de informações bibliográficas. A classificação é dada por meio da propagação de rótulos entre os diferentes tipos de objetos considerando os diferentes tipos de relações entre estes, na qual é dado um peso diferente para cada tipo de relação.

Em geral, as redes heterogêneas são aplicadas apenas em domínios específicos. Além disso, as redes existentes são geradas considerando apenas informações explícitas entre os objetos. Não são consideradas relações de similaridade entre os objetos, que de acordo com a literatura, provê bons resultados para a classificação de textos, principalmente no contexto de aprendizado de máquina semissupervisionado. 


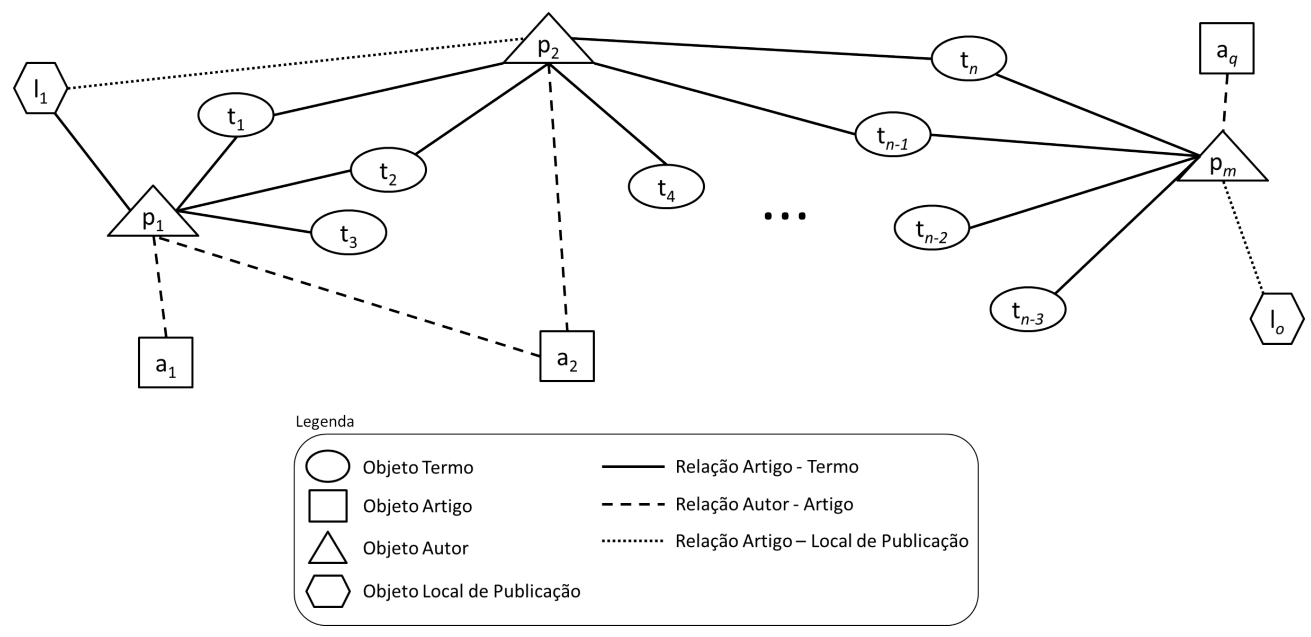

Figura 2.13: Ilustração de uma rede de informações bibliográficas.

\subsubsection{Representações em Redes Propostas e Utilizadas para Classificação de Textos}

Nesta tese foram propostas tanto a utilização de redes existentes, que não haviam sido utilizadas para a classificação, quanto propostas novas representações baseadas em redes. Foram considerados cinco requisitos tanto para propor novas representações em redes quanto para utilizar redes existentes:

Representação de qualquer tipo de coleção de textos. Várias das redes apresentadas na seção anterior são baseadas em informações explícitas, como hyperlinks e citações, ou do uso vocabulários específicos ou ontologias, como a WordNet. Isso limita a modelagem de coleções de textos em redes a domínios específicos. Optou-se nesta tese por utilizar redes que permitam representar qualquer tipo de coleção de textos independente de informações de domínio. Sendo assim, as redes propostas e utilizadas nesta tese poderão ser aplicadas a qualquer tipo de texto (notícias, tweets, artigos científicos, etc.) além de textos escritos em qualquer língua.

Representação de toda a coleção de textos em uma única rede. As pesquisas que envolvem a modelagem de redes para cada documento da coleção requerem o cálculo da similaridade entre as redes, que é custoso computacionalmente, ou a extração das propriedades dos objetos das redes ou das redes como um todo, que também apresenta alto custo computacional devido aos diversos cálculos de propriedades para cada rede. Além disso, redes individuais para cada documento apresentam um consumo de memória maior, uma vez que uma aresta que ocorre várias vezes entre o mesmo par de objetos ao longo da coleção de documento tem de ser representada várias vezes. Isso torna a classificação de textos baseadas em redes inviável ou mesmo impossível para grandes coleções de textos. Portanto, representar toda a coleção de textos em uma única rede pode diminuir o consumo de memória e tornar o processo de aprendizado de máquina para classificação de textos viável mesmo para grandes coleções de textos. Outro fator importante é que ao modelar textos em uma única 
rede permite-se utilizar algoritmos de propagação de rótulos em redes que são os mais utilizados no aprendizado semissupervisionado.

Extração de relações entre objetos desconsiderando a classe dos textos. Algumas pesquisas da literatura fazem uso das classes dos documentos de uma coleção para extrair relações entre objetos da coleção de documentos. Entretanto, como o escopo desta tese envolve tanto o aprendizado supervisionado, quanto semissupervisionado, que em casos extremos pode conter apenas um documento rotulado para cada classe, considerar a classe para extrair relações entre os objetos pode levar a relações espúrias, uma vez que padrões extraídos considerando poucos exemplos rotulados podem não refletir os padrões reais presentes na coleção de textos. Além disso, a extração de relações de maneira não supervisionada tem sido comumente utilizada na literatura, apresentando resultados equiparáveis a outras técnicas mais sofisticadas que utilizam informações de classe para extração de relações.

Representação de diferentes tipos de relações em uma única rede. Ao modelar diferentes tipos de relações em uma única rede, as diferentes semânticas das diferentes relações, e consequentemente, os diferentes padrões estruturados pelas diferentes relações, são considerados diretamente e em conjunto para definir a classe dos objetos da rede. Isso não é possível ao considerar redes compostas por relações simples, uma vez que as classes dos objetos seriam definidas considerando um único tipo de relação. Pode-se utilizar técnicas de ensemble para classificar diferentes relações modeladas cada qual em uma rede para definir as classes dos objetos utilizando diferentes relações. Entretanto, em cada rede as classes dos objetos seriam definidas utilizando relações simples. Além disso, uma gama de técnicas pode ser aplicada para combinar as classificações obtidas em cada rede (Jurek et al., 2014; Dietterich, 2000), dificultando assim a avaliação das combinações dos diferentes tipos de relações devido à combinação dos tipos de relações e tipos de ensemble. Outros dois pontos relevantes são o desperdício de memória ao modelar um mesmo objeto em diferentes redes e o tempo de classificação, que é menor ao considerar uma única rede composta por diferentes relações do que diversas redes com relações simples.

Custo benefício entre tempo e performance de classificação. Nesta tese foram propostas redes com diferentes custos de geração, número de objetos e relações, e consequentemente consumo de memória e impacto no tempo de classificação. Isso permite ao usuário adequar o tempo de classificação e requisitos computacionais de acordo com suas necessidades. Além disso, por meio das avaliações apresentadas nos Capítulos 3, 4 e 5, é possível o usuário das propostas ter conhecimento das perdas ou ganhos na performance de classificação ao utilizar representações mais simples ou mais complexas respectivamente.

De acordo com os requisitos apresentados acima, as redes consideradas/propostas são baseadas em dois tipos de objetos que podem ser extraídos de qualquer tipo de coleção 
de textos: documento e termo. Esses dois tipos de objetos também permitem representar toda a coleção de documentos em uma única rede, extrair redes com um único tipo de relação, documento-documento, documento-termo ou termo-termo, além da combinação dessas relações para gerar redes compostas por mais de um tipo de relação. Tanto as redes compostas por relações simples quanto as redes compostas por mais de um tipo de relação possuem diferentes custos de geração, número de objetos e relações. Além disso, relações entre documentos (documento-documento) ou relações entre termos (termo-termo) podem ser geradas por meio da similaridade entre os respectivos objetos. Conforme apresentado na Seção 2.3.2, relações baseadas em similaridades têm sido empregadas com sucesso na tarefa de classificação, entretanto, conforme apresentado na mesma seção, não vem sendo utilizadas na representação de textos em redes heterogêneas.

Todas as representações em redes consideradas/propostas nesta tese são derivadas da representação bag-of-words. Segundo Joachims (1998), pesquisas sugerem que palavras radicalizas são boas unidades de representação e que a ordem das palavras têm pouca importância para várias tarefas. Além disso, termos compostos por múltiplas palavras aumentam demasiadamente a dimensionalidade da coleção, aumentando o consumo de memória e tempo de processamento, além de não haver garantias quanto a melhora da performance de classificação considerando esse tipo de termo, como apresentado na Seção 2.2.1. Nas próximas seções serão detalhados os tipos de redes propostas nesta tese.

\section{Redes de Termos}

Usualmente os algoritmos de aprendizado de máquina consideram apenas a frequência dos termos para (i) diretamente classificar textos representados no modelo espaço-vetorial ou (ii) indiretamente classificar textos via construção de redes baseadas em similaridades ou redes de índices de palavras chaves. Portanto, não são consideradas relações entre termos. Esse tipo de relação pode ser útil para melhorar a definição de valores de relevância de termos para classes, e consequentemente melhorar a classificação de textos.

Conforme descrito na Seção 2.3.2, existem diferentes formas para gerar relações entre termos em uma rede, como a precedência ou sucessão de termos em uma sentença ou janela de palavras, relações sintáticas ou semânticas entre palavras de uma sentença, ou coocorrência de termos na coleção de documentos. Porém, como já mencionado, as redes de termos existentes para a classificação de textos não atendem os requisitos estabelecidos nesta tese. Portanto, nesta foi proposta uma forma para gerar redes de termos que considerem os requisitos apresentados anteriormente

Além dos requisitos definidos na Seção 2.3.3, também foram consideradas as seguintes premissas para a geração de uma rede de termos: (i) uma coleção de textos é composta por termos "genéricos", os quais ocorrem em documentos de diversas classes; (ii) uma coleção de textos também é composta por termos específicos "específicos", os quais ocorrem em documentos de uma ou poucas classes; e (iii) termos específicos tendem a estar fortemente relacionados entre si e fracamente relacionados com termos genéricos. Redes geradas 
com as características descritas nestas premissas podem ser úteis para definir valores de relevância de termos para as classes. Diversos algoritmos da literatura geram valores de relevância dos termos para as classes, como Support Vector Machines, Multinomial Naïve Bayes, e Linear Least Squares Fit (Aggarwal e Zhai, 2012). Entretanto, esses algoritmos só consideram as frequências dos termos para gerar tais valores. As relações entre termos podem ser úteis neste cenário, uma vez que termos específicos devem apresentar altos valores de relevância para determinadas classes, enquanto que termos genéricos devem apresentar baixos valores de relevância para todas as classes. Além disso, termos fortemente relacionados devem apresentar valores de relevância próximos, e termos fracamente relacionados devem apresentar valores de relevância distintos.

As premissas consideradas acima podem ser realizadas por meio de representações em redes de termos considerando a similaridade entre os termos ${ }^{5}$ para gerar as relações. $\mathrm{Na}$ Figura 2.14 é apresentada uma ilustração de uma rede de termos baseada em similaridade.

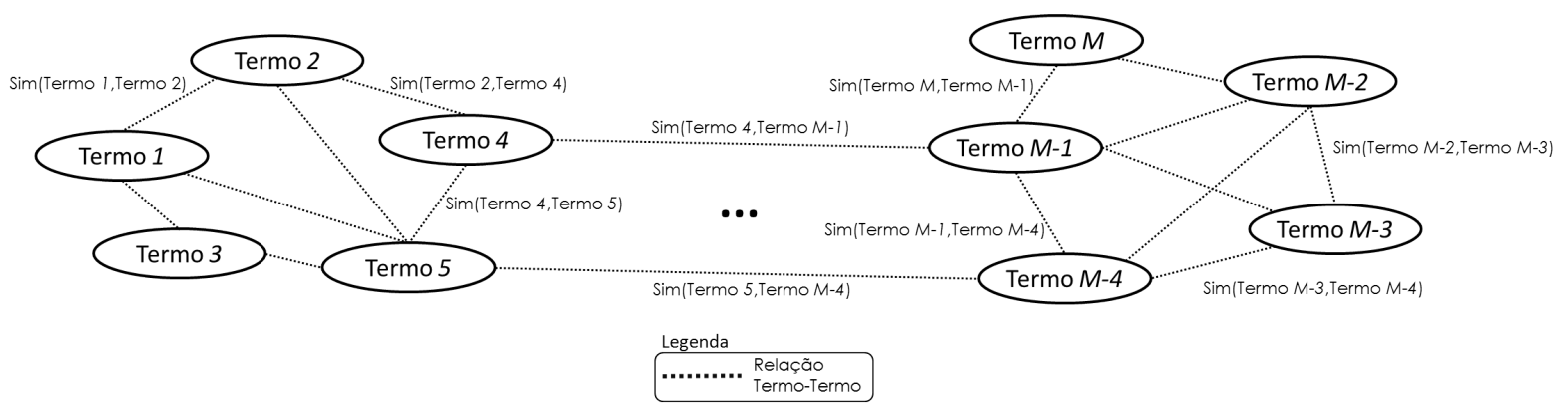

Figura 2.14: Ilustração de uma rede de termos baseada similaridade.

Diferentes medidas de similaridade entre termos podem ser utilizadas para gerar redes de termos. Entretanto, nota-se na literatura que comumente são utilizadas medidas derivadas da área de Análise de Associações. Ao utilizar medidas oriundas da área de Análise de Associações, considera-se os documentos como transações, isto é, cada documento corresponde a um conjunto de itens, e os termos que ocorrem nos documentos como itens das transações (Lopes et al., 2007; Fung et al., 2003; Liu et al., 1998). Neste caso, a frequência bem como a ordem dos termos nos documentos são ignoradas. Segundo Figueiredo et al. (2011), dois termos podem ser fortemente relacionados mesmo que estes não apareçam em sequência ou próximos nos textos de uma coleção de documentos. Além disso, dois termos podem ser fortemente relacionados mesmo que suas frequências nos textos sejam diferentes (Rossi e Rezende, 2011a; Figueiredo et al., 2011). Por exemplo, em uma coleção de textos sobre classificação de dados, os termos "aprendizado" e "máquina" podem coocorrer ao longo da coleção de textos com termos "classificação" e "dados" mesmo que as frequência dos termos "classificação" e "dados" nos documentos sejam diferentes e não linearmente proporcionais aos termos "aprendizado" e "máquina".

Vários trabalhos da literatura consideram sentenças, parágrafos e janelas de palavras dos textos como transações (redes de coocorrência) (Palshikar, 2007; Mihalcea e Tarau,

\footnotetext{
${ }^{5} \mathrm{~A}$ análise de similaridade entre termos também são tratadas na literatura por análise de associação par-a-par, análise de co-termos, análise de coocorrência.
} 
2004; Tomita et al., 2004; Matsuo et al., 2001). Entretanto, textos com poucas palavras não possibilitam a extração de relações significativas entre termos, enquanto que considerar textos como transações permite calcular a similaridade entre termos mesmo em coleções com textos curtos. Vale ressaltar também que dois termos que coocorrem nas sentenças de um texto também coocorrem na coleção de documentos. Portanto, relações entre termos extraídas considerando toda a coleção de documentos englobam as relações extraídas considerando sentenças, parágrafos ou janelas de palavras como transações.

Foram extraídas relações apenas entre pares de termos, uma vez que relações entre pares de objetos são predominantes na literatura e permitem o uso de algoritmos estado da arte para a classificação de termos. Além disso, ao considerar combinações envolvendo três ou mais termos, o número de combinações possíveis tornaria inviável sua utilização mesmo para pequenas coleções de textos, além do tempo demandado para gerar as redes de termos.

As medidas de similaridade entre um par de termos $t_{i}$ e $t_{j}$ utilizadas nesta tese são derivadas das informações contidas em uma matriz de contingência apresentada na Tabela 2.3 (Geng e Hamilton, 2006; Blanchard et al., 2005; Tan et al., 2002b). A matriz de contingência contém a probabilidade de ocorrer o termo $t_{i}\left(p\left(t_{i}\right)\right)$ e de ocorrer o termo $t_{j}\left(p\left(t_{j}\right)\right)$, probabilidade de não ocorrer o termo $t_{i}\left(p\left(\neg t_{i}\right)\right)$ ou $t_{j}\left(p\left(\neg t_{j}\right)\right)$, a probabilidade de ocorrência conjunta dos termos $t_{i}$ e $t_{j}\left(p\left(t_{i}, t_{j}\right)\right)$, a probabilidade dos termo $t_{i}$ e $t_{j}$ não ocorrerem conjuntamente $\left(p\left(\neg t_{i}, \neg t_{j}\right)\right)$ e a probabilidade de um termo ocorrer sem o outro termo $\left(p\left(t_{i}, \neg t_{j}\right)\right.$ e $\left.p\left(\neg t_{i}, t_{j}\right)\right)$.

Tabela 2.3: Matriz de contingência para os termos $t_{i}$ e $t_{j}$.

\begin{tabular}{c||c|c|c} 
& $t_{j}$ & $\neg t_{j}$ & Total \\
\hline \hline$t_{i}$ & $p\left(t_{i}, t_{j}\right)$ & $p\left(t_{i}, \neg t_{j}\right)$ & $p\left(t_{i}\right)$ \\
\hline$\neg t_{i}$ & $p\left(\neg t_{i}, t_{j}\right)$ & $p\left(\neg t_{i}, \neg t_{j}\right)$ & $p\left(\neg t_{i}\right)$ \\
\hline Total & $p\left(t_{j}\right)$ & $p\left(\neg t_{j}\right)$ & 1
\end{tabular}

A medida Suporte, apresentada na Equação 2.27, é comumente utilizada para calcular a similaridade entre termos (Marcacini e Rezende, 2010; Palshikar, 2007; Wang et al., 2005; Mihalcea e Tarau, 2004; Tomita et al., 2004) e vem sendo utilizada em diferentes áreas da mineração de textos como agrupamento (Zhang et al., 2010; Fung et al., 2003) e geração de atributos compostos por conjuntos de palavras para a classificação (Rossi e Rezende, 2011a,b; Figueiredo et al., 2011; Cheng et al., 2007; Fürnkranz, 1998). Essa medida considera apenas a probabilidade de dois termos $t_{i}$ e $t_{j}$ coocorrerem na coleção de documentos $\left(p\left(t_{i}, t_{j}\right)\right)$.

$$
\text { Suporte }\left(t_{i}, t_{j}\right)=p\left(t_{i}, t_{j}\right)
$$

Apesar de comumente usada, a medida suporte pode não atender as premissas estabelecidas para a geração da rede de termos propostas nesta tese. Isso ocorre pelo fato de que termos genéricos, que ocorrem em vários documentos da coleção, independentemente 
da classe, podem coocorrer frequentemente com termos específicos. Nestas situações, de acordo com a medida Suporte, um termo genérico e um termo específicos estariam fortemente relacionados, uma vez que esta medida não considera a ocorrência individual desses termos na coleção de documentos. Com isso, outras medidas de similaridades entre termos foram utilizadas na literatura para gerar redes de termos com relações mais significativas do que as extraídas pela medida Suporte. Por exemplo, em Tseng et al. (2012); Jacobs (2002) é utilizada a media Inclusão, na qual o valor da relação entre dois termos $t_{i}$ e $t_{j}$ é dada por

$$
\operatorname{Inclus\tilde {a}o}\left(t_{i}, t_{j}\right)=\frac{p\left(t_{i}, t_{j}\right)}{\min \left(p\left(t_{i}\right), p\left(t_{j}\right)\right.} .
$$

Apesar da medida Inclusão ser utilizada como alternativa à medida suporte, ela apresenta as mesmas deficiências. Supondo um termo genérico $t_{i}$ que ocorra em vários documentos da coleção e que sempre coocorre com um termo específico $t_{j}$. Ao dividir a probabilidade de coocorrência de $t_{i}$ e $t_{j}$ pela menor probabilidade de coocorrência de um dos termos, neste caso $t_{j}$, o valor de Inclusão será 1, indicando forte relação entre os termos, o que, de acordo com as premissas estabelecidas nesta tese, não é verdade.

Em Tseng et al. (2012), também são utilizadas outras medidas que tentam sanar as deficiências apresentadas pelas medidas Suporte e Inclusão considerando as ocorrências individuais dos termos na coleção. As medidas utilizadas são Dice, Índice de Proximidade, Equivalência e Cosseno, apresentadas respectivamente nas Equações 2.29, $2.30,2.31$ e 2.32 .

$$
\begin{gathered}
\operatorname{Dice}\left(t_{i}, t_{j}\right)=\frac{2 \cdot p\left(t_{i}, t_{j}\right)}{p\left(t_{i}\right)+p\left(t_{j}\right)} \\
\text { Indice_Proximidade }\left(t_{i}, t_{j}\right)=\frac{p\left(t_{i}, t_{j}\right) \cdot|\mathcal{D}|}{p\left(t_{i}\right) \cdot p\left(t_{j}\right)} \\
\text { Equivalência }\left(t_{i}, t_{j}\right)=\frac{p\left(t_{i}, t_{j}\right)}{p\left(t_{i}\right)} \cdot \frac{p\left(t_{i}, t_{j}\right)}{p\left(t_{j}\right)} \\
\text { Cosseno }\left(t_{i}, t_{j}\right)=\frac{p\left(t_{i}, t_{j}\right)}{\sqrt{p\left(t_{i}\right) \cdot p\left(t_{j}\right)}}
\end{gathered}
$$

Apesar das diferentes medidas apresentadas em Tseng et al. (2012), observa-se uma semelhança nas fórmulas, fazendo com que basicamente seja alterado apenas o valor real da similaridade entre termos $t_{i}$ e $t_{j}$, mas não a diferença relativa entre as similaridades dos termos. Outra gama de medidas de similaridade, além dessas apresentadas acima, podem ser utilizadas para calcular as relações entre os termos (Geng e Hamilton, 2006; Blanchard et al., 2005; Tan et al., 2002b). Foram selecionadas nesta tese medidas de similaridade com diferentes semânticas, propriedades e intervalo de valores. Isso permite analisar quais as características das medidas de similaridades podem apresentar melhores resultados.

Primeiramente foram selecionadas medidas de similaridade simétricas, isto é, $\Omega\left(t_{i}, t_{j}\right)$ 
$=\Omega\left(t_{j}, t_{i}\right)$, na qual $\Omega(\ldots)$ refere-se a uma função de similaridade qualquer. Portanto, medidas de similaridades simétricas irão gerar relações não direcionadas entre os objetos de uma rede. Medidas de similaridades simétricas foram selecionadas por duas razões: (i) possibilidade de utilizar esse tipo de rede em algoritmos estado da arte que consideram redes não direcionadas; e (ii) para fazer uma comparação justa com redes de documentos baseadas em similaridade ou com redes bipartidas, uma vez que estes tipos de redes contém relações simétricas. Além disso, outras medidas de similaridades entre termos utilizadas na literatura, como Suporte, Inclusão, Índice de Proximidade, Equivalência e Cosseno também são simétricas.

Além da propriedade simétrica, que foi utilizada como critério fixo, foram selecionadas outras medidas que atendam diferentes propriedades de medidas de similaridades para que se possam selecionar medidas com diferentes características. As propriedades consideradas para seleção de medidas de similaridade são (Geng e Hamilton, 2006; Tan et al., 2002b):

- P1: $\Omega\left(t_{i}, t_{j}\right)=0$ se $t_{i}$ e $t_{j}$ são estatisticamente independentes.

- P2: $\Omega\left(t_{i}, t_{j}\right)$ decresce monotonicamente com $P\left(t_{i}, t_{j}\right)$ se $P\left(t_{i}\right)$ e $P\left(t_{j}\right)$ permanecem os mesmos.

- P3: $\Omega\left(t_{i}, t_{j}\right)$ monotonicamente diminui com $P\left(t_{i}\right)$ (ou $\left.P\left(t_{j}\right)\right)$ quando os demais valores $\left(P\left(t_{i}, t_{j}\right)\right.$ e $P\left(t_{j}\right)$ (ou $\left.\left.P_{t_{i}}\right)\right)$ permanecem inalterados.

- P4: $\Omega\left(t_{i}, t_{j}\right)$ deve permanece o mesmo quando ambas linhas e colunas são permutadas.

- P5: $\Omega\left(t_{i}, t_{j}\right)$ deve se tornar $-\Omega\left(t_{i}, t_{j}\right)$ quando linhas ou colunas são permutadas.

- P6: $\Omega\left(t_{i}, t_{j}\right)$ deve permanecer o mesmo quando alguma linha ou coluna é multiplicada por um valor positivo.

As medidas de similaridade que atendem as diferentes propriedades acima e selecionadas para esta tese foram: Suporte, Q de Yule, Informação Mútua, Kappa, e Piatetsky-Shapiro. Na Tabela 2.4 são apresentadas as medidas de similaridade e suas fórmulas, e na Tabela 2.5 são apresentadas as propriedades atendidas pelas medidas e intervalos de valores. Vale ressaltar que apesar da medida Piatetsky-Shapiro atender as mesmas propriedades das medidas Kappa e Informação Mútua, o intervalo de valores da medida Piatetsky-Shapiro é diferente de ambas. Já as medidas Kappa e Informação Mútua apresentam as mesmas propriedades e o mesmo intervalo de valores. Entretanto, a semântica da medida Informação Mútua é diferente da medida Kappa, uma vez que na medida Informação Mútua são consideradas as probabilidade de ocorrer os dois termos, a probabilidade de ocorrer um termo e não ocorrer outro, e a probabilidade de não coocorrência dos termos, enquanto que na medida Kappa é considerada apenas a probabilidade de ocorrência e a probabilidade de não ocorrência dos termos.

Assim como nas redes de documentos baseadas em similaridade, redes de termos podem ser geradas considerando diferentes abordagens. Nesta tese foram consideradas 
Tabela 2.4: Fórmulas das medidas de similaridade selecionadas (Geng e Hamilton, 2006; Blanchard et al., 2005; Tan et al., 2002b).

\begin{tabular}{l|l}
\hline \hline Medida & Fórmula \\
\hline \hline Suporte & $p\left(t_{i}, t_{j}\right)$ \\
\hline & $p\left(t_{i}, t_{j}\right) \log _{2}\left(\frac{p\left(t_{i}, t_{j}\right)}{p\left(t_{i}\right) p\left(t_{j}\right)}\right)+$ \\
& $p\left(t_{i}, \neg t_{j}\right) \log _{2}\left(\frac{p\left(t_{i}, \neg t_{j}\right)}{p\left(t_{i}\right) p\left(\neg t_{j}\right)}\right)+$ \\
Informação Mútua & $p\left(\neg t_{i}, t_{j}\right) \log _{2}\left(\frac{p\left(\neg t_{i}, t_{j}\right)}{p\left(\neg t_{i}\right) p\left(t_{j}\right)}\right)+$ \\
& $p\left(\neg t_{i}, \neg t_{j}\right) \log _{2}\left(\frac{p\left(\neg t_{i}, \neg t_{j}\right)}{p\left(\neg t_{i}\right) p\left(\neg t_{j}\right)}\right)$ \\
\hline Q de Yule & $\frac{p\left(t_{i}, t_{j}\right) p\left(\neg t_{i}, \neg t_{j}\right)-p\left(t_{i}, \neg t_{j}\right) p\left(\neg t_{i}, t_{j}\right)}{p\left(t_{i}, t_{j}\right)\left(P \neg t_{i}, \neg t_{j}\right)+p\left(t_{i}, \neg t_{j}\right) p\left(\neg t_{i}, t_{j}\right)}$ \\
\hline Kappa & $\frac{p\left(t_{i}, t_{j}\right)+p\left(\neg t_{i}, \neg t_{j}\right)-p\left(t_{i}\right) p\left(t_{j}\right)-p\left(\neg t_{i}\right) p\left(\neg t_{j}\right)}{1-p\left(t_{i}\right) p\left(t_{j}\right)-p\left(\neg t_{i}\right) p\left(\neg t_{j}\right)}$ \\
\hline Piatetsky-Shapiro & $p\left(t_{i}, t_{j}\right)-p\left(t_{i}\right) p\left(t_{j}\right)$ \\
\hline \hline
\end{tabular}

Tabela 2.5: Propriedades e intervalos de valores das medidas de similaridade selecionadas (Geng e Hamilton, 2006; Tan et al., 2002b).

\begin{tabular}{l||c|c|c|c|c|c|c}
\hline \hline Medida & P1 & P2 & P3 & P4 & P5 & P6 & Intervalo \\
\hline \hline Suport & NÃO & SIM & NÃO & NÃO & NÃO & NÃO & {$[0,1]$} \\
\hline Mutual Information & SIM & SIM & SIM & SIM & NÃO & NÃO & {$[-1,1]$} \\
\hline Yule's Q & SIM & SIM & SIM & SIM & SIM & SIM & {$[-1,1]$} \\
\hline Kappa & SIM & SIM & SIM & SIM & NÃO & NÃO & {$[-1,1]$} \\
\hline Piatetsky-Shapiro & SIM & SIM & SIM & SIM & NÃO & NÃO & {$[-0.25,0.25]$} \\
\hline \hline
\end{tabular}

duas abordagens: (i) Limiar, na qual dois termos são conectados se sua similaridade é maior que um limiar, e (ii) TopK, na qual um termo é conectado à seus $k$ termos mais similares mútuos, semelhante a rede $M k N N$ apresentada na Seção 2.3.2. A abordagem Limiar foi escolhida pelo fato de ser comumente utilizada na literatura (Tseng et al., 2012; Wang et al., 2005). Já a abordagem TopK foi escolhida pelas suas características e benefícios que pode trazer ao processo de aprendizado de máquina, principalmente no quesito velocidade, como a geração de menos hubs e o número máximo de relações de um objeto ser limitado pelo valor de $k$.

O valor de similaridade entre dois termos $t_{i}$ e $t_{j}$ é usado como peso da relação entre eles, ou seja, $w_{t_{i}, t_{j}}=\Omega\left(t_{i}, t_{j}\right)^{6}$. Uma vez gerada todas as relações entre os termos, se dois termos apresentam relação com peso negativo, todas as outras relações da rede têm seu peso incrementado com o módulo do peso de relação mais negativo. Isto é feito para garantir o correto funcionamento dos algoritmos de propagação de rótulos ou de algoritmos que necessitam normalizar os pesos das conexões ou calcular medidas como o grau.

\footnotetext{
${ }^{6}$ Vale ressaltar que as técnicas de extração de tópicos, apresentadas na Seção 2.2.4, agrupam termos coocorrentes em um único atributo, como forma de manter a relação entre termos no espaço-vetorial. Entretanto, todos os termos agrupados tem o mesmo peso na dimensão, enquanto que na rede de termos é extraída a força da relação entre cada par de termos.
} 


\section{Redes Heterogêneas}

Nas redes heterogêneas propostas nesta tese, $\mathcal{O}=\mathcal{D} \cup \mathcal{T}$, isto é, os objetos da rede correspondem a documentos e termos. Os tipos de relações possíveis considerando esses dois tipos de objetos são documento-documento, documento-termo e termo-termo. Esses tipos de objetos e relações permitem representar as redes de acordo com os requisitos estabelecidos nesta tese.

As relações entre documentos (documento-documento) foram extraídas considerando as abordagens de redes Gaussiana e $M k N N$ apresentadas na Seção 2.3.2. Já nas relações entre termos (termo-termo) foram extraídas considerando a abordagem proposta, apresentada na Seção 2.3.3.

Ao considerar apenas relações entre documentos e termos tem-se uma rede bipartida. As redes bipartidas são o caso mais simples de uma rede heterogênea. No caso de uma rede bipartida para representar coleções de textos, um documento $d_{i}$ é conectado a um termo $t_{j}$ se $t_{j}$ ocorre em $d_{i}$. O peso da relação entre um documento $d_{i}$ e um termo $t_{j}$, denotado por $w_{d_{i}, t_{j}}$, corresponde à frequência de $t_{j}$ em $d_{i}$. Na Figura 2.15 é apresentada uma ilustração de uma rede bipartida para representar coleções de textos.

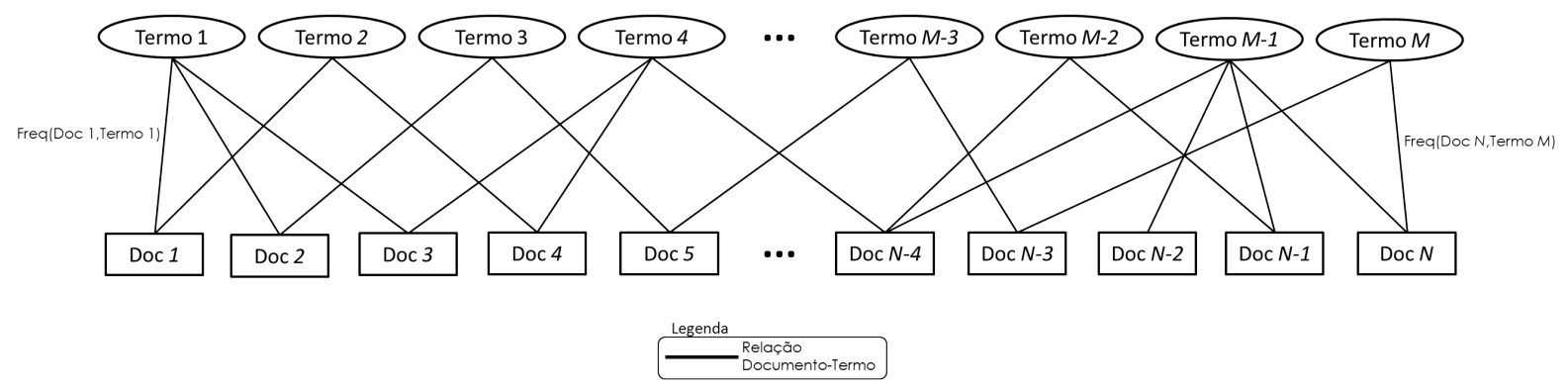

Figura 2.15: Ilustração de uma rede bipartida para representar coleções de textos.

A rede bipartida corresponde às redes de índices de palavras-chaves apresentadas em Newman (2010). Esse tipo de rede não precisa de parâmetros para ser gerada ou de cálculo de similaridade entre os objetos, o que torna sua utilização mais viável em situações práticas do que outros tipos de redes.

Apesar da facilidade de geração da rede bipartida, esse tipo de rede não havia sido utilizada na classificação de textos. Nesta tese, foi proposto o uso desse tipo de rede, além da proposta de algoritmos de classificação baseados em redes bipartidas.

Além dos diferentes tipos de redes compostas por relações simples (redes de documento, redes de termos e redes bipartidas), nesta tese também foram consideradas redes compostas por diferentes tipos de relações. Para tal, foram consideradas redes compostas por combinações dos diferentes tipos objetos e relações definidas nesta seção. Portanto, foram propostas as seguintes redes heterogêneas:

Rede Doc-Doc-Doc-Termo: as relações desta rede são do tipo documento-termo e termo-termo. Na Figura 2.16 é apresentada uma ilustração de uma rede Doc-DocDoc-Termo para representar coleções de textos. Essa rede é semelhante à rede 
apresentada em Aggarwal e Li (2011). A diferença é que em Aggarwal e Li (2011) são consideras relações explícitas entre os documentos enquanto que a rede proposta nesta tese considera relações baseadas em similaridade.

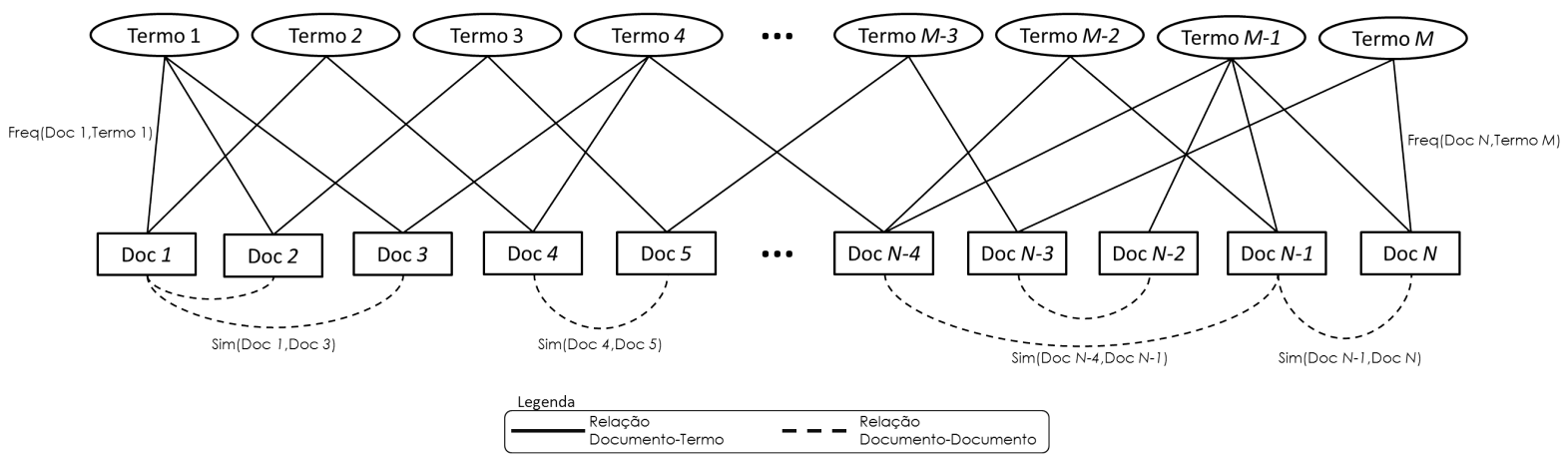

Figura 2.16: Ilustração de uma rede Doc-Doc-Doc-Termo.

Rede Doc-Termo-Termo-Termo: as relações desta rede são do tipo documento-termo e termo-termo. Na Figura 2.17 é apresentada uma ilustração de uma rede Doc-TermoTermo-Termo para representar coleções de textos.

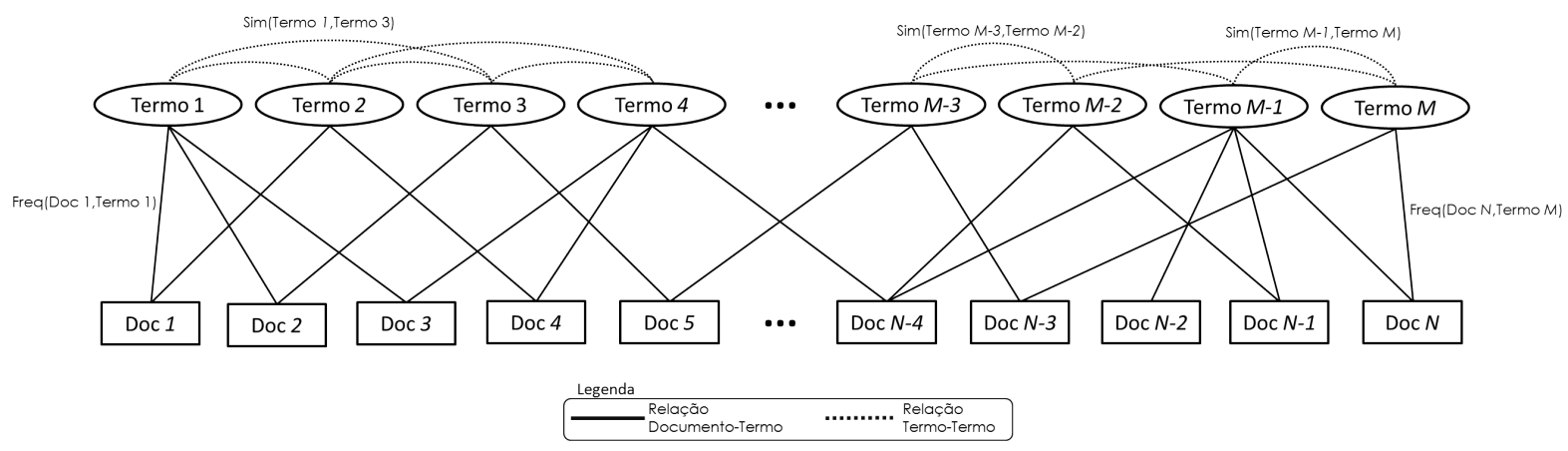

Figura 2.17: Ilustração de uma rede Doc-Termo-Termo-Termo.

Rede Doc-Doc-Doc-Termo-Termo-Termo: as relações desta rede são do tipo documento-documento, documento-termo, e termo-termo. Na Figura 2.18 é apresentada uma ilustração de uma rede Doc-Doc-Doc-Termo-Termo-Termo para representar coleções de textos.

Vale ressaltar que todas as redes heterogêneas propostas nesta tese possuem relações do tipo documento-termo. Isso se deve ao fato de que esse tipo de relação funciona como um elo de ligação entre os diferentes objetos. Sem esse tipo de relação, documentos não estariam conectados a termos, e vice-versa, sendo portanto geradas redes separadas, de documento e termos, ao invés de uma única rede heterogênea.

A combinação entre os diferentes tipos de relações em uma única relação não é trivial. Os diferentes tipos de relações podem apresentar diferentes intervalos de valores, e pode-se dar mais peso a um tipo de relação devido a isso. Por exemplo, o intervalo de valores das relações do tipo documento-documento é $[0,1]$, valores que correspondem ao intervalo de 


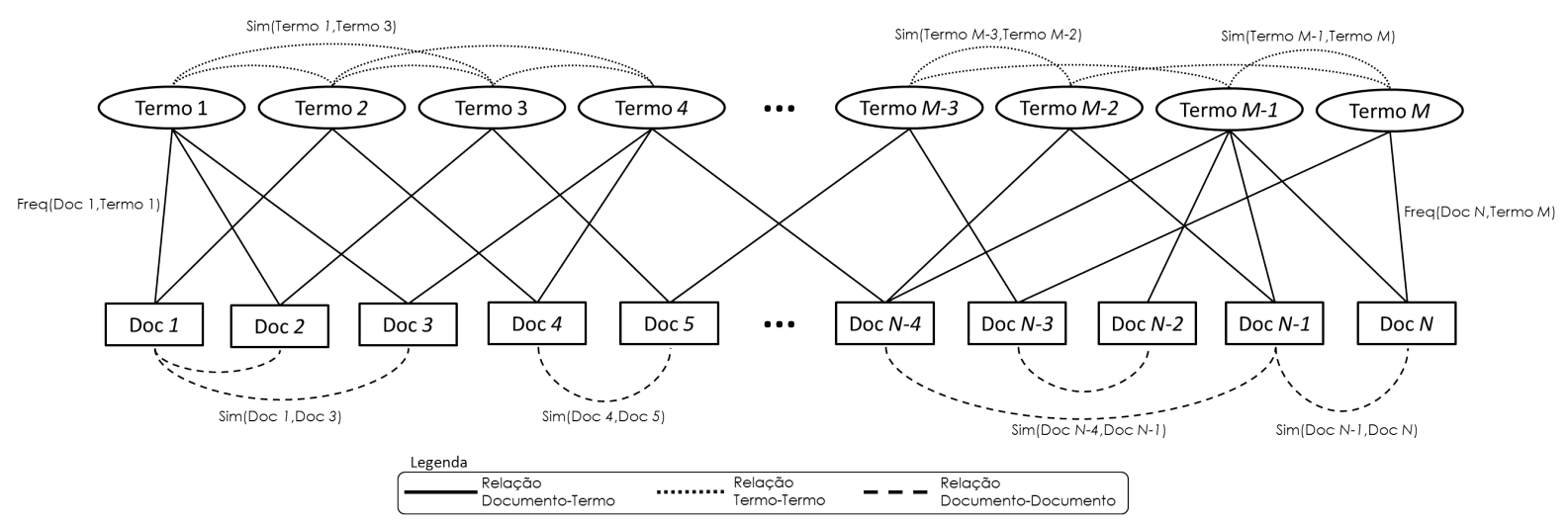

Figura 2.18: Ilustração de uma rede Doc-Doc-Doc-Termo-Termo-Termo.

valores da medida de similaridade cosseno. O intervalo de valores das relações termo-termo são diferentes de acordo com a medida de similaridade adotada, podendo variar entre $[-0,25,0,25]$ no caso da medida Piatetsky-Shapiro, $[0,1]$ no caso do Suporte, e $[-1,1]$ no caso da Informação Mútua, Kappa, e Q de Yule. Já as relações documento-termo o intervalo de valores é [1, MaxFreq], na qual MaxFreq é a frequência máxima de um termo em uma coleção de documentos.

Como os pesos das arestas interferem diretamente no aprendizado baseado em redes (quanto maior o peso da relação maior a chance de dois objetos pertencerem à mesma classe), as arestas do tipo documento-termo e termo-termo são normalizadas para que ambas fiquem com intervalo de valores $[0,1]$. Sendo assim, todos os tipos de relações das redes propostas terão o mesmo intervalo de valores. Portanto, nas redes geradas, um tipo de relação não terá maior influência em relação à outro tipo de relação, ficando a cargo dos algoritmos de classificação definir quais tipos de relações devem ter maior importância, caso isso seja de interesse do usuário.

A normalização dos pesos das relações do tipo documento-termo de um documento $d_{i}$ é apresentada na Equação 2.33. A normalização dos pesos das relações documento-termo de um termo $t_{j}$ é apresentada na Equação 2.34. Por fim, a normalização dos pesos das relações do tipo termo-termo de um termo $t_{j}$ é apresentada na Equação 2.35.

$$
\begin{aligned}
& w_{d_{i}, t_{j}}^{\prime}=\frac{w_{d_{i}, t_{j}}}{\sum_{t_{k} \in \mathcal{T}} w_{d_{i}, t_{k}}} \\
& w_{t_{j}, d_{i}}^{\prime}=\frac{w_{d_{i}, t_{j}}}{\sum_{d_{k} \in \mathcal{D}} w_{d_{k}, t_{j}}} \\
& w_{t_{j}, t_{i}}^{\prime}=\frac{w_{t_{j}, t_{i}}}{\sum_{t_{k} \in \mathcal{T}} w_{t_{j}, t_{k}}}
\end{aligned}
$$




\subsection{Estruturas Computacionais para a Classificação de Textos}

Seja $\mathcal{C}=\left\{c_{1}, c_{2}, \ldots, c_{l}\right\}$ o conjunto de classes de uma coleção de documentos. A classificação de textos, independente de tipo, algoritmo utilizado, ou representação adotada, pode ser vista como a atribuição de um peso ou relevância de um elemento da coleção, objeto no caso de redes, ou documento ou termo no caso do modelo espaço-vetorial, para cada uma das classes ${ }^{7}$. Para tal, é utilizado um vetor $\mathbf{f}_{o_{i}}=\left\{f_{1}, f_{2}, \ldots, f_{|\mathcal{C}|}\right\}$ para armazenar o peso de um objeto $o_{i}$ para cada classe da coleção de documentos. Também é utilizado o termo "informação de classe" para denotar o vetor de pesos dos objetos para as classes. Os valores atribuídos ao vetor $\mathbf{f}$ pelos algoritmos de aprendizado de máquina também são conhecidos por confiança de classificação. Todos os vetores de objetos são armazenados em uma matriz $\mathbf{F}=\left\{\mathbf{f}_{o_{1}}, \mathbf{f}_{o_{2}}, \ldots, \mathbf{f}_{o_{|\mathcal{O}|}}\right\}^{T}$, como ilustrado na Tabela 2.6.

Tabela 2.6: Matriz de informações de classes dos objetos.

\begin{tabular}{c||c|c|c|c}
\hline \hline & $\mathbf{c}_{\mathbf{1}}$ & $\mathbf{c}_{\mathbf{2}}$ & $\ldots$ & $\mathbf{c}_{|\mathcal{C}|}$ \\
\hline \hline $\mathbf{O}_{\mathbf{1}}$ & $f_{o_{1}, c_{1}}$ & $f_{o_{1}, c_{2}}$ & $\ldots$ & $f_{o_{1}, c_{|\mathcal{C}|}}$ \\
\hline $\mathbf{O}_{\mathbf{2}}$ & $f_{o_{2}, c_{1}}$ & $f_{o_{2}, c_{2}}$ & $\cdots$ & $f_{o_{2}, c_{|\mathcal{C}|}}$ \\
\hline$\vdots$ & $\vdots$ & $\vdots$ & $\ddots$ & $\vdots$ \\
\hline $\mathbf{O}_{|\mathcal{O}|}$ & $f_{o_{|\mathcal{O}|}, c_{1}}$ & $f_{o_{|\mathcal{O}|}, c_{2}}$ & $\cdots$ & $f_{o_{|\mathcal{O}|}, c_{|\mathcal{C}|}}$ \\
\hline \hline
\end{tabular}

Os valores dos vetores $\mathbf{f}$ são obtidos por meio de algoritmos de aprendizado de máquina. Em determinadas situações, deseja-se classificar apenas um ou alguns tipos de objetos da rede. No caso desta tese, deseja-se classificar apenas os objetos do tipo documento. Para classificar os objetos de interesse, os valores dos vetores $\mathbf{f}$ dos respectivos objetos são analisados.

Os valores de um vetor $\mathbf{f}$ podem ser binários, isto é, 1 para a classe do objeto e 0 para as demais, ou numéricos. No primeiro caso, a classificação é denominada "hard", isto é, um objeto pertence a uma única classe da coleção. Já no segundo caso, a classificação é denominada "soft", sendo que cada objeto terá um valor, que pode representar um grau de pertinência, grau de relevância, ou probabilidade para cada classe da coleção. No caso da classificação soft, pode-se atribuir um objeto $o_{i}$ a uma única classe correspondente ao maior valor do vetor $\mathbf{f}_{o_{i}}$, denominada classificação multiclasse, ou atribuir um objeto $o_{i}$ à várias classes considerando um limiar nos valores de $\mathbf{f}_{o_{i}}$ ou simplesmente utilizando os $k$ maiores valores de $\mathbf{f}_{o_{i}}$ como as $k$ classes de $o_{i}$ (Draszawka e Szymanski, 2013; Ráez e López, 2006), denominada classificação multirrótulo.

Os rótulos definidos para um objeto $o_{i}$ por um usuário ou especialista, previamente ao início do processo de aprendizado, são armazenados em um vetor $\mathbf{y}_{o_{i}}=\left\{y_{1}, y_{2}, \ldots, y_{|C|}\right\}^{T}$. Também utilizaremos o termo "informações de classe real" para denotar o vetor de pesos y. Todas as informações de classe reais dos objetos rotulados são armazenados na matriz

\footnotetext{
${ }^{7}$ Por facilidade de explicação, o termo objeto é utilizado tanto para referir-se a um objeto da rede quanto para referir-se a um documento ou termo no modelo espaço-vetorial.
} 
Y, como ilustrado na Tabela 2.7.

Tabela 2.7: Matriz de informações de classes reais.

\begin{tabular}{c||c|c|c|c}
\hline \hline & $\mathbf{c}_{\mathbf{1}}$ & $\mathbf{c}_{\mathbf{2}}$ & $\ldots$ & $\mathbf{c}_{|\mathcal{C}|}$ \\
\hline \hline $\mathbf{O}_{\mathbf{1}}$ & $y_{o_{1}, c_{1}}$ & $y_{o_{1}, c_{2}}$ & $\ldots$ & $y_{o_{1}, c_{|\mathcal{C}|}}$ \\
\hline $\mathbf{O}_{\mathbf{2}}$ & $y_{o_{2}, c_{1}}$ & $y_{o_{2}, c_{2}}$ & $\ldots$ & $y_{o_{2}, c_{|\mathcal{C}|}}$ \\
\hline$\vdots$ & $\vdots$ & $\vdots$ & $\ddots$ & $\vdots$ \\
\hline $\mathbf{O}_{|\mathcal{O}|}$ & $y_{o_{|\mathcal{O}|}, c_{1}}$ & $y_{o_{|\mathcal{O}|}, c_{2}}$ & $\ldots$ & $y_{o_{|\mathcal{O}|}, c_{|\mathcal{C}|}}$ \\
\hline \hline
\end{tabular}

O valor de um objeto $o_{i}$ para uma classe $c_{j}$ na matriz $\mathbf{Y}$ é dada pela seguinte regra:

$$
y_{o_{i}, c_{j}}= \begin{cases}1, & \text { se } o_{i} \text { foi rotulado com a classe } c \\ 0 & \text { caso contrário. }\end{cases}
$$

Alguns algoritmos da literatura, principalmente indutivos supervisionados e binários (Capítulo 3), utilizam os valores +1 e -1 respectivamente no lugar dos valores 1 e 0 . Entretanto, ao tratar de algoritmos baseados em redes, os valores 1 e 0 são mais comuns.

O conjunto de objetos rotulados, isto é, objetos nos quais algum valor do vetor y é diferente de 0 , será denotado por $\mathcal{O}^{L}$. O conjunto de objetos não rotulados, isto é, objetos nos quais todos os valores do vetor y são iguais a 0 , será denotado por $\mathcal{O}^{U}$. Quando for necessário referir-se à matriz $\mathbf{F}$ ou a matriz $\mathbf{Y}$ para conjuntos de objetos específicos, esses senão denotados por $\mathbf{F}$ ([conjunto-objetos] $)$ ou $\mathbf{Y}$ ([conjunto-objetos $]$ ). Por exemplo, $\mathbf{F}(\mathcal{T})$ corresponde às informações de classe dos termos da coleção e $\mathbf{Y}\left(\mathcal{D}^{L}\right)$ corresponde às informações de classes reais dos objetos rotulados.

Tanto algoritmos baseados em redes como baseados no modelo espaço-vetorial podem ser tratados como contendo as estruturas apresentadas acima. Um exemplo de uma rede homogênea contendo objetos rotulados e não rotulados e seus respectivos vetores de informações de classe para uma tarefa de classificação, válido tanto para a rede de documentos quanto redes de termos apresentadas nas Seções 2.3.2 e 2.3.3 respectivamente, é apresentada na Figura 2.19(a). Já na Figura 2.19(b) é apresentada uma estrutura com vetores de informações de classe para classificação em uma rede bipartida. Vale ressaltar que em ambas as redes, um objeto rotulado possui um vetor $\mathbf{y}$ e um vetor $\mathbf{f}$. Em alguns algoritmos, permite-se alterar a informação de classe real de um objeto durante o aprendizado. A informação de classe real modificada é armazenada no vetor $\mathbf{f}$ do objeto rotulado.

Vários algoritmos baseados no modelo espaço-vetorial realizam um processo de classificação semelhante ao que ocorre na rede bipartida, isto é, dado um conjunto de documentos rotulados, são induzidos os valores de informações de classe dos termos, que por sua vez são utilizados para classificar documentos não rotulados. Exemplos desses algoritmos são Multinomial Naïve Bayes, Bayesian Logistic Regression, Support Vector Machines e Linear Least Squares Fit, descritos no Capítulo 3.

Vale ressaltar que alguns algoritmos de classificação, como o Bayesian Logistic Re- 


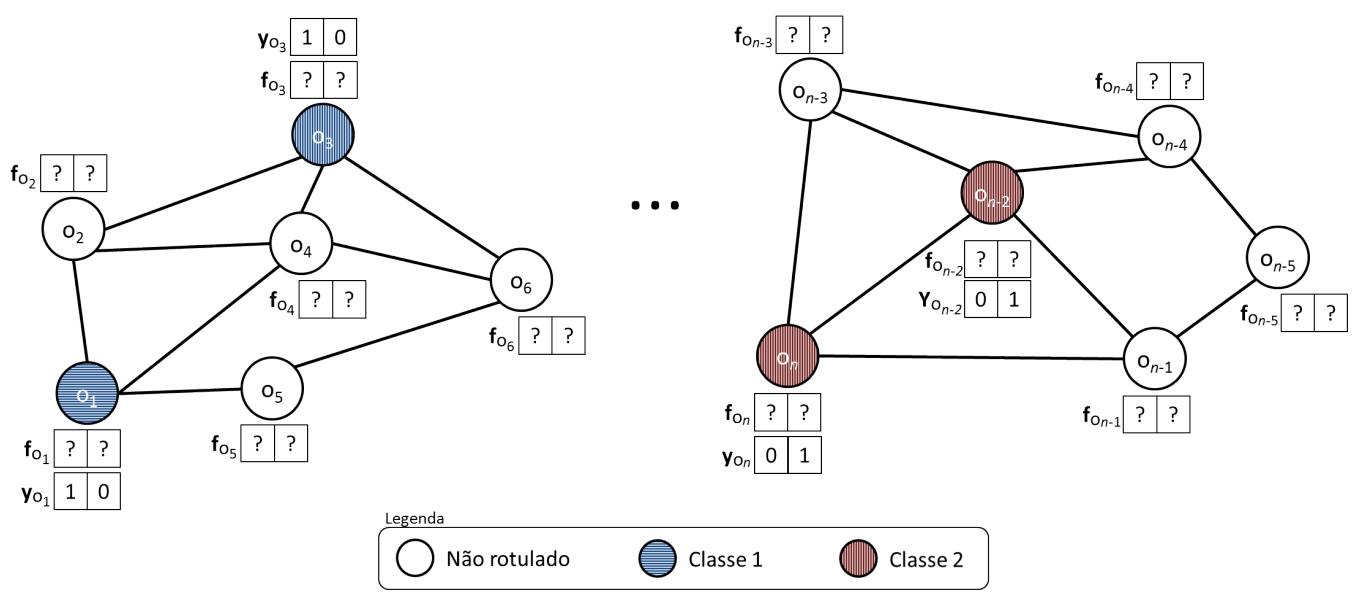

(a)

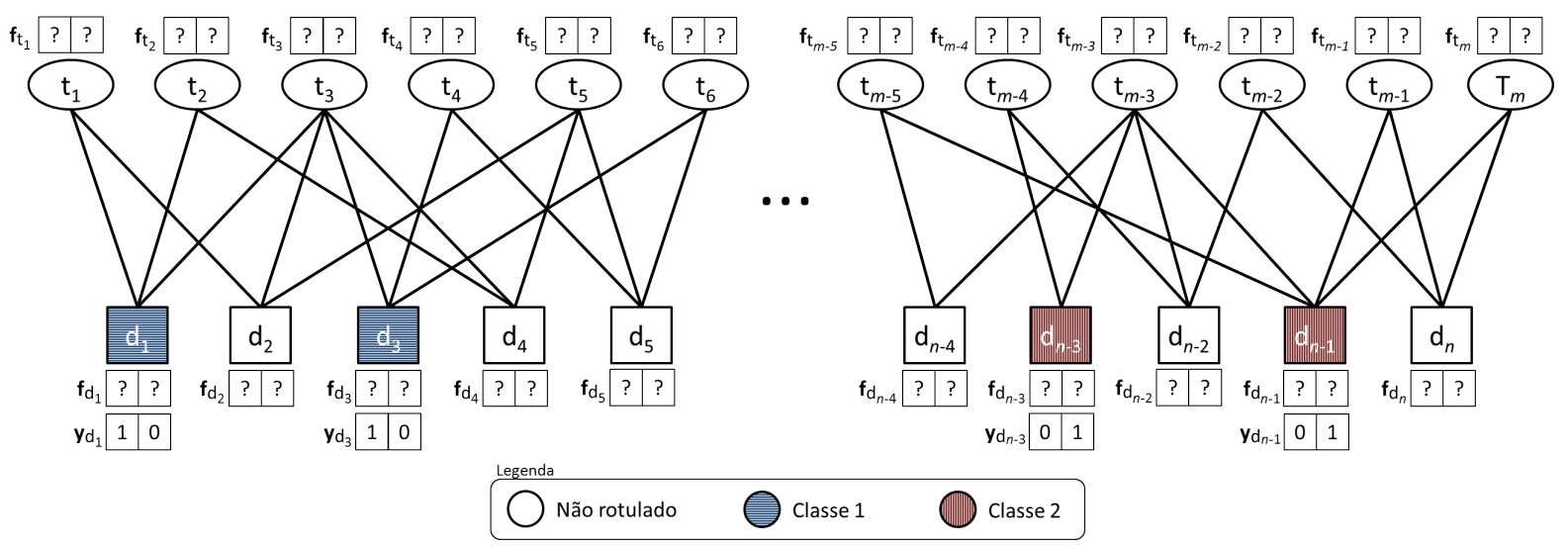

(b)

Figura 2.19: Ilustração das estruturas computacionais para classificação em: (a) rede homogênea e (b) rede bipartida.

gression, Support Vector Machines e Linear Least Squares Fit, são binários, isto é, $y_{d_{i}} \in\{+1,-1\}$. Neste caso, os vetores de informação de classe possuem apenas uma posição, que corresponde aos parâmetros de um hiperplano de separação ou aos coeficientes de regressão para a classe positiva (maiores detalhes sobre esses algoritmos são apresentados no Capítulo 3). Classificadores com tais características podem ser aplicados na classificação multiclasse por meio de duas estratégias: (i) um-contra-todos e (ii) um-contra-um. Na estratégia um-contra-todos, são induzidos classificadores binários para cada classe $c_{j} \in \mathcal{C}$, na qual um documento $d_{i}$ pertence a classe $c_{j}$ será tratado como positivo $\left(y_{d_{i}}=+1\right)$ e um documento $d_{k}$ pertencente à classe $c_{l}, c_{l} \neq c_{j}$ será tratado como negativo $\left(y_{d_{k}}=-1\right)$. A classificação se dá pelo classificador que disparar a classe positiva. Em caso de empates pode-se utilizar a confiança de classificação como desempate (Tan et al., 2005).

Na estratégia um-contra-um são construídos classificadores binários para cada par de classes $\left(c_{i}, c_{j}\right) \in \mathcal{C}$. Instâncias que não pertencem à $c_{i}$ ou $c_{j}$ são ignoradas na construção do classificador binário para as classes $c_{i}, c_{j}$. É realizado uma votação e a classe com maior número de votos é utilizada para definir a classe de um novo documento. 


\subsection{Considerações Finais}

Neste capítulo foram apresentadas abordagens para representar textos no modelo espaço-vetorial e em redes. Referente às representações no modelo espaço-vetorial, foram apresentadas diferentes formas de geração de termos e atributos, métodos de seleção de termos, e formas de manter relações entre as entidades de uma coleção de documentos. Referente às redes, foram apresentadas as diversas formas de representar textos por meio de redes. Também foram apresentadas as desvantagens das redes existentes utilizadas na classificação de textos e foram propostas modelagens em redes que permitem (i) representar qualquer tipo de coleção de documentos; (ii) representar toda a coleção de documentos com diferentes tipos de relações em uma única rede; (iii) extrair relações entre objetos da rede desconsiderando a classe dos documentos. Além disso, as redes propostas, apresentadas na Seção 2.3.3, possuem diferentes custos de geração, processamento, e consumo de memória, permitindo ao usuário adequar a escolha da rede de acordo com seus requisitos. Destaca-se que as estruturas computacionais bem como os demais conceitos e notações apresentadas neste capítulo também serão utilizadas nas explicações dos algoritmos apresentados nos capítulos seguintes.

Vale ressaltar que as redes apresentadas neste capítulo serão utilizadas nos algoritmos de aprendizado de máquina detalhados nos Capítulos 3, 4 e 5. Vale ressaltar também que apesar do foco deste projeto de doutorado ser a classificação de documentos textuais, as redes propostas neste projeto de doutorado podem ser facilmente adaptadas e aplicadas na classificação de dados em outros domínios de aplicação tanto nos que envolvem dados textuais, como na extração de termos de domínio (Conrado et al., 2005), identificação de verbos causais (Drury et al., 2014) e extração de aspectos de produtos e serviços (Matsuno et al., 2015), quanto em outros dados com as mesmas características dos dados textuais, como na identificação de gêneros músicas (Silva et al., 2014). 



\section{Classificação de Textos por Meio de Aprendizado Indutivo Supervisionado}

\subsection{Considerações Iniciais}

Devido ao grande volume de dados textuais, a classificação de textos tem-se tornado essencial na organização, gerenciamento da informação e extração de conhecimento. A classificação de textos pode ser feita de forma manual, como em Dewey ${ }^{1}, \mathrm{MeSH}^{2}$, Yahoo! ${ }^{3}$ e $\mathrm{DMOZ}^{4}$, nos quais profissionais treinados realizavam ou ainda realizam a classificação manual de novos textos (livros, artigos e páginas web). Obviamente há um alto custo tanto humano quanto de tempo ao realizar a classificação de textos manualmente, além de dificultar sua aplicação em outros locais e domínios devido ao custo de treinamento humano, quantidade de pessoas e tempo requeridos.

Uma das alternativas à classificação manual foi o desenvolvimento de sistemas especialistas, os quais contêm um conjunto de regras de classificação informadas por especialista de domínios (Hayes e Weinstein, 1991). Porém, este tipo de classificação também é difícil de ser aplicada em diferentes locais e domínios devido à necessidade de um especialista de domínio/engenheiro de conhecimento para a definição manual das regras de classificação. Além disso, as regras geradas manualmente são difíceis de serem atualizadas (Manning et al., 2008; Sebastiani, 2002; Dumais et al., 1998).

Devido às limitações da classificação manual ou do uso de regras formuladas por especialistas de domínio, houve um crescente interesse no desenvolvimento e utilização de

\footnotetext{
${ }^{1}$ Dewey Decimal or Library of Congress Classification Systems: http://en.wikipedia.org/wiki/ Dewey_Decimal_Classification

${ }^{2}$ Medical Subject Headings: http://en.wikipedia.org/wiki/Medical_Subject_Headings

${ }^{3}$ Hierarquia de tópicos do Yahoo!: https://dir.yahoo.com/

${ }^{4}$ Open Directory Project: http://en.wikipedia.org/wiki/DMOZ
} 
técnicas de aprendizado de máquina visando à classificação automática de textos. Observase na literatura que técnicas de aprendizado supervisionado para induzir modelos de classificação têm sido amplamente desenvolvidas, estudadas e utilizadas para a classificação automática de textos (Aggarwal e Zhai, 2012; Weiss et al., 2012; Manning et al., 2008; Feldman e Sanger, 2006; Sebastiani, 2002; Dumais et al., 1998).

O uso de técnicas de aprendizado de máquina supervisionado permite aprender automaticamente um conjunto de regras ou critérios de decisão considerando uma coleção na qual todos os documentos possuem rótulos (Manning et al., 2008; Feldman e Sanger, 2006; Sebastiani, 2002). Apesar de ainda haver a necessidade de intervenção humana por meio da rotulação dos documentos, essa atividade é menos custosa ou ainda mais fácil que a escrita de regras por especialistas de domínio/engenheiros de conhecimentos. Além disso, os modelos de classificação construídos utilizando aprendizado indutivo supervisionado são mais fáceis de serem construídos e atualizados em comparação com a classificação manual ou a geração de regras por especialistas, podem ser facilmente customizados de acordo com os interesses do usuário e realizam tanto a classificação do tipo soft quanto do tipo hard (Dumais et al., 1998).

Formalmente, o objetivo da classificação indutiva supervisionada é induzir uma função $F$ que seja capaz de mapear documentos rotulados $\left(\mathcal{D}^{L}\right)$ para seus respectivos rótulos $\left(\mathcal{Y}^{L}\right)$, isto é, $F: \mathcal{D}^{L} \rightarrow \mathcal{Y}^{L}$. A função $F$, também denominada "modelo de classificação" ou "classificador", relaciona os termos e suas frequências com cada uma das classes. O modelo de classificação induzido por meio de aprendizado indutivo supervisionado é então utilizado para predizer a classe ou rotular novos documentos. A indução da função $F$ é também denominada "treinamento do modelo de classificação" e o conjunto de documentos rotulados que são utilizados na indução do modelo são denominados "conjunto de treinamento". Na Figura 3.1 é apresentado um exemplo ilustrativo da classificação indutiva supervisionada.

Vale ressaltar que uma função de classificação que realizasse um casamento simples entre a frequência de cada termo em cada documento para a classe seria suficiente para induzir um mapeamento exato entre $\mathcal{D}^{L}$ e $\mathcal{Y}^{L}$. Entretanto, novos documentos dificilmente teriam os mesmos termos com as mesmas frequências dos documentos de treinamento. Portanto, o modelo de classificação deve considerar o conjunto de treinamento para extrair os padrões das classes, de forma que estes sejam capazes de obter performances de classificação satisfatórias na classificação de novos documentos, isto é, documentos diferentes dos documentos de treinamento. Para isso é necessário que os documentos sejam representativos em relação às classes, de forma com que o modelo de classificação seja capaz de generalizar os conceitos de classe e classificar corretamente novos exemplos.

A classificação indutiva supervisionada de textos tem sido aplicada para diversas finalidades. Além disso, algoritmos desenvolvidos para a classificação indutiva supervisionada de textos também têm sido aplicados em outros domínios com características semelhantes ao domínio textual. Alguns exemplos de aplicações e do uso da classificação indutiva supervisionada de textos são: 


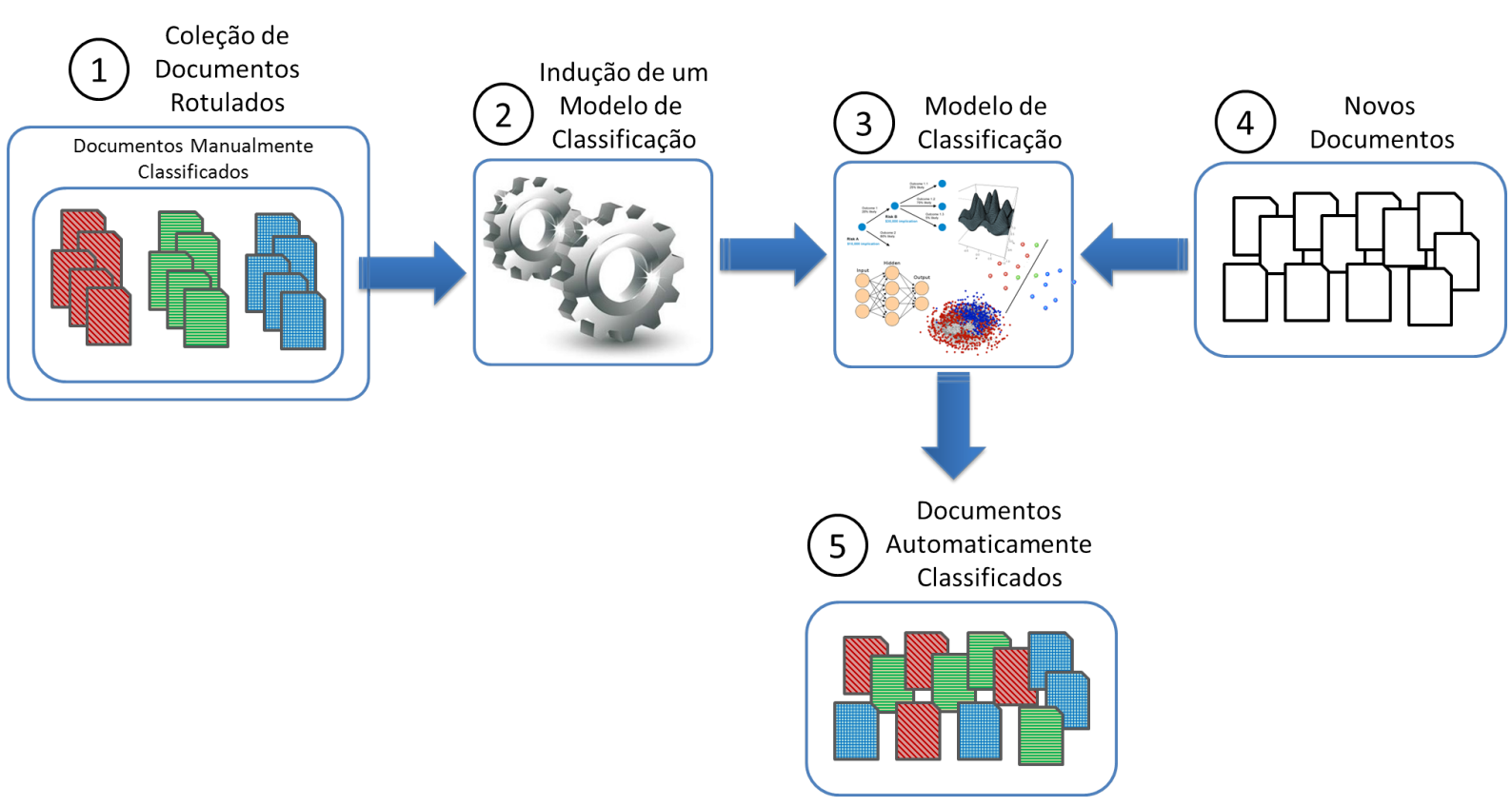

Figura 3.1: Esquema ilustrativo da classificação automática de textos por meio de aprendizado indutivo supervisionado.

- Filtragem e organização de notícias: utilizada para atribuição direta de notícias às categorias ou atribuição de tags ou metadados para indexação (Weiss et al., 2012), ou ainda filtrar notícias para um leitor de acordo com seus interesses (Billsus e Pazzani, 1999; Lang, 1995).

- Organização e recuperação de documentos: consiste em classificar documentos em tópicos pré-definidos (normalmente em hierárquias de tópicos) de maneira a facilitar a navegação e recuperação de documentos (Marcacini e Rezende, 2010; Chen e Hsieh, 2006b; Sun et al., 2002; Yu et al., 2002; Yang et al., 2002; Dumais e Chen, 2000; Chakrabarti et al., 1997; Koller e Sahami, 1997).

- Recuperação de informação: a classificação é utilizada no ranqueamento de páginas retornadas por uma consulta ou para filtrar páginas spam ou páginas com conteúdos inapropriados (Manning et al., 2008).

- Classificação de e-mails, detecção de spams e resposta automática: aplicados para redirecionar e-mails em empresas para os departamentos mais adequados (Coussement e den Poel, 2008; Provost, 1999), filtrar e-mails indesejados (spams) (Saberi et al., 2007; Androutsopoulos et al., 2000; Drucker et al., 1999), ou responder e-mails automaticamente por meio da detecção de assuntos (Weng e Liu, 2004).

- Mineração de opinião/Análise de sentimentos: muitas opiniões sobre empresas, produtos, serviços, políticos, celebridades e acontecimentos expressas em redes sociais, sites especializados ou em comentários de notícias e produtos podem ser automaticamente classificadas como positivas, neutras e negativas. Com isso, pode-se quantificar a avaliação popular sobre produtos, serviços e personalidades, o impacto 
de declarações, ações ou notícias, e mudanças na percepção da imagem de pessoas, produtos e serviços (Liu e Zhang, 2012; Weiss et al., 2012; Melville et al., 2009; Boiy et al., 2007; Durant e Smith, 2006).

- Outras aplicações: a classificação de textos também têm sido aplicada à outras finalidades em conjuntos de dados com conteúdo textual como recomendação de livros (Mooney e Roy, 2000; Mooney et al., 1998) e filmes (Mak et al., 2003), predição e gerenciamento de erros na produção de softwares (Xia et al., 2014; Cubranic e Murphy, 2004), detecção de spams em mensagens de telefones celulares do tipo Short Message Service (SMS) (Delany et al., 2012), predição de valores de ações (Zhai et al., 2007; Gidó, 2003; Fung et al., 2002), atribuição de notas à redações (Larkey, 1998), determinação de autorias em textos (Jockers e Witten, 2010; Diederich et al., 2003; Zheng et al., 2003), detecção de cyberbulling, aliciamento de menores e assédio sexual (Nalini e Sheela, 2014; Singhal e Bansal, 2013; Dinakar et al., 2012, 2011; Yin et al., 2009a; Pendar, 2007), respostas automáticas por meio de classificação de questões (Metzler e Croft, 2005; Solorio et al., 2004; Zhang e Lee, 2003), desambiguação de palavras (Escudero et al., 2000; Mooney, 1996), classificação de respostas dissertativas (Esuli e Sebastiani, 2010; Giorgetti e Sebastiani, 2003), e classificação de registros médicos (Chapman et al., 2005). Além disso, outros domínios não textuais podem ser representados com características de representações textuais, possibilitando à aplicação de algoritmos de classificação de textos, como deteç̧ão de intrusão (Sharma et al., 2007; Rawat et al., 2006; Liao e Vemuri, 2002), classificação de função de proteínas (Koussounadis et al., 2009; Rakotomalala e Mhamdi, 2008; Mhamdi et al., 2006), e classificação de gêneros musicais (Su et al., 2014; Nam et al., 2012; Yeh e Yang, 2012).

Apesar dos benefícios das representações em redes apresentadas nos Capítulos 1 e 2, os algoritmos existentes para classificação de textos baseados em redes em sua maioria apresentam alto custo de classificação, uma vez que necessitam calcular as similaridades entre as redes ou objetos que representam os textos da coleção, além de não apresentarem uma performance de classificação satisfatória, sendo muitas vezes inferior à dos algoritmos baseados no modelo espaço-vetorial. Além disso, as redes utilizadas em várias das abordagens são específicas para determinados domínios ou são dependentes de língua. Dado isso, nesse projeto de doutorado foi proposto um algoritmo de aprendizado indutivo supervisionado para a classificação de textos que (i) considera as redes também propostas neste projeto, permitindo assim a aplicação do algoritmo em textos de diferentes línguas e domínios; (ii) possui um tempo de indução do modelo de classificação e tempo de classificação satisfatórios; e (iii) apresenta uma performance de classificação superior à de algoritmos tanto baseados em redes quanto baseados no modelo espaço-vetorial.

O restante deste capítulo está dividido da seguinte forma. A revisão da literatura referente a algoritmos indutivos supervisionados baseados no modelo espaço-vetorial ou em redes é apresentada na Seção 3.2. Na Seção 3.3 são apresentados os algoritmos de 
aprendizado indutivo supervisionado propostos neste projeto de doutorado. Na Seção 3.4 é apresenta a avaliação experimental comparando os algoritmos apresentados na Seção 3.2 com os algoritmos propostos na Seção 3.3. Por fim, na Seção 3.4.2 são feitas as considerações finais sobre classificação indutiva supervisionada de textos.

\subsection{Trabalhos Relacionados}

Nas próximas seções são apresentados algoritmos de aprendizado de máquina indutivos supervisionados baseados no espaço-vetorial, os quais são mais adequados e utilizados na classificação automática de textos. Também são apresentadas considerações a respeito das induções de modelos de classificação no modelo espaço-vetorial e das correspondências entre abordagens baseadas em redes e baseados no espaço-vetorial quando utilizadas redes existentes para representar qualquer tipo de coleção de textos.

\subsubsection{Aprendizado Indutivo Supervisionado Considerando Textos Representados no Modelo Espaço-Vetorial}

É possível aplicar qualquer algoritmo de aprendizado de máquina supervisionado uma vez que a coleção de textos pode ser representada por conjuntos de vetores numéricos. Porém, como mencionado anteriormente, devido às características das representações de coleções de textos no modelo espaço-vetorial, alta dimensionalidade e esparsidade, alguns algoritmos são mais adequados para lidar com tais representações. Além disso, foram propostos na literatura variações de algoritmos existentes ou mesmo novos algoritmos de maneira a melhorar a performance classificação de textos. A seguir são apresentados algoritmos existentes, adaptados ou ainda desenvolvidos especificamente para a classificação de textos que são mais indicados e utilizados na literatura (Aggarwal e Zhai, 2012; Feldman e Sanger, 2006; Sebastiani, 2002; Yang e Liu, 1999; Dumais et al., 1998). Os algoritmos de aprendizado indutivo supervisionado baseado no modelo espaço-vetorial para classificação de textos que são apresentados nas próximas seções estão divididos em 5 categorias: (i) classificação linear, (ii) classificação probabilística, (iii) classificação baseada em regras, (iv) classificação baseada em árvores de decisão, e (v) classificação baseada em proximidade.

\section{Classificação Probabilística}

A classificação probabilística consiste em inferir a probabilidade de ocorrer uma classe $c_{j}$ dado um documento $d_{i}\left(P\left(c_{j} \mid d_{i}\right)\right)$. No contexto desta tese, $P\left(c_{j} \mid d_{i}\right)$ corresponde à informação de classe de um documento $d_{i}$ para a classe $c_{j}$.

A classificação probabilística pode ser realizada por meio de algoritmos baseados em modelos generativos ou regressão logística. Os algoritmos baseados em modelos generativos assumem que os documentos são gerados por um mistura de componentes, na qual cada componente está associado a uma classe, e o objetivo é inferir os componentes. No caso 
da classificação de textos, cada componente contém a probabilidade de cada termo $t_{i} \in \mathcal{T}$ a cada classe $c_{j} \in \mathcal{C}\left(P\left(t_{i}, c_{j}\right)\right)$, que corresponde às informações de classe dos termos nesta tese $\left(f_{t_{i}, c_{j}}\right)$.

O algoritmo Naïve Bayes é um dos algoritmos baseados em modelos generativos mais simples e amplamente utilizados na classificação de textos (Aggarwal e Zhai, 2012; Kim et al., 2006). Neste algoritmo, a probabilidade $P\left(c_{j} \mid d_{i}\right)$ é calculada utilizado a regra de Bayes, que é dada por

$$
P\left(c_{j} \mid d_{i}\right)=\frac{P\left(d_{i} \mid c_{j}\right) P\left(c_{j}\right)}{P\left(d_{i}\right)}
$$

na qual $P\left(c_{j}\right)$ é a probabilidade a priori de ocorrer a classe $c_{j}$, isto é ${ }^{5}$,

$$
P\left(c_{j}\right)=\frac{1+\sum_{d_{i} \in \mathcal{D}} P\left(c_{j} \mid d_{i}\right)}{|\mathcal{C}|+|\mathcal{D}|},
$$

e $P\left(d_{i}\right)$ é a probabilidade de ocorrer o documento $d_{i}$, que é dada por

$$
\left.P\left(d_{i}\right)=\sum_{c_{j} \in \mathcal{C}} P\left(c_{j}\right) P\left(d_{i} \mid c_{j}\right)\right)
$$

O algoritmo Naïve Bayes assume que os termos ocorrem nos documentos de maneira independente. Com isso, a probabilidade de ocorrer $d_{i}$ dada a classe $c_{j}$ é dado pelo produtório dos termos em $d_{i}$ pertencerem a classe $c_{j}$, ou seja,

$$
P\left(d_{i} \mid c_{j}\right)=\prod_{t_{k} \in \mathcal{T}, w_{d_{i}, t_{k}>0}} P\left(t_{k} \mid c_{j}\right)
$$

Dois modelos comumente utilizados para computar a probabilidade a posteriori de um termo para uma classe são (Aggarwal e Zhai, 2012; Nigam et al., 2000; McCallum e Nigam, 1998):

- Modelo Multivariado de Bernoulli: considera apenas a presença ou ausência dos termos em um documento. Uma vez que os atributos a serem modelados são binários, o modelo de distribuição dos documentos para as classes é um modelo de Bernoulli multivariado.

- Modelo Multinomial: considera a frequência das palavras. Os documentos em cada classe são modelados como amostras extraídas de uma distribuição multinomial dos termos.

Nesta tese foi considerado para comparação com os algoritmos propostos o modelo multinomial, o qual apresenta melhores resultados para a classificação indutiva supervisionada

\footnotetext{
${ }^{5}$ Vale ressaltar que nas Equações 3.2 e 3.4 é utilizado o estimador de Laplace (Manning et al., 2008; Nigam et al., 2000) para evitar que um termo $t_{i}$ que não ocorra em ao menos um documento de uma classe $c_{j}$, ou ainda classes que não ocorram em nenhum documento de treinamento, façam com que respectivamente $P\left(t_{k} \mid c_{j}\right)=0$ ou $P(c j)=0$ e consequentemente que $P\left(c_{j} \mid d_{i}\right)=0$.
} 
de textos (Eyheramendy et al., 2003; McCallum e Nigam, 1998). No modelo multinomial, $P\left(t_{k} \mid c_{j}\right)$ é dado por

$$
P\left(t_{k} \mid c_{j}\right)=\frac{1+\sum_{d_{l} \in \mathcal{D}} w_{d_{l}, t_{k}} P\left(c_{j} \mid d_{l}\right)}{|\mathcal{T}|+\sum_{t_{n} \in \mathcal{T}} \sum_{d_{m} \in \mathcal{D}} w_{d_{m}, t_{n}} P\left(c_{j} \mid d_{m}\right)} .
$$

São também encontradas na literatura variações do modelo multinomial que consideram no cálculo das probabilidades, por exemplo, as diferentes ordens que se podem amostrar os termos dos documentos (Kalt, 1998; Mitchell, 1997; Nigam et al., 2000; McCallum e Nigam, 1998; Lewis e Gale, 1994).

A probabilidade $P\left(c_{j} \mid d_{i}\right)$ também pode ser inferida utilizando modelo Bayesian Logistic Regression (BLR) (Genkin et al., 2007). Neste modelo, a probabilidade de ocorrer uma classe $c_{j}$ dado um documento $d_{i}$ é dada por

$$
P\left(c_{j} \mid d_{i}\right)=\varphi\left(\sum_{t_{k} \in \mathcal{T}} f_{t_{k}, c_{j}} \cdot w_{d_{i}, t_{k}}\right),
$$

na qual $\varphi(. .$.$) é a função logística dada por$

$$
\varphi\left(\sum_{t_{k} \in \mathcal{T}} f_{t_{k}, c_{j}} \cdot w_{d_{i}, t_{k}}\right)=\frac{\exp \left(\sum_{t_{k} \in \mathcal{T}} f_{t_{k}, c_{j}} \cdot w_{d_{i}, t_{k}}\right)}{1+\exp \left(\sum_{t_{k} \in \mathcal{T}} f_{t_{k}, c_{j}} \cdot w_{d_{i}, t_{k}}\right)} .
$$

O modelo $B L R$ é binário. Neste caso, têm-se $y_{d_{i}} \in\{+1,-1\}$. Portanto, as adaptações apresentadas na Seção 2.4 devem ser empregadas caso deseje-se realizar a classificação multi-classe.

O objetivo da regressão logística é inferir a informação de classe dos termos de forma a maximizar a verossimilhança condicional $\prod_{d_{i} \in \mathcal{D}^{L}} P\left(y_{d_{i}} \mid d_{i}\right)$ ou o $\log$ da verossimilhança condicional $\sum_{d_{i} \in \mathcal{D}^{L}} \ln \left(P\left(y_{d_{i}} \mid d_{i}\right)\right)$.

A otimização dos valores de $\mathbf{F}(\mathcal{T})$ no $B L R$ da forma como é aplicada em dados numéricos é ineficiente em quentão de tempo, memória e performance de classificação (Genkin et al., 2007). Em Genkin et al. (2007) e Feldman e Sanger (2006) são apresentadas distribuições de probabilidades a priori Gaussiana e Laplaciana que favorecem a questão da esparsidade e eficiência computacional, além de gerar modelos de classificação que apresentam maior performance de classificação. Ambas as distribuições tem como característica o fato de que maioria dos valores estimados de $\mathbf{f}_{t_{i}, c_{j}}$ é ou está próxima a zero.

Na distribuição Gaussiana considera-se que as funções de classe são geradas uma função Gaussiana univariada com média zero e variância $\tau_{i}>0$ para cara parâmetro $\mathbf{f}_{t_{i}}$, como apresentado na Equação 3.8 .

$$
p\left(\mathbf{f}_{t_{i}} \mid \tau_{t_{i}}\right)=\frac{1}{\sqrt{2 \pi \tau_{t_{i}}}} \exp \left(\frac{-\mathbf{f}_{t_{i}}^{2}}{2 \tau_{t_{i}}}\right)
$$


Por simplicidade os valores de $\tau_{t_{i}}$ são os mesmos para todo $t_{i} \in \mathcal{T}$. Pequenos valores de $\tau_{t_{i}}$ fazem com que os valores de $\mathbf{f}_{t_{i}}$ sejam próximos de 0 . Para a distribuição Gaussiana com média 0 e variância $\tau$, o $\log$ a posteriori é dado por

$$
l(\mathbf{F})-\sum_{d_{i} \in \mathcal{D}} \ln \left(1+\exp \left(-\mathbf{f}^{T} \mathbf{w}_{d_{i}} y_{d_{i}}\right)\right)-\sum_{t_{i} \in \mathcal{T}}\left(\ln \sqrt{\tau_{j}}+\frac{\ln 2 \pi}{2}+\frac{\mathbf{f}_{t_{i}}^{2}}{2 \tau_{t_{i}}}\right)
$$

Na distribuição Laplaciana também assume-se que cada $\mathbf{f}_{t_{i}}$ é gerado por uma função gaussiana com média zero e variância $\tau_{t_{i}}$ como na distribuição Gaussiana (Equação 3.8). Para gerar soluções esparsas, assume-se que cada $\tau_{t_{i}}$ também é dado por uma distribuição exponencial com densidade

$$
p\left(\tau_{t_{i}} \mid \gamma\right)=\frac{\gamma_{t_{i}}}{2} \exp \left(-\frac{\gamma_{t_{i}}}{2} \tau_{t_{j}}\right)
$$

no qual $\gamma_{t_{i}}>0$ e um hiperparâmetro da distribuição Laplaciana e valor de $\gamma_{t_{i}}$ é o mesmo para todo $t_{i} \in \mathcal{T}$. Para a distribuição Laplaciana com média 0 e variância $2 / \gamma_{t_{i}}^{2}$, o $\log a$ posteriori é dado por

$$
l(\mathbf{F})=-\sum_{d_{i} \in \mathcal{D}} \ln \left(1+\exp \left(-\mathbf{f}^{T} \mathbf{w}_{d_{i}} y_{d_{i}}\right)\right)-\sum_{t_{i} \in \mathcal{T}}\left(\ln 2-\ln \sqrt{\gamma_{t_{i}}}+\sqrt{\gamma_{t_{i}}}\left|f_{t_{i}}\right|\right)
$$

O negativo do log a posteriori para o modelo de regressão logística é convexo tanto para as a prioris Gaussiana e Laplaciana, e portanto pode-se utilizar uma grande variedade de métodos de otimização convexos para estimar os valores de $\mathbf{f}_{t_{i}}$.

\section{Classificação Linear}

Basicamente existem dois tipos de classificadores lineares: (i) classificadores que obtêm os pesos dos termos para as classes de forma a predizer exatamente o valor da informação de classe dos exemplos de treinamento, ou (ii) classificadores que induzem um hiperplano de separação entre os exemplos de classes diferentes. Normalmente, classificadores lineares são binários e os vetores de informação de classes possuem uma única posição, que dependendo do tipo de algoritmo, pode corresponder aos coeficientes de regressão ou aos parâmetros de um hiperplano de separação. Novamente, as adaptações apresentadas no Capítulo 2 devem ser utilizadas para problemas de classificação multi-classe.

O objeto dos classificadores que obtêm os pesos dos termos para as classes para predizer exatamente o valor das informações de classe dos exemplos de treinamento é minimizar a seguinte função objetivo:

$$
Q(\mathbf{F}(\mathcal{T}))=\sum_{d_{i} \in \mathcal{D}^{L}} \sum_{c_{j} \in \mathcal{C}}\left\|\left(\sum_{t_{k} \in \mathcal{T}} f_{t_{k}, c_{j}} w_{t_{k}, d_{i}}\right)-y_{d_{i}, c_{j}}\right\|^{2} .
$$

O algoritmo Linear Least Squares Fit (LLSF) (Yang e Chute, 1994, 1992) realiza uma regressão linear por meio da decomposição de valores singulares para minimizar a 
Equação 3.12. Entretanto, as implementações eficientes para decomposição de valores singulares da literatura necessitam que o número de documentos deve seja maior que o número de termos (Dongarra et al., 1979; Mathworks e NIST, 1999), situação esta que normalmente ocorre por meio de seleção de termos, o que introduz novos problemas como a definição do número de atributos e a possível redução do poder discriminativo da representação.

A Equação 3.12 pode ser modificada acrescentando um regularizador para definir a amplitude dos valores das informações de classe dos termos. Neste caso, têm-se a seguinte equação:

$$
Q(\mathbf{F}(\mathcal{T}))=\sum_{d_{i} \in \mathcal{D}^{l}} \sum_{c_{j} \in \mathcal{C}}\left\|\sum_{t_{k} \in \mathcal{T}}\left(\sum_{t_{k} \in \mathcal{T}} f_{t_{k}, c_{j}} w_{t_{k}, d_{i}}\right)\right\|^{2}+\lambda \sum_{c_{j} \in \mathcal{C}} \sum_{t_{k} \in \mathcal{T}}\left\|f_{t_{k}, c_{j}}\right\|^{2}
$$

A minimização da Equação 3.13 é denominada Ridge Regression $(R R) . R R$ tem sido utilizada na classificação de textos e alguns autores afirmam que a uso do termo regularizador diminuem a variância nas estimativas dos parâmetros e aumenta a performance de classificação (Li e Yang, 2003; Zhang e J. Oles, 2001).

Outro conjunto de algoritmos baseados em classificação linear visa induzir um hiperplano de separação entre os exemplos de duas classes. Formalmente, um hiperplano ou superfície de decisão de um classificador é definido por

$$
\mathbf{f} \cdot \mathbf{w}+b=0
$$

no qual f representa os coeficientes lineares (no caso da classificação de textos são pesos atribuídos aos termos) e $b$ é um valor escalar denominado bias ou threshold.

Um documento $d_{i}$ acima do hiperplano de separação pertence à classe +1 e um exemplo abaixo do hiperplano de separação é classificado com -1, ou seja,

$$
y_{d_{i}}=\left\{\begin{array}{l}
+1, \quad \text { se } \sum_{t_{k} \in \mathcal{T}} f_{t_{k}} \cdot w_{d_{i}, t_{k}}+b>0 \\
-1 \quad \text { se } \sum_{t_{k} \in \mathcal{T}} f_{t_{k}} \cdot w_{d_{i}, t_{k}}+b<0
\end{array}\right.
$$

Em geral, o objeto dos algoritmos que geram hiperplanos para separar os documentos de classes diferentes é induzir um hiperplano de tal forma que todo documento da classe positiva esteja acima do hiperplano e todo documento da classe negativa esteja abaixo do hiperplano. Um dos algoritmos estado da arte e um dos mais estudados para a classificação de textos é o Support Vector Machines (SVM) (Joachims, 1998; Vapnik, 1998). O SVM possui uma característica diferente dos demais métodos de classificação linear uma vez que visa obter um hiperplano de separação de margem máxima entre exemplos pertencentes à classe +1 e exemplos pertencentes à classe -1 , isto é, um hiperplano com maior distância entre qualquer exemplo da classe positiva e qualquer exemplo da classe negativa. Para tal, seja $\mathcal{H}$ o conjunto de hiperplanos possíveis, $H_{l} \in \mathcal{H}$ um hiperplano, $H_{l}^{+}$o hiperplano 
paralelo mais próximo de $H_{l}$, e seja $d_{i}$ um documento da classe +1 cortado pelo hiperplano $H_{l}^{+}$, isto é

$$
H_{l}^{+}: \sum_{t_{k} \in \mathcal{T}} f_{t_{k}} \cdot w_{d_{i}, t_{k}}+b=0, y_{d_{i}}=+1
$$

Seja $H_{l}^{-}$o hiperplano paralelo mais próximo à $H_{l}$ e seja $d_{j}$ um documento da classe -1 cortado pelo hiperplano $H_{l}^{-}$, isto é

$$
H_{l}^{-}: \sum_{t_{k} \in \mathcal{T}} f_{t_{k}} \cdot w_{d_{i}, t_{k}}+b=0, y_{d_{i}}=-1 .
$$

A distância euclidiana entre os hiperplano $H_{l}^{+}$e $H_{l}^{-}$é denominada margem de separação (Tan et al., 2005). Portanto, o algoritmo $S V M$ visa induzir um hiperplano $H_{l}$ tal que os hiperplanos paralelos $H_{l}^{+}$e $H_{l}^{-}$tenham margem de separação máxima. A hipótese do $S V M$ é que hiperplanos de separações com maiores margens tendem a apresentar maior performance na classificação de novos exemplos.

Outra característica do $S V M$ é que os hiperplanos são determinados por um subconjuntos de exemplos de treinamento, os quais são denominados support vectors, que correspondem aos documentos de treinamento cortados pelos hiperplanos $H_{l}^{+}$e $H_{l}^{-}$. Portanto, uma parcela dos documentos de treinamento não têm influência na indução do modelo de classificação do SVM.

Reescalando os parâmetros f e $b$ para facilitar o problema de otimização da margem máxima têm-se (Zhu e Goldberg, 2009; Tan et al., 2005):

$$
\begin{gathered}
H_{l}^{+}: \sum_{t_{k} \in \mathcal{T}} f_{t_{k}} \cdot w_{d_{i}, t_{k}}+b=1, y_{d_{i}}=+1 \\
H_{l}^{-}: \sum_{t_{k} \in \mathcal{T}} f_{t_{k}} \cdot w_{d_{j}, t_{k}}+b=-1, y_{d_{j}}=-1 .
\end{gathered}
$$

O treinamento do $S V M$ consiste em estimar parâmetros $\mathbf{f}$ e $b$ tal que satisfaça a condições das Equações 3.20 e 3.21

$$
\begin{gathered}
\sum_{t_{k} \in \mathcal{T}} f_{t_{k}} \cdot w_{d_{i}, t_{k}}+b \geq 1 \text { se } y_{d_{i}}=+1, \\
\sum_{t_{k} \in \mathcal{T}} f_{t_{k}} \cdot w_{d_{i}, t_{k}}+b \leq-1 \text { se } y_{d_{j}}=-1,
\end{gathered}
$$

As Equações 3.20 e 3.21 podem ser sumarizadas por:

$$
y_{d_{i}}\left(\sum_{t_{k} \in \mathcal{T}} f_{t_{k}} \cdot w_{d_{i}, t_{k}}+b\right) \geq 1, \forall d_{i} \in \mathcal{D}^{L}
$$

Seja dist $\left(d_{i}, d_{j}\right)$ a distância euclidiana entre dois pontos tal que $d_{i}$ é cortado pelo hiperplano $H_{l}^{+}$e $d_{j}$ é cortado pelo hiperplano $H_{l}^{-}$. Subtraindo ambos os hiperplanos para 
obter sua distância têm-se

$$
\begin{array}{r}
\mathbf{f} \cdot\left(\mathbf{w}_{d_{i}}-\mathbf{w}_{d_{j}}\right)=2 \\
\|\mathbf{f}\| \times \operatorname{dist}\left(\mathbf{w}_{d_{i}}, \mathbf{w}_{d_{j}}\right)=2 \\
\therefore \operatorname{dist}\left(\mathbf{w}_{d_{i}}, \mathbf{w}_{d_{j}}\right)=\frac{2}{\|\mathbf{f}\|}
\end{array}
$$

Portanto, considerando a restrição da Equação 3.22 e o objetivo de obter a margem de separação máxima, o objetivo do treinamento do $S V M$ linear é minimizar a seguinte função:

$$
\begin{gathered}
\min _{\mathbf{f}} \frac{\|\mathbf{f}\|^{2}}{2} \\
\text { sujeito à } \quad y_{d_{i}}\left(\sum_{t_{k} \in \mathcal{T}} f_{t_{k}} \cdot w_{d_{i}, t_{k}}+b\right) \geq 1, \forall d_{i} \in \mathcal{D}^{L} .
\end{gathered}
$$

A superfície de decisão obtida pela minimização da Equação 3.24 não permite erros de treinamento, ou seja, um exemplo positivo não pode estar localizado abaixo do hiperplano e nem um exemplo negativo pode estar localizado acima do hiperplano. Esta solução também é conhecida por hard margin. Além disso, uma margem de separação maior mesmo com erros de treinamento pode generalizar melhor os padrões das classes e ter uma performance de classificação maior na classificação de novos exemplos.

O problema de minimização do $S V M$ pode ser modificado para considerar um trade-off entre tamanho da margem e erro de treinamento. Este tipo de modificação é denominado soft margin. Para isso são introduzidas as variáveis denominadas slack $(\xi)$ no problema de otimização. O função de otimização do $S V M$ com variáveis slack é dada por

$$
\begin{gathered}
\sum_{t_{k} \in \mathcal{T}} f_{t_{k}} \cdot w_{d_{i}, t_{k}}+b \geq 1-\xi_{d_{i}} \text { se } y_{d_{i}}=+1 \\
\sum_{t_{k} \in \mathcal{T}} f_{t_{k}} \cdot w_{d_{i}, t_{k}}+b \leq-1+\xi_{d_{i}} \text { se } y_{d_{i}}=-1,
\end{gathered}
$$

tal que $\xi_{d_{i}}>0, \forall d_{i} \in \mathcal{D}^{L}$. $\xi_{i}$ provê uma estimativa do erro de um exemplo $d_{i}$, que consiste na distância do documento até o hiperplano de separação. A função de otimização considerando a abordagem soft margin é dada por:

$$
\min _{\mathbf{f}} \frac{\|\mathbf{f}\|^{2}}{2}+C\left(\sum_{d_{i} \in \mathcal{D}^{L}} \xi_{d_{i}}\right)
$$

na qual $C$ é um parâmetro definido pelo usuário que pondera os erros de classificação nos exemplos de treinamento. Quanto maior o valor de $C$, menos erros serão considerados ao gerar a margem de separação máxima e consequentemente menor será o tamanho da margem. 
O método $S V M$ pode ser modificado para gerar hiperplanos de separação não lineares. Para isso, os dados não linearmente separáveis são mapeados para um novo espaço de maior dimensionalidade de forma que um hiperplano de separação linear possa ser usado para transformar o espaço de dados. Para poder utilizar esse tipo de mapeamento, o problema de otimização do SVM (Equação 3.24) pode ser modificado e resolvido por meio de Multiplicadores de Lagrange, como apresentado na Equação 3.28.

$$
L_{D}=\sum_{d_{i} \in \mathcal{D}^{L}} \lambda_{d_{i}}-\frac{1}{2} \sum_{d_{i}, d_{j} \in \mathcal{D}^{L}} \lambda_{d_{i}} \lambda_{d_{j}} y_{d_{i}} y_{d_{j}} \mathbf{w}_{d_{i}} \cdot \mathbf{w}_{d_{j}}
$$

Um dos componentes da Equação 3.28 consiste da produto vetorial que mede a distância entre dois documentos. Pode-se modificar esse componente com o uso do chamado kernel trick, que consiste em utilizar uma função de kernel no lugar do produto vetorial entre os vetores dos documentos para modificar as distâncias entre estes e torná-los linearmente separáveis. Uma função de kernel é dada por:

$$
K\left(\mathbf{w}_{d_{i}}, \mathbf{w}_{d_{i}}\right)=\Phi\left(\mathbf{w}_{d_{i}}\right)^{T} \cdot \Phi\left(\mathbf{w}_{d_{j}}\right)
$$

na qual $\Phi\left(\mathbf{w}_{d_{i}}\right)$ é uma função que mapeia $\mathbf{w}_{d_{i}}$ a um espaço de maior dimensionalidade em relação ao espaço original. Duas funções de kernel admissíveis e das mais utilizadas para realizar o mapeamento são (Tan et al., 2005; Han et al., 2001):

- Kernel Polinomial:

$$
K\left(\mathbf{w}_{d_{i}}, \mathbf{w}_{d_{j}}\right)=\left(\mathbf{w}_{d_{i}} \cdot \mathbf{w}_{d_{j}}+1\right)^{p}
$$

na qual $p$ é um parâmetro real informado pelo usuário que corresponde ao grau do polinômio.

- Kernel Radial Basis Function (RBF):

$$
K\left(\mathbf{w}_{d_{i}}, \mathbf{w}_{d_{j}}\right)=\exp \left(-\frac{\left\|\mathbf{w}_{d_{i}}-\mathbf{w}_{d_{j}}\right\|}{2 \sigma^{2}}\right)
$$

na qual $\sigma$ é uma parâmetro real informado pelo usuário que define o tamanho da abertura da função gaussiana.

A incorporação das funções de kernel na função de otimização do $S V M$ faz com que a mesma fique da seguinte forma:

$$
L_{D}=\sum_{d_{i} \in \mathcal{D}^{L}} \lambda_{d_{i}}-\frac{1}{2} \sum_{d_{i}, d_{j} \in \mathcal{D}^{L}} \lambda_{d_{i}} \lambda_{d_{j}} y_{d_{i}} y_{d_{j}} K\left(\mathbf{w}_{d_{i}}, \mathbf{w}_{d_{j}}\right)
$$

Os hiperplanos encontrados por pelo SVM com uso de kernel tricks são similares encontrados por alguns classificadores baseados em redes neurais, como o $S V M$ com soft-margin e função de kernel do tipo $R B F$ e as redes neurais do tipo $R B F$. Porém, $S V M$ sempre encontram uma solução global, enquanto que os algoritmos de redes neurais, como backpropagation, podem encontrar soluções ótimas locais (Han e Kamber, 2011). 


\section{Clasificação Baseada em Regras}

Os classificadores baseados em regras geram um conjunto de regras de forma que todos os exemplos de um conjunto de treinamento sejam classificados por ao menos uma das regras. As regras de classificação têm o seguinte formato:

$$
\operatorname{freq}\left(t_{a}\right)>X \wedge \operatorname{freq}\left(t_{b}\right)>Y \wedge \ldots \wedge \operatorname{freq}\left(t_{c}\right)>Z \rightarrow c_{j}
$$

na qual freq $\left(t_{a}\right)$, freq $\left(t_{b}\right)$ e $f r e q\left(t_{c}\right)$ representam frequências dos termos $t_{a}$, $t_{b}$ e $t_{c}$ respectivamente, $X, Y$ e $Z$ são valores numéricos e $c_{j}$ é uma classe da coleção de documentos. Portanto, a indução visa obter o quanto a presença de um conjunto de termos irá contribuir para atribuir um rótulo a um documento para uma determinada classe. Não são consideradas ausências de termos nas regras, uma vez que como o domínio textual é esparso e possui uma grande quantidade de termos com frequência 0. Além disso, regras geradas considerando ausência de termos seriam muito longas e difíceis de serem interpretadas.

Vale ressaltar que nos classificadores lineares, probabilísticos ou baseados em proximidade, a presença de cada termo em um documento é tratada independentemente e individualmente, ou seja, cada termo tem a mesma importância na rotulação de um documento e não são consideradas as coocorrências entre os termos. Já nos algoritmos baseados em regras e em árvores de decisão, que serão apresentados a seguir, é considerada a presença de um conjunto de termos para realizar a classificação.

O lado esquerdo da regra, que contém um conjunto de condições, é chamado da antecedente da regra, e o lado direito, que contém a classe, é chamado de consequente da regra. Quando um documento satisfaz todas as condições de uma regra é dito que o documento "dispara" a regra. A cobertura de uma regra refere-se ao conjunto de documentos disparados pela mesma.

Para cada classe são geradas regras que cubram corretamente todos os exemplos disparados pelas mesmas. Além disso, a geração de uma regra é obtida por um processo guloso, uma vez que a avaliação da combinação de todos os termos com respectivas frequências para a geração das regras é inviável. No processo guloso, inicialmente é gerada uma regra vazia, a qual é incrementada iterativamente até que as condições da regra façam com que todos os exemplos cobertos por ela sejam classificados corretamente.

Um dos algoritmos baseados em regras mais utilizados e aconselháveis para a classificação de textos é o algoritmo Repeated Incremental Pruning to Produce Error Reduction (RIPPER) (Cohen e Singer, 1999; Cohen, 1995). Dada uma classe $c_{j}$, o algoritmo RIPPER constrói um conjunto de regras (RuleSet) de forma que elas cubram todos os exemplos da classe $c_{j}$ e posteriormente aplica um mecanismo de poda para evitar a superespecialização.

Após gerar uma regra, todos os exemplos cobertos pela mesma são excluídos do conjunto de treinamento. São geradas regras para cada classe $c_{j} \in \mathcal{C}$ até que todos os exemplos de $c_{j}$ sejam cobertos pelas regras). As regras são geradas da classe menos frequente para a mais frequente. A exceção é a última classe, a qual é disparada por uma regra "padrão", 
isto é, uma regra que é disparada apenas se nenhuma das regras geradas para as demais classes for disparada.

As regras são incrementadas com uma condição simples a cada iteração utilizando um subconjunto de documentos denominado $\mathcal{D}^{\text {Grow }}$ (usualmente $2 / 3$ do conjunto de treinamento) e decrementadas, também com uma condição simples, utilizando um conjunto de documentos denominado $\mathcal{D}^{\text {Prune }}$ (usualmente $1 / 3$ do conjunto de treinamento). Uma regra $r_{i}$ é repetidamente incrementada, a partir de um conjunto vazio, considerando a condição que leve ao maior ganho de informação relativo (Cohen, 1995). Portanto um regra $r_{i}^{\prime}$ que corresponde ao incremento de uma condição na regra $r_{i}$ é aquele que maximiza a função:

$$
\operatorname{Gain}\left(r_{i}^{\prime}, r_{i}\right)=\left|\mathcal{D}_{r_{i}^{\prime}}^{c_{j}}\right| \cdot\left(-\log _{2} \frac{\left|\mathcal{D}_{r_{i}}^{c_{j}}\right|}{\left|\mathcal{D}_{r_{i}}^{c_{j}}\right|+\left|\mathcal{D}_{r_{i}}^{\mathcal{C}-c_{j}}\right|}+\log _{2} \frac{\left|\mathcal{D}_{r_{i}^{\prime}}^{c_{j}}\right|}{\left|\mathcal{D}_{r_{i}^{\prime}}^{c_{j}}\right|+\left|\mathcal{D}_{r_{i}^{\prime}}^{\mathcal{C}-c_{j}}\right|}\right)
$$

na qual $\left|\mathcal{D}_{r_{i}}^{c_{j}}\right|$ é o número de documentos da classe $c_{j}$ coberto pela regra $r_{i}$ no conjunto $\mathcal{D}^{\text {Grow }}$. Esta medida fará com que a regra $r_{i}^{\prime}$ aumente a densidade de exemplos da classe $c_{j}$ sem diminuir drasticamente o número de exemplos cobertos pela regra $r_{i}$.

Após atingir a critério de parada para incremento da regra, a mesma é podada ou simplificada. Novamente, é realizada um busca gulosa para a simplificação da regra. O algoritmo RIPPER irá deletar as condições finais de uma regra de forma a maximizar a função

$$
f\left(r_{i}\right)=\frac{\left|\mathcal{D}_{r_{i}^{\prime}}^{c_{j}}\right|-\left|\mathcal{D}_{r_{i}^{\prime}}^{\mathcal{C}-c_{j}}\right|}{\left|\mathcal{D}_{r_{i}^{\prime}}^{c_{j}}\right|+\left|\mathcal{D}_{r_{i}^{\prime}}^{\mathcal{C}-c_{j}}\right|}
$$

na qual $\left|\mathcal{D}_{r_{i}^{\prime}}^{c_{j}}\right|$ é o número de exemplos da classe $c_{j}$ cobertos pela nova regra considerando o conjunto $\mathcal{D}^{\text {Prune }}$. Após a poda, a regra $r_{i}^{\prime}$ é adicionada no RuleSet e os exemplos cobertos pela regra $r_{i}$ são removidos de $\mathcal{D}^{\text {Grow }}$.

O algoritmo RIPPER também controla o crescimento das regras utilizando a heurística Minimum Description Length ( $M D L)$ (Quinlan, 1995). A heurística $M D L$ baseia-se na premissa que o melhor modelo dado um conjunto de dados é o modelo mais compacto e com menor erro de classificação. Portanto o uso do $M D L$ faz com que não se gere regras com muitas conjunções e portanto super ajustadas ao conjunto de treinamento. Para isso, tanto o modelo, o erro de classificação obtido pelo modelo e o conjunto de dados são codificados tal que o número de bits necessário para a codificação irá medir a complexidade do modelo. O modelo preterido pelo algoritmo é o com menor description length $(D L)$ ou número de bits necessários para realizar a codificação. O $D L$ de um modelo de classificação é dado por:

$$
\log _{2}(|\mathcal{D}|+1)+e \cdot\left(-\log \left(\frac{e}{|\mathcal{D}|}\right)\right)+(|\mathcal{D}|-e) \cdot\left(-\log \left(1-\frac{e}{|\mathcal{D}|}\right)\right)
$$


na qual e é o número de erros de classificação considerando os documentos em $\mathcal{D}^{\text {Grow }}$.

Após gerado o conjunto de regras o algoritmo RIPPER inclui um passo adicional objetivando aumentar a acurácia e reduzir o tamanho das regras. Esse passo é denominado Otimização. Para cada regra rule duas regras alternativas são construídas, chamadas de regra revisada $\left(\right.$ rule $\left.^{\prime}\right)$ e regra de substituição $\left(\right.$ rule $\left.^{\prime \prime}\right)$. O algoritmo opta por manter a regra que tenha o menor $D L$. A regra revisada é construída da mesma forma como apresentada anteriormente, ou seja, incrementando o antecedente de uma regra a partir da regra vazia. A regra de substituição utiliza a regra rule como base e a incrementa. Ambas as regras são submetidas a um processo de poda. Após a otimização, o novo conjunto de regras pode deixar de cobrir alguns exemplos. Para isso a construção de regras deve ser executada novamente.

No Algoritmo 1 é apresentado o pseudocódigo do algoritmo RIPPER. Em suma, o algoritmo RIPPER utiliza o algoritmo Incremental Reduced Error Pruning (IREP) (Fürnkranz e Widmer, 1994) para gerar regras, apresentado no Algoritmo 2, e adiciona o procedimento de otimização, apresentado no Algoritmo 3.

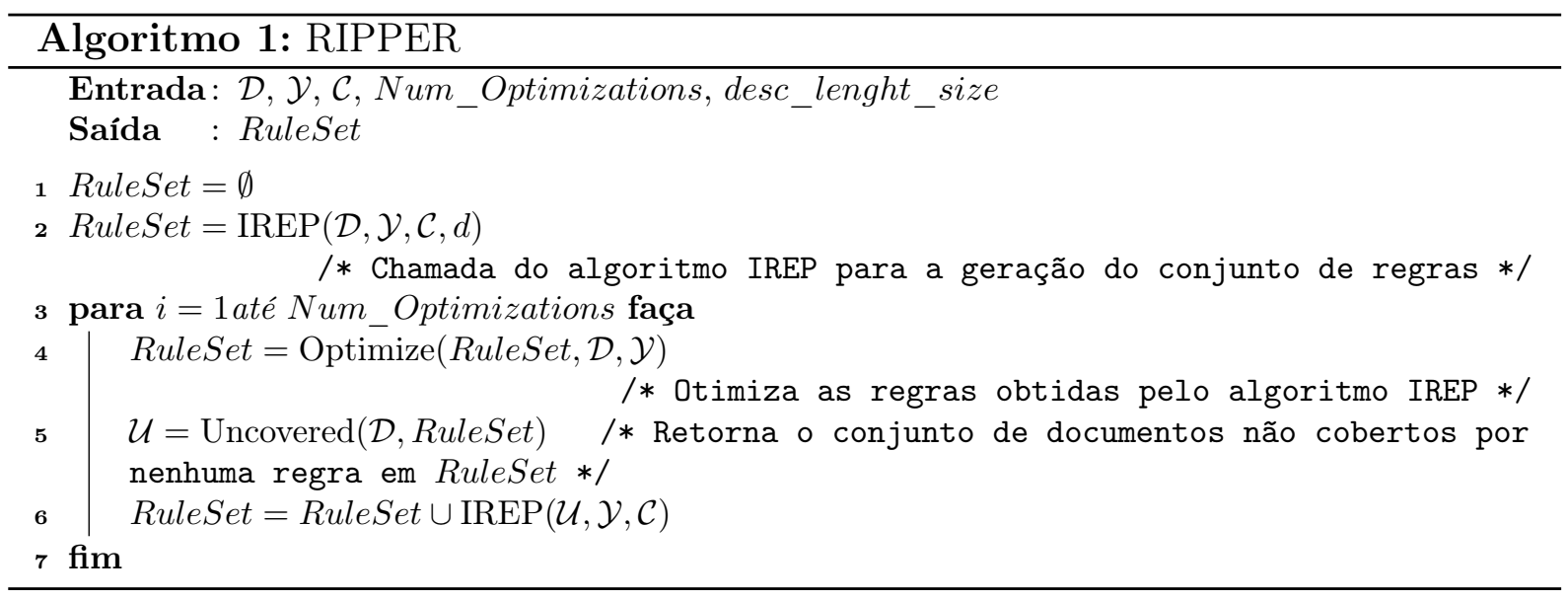

Além do algoritmo RIPPER, apresentado acima, outros algoritmos baseados em regras podem ser utilizados na classificação de textos (Johnson et al., 2002; Cohen e Singer, 1999; Frank e Witten, 1998; Gaines e Compton, 1995; Apté et al., 1994). Porém, vários deles baseiam-se nos mesmos conceitos do algoritmo RIPPER ou ainda na extração de regras de árvores de decisão (apresentadas na próxima seção)

Existem também algoritmos de indução de regras de classificação baseados em regras de associação, que visam encontrar correlações entre padrões frequentes de conjuntos de dados (Yoon e Lee, 2008; Liu et al., 1998). Esses algoritmos também são denominados algoritmos de classificação associativa. Esse tipo de algoritmo encontra todo intervalo de frequência de termos que ocorrem acima de uma frequência e confiança mínimas com as classes da coleção de documentos. Entretanto, na prática, é necessário discretizar os atributos para obter intervalos de frequências dos termos e permitir a aplicação de algoritmos de extração de regras de associação, e os valores de suporte e confiança mínimos devem ser cuidadosamente ajustados, uma vez que uma pequena variação no valor, principalmente 

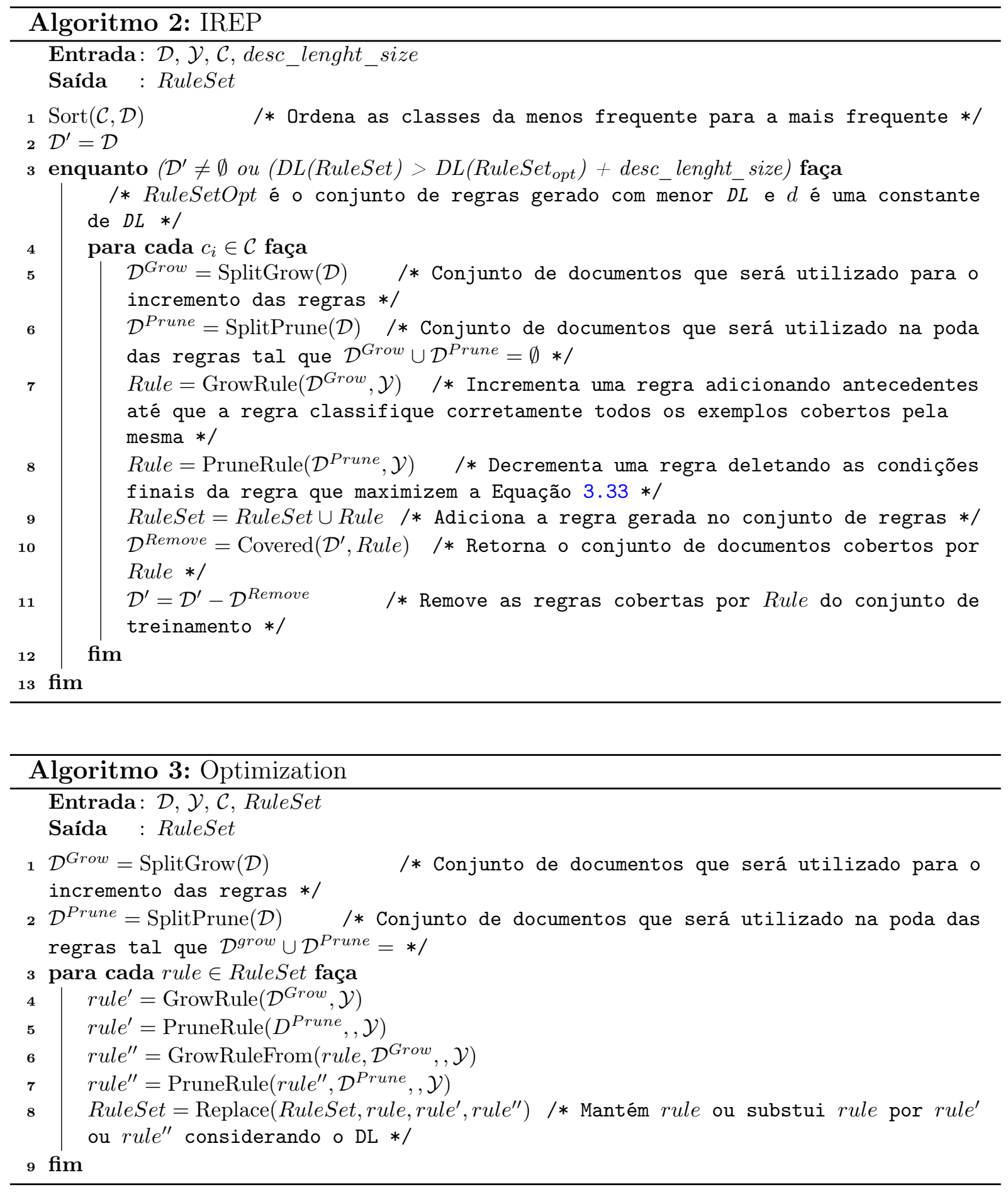

da medida suporte, pode levar a extração de nenhuma regra a extração de milhares de regras.

Para classificar um novo documento, primeiro são determinadas as regras de classificação disparadas pelo novo documento. Em seguida, o rótulo é dado em função dos rótulos das classes das regras disparadas podendo, por exemplo, considerar somente a primeira regra disparada, a regra com maior número de testes, ou dar um peso de voto para cada uma das regras disparadas. A limitação dos algoritmos baseados em regras é que a busca pelo conjunto de regras e a poda tornam a geração do modelo de classificação computacionalmente custoso. 


\section{Classificação Baseada em Árvores de Decisão}

A classificação baseada em árvores de decisão consiste em induzir uma árvore em que: (i) cada nó interno é rotulado com um termo $t_{i} \in \mathcal{T}$, (ii) as aresta da árvore que conectam os nós são rotuladas com testes sobre as frequências dos termos, e (iii) os nós folhas são rotulados com as classes da coleção. Na Figura 3.2 é apresentada uma ilustração de uma árvore de decisão.

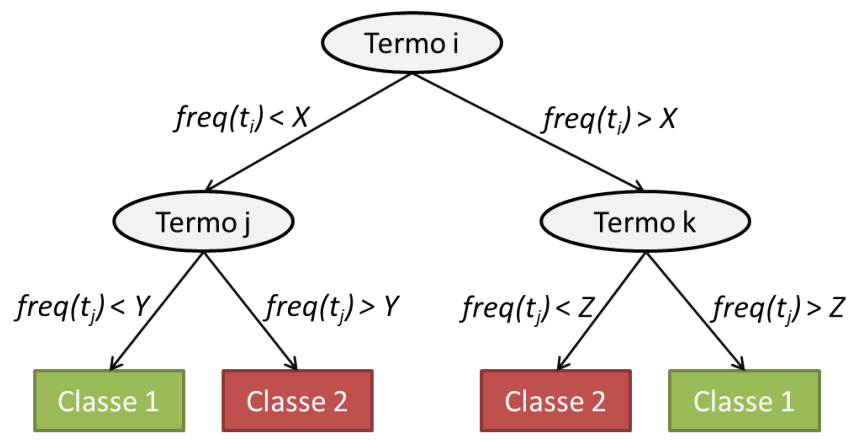

Figura 3.2: Ilustração de uma árvore de decisão.

Cada teste da árvore divide o conjunto de documentos de treinamento em subconjuntos que satisfaçam o teste. A divisão é realizada até que todos os documentos do subconjunto pertençam a uma única classe. Portanto, pode-se entender a árvore de decisão como uma divisão hierárquica do espaço de dados. Para textos representados no modelo espaço-vetorial, as condições de teste normalmente são expressas por testes binários do tipo $\left(\right.$ freq $\left.\left(t_{i}\right)<X\right)$ ou $\left(\right.$ freq $\left.\left(t_{i}\right) \geq X\right)$ (Tan et al., 2005) na qual $f r e q\left(t_{i}\right)$ representa a frequência do termo $t_{i}$ e $X$ é um valor de frequência. Como a divisão na maioria dos algoritmos é realizada utilizando um único termo por vez, as divisões são perpendiculares aos eixos do espaço-vetorial. Assim como na classificação baseada em regras, encontrar todas as possíveis árvores de decisão para escolher a árvore de decisão ótima é inviável. Portanto, as árvores de decisão também são construídas de maneira gulosa.

Segundo Aggarwal e Zhai (2012), a maioria das implementações de árvores de decisão tem a ser pequenas variações de algoritmos tradicionais como ID3 (Quinlan, 1986) e C4.5 (Quinlan, 1993). Nestes algoritmos, a escolha dos nós e suas respectivas divisões (ramos) são baseadas em medidas de teoria de informação ou medidas de "impureza".

O C4.5 é um dos algoritmos baseado em árvores de decisão mais utilizados (Wu et al., 2007). No algoritmo C4.5 é utilizado a medida Razão de Ganho (do inglês Gain Ratio) para analisar qual atributo, com seus respectivos testes, proporciona uma partição mais "pura" no conjunto de treinamento, isto é, uma separação no espaço de dados em que haja a maioria de exemplos de uma única classe em cada uma das partições. Além disso, é dado maior peso a atributos cujos testes realizem um menor número de partições no conjunto de dados. A Razão de Ganho de um termo $t_{i}$ é dada por:

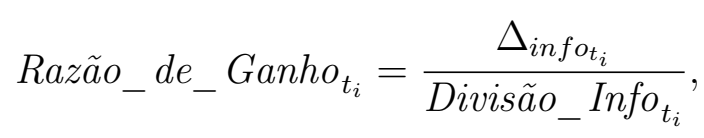


na qual $\Delta_{\text {info }}$ calcula a variação da impureza do nó pai para os possíveis nós filhos, e é dada por

$$
\Delta_{\text {info }_{i}}=I\left(t_{i}\right)-\sum_{s_{j} \in \mathcal{S}_{t_{i}}} \frac{N\left(s_{j}\right)}{N} I\left(s_{j}\right),
$$

sendo $I(.$.$) uma função de impureza, N$ o número de registros cobertos pelo nó pai, $\mathcal{S}_{t_{i}}=\left\{s_{1}, s_{2}, \ldots, s_{r}\right\}$ representa o conjunto de testes realizados sobre o termo $t_{i}, N\left(s_{j}\right)$ é o número de exemplos cobertos pelo teste $s_{j}$ no termo $t_{i}$ e Divisão_ Info $o_{t_{i}}$ é uma função para reduzir o valor da razão de ganho para termos que gerem um alto número de testes, e é dada por

$$
\text { Divisão_Info }{ }_{t_{i}}=-\sum_{s_{j} \in \mathcal{S}_{t_{i}}} P\left(s_{j}\right) \log _{2} P\left(s_{j}\right) .
$$

A entropia é utilizada como medida de impureza no algoritmo C4.5. Para um termo $t_{i}$, a entropia é dada por

$$
\text { Entropia }\left(t_{i}\right)=-\sum_{c_{j} \in \mathcal{C}} p\left(c_{j} \mid t_{i}\right) \log _{2} p\left(c_{j} \mid t_{i}\right)
$$

na qual $p\left(c_{j} \mid t_{i}\right)$ é a fração de documentos da classe $c_{j}$ em que ocorre o termo $t_{i}$ e $\log _{2} 0=0$. Quanto maior o número de ocorrências de um termo $t_{i}$ para uma única classe, menor será o valor da Entropia.

Testes são adicionados aos nós da árvore de decisão até que que todos os documentos pertençam à uma mesma classe ou até que as partições sejam puras, ou seja, contenham exemplos de apenas uma única classe. No Algoritmo 4 é apresentado o pseudocódigo do algoritmo C4.5 para se construir uma árvore de decisão.

A estratégia de dividir o conjunto de dados até obter uma partição pura faz com que as árvores induzidas se super ajustem aos dados, o que pode causar uma performance de classificação insatisfatória para novos documentos. Para evitar a superespecialização, podese utilizar estratégias para "podar" a árvore de decisão (Quinlan, 1993). A poda da árvore é realizada de forma a substituir subárvores por nós folha (Quinlan, 1993). Neste caso, o novo nó folha será rotulado com a classe majoritária dos exemplos cobertos pelo nó. C4.5 considera o cálculo do valor limite superior da confiança do erro, ou também denominado erro de generalização, para realizar a poda da árvore de decisão. O limite superior do erro de generalização é baseado no erro observado no conjunto de treinamento. Para um dado intervalo de confiança, o limite superior do erro pode ser calculado considerando o limite superior de uma distribuição binomial. O intervalo de confiança é dado por:

$$
\varepsilon_{U B}(T, S)=\varepsilon(T, S)+Z_{\alpha} \cdot \sqrt{\frac{\varepsilon(T, S) \cdot(1-\varepsilon(T, S))}{|S|}}
$$

na qual $\varepsilon(T, S)$ é a taxa de erro de classificação da árvore $T$ no conjunto de treinamento 


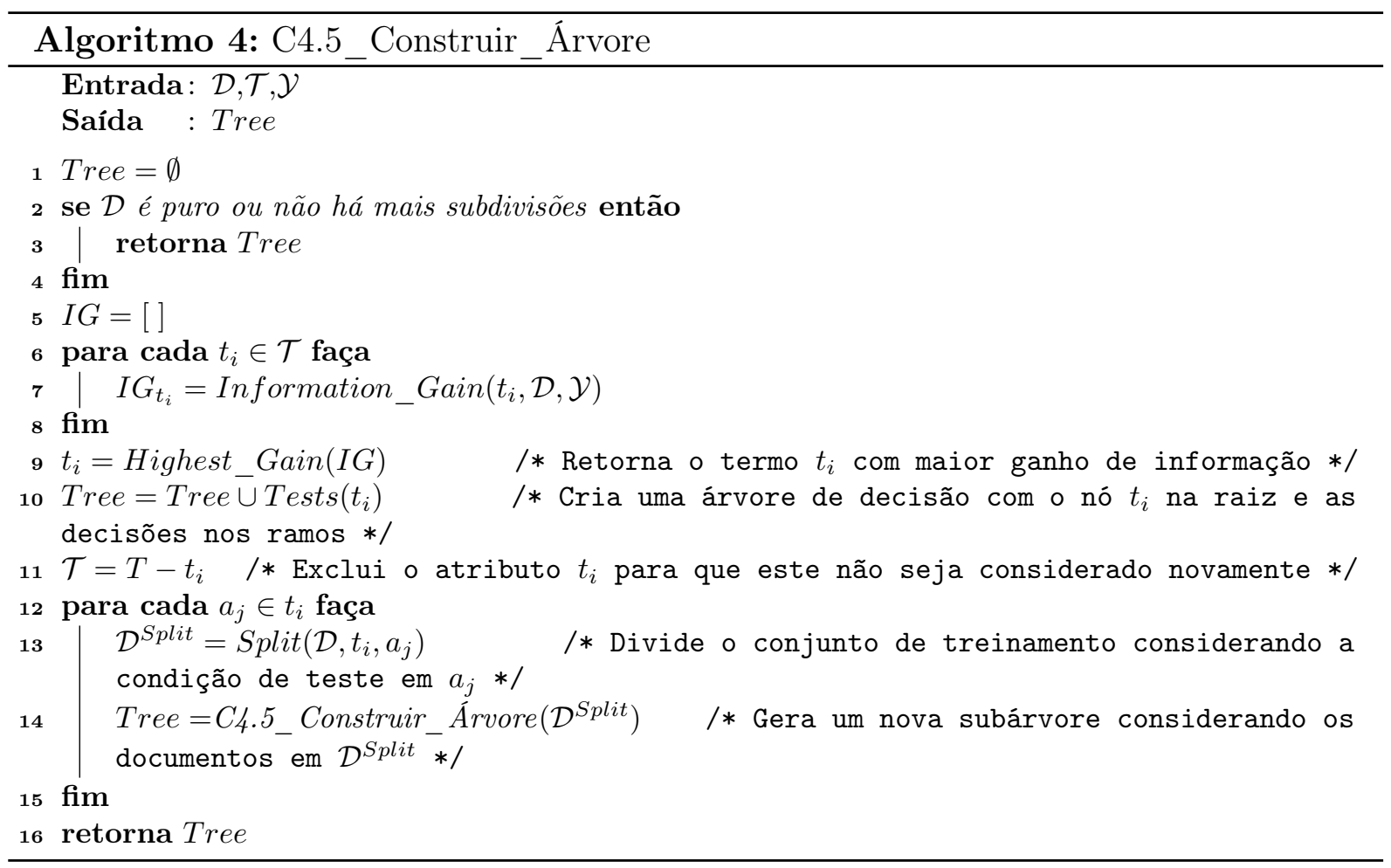

$S$, e $Z$ é o valor da distribuição normal acumulativa e $\alpha$ é o nível de significância desejado. Uma subárvore será substituída por um nó folha se o erro gerado estiver dentro limite da confiança.

Para classificar um documento, percorre-se da raiz até a folha pelo caminho que satisfaz as condições da árvore. A desvantagem da árvore de decisão é a mesma das regras, ou seja, o custo computacional pode ser alto uma vez que todos os atributos restantes são testados para selecionar a melhor divisão em cada nó da árvore.

\section{Classificação Baseada em Proximidade}

Basicamente existem dois tipos de classificação baseada em proximidade: (i) classificação baseada em protótipos e (ii) classificação baseada em exemplos. O objetivo da classificação baseada em protótipos é criar um objeto representativo para cada classe, denominado protótipo (Han e Karypis, 2000; Boley et al., 1999; Lam e Ho, 1998; Rocchio, 1971). O protótipo para uma classe $c_{l}$, no caso da classificação de textos, corresponde a um vetor de pesos dos termos para cada classe $c_{j}$.

Um dos principais classificadores baseados em protótipos utilizados na classificação de textos é o algoritmo Rocchio (Rocchio, 1971). Neste algoritmo, o peso de um termo $t_{i}$ no protótipo de uma categoria $c_{j}$ é dada por:

$$
p_{c_{j}, t_{i}}=\frac{\alpha}{\left|\mathcal{D}_{c_{j}}^{L}\right|} \sum_{d_{k} \in \mathcal{D}_{c_{j}}^{L}} w_{d_{k}, t_{i}}-\frac{\beta}{\left|\mathcal{D}_{c_{l}, c_{l} \neq c_{j}}^{L}\right|} \sum_{d_{k} \in \mathcal{D}_{c_{l}, c_{l} \neq c_{j}}^{L}} w_{d_{k}, t_{i}},
$$

na qual $\mathcal{D}_{c_{j}}^{L}$ corresponde ao conjunto de documentos rotulados com a classe $c_{j}$ e $\mathcal{D}_{c_{l}, c_{l} \neq c_{j}}^{L}$ corresponde ao conjunto de documentos não rotulados com a classe $c_{j}$. Portanto, um 
protótipo para uma classe $c_{j}$ no algoritmo Rocchio corresponde a um vetor que contém a frequência média dos termos nos documentos da classe $c_{j}$ menos a frequência média dos termos nos documentos da classe que não pertencem à classe $c_{j}$. Os pesos $\alpha$ e $\beta$ definem respectivamente a importância dada aos documentos da classe $c_{j}$ e aos documentos das demais classes para calcular o protótipo. Para $\alpha=1$ e $\beta=0$ têm-se um protótipo equivalente ao gerado pelo algoritmo Centroid Based Classifier $(C B C)$ (Han e Karypis, 2000; Aggarwal e Zhai, 2012).

A informação de classe de um documento $d_{i}$, para uma classe $c_{j}$ é dada por:

$$
f_{d_{i}, c_{j}}=\operatorname{sim}\left(\mathbf{w}_{d_{i}}, \mathbf{p}_{c_{j}}\right)
$$

na qual $\operatorname{sim}\left(\mathbf{w}_{d_{i}}, \mathbf{p}_{c_{j}}\right)$ é a similaridade entre o vetor de termos de um novo documento $d_{i}$ e o protótipo da classe $c_{j}$. Um novo documento é classificado considerando o arg-max de $\mathbf{f}_{d_{i}}$, ou seja, é classificado de acordo com a classe do protótipo mais próximo. A principal vantagem do algoritmo Rocchio é o tempo computacional para a indução do modelo de classificação, que é linear em relação ao número de documentos rotulados. Em contrapartida, se os documentos de uma mesma classe não estão distribuídos em grupos bem definidos, o protótipo pode não ser suficiente para distinguir as classes.

Já na classificação baseada em exemplos, diferentemente dos algoritmos apresentados anteriormente, não é construído um modelo de classificação com base nos documentos rotulados que seja capaz de classificar rapidamente um novo documento. Ao invés disso, o modelo de classificação consiste apenas no armazenamento dos documentos de treinamento. Já na etapa de classificação, dado um novo documento, todo o conjunto de treinamento é consultado de forma a se obter quais os exemplos mais próximos e utilizar a classe desses exemplos para a classificação. Portanto, o treinamento dos algoritmos de classificação baseados em exemplos é mais rápido que os demais, porém, a classificação é mais lenta.

O algoritmo de classificação baseado em exemplos mais utilizado na literatura é o $k$ Nearest Neighbors ( $k$-NN) (Aggarwal e Zhai, 2012; Wu et al., 2007; Han et al., 2001). Neste algoritmo, um novo documento é classificado de acordo com as classes dos $k$ documentos mais próximos, denominados vizinhos. A classificação no algoritmo $k-N N$ pode ser (i) "não ponderada" ou (ii) "ponderada". Na classificação não ponderada, a informação de classe de um documento $d_{i}$ para uma classe $c_{j}$ é dada pelo número de vizinhos mais próximos pertencentes à classe $c_{j}$, ou seja

$$
f_{d_{i}, c_{j}}=\sum_{d_{k} \in \mathcal{K}^{d_{i}}} y_{d_{k}, c_{j}}
$$

na qual $\mathcal{K}^{d_{i}}$ representa o conjunto do $k$ vizinhos mais próximos de $d_{i}$. Na classificação ponderada, a definição da informação de classe de um documentos $d_{i}$ para um classe $c_{j}$ considera a similaridade entre $d_{i}$ e seus vizinhos mais próximos. Neste caso, quanto maior a similaridade entre um documento $d_{i}$ e seu vizinho, maior a importância do vizinho na definição da informação de classe de $d_{i}$. Desta forma, a informação de classe de $d_{i}$ para a 
classe $c_{j}$ é dada por:

$$
f_{d_{i}, c_{j}}=\sum_{d_{k} \in \mathcal{K}^{d_{i}}} \frac{1}{\left(1-\operatorname{sim}\left(\mathbf{w}_{d_{i}}, \mathbf{w}_{d_{k}}\right)\right) \cdot y_{d_{i}, c_{j}}}
$$

Tanto na classificação ponderada quanto não ponderada, um novo documento é classificado considerado o arg-max de $\mathbf{f}_{d_{i}}$.

Segundo Feldman e Sanger (2006), o algoritmo $k$ - $N N$ é robusto pelo fato de não requerer categorias linearmente separáveis e é um dos classificadores de textos que apresentam maior performance de classificação. A principal desvantagem reside no alto custo computacional de calcular a proximidade entre cada novo documento e todos os exemplos de treinamento. Vale ressaltar que estruturas de indexação (Ciaccia et al., 1997; Yianilos, 1993) ou remoção de exemplos de treinamento (Guan e Zhou, 2002; Brighton e Mellish, 1999) podem ser utilizados para reduzir o tempo de classificação do algoritmo $k-N N$.

Outro ponto importante a respeito do algoritmo $k$-NN é que o valor de $k$ tem um grande impacto na performance de classificação. Valores de $k$ pequenos torna a função de discriminação entre classes muito flexível, porém, tendem a ser sensíveis à ruídos. Valores altos para $k$ tendem a gerar funções de discriminação menos flexíveis, porém, tendem a incluir muitos pontos de outras classes.

Na classificação de textos é recomendada a utilização da medida cosseno para os cálculos de similaridade tanto na classificação baseada em protótipos quanto na classificação baseada em exemplos (Manning et al., 2008; Tan et al., 2005; Salton, 1989). A similaridade cosseno um documento $d_{i}$ e um documento $d_{j}$ é dada por:

$$
\cos \left(\mathbf{w}_{d_{i}}, \mathbf{w}_{d_{j}}\right)=\frac{\mathbf{w}_{d_{i}} \cdot \mathbf{w}_{d_{j}}}{\left\|\mathbf{w}_{d_{i}}\right\| \cdot\left\|\mathbf{w}_{d_{j}}\right\|}
$$

na qual and $\left\|\mathbf{w}_{d_{i}}\right\|$ é a norma do vetor $\mathbf{w}_{d_{i}}$ (Tan et al., 2005).

\subsubsection{Aprendizado Indutivo Supervisionado Considerando Textos Representados em Redes}

Algoritmos baseados no modelo espaço-vetorial assumem que as entidades de uma coleção de documentos, como documentos e termos, são independentes. Essa premissa por parte dos algoritmos pode degradar a performance de classificação (Schenker et al., 2003).

Nas últimas décadas têm-se utilizado redes para considerar as dependências entre as entidades de uma coleção de documentos e consequentemente aumentar a performance de classificação. A modelagem em redes pode ser utilizada tanto para extrair atributos para gerar uma representação baseada no modelo espaço-vetorial, e consequentemente aplicar qualquer algoritmo de aprendizado de máquina baseado no modelo espaço-vetorial para realizar a classificação, quanto para induzir um modelo de classificação diretamente considerando os objetos e relações da rede.

A extração de atributos para gerar uma representação baseada no modelo espaço- 
vetorial pode ser realizada (i) considerando como atributos as sub-redes frequentes que ocorrem em cada classe da coleção de documentos (Markov et al., 2006; Jiang et al., 2010), (ii) utilizando os objetos dos possíveis caminhos da rede como atributos (Aggarwal e Zhao, 2013), ou (iii) redefinindo pesos dos atributos originais do modelo espaço-vetorial por meio de medidas de centralidade (Liu et al., 2008). Porém, essas abordagens representam pequenas variações das abordagens baseadas no modelo espaço-vetorial que realizam agrupamento de termos, geração de $n$-gramas ou que alteram os pesos dos termos. Além disso, os passos utilizados para o cálculo de sub-redes, todos os possíveis caminhos, ou cálculos de centralidades de objetos podem apresentar um alto custo computacional. Vale ressaltar que no caso da extração de sub-redes frequentes ou a utilização dos objetos dos caminhos da rede como atributos, pode-se gerar uma dimensionalidade muito maior que da representação bag-of-words. Vale ressaltar também que há o custo adicional de se induzir um modelo de classificação após gerar a representação no modelo espaço-vetorial.

As representações em redes também podem ser utilizadas diretamente para induzir um modelo de classificação. Com isso evita-se altos custos computacionais para se gerar representações no modelo espaço-vetorial, representações com alta dimensionalidade ou custos adicionais para de induzir um modelo de classificação. Além disso, o relacionamento entre as entidades é mantido durante a indução do modelo de classificação. A maioria das abordagens realiza a classificação de novos documentos considerando as similaridades entre redes ou objetos rotulados, gerando assim um alto custo computacional para realizar a classificação. Nas próximas seções são apresentados os algoritmos considerados mais relevantes para esta tese que realizam aprendizado indutivo supervisionado em coleções de textos representadas em redes.

\section{Text Network with Maximum Common Subgraphs}

Em Schenker et al. (2003), um novo documento é classificado considerando as $k$ redes de termos mais similares. Cada rede de termo representa um documento. A similaridade entre as redes é definida considerando o Máximo Subgrafo Comum (MSC) (Bunke e Shearer, 1998). A similaridade entre uma rede $N_{i}$ e uma rede $N_{j}$ proposta em Schenker et al. (2003) é dada por:

$$
\operatorname{dist}_{M C S}\left(N_{i}, N_{j}\right)=1-\frac{\left|\operatorname{MCS}\left(N_{i}, N_{j}\right)\right|}{\max \left(\left|N_{i}\right|,\left|N_{j}\right|\right)}
$$

na qual $N_{i}$ e $N_{j}$ são redes, $M S C\left(N_{i}, N_{j}\right)$ é o máximo subgrafo comum entre as redes $N_{i}$ e $N_{j}$, e $\left|N_{i}\right|$ e $\left|N_{j}\right|$ correspondem ao tamanho das redes (número de objetos e relações) $N_{i}$ e $N_{j}$ respectivamente.

As redes de termos utilizadas em Schenker et al. (2003) são específicas para domínios nos quais há informações sobre a ocorrência de palavras em determinadas seções como em páginas web (Figura 2.7). Além disso, o algoritmo apresentado em Schenker et al. (2003) possui os mesmos problemas do algoritmos $k-N N$, como escolha do valor de $k$ e o alto tempo computacional na classificação de novos exemplos devido ao custo de calcular o 
MSC entre a rede do novo documento e todas as redes dos documentos de treinamento.

\section{Text Categorization with Concept Graph Representations Using a Controlled Vocabulary}

Em Mishra et al. (2012) são utilizadas funções da kernel para calcular as similaridades entre as redes que representam cada documento da coleção. Os kernels entre todas as redes são armazenadas em uma matriz de kernel que pode tanto ser utilizada para retornar os $k$ vizinhos mais próximos ou usada em um algoritmo baseado em kernel como o SVM.

A função de kernel para medir a similaridade entre uma rede $N_{i}$ e uma rede $N_{j}$ é dada por:

$$
K\left(N_{i}, N_{j}\right)=K_{O}\left(N_{i}, N_{j}\right)+K_{R}\left(N_{i}, N_{j}\right)
$$

na qual $K_{O}\left(N_{i}, N_{j}\right)$ é a função de kernel para calcular a similaridade entre os objetos das redes $N_{i}$ e $N_{j}$, e $K_{R}\left(N_{i}, N_{j}\right)$ é a função de similaridade para calcular a similaridade entre as relações das redes $N_{i}$ e $N_{j}$. $K_{O}\left(N_{i}, N_{j}\right)$ é dado por:

$$
K_{O}\left(N_{i}, N_{j}\right)=\sum_{t_{k} \in \mathcal{T}^{N_{i}}} \sum_{t_{l} \in \mathcal{T}^{N_{j}}} \frac{I\left(t_{k}, t_{l}\right) \cdot w_{t_{k}, d_{i}}}{w_{t_{k}, d_{i}}+w_{t_{l}, d_{j}}-I\left(t_{i}, t_{j}\right) \cdot w_{t_{k}, d_{i}}},
$$

na qual $\mathcal{T}^{N_{i}}$ representa o conjunto de termos da rede $N_{i}, I\left(t_{i}, t_{j}\right)$ é uma função que retorna o valor 1 se $t_{i}=t_{j}$ e 0 caso contrário, e $w_{t_{k}, d_{i}}$ é o peso do termo $t_{k}$ no documento $d_{i}$. A similaridade considerando as relações das redes $N_{i}$ e $N_{j}$ é dada por:

$$
K_{R}\left(N_{i}, N_{j}\right)=\sum_{e_{t_{k}, t_{l}} \in \mathcal{E}^{N_{i}}} \sum_{e_{t_{m}, t_{n}} \in \mathcal{E}^{N_{j}}} \frac{I\left(e_{t_{k}, t_{l}}, e_{t_{m}, t_{n}}\right) \cdot w_{t_{k}, d_{i}}}{w_{t_{k}, d_{i}}+w_{t_{m}, d_{j}}-I\left(e_{t_{k}, t_{l}}, e_{t_{m}, t_{n}}\right) \cdot w_{t_{k}, d_{i}}},
$$

na qual $\mathcal{E}^{N_{i}}$ representa o conjunto de arestas da rede $N_{i}$ e $I\left(e_{t_{k}, t_{l}}, e_{t_{m}, t_{n}}\right)$ é uma função que retorna 1 se $t_{k}=t_{m}$ e $t_{l}=t_{n}$ ou 0 caso contrário.

As redes de termos em Mishra et al. (2012) são geradas considerando um vocabulário controlado que contém termos, conceitos, entidades e relações semânticas entre estes. Especificamente é utilizado um vocabulário controlado do domínio biomédico. Portanto, não é apresentada a viabilidade da aplicação deste tipo de algoritmos em outros domínios em que não haja dicionários e ontologias para se gerar as redes de termos. Além disso, o cálculo de similaridade entre todas as redes de termos pode ser custoso.

\section{InfoSift}

Em Chakravarthy et al. (2014) e Aery e Chakravarthy (2005) é apresentado um algoritmo para classificação denominado InfoSift. O objetivo do algoritmo InfoSift é extrair sub-redes representativos para cada classe da coleção de documentos e classificar um novo documentos considerando as subestruturas mais similares. 
Os documentos são representados por uma rede estrela, na qual o nó central é o próprio documento e as palavras contidas no documento são ligadas ao nó central. As relações são rotuladas com as seções do documento em que o termo aparece, como título ou corpo (Figura 2.11).

Após geradas as redes, é utilizado o algoritmo Subdue (Cook e Holder, 2000) para a descoberta de sub-redes frequentes. Para tal são consideradas operações de inserção, remoção e troca para considerar as redes como isomorfas e consequentemente contabilizar a sua frequência. Entretanto, é considerado um custo para cada tipo de operação e no final, para duas redes serem consideradas isomorfas é necessário que o custo total seja menor que um limiar informado pelo usuário. Após extraídos os sub-redes frequentes, as classes dos sub-redes que forem mais similares a da rede de um novo documento são utilizadas para a rotulação.

Vale ressaltar que para textos mais gerais, sem informações de seções, a descoberta de sub-redes frequentes consiste simplesmente em extrair os termos que ocorrem frequentemente em uma classe e usá-los como atributos. Além disso, há um alto custo computacional (exponencial nos melhores casos) para se calcular o isomorfismo entre as redes.

\section{Term Graph Model}

Em Wang et al. (2005) é apresentado o algoritmo Term Graph Model (TGM), que se difere dos demais algoritmos indutivos supervisionados baseados em redes de termos por não realizar a classificação considerando diretamente as similaridades entre as redes de termos. O algoritmo TGM gera uma rede de termos para cada classe, na qual são geradas relações entre termos que ocorrem frequentemente nos documentos de uma determinada classe da coleção de documentos. A rede de termos de cada classe é utilizada para definir os pesos dos termos para cada classe (informações de classe dos termos) e esses pesos são utilizados como protótipos das classes. O algoritmo TGM, portanto, pode ser visto como uma versão do algoritmo Rocchio para classificação de textos baseada em rede de termos.

Para uma rede de termos da classe $c_{j}$, os pesos dos termos são obtidos utilizando o algoritmo PageRank (Page et al., 1999b). Considerando as características da rede a utilizada pelo algoritmo TGM (Seção 2.3.2), foi utilizado nesta tese nós utilizamos a versão do algoritmo PageRank apresentada em (Mihalcea e Tarau, 2004) que considera redes pesadas e não direcionadas. Com isso, o peso de um termo $t_{i}$ para uma classe $c_{j}$ na iteração $s+1$ é dado por:

$$
f_{t_{i}, c_{j}}^{(s+1)}=(1-\lambda)+\lambda \cdot \frac{\sum_{t_{k} \in \mathcal{T}} w_{t_{k}, t_{i}} \cdot f_{t_{k}, c_{j}}^{(s)}}{\sum_{t_{k} \in \mathcal{T}} w_{t_{k}, t_{i}}},
$$

no qual $0<\lambda<1$ é um fator de atenuação que serve para definir um peso mínimo aos termos da rede e o quanto o os pesos dos objetos vizinhos deve ser considerada na definição da informação de classe de um determinado termo. 
Uma vez gerados os pesos de todos os termos para uma determinada classe, os termos são ranqueados de acordo com seus pesos e a posição do ranking é definida como peso do termo no protótipo da classe. Para classificar um novo documento $d_{i}$, seus termos são ranqueados de acordo com a frequência e é utilizada a correlação de Spearman, que mede a correlação entre rankings, para medir a similaridade entre o documentos $d_{i}$ e os protótipos das classes. Entretanto, não é possível calcular a correlação de Spearman se o número de termos de um documento $d_{i}$ for diferente do número de termos presentes no protótipo de uma classe $c_{j}$. Wang et al. (2005) propõe diferentes formas para criar termos fictícios para equiparar o tamanho dos rankings. Entretanto, foi verificado empiricamente que pode-se obter resultados similares aos melhores resultados apresentados por Wang et al. (2005) apenas substituindo a correlação de Spearman pela diferença ao quadrado dos rankings de termos que ocorrem tanto na classe quanto nos documentos. Com isso, a similaridade entre o ranking dos termos de um documento $d_{i}$ e uma classe $c_{j}$ é dada por:

$$
f_{d_{i}, c_{j}}=\sum_{t_{k} \in \mathcal{T}, w_{d_{i}, t_{k}}>0}\left(r_{t_{k}, d_{i}}-r_{t_{k}, c_{j}}\right)^{2}
$$

na qual $r_{t_{k}, d_{i}}$ é o ranking de $t_{k}$ no documento $d_{i}$ e $r_{t_{k}, c_{j}}$ é o ranking de $t_{k}$ na classe $c_{j}$. O classificador TGM apresenta um tempo de classificação menor que os demais algoritmos baseados em redes de termos.

\section{k-Associated Classifier}

Em Bertini et al. (2011) e Lopes et al. (2009) é apresentado um algoritmo para a criação de um modelo de classificação que têm como base a rede $k$-Associada (Seção 2.3.2) denominado $k$-Associated Classifier $(k-A C)$. No contexto desta tese, os objetos da rede $k$-Associada correspondem aos documentos da coleção.

Na rede $k$-Associada, todos os objetos de um mesmo componente pertencem a uma mesma classe. A rede, portanto, é composta por um conjunto de componentes, ou subredes, cada qual composta por seus objetos e conexões, ou seja, $N=N_{1} \cup N_{2} \cup \ldots \cup N_{p}$. A cada componente é associada uma medida denominada pureza, que mede a densidade do componente ou a probabilidade de ocorrer conexões entre os objetos de um componente. A medida de pureza de um componente $N_{l}\left(\Phi_{N_{l}}\right)$ é dada por:

$$
\Phi_{N_{l}}=\frac{\sum_{o_{i} \in \mathcal{O}^{N_{l}}} \sum_{o_{j} \in \mathcal{O}^{N_{l}}} w_{o_{i}, o_{j}}}{2 \cdot\left|\mathcal{O}^{N_{l}}\right| \cdot K_{N_{l}}},
$$

na qual $\mathcal{O}^{N_{l}}$ os objetos pertencentes ao componente $N_{l}$ e $K_{N_{l}}$ é o valor de $K$ utilizado para gerar as relações no componente $N_{l}$.

O objetivo do $k$ - $A C$ é encontrar a probabilidade a posteriori de um novo vértice $o_{i}$ pertencer a $N_{l}$ dado os vizinhos de $o_{i}\left(\mathcal{N}_{o_{i}}\right)$, ou seja, 


$$
P\left(o_{i} \in N_{l} \mid \mathcal{N}_{o_{i}}\right)=\frac{P\left(\mathcal{N}_{o_{i}} \mid o_{i} \in N_{l}\right)\left(P\left(o_{i} \in N_{l}\right)\right.}{P\left(\mathcal{N}_{o_{i}}\right)},
$$

na qual a probabilidade de ocorrer os vizinhos de $o_{i}$ dado que $o_{i}$ pertença a $N_{l}$ é dada por

$$
P\left(\mathcal{N}_{o_{i}} \mid o_{i} \in N_{l}\right)=\frac{\left|\mathcal{N}_{o_{i}, K_{N_{l}}} \cap N_{l}\right|}{K_{N_{l}}}
$$

na qual $\mathcal{N}_{o_{i}, K_{N_{l}}}$ representa os vizinhos de $o_{i}$ que estão no componente $N_{l}$. O termo de normalização $P\left(\mathcal{N}_{o_{i}}\right)$ considera todos os componentes $N_{l}$ que $o_{i}$ está conectado no momento da classificação, ou seja

$$
P\left(\mathcal{N}_{o_{i}}\right)=\sum_{N_{l},\left(\mathcal{N}_{o_{i}, K_{N_{l}}} \cap N_{l}\right) \neq \emptyset} P\left(\mathcal{N}_{o_{i}} \mid o_{i} \in N_{l}\right) P\left(o_{i} \in N_{l}\right)
$$

A probabilidade de $o_{i}$ pertencer a um componente $N_{l}$ é dada pela pureza do componente, ou seja, quanto mais puro o componente maior é o seu peso na classificação de $o_{i}$. Portanto, $P\left(o_{i} \in N_{l}\right)$ é dado por:

$$
P\left(o_{i} \in N_{l}\right)=\frac{\Phi_{N_{l}}}{\sum_{N_{m},\left(\mathcal{N}_{o_{i}, K_{N_{m}}} \neq \emptyset\right)} \Phi_{N_{m}}} .
$$

A probabilidade de ocorrer um vértice $o_{i}$ dada uma classe $c_{j}$ é definida pela soma da probabilidade de $o_{i}$ ocorrer para os componentes associados à classe $c_{j}$, isto é

$$
P\left(o_{i} \mid c_{j}\right)=\sum_{N_{l} \in N, \operatorname{classe}\left(N_{l}\right)=c_{j}} P\left(o_{i} \in N_{l} \mid \mathcal{N}_{o_{i}}\right)
$$

na qual classe $\left(N_{l}\right)$ retorna a classe dos objetos do componente $N_{l}$. Um novo documento $o_{i}$ é então classificado considerando o arg-max de $P\left(o_{i} \mid c_{j}\right)$ (informação de classe do objeto $o_{i}$ para a classe $c_{j}$ no contexto dessa tese) para todo $c_{j} \in \mathcal{C}$.

\subsection{Proposta para a Classificação de Textos por Meio de Aprendi- zado Indutivo Supervisionado Baseado em Redes}

Conforme apresentado na seção anterior, algoritmos de aprendizado indutivo supervisionado baseado em redes, em geral, apresentam alto custo computacional na classificação de novos exemplos. Além disso, muitos deles são baseados em domínios específicos, e ao empregá-los para considerar coleções de textos de domínios gerais, esses são equivalentes a algoritmos baseados nos modelo espaço-vetorial.

Outro fator importante a ser destacado é que apesar dos benefícios das representações em redes apresentadas nos Capítulos 1 e 2, os algoritmos de aprendizado indutivo supervisionado baseado em redes existentes apresentam performances de classificação 
inferiores a dos algoritmos baseados no modelo espaço-vetorial, conforme será apresentado na Seção 3.4.

Analisando e considerando os pontos positivos e negativos tanto dos algoritmos baseados no modelo espaço-vetorial quanto dos algoritmos baseados em redes, nesse projeto de doutorado foi proposto um algoritmo para classificação de textos denominado Indutive Model using Heterogeneous Networks (IMHN). O algoritmo visa induzir o peso dos termos para as classes (informações de classe dos termos) e utilizar os pesos induzidos como modelo de classificação.

Na literatura, algoritmos que induzem pesos de termos para as classes estão entre os algoritmos que obtêm as maiores performances de classificação, como o algoritmo Multinomial Naïve Bayes e Support Vector Machines. A definição de pesos dos objetos para as classes também têm sido utilizada com sucesso na classificação transdutiva (Ji et al., 2010; Zhou et al., 2004) ou indutiva semissupervisionada (Belkin et al., 2006; Sindhwani et al., 2005). Além disso, métodos baseados na indução de informações de classe dos termos obtém bons resultados mesmo para representações de coleções de textos com stopwords ou termos pouco discriminativos, uma vez que serão atribuídos valores de informações de classe equivalentes em todas as classes para tais termos, e portanto estes não terão influência na classificação de novos documentos. Porém, na literatura, os algoritmos de aprendizado indutivo supervisionado induzem as informações de classes dos termos considerando apenas a frequência dos termos nos documentos e ignoram informações importantes como o relacionamento entre termos ao longo da coleção de documentos. Ao utilizar técnicas para, por exemplo, manter relações na forma de agrupamento de termos nos atributos do espaço-vetorial, perde-se a informação do quão frequente são os termos nos documentos e qual o grau de relação entre os pares de termos nos atributos, as quais também são importantes para induzir um modelo de classificação.

No algoritmo $I M H N$, as definições das informações de classe dos termos são obtidas considerando as diferentes relações da rede. Dado o cenário de aprendizado supervisionado, foram consideradas redes compostas por relações do tipo documento-termo, que corresponde a frequência dos termos nos documentos, e(ou) termo-termo, que corresponde a similaridade entre os termos da coleção. Não foram consideradas relações do tipo documento-documento uma vez que estas não teriam impacto na definição das informações de classes dos termos, já que todos os documentos da coleção são rotulados e portanto não há alteração em suas informações de classe durante o processo de classificação.

Vale ressaltar que o algoritmo IMHN foi desenvolvido utilizado uma solução iterativa para obter as informações de classe dos termos, sendo robusto mesmo para coleções com alto número de documentos e termos. Vale ressaltar também que ao induzir as informações de classes dos termos, essas são utilizadas para classificar os novos documentos, produzindo assim uma resposta rápida para a classificação de novos exemplos, diferentemente do que acontece com a maioria dos algoritmos de aprendizado indutivos supervisionados baseados em redes, que em sua maioria necessita comparar uma nova rede com objetos ou mesmo 
redes de treinamento. Além disso, conforme é apresentado na Seção 3.4, o algoritmo proposto $I M H N$ é capaz de superar a performance de classificação tanto dos algoritmos baseados em redes quanto dos algoritmos baseados no modelo espaço-vetorial.

Nas próximas seções são apresentados os detalhes do algoritmo IMHN, um exemplo de funcionamento, a complexidade computacional e como o algoritmo IMHN pode ser estendido para considerar coleções de textos compostas por outros tipos de objetos ou mesmo para estender o algoritmo IMHN para outros tipos de dados.

\subsubsection{Inductive Model using Heterogeneous Networks}

Nesta seção são apresentados os detalhes do algoritmo IMHN. O objetivo do algoritmo proposto é induzir informações de classes para os termos $(\mathbf{F}(\mathcal{T}))$ utilizando diferentes tipos de relações, documento-termo e(ou) termo-termo, e utilizar esses informações de classe como modelo de classificação. Foram desenvolvidas duas versões do algoritmo $I M H N$ : (i) o $I M H N^{C}$ que somente altera as informações de classe dos termos se as informações de classe correntes produzirem um erro de classificação, e (ii) o $I M H N^{R}$ que realiza uma regressão para induzir as informações de classe dos termos.

$\mathrm{O}$ algoritmo $I M H N^{C}$ minimiza a seguinte função de custo:

$$
\begin{aligned}
Q(\mathbf{F}(\mathcal{T}))=\frac{1}{2} & \left(\sum_{c_{j} \in \mathcal{C}} \sum_{d_{k} \in \mathcal{D}^{L}} y_{d_{k}, c_{j}}-\operatorname{class}\left(\sum_{t_{i} \in \mathcal{T}} w_{d_{k}, t_{i}} \cdot f_{t_{i}, c_{j}}\right)\right)^{2} \\
& +\frac{1}{2}\left(\sum_{c_{j} \in \mathcal{C}} \sum_{t_{i} \in \mathcal{T}} \sum_{t_{k} \in \mathcal{T}} w_{t_{i}, t_{k}}\left(f_{t_{i}, c_{j}}-f_{t_{k}, c_{j}}\right)\right)^{2}
\end{aligned}
$$

na qual

$$
\operatorname{class}(\ldots)= \begin{cases}1 & \text { se } c_{j} \text { é a classe que corresponde ao } \arg \max _{c_{j} \in \mathcal{C}}\left(\sum_{t_{i} \in \mathcal{T}} w_{d_{k}, t_{i}} f_{t_{i}, c_{j}}\right) \\ 0 & \text { para as demais classes. }\end{cases}
$$

Já o algoritmo IMHN ${ }^{\mathrm{R}}$ obtém as informações de classe dos termos para as classes minimizando a seguinte função:

$$
\begin{aligned}
Q(\mathbf{F}(\mathcal{T}))= & \frac{1}{2}\left(\sum_{c_{j} \in \mathcal{C}} \sum_{d_{k} \in \mathcal{D}^{L}} y_{d_{k}, c_{j}}-\left(\sum_{t_{i} \in \mathcal{T}} w_{d_{k}, t_{i}} \cdot f_{t_{i}, c_{j}}\right)\right)^{2} \\
& +\frac{1}{2}\left(\sum_{c_{j} \in \mathcal{C}} \sum_{t_{i} \in \mathcal{T}} \sum_{t_{k} \in \mathcal{T}} w_{t_{i}, t_{k}}\left(f_{t_{i}, c_{j}}-f_{t_{k}, c_{j}}\right)\right)^{2}
\end{aligned}
$$

Portanto, a diferença entre as versões $I M H N^{C}$ e $I M H N^{R}$ está na função class(...), que é utilizada na versão $I M H N^{C}$ e que faz com que somente sejam alteradas as informações de 
classe dos termos se as informações de classe atuais produzirem um erro de classificação, enquanto que no $I M H N^{R}$ é feita uma regressão para obter as informações de classe dos termos. Como consequência da utilização da função $\operatorname{class}(\ldots)$, o algoritmo $I M H N^{C}$ na prática realiza um número menor de alterações das informações de classe dos termos durante a indução do modelo de classificação, tornando-o computacionalmente mais rápido que a versão $I M H N^{R}$.

A indução das informações de classe dos termos é obtida por meio do algoritmo LestMean-Square (LMS) (Widrow e Hoff, 1960). Este método foi escolhido devido à sua simplicidade e obtenção de resultados satisfatórios. Além disso, o $L M S$ é um método iterativo, permitindo controlar o tempo de indução do modelo de classificação de acordo com o número de iterações.

O algoritmo LMS atualiza iterativamente as informações de classe dos termos para as classes na direção negativa do vetor gradiente, o que leva a diminuição do erro quadrático médio mínimo a cada iteração do algoritmo. A equação de atualização das informações de classe de acordo com o LMS é dada por:

$$
\mathbf{F}(\mathcal{T})^{(s+1)}=\mathbf{F}(\mathcal{T})^{(s)}+\eta[-\nabla(Q(\mathbf{F}(\mathcal{T})))]
$$

na qual $\eta$ é a taxa de correção de erro, isto é, a taxa com que o erro será considerado na atualização das informações de classe dos termos e $s$ corresponde ao número da interação. A direção do vetor gradiente pode ser estimada pela derivada de $Q(\mathbf{F})$, como apresentado na Equação 3.62 .

$$
\begin{aligned}
\nabla(Q(\mathbf{F}(\mathcal{T})))=\frac{\partial Q(\mathbf{F}(\mathcal{T}))}{\partial \mathbf{F}(\mathcal{T})}= & \sum_{c_{j} \in \mathcal{C}} \sum_{d_{k} \in \mathcal{D}^{L}} y_{d_{k}, c_{j}}-\left(\sum_{t_{i} \in \mathcal{T}} w_{d_{k}, t_{i}} \cdot f_{t_{i}, c_{j}}\right) \sum_{c_{j} \in \mathcal{C}} \sum_{d_{k} \in \mathcal{D}^{L}} \sum_{t_{i} \in \mathcal{T}}-w_{d_{k}, t_{i}} \\
& +\sum_{c_{j} \in \mathcal{C}} \sum_{t_{i} \in \mathcal{T}} \sum_{t_{k} \in \mathcal{T}}\left(f_{t_{i}, c_{j}}-f_{t_{k}, c_{j}}\right) \sum_{c_{j} \in \mathcal{C}} \sum_{t_{i} \in \mathcal{T}} \sum_{t_{k} \in \mathcal{T}} w_{t_{i}, t_{k}}^{2}
\end{aligned}
$$

A diferença $y_{d_{k}, c_{j}}-\sum_{t_{i} \in \mathcal{T}} w_{d_{k}, t_{i}} f_{t_{i}, c_{j}}$ será denotada por $\operatorname{erro}_{d_{k}, c_{j}}$ e a diferença $\sum_{t_{k} \in \mathcal{T}}\left(f_{t_{i}, c_{j}}\right.$ $f_{t_{k}, c_{j}}$ ) por erro $_{t_{i}, c_{j}}$. Considerando as Equações 3.61 e 3.62, a informação de classe de um termo $t_{i}$ para a classe $c_{j}$ na iteração $(s+1)$ é dada por:

$$
f_{t_{i}, c_{j}}^{(s+1)}=f_{t_{i}, c_{j}}^{(s)}+\eta\left(\sum_{d_{k} \in \mathcal{D}^{L}} w_{d_{k}, t_{i}} \cdot \operatorname{erro}_{d_{k}, c_{j}}^{(s)}+\sum_{t_{k} \in \mathcal{T}} w_{d_{k}, t_{i}}^{2} \cdot \operatorname{erro}_{t_{k}, c_{j}}^{(s)}\right)
$$

Como as relações do tipo documento-termo e termo-termo podem ter diferentes ranges de valores, e com isso um tipo de relação influenciar mais a indução das informações de classe do que outro tipo de relação, as relações do tipo documento-termo foram padronizadas para que o valor máximo de seu intervalo de valores seja igual a 1, que também é o valor máximo do intervalo de valores das relações do tipo termo-termo. Além 
disso, a normalização pode melhorar os resultados do LMS (Valin e Collings, 2007; Mandic, 2004). O peso padronizado da relação entre um termo $t_{j}$ e um documento $d_{i}$ é dado pela Equação 3.64 .

$$
w_{d_{i}, t_{j}}=\frac{w_{d_{i}, t_{j}}}{\sum_{t_{k} \in \mathcal{T}} w_{d_{i}, t_{k}}}
$$

Se a Equação 3.63 for aplicada diretamente, a informações de classe dos termos serão definidas erroneamente. Por exemplo, considere a atualização das informações de classe do primeiro termo $t_{1}$ de uma coleção na primeira iteração. Todos os termos conectados à $t_{1}$ não possuem as informações de classe induzidas na primeira iteração. Portanto, o processo de otimização irá atualizar as informações de classe de $t_{1}$ considerando as relações documento-termo e posteriormente irá atualizar as informações de classe do termos considerando as relações termo-termo, fazendo as informações de classe tenderem a 0 na tentativa de minimizar as diferenças da informações de classe entre os termos. Para resolver esse problema foi proposta uma abordagem para atualizar as informações de classe dos termos considerando dois passos: (i) minimizar a diferença das informações de classe dos termos e a informação de classe dos documentos considerando relações documento-termo e após induzir as informações de classe de todos os termos (ii) minimizar a diferença das informações de classe de termos relacionados considerando relações termo-termo. Portanto, a Equação 3.63 é dividida em duas equações para atualizar as informações de classe dos termos: uma considerando as relações documento-termo, apresentado na Equação 3.65, e outra considerando relações termo-termo, como apresentado na Equação 3.66.

$$
\begin{gathered}
f_{t_{i}, c_{j}}^{(s+1)}=f_{t_{i}, c_{j}}^{(s)}+\eta\left(\sum_{d_{k} \in \mathcal{D}^{L}} w_{d_{k}, t_{i}} \cdot \operatorname{erro}_{d_{k}, c_{j}}^{(s)}\right) \\
f_{t_{i}, c_{j}}^{(s+1)}=f_{t_{i}, c_{j}}^{(s)}+\eta\left(\sum_{t_{k} \in \mathcal{T}} w_{t_{k}, t_{i}}^{2} \cdot \operatorname{erro}_{t_{i}, c_{j}}^{(s)}\right)
\end{gathered}
$$

As Equações 3.65 e 3.66 são aplicadas até que um critério de parada seja atingido. Como mencionado anteriormente, pode-se definir o número de iterações do algoritmo $L M S$ como critério de parada. Além desse, pode-se parar a atualização das informações de classe dos termos quando o erro quadrático médio (média do quadrado de erro $_{d_{k}, c_{j}}$ considerando todos os documentos de treinamento ou média do quadrado de err $_{t_{k}, c_{j}}$ considerando todos os termos) estiver abaixo de um limiar $\epsilon$ definido pelo usuário. As iterações de atualização das informações de classe considerando cada tipo de relação são denominadas iterações locais.

Os dois processos iterativos, aplicando a Equação 3.65 até o critério de parada e posteriormente a Equação 3.66 até o critério de parada, são aplicados iterativamente até 
que as a soma dos erros quadráticos das iterações locais esteja abaixo de um limiar ou até um determinado número de iterações. Esse tipo de iteração é denominada iteração global.

O pseudocódigo do algoritmo IMHN é apresentado no Algoritmo 5. Nas linhas 212 são atualizadas as informações de classe dos termos considerando relações do tipo documento-termo. Nas linhas 13-22 são atualizadas as informações de classe dos termos considerando relações do tipo termo-termo. A função Classificar_Documento $\left(d_{i}, \mathbf{F}(\mathcal{T})\right)$ retorna a informação de classe de um documento $d_{i}$ considerando as informações de classe dos termos atuais. A informação de classe de um documento $d_{i}$ para uma classe $c_{j}$ é definida por uma função linear pesada apresentada na Equação 3.67.

$$
f_{d_{i}, c_{j}}=\sum_{t_{k} \in \mathcal{T}} w_{d_{i}, t_{k}} \cdot f_{t_{k}, c_{j}}
$$

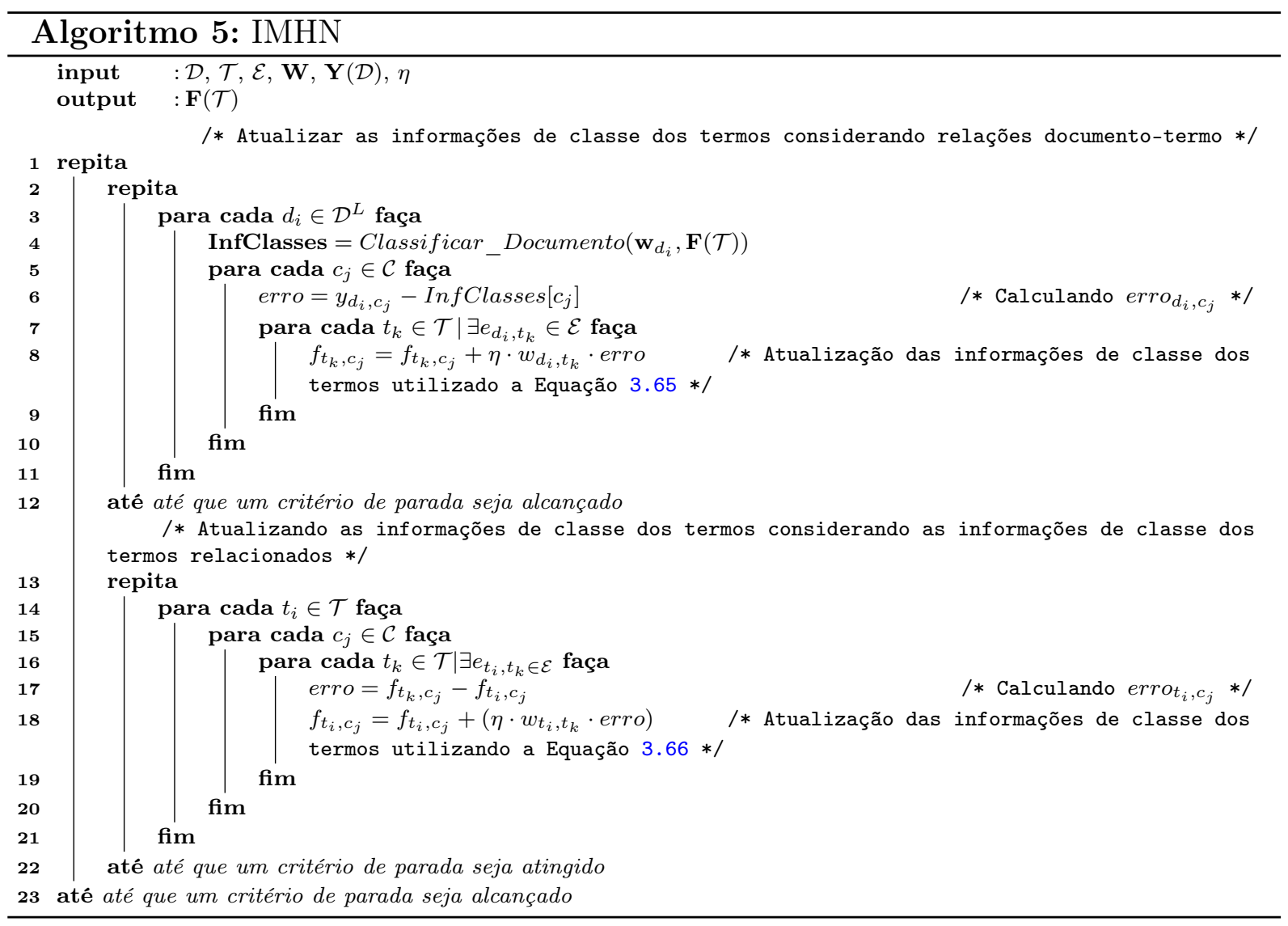

Para classificar um novo documento, a informações de classe do mesmo são inferidas considerando a Equação 3.67. Após isso, é considerado o arg-max do vetor de informações de classe para definir o rótulo do novo documento.

Vale ressaltar que um caso particular do algoritmo $I M H N$ é quando a rede é formada apenas por relações do tipo documento-termo, na qual a função objetivo corresponde apenas ao primeiro termo das Equações 3.58 ou 3.60. Neste caso, o algoritmo é denominado Inductive Model Based on Bipartite Heterogeneous Network (IMBHN) (Rossi et al., 2014a, 2012). Vale ressaltar também que pode ser incorporado ao algoritmo IMHN um parâmetro 
para definir a importância de cada tipo de relação, como considerado em Ji et al. (2010). Entretanto, optou-se por deixar o algoritmo com a menor quantidade de parâmetros possível para ser utilizado com mais facilidade em aplicações reais.

\subsubsection{Exemplo de Funcionamento do Algoritmo IMHN}

Para facilitar o exemplo de funcionamento do algoritmo proposta nesta seção, considere uma rede bipartida com 7 termos e 6 documentos e que todos os pesos das relações são iguais a 1, conforme apresentado na Figura 3.3(a). Nesta Figura também é apresentado as informações de classe iniciais dos objetos da rede.

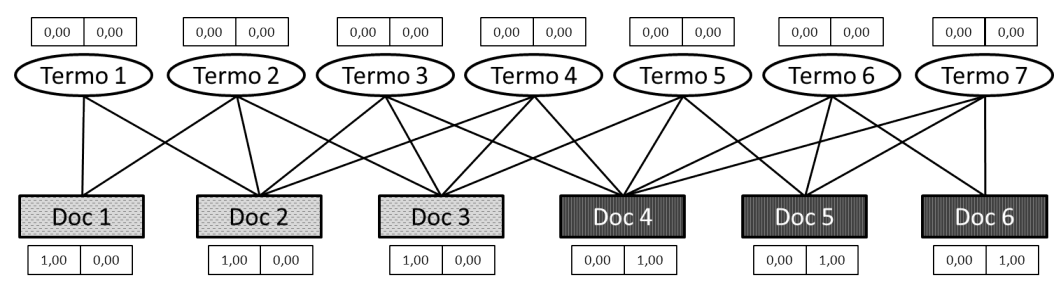

(a) Rede bipartida de exemplo com as informações de classes iniciais dos objetos da rede.

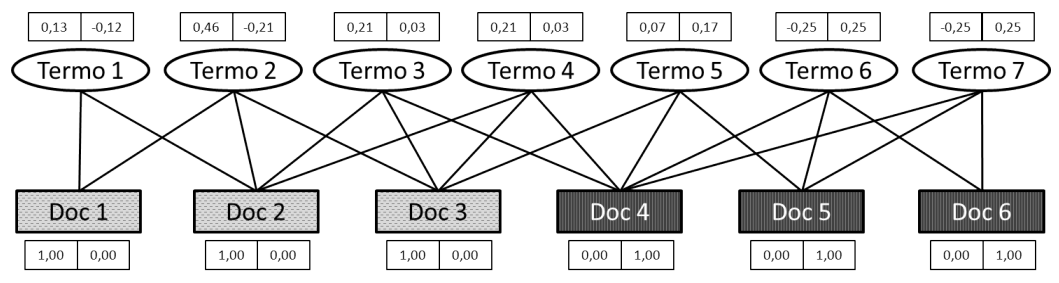

(b) Definição das informações de classes dos termos utilizando o algoritmo $I M B H N^{R} \operatorname{com} \eta=1.0$ e $\epsilon=0.01$.

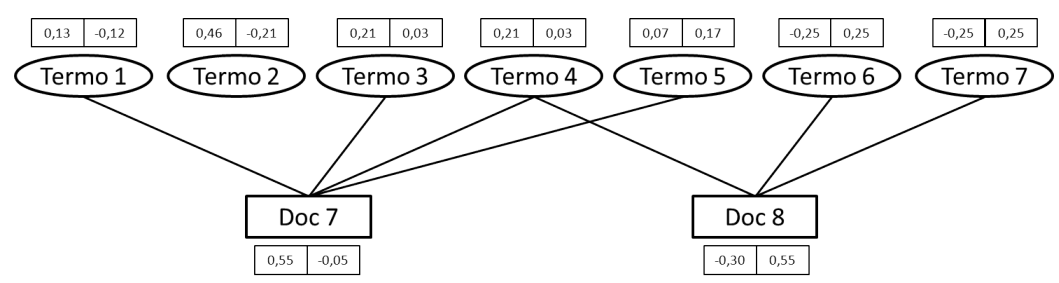

(c) Definição das informações de classe de novos documentos por meio da propagação das informações de classes dos termos relacionados.

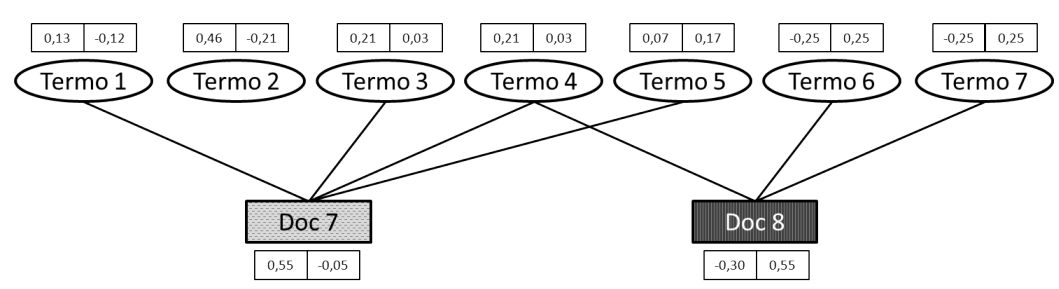

(d) Definição dos rótulos dos documentos considerando o arg-max das informações de classe.

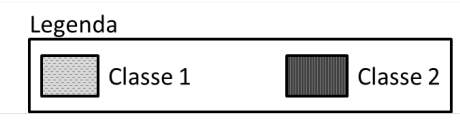

(e) Legenda.

Figura 3.3: Exemplo de funcionamento do algoritmo IMBHN. 
Na Figura 3.3(b) são apresentados as informações de classe dos objetos da rede obtidos pelo algoritmo $I M B H N^{R} \operatorname{com} \eta=1.0$ e $\epsilon=0.01$. Pode-se observar por esta figura que termos que ocorrem em vários documentos de uma única classe apresentam alto valor de informação de classe para a classe em questão em relação à outra classe. Por exemplo, Termo 2 apresenta o valor 0,46 para a Classe1 e -0,21 para a Classe2. Vale ressaltar que o algoritmo $I M H N$ também define valores de informações de classe negativos para os termos da rede. Com isso, a presença de termos com valores de informação de classe negativa inibem a rotulação de um documento para as classes em questão.

Na Figura 3.3(c) é ilustrado o processo de classificação de um novo documento. Para isso, os novos documentos são conectados aos termos que contidos nos mesmos e é utilizada a Equação 3.67 para definir as informações de classe dos documentos. Pose-se observar que, por exemplo, como o Doc 7 está conectado a termos os quais possuem maior informação de classe para a Classe 1 em relação a Classe 2, consequentemente este terá um maior valor de informação de classe para a Classe 1. Após induzidas as informações de classe dos novos documentos, esses são rotulados de acordo com a classe com maior valor de informação de classe, como apresentado na Figura 3.3(d).

\subsubsection{Análise de Complexidade do Algoritmo IMHN}

Seja $\overline{|\mathcal{E}(\mathcal{D}, \mathcal{T})|}$ o número médio de relações entre documentos e termos, $\overline{|\mathcal{E}(\mathcal{T}, \mathcal{T})|}$ o número médio de relações entre termos, $n_{\text {local }}$ o número de iterações locais, e $n_{\text {global }}$ o número de iterações globais. O custo para induzir as informações de classe dos termos para as classes utilizando relações documento-termo é $O\left(n_{\text {Local }} \cdot|\mathcal{D}| \cdot \overline{\mathcal{E}(\mathcal{D}, \mathcal{T}) \mid} \cdot|\mathcal{C}|\right)$, uma vez que as informações de classe dos termos conectados aos $|\mathcal{D}|$ são atualizados $n_{\text {local }}$ vezes para as $|\mathcal{C}|$ classes. O custo para induzir as informações de classe dos termos considerando relações termo-termo é $O\left(n_{\text {local }} \cdot|T| \cdot \overline{\mathcal{E}(\mathcal{T}, \mathcal{T}) \mid} \cdot|\mathcal{C}|\right)$, uma vez que as informações de classe dos $|\mathcal{T}|$ termos são atualizadas $n_{\text {local }}$ vezes para as $|\mathcal{C}|$ classes considerando os termos relacionados. Ambas as induções são repetidas $n_{\text {global }}$ vezes até a convergência. Portanto, o custo total do algoritmo IMHN é $O\left(n_{\text {global }} \cdot\left(O\left(n_{\text {local }} \cdot|\mathcal{D}| \cdot \overline{|\mathcal{E}(\mathcal{D}, \mathcal{T})|} \cdot|\mathcal{C}|\right)\right)+\left(n_{\text {Local }} \cdot|T| \cdot \overline{\mathcal{E}(\mathcal{T}, \mathcal{T}) \mid}\right)\right)=$ $O\left(n_{\text {global }} \cdot n_{\text {local }} \cdot|\mathcal{C}| \cdot(|\mathcal{D}| \cdot \overline{|\mathcal{E}(\mathcal{D}, \mathcal{T})|}+|T| \cdot \overline{|\mathcal{E}(\mathcal{T}, \mathcal{T})|})\right)$

\subsubsection{Extensão do Algoritmo IMHN para Outros Objetos e Domínios}

O algoritmo $I M H N$ pode ser facilmente estendido para incorporar outros objetos que possam vir a compor uma coleção de textos. Por exemplo, caso exista informações sobre os autores dos textos, com $\mathcal{A}=\left\{a_{1}, a_{2}, \ldots, a_{o}\right\}$ sendo o conjunto de autores, pode-se utilizar as relações do tipo autor-documento acrescentando o seguinte termo na Equação 3.58 ou 3.60:

$$
+\frac{1}{2}\left(\sum_{c_{j} \in \mathcal{C}} \sum_{d_{k} \in \mathcal{D}} \sum_{a_{i} \in \mathcal{A}} w_{d_{k}, a_{i}}\left(f_{d_{k}, c_{j}}-f_{a_{i}, c_{j}}\right)\right)^{2} .
$$


Generalizando, para uma rede heterogênea utilizada para qualquer conjunto de dados com quaisquer tipos de objetos, a algoritmo $I M H N$ pode ser aplicado minimizando a seguinte função objetivo:

$$
\begin{aligned}
Q(\mathbf{F})=\frac{1}{2} & \left(\sum_{c_{j} \in \mathcal{C}} \sum_{o_{k} \in \mathcal{O}^{L}} y_{o_{k}, c_{j}}-\left(\sum_{o_{i} \in \mathcal{O}} w_{o_{i}, o_{k}} \cdot f_{o_{i}, c_{j}}\right)\right)^{2} \\
& \frac{1}{2}\left(\sum_{c_{j} \in \mathcal{C}} \sum_{o_{k} \in \mathcal{O}} \sum_{o_{i} \in \mathcal{O}} w_{o_{i}, o_{k}\left(f_{o_{i}, c_{j}}-f_{o_{k}, c_{j}}\right)}\right)^{2}
\end{aligned}
$$

\subsection{Avaliação Experimental}

Nesta seção são apresentados os resultados da avaliação experimental para classificação de textos utilizando algoritmos de aprendizado indutivo supervisionado. Nesta avaliação foram comparados e analisados diferentes algoritmos de classificação: baseados no modelo espaço-vetorial, baseados em redes existentes e também o algoritmo proposto baseados em redes. Também foi comparado e analisado e impacto dos diferentes tipos de redes na performance de classificação.

O objetivo desta avaliação experimental é verificar se as representações em redes de fato proveem melhores performances de classificação em relação às representações no modelo espaço-vetorial e se a utilização de mais de um tipo de relação na rede é benéfica para aumentar a performance de classificação. Todos os códigos-fonte utilizados e implementados nesta avaliação bem como os resultados de todos os algoritmos e seus parâmetros estão disponíveis na pagina web http://sites.labic.icmc.usp.br/ragero/thesis/ supervised_inductive_learning/. Nas próximas seções são apresentados detalhes da configuração experimental e os principais resultados.

\subsubsection{Configuração Experimental}

As coleções de textos, as características das representações baseadas no modelo espaçovetorial e em redes, bem como as medidas de performance de classificação utilizadas nesta avaliação experimental, são detalhadas nos Apêndices A e B respectivamente. Os valores das medidas de performance de classificação utilizadas, $F 1^{\text {Micro }}$ e $F 1^{\text {Macro }}$, correspondem à media dos resultados obtidos pelo processo 10-fold cross validation (Tan et al., 2005).

Foram utilizados algoritmos de classificação baseados no modelo espaço-vetorial e algoritmos baseados em redes, tanto os existentes quanto os propostos. Todos os algoritmos utilizados para comparação foram apresentados nas Seções 3.2.1 e 3.2.2. Para os algoritmos baseados no modelo espaço-vetorial, foram considerados tanto representações bag-of-words quanto representações documento-tópico extraídas pela técnica $L D A$.

Os algoritmos baseados no modelo espaço-vetorial são aqueles indicados em livros (Aggarwal e Zhai, 2012; Feldman e Sanger, 2006; Weiss et al., 2012; Benbrahim e Bramer, 
2009) que aparecem em surveys (Sebastiani, 2002), comparativos de algoritmos para classificação de textos (Dumais et al., 1998; Yang e Liu, 1999) e que foram detalhados na Seção 3.2.1. Os algoritmos baseados no modelo espaço-vetorial e seus respectivos parâmetros são:

1. MNB: não há parâmetros para este algoritmo.

2. BLR: foram utilizadas as priores do tipo Gaussiana e Laplaciana, como indicado em Genkin et al. (2007) e Feldman e Sanger (2006), os parâmetros das priores foram obtidos por meio do processo 10 -fold cross validation e foi utilizado $5 \cdot 10^{-4}$ como valor de tolerância (Genkin et al., 2007).

3. C4.5: foi utilizado o nível de confiança igual a 0,25, como indicado em Quinlan (1993) e Witten e Frank (2005) e outros dois níveis, 0, 15 e 0,25, que empiricamente apresentaram resultados satisfatórios.

4. RIPPER: foram utilizados 3 pastas para poda das regras e duas repetições do processo otimizações, como fixado em Cohen e Singer (1999). Além desses valores, também foram considerados 10 pastas para poda de regras e 10 como número de otimizações, uma vez que foi empiricamente verificado que esses dois valores apresentaram melhores performances de classificação para algumas coleções de textos em relação aos parâmetros definidos em Cohen e Singer (1999).

5. SVM: foram considerados os três tipos de kernel mais comuns, linear, polynomial (expoente $=2$ ) e radial basis function, sendo que o kernel linear é o mais aconselhável para representações com alta dimensionalidade (Caruana e Niculescu-Mizil, 2006). Como $C$ é um parâmetro real, positivo e sem limite, o valor desse parâmetro é normalmente definido por $10^{x}$ para representações com alta dimensionalidade. Para cada tipo de kernel foram utilizados valores de $C \in\left\{10^{-5} ; 10^{-4} ; 10^{-3} ; 10^{-2} ; 10^{-1} ; 10^{0} ; 10^{1} ; 10^{2}\right.$; $\left.10^{3} ; 10^{4} ; 10^{5}\right\}$ (Genkin et al., 2007; Caruana e Niculescu-Mizil, 2006).

6. $k-N N$ : foi utilizado o algoritmo $k-N N$ com e sem voto ponderado pela distância. Foi considerado $k \in\{1 ; 3 ; 5 ; 7 ; 9 ; 11 ; 13 ; 15 ; 17 ; 19 ; 21 ; 25 ; 29 ; 35 ; 41 ; 49 ; 57 ; 73 ; 89\}$. Em alguns estudos o valor de $k$ varia de 1 a $\left|\mathcal{D}^{L}\right|$. Não foi considerado esse intervalo de valores uma vez que ao utilizar o $k-N N$ sem ponderação no voto pela distância, os exemplos seriam atribuídos a classe majoritária quando o valor de $k$ se aproxima de $\left|\mathcal{D}^{L}\right|$.

7. Rocchio: foram utilizados valores de $\alpha$ variando em 0,2 até atingir 1 , no qual o protótipo para classe $c_{j}$ é calculado somente considerando documentos da classe $c_{j}$. Portanto, os valores de $\alpha$ utilizados foram $\{0,2 ; 0,4 ; 0,6 ; 0,8 ; 1,0\}$. Não foi considerado $\alpha=0$ para definir o protótipo de uma classe $c_{i}$ uma vez que neste caso todos os documentos da classe $c_{i}$ seriam desconsiderado, o que empiricamente não provê bons resultados. Os valores de $\beta$ foram definidos como sendo $\beta=1-\alpha$. 
Os algoritmos baseados em redes utilizados para comparação neste capítulo foram aqueles considerados viáveis em questão de tempo de execução, além de poderem ser empregados em coleções de textos de qualquer língua e domínio. Além disso, foram escolhidos algoritmos que possuem versões correspondentes no modelo espaço-vetorial, podendo assim verificar se o uso de representações em redes de fato melhora a performance de classificação de algoritmos indutivos supervisionados. Os algoritmos baseados em redes utilizados para comparação e seus respectivos parâmetros são:

1. $T G M$ : o número máximo de iterações foi definido em 1000, mesmo do algoritmo $I M H N$, a diferença média mínima igual à 0.01 e $\lambda=0.85$ conforme definido em Mihalcea e Tarau (2004). O valor de suporte mínimo para gerar as redes para cada uma das classes foi definido em sup_min $=\{0,0 ; 0,15 ; 0,30 ; 0,45\}$. O valor de sup_min $=0$ gera relações entre termos que coocorrem em ao menos um documento da classe. Foi verificado que esse valor empiricamente gera melhores resultados para o algoritmo TGM. O valor de sup_min foi variado com intervalos fixos de 0.15 na tentativa de gerar um menor número de relações entre os termos e tornar o processo de indução do modelo de classificação mais rápido. Foi também verificado que o valor de sup_min $=0,45$ gerava poucas conexões entre os termos causando uma degradação na performance de classificação e por isso não foram utilizados valores de suporte mínimo além desse valor.

2. $k$ - $A C$ : os valores de $k$ para o algoritmo $k-A C$ são os mesmos utilizados no algoritmo $k$ - $N N$, ou seja, $k \in\{1 ; 3 ; 5 ; 7 ; 9 ; 11 ; 13 ; 15 ; 17 ; 19 ; 21 ; 25 ; 29 ; 35 ; 41 ; 49 ; 57 ; 73 ; 89\}$. Também foi considerado o k-Associated Optimal Graph, apresentado em Bertini et al. (2011), no qual é gerada uma rede $k$-Associada sem a necessidade de definir o valor de $k$. Nesse caso o valor de $k$ é incrementado até que se encontrem os componentes ótimos da rede. O valor máximo de $k$ foi definido em 100 nesta avaliação experimental.

No caso do algoritmo baseado em redes proposto, IMHN, são considerados dois tipos de redes: redes compostas somente por relações documento-termo e redes compostas por relações documento-termo e termo-termo. No primeiro caso o algoritmo IMHN, é denotado por $\operatorname{IMHN}(D T)$ e no segundo caso por $\operatorname{IMHN}(D T-T T)$. Vale ressaltar que o algoritmo proposto possui duas versões para inferir as informações de classe dos termos: a versão baseada em uma função de classificação $\left(I M H N^{C}\right)$ e outra baseada em regressão $\left(I M H N^{R}\right)$.

Os parâmetros utilizados nos algoritmos $I M H N^{C}(D T), I M H N^{R}(D T), I M H N^{C}(D T-$ $\boldsymbol{T} \boldsymbol{T})$ e $\boldsymbol{I M H} \boldsymbol{N}^{R}(\boldsymbol{D} \boldsymbol{T}-\boldsymbol{T} \boldsymbol{T})$ são: $\epsilon=0,01$, o número máximo de iterações foi definido em 1000 e $\eta \in\{0,01 ; 0,05 ; 0,1 ; 0,5\}$. Valores mais altos de $\eta$ podem levar a uma minimização mais rápida do erro, porém, os valores de informações de classe podem ficar oscilando entre estados próximos ao erro mínimo. Por outro lado, valores menores de $\eta$ minimizam 
essa instabilidade, porém, podem levar a um número maior de iterações para atingir o erro mínimo. Portanto, $\eta$ foi variado considerando ambos os casos.

\subsubsection{Resultados}

Na Tabela 3.1 são apresentados os resultados dos maiores valores da medida $F 1^{\text {Micro }}$ dos algoritmos de aprendizado supervisionado considerando todos os parâmetros definidos na seção anterior. Os algoritmos baseados no modelo espaço-vetorial foram executados considerando representações bag-of-words das coleções de textos. Os maiores valores da medida $F 1^{\text {Micro }}$ para cada coleção estão assinalados em negrito. Vale ressaltar que não foi possível executar todos os algoritmos com seus respectivos parâmetros para todas as coleções de textos, sendo utilizada a marcação "-" para denotar esses casos.

Pode-se notar na Tabela 3.1 que o algoritmo IMHN obtém a maior performance de classificação para a maioria das coleções. Pode-se notar também que para a grande maioria das coleções, o uso de redes compostas por relações documento-termo e termo-termo proporcionou uma performance de classificação maior, segundo a medida $F 1^{\text {Micro }}$, do que as redes compostas apenas por relações documento-termo. No caso do algoritmo $I M H N^{C}$, o algoritmo $I M H N^{C}(D T-T T)$ superou a performance de classificação do algoritmo $I M H N^{C}(D T)$ em 30 das 38 coleções em que foram obtidos resultados para ambos os algoritmos. O aumento na performance chegou a 14\% para a coleção Dmoz_Health_500, $7 \%$ na $\operatorname{Tr} 12$ e $\operatorname{Tr} 21$, e $6 \%$ na $\operatorname{Tr} 45$. Já para o algoritmo $I M H N^{R}$, o algoritmo $I M H N^{R}(D T$ TT) superou a performance de classificação do algoritmo $I M H N^{R}(D T)$ em 35 das 38 coleções. O aumento na performance chegou a $18 \%$ na Dmoz-Health, $11 \%$ na Dmoz-Sports, $8 \%$ na Oh15 e $7 \%$ na NFS e Re1.

Para elucidar a comparação das performances de classificação dos diferentes algoritmos,

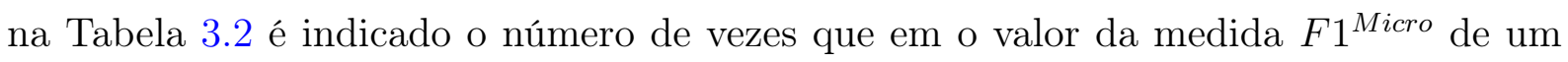

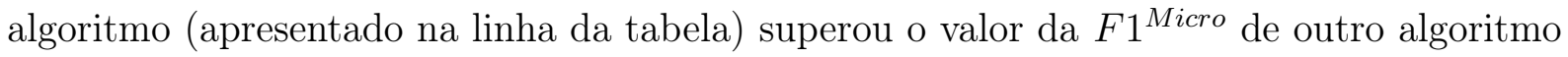
(apresentado na coluna da Tabela). Os empates não foram contabilizados. Nesta análise foram considerados somente os resultados das coleções em que foi possível gerar os resultados da medida $F 1^{\text {Micro }}$ para todos os algoritmos. Portanto, foram consideradas 34 coleções. As células da Tabela 3.2 em que um algoritmo superou outro em um número de coleções maior ou igual a metade das coleções analisadas, portanto 17 coleções, estão hachuradas (cor verde na versão colorida).

Pode-se notar pela Tabela 3.2 que o algoritmo $I M H N^{R}(D T-T T)$ supera a performance de classificação de todos os algoritmos utilizados nesta avaliação para a maioria das coleções, inclusive as demais versões do algoritmo $I M H N$. O algoritmo MNB, que apresentou os melhores resultados dentre os algoritmos baseados no modelo espaço-vetorial, foi superado pelo algoritmo $I M H N^{R}(D T-T T)$ em 25 das 34 coleções, ou seja, em aproximadamente $75 \%$ das coleções. Em geral, todas as versões do algoritmo $I M H N$ superaram os demais algoritmos para a maioria das coleções. A única exceção ocorre para o algoritmo $\operatorname{IMHN}^{R}(D T)$ que superou o algoritmo $M N B$ em 15 coleções. 


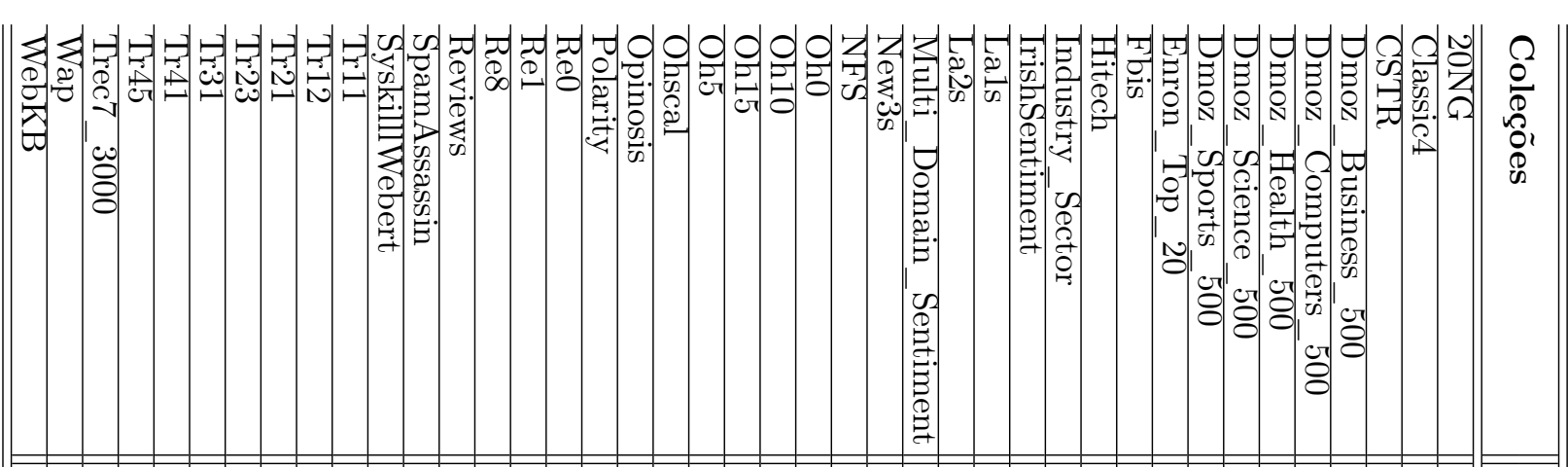

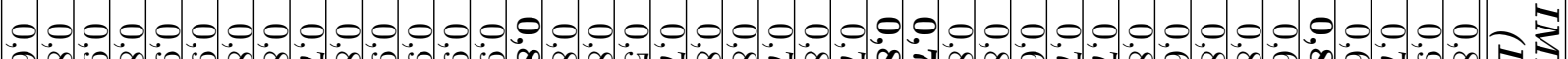

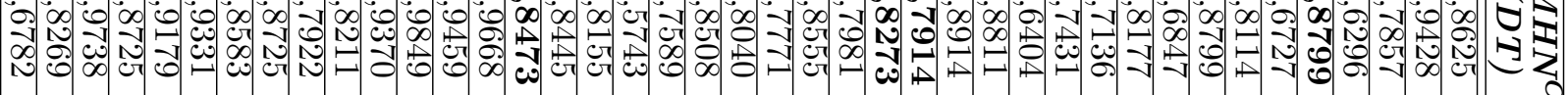

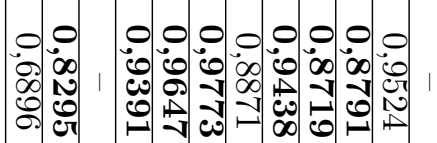

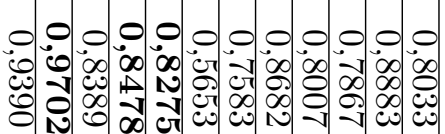

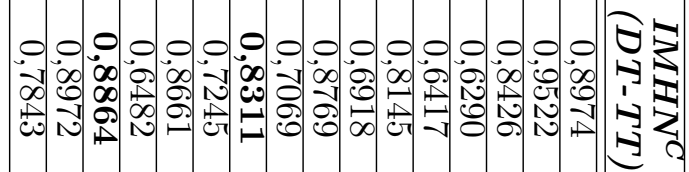

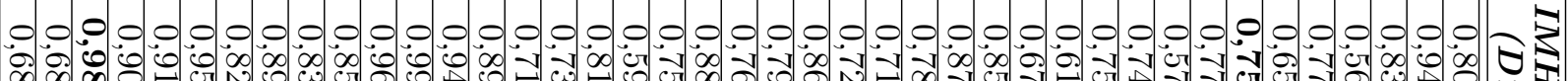
等

0.0 .0 .0 .0 .0 .0 .0 .0 .0 .0 .0 .0 .0 .0 .0 .0 .0 .0 .0 .0 .0$.

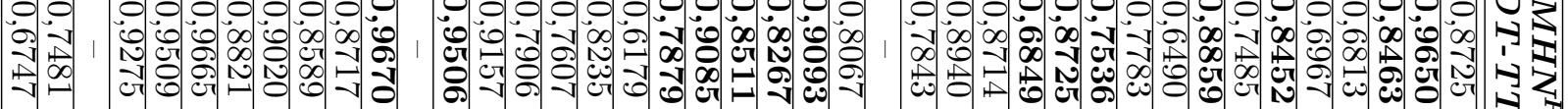

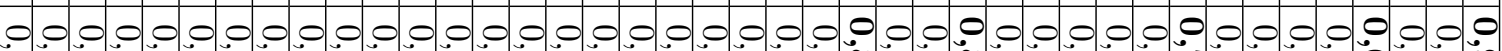
$\therefore$ :

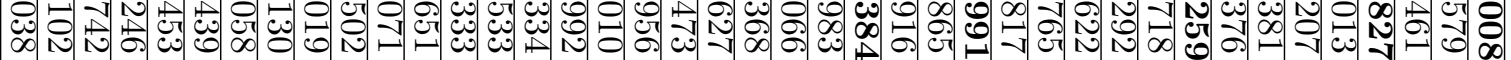

0000000000000000000000000000000000000000 :

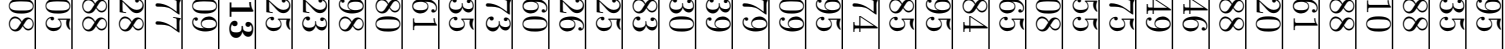

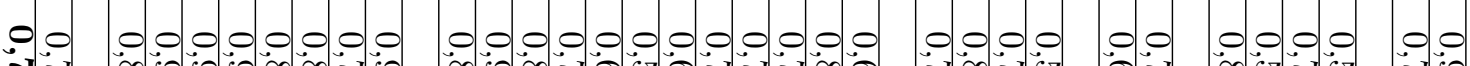

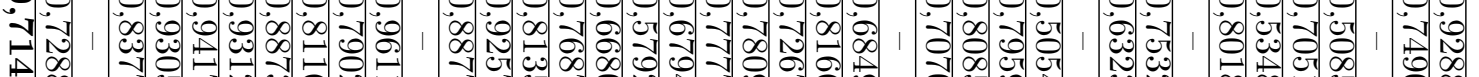

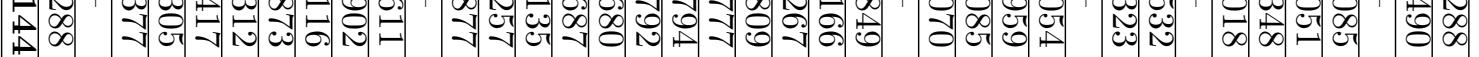

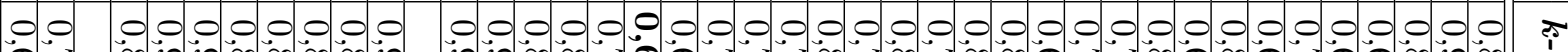

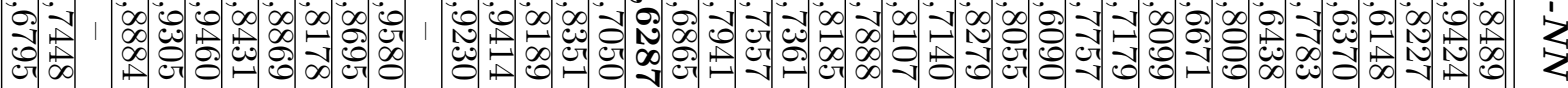

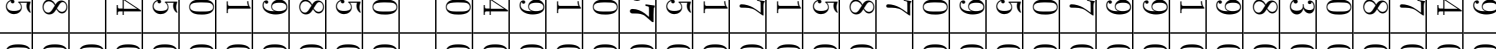

0000000000000000000000000000000000

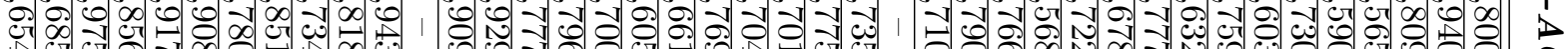

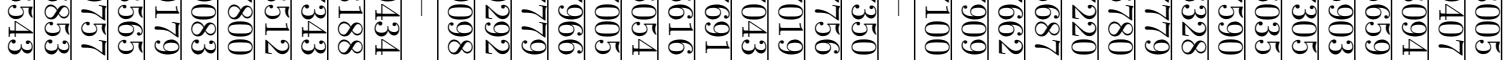

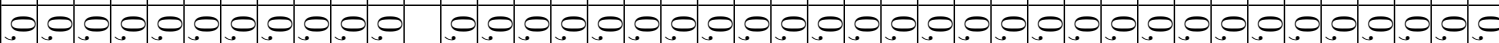

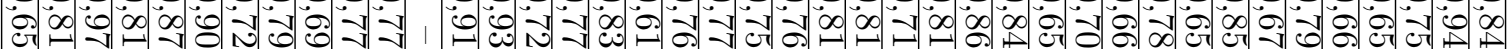

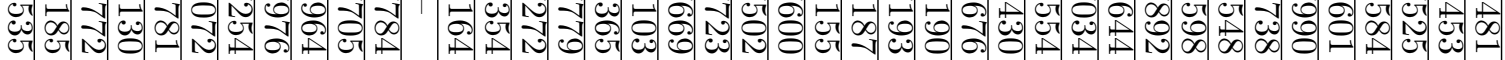

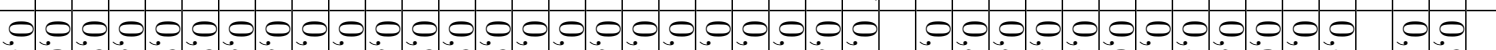
:

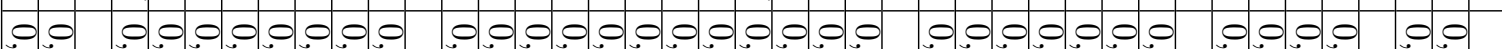

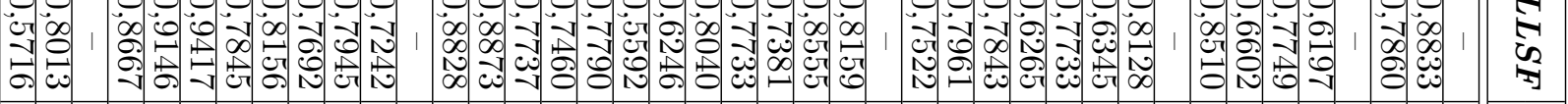

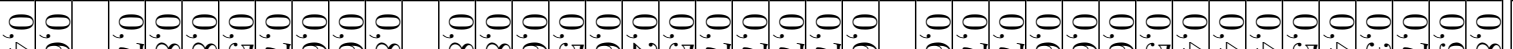

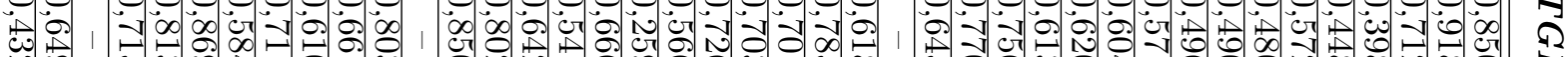

党党

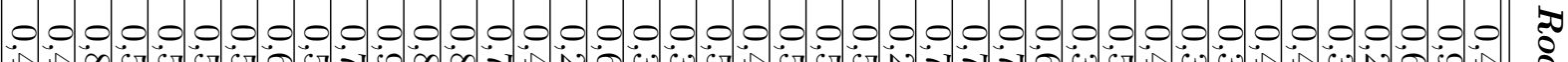

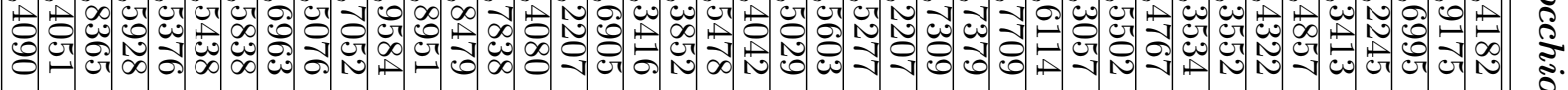


Tabela 3.2: Número de vezes em que um algoritmo apresentado na linha superou o valor da medida $F 1^{\text {Micro }}$ de um algoritmo apresentado na coluna considerando os valores apresentados na Tabela 3.1.

\begin{tabular}{|c|c|c|c|c|c|c|c|c|c|c|c|c|c|c|}
\hline & $\begin{array}{c}\text { IMHN } \\
\text { (DT) }\end{array}$ & \begin{tabular}{|l|l} 
IMHNC $^{C}$ \\
$(\mathrm{DT}-\mathrm{TT})$
\end{tabular} & $\begin{array}{c}\text { IMHN }^{\mathrm{R}} \\
\text { (DT) }^{-1}\end{array}$ & \begin{tabular}{|l|} 
IMHN $^{\mathrm{R}}$ \\
(DT-TT)
\end{tabular} & MNB & C4.5 & RIPPER & $\mathrm{k}-\mathrm{NN}$ & $\mathrm{k}-\mathrm{AC}$ & SVM & BLR & LLSF & TGM & Rocchio \\
\hline IMHN $^{\mathrm{C}}$ (DT) & - & 9 & 19 & 10 & 17 & 27 & 25 & 22 & 29 & 26 & 27 & 29 & 34 & 33 \\
\hline IMHN $^{\mathrm{C}}(\mathrm{DT}-\mathrm{TT})$ & 25 & - & 25 & 16 & 20 & 30 & 30 & 32 & 33 & 27 & 32 & 33 & 34 & 33 \\
\hline IMHN $^{\mathrm{R}}(\mathrm{DT})$ & 15 & 9 & - & 3 & 15 & 25 & 22 & 22 & 26 & 22 & 24 & 25 & 34 & 34 \\
\hline IMHN $^{\mathrm{R}}(\mathrm{DT}-\mathrm{TT})$ & 24 & 17 & 31 & - & 25 & 31 & 29 & 28 & 32 & 27 & 32 & 31 & 34 & 34 \\
\hline MNB & 17 & 14 & 19 & 9 & - & 27 & 28 & 23 & 27 & 24 & 29 & 29 & 33 & 32 \\
\hline C4.5 & 7 & 4 & 9 & 3 & 7 & - & 13 & 8 & 17 & 12 & 15 & 12 & 29 & 28 \\
\hline RIPPER & 9 & 4 & 11 & 5 & 6 & 21 & - & 6 & 17 & 13 & 13 & 16 & 33 & 31 \\
\hline $\mathrm{k}-\mathrm{NN}$ & 12 & 2 & 12 & 6 & 11 & 25 & 27 & - & 34 & 20 & 23 & 22 & 33 & 31 \\
\hline $\mathrm{k}-\mathrm{AC}$ & 4 & 1 & 8 & 2 & 7 & 17 & 17 & 0 & - & 13 & 13 & 14 & 31 & 30 \\
\hline SVM & 8 & 7 & 12 & 7 & 10 & 22 & 21 & 14 & 21 & - & 18 & 21 & 33 & 33 \\
\hline BLR & 7 & 2 & 9 & 2 & 5 & 19 & 21 & 11 & 21 & 16 & - & 15 & 32 & 32 \\
\hline LLSF & 4 & 1 & 9 & 3 & 5 & 22 & 17 & 12 & 20 & 13 & 19 & - & 32 & 32 \\
\hline TGM & 0 & 0 & 0 & 0 & 1 & 5 & 1 & 1 & 2 & 1 & 2 & 2 & - & 28 \\
\hline Rocchio & 1 & 1 & 0 & 0 & 2 & 6 & 3 & 3 & 4 & 1 & 2 & 2 & 6 & 0 \\
\hline
\end{tabular}

Ao utilizar apenas redes compostas por relações documento-termo, o algoritmo $I M H N^{C}$ (DT) apresentou melhores resultados que o algoritmo $\operatorname{IMHN}^{R}(D T)$ em 19 das 34 coleções, ou seja, em aproximadamente $55 \%$ das coleções. Já em relação às redes compostas por relações documento-termo e termo-termo, foram 17 vitórias para o algoritmo $\operatorname{IMHN}^{R}(D T$ TT) contra 16 vitórias do algoritmo $I M H N^{C}(D T-T T)$.

Outro ponto interessante que vale ressaltar é a comparação de algoritmo baseados em redes em relação às versões desses algoritmos baseadas no modelo espaço-vetorial. Por exemplo, o algoritmo TGM, baseado em redes de termos, superou sua versão baseada no modelo espação vetorial, algoritmo Rocchio, em 28 coleções. Por outro lado, o algoritmo $k$ - $N N$ superou sua versão baseada em redes, $k$ - $A C$, em todas as coleções. Isso pode ter ocorrido devido ao fato de o algoritmo $k-A C$ ter sido projetado para considerar distâncias Euclidiana ou qualquer instanciação da distância l-norm entre os objetos. Por exemplo, dois vetores $[2 ; 2]$ e $[150 ; 150]$ apresentariam alta distância segundo a distância Euclidiana, e portanto estariam em componentes diferentes, enquanto que teriam alta similaridade segundo a medida cosseno, e portanto estariam no mesmo componente.

Também foi executado o teste de significância estatística de Friedman $N \times N$ com pósteste de Nemenyi e $95 \%$ de confiança para verificar se existem diferença estatisticamente significantes entre os algoritmos de classificação segundo a medida $F 1^{\text {Micro }}$. Este é um teste não paramétrico, baseado em ranking e aconselhável para a análise estatística dos resultados de múltiplos classificadores para múltiplas coleções (Trawinski et al., 2012; García et al., 2010; Demsar, 2006). Novamente, só foram consideradas nos testes as coleções nas quais foram gerados resultados para todos os algoritmos. Na Figura 3.4 é apresentado o diagrama de diferença crítica que corresponde à uma ilustração gráfica do resultado do teste estatístico. Nesta figura, é apresentado o ranking médio de cada algoritmo e os métodos conectados por uma linha não apresentam diferenças estatisticamente significantes entre si. Pelo diagrama, pode-se observar que os algoritmos propostos baseados em redes compostas por relações do tipo documento-termo e termo-termo, $I M H N^{C}(D T-T T)$ e $I M H N^{R}(D T$ $T T$ ), obtiveram as primeiras posições do ranking. Além disso, o algoritmo $I M H N^{R}(D T-T T)$ apresentou melhores resultados com diferenças estatisticamente significantes para todos os algoritmos baseados no modelo espaço-vetorial, exceto o MNB, e todos os baseados em 
redes, exceto as próprias versões do algoritmo $I M H N$.

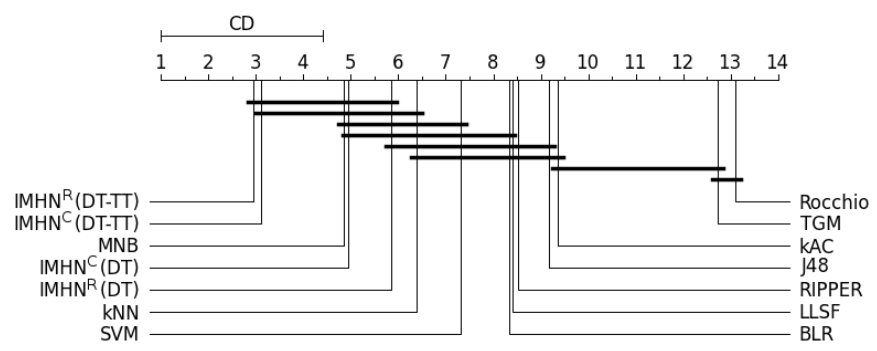

Figura 3.4: Diagrama de diferença crítica para a medida $F 1^{\text {Micro }}$.

Vale ressaltar que o teste de Friedman com pós-teste de Nemenyi é um teste conservador além do fato de que quanto maior o número de algoritmos, maior o valor do intervalo de diferença crítica. Por exemplo, na Figura 3.5 é apresentado o diagrama de diferença crítica comparando somente as versões do algoritmo IMHN com o algoritmo MNB. Pode-se observar neste caso que o intervalo de diferença crítica é menor que o apresentado na Figura 3.4. Pode-se observar também que que nesta análise o algoritmo $\operatorname{IMHN}^{R}(D T$ TT) apresentou melhores resultados com diferenças estatisticamente significantes para o algoritmo MNB.

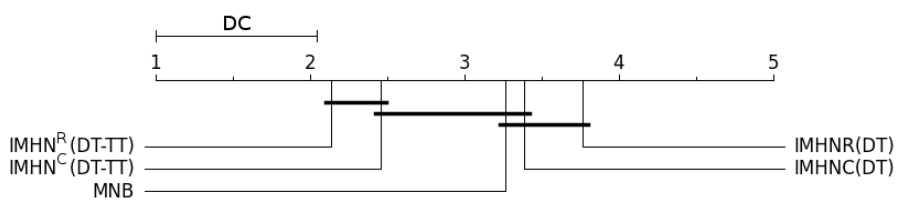

Figura 3.5: Diagrama de diferença crítica para a medida $F 1^{\text {Micro }}$ consideando apenas os algoritmos $I M H N^{C}(D T), I M H N^{C}(D T-T T), I M H N^{R}(D T)$ e $I M H N^{R}(D T-T T)$.

Na Tabela 3.3 é apresentado os resultados dos maiores valores da medida $F 1^{\text {Macro }}$ dos algoritmos de aprendizado indutivo supervisionado considerando todos os parâmetros definidos na seção anterior. Os algoritmos baseados no modelo espaço-vetorial foram executados considerando representações bag-of-words das coleções de textos. Os maiores valores da valores da medida $F 1^{\text {Macro }}$ nesta tabela estão assinalados em negrito. Pode-se notar por esta tabela que o algoritmo $I M H N$ novamente obtém a maior performance de classificação para a maioria das coleções. Pode-se notar também que o uso de redes compostas por relações documento-termo e termo-termo proporcionou uma performance de classificação maior do que as redes compostas apenas por relações documento-termo para a grande maioria das coleções. No caso do algoritmo $I M H N^{C}$, o algoritmo $I M H N^{C}(D T$ TT) superou a performance de classificação do algoritmo $I M H N^{C}(D T)$ em 30 das 38 coleções em que foram obtidos resultados para ambos os algoritmos. O aumento na performance chegou a $13 \%$ na Dmoz_Health_500, $10 \%$ na $\operatorname{Tr} 11,8 \%$ na $\operatorname{Tr} 12$ e $7 \%$ na $\operatorname{Tr} 11, \operatorname{Tr} 31$ e Tr41. Já para o algoritmo $I M H N^{R}$, o algoritmo $I M H N^{R}(D T-T T)$ superou a performance de classificação do algoritmo $I M H N^{R}(D T)$ em 35 das 38 coleções. O aumento na performance chegou a 18\% na Dmoz_Health_500, 11\% na Re1, Tr23 e Tr41, 9\% na Dmoz_Sports_500 e Re0, e $8 \%$ na Wap. 


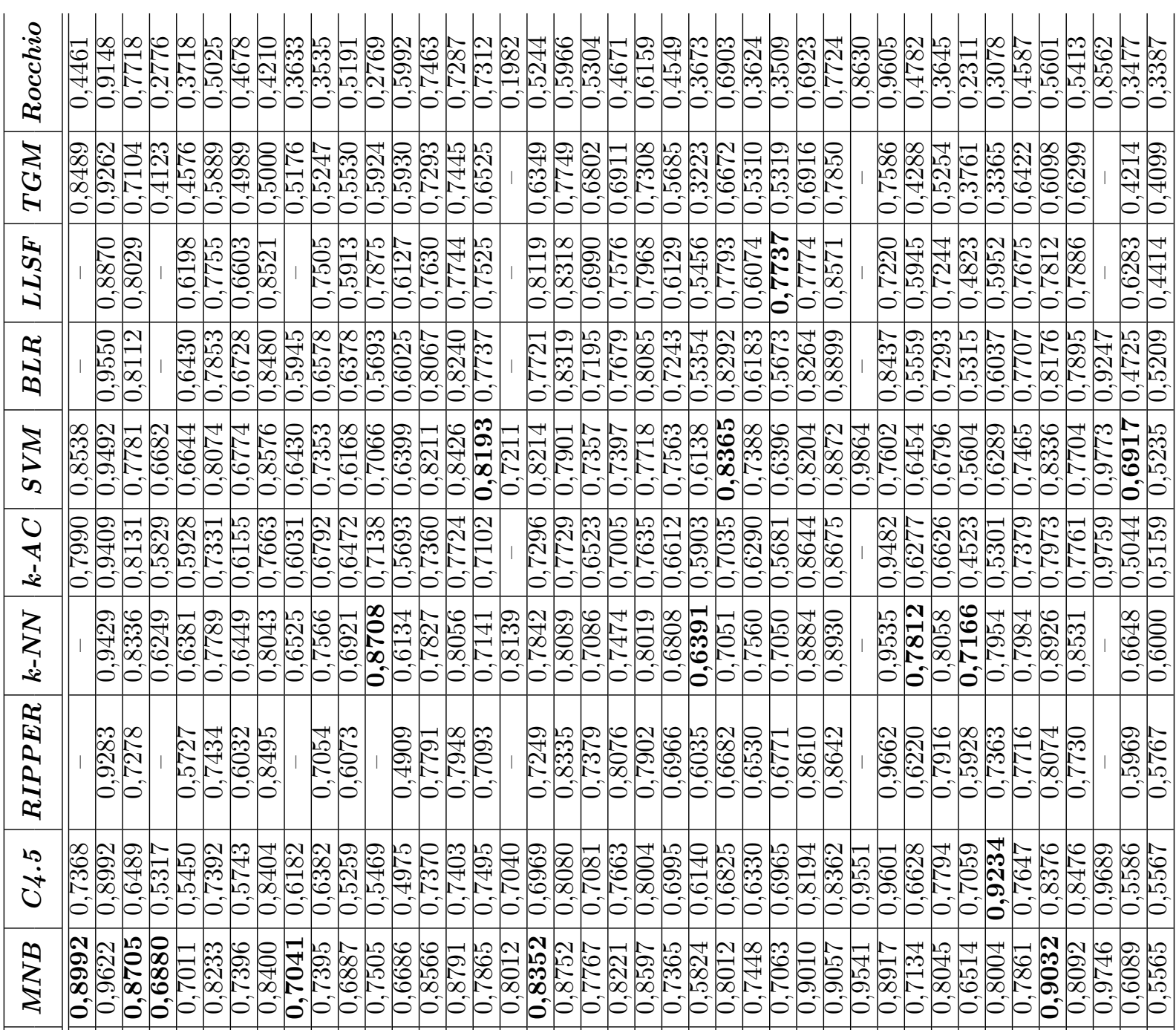

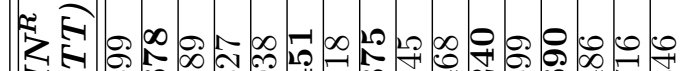

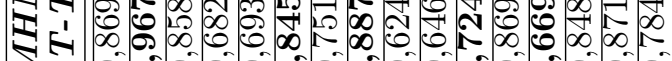

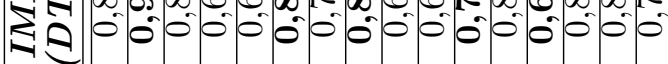

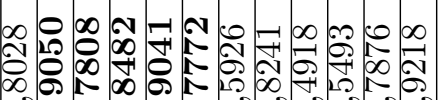

0.00000000000

20

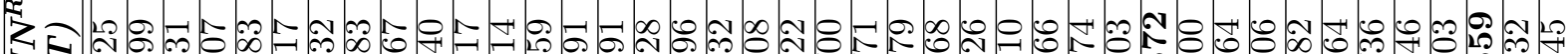

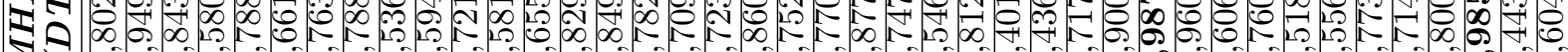

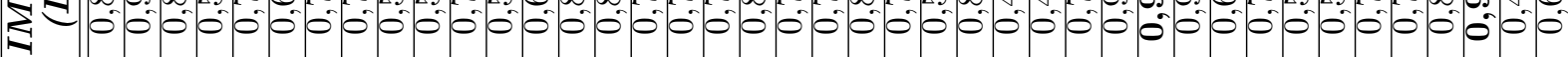

Z E E

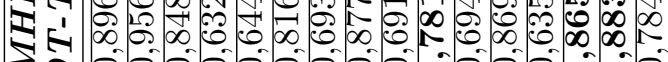

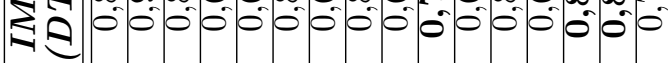

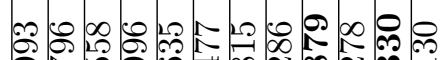

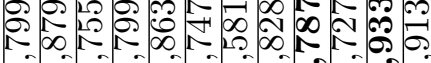

0.00000000000

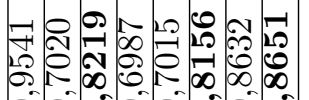

$\overrightarrow{2} \cdot \overrightarrow{-1}$

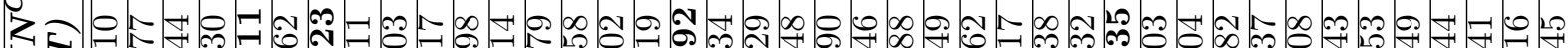

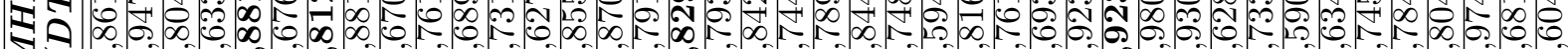

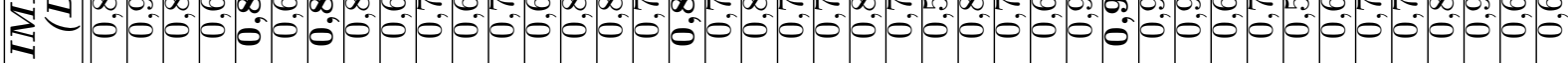

\section{8}

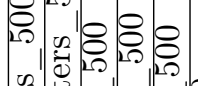

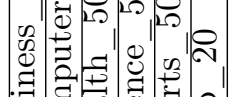


As mesmas análises realizadas para os resultados da medida $F 1^{\text {Micro }}$ também foram realizados para os valores da medida $F 1^{\text {Macro }}$. Na Tabela 3.4 são apresentados o número de vezes que em o valor da medida $F 1^{\text {Macro }}$ de um algoritmo (apresentado na linha da tabela) superou o valor da $F 1^{\text {Macro }}$ de outro algoritmo (apresentado na coluna da tabela). Novamente, nesta análise foram considerados somente os resultados das coleções em que foi possível gerar os resultados da medida $F 1^{\text {Macro }}$ para todos os algoritmos, ou seja, 34 coleções. As células da Tabela $3.2 \mathrm{em}$ que um algoritmo superou o outro em um número de coleções maior ou igual a metade das coleções analisadas (17 coleções) estão hachuradas com a cor verde.

Tabela 3.4: Número de vezes em que um algoritmo apresentado na linha superou o valor da medida $F 1^{\text {Macro }}$ de um algoritmo apresentado na coluna considerando os valores apresentados na Tabela 3.3.

\begin{tabular}{|c|c|c|c|c|c|c|c|c|c|c|c|c|c|c|}
\hline & \begin{tabular}{|c} 
IMHNC \\
(DT)
\end{tabular} & \begin{tabular}{|l} 
IMHNC \\
(DT-TT)
\end{tabular} & \begin{tabular}{|c} 
IMHN $^{\mathrm{R}}$ \\
(DT)
\end{tabular} & \begin{tabular}{|c|} 
IMHN $^{\mathrm{R}}$ \\
(DT-TT) $^{-}$
\end{tabular} & MNB & C4.5 & RIPPER & k-NN & $\mathrm{k}-\mathrm{AC}$ & SVM & BLR & LLSF & TGM & Rocchio \\
\hline$\overline{\text { IMHN }^{\mathrm{C}}(\mathrm{DT})}$ & - & 7 & 23 & 13 & 15 & 23 & 25 & 21 & 30 & 22 & 28 & 30 & 34 & 33 \\
\hline $\mathrm{IMHN}^{\mathrm{C}}(\mathrm{DT}-\mathrm{TT})$ & 27 & 0 & 27 & 16 & 20 & 30 & 30 & 29 & 33 & 26 & 33 & 32 & 34 & 33 \\
\hline $\mathrm{IMHN}^{\mathrm{R}}(\mathrm{DT})$ & 10 & 7 & - & 3 & 8 & 19 & 18 & 18 & 24 & 18 & 21 & 24 & 32 & 33 \\
\hline IMHN $^{\mathrm{R}}(\mathrm{DT}-\mathrm{TT})$ & 21 & 18 & 31 & - & 18 & 24 & 25 & 21 & 29 & 22 & 28 & 29 & 33 & 34 \\
\hline MNB & 19 & 14 & 26 & 16 & - & 27 & 30 & 22 & 32 & 28 & 32 & 30 & 34 & 33 \\
\hline $\mathrm{C} 4.5$ & 11 & 4 & 15 & 10 & 7 & - & 12 & 6 & 22 & 14 & 12 & 16 & 29 & 28 \\
\hline RIPPER & 9 & 4 & 16 & 9 & 4 & 22 & - & 6 & 21 & 13 & 17 & 20 & 33 & 30 \\
\hline $\mathrm{k}-\mathrm{NN}$ & 13 & 5 & 16 & 13 & 12 & 28 & 28 & - & 34 & 20 & 20 & 26 & 34 & 32 \\
\hline k-AC & 4 & 1 & 10 & 5 & 2 & 12 & 13 & - & 0 & 5 & 10 & 12 & 31 & 30 \\
\hline SVM & 12 & 8 & 16 & 12 & 6 & 20 & 21 & 14 & 29 & - & 22 & 25 & 34 & 33 \\
\hline BLR & 6 & 1 & 13 & 6 & 2 & 22 & 17 & 14 & 24 & 12 & - & 26 & 34 & 33 \\
\hline LLSF & 4 & 2 & 10 & 5 & 4 & 18 & 14 & 8 & 22 & 9 & 8 & - & 32 & 32 \\
\hline TGM & 0 & 0 & 2 & 1 & 0 & 5 & 1 & 0 & 3 & 0 & 0 & 2 & - & 25 \\
\hline Rocchio & 1 & 1 & 1 & 0 & 1 & 6 & 4 & 2 & 4 & 1 & 1 & 2 & 9 & - \\
\hline
\end{tabular}

Pode-se notar pela Tabela 3.4 que o algoritmos $I M H N^{C}(D T-T T)$ e $I M H N^{R}(D T-T T)$ obtém maiores valores para a medida $F 1^{\text {Macro }}$ em relação aos demais algoritmos para a maioria das coleções. O algoritmo MNB, que apresentou os melhores resultados dentre os algoritmos baseados no modelo espaço-vetorial, foi superado pelo algoritmo $I M H N^{R}(D T$ TT) em 18 coleções e pelo algoritmo $\operatorname{IMHN}^{R}$ (DT-TT) em 20 coleções.

Ao utilizar apenas redes compostas por relações documento-termo, o algoritmo $I M H N^{C}$ (DT) apresentou melhores resultados que o algoritmo $\operatorname{IMHN}^{R}(D T)$ em 23 das 34 coleções. Já em relação às redes compostas por relações documento-termo e termo-termo, foram 18 vitórias para o algoritmo $\operatorname{IMHN}^{R}(D T-T T)$ contra 16 vitórias do algoritmo $\operatorname{IMHN}^{C}(D T$ TT). Referente aos algoritmos baseados no modelo vetorial e que possuem versões em redes, o algoritmo Rocchio foi superado pelo algoritmo TGM em 25 coleções e o algoritmo $k-N N$ superou o algoritmo $k$ - $A C$ nas 34 coleções.

Também foi executado o teste de significância estatística de Friedman $N \times N$ com pósteste de Nemenyi com $95 \%$ de confiança para verificar se existem diferenças estatisticamente significantes entre os algoritmos de classificação segundo a medida $F 1^{\text {Macro }}$. Na Figura 3.6 é apresentado o diagrama de diferença crítica do teste estatístico realizado. Pode-se observar por esta figura que o algoritmo $I M H N^{C}(D T-T T)$ é o primeiro do ranking médio, porém, sem diferenças estatisticamente significantes para o algoritmo $I M H N^{R}(D T-T T)$. Além disso, o algoritmo $I M H N^{C}(D T-T T)$ apresentou melhores resultados com diferenças estatisticamente significantes para todos os algoritmo baseados no modelo espaço-vetorial, exceto $M N B$ e $k-N N$, e para todos os algoritmos baseados em rede, exceto as próprias 
versões do algoritmo $I M H N$.

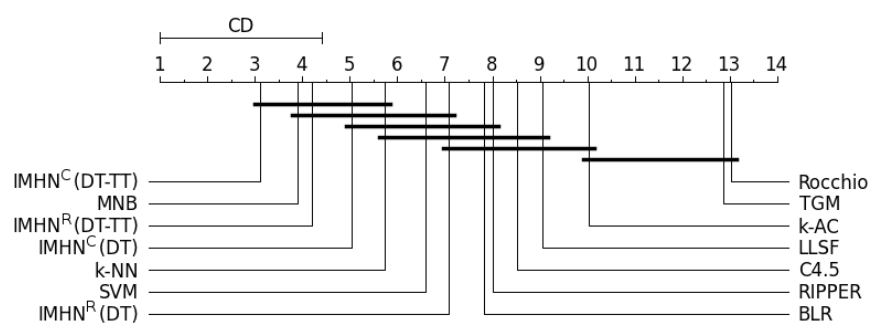

Figura 3.6: Diagrama de diferença crítica para a medida $F 1^{\text {Macro }}$.

Conforme apresentado na seção sobre a configuração experimental (Seção 3.4.1), também foram geradas representações por meio da técnica LDA, gerando assim matrizes documento-tópico (Seção 2.2.4). Isso foi utilizado de forma a manter termos relacionados como atributos da representação no espaço-vetorial e com isso verificar se a proposta para representação de relações entre termos em redes é mais eficiente em relação à performance de classificação.

Nas Tabelas 3.5 e 3.7 são apresentados respectivamente os resultados das medidas $F 1^{\text {Micro }}$ e $F 1^{\text {Macro }}$ obtidos pelas versões do algoritmo $I M H N$ e pelos algoritmos baseados no modelo espaço-vetorial considerando as matrizes documento-tópico geradas pela técnica $L D A$. Vale ressaltar que para os algoritmos baseados no modelo espaço-vetorial foram consideradas as melhores performances de classificação considerando os diferentes números de tópicos utilizados para gerar as representações documento-tópico.

Pode-se notar pelas Tabelas 3.5 e 3.7 que o algoritmo IMHN obtém as maiores performances de classificação para a grande maioria das coleções. Para ilustrar esse ponto, nas Tabelas 3.6 e 3.8 é apresentado o número de vezes em que um algoritmo (apresentado na linha) superou outro algoritmo (apresentado na coluna) considerando as medidas $F 1^{\text {Micro }}$ e $F 1^{\text {Macro }}$ respectivamente. Pode-se observar pelas Tabelas 3.6 e 3.8 que as versões do algoritmo $I M H N$, exceto a versão $I M H N^{R}(D T)$, obtém os maiores valores para as medidas $F 1^{\text {Micro }}$ e $F 1^{\text {Macro }}$ para a maioria das coleções em relação aos algoritmos baseados no modelo espaço-vetorial.

Na Figuras 3.7 e 3.8 são apresentados os diagramas de diferença crítica resultantes do teste de significância estatística de Friedman $N \times N$ com pós-teste de Nemenyi e $95 \%$ de confiança para as medidas $F 1^{\text {Micro }}$ e $F 1^{\text {Macro }}$ respectivamente. Pode-se observar por ambas as figuras que as versões $I M H N^{R}(D T-T T), I M H N^{C}(D T-T T)$ e $I M H N^{C}(D T)$ obtém as primeiras posições no ranking para ambas as medidas. Pode-se observar também que as versões $I M H N^{R}(D T-T T)$ e $I M H N^{C}(D T-T T)$ apresentaram melhores resultados com diferenças estatisticamente significantes para todos os algoritmos baseados no modelo espaço-vetorial exceto $L L S F$ e $S V M$. 


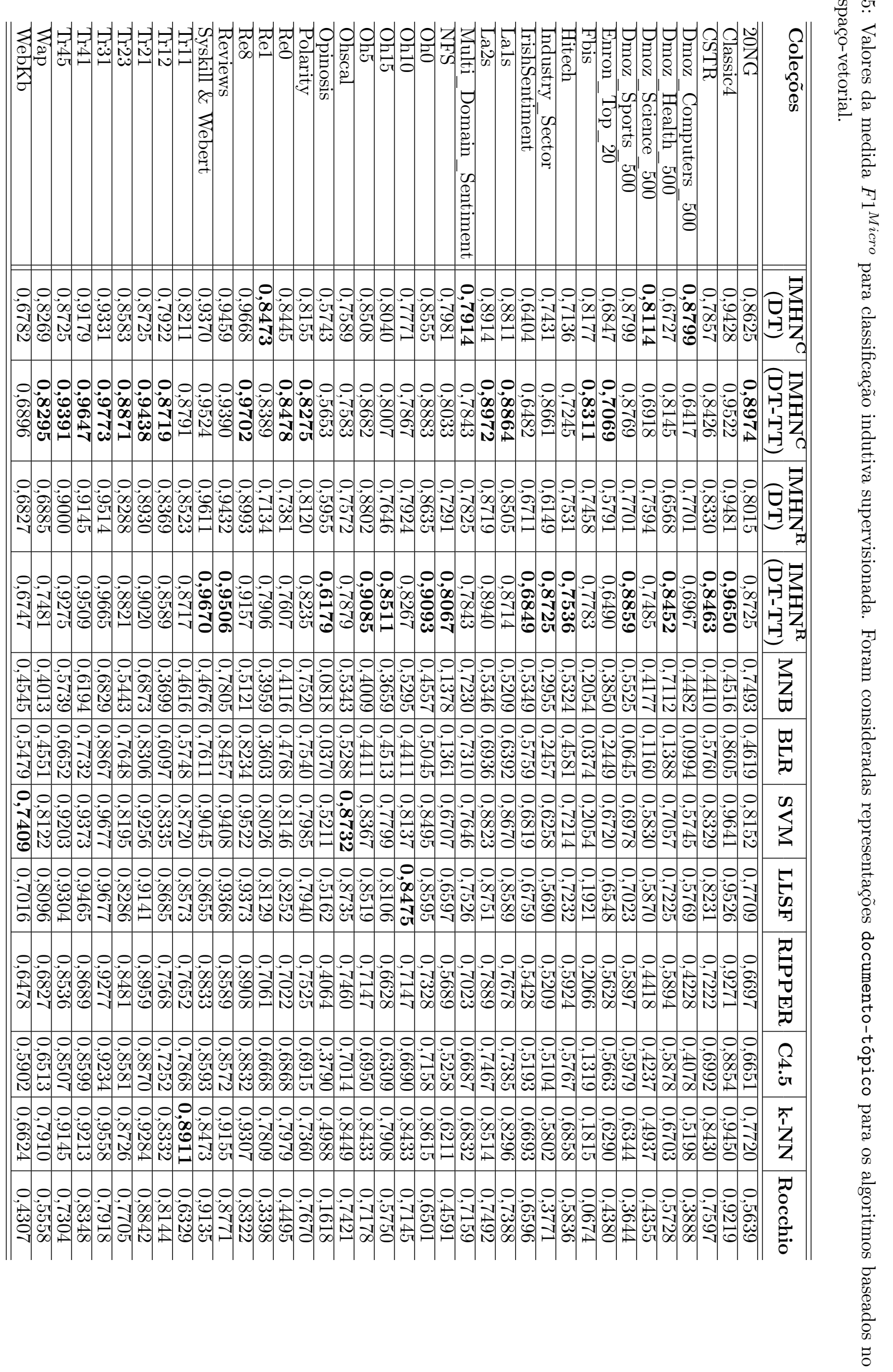


Tabela 3.6: Número de vezes em que um algoritmo apresentado na linha superou o valor da medida $F 1^{\text {Micro }}$ de um algoritmo apresentado na coluna considerando os valores apresentados na Tabela 3.5.

\begin{tabular}{|c|c|c|c|c|c|c|c|c|c|c|c|c|}
\hline & \begin{tabular}{|c} 
IMHNC $^{\mathbf{C}}$ \\
$(\mathrm{DT})$
\end{tabular} & \begin{tabular}{|l|} 
IMHNC \\
(DT-TT)
\end{tabular} & \begin{tabular}{|c|}
$\mathbf{I M H N}^{\mathbf{R}}$ \\
$(\mathrm{DT})$
\end{tabular} & \begin{tabular}{|l|} 
IMHN $^{\mathbf{R}}$ \\
$(\mathrm{DT}-\mathrm{TT})$ \\
\end{tabular} & MNB & BLR & SVM & LLSF & RIPPER & C4.5 & k-NN & Rocchio \\
\hline $\mathrm{IMHN}^{\mathrm{C}}(\mathrm{DT})$ & - & 9 & 22 & 11 & 36 & 37 & 23 & 20 & 36 & 36 & 24 & 34 \\
\hline IMHN $^{\mathrm{C}}$ (DT-TT) & 28 & - & 28 & 18 & 37 & 37 & 31 & 31 & 37 & 37 & 32 & 36 \\
\hline IMHN $^{\mathrm{R}}(\mathrm{DT})$ & 15 & 9 & - & 3 & 36 & 37 & 16 & 17 & 35 & 36 & 21 & 37 \\
\hline IMHN $^{\mathrm{R}}(\mathrm{DT}-\mathrm{TT})$ & 26 & 18 & 34 & - & 37 & 37 & 27 & 25 & 37 & 37 & 30 & 37 \\
\hline MNB & 1 & 0 & 1 & 0 & & 14 & 1 & 1 & 4 & 7 & 4 & 8 \\
\hline BLR & 0 & 0 & 0 & 0 & 23 & - & 0 & 0 & 3 & 3 & 2 & 5 \\
\hline SVM & 14 & 6 & 21 & 10 & 35 & 37 & - & 20 & 35 & 36 & 29 & 36 \\
\hline LLSF & 17 & 6 & 20 & 12 & 36 & 37 & 16 & - & 34 & 36 & 30 & 36 \\
\hline RIPPER & 1 & 0 & 2 & 0 & 33 & 34 & 2 & 3 & - & 33 & 4 & 29 \\
\hline C4.5 & 1 & 0 & 1 & 0 & 30 & 34 & 1 & 1 & 4 & & 1 & 22 \\
\hline $\mathrm{k}-\mathrm{NN}$ & 13 & 5 & 16 & 7 & 33 & 35 & 8 & 7 & 33 & 36 & - & 34 \\
\hline Rocchio & 3 & 1 & 0 & 0 & 29 & 32 & 1 & 1 & 8 & 15 & 3 & \\
\hline
\end{tabular}

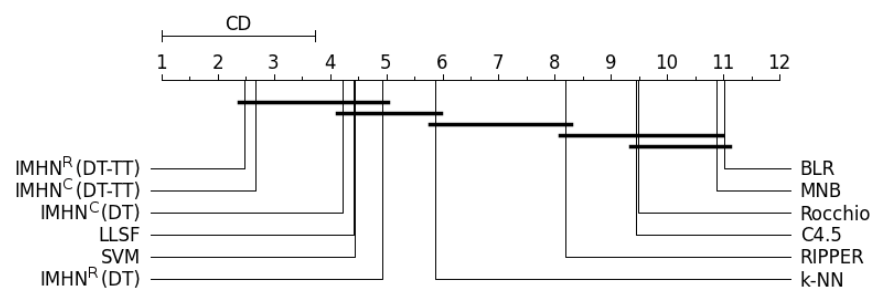

Figura 3.7: Diagrama de diferença crítica para a medida $F 1^{\text {Micro }}$ considerando representações documento-tópico para os algoritmos baseados no modelo espaço-vetorial.

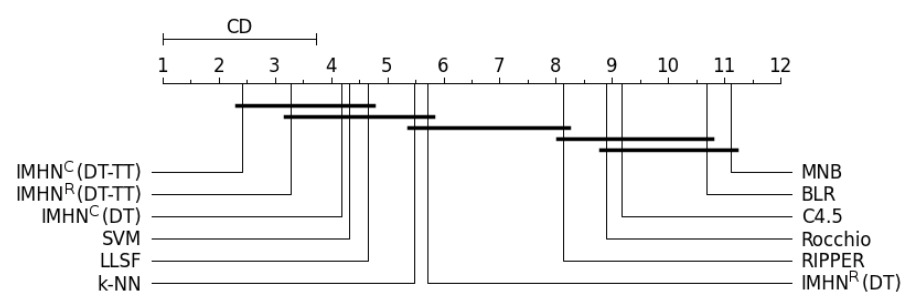

Figura 3.8: Diagrama de diferença crítica para a medida $F 1^{\text {Macro }}$ considerando representações documento-tópico para os algoritmos baseados no modelo espaço-vetorial. 


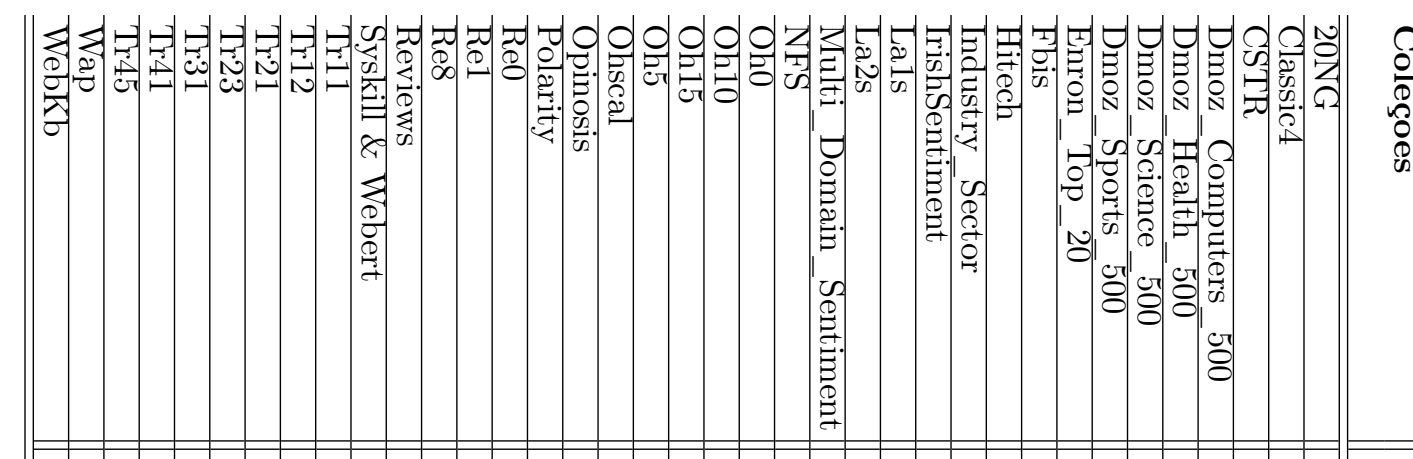

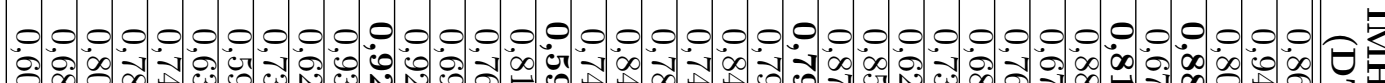

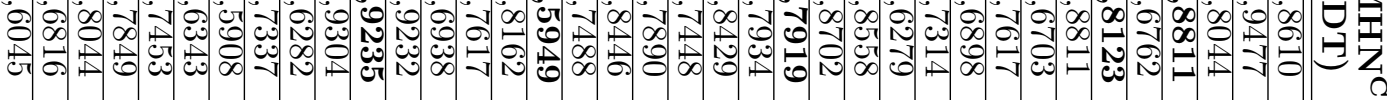

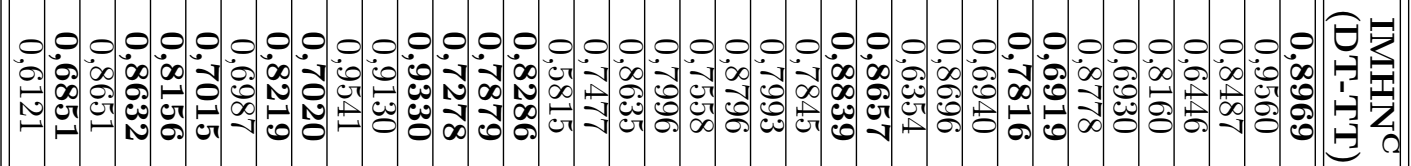

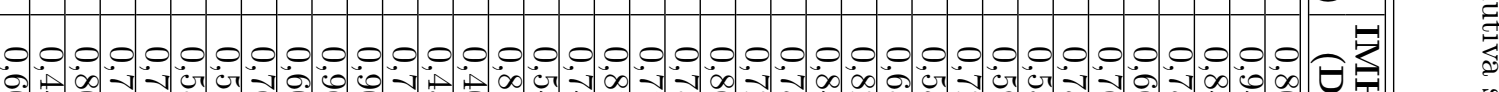

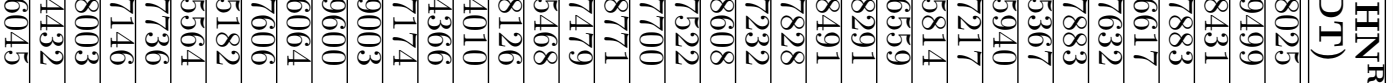

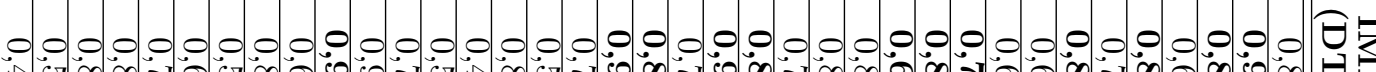

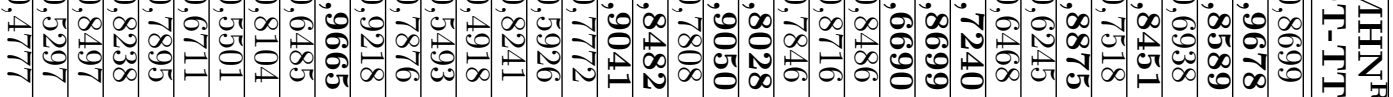

0.0.0.0.0.0.0.0.0.0.0.0.0.0.0.0.0.0.0

क 0 类

过

0.0000000000000000000000000000000

记

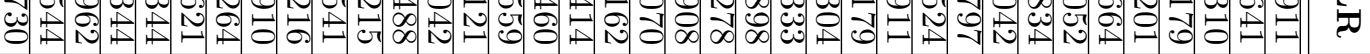

000.00000 .00000000000000000000000000

施

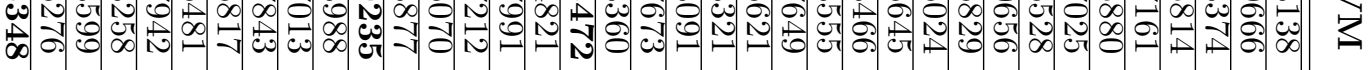

000000000000000000000000000000000

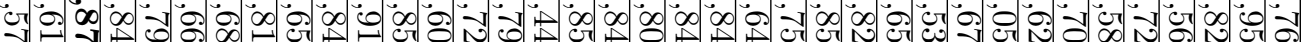

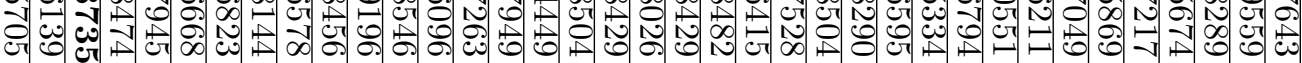

0.00000000000 .0000000000000000000000

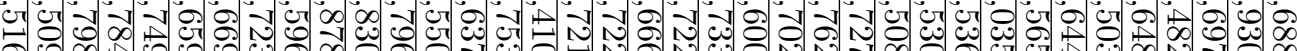

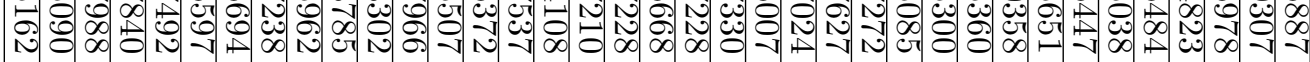

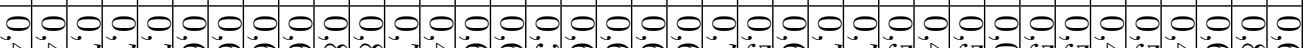

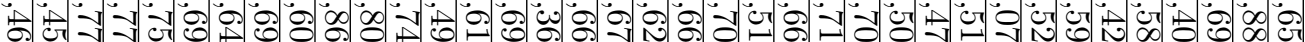

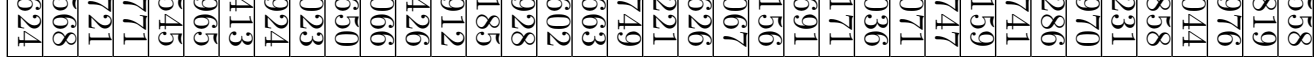

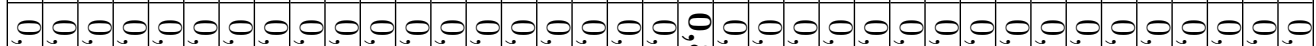

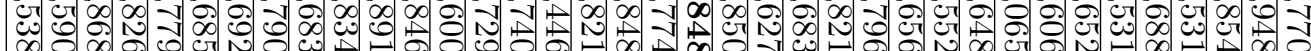

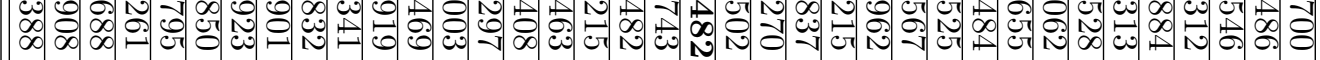

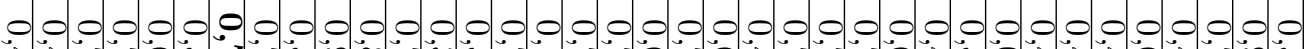

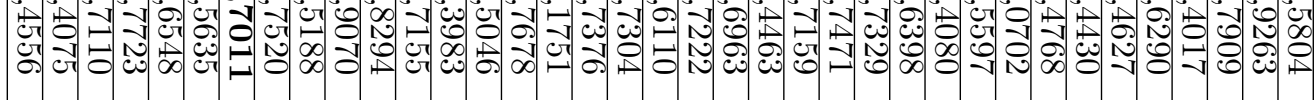


Tabela 3.8: Número de vezes em que um algoritmo apresentado na linha superou o valor da medida $F 1^{\text {Macro }}$ de um algoritmo apresentado na coluna considerando os valores apresentados na Tabela 3.7.

\begin{tabular}{|c|c|c|c|c|c|c|c|c|c|c|c|c|}
\hline & $\begin{array}{c}\text { IMHN }^{\mathbf{C}} \\
(\mathrm{DT})\end{array}$ & \begin{tabular}{|l} 
IMHNC \\
(DT-TT)
\end{tabular} & \begin{tabular}{|c|} 
IMHN $^{\mathbf{R}}$ \\
(DT)
\end{tabular} & \begin{tabular}{|l|} 
IMHN $^{\mathbf{R}}$ \\
$(\mathrm{DT}-\mathrm{TT})$
\end{tabular} & MNB & BLR & SVM & LLSF & RIPPER & C4.5 & k-NN & Rocchio \\
\hline IMHN $^{\mathrm{C}}$ (DT) & $\overline{-1}$ & 7 & 26 & 14 & 36 & 37 & 22 & 22 & 34 & 34 & 22 & 34 \\
\hline IMHN $^{\mathrm{C}}$ (DT-TT) & 30 & - & 30 & 18 & 37 & 37 & 31 & 31 & 37 & 37 & 32 & 35 \\
\hline IMHN $^{\mathrm{R}}(\mathrm{DT})$ & 10 & 7 & - & 3 & 36 & 34 & 14 & 17 & 29 & 30 & 19 & 33 \\
\hline IMHN $^{\mathrm{R}}(\mathrm{DT}-\mathrm{TT})$ & 23 & 19 & 34 & - & 37 & 37 & 23 & 24 & 32 & 34 & 25 & 35 \\
\hline $\mathrm{MNB}$ & 1 & 0 & 1 & 0 & 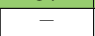 & 7 & 0 & 0 & 7 & 7 & 4 & 6 \\
\hline BLR & 0 & 0 & 3 & 0 & 30 & - & 0 & 0 & 3 & 7 & 2 & 4 \\
\hline SVM & 14 & 6 & 23 & 14 & 37 & 37 & - & 22 & 36 & 35 & 26 & 34 \\
\hline LLSF & 15 & 6 & 20 & 13 & 37 & 37 & 15 & - & 36 & 34 & 25 & 34 \\
\hline RIPPER & 3 & 0 & 8 & 5 & 30 & 34 & 1 & 1 & - & 33 & 3 & 25 \\
\hline C4.5 & 3 & 0 & 7 & 3 & 30 & 30 & 2 & 3 & 4 & 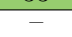 & 3 & 20 \\
\hline $\mathrm{k}-\mathrm{NN}$ & 15 & 5 & 18 & 12 & 33 & 35 & 11 & 12 & 34 & 34 & & 32 \\
\hline Rocchio & 3 & 2 & 4 & 2 & 31 & 33 & 3 & 3 & 12 & 17 & 5 & - \\
\hline
\end{tabular}




\subsection{Considerações Finais}

Neste capítulo foram apresentados os algoritmos baseados no modelo espaço-vetorial mais aconselháveis e utilizados para a classificação de textos (Seção 3.2.1) bem como algoritmos existentes baseados em redes (Seção 3.2.2). Em seguida, foi apresentado o algoritmo proposto IMHN (Seção 3.3), que induz um modelo de classificação tanto utilizado redes compostas somente por relações documento-termo ou redes compostas por relações documento-termo e termo-termo.

Com a avaliação experimental realizada neste capítulo, pode-se comprovar a hipótese que diferentes tipos de relações combinadas em uma rede heterogênea de fato podem melhorar a performance de classificação. Observou-se que as redes compostas por relações documento-termo e termo-termo aumentaram a performance de classificação em relação a redes compostas apenas por relações do tipo documento-termo para a maioria das coleções. Além disso, o algoritmo proposto juntamente com as redes compostas por relações documento-termo e termo-termo obteve uma maior performance de classificação para a maioria das coleções tanto para a medida $F 1^{\text {Micro }}$ quanto para a medida $F 1^{\text {Macro }}$. A validação da hipótese foi comprovada com diferenças estatisticamente significantes dos resultados obtidos utilizando redes compostas por mais de um tipo de relações em relação aos resultados obtidos utilizando representações no modelo espaço-vetorial. Vale ressaltar que mesmo as redes compostas apenas por relações documento-termo foram capazes de prover performances de classificação superiores a grande maiorias dos algoritmos baseados no modelo-espaço vetorial e todos os algoritmos baseados em redes utilizados para comparação.

Com os resultados apresentados na avaliação experimental, pôde-se comprovar que tanto as redes propostas foram capazes de prover performances de classificação satisfatórias bem como o algoritmo proposto. Vale ressaltar também que o modelo de classificação gerado realiza uma classificação mais rápida que os algoritmos baseados em redes existentes, que em sua maioria necessitam do cálculo de similaridades entre redes ou entre objetos das redes. Assim, as redes propostas e o algoritmo proposto podem ser utilizados efetivamente no aprendizado indutivo supervisionado para a classificação de textos. 
CAPÍTUlo

Classificação de Textos por Meio de Aprendizado Transdutivo

\subsection{Considerações Iniciais}

Nos dias atuais consegue-se facilmente coletar milhares de textos não rotulados oriundos de páginas web, tweets, artigos ou comentários em redes sociais. Entretanto, a rotulação de grandes quantidades de textos para organização, gerenciamento e extração de conhecimento requer um grande número de anotadores humanos e despende uma grande quantidade de tempo.

Dado isso, nos últimos anos têm-se dado foco em algoritmos de aprendizado de máquina semissupervisionados para realizar a classificação automática. O objetivo desses algoritmos é utilizar exemplos não rotulados para melhorar a performance de classificação em relação a utilização de somente exemplos rotulados. Por exemplo, considere os 3 textos da Figura 4.1, na qual apenas o texto "Ensino e educação" possui rótulo ("Educação"). Nesse caso, o texto "Matemática para crianças" não seria rotulado com "Educação", uma vez que seus termos não ocorrem em nenhum documento rotulado por tal classe. Porém, ao utilizar textos não rotulados, pode-se atribuir o rótulo "Educação" ao texto "Matemática para crianças", uma vez que esse texto possui termos em comum com o texto "Ensino de matemática" e este com o texto rotulado "Ensino e educação". Portanto, o uso de exemplos não rotulados permite a descoberta de padrões que não seriam descobertos ao considerar apenas exemplos rotulados.

Outro ponto interessante em relação aos algoritmos de aprendizado semissupervisionado é que, em algumas situações, com $90 \%$ menos exemplos rotulados é possível obter uma performance de classificação comparável a algoritmos de aprendizado de máquina indutivos supervisionados (Rossi et al., 2014b). Portanto, dado a facilidade de coleta de 

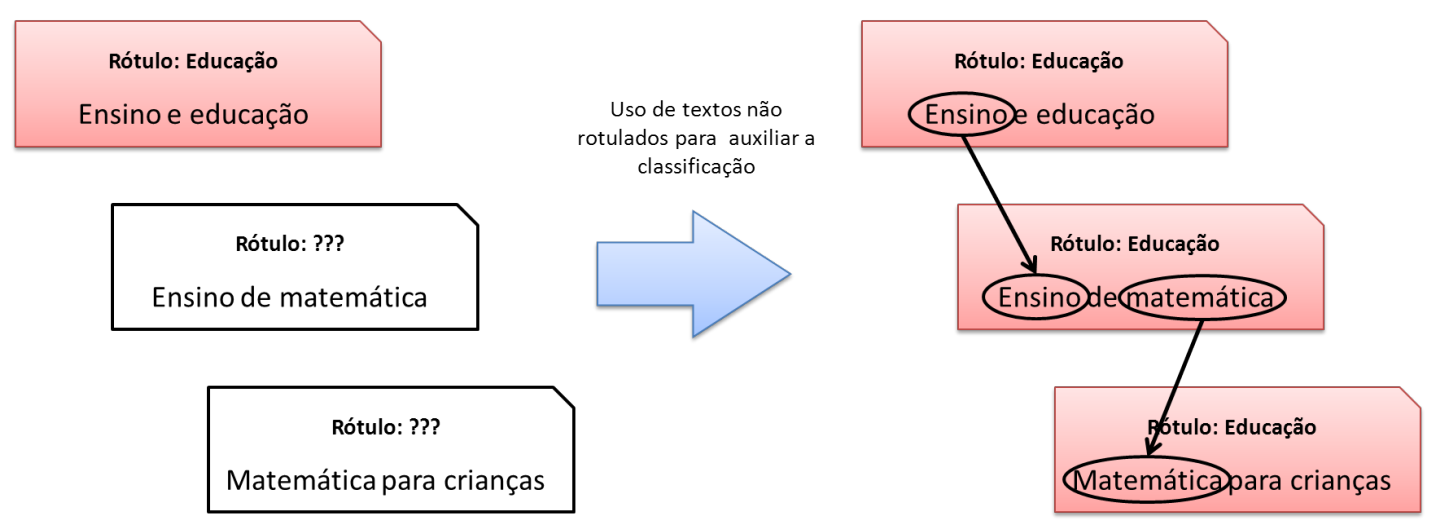

Figura 4.1: Exemplo de uso de documentos não rotulados para auxiliar a classificação de textos.

exemplos não rotulados e o menor custo para se rotular exemplos, o uso de aprendizado de máquina semissupervisionado é interessante em situações práticas e permitirem aos usuários facilmente customizarem a classificação de textos de acordo com seus interesses.

Existem dois tipos de aprendizado de máquina semissupervisionado: aprendizado transdutivo, que será apresentado neste capítulo, e aprendizado indutivo que será apresentado no próximo capítulo. Formalmente, o objetivo da classificação transdutiva é gerar uma função $F: \mathcal{O}^{L+U} \rightarrow \mathcal{Y}^{L+U}$ tal que $F$ seja um bom preditor sobre os dados não rotulados. Tanto os dados rotulados quanto não rotulados são considerados para gerar a função $F$.

Diferente da classificação indutiva, na classificação transdutiva os rótulos dos exemplos não rotulados são estimados diretamente sem a necessidade da indução de um modelo de classificação. Outra diferença é que no aprendizado transdutivo o algoritmo de aprendizado pode observar todos os exemplos a serem classificados, e portanto explorar suas características para melhorar a performance de classificação (Joachims, 2006), além do fato de que uma vez que os exemplos são finitos, o espaço de hipóteses do aprendizado transdutivo também é necessariamente finito (Chapelle et al., 2006). Na Figura 4.2 é apresentado uma ilustração sobre a classificação de textos utilizando aprendizado transdutivo.

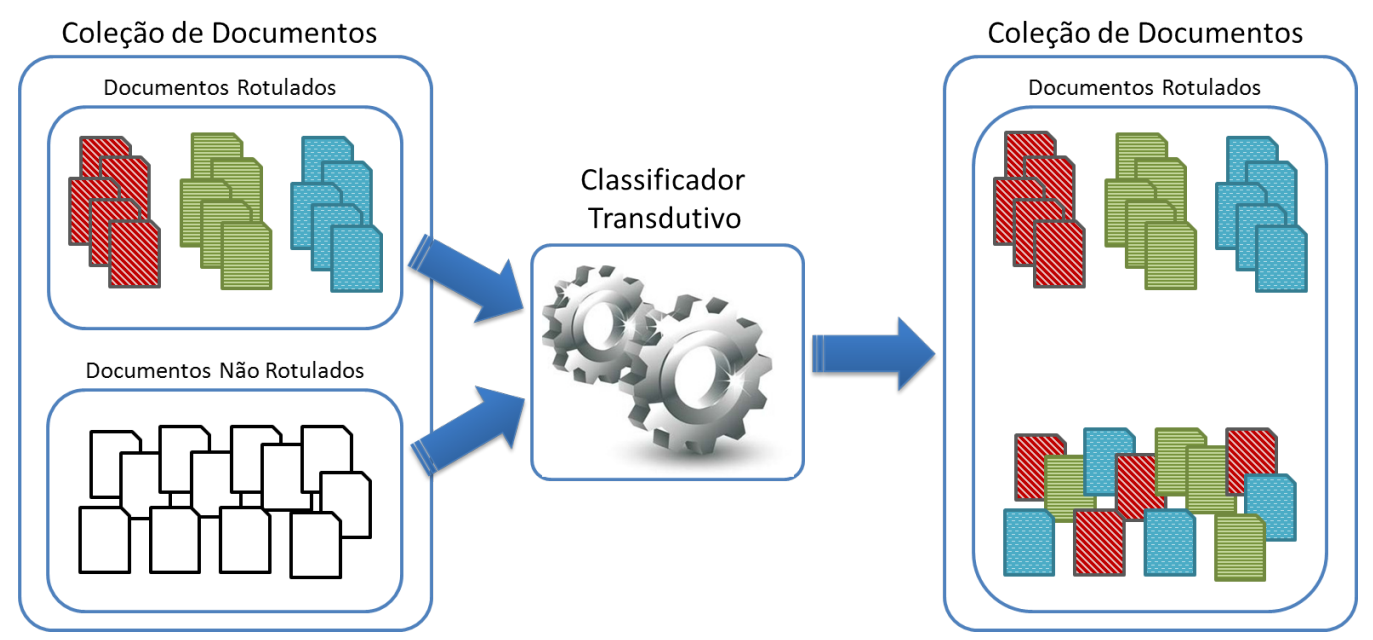

Figura 4.2: Esquema ilustrativo da classificação automática de textos por meio de aprendizado transdutivo.

Diversas aplicações da classificação automática de textos envolvem situações na qual toda a coleção de documentos é conhecida, podendo assim aplicar algoritmos de aprendizado 
transdutivo para a classificação de exemplos não rotulados. Alguns exemplos dessas aplicações são:

- Realimentação de relevância: utilizada na recuperação de informação, na qual o usuário rotula documentos retornados por uma busca como relevantes e não relevantes. É então executado o aprendizado transdutivo considerando os documentos rotulados e os não rotulados retornados pela busca, e no final do processo, o sistema é capaz de retornar ao usuário um conjunto de documentos relevantes à consulta (Baeza-Yates e Ribeiro-Neto, 1999).

- Filtro de notícias: dado o grande número de notícias postadas todos os dias, o usuário pode marcar algumas notícias como interessantes e o sistema pode retornar somente as notícias de acordo com seu interesse naquele dia (Joachims, 2003).

- Organização de coleções de documentos: consiste em uma tarefa geral em que dada uma coleção de documentos, o usuário pode organizá-la informando exemplos de documentos das categorias definidas (Joachims, 2003).

- Mineração de Opinião/Análise de Sentimentos: consiste em coletar um conjunto de comentários ou avaliações de páginas web, blogs, fóruns e redes sociais, em um determinado período de tempo e determinar o sentimento de todos os comentários e avaliações por meios de poucos exemplos rotulados como positivos, negativos ou neutros (Tan et al., 2011; Dasgupta e Ng, 2009; Sindhwani e Melville, 2008; Goldberg e Zhu, 2006). Isso permite quantificar a opinião pública a respeito de determinado produto, serviço, ou personalidade em um período de tempo e auxiliar a tomada de decisões.

- Outras aplicações: a classificação transdutiva também tem sido aplicada à outras finalidades em conjunto de dados textuais, como identificação de aspectos (componentes) de produtos (Matsuno et al., 2015; Zhai et al., 2010), detecção de sentenças subjetivas e objetivas (Riloff et al., 2003), parsing (McClosky et al., 2006; Steedman et al., 2003), desambiguação de nomes (Mihalcea, 2004), extração de entidades como nomes próprios, organizações e localizações (Jones, 2005), construção de dicionários de domínio (Conrado et al., 2005), tradução de textos (Alexandrescu e Kirchhoff, 2009; Ueffing et al., 2007), e identificação de funções de genes considerando textos biomédicos (Krogel e Scheffer, 2004). Além disso, outros domínios não textuais podem ser representados com características de representações textuais, possibilitando à aplicação de algoritmos de classificação de textos, como a classificação de gêneros musicais (Silva et al., 2014; Dupont e Ravet, 2013) e a identificação de regras de associação interessantes (de Padua et al., 2014).

Vale ressaltar que todos os exemplos de aplicações de classificação de textos apresentados no Capítulo 3 também podem ser realizados por meio da classificação transdutiva desde que o objetivo seja classificar exemplos não rotulados conhecidos. 
Vários métodos com diferentes características vêm sendo propostos ao longo dos anos para a classificação transdutiva, principalmente nas últimas décadas onde há uma crescente produção de dados digitais. Inicialmente foram propostos métodos baseados no modelo espaço-vetorial. Entretanto, as premissas por parte desses métodos a respeito da distribuição dos dados são frequentemente violadas em conjuntos de dados reais, fazendo com que o uso de dados não rotulados não melhore ou muitas vezes degrade a performance de classificação (Zhu e Goldberg, 2009; Druck et al., 2008; Cozman et al., 2003; Elworthy, 1994).

Posteriormente foram propostos algoritmos transdutivos baseados em redes, que demonstraram obter melhor performance de classificação do que algoritmos baseados no modelo espaço-vetorial. Porém, as pesquisas sobre classificação transdutiva de textos baseada em redes (i) consideram apenas redes de documentos; (ii) consideram redes heterogêneas mas possuem um grande número de parâmetros; ou (iii) consideram apenas a propagação direta das informações de classe para objetos vizinhos, enquanto que um processo de otimização para gerar informações de classe que melhor representem o estado da rede poderia melhorar a performance de classificação. Dado isso, nesse projeto de doutorado foram propostos métodos para classificação em redes que (i) consideram redes compostas por diferentes tipos de relações, (ii) são livre de parâmetros; ou (ii) realizam um processo de otimização anterior a propagação de rótulos.

O restante deste capítulo está dividido da seguinte forma. Na Seção 4.2 são apresentados os trabalhos sobre classificação transdutiva que consideram dados representados no modelo espaço-vetorial ou representados em redes. Na Seção 4.3 são apresentadas as propostas para a classificação transdutiva de textos representados em redes. Na Seção 4.4 são apresentados os resultados obtidos pelos algoritmos existentes na literatura e pelos algoritmos propostos nesta tese para a classificação transdutiva de textos. Por fim, na Seção 4.5 são apresentadas as considerações finais sobre o conteúdo apresentado neste capítulo.

\subsection{Trabalhos Relacionados}

Nesta seção serão apresentados trabalhos relacionados à classificação transdutiva considerando textos representados no modelo espaço-vetorial, os quais envolvem as primeiras pesquisas sobre aprendizado transdutivo, e em seguida a classificação transdutiva considerando dados modelados em redes, os quais tem ganhado atenção nos últimos anos e têm sido o foco de pesquisas envolvendo aprendizado transdutivo. Vale ressaltar que a formulação dos algoritmos, suas funções matemáticas e pseudocódigos já estão instanciados para a tarefa de classificação de textos.

\subsubsection{Aprendizado Transdutivo no Modelo Espaço-Vetorial}

Os algoritmos mais tradicionais para a classificação transdutiva baseada no modelo espaço-vetorial são (Zhu e Goldberg, 2009; Chapelle et al., 2006): Self-Training, Co- 
Training, Expectation Maximization, e Transductive Support Vector Machines. Esses algoritmos são comumente encontrados na literatura sendo aplicados na classificação transdutiva de textos e em outras tarefas de classificação contendo dados textuais (McClosky et al., 2006; Jones, 2005; Mihalcea, 2004; Riloff et al., 2003; Steedman et al., 2003; Tong e Koller, 2002; Sarkar, 2001; Collins e Singer, 1999; Joachims, 1999). Nas próximas seções são detalhados os algoritmos mencionados acima.

\section{Self-Training}

Uma das maneiras mais naturais de se realizar a classificação transdutiva é por meio da abordagem Self-Training (Culp e Michailidis, 2008; Haffari e Sarkar, 2007; Yarowsky, 1995). Nesta abordagem, inicialmente é induzido um modelo de classificação utilizando somente documentos rotulados. O classificador é aplicado a todos os documentos não rotulados e os $X$ documentos que foram classificados com maior confiança são inseridos no conjunto do treinamento com seus respectivos rótulos atribuídos pelo modelo de classificação. $\mathrm{O}$ processo se repete até que todos os documentos não rotulados sejam inseridos no conjunto de treinamento. No Algoritmo 6 é apresentado o pseudocódigo da abordagem Self-Training.

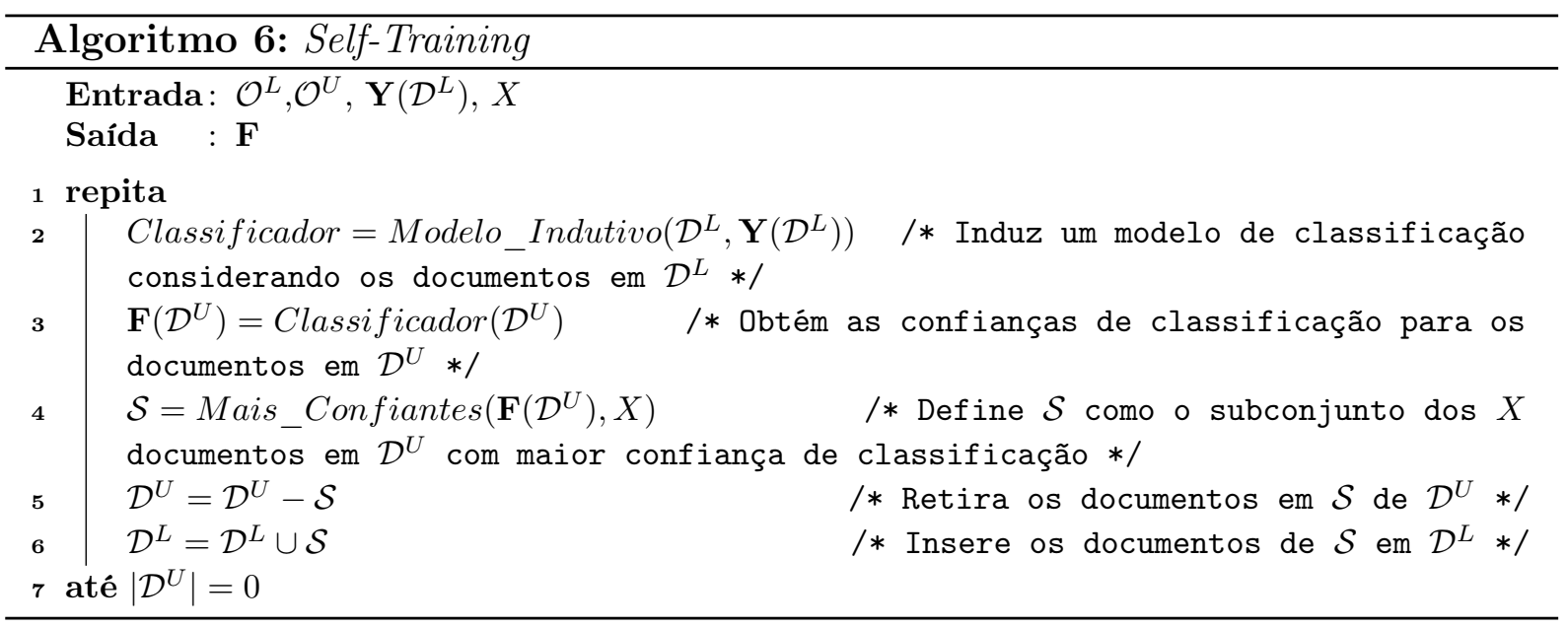

A premissa da abordagem Self-Training é que as classificações com maior confiança estão corretas. Porém, isso provavelmente só ocorre quando as classes formam grupos bem separados (Zhu e Goldberg, 2009). Além disso, erros nas classificações inserem documentos com rótulos incorretos no conjunto de treinamento, degenerando o modelo de classificação para as próximas iterações. Destaca-se também que a abordagem Self-Training pode apresentar um alto custo computacional devido à necessidade de reindução de modelos de classificação, $|\mathcal{O}| / X$ vezes, além da ordenação da confiança dos exemplos rotulados em cada iteração.

\section{Co-Training}

Em Blum e Mitchell (1998) é apresentada a abordagem Co-Training. Essa abordagem pode ser vista como uma extensão da abordagem Self-Training para conjunto de dados 
com mais de uma visão. Por exemplo, uma página web pode ser descrita em uma visão pelas palavras contidas na própria página e em outra visão pelas palavras contidas nas páginas que apontam para a mesma (Blum e Mitchell, 1998). Já uma entidade nomeada pode ser descrita em uma visão pelas próprias palavras que compõem a entidade e em outra visão pelas palavras adjacentes a entidade (Zhu e Goldberg, 2009).

O objetivo da abordagem Co-Training é que uma visão contribua na classificação dos documentos de outra visão. Seja $\mathcal{O}^{L 1}$ o conjunto de objetos rotulados da $1^{\text {a }}$ visão, $\mathcal{O}^{L 2}$ o conjunto de objetos rotulados da $2^{\mathrm{a}}$ visão, $\mathcal{O}^{U 1}$ o conjunto de objetos não rotulados da $1^{\text {a }}$ visão e $\mathcal{O}^{U 2}$. Na versão simplificada da abordagem Co-Training apresentada em Zhu e Goldberg (2009), é induzido um modelo de classificação considerado os objetos em $\mathcal{O}^{L 1}$ e outro modelo considerando os objetos em $\mathcal{O}^{L 2}$. Os $X$ objetos em $\mathcal{O}^{L 1}$ com maior confiança de classificação são inseridos como objetos rotulados em $\mathcal{O}^{L 2}$, e os $X$ objetos em $\mathcal{O}^{L 2}$ com maior confiança de classificação são inseridos como objetos rotulados em $\mathcal{O}^{L 1}$. Esse processo de repete até que não haja mais exemplos no conjunto de documentos não rotulados.

A diferença entre Self-Training e Co-Trainig está no fato de que um objeto que tenha baixa confiança de classificação em $\mathcal{O}^{L 1}$, e que não seria inserido como documento rotulado utilizando Self-Training, podem ter alta confiança na $2^{\text {a }}$ visão devido ao conjunto de atributos diferentes e portanto serem inseridos no conjunto de objetos rotulados. No Algoritmo 7 é apresentado o pseudocódigo da abordagem Co-Training (Zhu e Goldberg, 2009).

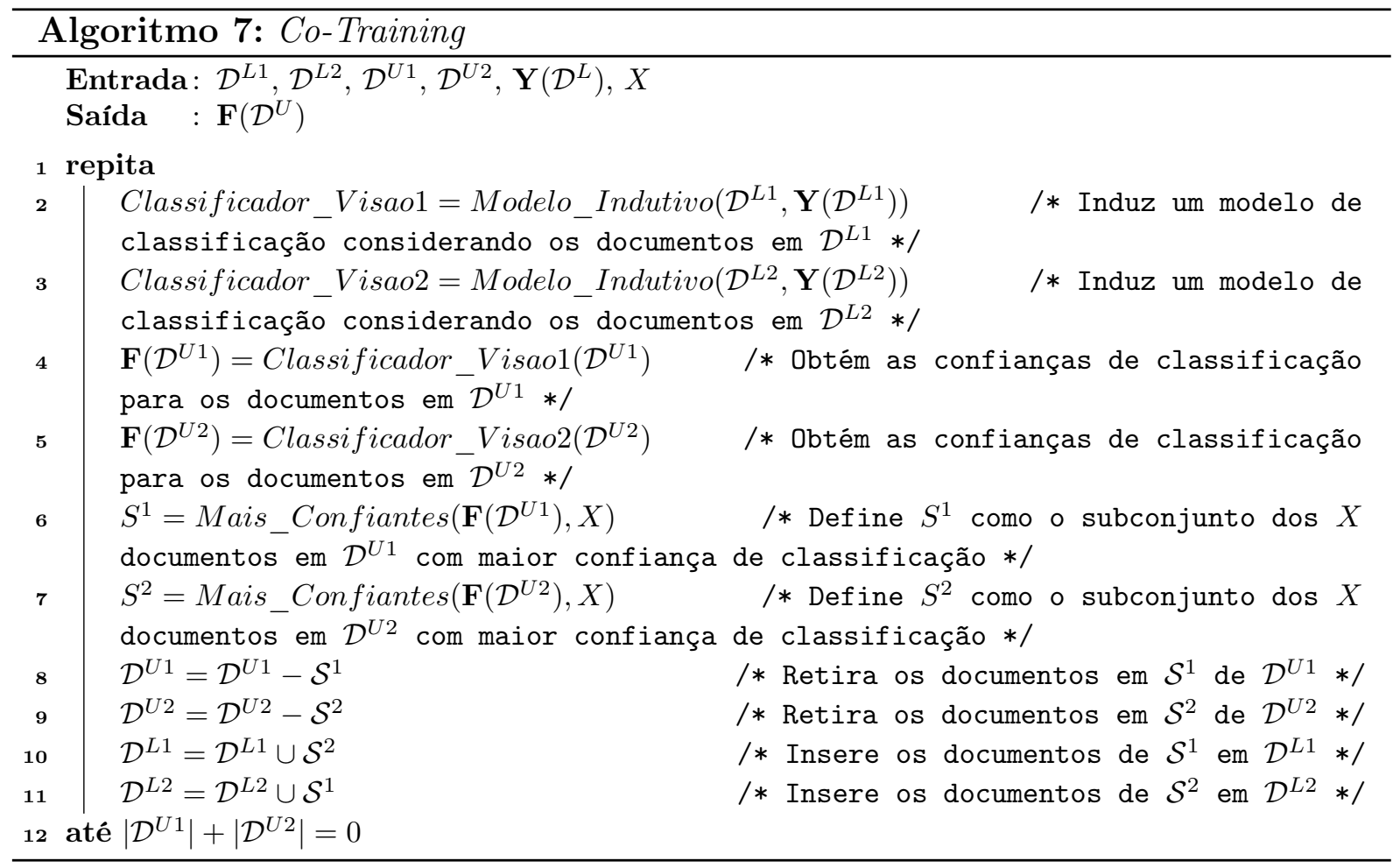

Para o correto funcionamento da abordagem Co-Training, assume-se que o conjunto de dados é composto por duas visões, que cada visão é suficiente para realizar classificações 
satisfatórias, e que as visões são independentes. Entretanto, é difícil encontrar conjuntos de dados que na prática satisfaçam completamente essas premissas. Além disso, a abordagem Co-Training apresenta as mesmas deficiências da abordagem Self-Training quanto à escalabilidade, tendo que induzir modelos de classificação e ordenar documentos pela confiança de classificação repetidas vezes.

Encontram-se também na literatura variações da abordagem Co-Training, como a combinação de Co-Training com Expectation Maximization (Nigam e Ghani, 2000), e o Tri-Training (Zhou e Li, 2005).

\section{Expectation Maximization}

O algoritmo Expectation Maximization (EM) (Dempster et al., 1977) permite atribuir informação de classe aos documentos não rotulados iterativamente, sem a necessidade de induzir modelos de classificação. No caso da classificação de textos, o objetivo é definir os componentes de misturas que geram os textos da coleção. Cada componente está associado a uma classe e o objetivo é definir as probabilidades dos termos para cada componente utilizando tanto documentos rotulados quanto não rotulados. No contexto desta tese, os componentes correspondem às informações de classe dos termos para as classes.

Em Nigam et al. (2000) é apresentada uma abordagem que combina $E M$ com a técnica Multinomial Naïve Bayes para realizar a classificação transdutiva de textos. Nesta abordagem, a probabilidade de ocorrer uma classe dado um documento, ou a informação de classe do documento no contexto desta tese, é dada de acordo com a regra de Bayes:

$$
P\left(c_{j} \mid d_{i} ; \mathbf{F}(\mathcal{T})\right)=\frac{P\left(c_{j} \mid \mathbf{F}(\mathcal{T})\right) P\left(d_{i} \mid c_{j} ; \mathbf{F}(\mathcal{T})\right)}{P\left(d_{i} \mid \mathbf{F}(\mathcal{T})\right)}
$$

na qual $P\left(c_{j} \mid \mathbf{F}(\mathcal{T})\right)$ é a probabilidade de ocorrer a classe $c_{j}$ considerando os pesos dos termos para classe correntes, e é dada por $^{1}$ :

$$
P\left(c_{j} \mid \mathbf{F}(\mathcal{T})\right)=\frac{1+\sum_{d_{i} \in \mathcal{D}} P\left(c_{j} \mid d_{i} ; \mathbf{F}(\mathcal{T})\right)}{|\mathcal{C}|+|\mathcal{D}|} .
$$

$P\left(d_{i} \mid c_{j} ; \mathbf{F}(\mathcal{T})\right)$ é a probabilidade de ocorrer um documento dada a classe $c_{j}$. De acordo com a premissa do algoritmo Naïve Bayes, cada palavra de um documento é gerada independentemente da ocorrência de outras palavras. Portanto a probabilidade de um documento dada a classe $c_{j}$ é dada pela probabilidade da ocorrência de seus termos para a classe $c_{j}$, isto é:

$$
P\left(d_{i} \mid c_{j}, \mathbf{F}(\mathcal{T})\right)=\prod_{t_{k} \in \mathcal{T}, w_{d_{i}, t_{k}}>0} P\left(t_{k} \mid c_{j} ; \mathbf{F}(\mathcal{T})\right)
$$

\footnotetext{
${ }^{1}$ Vale ressaltar que foi utilizado o Estimador de Laplace (Nigam et al., 2000) nas Equações 4.2 e 4.5 para evitar que $P\left(t_{i} \mid c_{j} ; \mathbf{F}(\mathcal{T})\right)$ ou $P\left(c_{j} \mid \mathbf{F}(\mathcal{T})\right)$ sejam iguais a 0 e com isso zerem as informações de classe dos documentos para as classes.
} 
$P\left(d_{i} \mid \mathbf{F}(\mathcal{T})\right)$ é o termo normalizador, e é dado por:

$$
P\left(d_{i}\right)=\sum_{c_{j} \in \mathcal{C}} P\left(c_{j}\right) P\left(d_{i} \mid c_{j}\right)
$$

A probabilidade de um termo $t_{i}$ ocorrer em uma classe $c_{j}$ dada as atuais informações de classe dos documentos é dada por:

$$
P\left(t_{i} \mid c_{j} ; \mathbf{F}(\mathcal{T})\right)=\frac{1+\sum_{d_{k} \in \mathcal{D}} w_{t_{i}, d_{k}} P\left(c_{j} \mid d_{i} ; \mathbf{F}(\mathcal{T})\right)}{|\mathcal{T}|+\sum_{t_{l} \in \mathcal{T}} \sum_{d_{m} \in \mathcal{D}} w_{t_{l}, d_{m}} P\left(c_{j} \mid d_{i} ; \mathbf{F}(\mathcal{T})\right)}
$$

No Algoritmo 8 é apresentado o pseudocódigo da abordagem EM para a classificação transdutiva de textos. O cálculo da informação de classe dos documentos não rotulados (linha 3) é denominada E-step e o cálculo da informação de classe dos termos (linha 4) é denominada $M$-step. E-step e $M$-step são executados iterativamente até a convergência, isto é, até que não haja alterações significativas nas informações de classe dos documentos não rotulados ou até um determinado número fixo de iterações. O algoritmo $E M$ executa uma busca do tipo Hill-Climbing no espaço de hipóteses, garantindo que os valores das informações de classe dos termos convirjam.

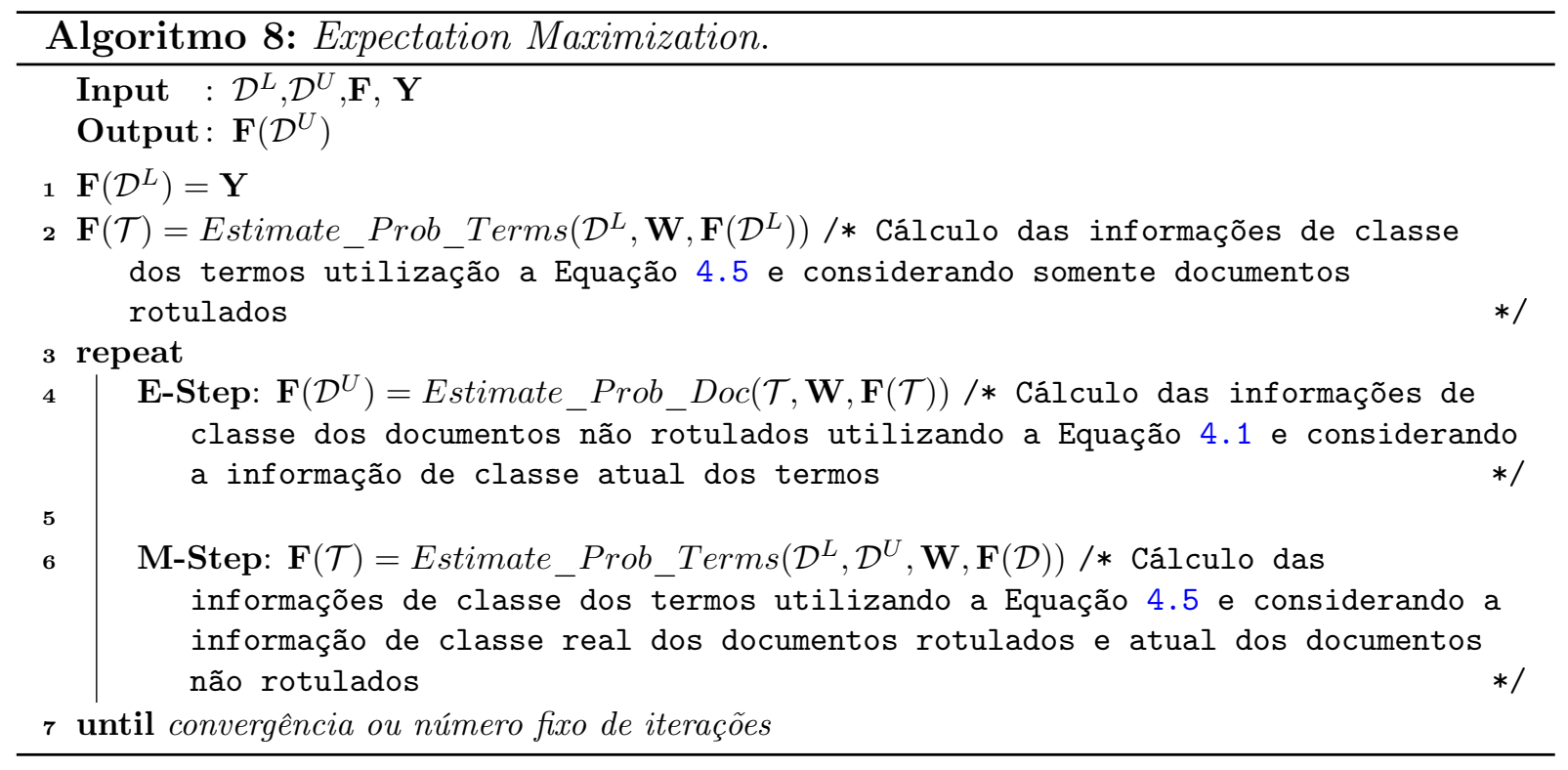

Em Nigam et al. (2000) são propostas duas extensões para aumentar a performance de classificação da abordagem EM: (i) ponderar a importância dos dados não rotulados e (ii) utilizar múltiplos componentes de mistura por classe. A primeira extensão refere-se ao fato de que a abordagem $E M$ seria utilizada praticamente para realizar um agrupamento não supervisionado em cenários onde o número de documentos rotulados é insignificante frente ao número de documentos não rotulados. Isso se deve ao fato de que os documentos rotulados só teriam impacto no cálculo da probabilidade de ocorrência das classes ou das informações de classe dos termos na inicialização, onde só são utilizados documentos 
rotulados. Para isso, em Nigam et al. (2000) é proposta a utilização da função $\Lambda\left(d_{i}\right)$ para ponderar o peso nas definições das probabilidades. $\Lambda\left(d_{i}\right)$ é dada por:

$$
\Lambda\left(d_{i}\right)= \begin{cases}\lambda & \text { se } d_{i} \in \mathcal{D}^{U} \\ 1 & \text { se } d_{i} \in \mathcal{D}^{L} .\end{cases}
$$

Com o uso da função $\lambda\left(d_{i}\right)$, as Equações 4.2 e 4.5 são reescritas nas Equações 4.7 e 4.8 respectivamente.

$$
\begin{gathered}
P\left(c_{j} \mid \mathbf{F}(\mathcal{T})\right)=\frac{1+\sum_{d_{i} \in \mathcal{D}} \Lambda\left(d_{i}\right) P\left(c_{j} \mid d_{i} ; \mathbf{F}(\mathcal{T})\right)}{|\mathcal{C}|+\left|\mathcal{D}^{L}\right|+\lambda\left|\mathcal{D}^{U}\right|} \\
f_{t_{i}, c_{j}}=P\left(w_{t} \mid c_{j} ; \mathbf{F}(\mathbf{T})\right)=\frac{1+\sum_{d_{k} \in \mathcal{D}} \Lambda\left(d_{k}\right) w_{d_{k}, t_{i}} P\left(c_{j} \mid d_{i} ; \mathbf{F}(\mathcal{T})\right)}{|\mathcal{T}|+\sum_{t_{l} \in \mathcal{T}} \sum_{d_{m} \in \mathcal{D}} \Lambda\left(d_{m}\right) w_{d_{m}, t_{l}} P\left(c_{j} \mid d_{m} ; \mathbf{F}(\mathcal{T})\right)}
\end{gathered}
$$

As segunda extensão apresentada por Nigam et al. (2000) refere-se ao relaxamento da premissa de correspondência de um componente de mistura por classe para muitos múltiplos componentes por classe, uma vez que uma classe pode ser formada por múltiplos tópicos ou assuntos. Seja $\mathcal{S}^{c_{j}}$ o conjunto dos componentes da classe $c_{j}$. Com um único componente, $P\left(c_{j} \mid d_{i} ; \mathbf{F}(\mathcal{T})\right)=1$ se $d_{i} \in \mathcal{D}^{L}$ e $y_{d_{i}, c_{j}}=1$. Para vários componentes, é possível atribuir valores entre 0 e 1 para cada um dos componentes de $c_{j}$. Com os múltiplos componentes por classe, a probabilidade do ocorrer $c_{j}$ dado um documento $d_{i}$ é dada pela probabilidade de ocorrer os componentes de $c_{j}$ dado $d_{i}$, como apresentado na Equação 4.9.

$$
P\left(c_{j} \mid d_{i} ; \mathbf{F}(T)\right)=\sum_{s_{k} \in \mathcal{S}^{c_{j}}} P\left(c_{j} \mid s_{k} ; \mathbf{F}(\mathcal{T})\right) \frac{P\left(s_{k} \mid \mathbf{F}(\mathcal{T})\right) \prod_{t_{k}, w_{d_{i}, t_{k}>0}} P\left(t_{k} \mid s_{k} ; \mathbf{F}(\mathcal{T})\right)}{\sum_{s_{m} \in \mathcal{S}} P\left(s_{m} \mid \mathbf{F}(\mathcal{T})\right) \prod_{t_{k}, w_{d_{i}, t_{k}>0}} P\left(t_{k} \mid s_{m} ; \mathbf{F}(\mathcal{T})\right)}
$$

Vale ressaltar que as premissas que os dados provêm de um modelo generativo e a independência das palavras são frequentemente violadas na prática, o que podem levar a performances de classificação insatisfatórias.

\section{Transductive Support Vector Machines}

O método Transductive Support Vector Machines (TSVM) (Vapnik, 1998; Joachims, 1999) utiliza os documentos rotulados e não rotulados para induzir um hiperplano que melhor separe as classes em comparação com um hiperplano induzido considerando apenas documentos rotulados, como apresentado na Figura 4.3. Intuitivamente, os dados não rotulados guiam o hiperplano de separação para regiões não densas.

Considerando a classificação binária $\left(y_{d_{i}}, f_{d_{i}} \in\{-1,1\}\right)$, caso dos algoritmos de classificação lineares, e considerando a explicação do método SVM apresentado na Seção 3.2.1, o 


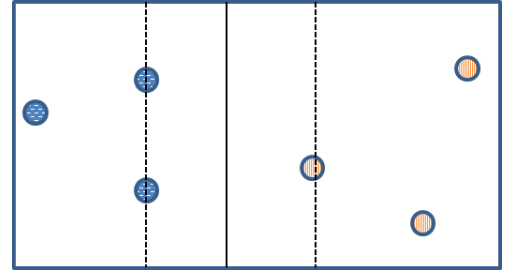

(a) SVM.

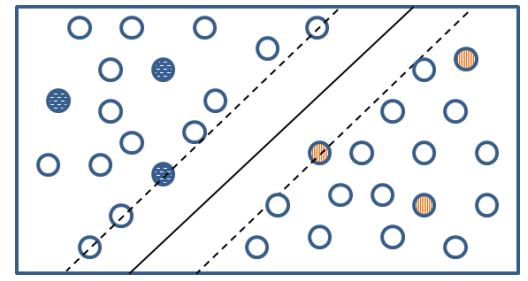

(b) TSVM.
- Classe 1

- Classe 2

Figura 4.3: Difereça entre SVM e TSVM (figura adaptada de Zhu e Goldberg (2009)).

objetivo do método TSVM é encontrar um hiperplano de separação $\left(\mathbf{f}^{T} \mathbf{w}+b\right)$ de margem máxima que minimize a seguinte função:

$$
\min _{\mathbf{f}, b} \frac{1}{2} \mathbf{f} \cdot \mathbf{f}
$$

Sujeito a: $\quad y_{d_{i}}\left(\mathbf{f}^{T} \mathbf{w}_{d_{i}} \geq 1\right), \forall d_{i} \in \mathcal{D}^{L}$

$$
\begin{gathered}
y_{d_{j}}\left(\mathbf{f}^{T} \mathbf{w}_{d_{i}} \geq 1\right), \forall d_{j} \in \mathcal{D}^{U} \\
y_{d_{j}} \in\{-1,1\}, \forall d_{j} \in \mathcal{D}^{U} .
\end{gathered}
$$

Portanto, resolver este problema consiste em encontrar os rótulos para os documentos não rotulados de forma a obter uma margem de separação máxima entre os exemplos de classes diferentes. Assim como no $S V M$, o TSVM também permite a ocorrência de documentos no lado errado do hiperplano de forma induzir hiperplanos com maiores margens. Portanto, pode-se também utilizar as variáveis slack $(\xi)$ para lidar com dados não linearmente separáveis. Neste caso, o problema de otimização do TSVM é dado por:

$$
\begin{gathered}
\min _{\mathbf{f}, b} \frac{1}{2}(\mathbf{f} \cdot \mathbf{f})+C \sum_{d_{i} \in \mathcal{D}^{L}} \xi_{d_{i}}+C^{\prime} \sum_{d_{j} \in \mathcal{D}^{U}} \xi_{d_{j}} \\
\text { Sujeito a: } \quad y_{d_{i}}\left(\mathbf{f}^{T} \mathbf{w}_{d_{i}} \geq 1-\xi_{d_{i}}\right), \forall d_{i} \in \mathcal{D}^{L} \\
y_{d_{j}}\left(\mathbf{f}^{T} \mathbf{w}_{d_{i}} \geq 1-\xi_{d_{j}}\right), \forall d_{j} \in \mathcal{D}^{U} \\
y_{d_{j}} \in\{-1,+1\}, \forall d_{j} \in \mathcal{D}^{U} \\
\xi_{d_{i}} \geq 0, \forall d_{i} \in \mathcal{D}^{L} \\
\xi_{d_{j}} \geq 0, \forall d_{j} \in \mathcal{D}^{U}
\end{gathered}
$$

Os parâmetros $C$ e $C^{\prime}$ permitem um balanceamento entre o tamanho da margem e o erro de classificação dos documentos rotulados e não rotulados respectivamente. Também podem ser usados kernels no TSVM, assim como no SVM, sem alterar o problema de otimização.

Devido à restrição de que $y_{o_{j}}$ tenha apenas valores inteiros, o problema de otimização do TSVM é não convexo. Em Joachims (2006) é retratado que as abordagens para obtenção 
do estado ótimo global (Vapnik e Sterin, 1977; Bennett e Demiriz, 1998) são capazes de classificar poucos documentos não rotulados, em torno de 100 documentos, em tempo razoável. Soluções envolvendo busca local ou relaxamento do problema de otimização são utilizadas para encontrar uma solução ótima local (Bie e Cristianini, 2003; Demiriz et al., 1999; Joachims, 1998) e permitir classificar uma grande quantidade de documentos não rotulados em tempo razoável. Nesta tese foi utilizada a solução apresentada por Joachims (1998), a qual foi utilizada para a classificação transdutiva de textos e executa um processo de busca local no espaço de hipóteses para os rótulos dos documentos não rotulados. A cada passo da busca o algoritmo seleciona dois documentos, um positivo e um negativo que encontram-se do lado errado do hiperplano, e troca seus rótulos. Essa troca garante uma estrita diminuição do erro de classificação nas iterações consecutivas. Além disso, o algoritmo inicia com um pequeno valor de $C^{\prime}$ que é incrementado durante as iterações do processo de otimização até atingir o valor definido pelo usuário. Isso faz com que mais documentos possam estar do lado errado do hiperplano nas primeiras iterações e menos documentos do lado errado nas últimas iterações.

No Algoritmo 9 é apresentado o pseudocódigo da solução de otimização do TSVM proposta por Joachims (1998). Segundo Zhu e Goldberg (2009); Joachims (1998), empiricamente o algoritmo TSVM gera soluções desbalanceadas. Para isso, pode-se restringir que as definições das classes dos documentos não rotulados tenham a mesma proporção dos documentos rotulados.

A premissa do método TSVM é que as classes são bem separadas, de forma que o hiperplano de separação esteja em uma região de baixa densidade. Caso essa premissa não seja válida, o método TSVM pode apresentar performances de classificação insatisfatórias.

\subsubsection{Aprendizado Transdutivo em Redes}

Devido as fortes premissas dos algoritmos baseados no modelo-espaço vetorial, as dificuldades da resolução de problemas de otimização por parte de alguns algoritmos e as próprias deficiências de algoritmos baseados no modelo espaço-vetorial, como alta dimensionalidade e a independência das entidades que compões as coleções de textos, levaram a busca por outros algoritmos e representações para realizar o aprendizado transdutivo.

Algoritmos de aprendizado transdutivo baseados em redes surgiram como uma alternativa aos algoritmos baseados no modelo espaço-vetorial e demonstraram sanar as deficiências apresentadas acima. A classificação transdutiva utilizando redes visa classificar objetos não rotulados considerando informações provindas dos objetos vizinhos, como os atributos (Jensen et al., 2004; Oh et al., 2000; Chakrabarti et al., 1998) ou as próprias informações de classe $^{2}$ (Zhou et al., 2009; Macskassy e Provost, 2007; Chapelle et al.,

\footnotetext{
${ }^{2}$ A classificação dos objetos de uma rede considerando unicamente a informação de classe dos objetos e suas relações é também conhecida por classificação univariada (do inglês univariate network classification) (Macskassy e Provost, 2007).
} 


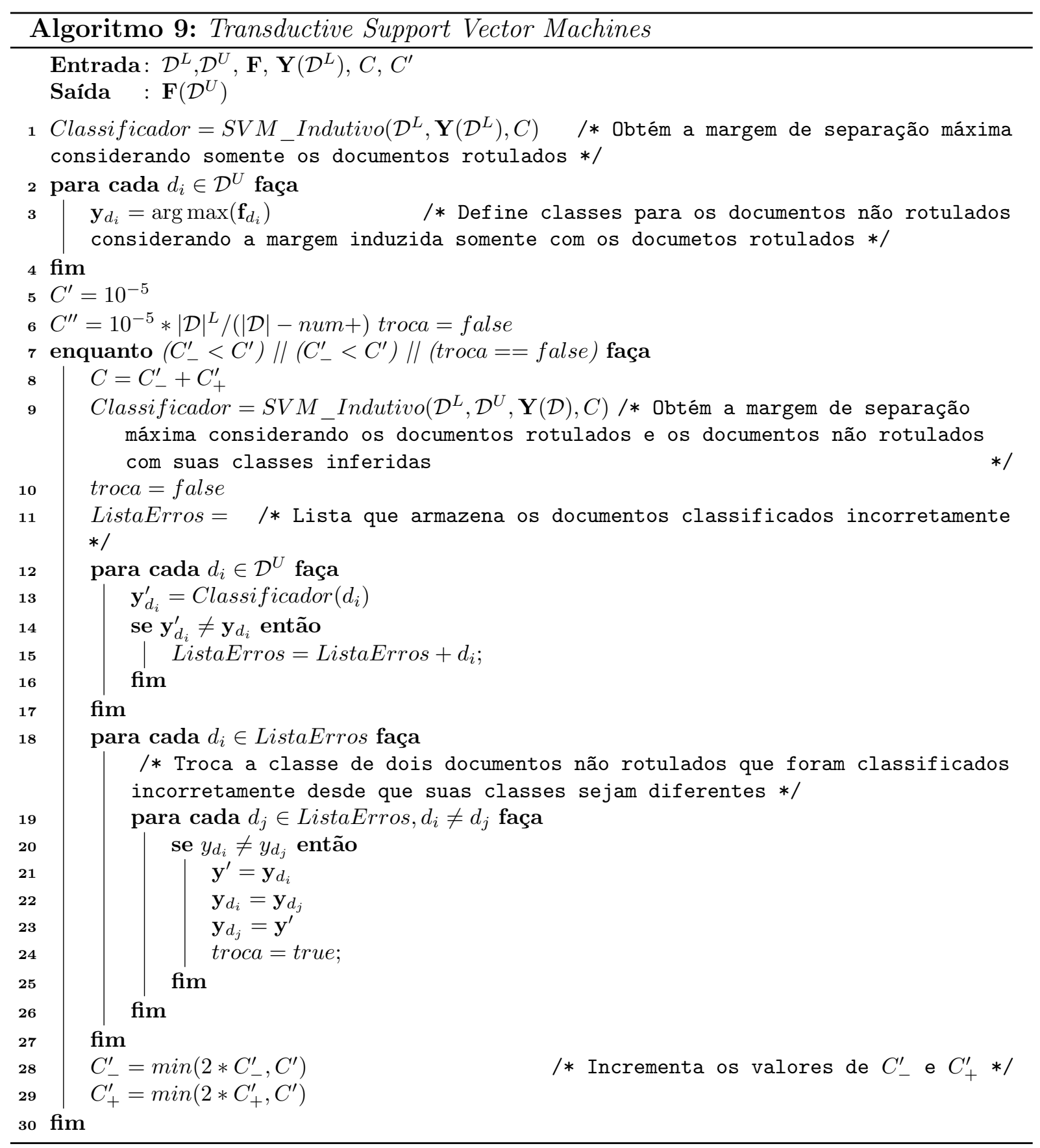

2006). Entretanto, diversos trabalhos da literatura demonstraram que a utilização das informações de classe dos objetos vizinhos são suficientes para obter uma performance de classificação tão boa quanto a utilização dos atributos dos objetos vizinhos (Liu et al., 2009a; Macskassy e Provost, 2007; Belkin et al., 2006; Angelova e Weikum, 2006; Zhou et al., 2004; Zhu et al., 2003a; Joachims, 2003; Macskassy e Provost, 2003; Blum e Chawla, 2001). Neste projeto foram focados métodos de classificação univariada uma vez que apresentam melhor performance de classificação além de um menor tempo computacional.

As redes que representam o conjunto de dados, como as apresentadas na Seção 2.3.3, são compostas por objetos rotulados e não rotulados. No caso do tipo de conjunto de dados tratado nesta tese, usualmente têm-se documentos como objetos rotulados. Uma vez gerada a rede, e considerando que esta possui alguns objetos rotulados, pode-se 
realizar a classificação transdutiva considerando dois tipos de estratégias: (i) classificação coletiva e (ii) regularização. A primeira é oriunda da área de Aprendizado Relacional (Getoor e Taskar, 2007), e normalmente considera redes geradas por informações explícitas, como hyperlinks e citações, enquanto que a segunda é oriunda da área de Aprendizado Semissupervisionado, na qual a rede pode ser gerada a partir de qualquer conjunto de dados, e por isso têm ganhado mais destaque nos últimos anos. Apesar disso, nas próximas seções serão apresentados algoritmos referentes às duas áreas, uma vez que há uma grande intersecção entre elas, além do fato de que as primeiras pesquisas sobre classificação transdutiva de textos representados em redes referem-se à classificação coletiva.

\section{Classificação Coletiva}

Os trabalhos de classificação coletiva são os primeiros trabalhos da literatura para classificação de textos utilizando redes, na qual normalmente as redes são direcionadas e as relações entre os objetos são geradas por meio de informações explícitas (Macskassy e Provost, 2007; Lu e Getoor, 2003; Oh et al., 2000; Chakrabarti et al., 1998). Macskassy e Provost (2007) definem que a classificação coletiva é composta por 3 componentes:

1. Modelo não relacional: consiste em utilizar as informações dos atributos dos objetos rotulados para estimar a informação de classe inicial dos objetos não rotulados. O modelo não relacional é tipicamente gerado por algoritmos de aprendizado de máquina indutivos supervisionados e baseados no modelo espaço-vetorial. O objetivo é definir um estado inicial da rede para aplicar o modelo relacional e consecutivamente para a inferência coletiva, que irão "refinar" ou inferir as classes dos objetos a partir do estado inicial da rede.

2. Modelo relacional: o modelo relacional faz uso das informações de classe dos objetos relacionados e pode considerar também os atributos dos objetos vizinhos para inferir a informação de classe dos objetos da rede. Pode-se considerar apenas os vizinhos diretos ou uma cadeia de vizinhos.

3. Inferência coletiva: determina como as informações oriundas dos objetos vizinhos serão utilizadas iterativamente para definir as informações de classe dos objetos da rede de forma consistente.

Na Figura 4.4 é apresentada uma ilustração gráfica da classificação coletiva. A classificação coletiva pode ser vista como um processo de refinamento das informações de classe atribuídas aos objetos da rede por um algoritmo de aprendizado de máquina não relacional (por exemplo os apresentados na Seção 3.2.1), sendo que vários estudos indicam que a classificação coletiva pode aumentar significativamente a acurácia de classificação quando comparada a classificação indutiva supervisionada baseada no modelo espaço-vetorial.

A classificação coletiva, independente da instanciação do framework, é probabilística. O objetivo é definir a probabilidade de um objeto $o_{i}$ pertencer a classe $c_{j}$ considerando a 


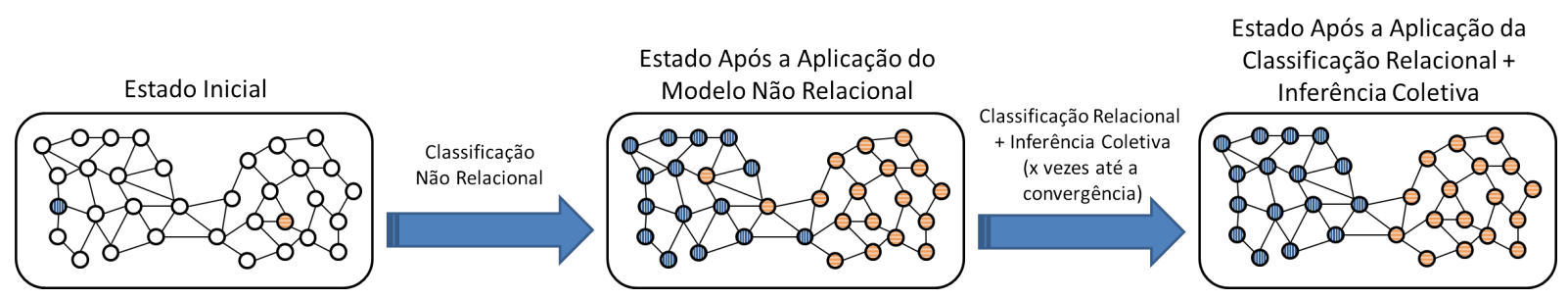

Figura 4.4: Ilustração da classificação coletiva.

probabilidade dos vizinhos pertencerem a esta classe. Portanto, os vetores de informação de classe dos objetos da rede irão conter as probabilidades desses objetos pertencerem às classes, isto é, $f_{o_{i}, c_{j}}=P\left(y_{o_{i}}=c_{j} \mid \Gamma\left(o_{i}\right)\right)$, na qual $\Gamma\left(o_{i}\right)$ é uma função que retorna os vizinho do objeto $o_{i}$. Normalmente utiliza-se apenas os vizinhos diretos, também conhecidos como vizinhos de primeira ordem, para a classificação, uma vez que cadeias de vizinhos não influenciam positivamente a classificação (Macskassy e Provost, 2007; Chakrabarti et al., 1998).

Diversos trabalhos da literatura são instanciações dos 3 componentes do framework para classificação coletiva apresentado nesta seção (Angelova e Weikum, 2006; Lu e Getoor, 2003; Oh et al., 2000; Chakrabarti et al., 1998).

Em Macskassy e Provost (2007) são apresentados 4 modelos de classificação relacional que fazem uso apenas da informação de classe dos objetos e que podem ser entendidos como extensões de algoritmos de classificação baseados no modelo espaço-vetorial que foram adaptados para a classificação em redes, ou que esses modelos correspondem à versões univariadas de algoritmos de classificação coletiva que considerando tanto as informações de classe quanto os atributos dos objetos vizinhos para realizar a classificação. Os 4 modelos relacionais apresentados em Macskassy e Provost (2007) são: (i) Weighted Vote Relational Neighbor, (ii) Class Distribution Relational Neighbor, (iii) Network-only Bayes Classifier, e (iv) Network-only Link-Based Classification.

O modelo Weighted Vote Relational Neighbor ( $W V R N)$ pode ser considerado como uma extensão do algoritmo $k$ - $N N$ com peso no voto, no qual $\mathbf{f}_{o_{i}}$ é dado pela média ponderada das informações de classe dos vizinhos. Portanto, a informação de classe de um objeto $o_{i}$ para a classe $c_{j}$ é dada por:

$$
\mathbf{f}_{o_{i}}=\frac{\sum_{o_{k} \in \Gamma\left(o_{i}\right)} w_{o_{i}, o_{k}} \mathbf{f}_{o_{k}}}{\sum_{o_{k} \in \Gamma\left(o_{i}\right)} w_{o_{i}, o_{k}}} .
$$

O modelo Class Distribution Relational Neighbor (CDRN) é baseado no algoritmo de classificação Rocchio. No $C D R N$ é gerado um vetor que representa o objeto a ser classificado (vetor de classe) e são gerados vetores que representam as classes (vetores de referência). O vetor de classe de um objeto $o_{i}\left(\mathbf{v c}_{o_{i}}\right)$ é dado pela soma das informações de classe dos objetos vizinhos ponderadas pelos pesos das relações, ou seja 


$$
\mathbf{v c}_{o_{i}}=\sum_{o_{k} \in \Gamma\left(o_{i}\right)} w_{o_{i}, o_{k}} \mathbf{f}_{o_{k}}
$$

O vetor de referência de uma classe $c_{j}$ é dada pela média das informações de classe dos objetos de treinamento que pertencem à classe, isto é

$$
\mathbf{v r}_{c_{j}}=\frac{1}{\left|\mathcal{O}_{c_{j}}^{L}\right|} \sum_{o_{i} \in \mathcal{O}_{c_{j}}^{L}} \mathbf{v c}_{o_{i}}
$$

na qual $\mathcal{O}_{c_{j}}^{L}$ representa o conjunto de objetos rotulados que pertence à classe $c_{j}$. É então gerado um vetor de similaridade para o objeto $o_{i}\left(\mathbf{s i m}_{o_{i}}\right)$ o qual armazena a similaridade entre $\mathbf{v c}_{o_{i}}$ e os vetores de referências das classes $\left(\mathbf{v r}_{c_{j}}, \forall c_{j} \in \mathcal{C}\right)$. O vetor de similaridades é então normalizado e seus valores são utilizados para definir $\mathbf{f}_{o_{i}}$.

No modelo Network-only Bayes Classifier $(N B C)$ é utilizado o algoritmo Multinomial Naive Bayes para a classificação dos objetos da rede. O $N B C$ é baseado no algoritmo para classificação de hipertextos apresentado em Chakrabarti et al. (1998), porém não são considerados os termos dos documentos vizinhos para realizar a classificação. A informação de classe de um objeto $o_{i}$ para a classe $c_{i}$ utilizando a rede e a regra de Bayes é dada por

$$
f_{o_{i}, c_{j}}=P\left(y_{o_{i}}=c_{j} \mid \Gamma\left(o_{i}\right)\right)=\frac{P\left(\Gamma\left(o_{i}\right) \mid c_{j}\right) P(c)}{P\left(\Gamma\left(o_{i}\right)\right)}
$$

na qual

$$
P\left(\Gamma\left(o_{i}\right) \mid c_{j}\right)=\prod_{o_{k} \in \Gamma\left(o_{i}\right)} f_{o_{k}, c_{j}}^{w_{o_{i}, o_{j}}}
$$

O modelo Network-only Link-based Classification (NLB) é baseado no algoritmo Linkbased Classification (Lu e Getoor, 2003). A diferença é que no primeiro são utilizados apenas os atributos das relações enquanto que no segundo são atualizados atributos das relações e dos textos da coleção. Lu e Getoor (2003) definem 3 tipos de atributos de relações: (i) mode-link, que corresponde ao valor da classe mais frequente nos vizinhos (ii) binary-link, que apresenta o valor 1 para cada classe que ocorre na vizinhança de um objeto, e (iii) cont-link, que corresponde à frequência das classes dos vizinhos. É então criado um vetor de atributos de relações para cada objeto vizinho e é utilizada regressão logística para construir um modelo de classificação, o qual é utilizado definir os valores de informação de classe dos objetos da rede.

Ao considerar a informação de classe de um objeto $o_{i}$ para definir a informação de classe de um objeto $o_{j}$ nos modelo relacionais, o objeto $o_{i}$ poderá, posteriormente, ter sua informação de classe alterada devido à ordem em que é feita a inferência das informações de classe dos objetos. Com isso, a alteração da informação de classe de um objeto $o_{i}$ implica na alteração da informação de classe do objeto $o_{j}$. Portanto, são necessários métodos para definir a ordem ou como as informações de classe dos objetos serão utilizadas para gerar um estado consistente, isto é, um estado em que as informações de classe dos objetos convirjam. 
Além disso, também é necessário definir se as inferências das informações de classe dos objetos da rede será do tipo hard ou soft, isto é, se será considerado apenas o maior valor da informação de classe do objeto, definindo o valor 1 para a classe correspondente e 0 para as demais, ou se serão mantidos os valores de informação de classe definidas pelo modelo relacional.

Os métodos de inferência coletiva são utilizados para definir como as informações de classe dos objetos serão utilizadas para definir um estado consistente para a classificação dos objetos da rede. Em todos os algoritmos de inferência coletiva são definidas informações de classe para os objetos não rotulados iterativamente, até que não haja alteração nas informações de classe dos objetos não rotulados ou até um número fixo de iterações. Em Macskassy e Provost (2007) são apresentados 3 métodos de inferência coletiva que são os mais utilizados na literatura e que possuem melhor desempenho prático: (i) Iterative Classification, (ii) Gibbs Sampling, e (iii) Relaxation Labeling.

No método Iterative Classification (IC) (Xue et al., 2004; Lu e Getoor, 2003), após definir as informações de classe para um objeto $o_{i}$ utilizando um modelos relacional, essas são substituídas pelo valor 1 na posição correspondente ao maior valor e 0 nas demais posições. No Algoritmo 10 é apresentado o pseudocódigo do método IC.

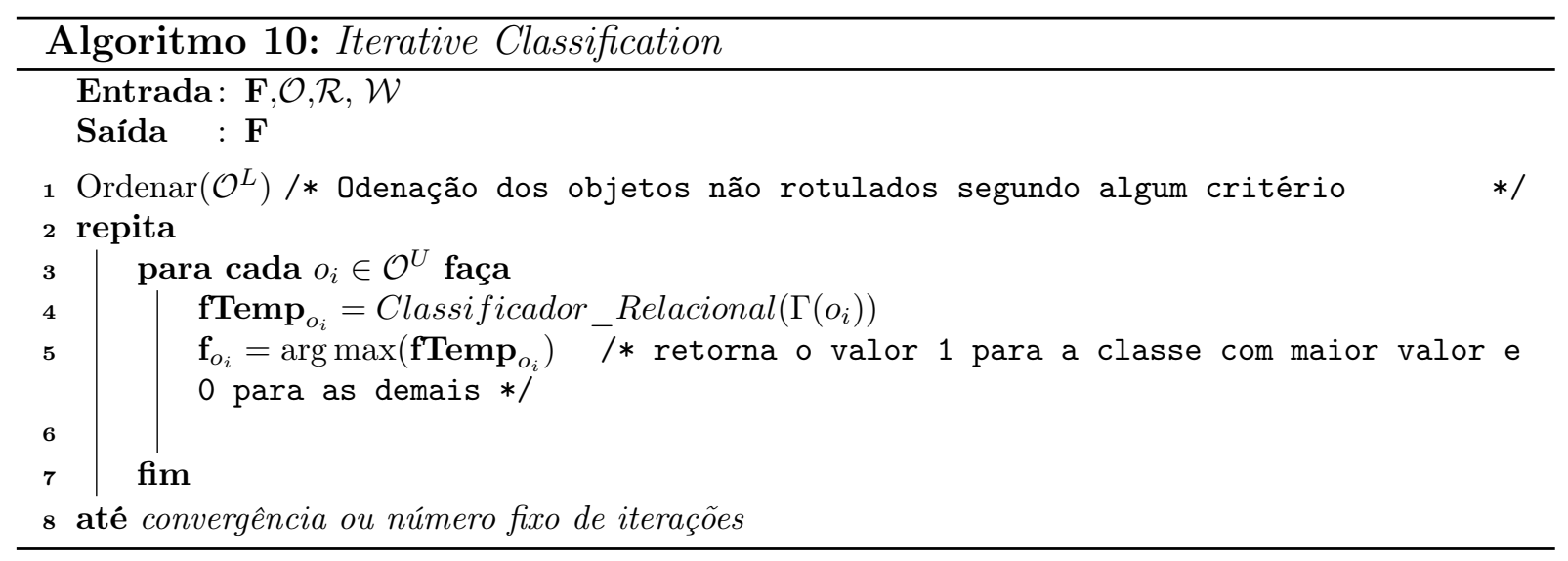

O método Gibbs Sampling (GS) (Geman e Geman, 1984) é considerado como um dos algoritmos mais acurados para aproximação de inferências (Sen et al., 2008). Assim como no $I C$, no método $G S$ são utilizadas as informações de classe corrente dos objetos na classificação relacional. A diferença é que são mantidas as informações de classe dos objetos e não é considerado somente o maior valor do vetor de informações de classe. Outra diferença é que são mantidos contadores dos objetos para as classes, os quais contabilizam qual a classe possuía o maior valor de informação de classe a cada iteração do algoritmo. No final do processo iterativo, as informações de classe dos objetos são substituídas pelas contagens. Outra característica pertinente ao GS é o "período de aquecimento", que consiste na execução das iterações do $G S$ sem manter as contagens das classes com maior valor confiança a cada iteração. No Algoritmo 11 é apresentado o pseudocódigo do método $G S$. 


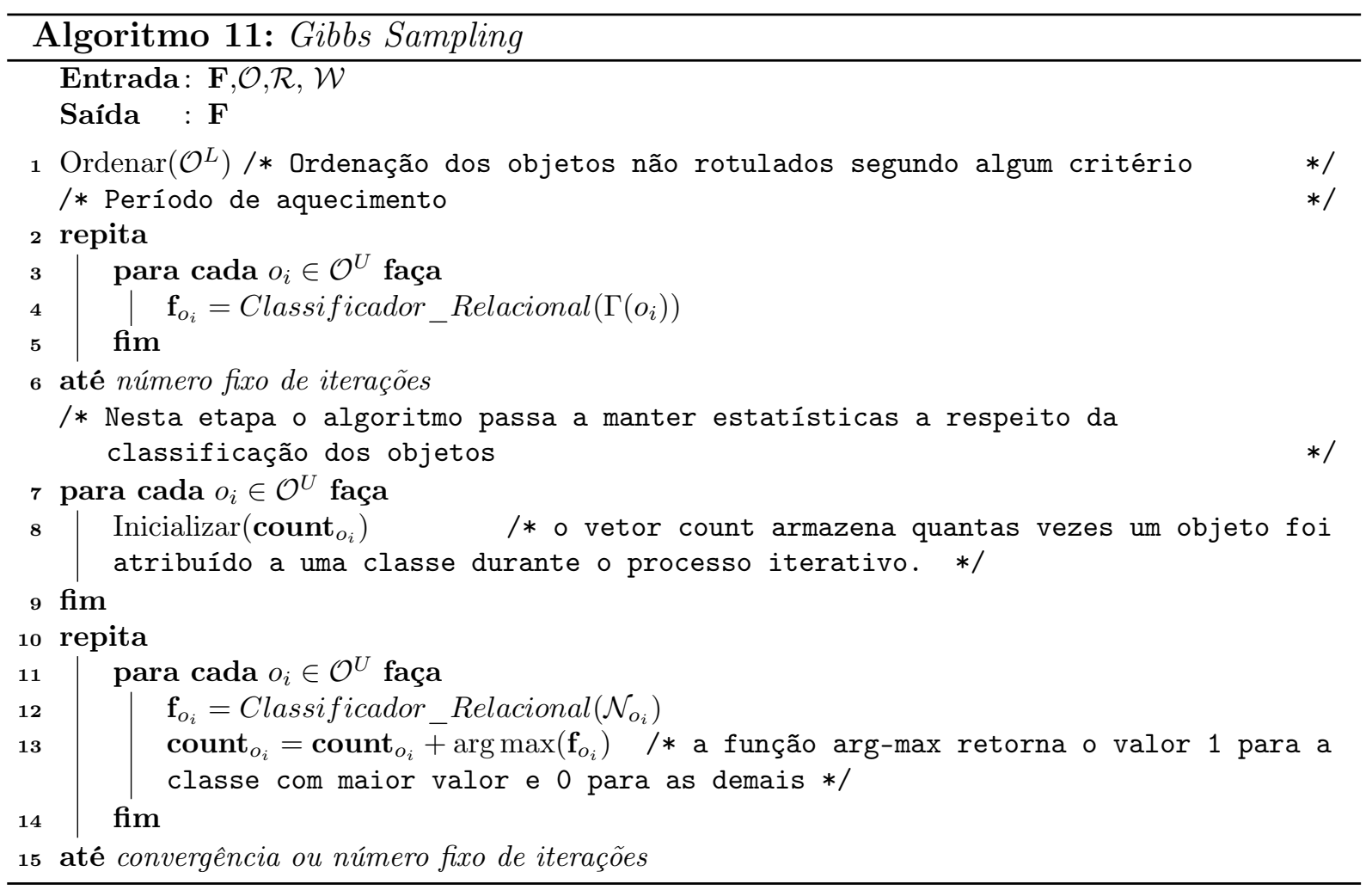

Vale ressaltar que a ordem com que os objetos não rotulados são considerados para a atualização da informação de classe pode ter impacto na classificação utilizando tanto $G S$ quanto $I C$, uma vez que ambos fazem uso da informações de classe corrente dos objetos. Pode-se ordenar os objetos de acordo com o número de relações (Oh et al., 2000), valores das informações de classe dos objetos (Neville e Jensen, 2000), número de diferentes categorias em que um objeto está conectado (Lu e Getoor, 2003), ou aleatoriamente. Nos experimentos realizados em Lu e Getoor (2003), a ordenação aleatória apresentou resultados tão bons quanto os demais tipos de ordenação.

No método Relaxation Labeling ( $R L$ ) (Angelova e Weikum, 2006; Chakrabarti et al., 1998) são consideradas as informações de classe dos objetos obtidas em uma iteração anterior no modelo relacional. Portanto, não é necessária a ordenação dos objetos, diferindo assim dos métodos dos métodos $I C$ e $G S$. Além disso, o método $R L$ mantém as informações de classe inferidas por um modelo relacional no processo iterativo e as retorna no final, enquanto que $I C$ mantém apenas o arg-max como informação de classe durante o processo iterativo, e $G S$ considera o número de atribuições a cada classe para definir a informação de classe de um objeto. No Algoritmo 12 é apresentado o pseudocódigo do método $R L$.

As informações de classe obtidas pelo método $R L$ apresentado no Algoritmo 12 podem não convergir e oscilar entre dois ou mais estados em iterações consecutivas. Macskassy e Provost (2007) propõem o uso da técnica de têmpera simulada para solucionar o problema de convergência. Neste caso, a atualização da informação de classe de um objeto $o_{i}$ é dada por: 


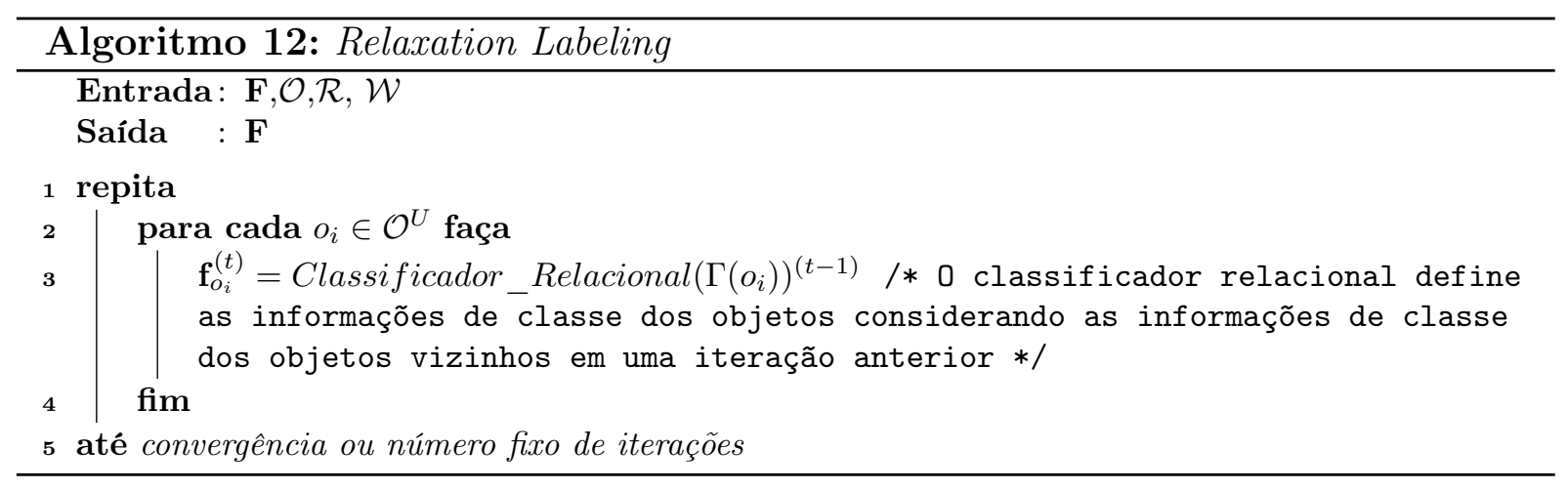

$$
\mathbf{f}_{o_{i}}^{(t)}=\beta^{(t)} \cdot \text { Classificador_Relacional }\left(\Gamma\left(o_{i}\right)\right)^{(t-1)}+\left(1-\beta^{t}\right) \cdot \mathbf{f}_{o_{i}}^{(t-1)},
$$

na qual

$$
\beta^{(t)}=\beta^{(t-1)} \cdot \alpha
$$

e $0 \leq \beta^{(0)} \leq 1$, e $0<\alpha<1$ é uma constante de decaimento. A proposta da têmpera simulada faz com que a cada iteração o algoritmo dê mais peso à informação de classe do próprio objeto na iteração anterior do que a informação de classe oriunda dos objetos vizinhos.

Os modelos relacionais juntamente com os métodos de inferência coletiva apresentados acima são tipicamente aplicados à redes homogêneas. Entretanto, nos últimos anos, detectou-se a possibilidade da modelagem de alguns conjuntos de dados em redes heterogêneas, possibilitando assim a representação de diferentes objetos e relações para obter uma melhor estruturação do conjunto de dados. Com isso, instanciações da classificação coletiva considerando diferentes tipos de objetos e as semânticas das diferentes relações surgiram para lidar com tais tipos de rede.

Por exemplo, em Xue et al. (2004) é proposta a abordagem Iterative Reinforcement Categorization $(I R C)$ para classificação coletiva em redes bipartidas. A rede é composta por um conjunto de objetos "alvo" $(\mathcal{A})$, que correspondem ao conjunto de objetos que se deseja classificar, e objetos "ponte" $(\mathcal{P})$, que correspondem a objetos que fazem a ligação entre dois objetos em $\mathcal{A}$. a abordagem IRC propõe o uso de Multinomial Nä̈ve Bayes ou Support Vector Machines como modelos não relacionais para definir informações de classe iniciais para os objetos alvo não rotulados $\left(\mathcal{A}^{U}\right)$, Weighted Vote Relational Neighbor como modelo relacional, e uma combinação de Iterative Classification e Relaxation Labeling como método de inferência coletiva.

É necessária a definição de 4 parâmetros para a inferência coletiva na abordagem IRC: (i) $\alpha$, que é o peso dado aos objetos em $\mathcal{A}^{L}$ na inferência das informações de classe dos objetos em $\mathcal{P}$; (ii) $\beta$, peso dado aos objetos em $\mathcal{A}^{U}$ na inferência das informações de classe dos objetos em $\mathcal{P}$; (iii) $\alpha^{\prime}$, peso dado a informação de classe do próprio objeto (em $\mathcal{A}^{U}$ ) na 
iteração anterior; e (iv) $\beta^{\prime}$, peso dado aos objetos em $\mathcal{P}$ na inferência das informações de classe dos objetos em $\mathcal{A}^{U}$. No Algoritmo 13 é apresentado o processo de inferência coletiva da abordagem IRC.

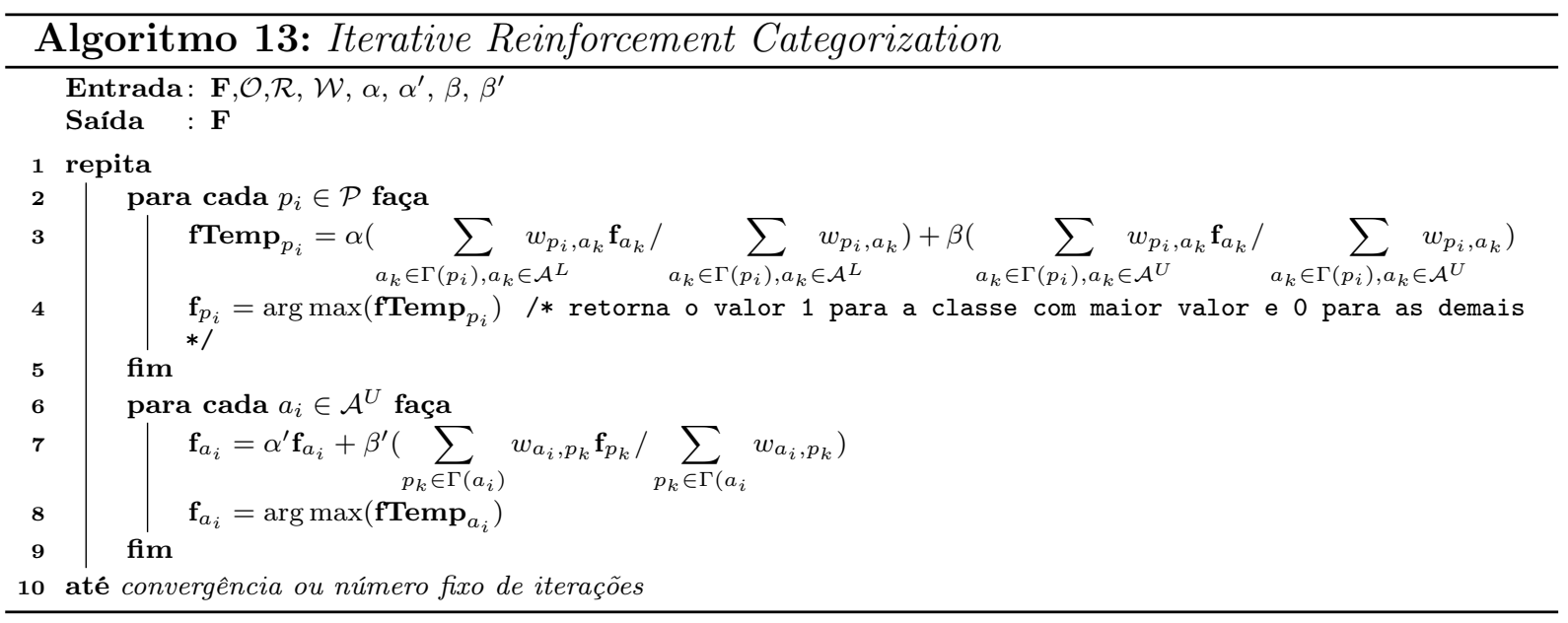

Outro exemplo de classificação coletiva em redes heterogêneas é apresentado em Angelova et al. (2012). Neste trabalho os autores apresentam o algoritmo Graffiti ${ }^{3}$, no qual o modelo não relacional corresponde ao algoritmo Naïve Bayes, o modelo relacional é baseado em caminhadas aleatórias, que pode ser entendido com uma versão do modelo Weighted Vote Relational Neighbor, e a inferência coletiva é realizada pelo método Relaxation Labeling.

A caminhada é executada de forma semelhante ao do algoritmo PageRank (Page et al., 1999b). Porém, em uma rede heterogênea, a transição de um objeto $o_{i}$ para um objeto $o_{k}$ deve considerar: (i) se $o_{k}$ pertence a mesma classe de $o_{i}$, (ii) se $o_{k}$ é um vizinho direto e é do mesmo tipo de $o_{i}$, se (iii) se $o_{k}$ é do mesmo tipo mas está conectado a $o_{i}$ por um objeto de outro tipo, e (iv) se $o_{k}$ pertence a uma classe diferente de $o_{i}$. Para cada tipo de transição, há um parâmetro de atenuação ( $q, \alpha, \beta$ ou a combinação destes). Com isso, a classe de um objeto $o_{i}$ para uma classe $c_{j}$ em um tempo $t$ utilizando o algoritmo Graffiti é dada por:

$$
\begin{gathered}
f_{o_{i}, c_{j}}^{(t)}=(1-q) \frac{y_{o_{i}, c_{j}}}{|\mathcal{O}|}+q \cdot(1-\alpha) \cdot \sum_{o_{k} \in \Gamma\left(o_{l}\right), e_{o_{l}, o_{i} \in \mathcal{E}}} \frac{f_{o_{k}, c_{j}}^{(t-1)}}{\left|\Gamma\left(o_{k}\right)\right| \cdot\left|\Gamma\left(o_{l}\right)^{\text {out }}\right|}+ \\
q \cdot \alpha \cdot(1-\beta) \cdot \sum_{o_{k} \in \Gamma\left(o_{l}\right), e_{o_{l}, o_{i}} \in \mathcal{E}} \sum_{c_{m} \in \mathcal{C}} \frac{f_{o_{k}, c_{m}}^{(t-1)}}{\left|\Gamma\left(o_{k}\right)\right| \cdot\left|\Gamma\left(o_{l}\right)^{\text {out }}\right|}+ \\
q \cdot \alpha \cdot \beta \cdot \sum_{o_{k} \in \Gamma\left(o_{i}\right)} \sum_{c_{m} \in \mathcal{C}} \frac{f_{o_{k}, c_{m}}^{(t-1)} y_{o_{k}, c_{m}}}{\left|\Gamma\left(o_{k}\right)\right|}
\end{gathered}
$$

na qual $\Gamma\left(o_{l}\right)^{\text {out }}$ representa o conjunto de objetos apontados pelo objeto $o_{l}$.

\footnotetext{
${ }^{3} \mathrm{O}$ nome Graffiti faz uma analogia ao fato de que a inferência das informações de classe pode ser vista como um processo de colorir dos nós da rede, no qual cada cor corresponde à uma classe.
} 
Vale ressaltar que os algoritmos de classificação possuem um custo adicional em relação aos algoritmos de regularização, que serão apresentados na próxima seção, correspondente à indução do modelo não relacional e a classificação dos exemplos não rotulados da rede para a definição das informações de classe iniciais dos objetos. Além disso, há a necessidade de todos os objetos da rede possuírem um conjunto de atributos para permitir a indução do modelo não relacional. Para alguns tipos de objetos, como autores em uma rede de informação bibliográfica, esse tipo de informação pode não ser trivial ou não possibilitar a extração de padrões bem definidos.

Vale ressaltar também que apesar da utilização da rede para "refinar" as informações de classe atribuídas pelo modelo não relacional, a indução do modelo não relacional com poucos exemplos pode apresentar uma baixa performance de classificação, sendo que o refinamento provido pela estrutura da rede pode não ser suficiente para melhorar a performance. Em Macskassy e Provost (2007) é retificada essa hipótese, sendo apresentada uma comparação entre algoritmos de classificação coletiva e um algoritmo baseado em regularização, na qual a regularização apresentou uma performance de classificação superior aos algoritmos de classificação coletiva. Com isso, nota-se nos últimos anos um maior uso de algoritmos baseados em regularização para realizar a classificação transdutiva (Liu et al., 2009a; Mei et al., 2008b; Camps-Valls et al., 2007; Goldberg e Zhu, 2006; Niu et al., 2005; Levin et al., 2004). Porém, pode-se notar algumas semelhanças nas soluções desses algoritmos em relação aos modelos relacionais e modelos de inferência coletiva. Nas próximas seções serão apresentados detalhes e algoritmos referentes à classificação transdutiva baseada em regularização.

\section{Regularização}

A classificação transdutiva baseada em regularização tem como objetivo minimizar uma função de custo que satisfaz duas premissas: (i) as informações de classe de objetos vizinhos devem ser semelhantes; e (ii) as informações de classe dos objetos rotulados atribuídas durante o processo de classificação devem ser semelhantes as informações de classe reais. Segundo Zhu (2005a), essas duas premissas podem ser expressadas em um framework de regularização, na qual o primeiro termo é a função de regularização e o segundo termo é a função de perda. Esse framework pode ser expresso pela seguinte função de custo (Delalleau et al., 2005):

$$
Q(\mathbf{F})=\frac{1}{2} \sum_{o_{i}, o_{j} \in \mathcal{O}} w_{o_{i}, o_{j}} \Omega\left(\mathbf{f}_{o_{i}}, \mathbf{f}_{o_{j}}\right)+\mu \sum_{o_{i} \in \mathcal{O}^{L}} \Omega^{\prime}\left(\mathbf{f}_{o_{i}}, \mathbf{y}_{o_{i}}\right)
$$

na qual $\mu$ é o parâmetro de regularização que define a importância que será dada a cada uma das premissas, e $\Omega(\ldots)$ e $\Omega^{\prime}(\ldots)$ são funções de distância. Portanto, para minimizar a função da Equação 4.21, quanto maior o peso da relação entre dois objetos menor deve ser a distância entre os vetores de informação de classe. Isso faz com que localmente os objetos altamente relacionados pertençam a mesma classe e globalmente os objetos pertencentes 
a uma mesma estrutura ou grupo de objetos também pertençam à mesma classe (Liu e Chang, 2009).

Os algoritmos baseados em regularização se diferem nas instanciações da função de similaridade e dos valores de $\mu$. Normalmente classificação transdutiva baseada em regularização é realizada em redes não direcionadas, nas quais as relações correspondem às similaridades entre os objetos da rede (Zhu e Goldberg, 2009; Chapelle et al., 2006; Zhou et al., 2004; Zhu et al., 2003a) ou baseadas na coocorrência dos objetos (Rossi et al., 2015b; Gao et al., 2012; Ji et al., 2010; Sun et al., 2009b). Além disso, como já ressaltado na seção anterior, há a necessidade de apenas alguns objetos da rede possuírem informações de classe iniciais (objetos rotulados) para iniciar o processo de classificação transdutiva baseada em regularização.

Pode-se resolver a solução fechada apresentada na Equação 4.21 ou pode-se utilizar soluções iterativas para gradualmente definir os valores das informações de classe dos objetos da rede. As soluções iterativas para minimizar a solução da Equação 4.21 são denominadas "propagação de rótulos", uma vez que iterativamente os objetos propagam suas informações de classe (rótulos) para os objetos vizinhos proporcionalmente ao peso de suas relações. Na Figura 4.5 é ilustrada a classificação por meio da propagação de rótulos. Vale ressaltar que a propagação de rótulos pode ser vista de forma semelhante ao método Relaxation Labeling, apresentado na seção anterior, uma vez que a definição das informações de classe em um tempo $t$ considera as informações de classe dos objetos relacionados em um tempo $t-1$.

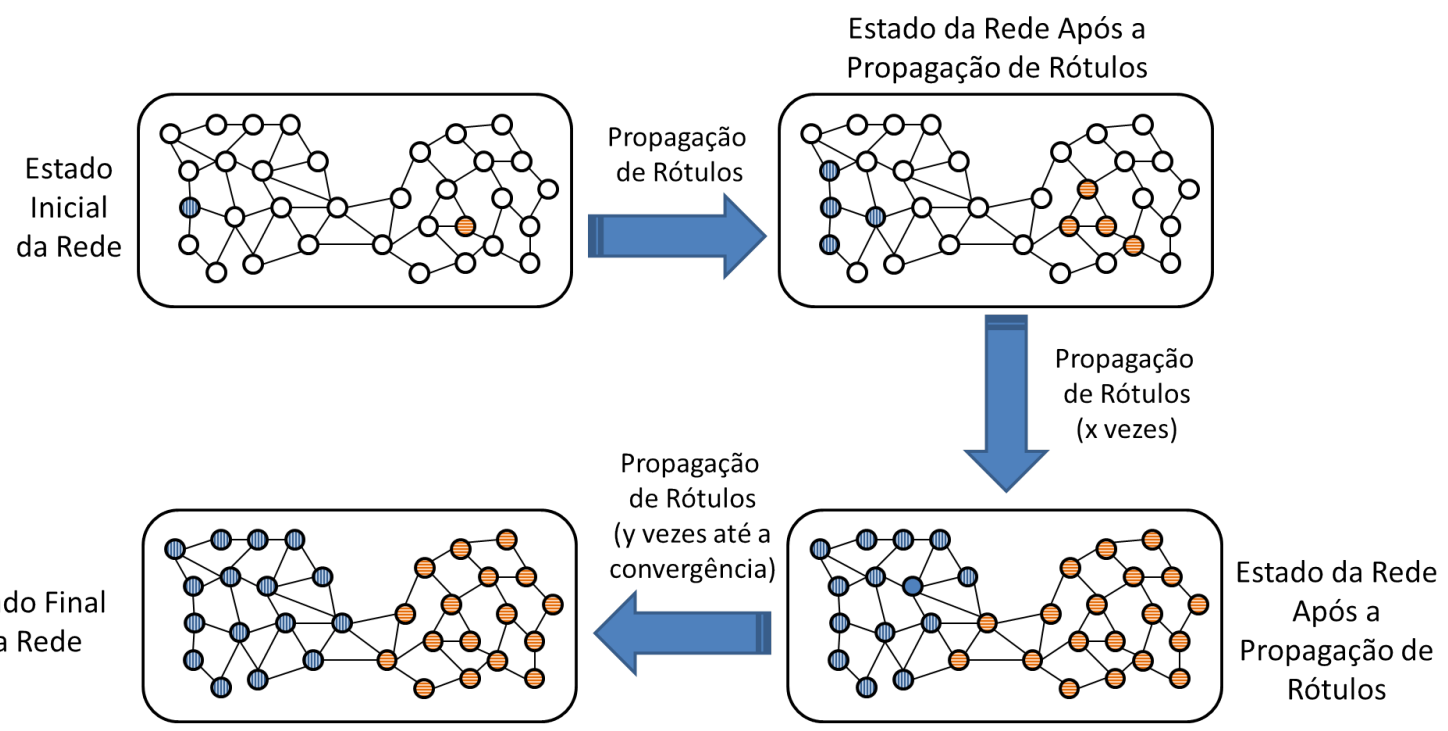

Figura 4.5: Ilustração da classificação transdutiva via propagação de rótulos.

Nesta tese foram considerados os algoritmos para classificação em redes homogêneas Min-Cut (Blum e Chawla, 2001), Gaussian Fields and Harmonic Functions (Zhu et al., 2003a) e Learning With Local and Global Consistency (Zhou et al., 2004), e para classificação em redes heterogêneas os algoritmos Tag-based Model (Yin et al., 2009b) e GNetMine (Ji et al., 2010). Outros algoritmos baseados em regularização não foram considerados uma 
vez que apresentam um número maior de parâmetros (Belkin et al., 2004, 2006; Liu e Chang, 2009) além de obterem performances de classificação próximas ou piores em relação aos algoritmos considerados nesta tese em diversas análises (de Sousa et al., 2013; Breve et al., 2012). Além disso, foram selecionados algoritmos baseados em regularização que possuam tanto versões para redes homogêneas quanto heterogêneas ou ainda algoritmos baseados em redes homogêneas mas que possam ser adaptados para redes heterogêneas. Isso permite uma comparação justa das performances de classificação obtidas utilizando diferentes redes, uma vez que estão sendo utilizados algoritmos de aprendizado de máquina com as mesmas características. Nas próximas seções são apresentados os detalhes dos algoritmos mais relevantes considerados para esta tese.

\section{Min-Cut}

Blum e Chawla (2001) propõem um algoritmo para classificar os objetos utilizando uma função de corte mínimo em redes (Min-Cut). O objetivo é gerar partições na rede eliminando um conjunto mínimo de relações que conectem objetos de classes diferentes, ou seja, minimizar

$$
\min \sum_{o_{i}, o_{j}, \mathbf{f}_{o_{i}} \neq \mathbf{f}_{o_{j}}} w_{o_{i}, o_{j}} .
$$

No final do particionamento, os vértices não rotulados que estiverem dentro de uma partição que contenha vértices da classe $c_{j}$ também serão rotulados com $c_{j}$. Com isso, a definição das informações de classe por meio do Min-Cut são do tipo hard, ou seja, é atribuído o valor 1 na posição correspondente a classe dos objetos da partição e zero nas demais classes. Portanto, não é possível obter a confiança de classificação de um objeto para cada classe ${ }^{4}$.

O algoritmo de corte mínimo pode ser visto como uma função de regularização minimizando a seguinte função:

$$
\begin{array}{cc} 
& Q(\mathbf{F})=\frac{1}{2} \sum_{o_{i}, o_{j} \in \mathcal{O}} w_{o_{i}, o_{j}}\left(\mathbf{f}_{o_{i}}-\mathbf{f}_{o_{j}}\right)^{2}+\lim _{\mu \rightarrow \infty} \mu \sum_{o_{i} \in \mathcal{O}^{L}}\left(\mathbf{f}_{o_{i}}-\mathbf{y}_{o_{i}}\right)^{2} \\
\text { Sujeito à: } \quad & y_{o_{i}, c_{j}}, f_{o_{i}, c_{j}} \in\{0,1\}, \forall o_{i} \in \mathcal{O} \text { e } \forall c_{j} \in \mathcal{C} .
\end{array}
$$

É utilizado $\lim _{\mu \rightarrow \infty} \mu$ para que seja satisfeita a restrição de que os os objetos rotulados devem manter suas informações de classe, isto é, $\mathbf{F}(\mathcal{D})^{L} \equiv \mathbf{Y}(\mathcal{D})^{L}$. Apesar de intuitivamente simples, o algoritmo Min-Cut tende a gerar cortes degenerados, isto é, tende a deixar poucos objetos em uma partição e muitos em outra (Zhu e Goldberg, 2009). Joachims (2003) propõem o corte normalizado (Shi e Malik, 2000) o qual tende a gerar

\footnotetext{
${ }^{4}$ Blum et al. (2004) propõem o uso diversas repetições do algoritmo de corte mínimo inserindo diferentes ruídos na redes para realizar a classificação do tipo soft, na qual o vetor f conterá a proporção de atribuições dos objetos a cada uma das classes nas diferentes repetições. Porém, segundo Zhu e Goldberg (2009), as informações de classe não são confiáveis uma vez que o para um mesmo conjunto de objetos rotulados o algoritmo Min-Cut pode gerar várias partições distintas.
} 
partições balanceadas. Entretanto, forçar o balanceamento das partições pode causar uma baixa performance de classificação em coleções naturalmente desbalanceadas. Além disso, experimentos realizados em Blum et al. (2004) empiricamente obtém resultados inferiores ao algoritmo Gaussian Fields and Harmonic Functions (Zhu et al., 2003a), apresentado na próxima seção.

\section{Gaussian Fields and Harmonic Functions}

Em Zhu et al. (2003a) é apresentado o algoritmo para classificação transdutiva em redes denominado Gaussian Field and Hamonic Functions (GFHF). O algoritmo GFHF é baseado em campos gaussianos (Rede Exp apresentada na Seção 2.3.2) e funções harmônicas. A função harmônica determina que a informação de classe de um objeto é dada pela média das informações de classe dos objetos vizinhos ponderada pelos pesos das conexões, ou seja

$$
\mathbf{f}_{o_{i}}=\frac{\sum_{o_{j} \in \mathcal{O}} w_{o_{i}, o_{j}} \mathbf{f}_{o_{j}}}{\sum_{o_{j} \in \mathcal{O}} w_{o_{i}, o_{j}}} .
$$

A função harmônica é aplicada somente a objetos não rotulados, e portanto, não há alteração da informação de classe dos objetos rotulados. O algoritmo GFHF pode ser instanciado como um algoritmo de regularização que minimiza a função

$$
Q(\mathbf{F})=\frac{1}{2} \sum_{o_{i}, o_{j} \in \mathcal{O}} w_{o_{i}, o_{j}}\left(\mathbf{f}_{o_{i}}-\mathbf{f}_{o_{j}}\right)^{2}+\lim _{\mu \rightarrow \infty} \mu \sum_{o_{i} \in \mathcal{O}^{L}}\left(\mathbf{f}_{o_{i}}-\mathbf{y}_{o_{i}}\right)^{2} .
$$

Novamente é utilizado $\lim _{\mu \rightarrow \infty}$ para que seja satisfeita a restrição de que os os objetos rotulados devem manter suas informações de classe reais durante o processo de classificação. A função apresentada na Equação 4.25 é semelhante a função de otimização do Min-Cut (Equação 4.23), porém, as informações de classe podem assumir valores reais. Este tipo relaxamento faz com que exista uma solução única globalmente ótima para $\mathbf{F}$ (Zhu e Goldberg, 2009). Vale ressaltar que apesar da modelagem do conjunto de dados em uma rede Exp ter sido definida na proposta do algoritmo GFHF, a classificação transdutiva por meio da minimização da função apresentada na Equação 4.25 pode ser aplicada considerando conjuntos de dados representados em outros tipos de rede, como os apresentados na Seção 2.3.2.

Em Zhu (2005b) é apresentado o algoritmo Label Propagation (LP) para minimizar iterativamente a função apresentada na Equação 4.25. A minimização é feita por meio da resolução da equação matricial $\mathbf{F}=\mathbf{P} \mathbf{F}$ iterativamente até a convergência dos valores da matriz $\mathbf{F}$. A matriz $\mathbf{P}$ possui tamanho $|\mathcal{O}| \times|\mathcal{O}|$ na qual uma célula $p_{o_{i}, o_{j}}$ contém a probabilidade de ocorrer uma conexão entre um objeto $o_{i}$ e um objeto $o_{j}$, e é dada por

$$
\mathbf{P}=\mathbf{D}^{-1} \mathbf{W}
$$


na qual $\mathbf{D}$ é uma matriz diagonal de tamanho $|\mathcal{O}| \times|\mathcal{O}|$ em que cada célula da diagonal contém o grau do nó, ou seja, $d_{o_{i}, o_{i}}=\sum_{o_{j} \in \mathcal{O} w_{o_{i}, o_{j}}}$, e o valores das outras células são iguais a 0. A multiplicação da matriz $\mathbf{F}$ pela matriz $\mathbf{P}$ corresponde à Equação 4.24. No Algoritmo 14 é apresentado o pseudocódigo do algoritmo Label Propagation.

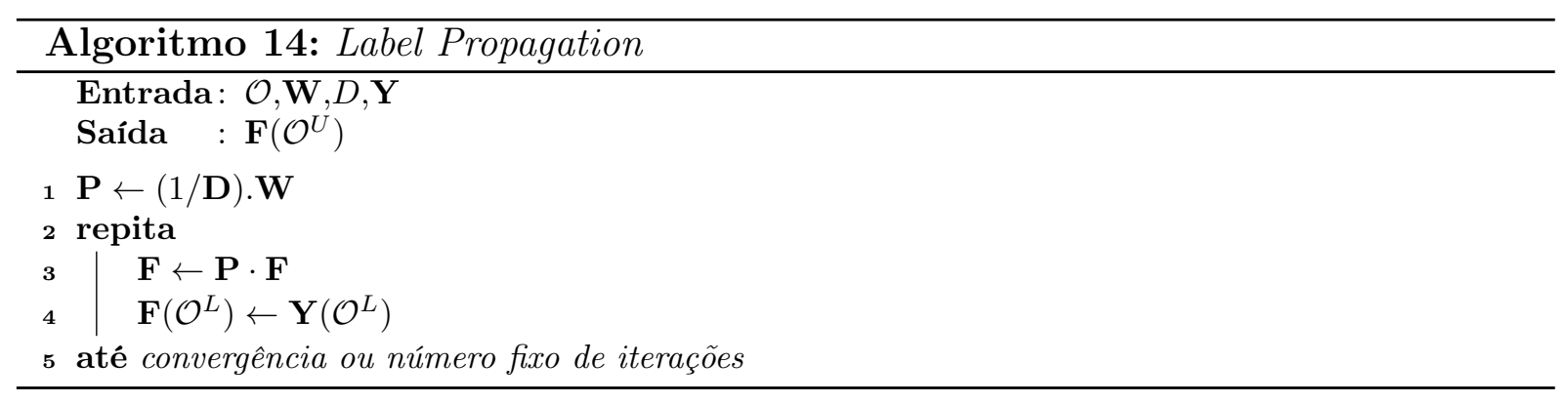

O conceito Class Mass Normalization ( CMN) é utilizado para pós-processar as informações de classe geradas pela solução iterativa. O $C M N$ consiste em dividir a informação de classe de um objeto $o_{i}$ para uma classe $c_{j}$ por todas as informações dos objetos para a mesma classe, como apresentado na Equação 4.27. Isso diminui as chances de atribuições de objetos às classes majoritárias. Após o pós-processamento, é utilizado o arg-max para definir a classe dos objetos.

$$
\operatorname{class}\left(o_{i}\right)=\arg \max _{c_{l} \in \mathcal{C}} \operatorname{Pr}\left[c_{l}\right] \cdot \frac{f_{o_{i}, c_{l}}}{\sum_{o_{j} \in \mathcal{O}} f_{o_{j}, c_{l}}} .
$$

A função harmônica também pode ser interpretada como uma caminhada aleatória na rede, uma vez que uma partícula no objeto $i$ irá mover-se aleatoriamente para uma partícula $j$ com probabilidade

$$
p\left(o_{j} \mid o_{i}\right)=\frac{w_{o_{i}, o_{j}}}{\sum_{o_{k} \in \mathcal{O}} w_{o_{i}, o_{k}}}
$$

A caminhada aleatória continua até que a partícula alcance um objeto rotulado (também conhecido por absorbing random walk). A informação de classe obtida no objeto $o_{i}$ por meio da caminhada aleatória corresponde a probabilidade da partícula iniciar no vértice $o_{i}$ e encontrar um vértice rotulado, que por sua vez corresponde às informações de classe definidas pelo algoritmo GFHF (Zhu et al., 2003a) ${ }^{5}$. Além da classificação baseada em caminhadas aleatórias, em Zhu et al. (2003a) também é apresentada a relação do algoritmo GFHF com redes elétricas e teoria espectral de grafos.

\section{Learning With Local and Global Consistency}

O algoritmo Learning with Local and Global Consistency (LLGC) (Zhou et al., 2004) permite que a informação de classe dos objetos rotulados sejam alteradas durante a

\footnotetext{
${ }^{5}$ Variações da classificação transdutiva utilizando caminhadas aleatórias podem ser encontradas em Breve et al. (2012); Szummer e Jaakkola (2002)
} 
classificação, uma vez que objetos podem ser erroneamente rotulados e com isso deteriorar a performance de classificação. Além disso, a influência de objetos com alto grua na definição das informações de classe de objetos vizinhos é diminuída, de forma que estes não tenham influência excessiva na classificação. O algoritmo $L L G C$ pode ser instanciado como um algoritmo de regularização que minimiza a função

$$
Q(\mathbf{F})=\frac{1}{2} \sum_{o_{i}, o_{j} \in \mathcal{O}} w_{o_{i}, o_{j}}\left\|\frac{\mathbf{f}_{o_{i}}}{\sqrt{\sum_{o_{k} \in \mathcal{O}} w_{o_{i}, o_{k}}}}-\frac{\mathbf{f}_{o_{j}}}{\sqrt{\sum_{o_{k} \in \mathcal{O}} w_{o_{j}, o_{k}}}}\right\|^{2}+\mu \sum_{o_{i} \in \mathcal{O}^{L}}\left\|\mathbf{f}_{o_{i}}-\mathbf{y}_{o_{i}}\right\|^{2}
$$

O algoritmo $L L G C$ pode ser resolvido aplicando iterativamente até a convergência dos valores da matriz $\mathbf{F}$ a seguinte equação:

$$
\mathbf{F}=\alpha \mathbf{S F}+(1-\alpha) \mathbf{Y}
$$

na qual

$$
\mathbf{S}=\mathbf{D}^{-1 / 2} \mathbf{W} \mathbf{D}^{1 / 2}
$$

A solução iterativa para minimizar a Equação 4.29 é apresentada no Algoritmo 15. No final do processo iterativo os objetos não rotulados são classificados de acordo com o arg-max do vetor de informação de classe.

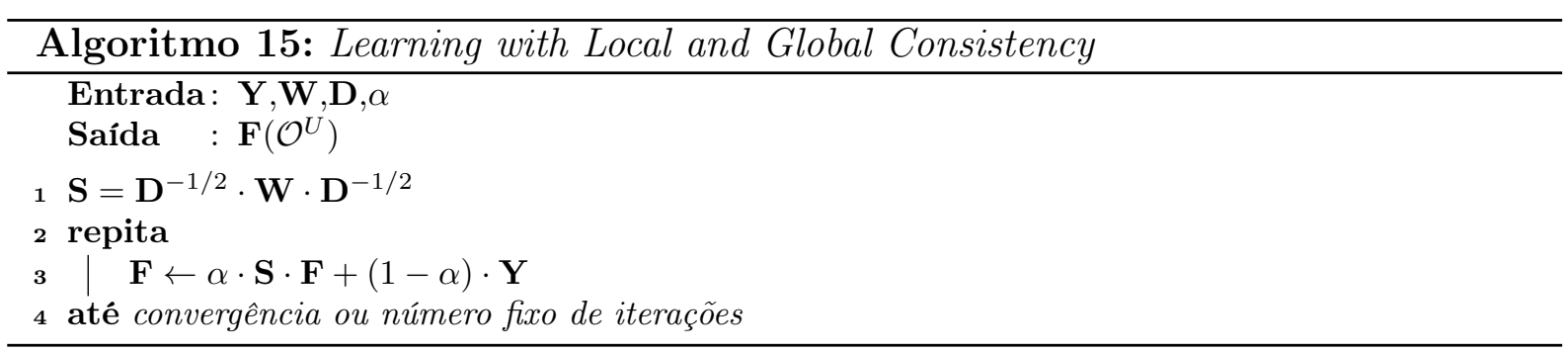

\section{Tag-based Model}

Em Yin et al. (2009b) é apresentado o algoritmo Tag-based Model (TM), que inicialmente foi proposto para classificar objetos web representados em redes bipartidas ou em redes estrela, nas quais objetos correspondentes às tags são conectados aos demais tipos de objetos, como vídeos, imagens e páginas web. Entretanto, esse tipo de algoritmo pode ser utilizado para classificar objetos em qualquer tipo de rede desde que haja um tipo de objeto que se conecta aos demais tipos de objetos.

Seja $\mathcal{P}$ o conjunto de objetos que se conectam aos demais tipos de objetos, seja $\mathcal{A}$ o conjunto de objetos que se deseja classificar, composto por objetos rotulados e não rotulados $\left(\mathcal{A}=\mathcal{A}^{L} \cup \mathcal{A}^{U}\right)$, e seja $\mathcal{B}$ o conjunto de objetos que auxiliam a classificação dos objetos em $\mathcal{A}$. Vale ressaltar que os objetos do tipo $\mathcal{B}$ são optativos. Dado esses tipos de objetos, o algoritmo $T M$ minimiza as seguintes diferenças: (i) a informação de 
classe inferidas inicialmente e as informações de classe atribuídas aos objetos em $\mathcal{B}$, (ii) as informações de classe reais e as informações atribuídas aos documentos em $\mathcal{A}^{L}$, (iii) as informações de classe inferidas inicialmente e as informações de classe atribuídas aos objetos em $\mathcal{A}^{U}$, e (iv) as informações de classe dos objetos em $\mathcal{A}$ e $\mathcal{B}$ com as informações de classe dos objetos em $\mathcal{P}$. Portanto, a função a ser minimizada pelo algoritmo $T M$ é dada por,

$$
\begin{aligned}
Q(\mathbf{F})= & \alpha \sum_{b_{i} \in \mathcal{B}}\left\|\mathbf{f}_{b_{i}}-\mathbf{y}_{b_{i}}\right\|^{2}+\beta \sum_{a_{i} \in \mathcal{A}^{L}}\left\|\mathbf{f}_{a_{i}}-\mathbf{y}_{a_{i}}\right\|^{2} \\
& +\gamma \sum_{a_{i} \in \mathcal{A}^{U}}\left\|\mathbf{f}_{a_{i}}-\mathbf{y}_{a_{i}}\right\|^{2}+\sum_{o_{i} \in \mathcal{A} \cup \mathcal{B}} \sum_{t_{j} \in \mathcal{T}} w_{o_{i}, t_{j}}\left\|\mathbf{f}_{o_{i}}-\mathbf{f}_{t_{j}}\right\|^{2}
\end{aligned}
$$

no qual os parâmetros $\alpha, \beta$ e $\gamma$ controlam a importância dada a cada termo da equação. A solução iterativa para a minimização da Equação 4.32 é apresentada no Algoritmo 16. Assim como no algoritmo GFHF, no final do processo iterativo o conceito Class Mass Normalization (Equação 4.27) é utilizado para pós-processar as informações de classe e é utilizado o arg-max para definir a classe dos objetos. Também como no algoritmo GFHF, o algoritmo $T M$ também pode ser considerado com um classificador baseado em caminhadas aleatórias na rede (Yin et al., 2009b).

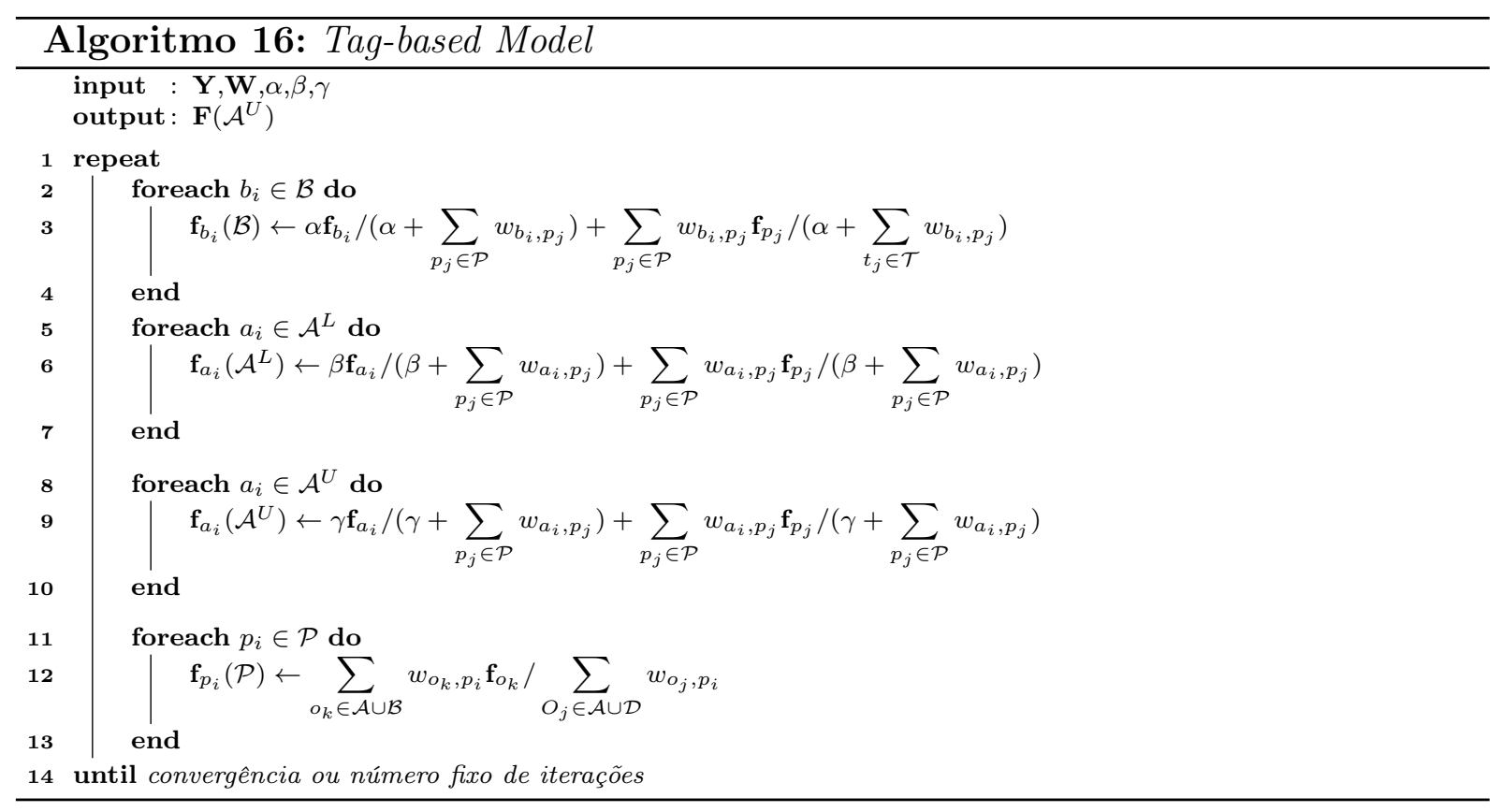

\section{GNetMine}

Em Ji et al. (2010) é proposto um framework geral para a classificação de objetos em redes heterogêneas denominado GNetMine (GNM). O algoritmo GNM é baseado no algoritmo $L L G C$, porém, são consideradas as diferentes semânticas das relações entre diferentes tipos de objetos. 
As premissas a serem satisfeitas pelo algoritmo GNM são (i) a atribuição de classes a dois objetos relacionados tende a ser similar, e (ii) a predição das classes de objetos rotulados tendem a ser similar às classes pré-definidas. A função a ser minimizar pelo algoritmo GNM é dada por:

$$
\begin{gathered}
Q(\mathbf{F})=\sum_{\mathcal{O}_{i}, \mathcal{O}_{j} \subset \mathcal{O}} \lambda_{\mathcal{O}_{i}, \mathcal{O}_{j}} \sum_{o_{k} \in \mathcal{O}_{i}} \sum_{o_{l} \in \mathcal{O}_{j}} w_{o_{k}, o_{l}}\left\|\frac{\mathbf{f}_{o_{k}}\left(\mathcal{O}_{i}\right)}{\sqrt{\sum_{o_{m} \in \mathcal{O}_{j}} w_{o_{k}, o_{m}}}}-\frac{\mathbf{f}_{o_{l}}\left(\mathcal{O}_{j}\right)}{\sqrt{\sum_{o_{m} \in \mathcal{O}_{i}} w_{o_{l}, o_{m}}}}\right\|^{2} \\
+\sum_{o_{j} \in \mathcal{O}^{L}} \alpha_{o_{j}}\left(\mathbf{f}_{o_{j}}-\mathbf{y}_{o_{j}}\right)
\end{gathered}
$$

no qual $\lambda_{\mathcal{O}_{i}, \mathcal{O}_{j}}\left(0 \leq \lambda_{\mathcal{O}_{i}, \mathcal{O}_{j}} \leq 1\right)$ é a importância dada à relação entre objetos do tipo $\mathcal{O}_{i} \mathrm{e}$ objetos do tipo $\mathcal{O}_{j}$, e $\alpha_{o_{j}}\left(0 \leq \alpha_{o_{i}} \leq 1\right)$ é a importância dada as informações de classe real de um objeto $o_{j} \in \mathcal{O}^{L}$.

A solução iterativa para minimizar a Equação 4.33 é apresentada no Algoritmo 17. No final do processo iterativo os objetos são classificados considerando o arg-max do vetor de informação de classes.

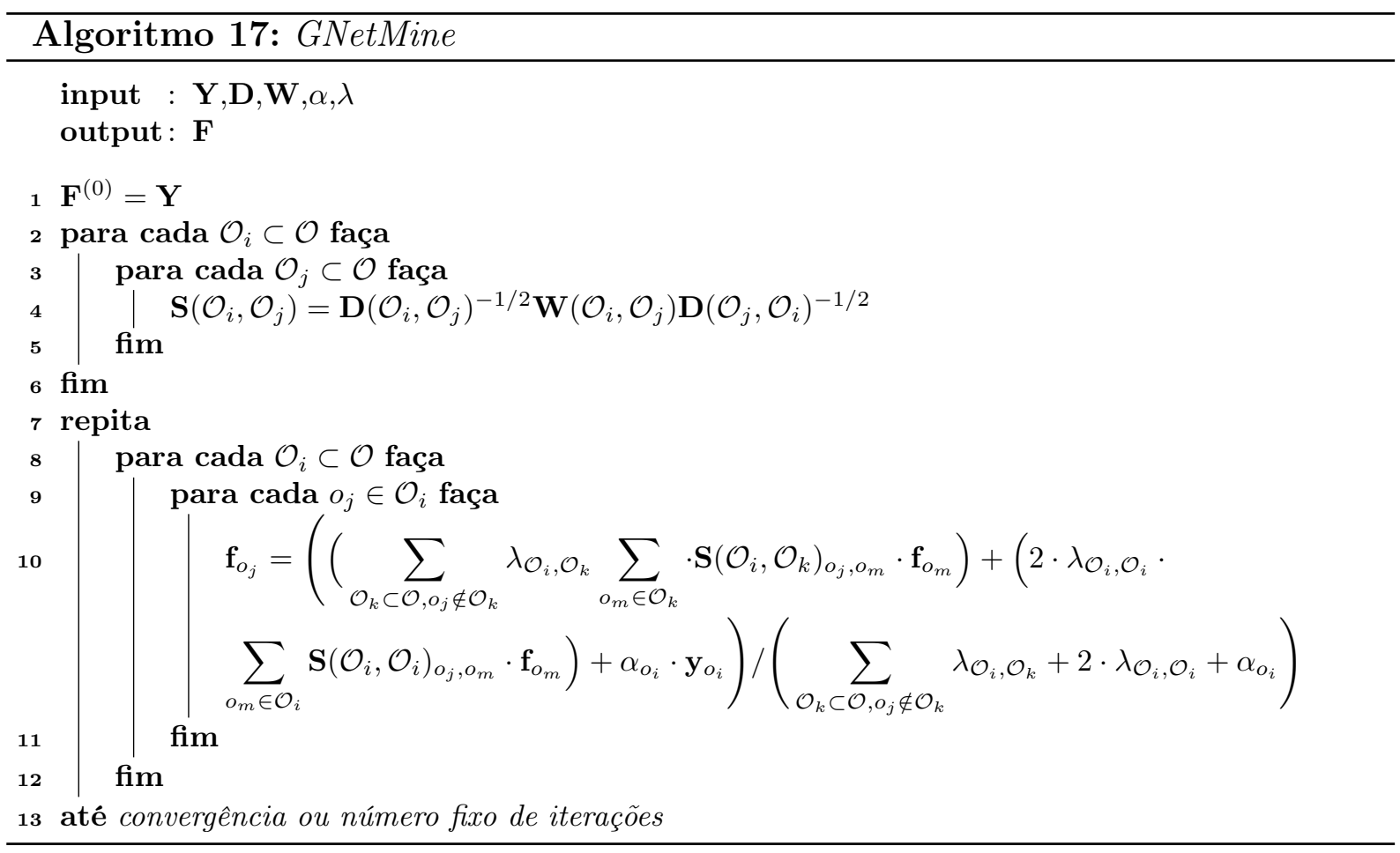

\subsection{Propostas para a Classificação de Textos por Meio de Apren- dizado Transdutivo Baseado em Redes}

Nesta tese foram propostos 3 algoritmos para sanar 3 deficiências encontrada na literatura à respeito da classificação transdutiva de textos representados em redes. As deficiências encontradas são listadas a seguir: 
1. Falta de algoritmos que considerem relações entre termos para realizar a classificação transdutiva e assim permitir comparar a performance individual de cada tipo de relação e medir o impacto na performance de classificação quando combinadas relações entre termos com outros tipos de relações;

2. Necessidade de definir um grande número de parâmetros nos algoritmos para classificação transdutiva em redes heterogêneas;

3. Falta de algoritmos que utilizam técnicas para otimizar as informações de classe dos termos considerando as informações de classe dos documentos, uma vez que esse tipo de abordagem apresentou excelentes resultados conforme apresentado no Capítulo 3.

Os algoritmos propostos para sanar cada um desses 3 pontos são denominados respectivamente Transductive Classification through Term Networks, Label Propagation through Heterogeneous Networks e Transductive Categorization based on Heterogeneous Networks. Nas próximas seções são apresentados os detalhes desses 3 algoritmos.

\subsubsection{Transductive Classification through Term Networks}

Usualmente as representações e algoritmos de classificação baseiam-se apenas na frequência dos termos, como (i) nos algoritmos de classificação baseados no modelo espaçovetorial, (ii) nos algoritmos baseados em redes de documentos, uma vez que a frequência dos termos é utilizada no cálculo de similaridades, ou (iii) nos algoritmos baseados em redes heterogêneas bipartidas, as quais são geradas utilizando as frequências dos termos como pesos das relações. Todas essas abordagens ignoram uma informação potencialmente útil para a classificação de textos que são as relações entre os termos, uma vez que termos altamente relacionados tendem a pertencer a mesma classe.

Além disso, a proposta de um algoritmo que considere relações entre termos para realizar a classificação transdutiva possibilita: (i) verificar se por si só as relações do tipo termo-termo são capazes de estruturar padrões nas coleções de textos e prover performances de classificação satisfatórias; e (ii) gerar um baseline para a análise comparativa das relações entre termos com outros tipos de relações, uma vez que não é possível analisar se a adição deste tipo de relação com outros tipos de relações é benéfica para a aumentar a performance de classificação.

Dado isso, neste projeto de doutorado foi proposto um framework para classificação transdutiva de textos representados em redes de termos denominado Transductive Classification through Term Networks (TCTN) (Rossi et al., 2015b). O framework TCTN considera as relações entre termos para definir as informações de classe dos termos e utilizar essas informações para classificar os documentos não rotulados. Para isso, o framework é divido em 4 etapas: (i) geração da rede de termos, (ii) definição das informações de classe iniciais para os termos, (iii) propagação das informações de classe, e (iv) classificação dos textos. Cada etapa pode ser instanciada independentemente das outras etapas. Nas próxi- 
mas subseções são detalhados os processamentos realizados em cada etapa do framework TCTN bem como as instanciações propostas para cada etapa.

\section{Geração da Rede de Termos}

O framework TCTN é baseado na rede de termos proposta neste projeto, apresentada na Seção 2.3.3, na qual cada termo da coleção é um objeto da rede e as relações entre termos são dadas pelas similaridades entre eles. Como já mencionado anteriormente, esse tipo de rede evita a geração de várias redes e permite definir as informações de classe dos termos para as classes por meio de mecanismos mais eficientes computacionalmente, como a propagação de rótulos, ao invés da extração de sub-redes frequentes.

Vale ressaltar que é possível aplicar um processo de seleção de termos (Seção 2.2.3) para reduzir o número de objetos na rede, o que não é possível em redes de documentos na qual descartar objetos da rede significaria descartar documentos a serem classificados. Vale ressaltar também que as similaridades entre os termos da coleção são calculadas considerando tanto os documentos rotulados quanto não rotulados.

\section{Definição das Informações de Classe Iniciais para os Termos}

Tendo a rede de termos, é necessário definir informações de classe iniciais para alguns termos da rede de forma a obter os pesos dos demais termos da rede. Definir as informações de classe dos termos requer o conhecimento sobre as classes da coleção e uma noção sobre a ocorrência dos termos para todas as classes. Por outro lado, rotular documentos tende a ser uma tarefa mais fácil que rotular termos. O usuário pode definir a classe de um documento baseado em seu conteúdo. Além disso, poucos documentos rotulados podem prover informações de classe para vários termos. Portanto, foi proposto nesta etapa do framework TCTN um mecanismo que infere as informações de classe inicias para termos considerando os documentos rotulados de uma coleção. A informação de classe inicial de um termo $t_{i}$ para a classe $c_{j}$ proposta esta tese é dada por:

$$
f_{t_{i}, c_{j}}^{(0)}=\frac{\sum_{d_{k} \in \mathcal{D}^{L}} w_{d_{k}, t_{i}} \cdot y_{d_{k}, c_{j}}}{\sum_{d_{k} \in \mathcal{D}^{L}} w_{d_{k}, t_{i}}},
$$

a qual retorna valores próximos à 1 para termos que ocorrem quase que exclusivamente para uma classe e pequenos valores para termos que estão igualitariamente distribuídos para várias classes.

Vale ressaltar que alguns poucos domínios possuem um léxico com valores de informações de classe definidas, como a SentiWordNet (Baccianella et al., 2010), que é utilizada na análise de sentimentos e possui pesos para as classes positivo, negativo e neutro para um conjunto pré-definido de palavras. Portanto, nesses domínios, pode-se utilizar este tipo de informação para definir ou complementar as informações de classe inicias dos termos 
da rede.

\section{Propagação das Informações de Classe}

Uma vez tendo as informações de classe para uma parcela dos termos da rede pode-se utilizar algoritmos de regularização/propagação de rótulos para definir as informações de classe dos demais termos. Para isso, pode-se utilizar algoritmos de propagação de rótulos em redes homogêneas, como os apresentado na Seção 4.2.2, para definir as informações de classe de todos os termos da coleção. Neste projeto de doutorado foram utilizados os algoritmos GFHF e $L L G C$ (apresentados na Seção 4.2.2) para tal finalidade, uma veste que esse dois algoritmos apresentam um custo-benefício satisfatório em relação ao número de parâmetros e performance de classificação.

\section{Classificação dos Textos}

As informações de classe inferidas para os termos da coleção são utilizadas para classificar os documentos não rotulados. Para isso, são consideradas as informações de classe dos termos de um documento e suas respectivas frequências. A informação de classe de um documento $d_{i} \in \mathcal{D}^{U}$ para uma classe $c_{j}$ é dada pela seguinte função linear pesada:

$$
f_{d_{i}, c_{j}}=\sum_{t_{k} \in \mathcal{T}} w_{d_{i}, t_{k}} \cdot f_{t_{k}, c_{j}}
$$

A classe de um documento $d_{i} \in \mathcal{D}^{U}$ é definida pelo arg-max do vetor $\mathbf{f}_{d_{i}}$.

\subsubsection{Label Propagation through Heterogeneous Networks}

Devido à grande quantidade de parâmetros dos algoritmos de classificação em redes heterogêneas (4 no algoritmo $I R C, 3$ no algoritmo $T M$, e o número de parâmetros corresponde à importância das relações entre todos os pares de tipos de objetos e o peso dado às informações de classe reais no algoritmo $G N M$ ), neste projeto de doutorado foi proposto o algoritmo Label Propagation through Heterogeneous Networks (LPHN), que realiza a classificação transdutiva sem a necessidade de definição de parâmetros.

O algoritmo $L P H N$ é uma extensão para redes heterogêneas do algoritmo GFHF (Zhu et al., 2003a), que é livre de parâmetros e um dos mais usados para classificação transdutiva em redes homogêneas. Portanto, a propagação de rótulos consiste na resolução da equação matricial $\mathbf{F}=\mathbf{P} \mathbf{F}$ iterativamente até a convergência dos valores de $\mathbf{F}$. A proposta do algoritmo $L P H N$ permite então comparar a performance de classificação obtida pelo algoritmo GFHF em redes homogêneas de documentos ou do algoritmo TCTN em redes de termos com as redes heterogêneas propostas nesta tese, além do fato de que a não necessidade da definição de parâmetros faz com que o algoritmo LPHN seja interessante em situações reais onde não é possível executar testes com uma grande quantidade de 
parâmetros ou que o usuário não tenha conhecimento à respeito da função dos parâmetros nos algoritmos.

\section{Propagação de Rótulos}

Considerando as redes propostas nesta tese, compostas por documentos rotulados $\left(\mathcal{D}^{L}\right)$, documentos não rotulados $\left(\mathcal{D}^{U}\right)$ e termos $(\mathcal{T})$, as matrizes $\mathbf{P}$ e $\mathbf{F}$ são subdividas considerando esses tipos de objetos e o a propagação de rótulos fica da seguinte forma:

$$
\left[\begin{array}{c}
\mathbf{F}\left(\mathcal{D}^{L}\right) \\
\mathbf{F}\left(\mathcal{D}^{U}\right) \\
\mathbf{F}(\mathcal{T})
\end{array}\right]=\left[\begin{array}{ccc}
\mathbf{P}\left(\mathcal{D}^{L}, \mathcal{D}^{L}\right) & \mathbf{P}\left(\mathcal{D}^{L}, \mathcal{D}^{U}\right) & \mathbf{P}\left(\mathcal{D}^{L}, \mathcal{T}\right) \\
\mathbf{P}\left(\mathcal{D}^{U}, \mathcal{D}^{L}\right) & \mathbf{P}\left(\mathcal{D}^{U}, \mathcal{D}^{U}\right) & \mathbf{P}\left(\mathcal{D}^{U}, \mathcal{T}\right) \\
\mathbf{P}\left(\mathcal{T}, \mathcal{D}^{L}\right) & \mathbf{P}\left(\mathcal{T}, \mathcal{D}^{U}\right) & \mathbf{P}(\mathcal{T}, \mathcal{T})
\end{array}\right]\left[\begin{array}{c}
\mathbf{F}\left(\mathcal{D}^{L}\right) \\
\mathbf{F}\left(\mathcal{D}^{U}\right) \\
\mathbf{F}(\mathcal{T})
\end{array}\right]
$$

Considerando as equações matriciais derivadas da Equação 4.36 e a restrição oriunda do algoritmo GFHF que define $\mathbf{F}_{\mathcal{D}^{L}}=\mathbf{Y}_{D^{L}}$, o algoritmo $L P H N$ realiza a classificação de rótulos conforme apresentada no Algoritmo 18. Portanto, a definição da informação de classe de um objeto da rede leva em consideração as informações de classe dos objetos relacionados proporcionalmente a probabilidade de ocorrência das relações. Assim como no algoritmo GFHF, no final do processo iterativo o conceito Class Mass Normalization (Equação 4.27) é utilizado para pós-processar as informações de classe. Após esse pósprocessamento, é utilizado o arg-max para definir a classe dos documentos não rotulados.

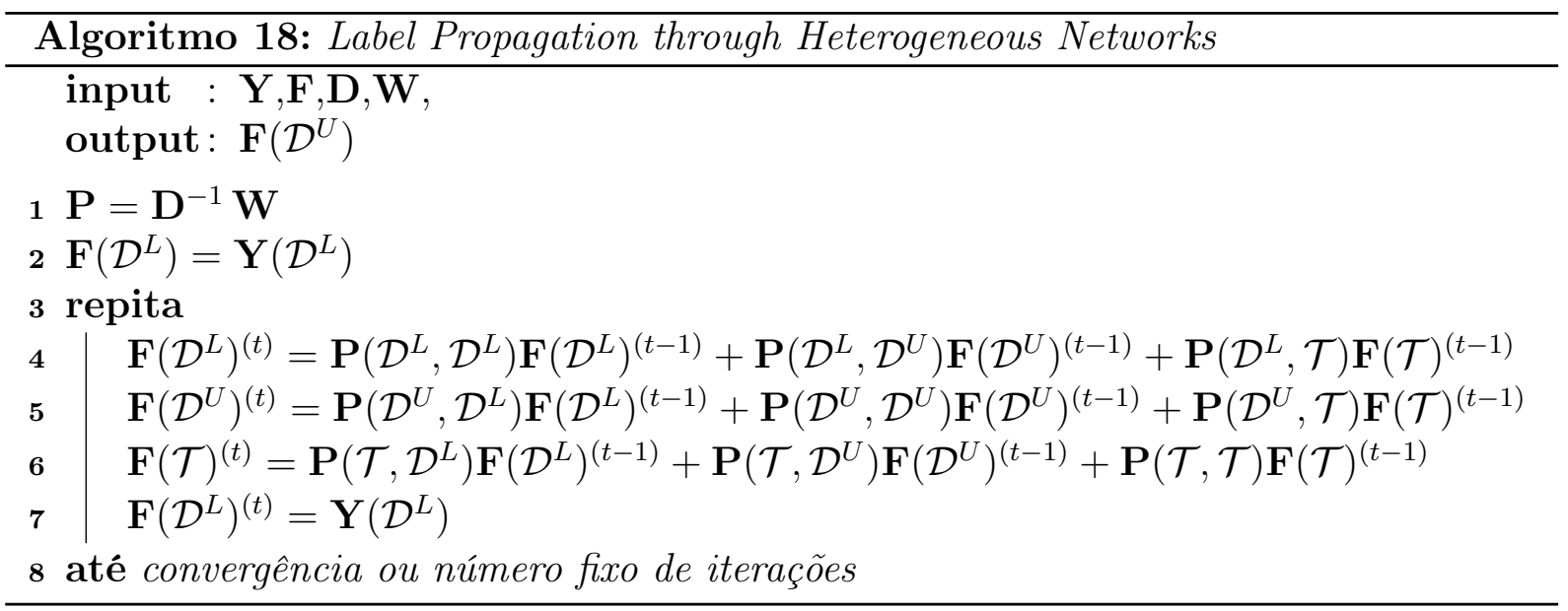

Vale ressaltar que cada linha da matriz $\mathbf{P}$ é estocástica, ou seja, a soma dos valores da linha é 1. Isso é necessário para garantir a convergência do algoritmo como será apresentada na próxima seção. Para tal, é preciso calcular o grau de cada objeto, que corresponde a cada linha da matriz $\mathbf{P}$, para normalizar seus valores e torná-la estocástica. Porém, como já apresentado na Seção 2.3.3, a relação do tipo documento-termo possui um intervalo de valores que varia de 1 até a frequência máxima de um termo na coleção de documentos, enquanto o valor máximo de relações entre termos ou entre documentos é 1 . Portanto, as relações entre documentos e termos devem ser padronizadas para que estas estejam no mesmo intervalo de valores das relações entre termos ou entre documento e 
não tenham peso excessivo na propagação de rótulos. A padronizações das relações entre documentos e termos e entre termos e documentos são apresentadas nas Equações 4.37 e 4.38 respectivamente.

$$
\begin{aligned}
& w_{d_{i}, t_{j}}^{\prime}=\frac{w_{d_{i}, t_{j}}}{\sum_{t_{k} \in \mathcal{T}} w_{d_{i}, t_{k}}} \\
& w_{t_{i}, d_{j}}^{\prime}=\frac{w_{t_{i}, d_{j}}}{\sum_{d_{k} \in \mathcal{D}} w_{t_{i}, d_{k}}}
\end{aligned}
$$

Após padronizadas as relações entre documentos e termos é calculado o grau dos objetos da rede que são utilizados para gerar a matriz P. Nessa matriz, a probabilidade de ocorrer uma conexão de um objeto $o_{i}$ para um objeto $o_{j}$, independentemente do tipo, é dada por:

$$
p_{o_{i}, o_{j}}=\frac{w_{o_{i}, o_{j}}}{\sum_{o_{k} \in \mathcal{D}} w_{d_{i}, d_{k}}}
$$

Vale ressaltar que um caso particular do algoritmo $L P H N$ é quando a rede é formada apenas por relações entre documento e termos (rede bipartida), na qual apenas $\mathbf{P}\left(\mathcal{D}^{L}, \mathcal{T}\right.$ ), $\mathbf{P}\left(\mathcal{D}^{U}, \mathcal{T}\right), \mathbf{P}\left(\mathcal{T}, \mathcal{D}^{L}\right)$ e $\mathbf{P}\left(\mathcal{T}, \mathcal{D}^{U}\right)$ são diferentes de 0 . Vários domínios de aplicação, inclusive os textuais, podem ser modelados por esse tipo de rede. No caso particular da utilização das redes bipartidas o algoritmo é denominado Label Propagation through Bipartite Heterogeneous Networks (LPBHN) (Rossi et al., 2014b), o qual já foi utilizando em outras aplicações além da classificação de textos (Matsuno et al., 2015; Silva et al., 2014).

\section{Análise de Convergência do algoritmo $L P H N$}

Para simplificar a análise de convergência do algoritmo $L P H N$, será considerada uma representação em redes bipartidas, ou seja, será apresentada a análise de convergência do algoritmo $L P B H N$. Vale ressaltar que os mesmos princípios aplicados na análise de convergência do $L P B H N$ valem para o algoritmo $L P H N$.

Aplicando iterativamente os passos apresentados no Algoritmo 18, e considerando uma representação em redes bipartidas, têm-se que $\mathbf{F}(\mathcal{T})$ e $\mathbf{F}\left(\mathcal{D}^{U}\right)$ na $n$-ésima iteração são dados pelas equações 4.40 e 4.41 respectivamente.

$$
\begin{aligned}
\mathbf{F}(\mathcal{T})^{(n)}= & \sum_{i=0}^{n-1}\left(\mathbf{P}\left(\mathcal{D}^{U}, \mathcal{T}\right) \mathbf{P}\left(\mathcal{T}, \mathcal{D}^{U}\right)\right)^{i} \mathbf{P}\left(\mathcal{T}, \mathcal{D}^{L}\right) \mathbf{Y}(\mathcal{D})^{L}+ \\
& \left(\mathbf{P}\left(\mathcal{T}, \mathcal{D}^{U}\right) \mathbf{P}\left(\mathcal{D}^{U}, \mathcal{T}\right)\right)^{n-1} \mathbf{P}\left(\mathcal{T}, \mathcal{D}^{U}\right) \mathbf{F}\left(\mathcal{D}^{U}\right)^{(0)}
\end{aligned}
$$




$$
\begin{aligned}
\mathbf{F}\left(\mathcal{D}^{U}\right)^{(n)}= & \sum_{i=0}^{n-1}\left(\mathbf{P}\left(\mathcal{D}^{U}, \mathcal{T}\right) \mathbf{P}\left(\mathcal{T}, \mathcal{D}^{U}\right)\right)^{i} \mathbf{P}\left(\mathcal{D}^{U}, \mathcal{T}\right) \mathbf{P}\left(\mathcal{T}, \mathcal{D}^{L}\right) \mathbf{Y}(\mathcal{D})^{L}+ \\
& \left(\mathbf{P}\left(\mathcal{D}^{U}, \mathcal{T}\right) \mathbf{P}\left(\mathcal{T}, \mathcal{D}^{U}\right)\right)^{n} \mathbf{F}\left(\mathcal{D}^{U}\right)^{(0)}
\end{aligned}
$$

A soma dos valores de cada linha em $\mathbf{P}\left(\mathcal{D}^{L}, \mathcal{T}\right)$ e $\mathbf{P}\left(\mathcal{D}^{U}, \mathcal{T}\right)$ é menor do que 1 para termos conectados tanto a documentos rotulados e quanto não rotulados, isto é, termos úteis para a propagação de rótulos. O mesmo ocorre para as submatrizes $\mathbf{P}\left(\mathcal{T}, \mathcal{D}^{L}\right)$ e $\mathbf{P}\left(\mathcal{T}, \mathcal{D}^{U}\right)$. Portanto, considerando o produto das matrizes $\mathbf{P}\left(\mathcal{D}^{U}, \mathcal{T}\right) \mathbf{P}\left(\mathcal{T}, \mathcal{D}^{U}\right)$ ) que compõe o primeiro termo das Equações 4.40 e 4.41, e considerando a soma dos valores de uma linha da matriz resultante desse produto de matricial, existe um $\gamma$ tal que

$$
\sum_{d_{j} \in \mathcal{D}^{U}}\left(P\left(\mathcal{D}^{U}, \mathcal{T}\right) P\left(\mathcal{T}, \mathcal{D}^{U}\right)_{d_{i}, d_{j}}\right) \leq \gamma<1
$$

Na n-ésima iteração têm-se:

$$
\begin{aligned}
\sum_{d_{j} \in \mathcal{D}^{U}}\left(\mathbf{P}\left(\mathcal{D}^{U}, \mathcal{T}\right) \mathbf{P}\left(\mathcal{T}, \mathcal{D}_{d_{i}, d_{j}}^{U}\right)\right)^{(n)} & =\sum_{d_{k} \in \mathcal{D}^{U}} \sum_{d_{j} \in \mathcal{D}^{U}}\left(\mathbf{P}\left(\mathcal{D}^{U}, \mathcal{T}\right) \mathbf{P}\left(\mathcal{T}, \mathcal{D}^{U}\right)_{d_{i}, d_{k}}\right)^{(n-1)} \\
& \left(\mathbf{P}\left(\mathcal{D}^{U}, \mathcal{T}\right) \mathbf{P}\left(\mathcal{T}, \mathcal{D}^{U}\right)_{d_{k}, d_{j}}\right) \\
\leq & \sum_{d_{k} \in \mathcal{D}}\left(\mathbf{P}\left(\mathcal{D}^{U}, \mathcal{T}\right) \mathbf{P}\left(\mathcal{T}, \mathcal{D}^{U}\right)_{d_{i}, d_{k}}\right)^{(n-1)} \gamma \\
\leq & \gamma^{(n)}
\end{aligned}
$$

Para $n \rightarrow \infty$,

$$
\lim _{n \rightarrow \infty} \gamma^{n}=0
$$

Portanto, as soluções propostas para $\mathbf{F}_{T}^{(n)}$ e $\mathbf{F}_{D^{U}}^{(n)}$ convergem para $n$ tendendo a infinito. Vale ressaltar que apesar da prova matemática que o algoritmo $L P B H N$ converge para $n$ tendendo a infinito, na prática a convergência é obtida em um número pequeno de iterações, chegando a aproximadamente 150 iterações para algumas coleções de documentos.

\section{Análise de Complexidade}

As informações de classe dos objetos da rede no algoritmo LPHN são atualizadas considerando as informações de classe dos objetos relacionados. Portanto, o custo para definir as informações de classe dos documentos é $|\mathcal{D}| \cdot|\mathcal{C}| \cdot(\overline{|\mathcal{E}(\mathcal{D}, \mathcal{D})|}+\overline{|\mathcal{E}(\mathcal{D}, \mathcal{T})|})$, na qual $\overline{|\mathcal{E}(\mathcal{D}, \mathcal{D})|}$ é o número médio de relações entre documentos e $\overline{|\mathcal{E}(\mathcal{D}, \mathcal{T})|}$ é o número médio de de relações entre documentos e termos. Já o custo de se atualizar as informações de classe dos termos é $|\mathcal{T}| \cdot|\mathcal{C}| \cdot(\overline{|\mathcal{E}(\mathcal{T}, \mathcal{T})|}+\overline{|\mathcal{E}(\mathcal{D}, \mathcal{T})|})$, na qual $\overline{|\mathcal{E}(\mathcal{T}, \mathcal{T})|}$ é o número de relações entre termos. Dado que o algoritmo executa $n$ iterações, o custo total do algoritmo $L P H N$ é $|\mathcal{C}| \cdot n(|\mathcal{D}| \cdot \overline{|\mathcal{E}(\mathcal{D}, \mathcal{D})|}+|\mathcal{D}| \cdot|\mathcal{T}| \cdot \overline{|\mathcal{E}(\mathcal{D}, T)|}+|\mathcal{T}| \cdot \overline{\mathcal{E}(\mathcal{T}, \mathcal{T}) \mid}$. Vale ressaltar que no caso 
mais simples, isto é, coleções representadas em redes bipartidas, a complexidade do LPHN é $|\mathcal{C}| \cdot n \cdot \overline{|\mathcal{E}(\mathcal{D}, \mathcal{T})|}$

\section{Extensão do Algoritmo $L P H N$ para Outro Objetos e Tipos de Dados}

O algoritmo $L P H N$ pode ser facilmente estendido para considerar outros tipos de objetos oriundos das coleções de textos ou ainda aplicado a outros domínios com outros tipos de objetos. Para uma rede heterogênea composta por $h$ tipos de objetos, a equação matricial do algoritmo $L P H N$ fica da seguinte forma:

$$
\left[\begin{array}{c}
\mathbf{F}_{\mathcal{O}_{1}} \\
\mathbf{F}_{\mathcal{O}_{2}} \\
\vdots \\
\mathbf{F}_{\mathcal{O}_{h}}
\end{array}\right]=\left[\begin{array}{cccc}
\mathbf{P}_{\mathcal{O}_{1} \mathcal{O}_{1}} & \mathbf{P}_{\mathcal{O}_{1} \mathcal{O}_{2}} & \cdots & \mathbf{P}_{\mathcal{O}_{1} \mathcal{O}_{h}} \\
\mathbf{P}_{\mathcal{O}_{2} \mathcal{O}_{1}} & \mathbf{P}_{\mathcal{O}_{2} \mathcal{O}_{2}} & \cdots & \mathbf{P}_{\mathcal{O}_{2} \mathcal{O}_{h}} \\
\vdots & \vdots & \ddots & \vdots \\
\mathbf{P}_{\mathcal{O}_{h} \mathcal{O}_{1}} & \mathbf{P}_{\mathcal{O}_{h} \mathcal{O}_{2}} & \cdots & \mathbf{P}_{\mathcal{O}_{h} \mathcal{O}_{h}}
\end{array}\right]\left[\begin{array}{c}
\mathbf{F}_{\mathcal{O}_{1}} \\
\mathbf{F}_{\mathcal{O}_{2}} \\
\vdots \\
\mathbf{F}_{\mathcal{O}_{h}}
\end{array}\right]
$$

Vale ressaltar que a formulação geral do $L P H N$, apresentada na Equação 4.43, corresponde à seguinte função de regularização:

$$
Q(\mathbf{F})=\sum_{\mathcal{O}_{j}, \mathcal{O}_{l} \subset \mathcal{O}} \frac{1}{2} \sum_{o_{i} \in \mathcal{O}_{j}} \sum_{o_{k} \in \mathcal{O}_{l}} w_{o_{i}, o_{k}}\left(\mathbf{f}_{o_{i}}-\mathbf{f}_{o_{k}}\right)^{2}+\lim _{\mu \rightarrow \infty} \mu \sum_{o_{i} \in \mathcal{O}^{L}}\left(\mathbf{f}_{o_{i}}-\mathbf{y}_{o_{i}}\right)^{2}
$$

Vale ressaltar também que para um único tipo de objeto, a função apresentada na Equação 4.44 corresponde a função de regularização do algoritmo GFHF (Equação 4.25).

\subsubsection{Transductive Categorization based on Heterogeneous Networks}

Neste projeto de doutorado foi proposto o algoritmo Transductive Categorization based on Heterogeneous Networks (TCHN), cujo objetivo é inferir as informações de classe dos termos considerando as informações de classe tanto dos documentos rotulados quanto dos documentos não rotulados da coleção, e utilizar as informações de classe dos termos para definir os rótulos dos documentos não rotulados. Esse algoritmo pode ser considerado como uma extensão do algoritmo IMHN (apresentado na Seção 3.3). Porém, no contexto da classificação transdutiva, na qual normalmente há poucos exemplos rotulados e muitos exemplos não rotulados, a inferência das informações de classe dos termos considerando apenas documentos rotulados, caso do algoritmo $I M H N$, pode não produzir uma performance de classificação satisfatória. Além disso, ter conhecimento a respeito de todos os documentos a serem classificado e utilizá-los durante o aprendizado pode aumentar a performance de classificação. Portanto, a consideração de documentos não rotulados para inferir as informações de classe dos termos é fundamental neste tipo de cenário. Nas próximas subseções são apresentados detalhes do algoritmo TCHN, a análise de complexidade, um exemplo de funcionamento do algoritmo, o impacto da consideração de documentos não rotulados na definição da informação de classes dos termos, e a extensão 
do algoritmo TCHN para considerar coleções de textos compostas por outros tipos de objetos ou mesmo para estender o algoritmo TCHN para outros tipos de dados.

\section{Descrição do Algoritmo}

A premissa do algoritmo $T C H N$ é que as informações de classe dos documentos em $\mathcal{D}^{L}$ e em $\mathcal{D}^{U}$ são úteis para definir as informações de classe dos termos e as informações de classe inferidas para os termos são úteis para inferir as informações de classe dos documentos não rotulados. No algoritmo TCHN, além das relações documento-documento e documento-termo, as quais foram consideradas no algoritmo $I M H N$, também são consideradas relações do tipo documento-documento, uma vez as informações de classe dos documentos não rotulados podem ser alteradas durante o processo de classificação. Neste caso, as relações entre documentos podem ser importantes na definição das informações de classe dos documentos não rotulados.

No algoritmo TCHN é realizado um processo de otimização e um processo de propagação de rótulos para definir as informações de classe dos documentos não rotulados. Para isso, são otimizadas as informações de classe dos termos considerando as informações de classe reais dos documentos rotulados, as informações de classe atribuídas aos documentos não rotulados e as informações de classe dos termos relacionados. Posteriormente, as informações de classe dos termos são propagadas para definir as informações de classe dos documentos não rotulados. Após isso, também são minimizadas as diferenças entre as informações de classe dos documentos relacionados.

A otimização das informações de classe dos termos e dos documentos conforme descrito acima visa minimizar a seguinte função objetivo ${ }^{6}$ :

$$
\begin{aligned}
Q(\mathbf{F})= & \frac{1}{2}\left(\sum_{c_{j} \in \mathcal{C}} \sum_{d_{k} \in \mathcal{D}^{L}} y_{d_{k}, c_{j}}-\sum_{t_{i} \in \mathcal{T}}\left(w_{d_{k}, t_{i}} \cdot f_{t_{i}, c_{j}}\right)\right)^{2}+ \\
& \frac{1}{2}\left(\sum_{c_{j} \in \mathcal{C}} \sum_{d_{k} \in \mathcal{D}^{U}} f_{d_{k}, c_{j}}-\sum_{t_{i} \in \mathcal{T}}\left(w_{d_{k}, t_{i}} \cdot f_{t_{i}, c_{j}}\right)\right)^{2}+ \\
& \frac{1}{2}\left(\sum_{c_{j} \in \mathcal{C}} \sum_{t_{k} \in \mathcal{T}} \sum_{t_{i} \in \mathcal{T}} w_{t_{i}, t_{k}} \cdot\left(f_{t_{i}, c_{j}}-f_{t_{k}, c_{j}}\right)\right)^{2}+ \\
& \frac{1}{2}\left(\sum_{c_{j} \in \mathcal{C}} \sum_{d_{k} \in \mathcal{D}} \sum_{d_{l} \in \mathcal{D}^{U}} w_{d_{l}, d_{k}} \cdot\left(f_{d_{l}, c_{j}}-f_{d_{k}, c_{j}}\right)\right)^{2},
\end{aligned}
$$

na qual (i) o primeiro termo da função objetivo visa minimizar as diferenças entre as informações de classe dos termos e as informações de classe dos documentos rotulados; (ii)

\footnotetext{
${ }^{6}$ Não foi considerada a utilização de uma versão do algoritmo TCHN com a função class(...), como no algoritmo $I M H N$ (Seção 3.3), uma vez que foi empiricamente verificado que com poucos exemplos rotulados, a não utilização dessa função apresenta melhor performance de classificação.
} 
o segundo termo visa minimizar as diferenças entre as informações de classe dos termos e as informações de classe atribuídas aos documentos não rotulados; (iii) o terceiro termo visa minimizar a diferença entre as informações de classe entre os termos relacionados; e (iv) e o quarto termo visa minimizar as diferenças entre as informações de classe dos documentos relacionados. Vale ressaltar que quanto maior o peso das relações, menor a diferença entre as informações de classe dos objetos relacionados. Todas as minimizações objetivam melhorar a inferência das informações de classe dos termos incluindo a minimização das diferenças entre as informações de classe dos documentos, uma vez que melhorando as informações de classe dos documentos haverá uma melhora nas informações de classe dos termos, que consequentemente melhoras as informações de classe dos documentos.

Foi utilizado o método Least-Mean-Square (LMS) (Widrow e Hoff, 1960) para realizar a inferência das informações de classe. O algoritmo $L M S$ iterativamente atualiza as informações de classe dos termos na direção negativa do vetor gradiente, diminuindo assim erro quadrático. A atualização das informações de classe utilizando o algoritmo $L M S$ é apresentado na Equação 4.46. A direção do vetor gradiente pode ser estimada pela derivada de $Q(\mathbf{F})$ da Equação 4.45, como apresentado na Equação 4.47.

$$
\begin{gathered}
\mathbf{f}^{(n+1)}=\mathbf{f}^{(n)}+\eta[-\nabla(Q(\mathbf{F}))] \\
\nabla(Q(\mathbf{F}))=\frac{\partial Q(\mathbf{F})}{\partial \mathbf{F}}=\sum_{c_{j} \in \mathcal{C}} \sum_{d_{k} \in \mathcal{D}^{L}} y_{d_{k}, c_{j}}-\left(\sum w_{t_{i}, t_{i}} \cdot f_{t_{i}, c_{j}}\right) \sum_{c_{j} \in \mathcal{C}} \sum_{d_{k} \in \mathcal{D}^{L}} \sum_{t_{i} \in \mathcal{T}} w_{d_{k}, t_{i}}+ \\
\sum_{c_{j} \in \mathcal{C}} \sum_{d_{k} \in \mathcal{D}^{U}} f_{d_{k}, c_{j}}-\left(\sum_{t_{i} \in \mathcal{T}} w_{d_{k}, t_{i}} f_{t_{i}, c_{j}}\right) \sum_{c_{j} \in \mathcal{C}} \sum_{d_{k} \in \mathcal{D}^{U}} \sum_{t_{i} \in \mathcal{T}} w_{d_{k}, t_{i}}+ \\
\sum_{c_{j} \in \mathcal{C}} \sum_{t_{i} \in \mathcal{T}} \sum_{t_{k} \in \mathcal{T}}\left(f_{t_{i}, c_{j}}-f_{t_{k}, c_{j}}\right) \sum_{c_{j} \in \mathcal{C}} \sum_{t_{i} \in \mathcal{T}} \sum_{t_{k} \in \mathcal{T}} w_{t_{i}, t_{k}}^{2}+ \\
\sum_{c_{j} \in \mathcal{C}} \sum_{d_{k} \in \mathcal{D}} \sum_{d_{l} \in \mathcal{D}}\left(f_{d_{k}, c_{j}}-f_{d_{l}, c_{j}}\right) \sum_{c_{j} \in \mathcal{C}} \sum_{d_{k} \in \mathcal{D}} \sum_{d_{l} \in \mathcal{D}} w_{d_{k}, d_{l}}^{2}
\end{gathered}
$$

A diferença $y_{d_{k}, c_{j}}-\left(\sum_{t_{i} \in \mathcal{T}} w_{d_{k}, t_{i}} \cdot f_{t_{i}, c_{j}}\right)$ será tratada por erro_classif_lab $b_{d_{k}, c_{j}}, f_{d_{k}, c_{j}}-$ $\left(\sum_{t_{i} \in \mathcal{T}} w_{d_{k}, t_{i}} \cdot f_{t_{i}, c_{j}}\right)$ será tratada por erro_classif_unlab $b_{d_{k}, c_{j}},\left(f_{t_{i}, c_{j}}-f_{t_{k}, c_{j}}\right)$ será tratada por erro_termo $t_{k}, c_{j}$, e $\left(f_{d_{k}, c_{j}}-f_{d_{l}, c_{j}}\right)$ será tratada por erro_doc $c_{d_{k}, c_{j}}$.

Considerando as Equações 4.46 e 4.47, a informação de classe de um termo $t_{i}$ para uma classe $c_{j}$ na iteração $s+1$ é dada por:

$$
\begin{aligned}
f_{t_{i}, c_{j}}^{(s+1)}=f_{t_{i}, c_{j}}^{(s)}+ & \eta\left(\sum_{d_{k} \in \mathcal{D}^{L}} w_{d_{k}, t_{i}} \cdot \text { erro_classif_lab } b_{d_{k}, c_{j}}^{(s)}\right. \\
+ & \sum_{d_{k} \in \mathcal{D}^{U}} w_{d_{k}, t_{i}} \cdot{\text { erro_classif_unlab }{ }_{d_{k}, c_{j}}^{(s)}} \\
& \left.+\sum_{t_{k} \in \mathcal{T}} w_{t_{k}, t_{i}}^{2} \cdot \text { erro_termo }_{t_{i}, c_{j}}^{(s)}\right)
\end{aligned}
$$


na qual $\eta$ é taxa de correção de erro, isto é, a taxa com que o erro será considerado na atualização da informação de classe. Após otimizar as informações de classe dos termos, estas são propagadas para definir as informações de classe dos documentos não rotulados. O valor da informação de classe de um documento não rotulado $d_{i}$ para uma classe $c_{j}$ é dada por:

$$
f_{d_{i}, c_{j}}=\sum_{t_{k} \in \mathcal{T}} w_{d_{i}, t_{k}} \cdot f_{t_{k}, c_{j}}
$$

Uma vez que a soma das informações de classe de cada documento rotulado é 1, após a definição das informações de classe dos documentos não rotulados, seja pela propagação das informações de classe dos termos (Equação 4.49) ou pela minimização das diferenças entre as informações de classe dos documentos relacionados (Equação 4.51), as informações de classe dos documentos não rotulados são padronizadas para que a soma das valores das suas informações de classe também seja 1 e com isso não tenham um peso maior na inferência das informações de classe dos termos em relação aos documentos rotulados. A padronização das informações de classe dos documentos é dada pela Equação 4.50. Em casos de presença de valores negativos no vetor de informação de classes, o módulo do valor mais negativo é somados aos valores das informações de classe anteriormente a aplicação da Equação 4.50.

$$
f_{d_{i}, c_{j}}=\frac{f_{d_{i}, c_{j}}}{\sum_{c_{k} \in \mathcal{C}} f_{d_{i}, c_{k}}}, \forall d_{i} \in \mathcal{D}^{U}
$$

Após definidas as informações de classe dos documentos não rotulados por meio da propagação das informações de classe dos termos e posterior padronização dos valores, é realizada a otimização das informação de classe dos documentos não rotulados considerando os documentos relacionados. A informação de classe de um documento $d_{i}$ para uma classe $c_{j}$ na iteração $s+1$ considerando as informações de classe de documentos relacionados é dada por:

$$
f_{d_{i}, c_{j}}^{(s+1)}=f_{d_{i}, c_{j}}^{(s)}+\eta\left(\sum_{d_{k} \in \mathcal{D}} w_{d_{i}, d_{k}} \cdot e r r o_{-} d o c_{d_{i}, c_{j}}^{(s)}\right) .
$$

As informações de classe dos termos e dos documentos são atualizadas iterativamente até que um critério de parada seja atingido. Foram considerados como critério de parada o número máximo de iterações e o erro quadrático médio mínimo, isto é, até que a média das soma quadrática dos erros erro_classif_lab $b_{d_{k}, c_{j}}$, erro_classif_unlab $b_{d_{k}, c_{j}}$, erro_termo $t_{k}, c_{j}$ no caso da Equação 4.48, e erro_doc $c_{d_{k}, c_{j}}$ no caso da Equação 4.51, sejam menores que um limiar $\epsilon$. As iterações para otimizar as informações de classe dos termos considerando a Equação 4.48 ou as iterações para otimizar as informações de classe dos termos considerando a Equação 4.51 são denominadas iterações locais. As Equações 4.48 e 4.51 juntamente com a função de propagação de informações de classe dos termos para 
os documento (Equação 4.49) e padronização das informações de classe dos documentos não rotulados (Equação 4.50) são aplicadas iterativamente até que as informações de classe dos termos e dos documentos não rotulados convirjam ou até um número fixo de iterações. A aplicação desse conjunto de iterações locais e propagação de rótulos é denominada iteração global.

No Algoritmo 19 é apresentado o pseudocódigo do TCHN. Nas linhas 1-11 são induzidas as informações de classe iniciais para os termos considerando apenas documentos rotulados, uma vez que os documentos não rotulados não possuem informações de classe no início da execução do algoritmo TCHN. A indução das informações de classe dos termos nesta etapa do algoritmo é realizada justamente para definir informações de classe inicias para os documentos não rotulados. Nas linhas 12-15 é feita a propagação das informações de classe dos termos para os documentos não rotulados e a padronização das informações de classe. A função Classificar_Documento $\left(\mathbf{w}_{d_{i}}, \mathbf{F}(\mathcal{T})\right)$ corresponde a aplicação da Equação 4.49 enquanto que a função Padronizar $\left(\mathbf{f}_{d_{i}}\right)$ corresponde a aplicação da Equação 4.50.

Após a atribuição das informações de classe aos documentos rotulados, são iniciadas as iterações globais do algoritmo TCHN (linhas 16-66). Nas linhas 17-27, as informações de classe dos termos são otimizadas considerando as informações de classe dos documentos não rotulados. Nas linhas 28-37 é feita a minimização das informações de classe entre termos relacionados. Após otimizada as informações de classe entre os termos, essas são propagadas para definir as informações de classe dos documentos não rotulados, conforme apresentado nas linhas 38-41. Posteriormente à propagação, são otimizadas as informações de classe dos documentos não rotulados considerando as relações entre os documentos, que corresponde às linhas 42-50. Por fim, nas linhas 55-65 as informações de classe dos termos são otimizadas considerando as informações de classe dos documentos rotulados.

Vale ressaltar que foram padronizadas as relações do tipo documento-termo na aplicação do algoritmo TCHN para que o valor máximo do peso deste tipo de relação seja igual à das relações termo-termo e documento-documento, isto é, para que o peso máximo de uma relação documento-termo seja igual a 1. Dado isso, o peso da relação entre um documento $t_{i}$ e um termo $t_{j}$ é padronizado considerando a Equação 4.52.

$$
w_{d_{i}, t_{j}}=\frac{w_{d_{i}, t_{j}}}{\sum_{t_{k} \in \mathcal{T}} w_{d_{i}, t_{k}}}
$$

Vale ressaltar que um caso particular do algoritmo TCHN é quando a rede é formada apenas por relações entre documento e termos (rede bipartida), na qual a função objetivo corresponde aos dois primeiros termos da Equação 4.45, conforme apresentado na Equação 4.53. Neste caso o algoritmo é denominado Transductive Classification based on Bipartite Heterogeneous Network (TCBHN) (Rossi et al., 2015a). 


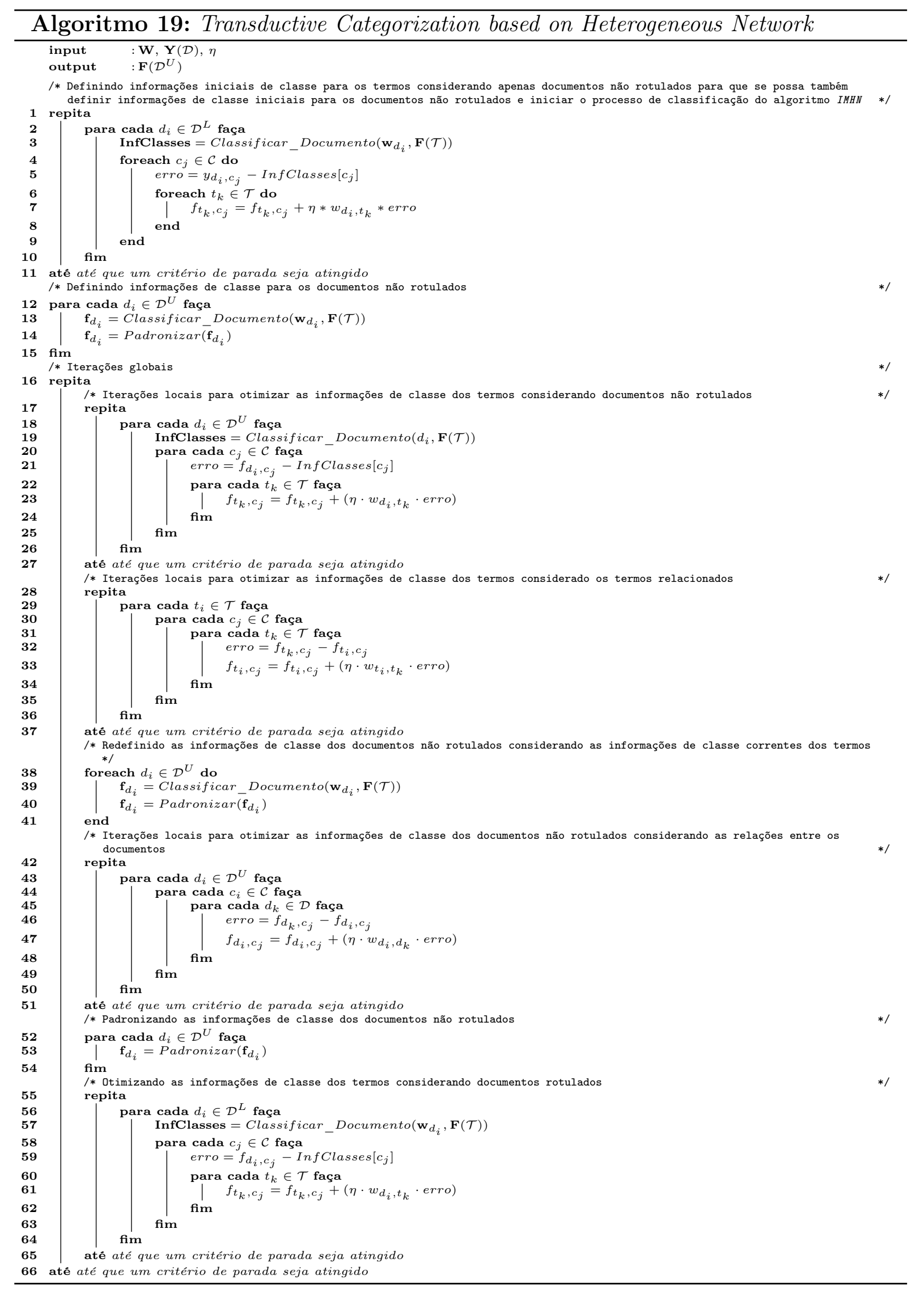

$$
Q(\mathbf{F})=\frac{1}{2}\left(\sum_{c_{j} \in \mathcal{C}} \sum_{d_{k} \in \mathcal{D}^{L}} y_{d_{k}, c_{j}}-\sum_{t_{i} \in \mathcal{T}}\left(w_{d_{k}, t_{i}} \cdot f_{t_{i}, c_{j}}\right)\right)^{2}+
$$




$$
\frac{1}{2}\left(\sum_{c_{j} \in \mathcal{C}} \sum_{d_{k} \in \mathcal{D}^{U}} f_{d_{k}, c_{j}}-\sum_{t_{i} \in \mathcal{T}}\left(w_{d_{k}, t_{i}} \cdot f_{t_{i}, c_{j}}\right)\right)^{2}
$$

Vale ressaltar que a possibilidade de alteração das informações de classe dos exemplos rotulados (Ji et al., 2010) ou a diminuição do peso de documentos não rotulados na otimização das informações de classe dos termos (Nigam et al., 2000) poderiam ser empregadas no algoritmo $T C H N$ para aumentar sua performance de classificação. Entretanto, isso acarretaria em um aumento no número de parâmetros no algoritmo, e neste projeto de doutorado optou-se por manter um menor número de parâmetros possível. Porém, conforme será apresentado na Seção 4.4, o algoritmo TCHN é capaz de obter uma performance de classificação maior que a de outros algoritmos mesmo tendo uma quantidade menor de parâmetros.

\section{Análise de Complexidade}

O processo de otimização das informações de classe para cada tipo de objeto (iterações locais) são repetidas no máximo $n_{\text {local }}$ vezes para cada tipo de objeto e o conjunto das iterações locais adicionados da propagação de rótulos (iterações globais) são repetidas no máximo $n_{\text {global }}$ vezes. Seja $\overline{|\mathcal{E}(\mathcal{D}, T)|}$ o número médio de relações entre documentos e termos, $\overline{|\mathcal{E}(\mathcal{T}, \mathcal{T})|}$ o número médio de relações entre termos e $\overline{|\mathcal{D}(\mathcal{D}, \mathcal{D})|}$ o número médio de relações entre documentos.

A complexidade das iterações locais para otimizar as informações dos termos é $O\left(n_{\text {local }} *\right.$ $(|\mathcal{D}| * \overline{|\mathcal{E}(\mathcal{D}, T)|})+(|\mathcal{E}| * \overline{|\mathcal{E}(\mathcal{T}, \mathcal{T})|}))$. Já a complexidade da otimização das informações de classe dos documentos considerado documentos relacionados é dada por $O\left(n_{\text {local }} *\right.$ $(|\mathcal{D}| * \overline{|\mathcal{E}(\mathcal{D}, \mathcal{D})|})$. Já o custo para propagar as informações de classe dos termos para os documentos é $O\left(n_{\text {global }} *(|\mathcal{D}| * \overline{|\mathcal{E}(\mathcal{D}, \mathcal{T})|})\right)$. Portanto, a complexidade do algoritmo TCHN é dada por $O\left(n_{\text {global }} *\left(n_{\text {local }} *(|\mathcal{D}| * \overline{|\mathcal{E}(\mathcal{D}, T)|})+|\mathcal{E}| * \overline{|\mathcal{E}(\mathcal{T}, \mathcal{T})|}+|\mathcal{D}| * \overline{|\mathcal{E}(\mathcal{D}, \mathcal{D})|}\right)\right.$.

Impacto do Uso de Documentos Não Rotulados na Definição das Informações de Classe dos Termos

Para ilustrar o funcionamento do algoritmo $T C H N$ e ilustrar o impacto dos documentos rotulados na inferência das informações de classe dos termos, por facilidade de explicação, foi gerada uma rede bipartida com 8 documentos e 9 termos, como apresentado na Figura 4.6. Nesta figura, os documentos 1, 2, 3, e 4 pertencem à Classe 1 e os documentos 5, 6, 7, 8 pertencem à Classe 2. Os termos 1, 2 e 3 ocorrem exclusivamente em documentos da Classe 1, e os termos 7, 8 e 9 ocorrem exclusivamente em documento da Classe 2. Os termos 4, 5 e 6 ocorrem em documentos de ambas as classes. Também para facilitar a ilustração do funcionamento, as frequências de todos os termos nos documentos são iguais a 1 e foi utilizado $\eta=0.5$.

Para este exemplo de funcionamento, a classificação transdutiva é inicializada com apenas um documento rotulado para cada classe, Doc 1 para a Classe 1 e Doc 8 para a 
Classe 2, como apresentado na Figura 4.6(a). Primeiramente, as informações de classe dos termos são inferidas considerando apenas documentos rotulados, como apresentado na Figura 4.6(b). As informações de classe dos termos são então propagadas para os documentos não rotulados e posteriormente normalizadas para definir as informações de classe dos mesmos, como apresentado na Figura 4.6(c). As informações atribuídas aos documentos agora também utilizadas para redefinir das informações de classe dos termos, que consequentemente, após propagadas, irão redefinir as informações de classe dos documentos não rotulados, como apresentado na Figura 4.6(d).

Na Figura 4.6(e) é apresentado as informações de classe da rede quando atingido um critério de parada do algoritmo TCHN. Após atingir um critério de parada, um documento não rotulado é classificado de acordo com o maior valor de informação de classe. Nesse exemplo ilustrativo, todos os documentos foram corretamente classificados. Vale ressaltar que sem o uso de documentos não rotulados (Figura 4.6(b)), os documentos 4 e 5 não teriam informações de classe inferidas e portanto não seriam classificados ou ainda seriam classificados aleatoriamente.

Para ilustrar o impacto do uso de documentos não rotulados na inferência das informações de classe dos termos em uma coleção de textos real, foi utilizada a coleção Computer Science Technical Reports (CSTR) (Rossi et al., 2013), a qual é composta por documentos das seguintes categorias: "Artificial Intelligence (AI)/Natural Language Processing(NLP)", "Robotics/Vision", "Systems", and "Theory". Foi utilizada uma rede bipartida para representar a coleção $C S T R$, uma vez que esse tipo de rede é suficiente para ilustrar o impacto dos documentos não rotulados nas informações de classe dos termos. Foram considerados os algoritmos (i) $I M H N^{\mathrm{R}}$, que infere as informações de classe dos termos considerando apenas documentos rotulados, e (ii) $T C H N$, que infere as informações de classe dos termos considerando documentos rotulados e não rotulados.

Para esse exemplo, foram selecionados aleatoriamente 10 documentos rotulados de cada classe para o exemplo. Foram utilizadas 100 iterações máximas locais e 10 iterações máximas globais para o algoritmo $T C H N$, e 1000 iterações máximas para o algoritmo $I M H N^{\mathrm{R}}$. Para ambos os algoritmos foi utilizado $\eta=0.05$. Para essa ilustração, as palavras foram radicalizadas utilizando o algoritmo de Porter (Porter, 1980).

Na Tabela 4.1 é apresentado o ranking das informações de classe dos termos considerando a classe $I A / N L P$ com e sem a utilização de documentos rotulados, isto é, inferidos pelos algoritmo $T C H N$ e $I M H N^{\mathrm{R}}$ respectivamente. Pode-se observar que termos importantes para a classe $I A / N L P$ como "learn", "label", e "language" não estão entre os primeiros termos do ranking quando são considerados apenas documentos rotulados. Outros termos importantes como "knowledge" e "class" estão presentes em ambos os rankings. Porém, esses dois termos apresentam um baixo valor de informação de classe para $I A / N L P$ considerando apenas documentos rotulados em comparação com o valor obtido considerando documentos rotulados e não rotulados.

Pode-se notar também que termos importantes para a classe $I A / N L P$ e não importantes 


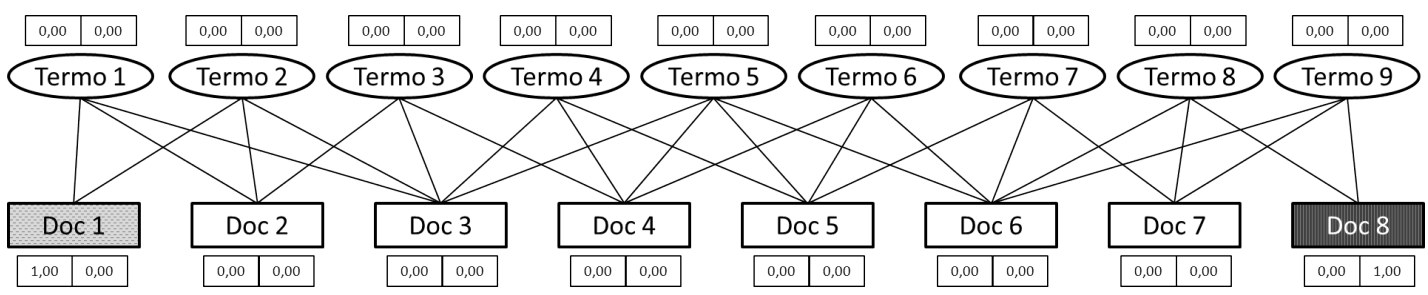

(a) Informações de classe inicias dos objetos da rede.

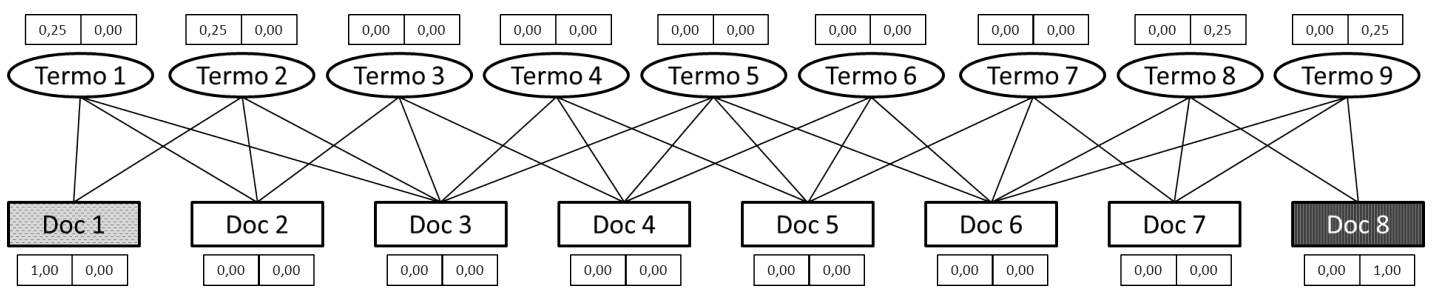

(b) Informações de classe dos termos inferidas considerando apenas documentos rotulados.

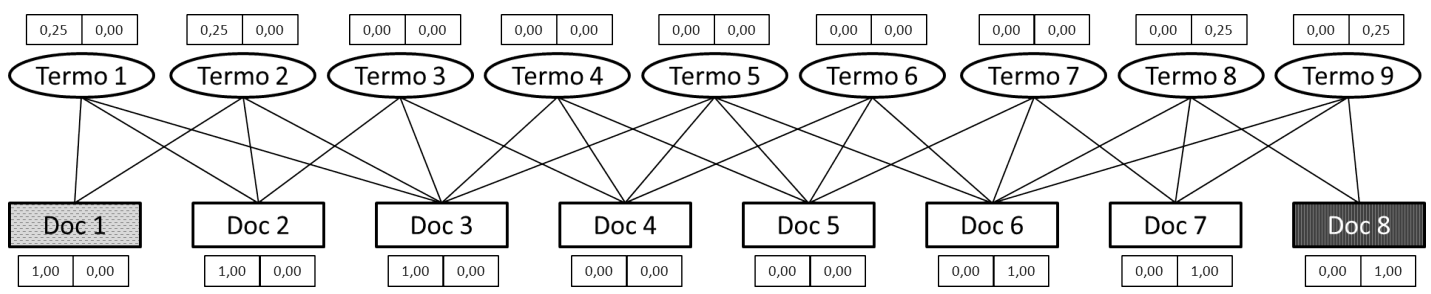

(c) Informações de classe dos documentos após a propagação de rótulos.

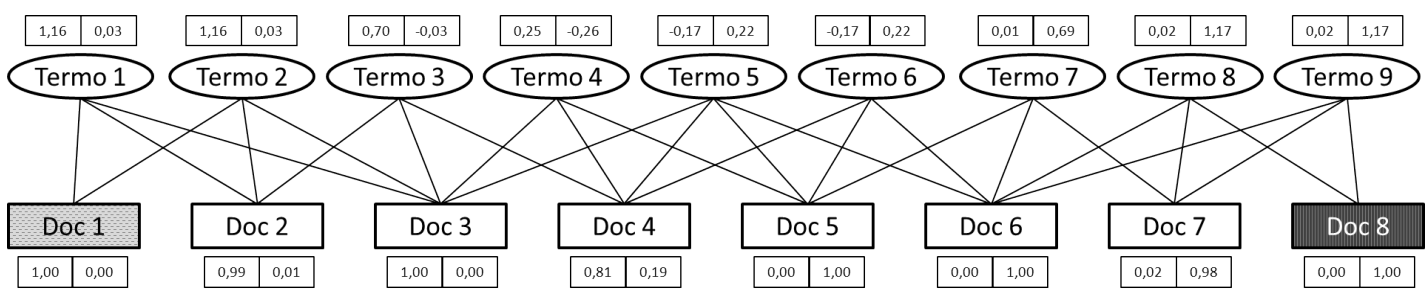

(d) Redefinição das informações de classe dos termos considerando documentos rotulados e não rotulados e redefinição das informações de classe dos documentos não rotulados com as novas informações de classe dos termos.

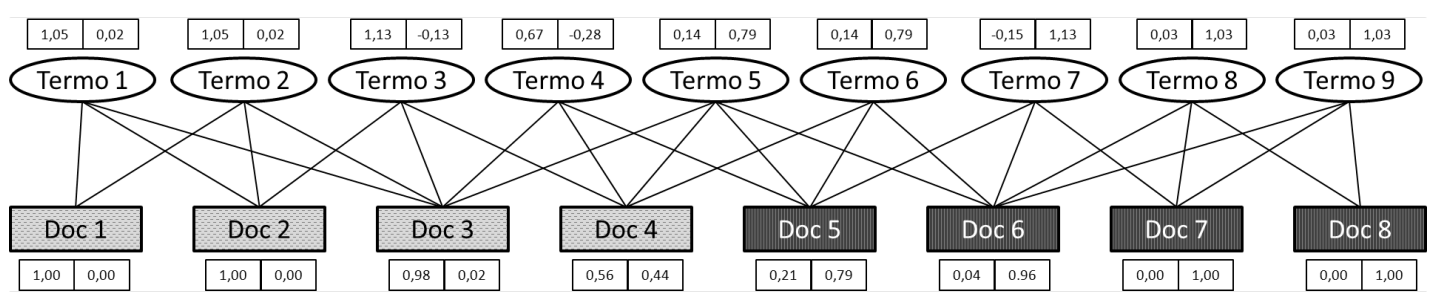

(e) Valores finais das informações de classe dos objetos da rede e classificação dos documentos não rotulados utilizando o arg-max das informações de classe.

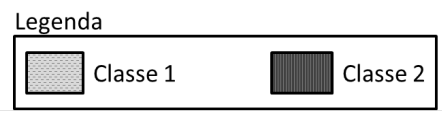

Figura 4.6: Funcionamento do algoritmo $T C B H N$ no exemplo ilustrativo.

para as outras classes da coleção CSTR, como "learn", "word", "label", "knowledge" e "discours", apresentam pequenos valores de informação de classe negativa ou informações de classe zeradas para as demais classes ao considerar apenas documentos rotulados. Por outro lado, ao considerar também documentos não rotulados, não há informações de classe 
zeradas para as outras classes e os valores negativos são significativamente maiores em relação ao primeiro caso. Assim, ao considerar documentos não rotulados na inferência das informações de classe dos termos, alguns termos importantes para a classe $I A / N L P$, como "learn", "word", "label", "knowledge", e "discours", favorece a rotulação de um documento que contenha esses termos com a classe $I A / N L P$ como inibe a rotulação desse documento para as demais classes. Vale ressaltar que as diferenças nas informações de classe obtidas pelo $T C H N$ em comparação com o $I M H N$ têm impacto direto na performance de classificação, conforme apresentado na Seção 4.4 .

\section{Extensão do Algoritmo TCHN para Outro Objetos e Conjuntos de Dados}

O algoritmo $T C H N$ pode ser facilmente estendido para incorporar outros objetos que possam vir a compor uma coleção de textos. Por exemplo, caso exista informações sobre os autores dos textos, e seja $\mathcal{A}=\left\{a_{1}, a_{2}, \ldots, a_{o}\right\}$ o conjunto de autores dos textos de uma coleção, pode-se utilizar as relações do tipo autor-documento acrescentando o seguinte termo na Equação 4.45

$$
+\frac{1}{2}\left(\sum_{c_{j} \in \mathcal{C}} \sum_{d_{k} \in \mathcal{D}} \sum_{a_{i} \in \mathcal{A}} w_{d_{k}, a_{i}}\left(f_{d_{k}, c_{j}}-f_{a_{i}, c_{j}}\right)\right)^{2} .
$$

Para uma rede heterogênea utilizada para representar qualquer conjunto de dados, o algoritmo $T C H N$ pode ser aplicado minimizando a seguinte função objetivo:

$$
\begin{aligned}
Q(\mathbf{F})= & \frac{1}{2}\left(\sum_{c_{j} \in \mathcal{C}} \sum_{o_{k} \in \mathcal{O}^{L}} y_{o_{k}, c_{j}}-\sum_{o_{i} \in \mathcal{O}}\left(w_{o_{i}, o_{k}} \cdot f_{o_{i}, c_{j}}\right)\right)^{2} \\
& \frac{1}{2}\left(\sum_{c_{j} \in \mathcal{C}} \sum_{o_{k} \in \mathcal{O}} \sum_{o_{i} \in \mathcal{O}} w_{o_{i}, o_{k}}\left(f_{o_{i}, c_{j}}-f_{o_{k}, c_{j}}\right)\right)^{2}
\end{aligned}
$$

\subsection{Avaliação Experimental}

Nesta seção são apresentados os resultados da avaliação experimental para classificação transdutiva de textos. Nesta avaliação foram comparados e analisados diferentes algoritmos de classificação baseados no modelo espaço-vetorial, baseados em redes existentes e os baseados em redes propostos. Também foi comparado e analisado o impacto de diferentes quantidades de documentos rotulados e dos diferentes tipos de redes na performance de classificação. Todos os códigos-fonte implementados e utilizados nesta avaliação bem como os resultados de todos os algoritmos e seus parâmetros estão disponíveis na pagina web http://sites.labic.icmc.usp.br/ragero/thesis/transductive_ learning/. Nas próximas seções são apresentados detalhes da configuração experimental e os resultados. 
Tabela 4.1: Valores de informações de classe dos termos inferidas pelo algoritmo $I M H N^{\mathrm{R}}$, isto é, considerando apenas documentos rotulados, e inferidas pelo algoritmo $T C H N$, isto é, considerando documentos rotulados e não rotulados.

\begin{tabular}{|c|c|c|c|c|}
\hline \multicolumn{5}{|c|}{ "Documentos Rotulados $\left(I M H N^{\mathrm{R}}\right)$} \\
\hline$\overline{\overline{\text { Termos }}}$ & $A I / N L P$ & Robotics & System & Theory \\
\hline extract & 0,0065 & $-0,0065$ & 0,0000 & $\overline{0,0000}$ \\
\hline knowledg & 0,0065 & $-0,0065$ & 0,0000 & 0,0000 \\
\hline acquisit & 0,0022 & $-0,0022$ & 0,0000 & 0,0000 \\
\hline addit & 0,0022 & $-0,0035$ & 0,0000 & 0,0014 \\
\hline analysi & 0,0022 & $-0,0022$ & 0,0000 & 0,0000 \\
\hline area & 0,0022 & $-0,0022$ & 0,0000 & 0,0000 \\
\hline art & 0,0022 & 0,0003 & 0,0000 & 0,0000 \\
\hline class & 0,0022 & $-0,0022$ & 0,0000 & 0,0000 \\
\hline compar & 0,0022 & $-0,0022$ & 0,0000 & 0,0000 \\
\hline condit & 0,0022 & $-0,0022$ & 0,0000 & 0,0000 \\
\hline current & 0,0022 & $-0,0022$ & 0,0000 & 0,0000 \\
\hline enabl & 0,0022 & $-0,0022$ & 0,0000 & 0,0000 \\
\hline entiti & 0,0022 & $-0,0022$ & 0,0000 & 0,0000 \\
\hline event & 0,0022 & $-0,0022$ & 0,0000 & $\overline{0,0000}$ \\
\hline exampl & 0,0022 & $-0,0022$ & 0,0000 & 0,0000 \\
\hline exist & 0,0022 & 0,0003 & 0,0000 & 0,0000 \\
\hline explor & 0,0022 & $-0,0022$ & 0,0000 & 0,0000 \\
\hline fact & 0,0022 & $-0,0022$ & 0,0000 & 0,0000 \\
\hline field & 0,0022 & 0,0003 & 0,0000 & 0,0000 \\
\hline focus & 0,0022 & $-0,0022$ & 0,0000 & 0,0000 \\
\hline follow & 0,0022 & $-0,0022$ & 0,0000 & 0,0000 \\
\hline gener & 0,0022 & $-0,0022$ & 0,0000 & 0,0000 \\
\hline give & 0,0022 & $-0,0022$ & 0,0000 & 0,0000 \\
\hline high & 0,0022 & $-0,0022$ & 0,0000 & 0,0000 \\
\hline idea & 0,0022 & $-0,0022$ & 0,0000 & 0,0000 \\
\hline individu & 0,0022 & $-0,0022$ & 0,0000 & 0,0000 \\
\hline inform & 0,0022 & $-0,0022$ & 0,0000 & 0,0000 \\
\hline linguist & 0,0022 & $-0,0022$ & 0,0000 & 0,0000 \\
\hline make & 0,0022 & $-0,0022$ & 0,0000 & 0,0000 \\
\hline norm & 0,0022 & $-0,0022$ & 0,0000 & 0,0000 \\
\hline order & 0,0022 & $-0,0022$ & 0,0037 & $-0,0037$ \\
\hline pertain & 0,0022 & $-0,0022$ & 0,0000 & 0,0000 \\
\hline prefer & 0,0022 & $-0,0026$ & 0,0012 & $-0,0008$ \\
\hline research & 0,0022 & $-0,0022$ & 0,0000 & 0,0000 \\
\hline respect & 0,0022 & $-0,0022$ & 0,0012 & $-0,0012$ \\
\hline simpl & 0,0022 & $-0,0022$ & 0,0000 & 0,0000 \\
\hline specif & 0,0022 & $-0,0022$ & 0,0000 & 0,0000 \\
\hline state & 0,0022 & 0,0003 & 0,0000 & 0,0000 \\
\hline techniqu & 0,0022 & $-0,0001$ & 0,0000 & 0,0005 \\
\hline throughput & 0,0022 & $-0,0022$ & 0,0000 & 0,0000 \\
\hline volum & 0,0022 & $-0,0022$ & 0,0000 & 0,0000 \\
\hline work & 0,0022 & $-0,0022$ & 0,0000 & 0,0000 \\
\hline abandon & 0,0000 & 0,0000 & 0,0000 & 0,0000 \\
\hline abil & 0,0000 & 0,0000 & 0,0000 & 0,0000 \\
\hline abort & 0,0000 & 0,0000 & 0,0000 & 0,0000 \\
\hline absenc & 0,0000 & 0,0000 & 0,0000 & 0,0000 \\
\hline absolut & 0,0000 & 0,0000 & 0,0000 & 0,0000 \\
\hline abstract & 0,0000 & 0,0000 & 0,0000 & 0,0000 \\
\hline acceler & 0,0000 & 0,0000 & 0,0000 & 0,0000 \\
\hline accept & 0,0000 & 0,0000 & 0,0000 & 0,0000 \\
\hline
\end{tabular}

$\overline{\text { Documentos Rotulados e Não Rotulados (TCHN) }}$

\begin{tabular}{l||l|l|l|l}
\hline \hline Termos & AI/NLP & Robotics & System & Theory \\
\hline
\end{tabular}

\begin{tabular}{l||c|c|c|c}
\hline \hline learn & 2,8961 & $-0,2465$ & $-0,4497$ & $-0,5075$ \\
\hline
\end{tabular}

\begin{tabular}{l|c|c|c|c}
\hline system & 2,8264 & 0,2930 & 0,8924 & 0,3062 \\
\hline
\end{tabular}

\begin{tabular}{l|c|c|c|c}
\hline reason & 2,2541 & $-0,3650$ & $-0,3968$ & $-0,3164$ \\
\hline
\end{tabular}

\begin{tabular}{l||c|c|c|c}
\hline word & 2,2303 & $-0,1227$ & $-0,1046$ & $-0,1820$ \\
\hline
\end{tabular}

\begin{tabular}{l|l|l|l|l}
\hline label & 2,2020 & $-0,9021$ & $-0,4309$ & $-0,4910$ \\
\hline
\end{tabular}

\begin{tabular}{l|c|c|c|c}
\hline languag & 2,0938 & $-0,0441$ & 0,0103 & 0,0151 \\
\hline
\end{tabular}

\begin{tabular}{l|ccccc}
\hline task & 1,9653 & 0,3391 & 0,1562 & 0,0782 \\
\hline approach & 1,8651 & 0,4169 & 0,0604 & $-0,2662$
\end{tabular}

\begin{tabular}{|l|l|l|l|l}
\hline knowledg & 1,8584 & $-0,0647$ & $-0,1534$ & $-0,3536$ \\
\hline
\end{tabular}

\begin{tabular}{l|c|c|c|c}
\hline goal & 1,85819 & 0,0248 & $-0,1752$ & $-0,3624$ \\
\hline
\end{tabular}

\begin{tabular}{|l|c|c|c|c|}
\hline gener & 1,7993 & $-0,6234$ & $-0,3756$ & 1,3022 \\
\hline
\end{tabular}

\begin{tabular}{|l|c|c|c|c|}
\hline discours & 1,6799 & $-0,2984$ & $-0,0774$ & $-0,3274$ \\
\hline
\end{tabular}

\begin{tabular}{l||c|c|c|c}
\hline mean & 1,6573 & $-0,3072$ & $-0,3520$ & $-0,3141$ \\
\hline
\end{tabular}

\begin{tabular}{l|c|c|c|c}
\hline includ & 1,6573 & $-0,3072$ & $-0,3520$ & $-0,3141$ \\
\hline
\end{tabular}

\begin{tabular}{l||c|c|c|c}
\hline class & 1,5588 & $-0,0769$ & $-0,0597$ & 0,3397 \\
\hline natur & 1,5527 & $-0,1602$ & $-0,2187$ & 0,5213
\end{tabular}

\begin{tabular}{l|ccc|c} 
natur & 1,5527 & $-0,1602$ & $-0,2187$ & 0,5213 \\
\hline speech & 1,5240 & 0,1083 & 0,0615 & $-0,0823$ \\
\hline featur & 1,4760 & 0,4561 & $-0,6301$ & $-0,0584$ \\
\hline
\end{tabular}

\begin{tabular}{l|c|c|c|c}
\hline work & 1,4612 & 0,3024 & $-0,0503$ & $-0,1407$ \\
\hline
\end{tabular}

\begin{tabular}{l|c|c|c|c}
\hline network & 1,3922 & $-0,0962$ & $-0,0399$ & $-0,1426$ \\
\hline
\end{tabular}

\begin{tabular}{l|ccc|c}
\hline plan & 1,3797 & 0,6019 & 0,0395 & 0,0899 \\
\hline extract & 1,2469 & $-0,4217$ & $-0,1095$ & $-0,2492$
\end{tabular}

\begin{tabular}{l||c|c|c|c}
\hline dialogu & 1,2307 & $-0,1604$ & $-0,0449$ & $-0,2403$ \\
\hline
\end{tabular}

\begin{tabular}{l|l|l|l|l}
\hline utter & 1,1998 & $-0,2322$ & $-0,0837$ & $-0,2575$ \\
\hline
\end{tabular}

\begin{tabular}{l||c|c|c|c}
\hline resolut & 1,1665 & $-0,3889$ & $-0,1815$ & $-0,2486$ \\
\hline
\end{tabular}

\begin{tabular}{l|cc|c|c}
\hline combin & 1,1544 & $-0,2087$ & 0,0432 & $-0,0751$ \\
\hline
\end{tabular}

\begin{tabular}{l||c|c|c|c}
\hline paper & 1,1501 & 0,6362 & 0,5113 & 0,0915 \\
\hline
\end{tabular}

\begin{tabular}{l|ccc|c}
\hline modul & 1,1335 & $-0,3997$ & $-0,2140$ & $-0,2892$ \\
\hline represent & 1,1070 & 0,5214 & $-0,0314$ & $-0,2501$ \\
\hline
\end{tabular}

\begin{tabular}{l||c|c|c|c}
\hline organ & 1,0750 & $-0,2204$ & $-0,1899$ & $-0,2716$ \\
\hline
\end{tabular}

\begin{tabular}{l|c|c|c|c}
\hline inform & 1,0534 & 1,3847 & $-0,4025$ & $-0,1084$ \\
\hline structur & 1,0294 & 0,4220 & 0,3224 & $-0,2304$ \\
\hline
\end{tabular}

\begin{tabular}{|c|c|c|c|c}
\hline understand & 1,0230 & $-0,1736$ & $-0,0709$ & $-0,2406$ \\
\hline
\end{tabular}

\begin{tabular}{l|c|c|c|c}
\hline speaker & 1,0027 & 0,0359 & 0,0433 & $-0,0755$ \\
\hline
\end{tabular}

\begin{tabular}{l|lll|l}
\hline spoken & 1,0020 & $-0,1459$ & $-0,0415$ & $-0,1680$ \\
\hline
\end{tabular}

\begin{tabular}{l|c|c|c|c}
\hline output & 1,0020 & $-0,1459$ & $-0,0415$ & $-0,1680$ \\
\hline
\end{tabular}

\begin{tabular}{l||c|c|c|c}
\hline process & 0,9942 & 1,0418 & $-0,0144$ & $-0,5005$ \\
\hline
\end{tabular}

\begin{tabular}{l||c|c|c|c}
\hline supervis & 0,9876 & $-0,4469$ & $-0,2053$ & $-0,3192$ \\
\hline user & 0,9858 & 0,0475 & 0,2628 & $-0,3132$
\end{tabular}

\begin{tabular}{l|ccccc}
\hline user & 0,9858 & 0,0475 & 0,2628 & $-0,3132$ \\
\hline convers & 0,9676 & $-0,1906$ & 0,0858 & $-0,1869$ \\
\hline
\end{tabular}

\begin{tabular}{l|c|c|c|c}
\hline domain & 0,9321 & 0,2116 & 0,1029 & 0,0787 \\
\hline
\end{tabular}

\begin{tabular}{l|ccccc}
\hline requir & 0,9230 & 0,3648 & 0,0985 & $-0,1814$ \\
\hline relat & 0,9125 & 0,3661 & $-0,1467$ & 0,2192
\end{tabular}

\begin{tabular}{l|c|c|c|c}
\hline specif & 0,8733 & $-0,0887$ & 0,1438 & $-0,0257$ \\
\hline
\end{tabular}

\begin{tabular}{l|c|c|c|c}
\hline specif & 0,8733 & $-0,0887$ & 0,1438 & $-0,0257$ \\
\hline report & 0,8716 & 0,7876 & $-0,1076$ & $-0,1491$ \\
\hline train & 0,8546 & 0,5378 & $-0,1125$ & $-0,0517$ \\
\hline
\end{tabular}

\begin{tabular}{|l|c|c|c|c}
\hline appli & 0,8513 & $-0,0968$ & $-0,0611$ & 0,0256 \\
\hline
\end{tabular}

\begin{tabular}{|l|c|c|c|c}
\hline appli & 0,8513 & $-0,0968$ & $-0,0611$ & 0,0256 \\
\hline individu & 0,8020 & $-0,1921$ & $-0,0656$ & $-0,1773$ \\
\hline
\end{tabular}

\begin{tabular}{l|l|l|l|l}
\hline individu & 0,8020 & $-0,1921$ & $-0,0656$ & $-0,1773$ \\
\hline transcript & 0,7851 & $-0,1900$ & $-0,0351$ & $-0,1285$ \\
\hline
\end{tabular}

\begin{tabular}{l||c|c|c|c} 
transcript & 0,7851 & $-0,1900$ & $-0,0351$ & $-0,1285$ \\
\hline present & 0,7822 & 1,3742 & 0,2544 & 0,2427 \\
\hline
\end{tabular}

\subsubsection{Configuração Experimental}

As coleções de textos, as características das representações baseadas no modelo espaçovetorial e em redes, bem como as medidas de performance de classificação utilizadas nesta 
avaliação experimental são detalhadas nos Apêndices A e B respectivamente. Vale ressaltar que na avaliação realizada neste capítulo foram consideradas somente as representações bag-of-words para os algoritmos baseados no modelo espaço-vetorial, uma vez que essa representação demonstrou uma performance de classificação superior para a maioria dos algoritmos indutivos supervisionados considerados na avaliação experimento do Capítulo 3 , inclusive para os algoritmos indutivos supervisionados que também são utilizados na avaliação experimental deste capítulo.

Os valores das medidas de performance de classificação utilizadas $\left(F 1^{\text {Micro }}\right.$ e $\left.F 1^{\text {Macro }}\right)$ correspondem à média dessas medidas em 10 execuções. Em cada execução foram selecionadas aleatoriamente $N$ documentos de cada classe como documentos rotulados. $\mathrm{O}$ restante dos documentos $(|\mathcal{D}|-N *|\mathcal{C}|)$ foram considerados como exemplos não rotulados no processo de classificação transdutiva. Esses documentos não rotulados também foram considerados como documentos de teste na avaliação, ou seja, a classificação desses documentos por meio da classificação transdutiva foi comparada com as classes reais para verificar a performance de classificação. Nesta avaliação experimental foi utilizado $N=\{1,10,20,30,40,50\}$. Foi considerado o menor número de documentos rotulados possível (1 exemplo rotulados por classe) e o número de documentos rotulados por classe foi incrementado em 10, indo de 10 a 50 exemplos rotulados por classe. Isso permite demonstrar o comportamento dos algoritmos para diferentes quantidades de exemplos rotulados, demostrar o custo-benefício entre número de exemplos rotulados e performance de classificação, e as diferenças entre os algoritmos de aprendizado transdutivo e os algoritmos de aprendizado indutivo semissupervisionado conforme aumenta o número de documentos rotulados.

Foram utilizados algoritmos de classificação baseados no modelo espaço-vetorial e algoritmos baseados em redes, tanto os existentes quanto os propostos. Os algoritmos baseados no modelo espaço-vetorial e seus respectivos parâmetros são:

- Self-Training (MNB-Se): foi considerado o algoritmo Multinomial Nä̈ve Bayes como algoritmo de aprendizado indutivo para a abordagem Self-Training, uma vez que esse foi o algoritmo baseado no modelo espaço-vetorial que apresentou o melhor custo benefício entre tempo e performance de classificação considerando os algoritmos de aprendizado supervisionados, conforme apresentado no Capítulo 3. Foi utilizado $X=\{5,10,15,20\}$ como número de exemplos não rotulados mais confiantes que são inseridos no conjunto de treinamento a cada iteração da abordagem Self-Training.

- Co-Training ( $M N B-C o$ ): também foi utilizado o algoritmo Multinomial Naïve Bayes como algoritmo de aprendizado indutivo supervisionado para a abordagem Co-Training. Além do custo benefício mencionado acima, a utilização do mesmo algoritmo indutivo permite realizar uma comparação justa entre a abordagem $C o$ Training com a abordagem Self-Training. Foi utilizado $X=\{5,10,15,20\}$ como número de exemplos não rotulados mais confiantes que são inseridos no conjunto de treinamento a cada iteração da abordagem Self-Training. Foram geradas divisões 
aleatórias do espaço de atributos para gerar as visões e assim permitir a execução do Co-Training (Brefeld et al., 2005; Nigam e Ghani, 2000). Outras formas de gerar as visões bem como a utilização de outros algoritmos de aprendizado supervisionado inviabilizariam a execução do Co-Training na avaliação experimental realizada neste capítulo. Para cada execução do Co-Training foram gerados 10 divisões aleatórias dos espaço de atributos, uma vez que diferentes divisões podem apresentar diferentes performances de classificação.

- $\boldsymbol{E} \boldsymbol{M}$ : foi considerada a instanciação da abordagem $E M$ apresentada em Nigam et al. (2000) que é específica para a classificação transdutiva de textos. Foi utilizado $\lambda=\{0.1,0.3,0.5,0.7,0.9\}$ como valor de peso dado aos documentos não rotulados e $\left|\mathcal{S}^{c_{j}}\right|=\{1,2,5,10\}$ como número de componentes por classe.

- $\boldsymbol{T} \boldsymbol{S} \boldsymbol{V} \boldsymbol{M}$ : foi considerada a solução iterativa apresentada em Joachims (1999) que foi utilizada para a classificação de textos. Foi utilizado $C=1$ para induzir o hiperplano de separação considerando apenas exemplos rotulados, uma vez que esse valor de parâmetro apresenta, em geral, a melhor performance de classificação (Rossi et al., 2012). Foi utilizado $C^{\prime}=\left\{10^{-5}, 10^{-4}, 10^{-3}, 10^{-2}, 10^{-1}, 10^{0}, 10^{1}\right\}$ como parâmetros de punição para os documentos não rotulados que se encontram do lado incorreto do hiperplano. O algoritmo TSVM foi executado com e sem a função proposta em Joachims (1999) para manter a mesma proporção de classes dos documentos rotulados na classificação dos documentos não rotulados.

Os algoritmos baseados em redes utilizados para comparação nesta avaliação experimental são os baseados em regularização, uma vez que apresentam melhor custo benefício entre tempo e performance de classificação, conforme apresentado na Seção 4.2.2. Os tipos de redes empregados nos algoritmos serão especificados no frente dos nomes dos mesmos. Redes compostas por relações do tipo documento-documento serão denotadas por DD, redes compostas por relações termo-termo serão denotadas por TT e redes compostas por relações por relações documento-termo serão denotadas por DT. Redes compostas por mais de um tipo de relação serão denotadas pelos tipos de relações que as compões separadas um "-". Por exemplo, redes compostas por relações do tipo documento-termo e termo-termo serão denotadas por DT-TT. Portanto, por exemplo, o algoritmo TCHN aplicado a redes com relações documento-termo e termo-termo será denotado por TCHN(DD-DT).

Todos os algoritmos transdutivos baseados em regularização utilizados para comparação foram detalhados na Seção 4.2.2. Já os algoritmos propostos e também empregados nesta avaliação experimental foram apresentados na Seção 4.3. Para todos os algoritmos foram utilizadas as soluções iterativas apresentadas neste capítulo. O número máximo de iterações foi fixado em 1000 para todos os algoritmos.

Vale ressaltar que os algoritmos tradicionais para a propagação de rótulos em redes de similaridades de documentos, GFHF e $L L G C$, correspondem aos algoritmos $L P H N(\mathrm{DD})$ e GNetMine(DD) respectivamente. Vale ressaltar também que no caso da proposta de 
classificação baseada em redes de termos $(T C T N)$, pode-se empregar qualquer algoritmo de propagação de rótulo baseado em redes homogêneas, como o GFHF e o $L L G C$. Por facilidade de notação e para facilitar a comparação o TCTN quando utilizado o algoritmo GFHF para propagação de rótulos será denotado por $L P H N(\mathrm{TT})$ e quando utilizado o $L L G C$ será denotado por GNetMine(TT).

Os algoritmos baseados em redes com as respectivas redes empregadas e os parâmetros usados são:

- $\boldsymbol{T} M(\mathbf{D T})$ : foi utilizado $\alpha=0$, uma vez que não foram considerados objetos de outros domínios, $\beta=\{0,1 ; 1 ; 10 ; 100 ; 1000\}$ e $\gamma=\{0,1 ; 1 ; 10 ; 100 ; 1000\}$.

- $\operatorname{LPHN}(\mathrm{DT}), \operatorname{LPHN}(\mathrm{DD}), \operatorname{LPHN}$ (TT), LPHN(DD-DT), LPHN(DT-TT), LPHN (DD-DT-TT): o algoritmo $L P H N$ não possui parâmetros a serem especificados.

- GNetMine(DD), GNetMine(DT) e GNetMine(TT): foi utilizado $\alpha=\{0.1$, $0.3,0.5,0.7,0.9\}$ como peso dado as informações reais durante a propagação de rótulos. Não foram considerados diferentes valores para $\lambda$ uma vez que as redes são compostas por relações simples.

- GNetMine(DD-DT) e GNetMine(DT-TT): foi utilizado $\alpha=\{0,1 ; 0,5 ; 0,9\}$, $\lambda_{\mathcal{D}, \mathcal{T}}=\{0,1 ; 0,5 ; 0,9\}$ e $\lambda_{\mathcal{D}, \mathcal{D}}=1-\lambda_{\mathcal{D}, \mathcal{T}}$ para GNetMine $(\mathrm{DD}-\mathrm{DT})$ e $\lambda_{\mathcal{T}, \mathcal{T}}=1-\lambda_{\mathcal{D}, \mathcal{T}}$ para GNetMine(DT-TT).

- GNetMine(DD-DT-TT): foi utilizado $\alpha=\{0,1 ; 0,5 ; 0,9\}$ e como valores de $\lambda$ para os diferentes tipos de relações foram utilizados as triplas $\left[\lambda_{\mathcal{D}, \mathcal{D}} ; \lambda_{\mathcal{D}, \mathcal{T}} ; \lambda_{\mathcal{T}, \mathcal{T}}\right]=$ $\{[0,33 ; 0,33 ; 0,33] ;[0,40 ; 0,40 ; 0,20] ;[0,40 ; 0,20 ; 0,40] ;[0,20 ; 0,40 ; 0,40] ;[0,20 ; 0,20$; $0,60] ;[0,20 ; 0,60 ; 0,20] ;[0,60 ; 0,20 ; 0,20]\}$.

- $T C H N(\mathrm{DD}), T C H N(\mathrm{DT}), T C H N(\mathrm{TT}), T C H N(\mathrm{DD}-\mathrm{DT}), T C H N(\mathrm{DT}-\mathrm{TT})$, $\boldsymbol{T C H N}$ (DD-DT-TT): foi utilizado $\eta=\{0,01 ; 0,05 ; 0,1 ; 0,5\}, \epsilon=0,01,10$ iterações máximas globais e 100 iterações máximas locais, totalizando 1000 iterações.

Também foram utilizados algoritmos indutivos supervisionados para comparar a diferença na performance de classificação ao considerar documentos rotulados e não rotulados em relação à utilização de somente documentos rotulados. Neste caso, é induzido um modelo de classificação considerando somente os exemplos rotulados e este modelo é utilizado para classificar os demais exemplos não rotulados. Os algoritmos de aprendizado indutivo supervisionado e seus respectivos parâmetros são:

- $M N B$ : foi considerado o algoritmo Multinomial Nä̈ve Bayes uma vez que esse algoritmo é utilizado como algoritmo indutivo nas abordagens Self-Training, CoTraining e é o algoritmo base da abordagem Expectation Maximization. Isso permite comparar as diferenças na performance de classificação entre aprendizado indutivo e aprendizado transdutivo dos algoritmos baseados no modelo espaço-vetorial. 
- $k-N N$ : algoritmos tradicionais para a classificação em redes, como o GFHF (ou $L P H N(\mathrm{DD})$ ) e $L L G C$ (ou GNetMine(DD)), consideram redes baseadas nas similaridades entre os documentos. Para verificar se o uso das redes e de documentos não rotulados são de fato úteis para melhorar a performance de classificação, foi utilizado o algoritmo $k-N N$, que também realiza a classificação baseada em similaridades, porém, considerando apenas documentos rotulados. Foi utilizado $k=\{7 ; 17 ; 37 ; 57\}$, que correspondem aos mesmos valores de $k$ utilizados para gerar as redes de documentos do tipo $M k-N N$.

- $\boldsymbol{I M H N} \boldsymbol{N}^{\mathrm{R}}(\mathbf{D T})$ : esse algoritmo infere as informações de classe dos termos considerando apenas documentos rotulados. Isso corresponde à utilização apenas do primeiro termo da função de minimização do algoritmo TCHN (Equação 4.45). Isso permite avaliar o impacto na performance de classificação ao considerar documentos não rotulados por meio da comparação entre o algoritmo $I M H N^{\mathrm{R}}(\mathrm{DT})$ e $T C H N(\mathrm{DT})$. Foi utilizado $\eta=\{0,01 ; 0,05 ; 0,1 ; 0,5\}, \epsilon=0,01$, e 1000 iterações máximas, que correspondem aos mesmos parâmetros do TCHN.

\subsubsection{Resultados}

Nesta seção são apresentados os resultados obtidos considerando a configuração experimental apresentada na seção anterior. São exibidos três tipos de resultados para comparar e analisar as performances de classificação dos algoritmos utilizados nesta avaliação experimental: (i) gráficos de performance de classificação, (ii) tabela de vitórias e (iii) diagramas de diferença crítica ${ }^{7}$.

Em cada gráfico de performance de classificação é exibido os valores da medida $F 1^{\text {Micro }}$ ou $F 1^{\text {Macro }}$ obtidos por um determinado algoritmo para um determinado número de exemplos rotulados por classe. Nesses gráficos, o eixo horizontal corresponde ao número de exemplos rotulados por classe e o eixo vertical corresponde ao valor da performance de classificação. Os gráficos permitem uma comparação visual das performances de classificação obtidas pelos diferentes algoritmos e representações ${ }^{8}$.

Vale ressaltar que os valores das medidas $F 1^{\text {Micro }}$ e $F 1^{\text {Macro }}$ tendem a aumentar conforme o número de documentos rotulados aumenta. Porém, para algumas coleções

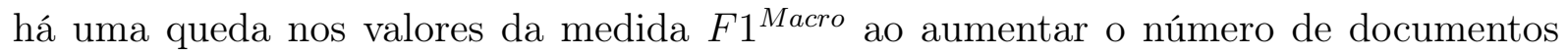
rotulados. Isso se deve ao fato de que para pequenas coleções de texto, nas quais o número de documentos de uma classe $c_{j}$ é menor ao igual ao número de documentos rotulados por classe, o número de documentos não rotulados para essa classe é zero, e portanto $F 1_{c_{j}}^{\text {Macro }}=0$, fazendo com que o valor total da medida $F 1^{\text {Macro }}$ decaia.

\footnotetext{
${ }^{7}$ Todas os resultado exibidos, análise e comparações consideram a maior performance de classificação obtida por determinado parâmetro ou configuração de rede empregada em um algoritmo, ou seja, as análises e comparações foram realizadas considerando o melhor caso dos algoritmos.

${ }^{8}$ Não foi possível executar todos os algoritmos com seus respectivos parâmetros para todas as redes e todas as coleções. Por isso, os resultados de alguns algoritmos foram omitidos dos gráficos.
} 
Em cada tabela de vitória é apresentado o número de vezes que um algoritmo (apresentado na linha) supera a performance de classificação de outro algoritmo (apresentado na coluna). Neste tipo de análise, foram consideradas somente coleções as quais foram possíveis executar todos os algoritmos e seus parâmetros com todas as representações apontadas na seção de configuração experimental. Nesse caso foram consideradas 30 coleções. Estão hachuradas (com a cor verde na versão colorida desta tese) as situações em que um algoritmo superou outro um maior número de vezes, isto é, quando a performance de classificação um algoritmo em relação ao outro foi maior em $50 \%$ das coleções, ou seja, em 16 ou mais coleções.

Cada diagrama de diferença crítica corresponde à uma ilustração gráfica do resultado do teste estatístico de Friedman $N \times N$ com pós-teste de Nemenyi e 95\% de confiança. Esse é um teste não paramétrico, baseado em ranking e aconselhável para a análise estatística dos resultados de múltiplos classificadores para múltiplas coleções (Trawinski et al., 2012; García et al., 2010; Demsar, 2006). Neste diagrama é exibido o ranking médio dos algoritmos e aqueles conectados por uma linha (diferença crítica) não apresentam diferenças estatisticamente significantes. Novamente, só foram considerados os resultados das coleções nas quais foi possível gerar resultados para todas as configurações apresentadas na seção anterior.

Devido à grande quantidade de algoritmos utilizados nesta avaliação experimental, foram criados 5 grupos de experimentos para melhor visualização, análise e compreensão dos resultados. No primeiro grupo de experimentos foram comparados os algoritmos $M N B$, $M N B-S e, M N B-C o, E M$ e TSVM. Os experimentos desse grupo visam avaliar o impacto do uso de documentos não rotulados na performance de classificação considerando algoritmos baseados no modelo espaço-vetorial.

Nas Figuras 4.7 e 4.8 são apresentados os gráficos de performance de classificação considerando a medida $F 1^{\text {Micro }}$ e nas Figuras 4.9 e 4.10 são apresentados os resultados considerando a medida $F 1^{\text {Macro }}$ para o primeiro grupo de experimentos. Por essas figuras pode-se observar que o algoritmo supervisionado $M N B$ apresentou maior performance de classificação para a maioria das coleções considerando as diferentes quantidades de documentos rotulados utilizadas. Portanto, pode-se observar que em coleções reais as premissas por parte dos algoritmos transdutivos baseados no modelo espaço-vetorial são violadas e suas performances de classificação são degradadas.

Para elucidar a comparação das performances de classificação dos diferentes algoritmos no primeiro grupo de experimentos, nas Tabelas 4.2 e Tabelas 4.3 são apresentadas as tabelas de vitórias para as medidas $F 1^{\text {Micro }}$ e $F 1^{\text {Macro }}$ respectivamente. Por essas tabelas pode-se observar que de fato o algoritmo supervisionado $M N B$ de fato obteve a maior performance de classificação para todas as quantidades de documentos rotulados utilizadas. O algoritmo TSVM obteve os menores números de vitórias em relação aos demais algoritmos. Pode-se observar também que a divisão das visões aleatórias para a execução do $M N B-C o$, em geral, obteve pior performance de classificação em relação a 


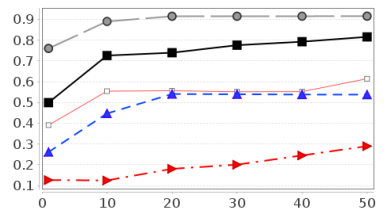

(a) Classic4

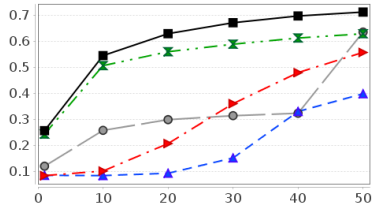

(e) Dmoz_Health_500

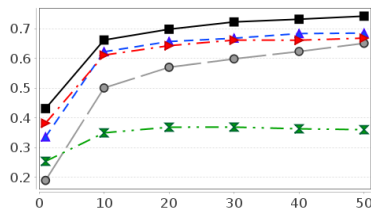

(i) FBIS

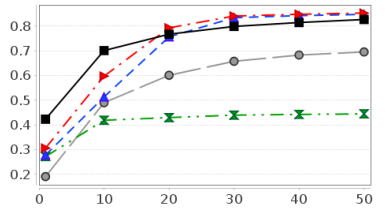

(m) La1s

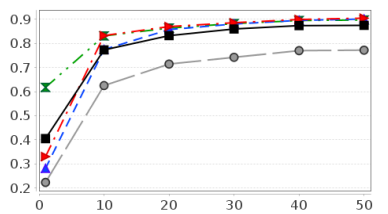

(q) $\mathrm{Oh} 0$

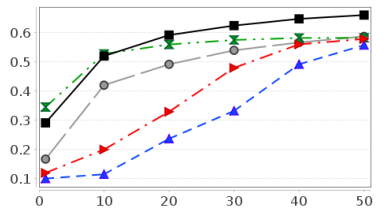

(u) Ohscal

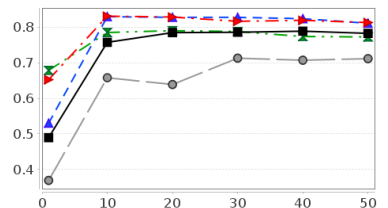

(b) CSTR

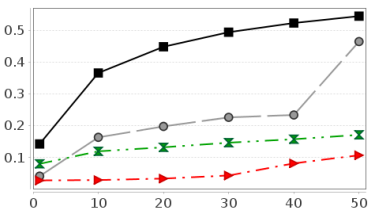

(c) Dmoz Business 500

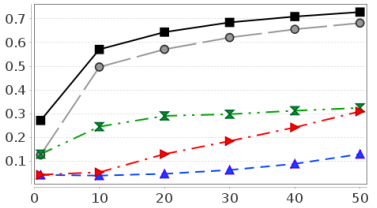

(g) Dmoz_Sports_500

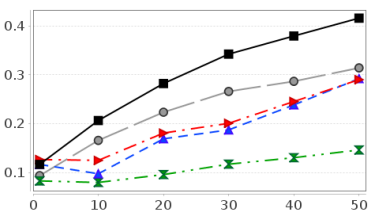

(k) Industry_Sector

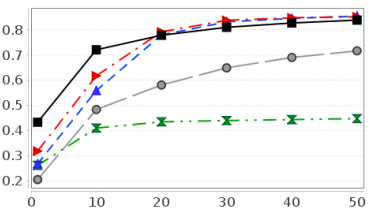

(n) La2s

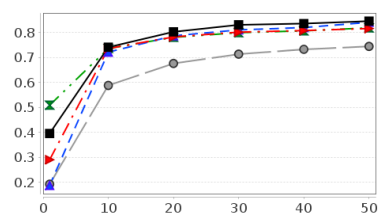

(r) Oh5

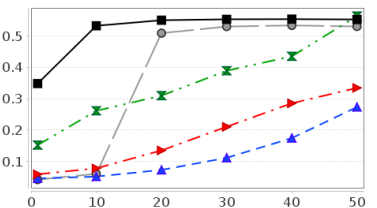

(v) Opinosis

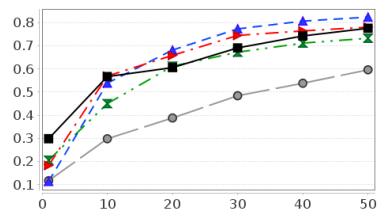

(y) Re1

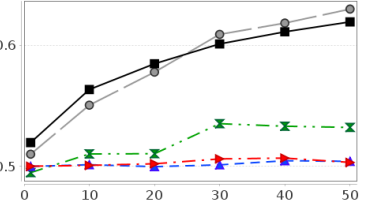

(o) Multi_Dom_Sentiment

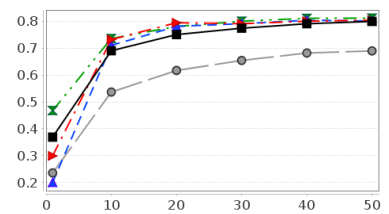

(s) Oh10

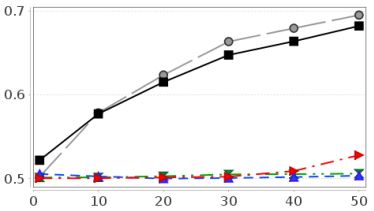

(w) Polarity

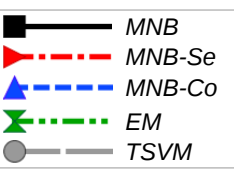

(z) Legenda

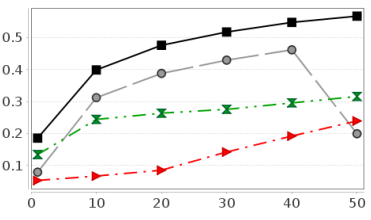

(d) Dmoz_Computers_500

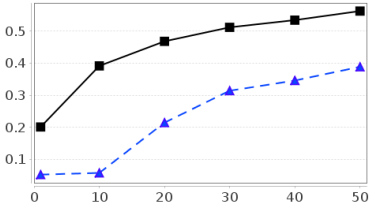

(h) Enron_Top_20

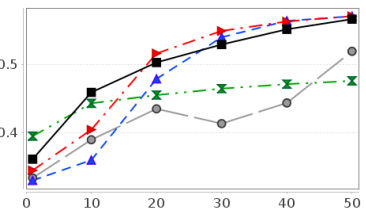

(l) IrishSentiment

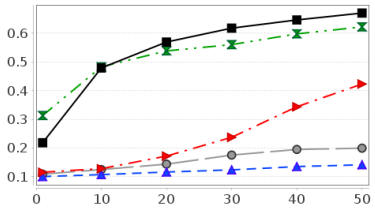

(p) NFS

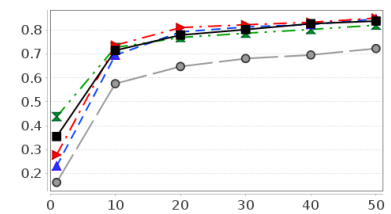

(t) Oh15

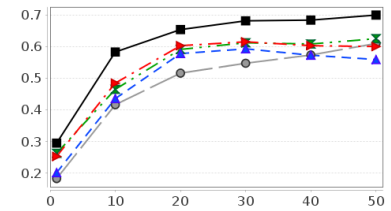

(x) $\operatorname{Re} 0$

Figura 4.7: Valores $F 1^{\text {Micro }}$ do $1^{\mathrm{o}}$ grupo de experimentos (parte I).

utilização de uma única visão com a execução do algoritmo $M N B$-Se.

Nas Figuras 4.11 e 4.12 são apresentados os diagramas de diferença crítica considerando os resultados do primeiro grupo de experimentos para as medidas $F 1^{\text {Micro }}$ e $F 1^{\text {Macro }}$ 


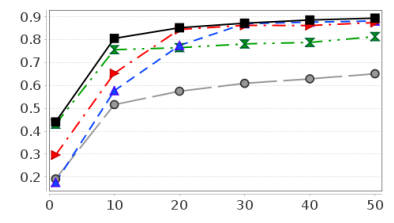

(a) $\operatorname{Re} 8$

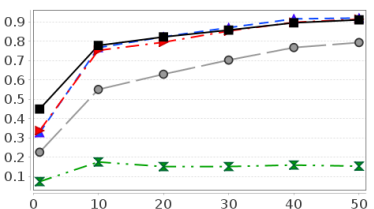

(e) $\operatorname{Tr} 11$

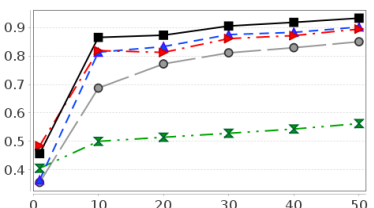

(i) $\operatorname{Tr} 31$

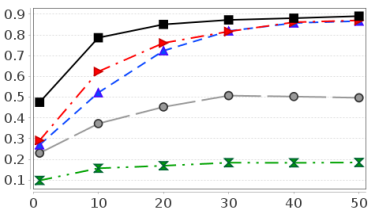

(b) Reviews

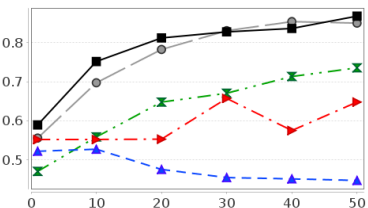

(c) SpamAssassin

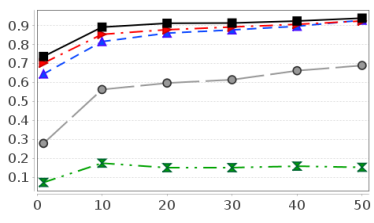

(d) SyskillWebert

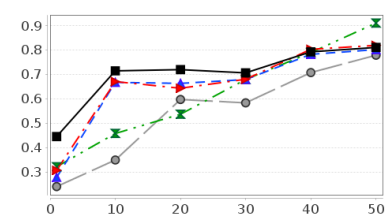

(f) $\operatorname{Tr} 12$

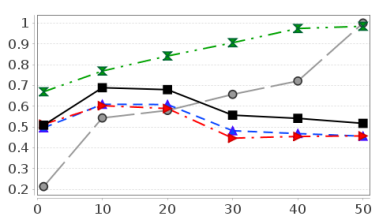

(g) $\operatorname{Tr} 21$

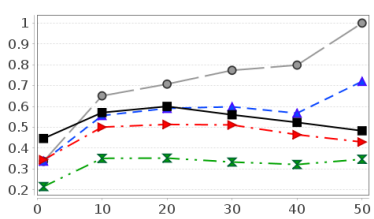

(h) $\operatorname{Tr} 23$

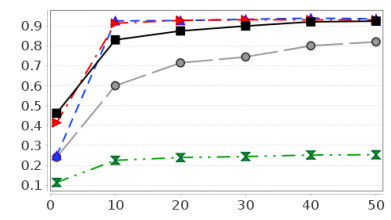

(j) $\operatorname{Tr} 41$

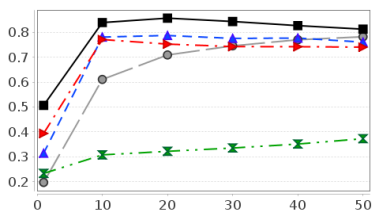

(k) $\operatorname{Tr} 45$

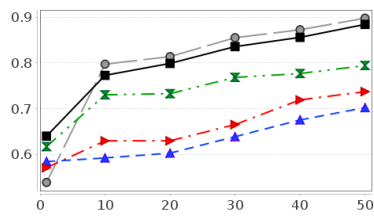

(1) Trec7_3000

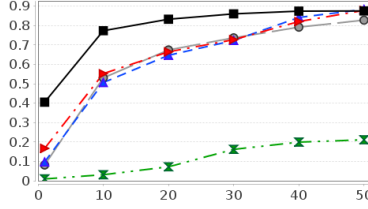

(m) Wap

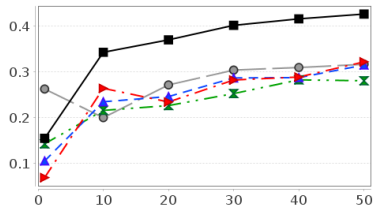

(n) WebKB

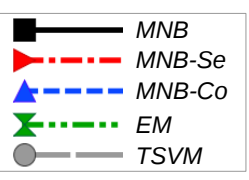

(o) Legenda

Figura 4.8: Valores $F 1^{\text {Micro }}$ do $1^{\circ}$ grupo de experimentos (parte II).

Tabela 4.2: Número de vitórias dos algoritmos indicados na linha em comparação com os algoritmos indicados na coluna para o primeiro grupo de experimentos considerando a medida $F 1^{\text {Micro }}$.

\begin{tabular}{|c|c|c|c|c|c|}
\hline \multicolumn{6}{|c|}{1 exemplo rotulado por classe } \\
\hline & $M N B$ & MNB-Se & $M N B-C o$ & $E M$ & TSVM \\
\hline$\overline{M N B}$ & - & 27 & 29 & 21 & 29 \\
\hline$M N B-S e$ & 3 & - & 25 & 13 & 24 \\
\hline$M N B-C o$ & 1 & 5 & - & 13 & 19 \\
\hline$E M$ & 9 & 17 & 17 & - & 21 \\
\hline$T S V M$ & 1 & 6 & 11 & 9 & - \\
\hline
\end{tabular}

\begin{tabular}{|c|c|c|c|c|c|}
\hline \multicolumn{6}{|c|}{10 exemplos rotulados por classe } \\
\hline & $M N B$ & $M N B-S e$ & $M N B-C o$ & $E M$ & $T S V M$ \\
\hline$\overline{M N B}$ & - & 24 & 26 & 23 & 28 \\
\hline MNB-Se & 6 & - & 21 & 19 & 24 \\
\hline$M N B-C o$ & 4 & 9 & - & 17 & 21 \\
\hline$E M$ & 7 & 10 & 13 & - & 17 \\
\hline$T S V M$ & 2 & 6 & 9 & 13 & - \\
\hline
\end{tabular}

\begin{tabular}{|c|c|c|c|c|c|}
\hline \multicolumn{6}{|c|}{20 exemplos rotulados por classe } \\
\hline & $M N B$ & $M N B-S e$ & $\overline{M N B-C o}$ & $E M$ & TSVM \\
\hline 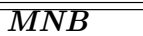 & - & 21 & $\overline{22}$ & 24 & $\overline{28}$ \\
\hline$M N B-S e$ & 9 & - & 19 & 23 & 22 \\
\hline$M N B-C o$ & 8 & 11 & - & 21 & 21 \\
\hline$E M$ & 6 & 7 & 9 & - & 15 \\
\hline$T S V M$ & 2 & 8 & 9 & 15 & - \\
\hline
\end{tabular}

\begin{tabular}{|c|c|c|c|c|c|}
\hline \multicolumn{6}{|c|}{30 exemplos rotulados por classe } \\
\hline & $M N B$ & $M N B-S e$ & $M N B-C o$ & $E M$ & TSVM \\
\hline$\overline{M N B}$ & & 21 & 19 & 25 & 26 \\
\hline$M N B-S e$ & 9 & & 15 & 22 & 21 \\
\hline$M N B-C o$ & 11 & 15 & - & 19 & 20 \\
\hline$E M$ & 5 & 8 & 11 & 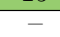 & 16 \\
\hline$T S V M$ & 4 & 9 & 10 & 14 & - \\
\hline
\end{tabular}

\begin{tabular}{|c|c|c|c|c|c|}
\hline \multicolumn{6}{|c|}{40 exemplos rotulados por classe } \\
\hline & 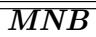 & $\overline{M N B-S e}$ & "MNB-Co & $E M$ & $\overline{T S V M}$ \\
\hline$\overline{M N N B}$ & - & 19 & 20 & 26 & 26 \\
\hline$M N B-S e$ & 11 & - & 15 & 22 & 22 \\
\hline$M N B-C o$ & 10 & 15 & - & 20 & 21 \\
\hline$E M$ & 4 & 8 & 10 & - & 15 \\
\hline$T S V M$ & 4 & 8 & 9 & 15 & - \\
\hline
\end{tabular}

\begin{tabular}{|c|c|c|c|c|c|}
\hline \multicolumn{6}{|c|}{50 exemplos rotulados por classe } \\
\hline & 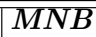 & $\overline{M N B-S e}$ & $M N B-C o$ & $E M$ & $\overline{T S V M}$ \\
\hline$\overline{M N B}$ & - & 18 & 18 & 25 & 26 \\
\hline MNB-Se & 12 & 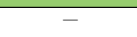 & 15 & 20 & 21 \\
\hline MNB-Co & 12 & 15 & - & 20 & 19 \\
\hline$E M$ & 5 & 10 & 10 & - & 11 \\
\hline TSVM & 4 & 9 & 11 & 19 & - \\
\hline
\end{tabular}

respectivamente. Pode-se observar que o algoritmo $M N B$ obteve a primeira posição do ranking médio e o algoritmo $M N B$-Se obteve a segunda posição no ranking para todas as situações avaliadas. Pode-se observar também que o algoritmo $M N B$ obteve diferenças 


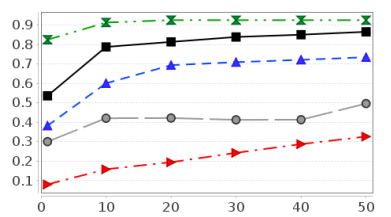

(a) Classic 4

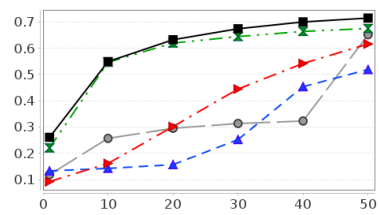

(e) Dmoz_Health_500

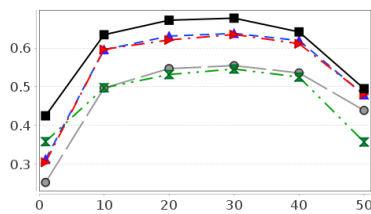

(i) FBIS

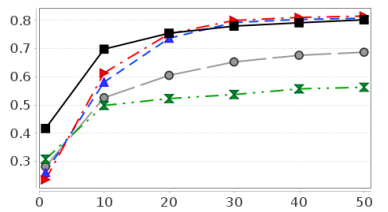

(m) La1s

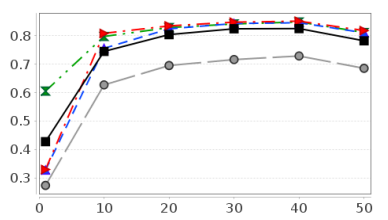

(q) $\mathrm{Oh} 0$

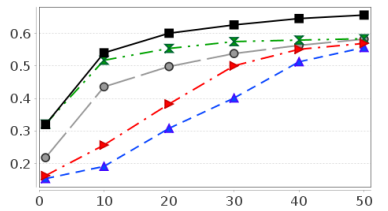

(u) Ohscal

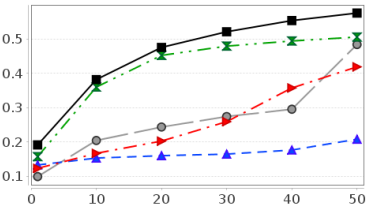

(f) Dmoz_Science_500

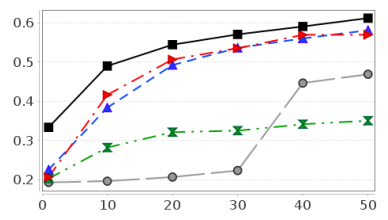

(j) Hitech

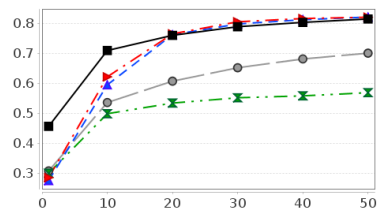

(n) La2s

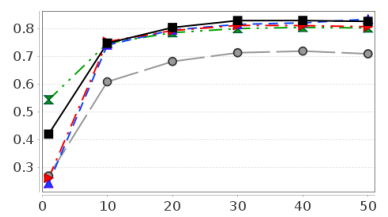

(r) Oh5

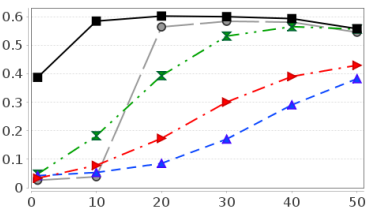

(v) Opinosis

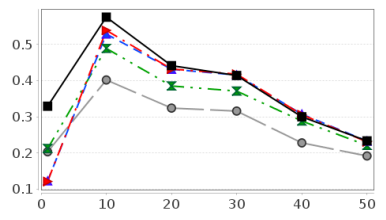

(y) Re1

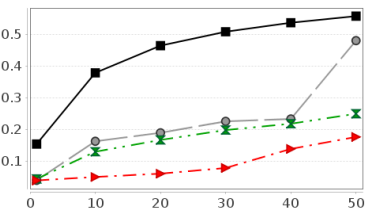

(c) Dmoz Business 500

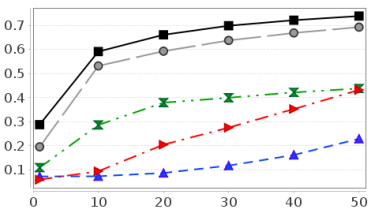

(g) Dmoz_Sports_500

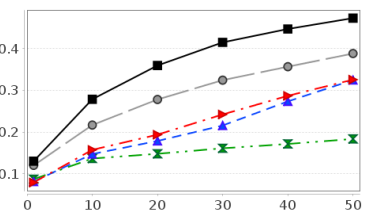

(k) Industry_Sector

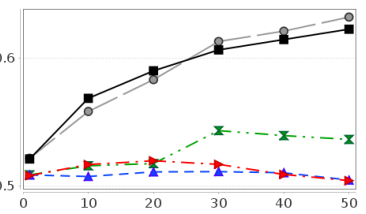

(o) Multi_Dom_Sentiment

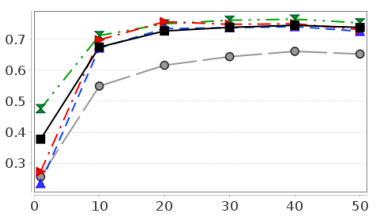

(s) Oh10

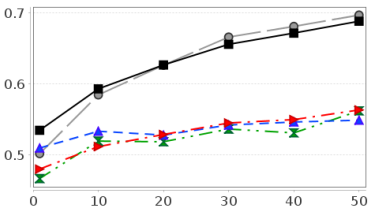

(w) Polarity

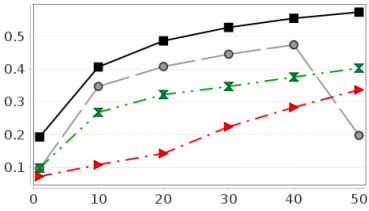

(d) Dmoz_Computers_500

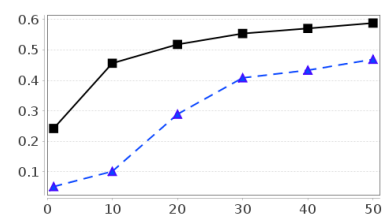

(h) Enron_Top_20

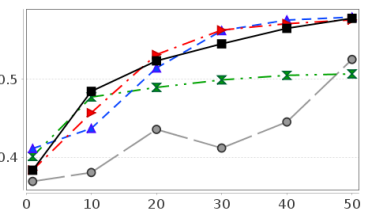

(l) IrishSentiment

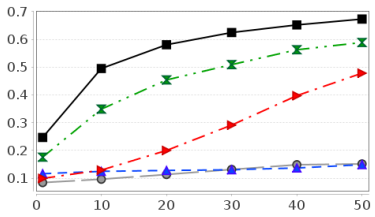

(p) NFS

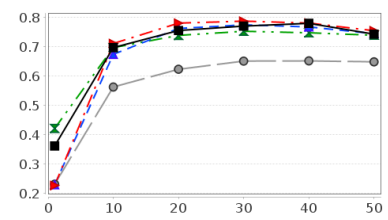

(t) Oh15

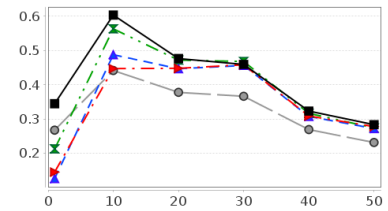

(x) $\operatorname{Re} 0$

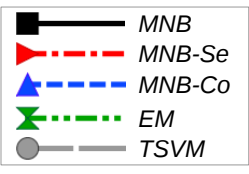

(z) Legenda

Figura 4.9: Valores $F 1^{\text {Macro }}$ do $1^{\circ}$ grupo de experimentos (parte I).

estatisticamente significantes para os algoritmo EM e TSVM em todas as situações avaliadas.

No segundo grupo de experimentos foram comparados os algoritmos $k$-NN, GNet- 


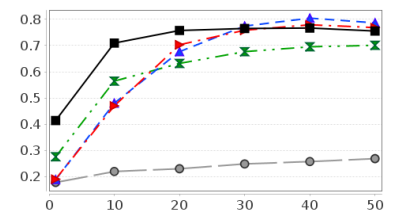

(a) $\operatorname{Re} 8$

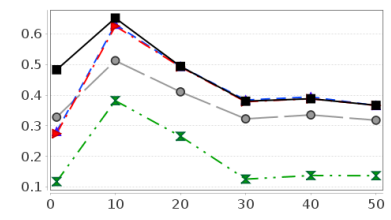

(e) $\operatorname{Tr} 11$

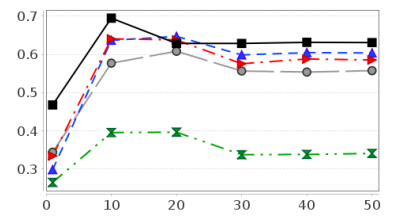

(i) $\operatorname{Tr} 31$

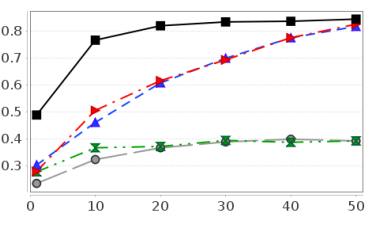

(b) Reviews

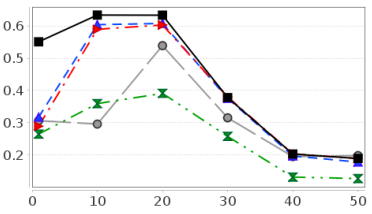

(f) $\operatorname{Tr} 12$

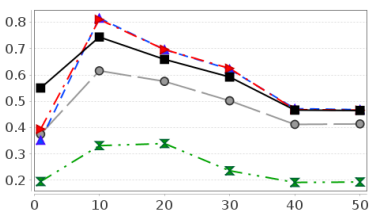

(j) $\operatorname{Tr} 41$

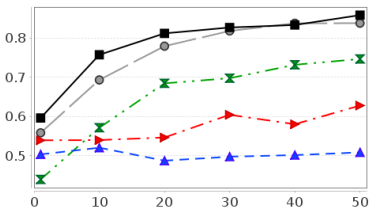

(c) SpamAssassin

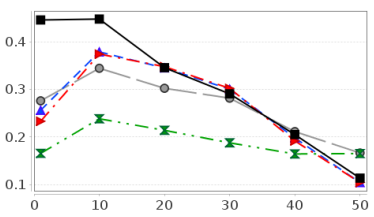

(g) $\operatorname{Tr} 21$

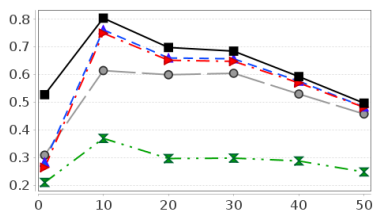

(k) $\operatorname{Tr} 45$

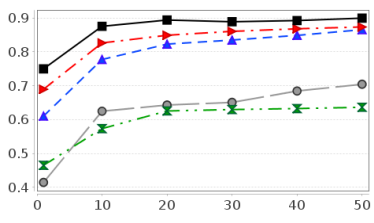

(d) SyskillWebert

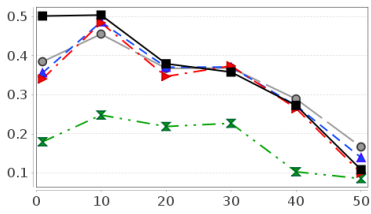

(h) $\operatorname{Tr} 23$

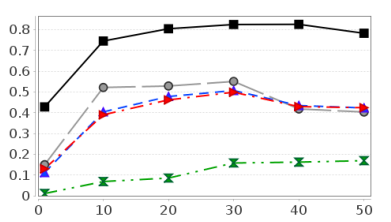

(m) Wap

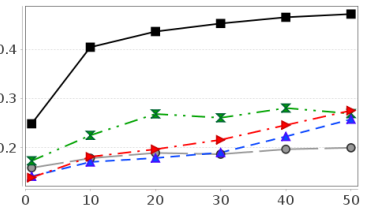

(n) WebKB

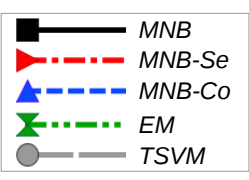

(o) Legenda

Figura 4.10: Valores $F 1^{\text {Macro }}$ do $1^{\circ}$ grupo de experimentos (parte II).

Tabela 4.3: Número de vitórias dos algoritmos indicados na linha em comparação com os algoritmos indicados na coluna para o primeiro grupo de experimentos considerando a medida $F 1^{\text {Macro }}$.

\begin{tabular}{|c|c|c|c|c|c|}
\hline \multicolumn{6}{|c|}{1 exemplo rotulado por classe } \\
\hline & $M N B$ & MNB-Se & MNB-Co & $E M$ & $T S V M$ \\
\hline$M N B$ & - & 28 & 28 & 23 & 29 \\
\hline$M N B-S e$ & 2 & - & 11 & 13 & 12 \\
\hline$M N B-C o$ & 2 & 19 & - & 13 & 14 \\
\hline$E M$ & 7 & 17 & 17 & - & 18 \\
\hline$T S V M$ & 1 & 18 & 16 & 12 & - \\
\hline
\end{tabular}

\begin{tabular}{|c|c|c|c|c|c|}
\hline \multicolumn{6}{|c|}{10 exemplos rotulados por classe } \\
\hline & $M N B$ & $M N B-S e$ & $M N B-C o$ & $E M$ & $T S V M$ \\
\hline$M N B$ & - & 24 & 27 & 25 & 30 \\
\hline$M N B-S e$ & 6 & & 18 & 20 & 24 \\
\hline$M N B-C o$ & 3 & 12 & - & 17 & 24 \\
\hline$E M$ & 4 & 10 & 13 & - & 18 \\
\hline$T S V M$ & 0 & 6 & 6 & 12 & - \\
\hline
\end{tabular}

\begin{tabular}{|c|c|c|c|c|c|}
\hline \multicolumn{6}{|c|}{20 exemplos rotulados por classe } \\
\hline & $M N B$ & $M N B-S e$ & $M N B-C o$ & $E M$ & $T S V M$ \\
\hline$\overline{M N B}$ & $=$ & 21 & $\overline{23}$ & 26 & $\overline{30}$ \\
\hline$M N B-S e$ & 9 & & 20 & 24 & 24 \\
\hline$M N B-C o$ & 7 & 10 & - & 21 & 24 \\
\hline$E M$ & 4 & 6 & 9 & - & 16 \\
\hline TSVM & 0 & 6 & 6 & 14 & - \\
\hline
\end{tabular}

\begin{tabular}{|c|c|c|c|c|c|}
\hline \multicolumn{6}{|c|}{30 exemplos rotulados por classe } \\
\hline & $M N B$ & $\overline{M N B-S e}$ & MNB-Co & $E M$ & $T S V M$ \\
\hline$\overline{M N B}$ & - & $\overline{18}$ & $\overline{18}$ & 26 & 27 \\
\hline$M N B-S e$ & 12 & $2-$ & 19 & 22 & 25 \\
\hline$M N B-C o$ & 12 & 11 & - & 22 & 24 \\
\hline$E M$ & 4 & 8 & 8 & - & 16 \\
\hline$T S V M$ & 3 & 5 & 6 & 14 & - \\
\hline
\end{tabular}

\begin{tabular}{|c|c|c|c|c|c|}
\hline \multicolumn{6}{|c|}{40 exemplos rotulados por classe } \\
\hline & "MNB & $M N B-S e$ & MNB-Co & $E M$ & $\overline{T S V M M}$ \\
\hline$M N B$ & 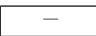 & 18 & 21 & 27 & 26 \\
\hline$M N B-S e$ & 12 & - & 15 & 22 & 25 \\
\hline$M N B-C o$ & 9 & 15 & - & 21 & 24 \\
\hline$E M$ & 3 & 8 & 9 & - & 14 \\
\hline$T S V M$ & 4 & 5 & 6 & 16 & - \\
\hline
\end{tabular}

\begin{tabular}{|c|c|c|c|c|c|}
\hline \multicolumn{6}{|c|}{50 exemplos rotulados por classe } \\
\hline & 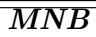 & $\overline{M N B-S e}$ & $M N B-C o$ & $E M$ & $\overline{T S V M}$ \\
\hline$M N B$ & - & 23 & 20 & 26 & 25 \\
\hline$M N B-S e$ & 7 & - & 18 & 23 & 22 \\
\hline$M N B-C o$ & 10 & 12 & - & 19 & 22 \\
\hline$E M$ & 4 & 7 & 11 & - & 14 \\
\hline$T S V M$ & 5 & 8 & 8 & 16 & - \\
\hline
\end{tabular}

Mine(DD), GNetMine(DT), GNetMine(TT), GNetMine(DD-DT), GNetMine(DT-TT) e GNetMine(DD-DT-TT). Isso permite comparar o impacto do uso de redes e exemplos não rotulados quando considerada a similaridade entre os documentos, além de permitir 


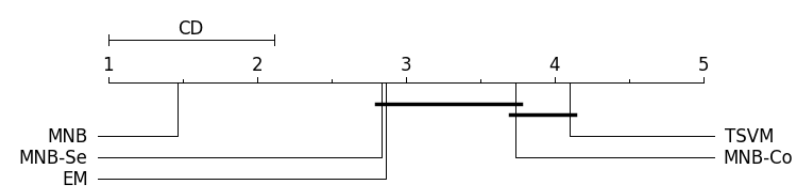

(a) 1 exemplo rotulado por classe.

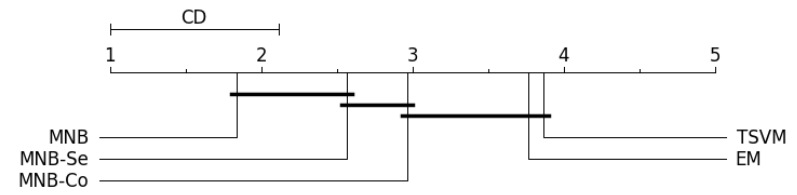

(c) 20 exemplos rotulados por classe.

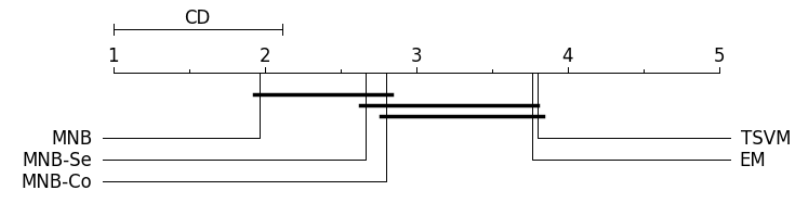

(e) 40 exemplos rotulados por classe.

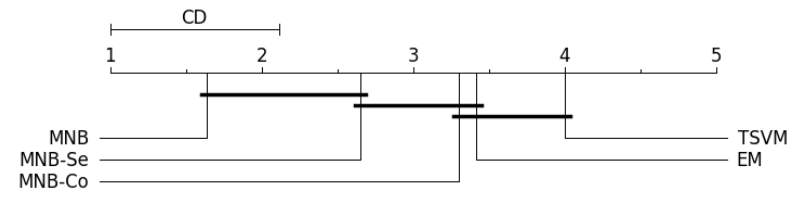

(b) 10 exemplos rotulados por classe.

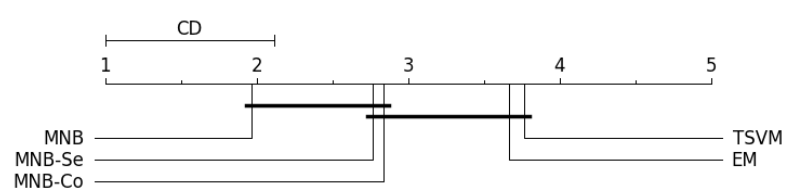

(d) 30 exemplos rotulados por classe.

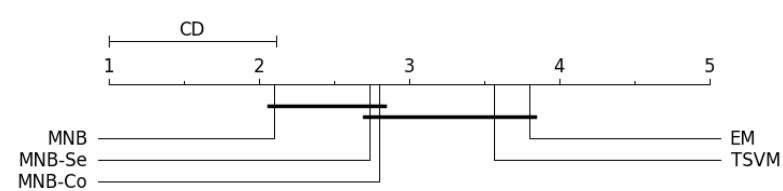

(f) 50 exemplos rotulados por classe.

Figura 4.11: Diagramas de diferença crítica para o primeiro grupo de experimentos considerando a medida $F 1^{\text {Micro }}$.

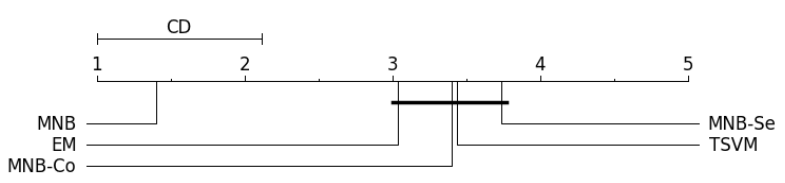

(a) 1 exemplo rotulado por classe.

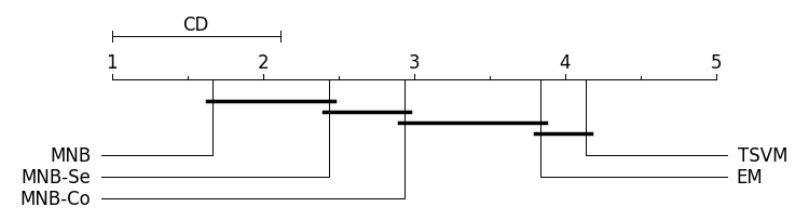

(c) 20 exemplos rotulados por classe.

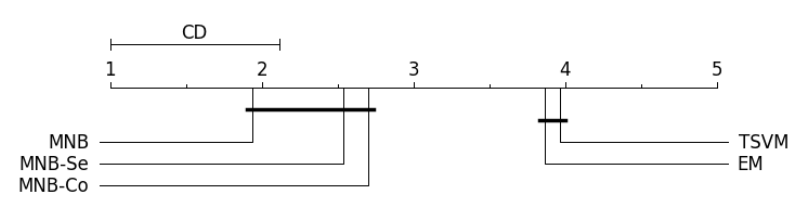

(e) 40 exemplos rotulados por classe.

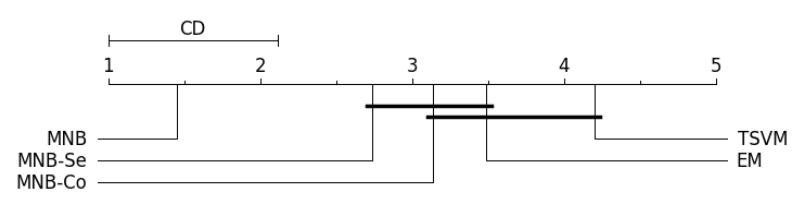

(b) 10 exemplos rotulados por classe.

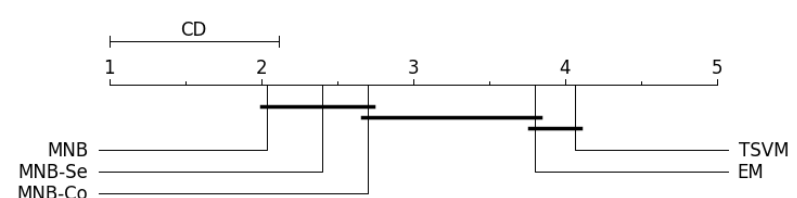

(d) 30 exemplos rotulados por classe.

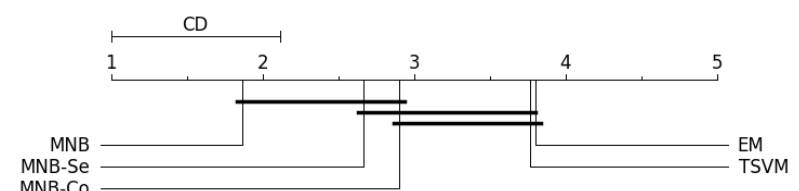

(f) 50 exemplos rotulados por classe.

Figura 4.12: Diagramas de diferença crítica para o primeiro grupo de experimentos considerando a medida $F 1^{\text {Macro }}$.

comparar o impacto dos diferentes tipos de redes no algoritmo GNetMine.

Nas Figuras 4.13 e 4.14 são apresentados os gráficos de performance de classificação considerando a medida $F 1^{\text {Micro }}$ e nas Figuras 4.15 e 4.16 são apresentados os resultados considerando a medida $F 1^{\text {Macro }}$ para o segundo grupo de experimentos considerados nesta avaliação experimental. Pode-se observar que os diferentes tipos de redes considerados no algoritmo GNetMine obtiveram diferentes performances de classificação. Inclusive, 
observa-se diferenças significativas entre os diferentes tipos de rede na maioria das coleções para as medidas $F 1^{\text {Micro }}$ e $F 1^{\text {Macro }}$. Pode-se observar também que, em geral, o algoritmo $k-N N$ é superado pelo algoritmo GNetMine.

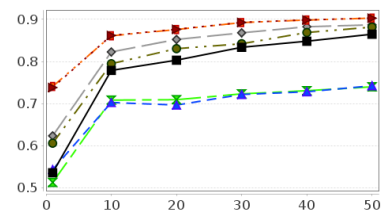

(a) Classic4

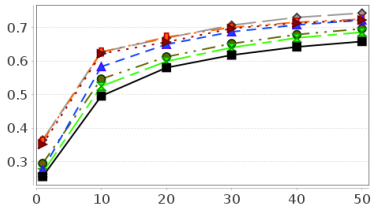

(e) Dmoz_Health_500

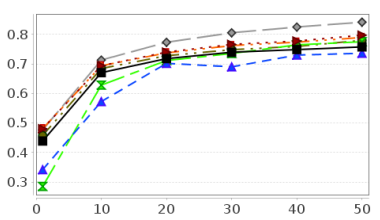

(i) FBIS

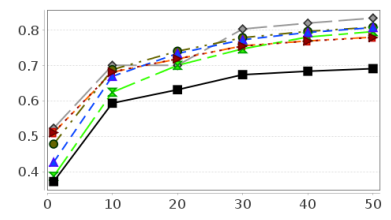

(m) La1s

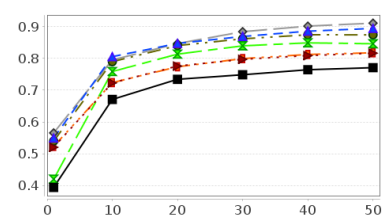

(q) Oh0

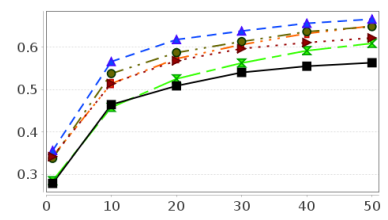

(u) Ohscal

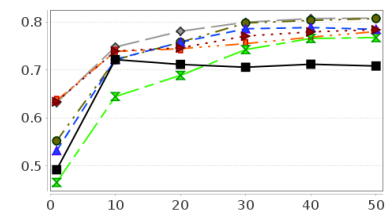

(b) CSTR

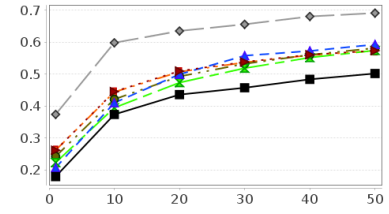

(f) Dmoz_Science_500

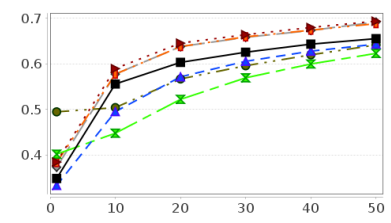

(j) Hitech

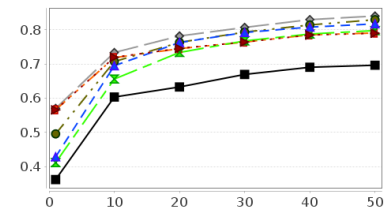

(n) La2s

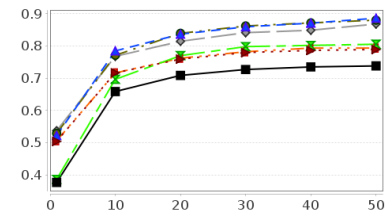

(r) Oh5

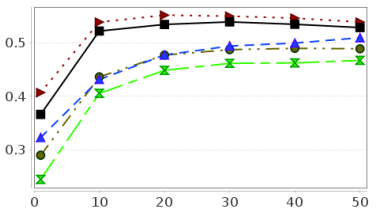

(v) Opinosis

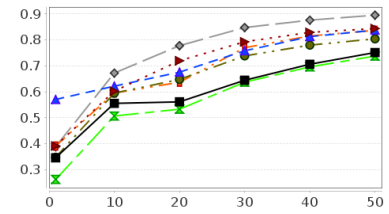

(y) Re1

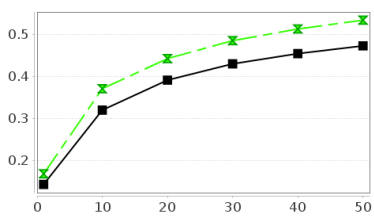

(c) Dmoz_Business_500

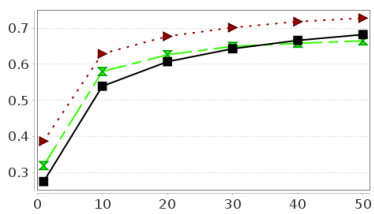

(g) Dmoz_Sports_500

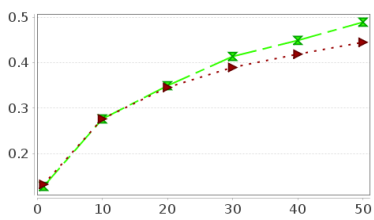

(k) Industry_Sector

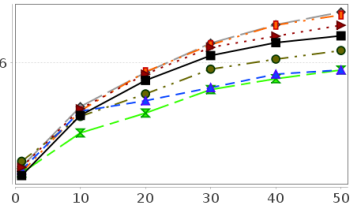

(o) Multi_Dom_Sentiment

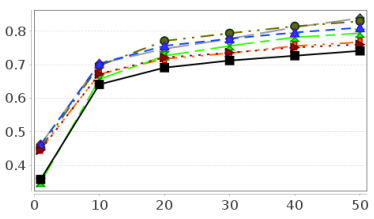

(s) Oh10

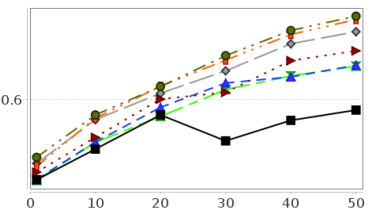

(w) Polarity

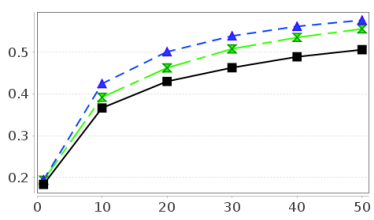

(d) Dmoz_Computers_500

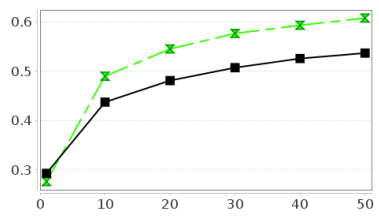

(h) Enron_Top_20

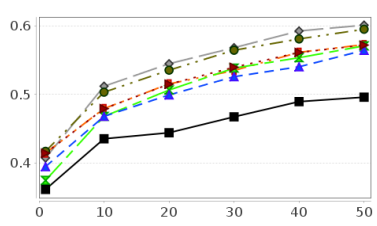

(1) IrishSentiment

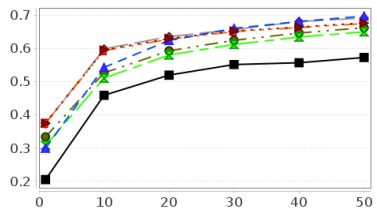

(p) NFS

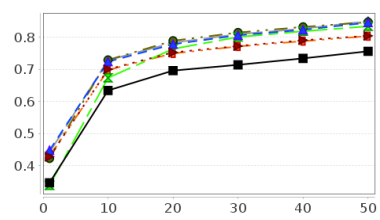

(t) Oh15

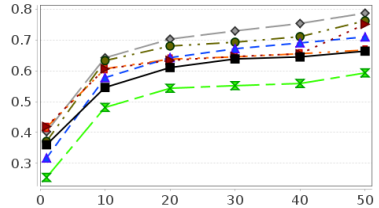

(x) $\operatorname{Re} 0$

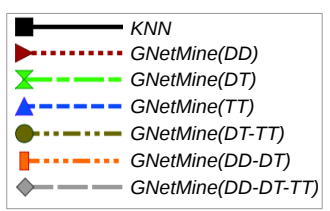

(z) Legenda

Figura 4.13: Valores $F 1^{\text {Micro }}$ do $2^{\circ}$ grupo de experimentos (parte I). 


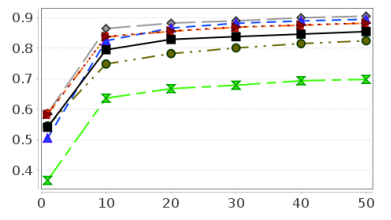

(a) $\operatorname{Re} 8$

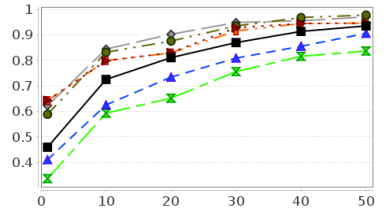

(e) $\operatorname{Tr} 11$

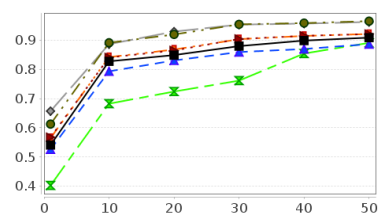

(i) $\operatorname{Tr} 31$

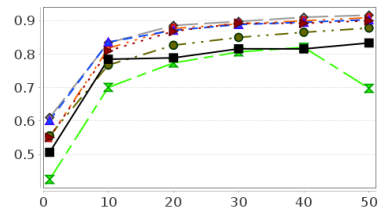

(b) Reviews

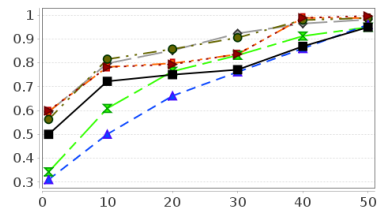

(f) $\operatorname{Tr} 12$

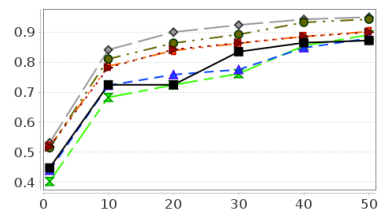

(j) $\operatorname{Tr} 41$

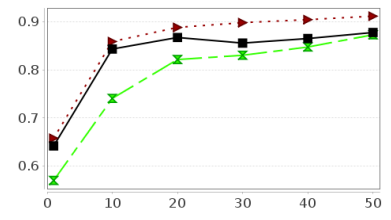

(c) SpamAssassin

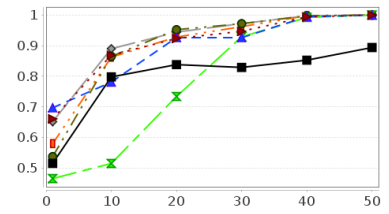

(g) $\operatorname{Tr} 21$

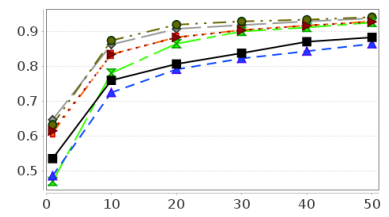

(k) $\operatorname{Tr} 45$

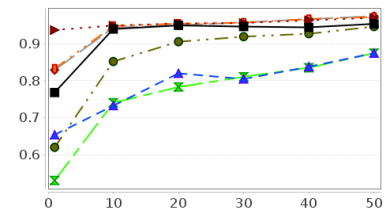

(d) SyskillWebert

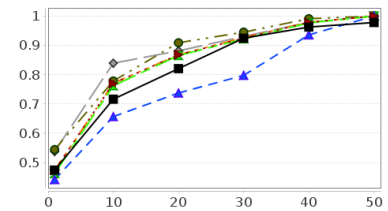

(h) $\operatorname{Tr} 23$

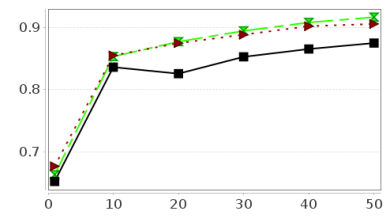

(1) Trec7_3000

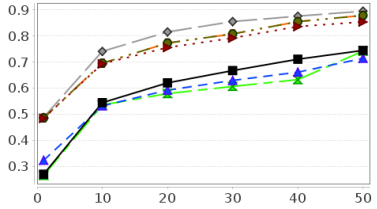

(m) Wap

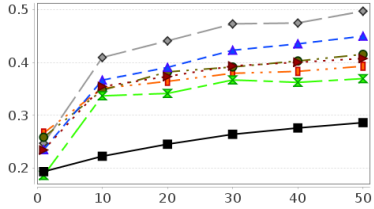

(n) WebKB

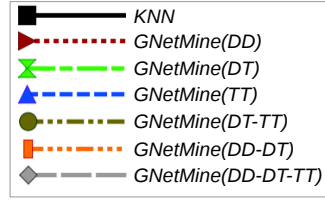

(o) Legenda

Figura 4.14: Valores $F 1^{\text {Micro }}$ do $2^{\circ}$ grupo de experimentos (parte II).

Para elucidar a comparação das performances de classificação dos diferentes algoritmos no segundo grupo de experimentos, nas Tabelas 4.4 e 4.5 é apresentado o número de vitórias dos algoritmos considerando as medidas $F 1^{\text {Micro }}$ e $F 1^{\text {Macro }}$ respectivamente. Podese observar que o uso das redes DD-DT-TT proporcionou uma maior performance ao algoritmo GNetMine em relação às demais redes em todas as quantidades de exemplos rotulados utilizadas. Em geral, as redes DT-TT proveram as melhores performances de classificação depois das redes DD-DT-TT. Dentre as redes com relações simples, a rede DD proveu melhores performances de classificação em relação às redes DT ou TT. Vale ressaltar que em praticamente todas as análises realizadas, o uso do algoritmo GNetMine com a rede baseada na similaridade de documentos proveu uma acurácia maior que a do algoritmo $k$ - $N N$, também baseado na similaridade de documentos.

Nas Figuras 4.17 e 4.18 são apresentados os diagramas de diferença crítica considerando os resultados do segundo grupo de experimentos para as medidas $F 1^{\text {Micro }}$ e $F 1^{\text {Macro }}$ respectivamente. Pode-se observar por essas figuras que as redes DD-DT-TT e DT-TT obtiveram respectivamente a primeira e segunda posições no ranking médio no segundo grupos de experimentos. As redes DD e DD-TT se alternaram na terceira e quarta posições nas diferentes situações analisadas. Pode-se observar também que GNetMine(DD-DT-TT) apresentou melhores resultados com diferenças estatisticamente significantes em relação 


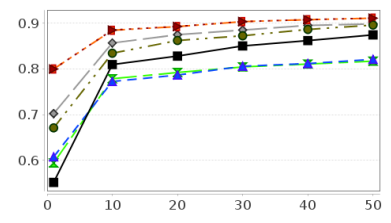

(a) Classic4

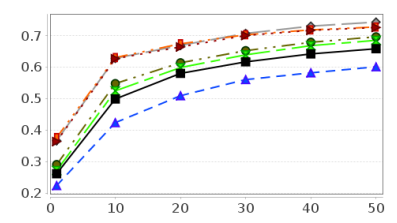

(e) Dmoz_Health_500

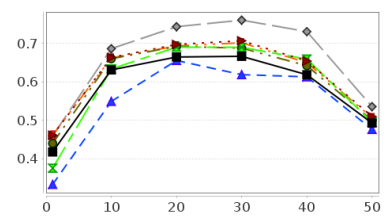

(i) FBIS

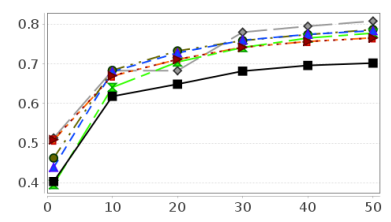

(m) La1s

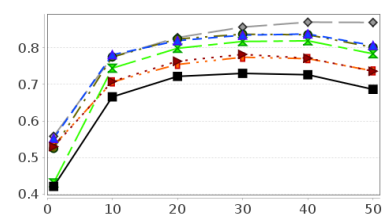

(q) Oh0

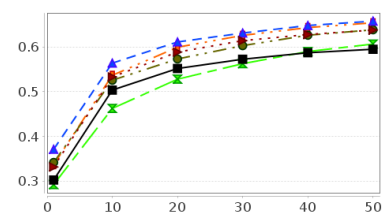

(u) Ohscal

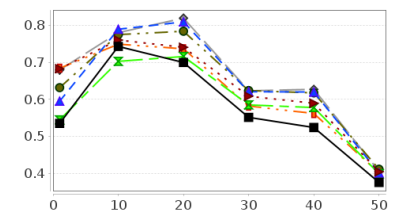

(b) CSTR

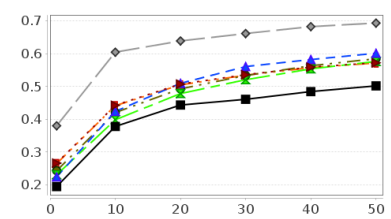

(f) Dmoz_Science_500

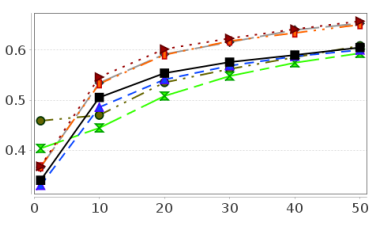

(j) Hitech

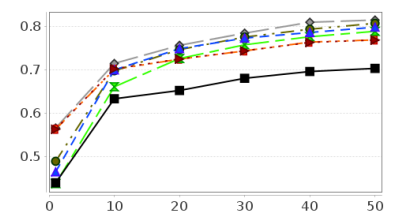

(n) La2s

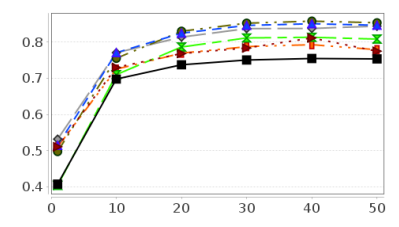

(r) Oh5

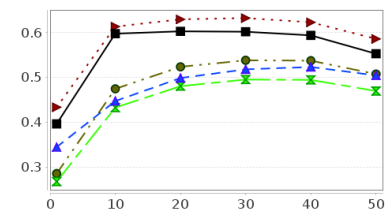

(v) Opinosis

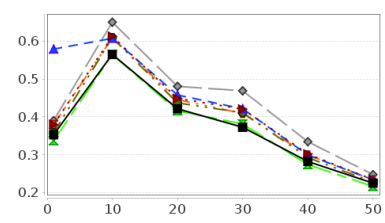

(y) Re1

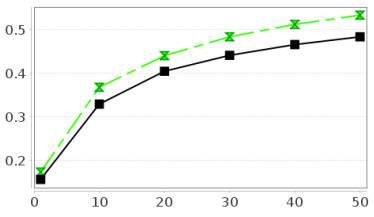

(c) Dmoz_Business_500

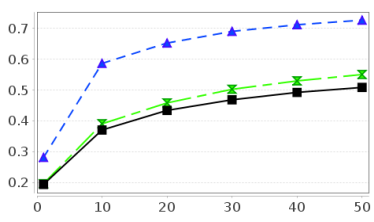

(d) Dmoz_Computers_500

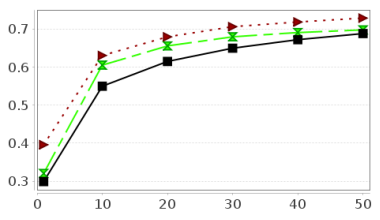

(g) Dmoz_Sports_500

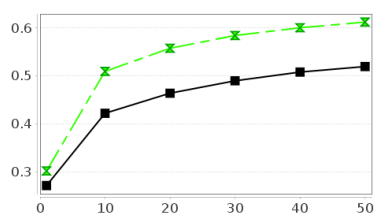

(h) Enron_Top_20

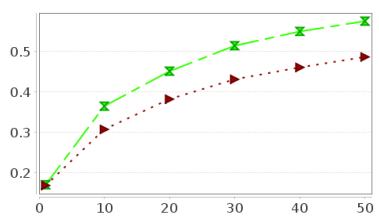

(k) Industry_Sector

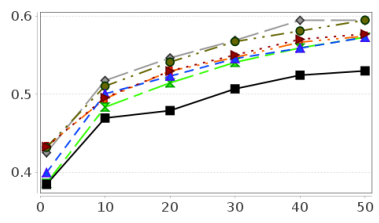

(l) IrishSentiment

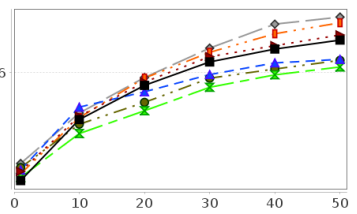

(o) Multi_Dom_Sentiment

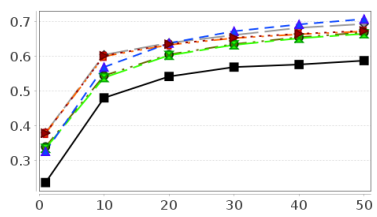

(p) NFS

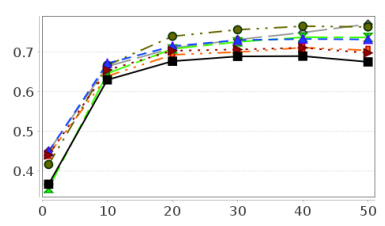

(s) Oh10

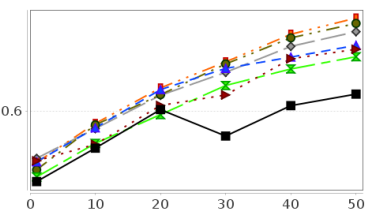

(w) Polarity

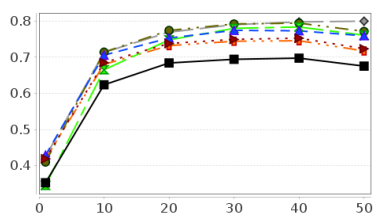

(t) Oh15

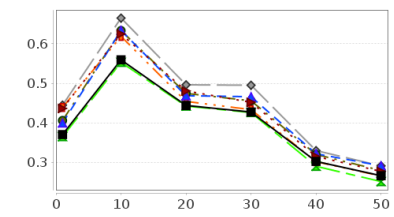

(x) $\operatorname{Re} 0$

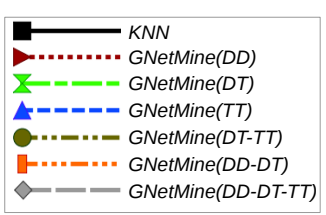

(z) Legenda

Figura 4.15: Valores $F 1^{\text {Macro }}$ para $2^{\circ}$ grupo de experimentos (parte I).

ao k-NN, GNetMine(DT) e GNetMine(TT) para todas as situações avaliadas. Também houve diferenças estatisticamente significantes do GNetMine(DD-DT-TT) em relação ao GNetMine(DD-DT) e GNetMine(DD) em várias das situações avaliadas. 


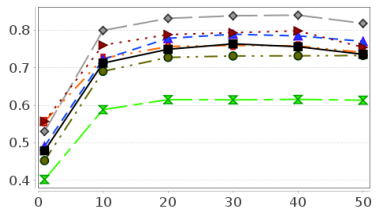

(a) $\operatorname{Re} 8$

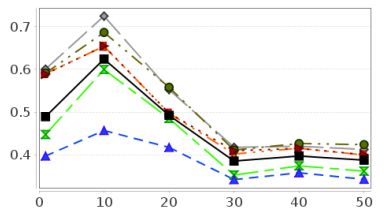

(e) $\operatorname{Tr} 11$

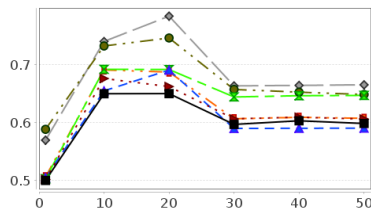

(i) $\operatorname{Tr} 31$

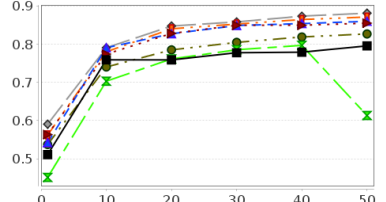

(b) Reviews

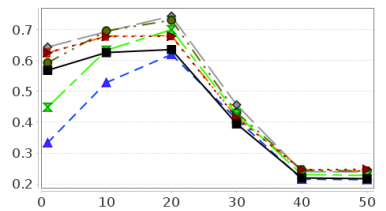

(f) $\operatorname{Tr} 12$

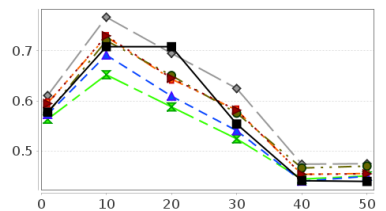

(j) $\operatorname{Tr} 41$

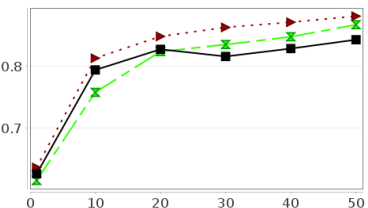

(c) SpamAssassin

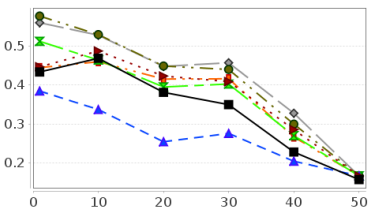

(g) $\operatorname{Tr} 21$

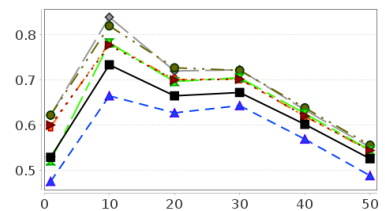

(k) $\operatorname{Tr} 45$

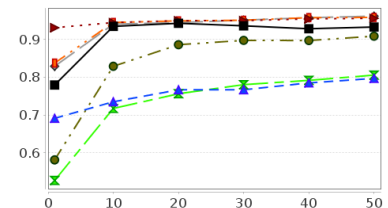

(d) SyskillWebert

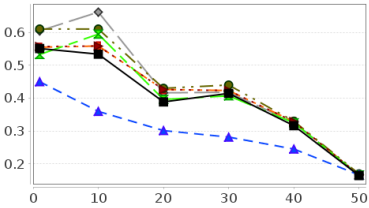

(h) $\operatorname{Tr} 23$

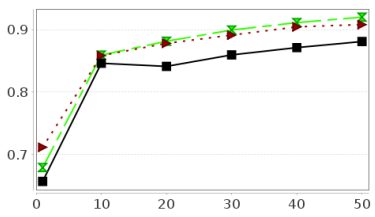

(l) Trec7_3000

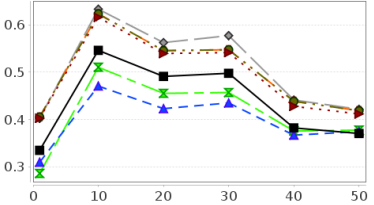

(m) Wap

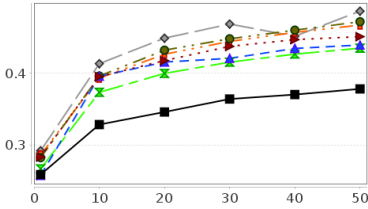

(n) WebKB

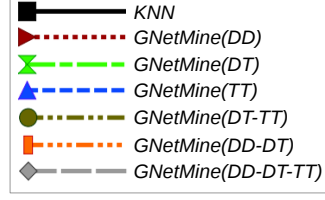

(o) Legenda

Figura 4.16: Valores $F 1^{\text {Macro }}$ para o $2^{\circ}$ grupo de experimentos (parte II).

Tabela 4.4: Número de vitórias dos algoritmos indicados na linha em comparação com os algoritmos indicados na coluna para o segundo grupo de experimentos considerando a medida $F 1^{\text {Micro }}$.
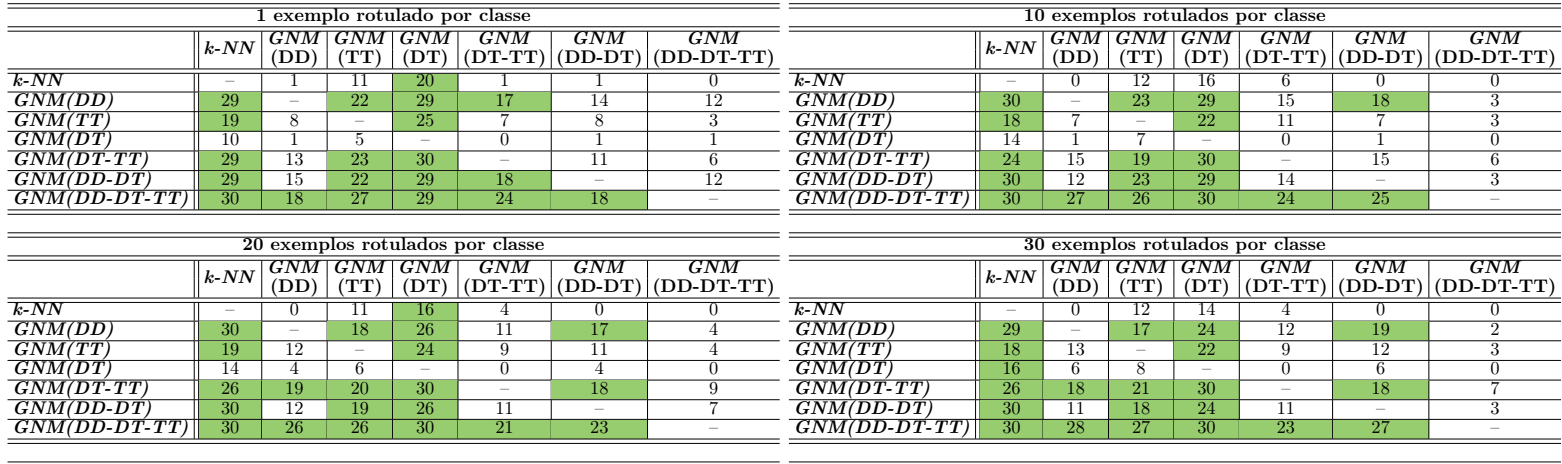

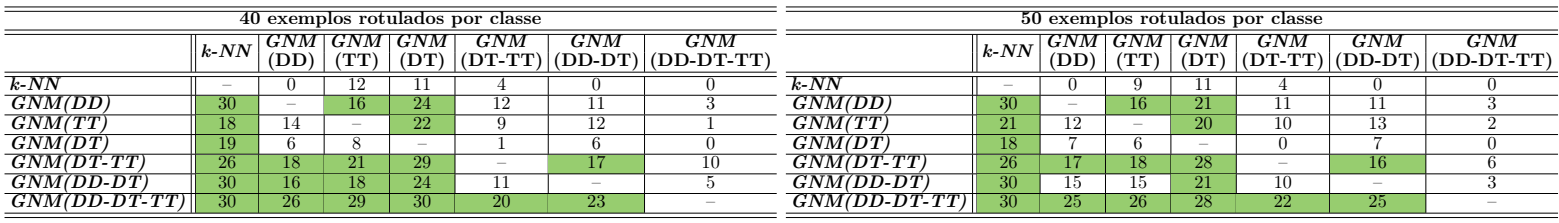

No terceiro grupo de experimentos, foram comparados os algoritmos $k-N N, L P H N(\mathrm{DD})$,

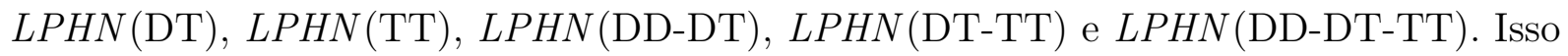
permite comparar o impacto do uso de redes e exemplos não rotulados quando considerado a similaridade entre os documentos, caso de $k-N N$ e $L P H N(\mathrm{DD})$, além de permitir comparar o impacto dos diferentes tipos de redes no algoritmo $L P H N$. 
Tabela 4.5: Número de vitórias dos algoritmos indicados na linha em comparação com os algoritmos indicados na coluna para o segundo grupo de experimentos considerando a medida $F 1^{\text {Macro }}$.
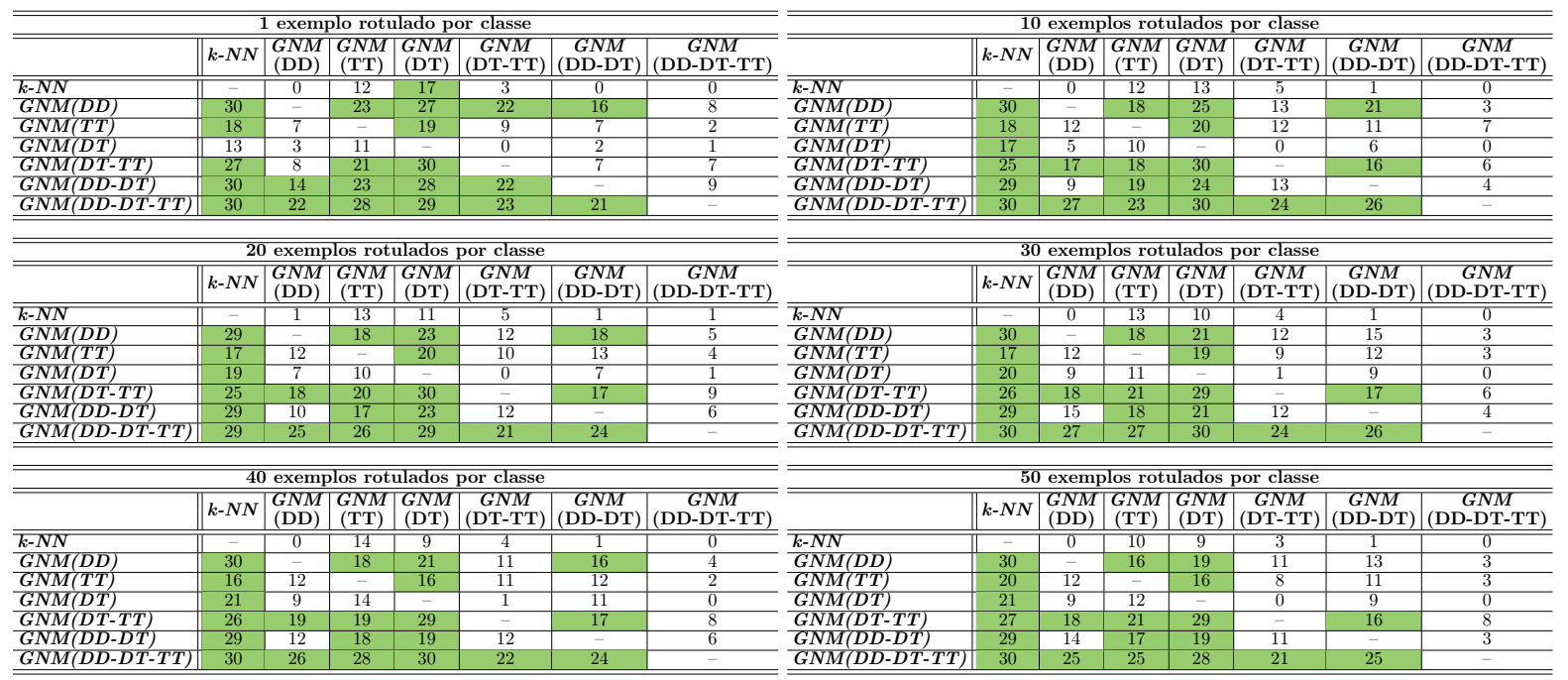

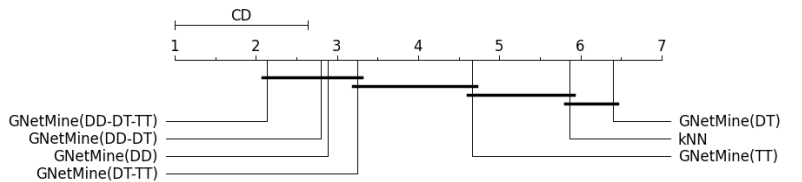

(a) 1 exemplo rotulado por classe.

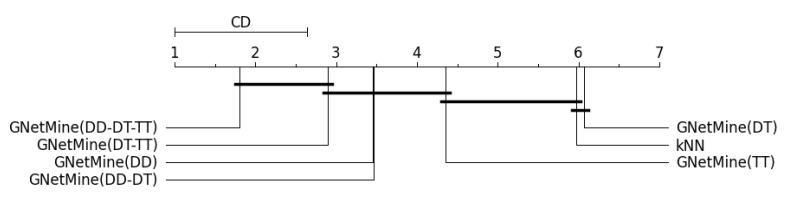

(c) 20 exemplos rotulados por classe.

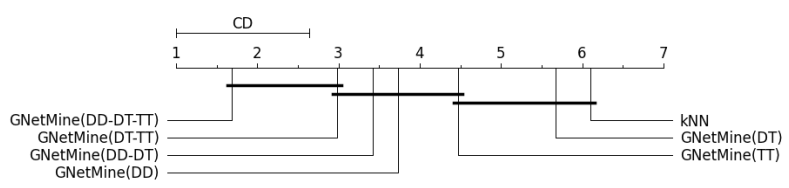

(e) 40 exemplos rotulados por classe.

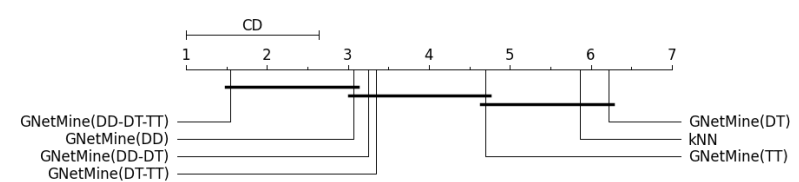

(b) 10 exemplos rotulados por classe.

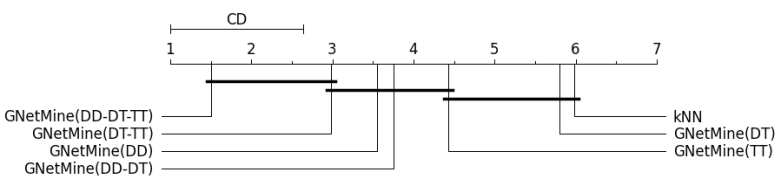

(d) 30 exemplos rotulados por classe.

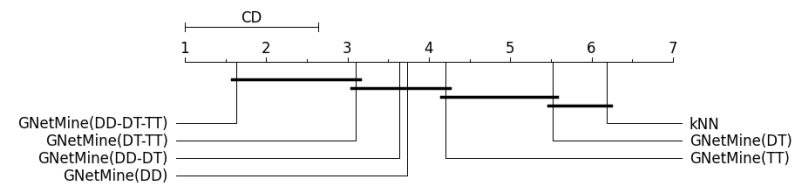

(f) 50 exemplos rotulados por classe.

Figura 4.17: Diagramas de diferença crítica para o segundo grupo de experimentos considerando a medida $F 1^{\text {Micro }}$.

Nas Figuras 4.19 e 4.20 são apresentados os gráficos de performance de classificação considerando a medida $F 1^{\text {Micro }}$ e nas Figuras 4.21 e 4.22 são apresentados os resultados considerando a medida $F 1^{\text {Macro }}$ para o terceiro grupo de experimentos considerados nesta avaliação experimental. Pode-se observar que, em geral, o algoritmo $k-N N$ foi superado pelos diferentes tipos de rede aplicados ao algoritmo $L P H N$, exceto quando utilizada a rede TT. O fato das redes TT terem obtidos resultados inferiores às demais redes é que as informações de classe iniciais para este tipo de rede não são informações de classe reais, como nas demais redes que possuem documentos rotulados como objetos rotulados, e sim informações estimadas. A não alteração das informações de classe iniciais dos objetos rotulados por parte do algoritmo $L P H N$ faz com que as informações estimadas não se alterem durante a classificação, o que causa uma degradação na performance de 


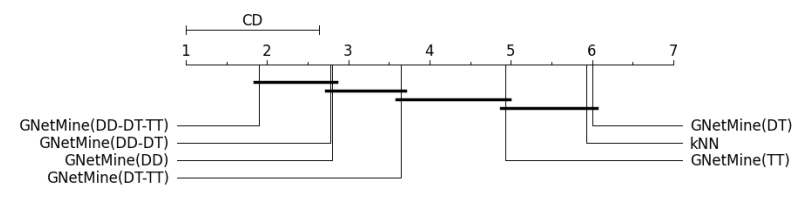

(a) 1 exemplo rotulado por classe.

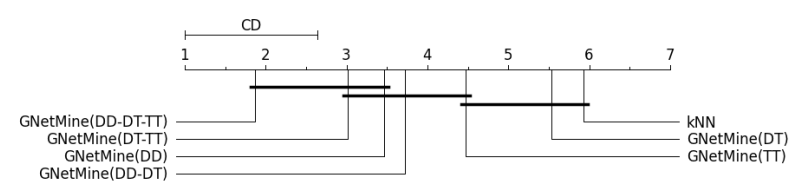

(c) 20 exemplos rotulados por classe.

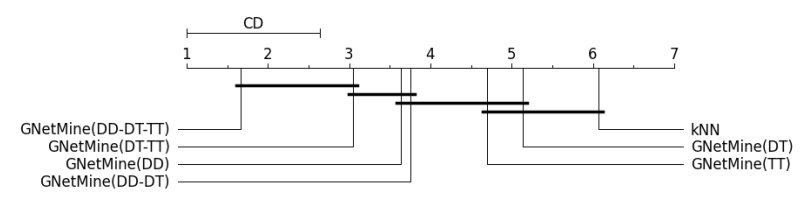

(e) 40 exemplos rotulados por classe.

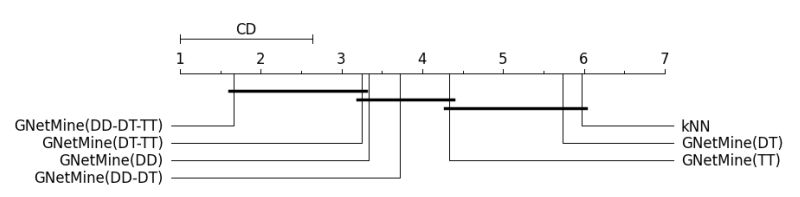

(b) 10 exemplos rotulados por classe.

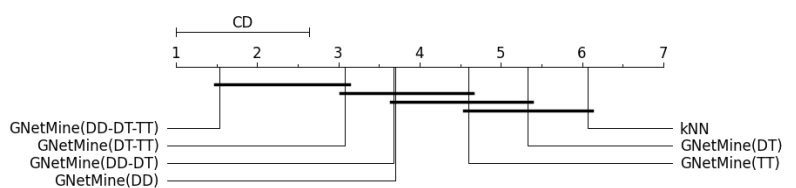

(d) 30 exemplos rotulados por classe.

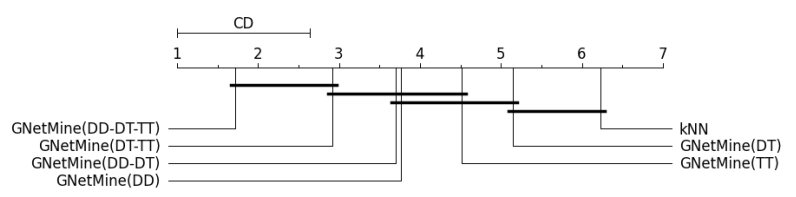

(f) 50 exemplos rotulados por classe.

Figura 4.18: Diagramas de diferença crítica para o segundo grupo de experimentos considerando a medida $F 1^{\text {Macro }}$.

classificação. Não é observada uma performance de classificação provida pela rede TT inferior aos demais tipos de redes no GNetMine, uma vez que esse algoritmo permite alterar as informações de classe iniciais.

Para elucidar a comparação das performances de classificação dos diferentes algoritmos no terceiro grupo de experimentos, nas Tabelas 4.6 e 4.7 é apresentado o número de vitórias dos algoritmos considerando as medidas $F 1^{\text {Micro }}$ e $F 1^{\text {Macro }}$ respectivamente. Podese observar que as redes DD-DT-TT proveram as maiores performances de classificação em relação às demais redes submetidas ao algoritmo $L P H N$ e em relação ao algoritmo $k-N N$. As redes DT-TT também superaram as demais redes, exceto a rede DD-DT-TT. Em geral, as performances de classificação obtidas pelas redes DT foram superadas pelas demais redes. Porém, o algoritmo $L P H N(\mathrm{DT})$, mesmo sendo livre de parâmetros e utilizando uma rede facilmente construída, superou o algoritmo $k-N N$ na maioria das situações analisadas.

Nas Figuras 4.23 e 4.24 são apresentados os diagramas de diferença crítica considerando os resultados do terceiro grupo de experimentos para as medidas $F 1^{\text {Micro }}$ e $F 1^{\text {Macro }}$ respectivamente. Pode-se observar pelos diagramas que o LPHN(DD-DT-TT) obtém a primeira posição no ranking médio em todas as situações avaliadas, exceto quando utilizado um exemplo rotulado por classe considerando a medida $F 1^{\text {Macro }}$, na qual o algoritmo $L P H N(D D)$ obtém a primeira posição no ranking. Em geral, ao aumentar o número de exemplos rotulados, o $L P H N(\mathrm{DD})$ decai de posição no ranking médio. Quando utilizados 10 ou mais exemplos rotulados por classe, o $L P H N(D D-D T-T T)$ e $L P H N(D D-D T)$ obtém melhores resultados com diferenças estatisticamente significantes em relação ao $k$ - $N N$, $\operatorname{LPHN}(\mathrm{DT})$ e $\operatorname{LPHN}(\mathrm{TT})$.

No quarto grupo de experimentos, foram comparados os algoritmos $I M H N^{\mathrm{R}}(\mathrm{DT})$ com os algoritmos TCHN(DT), TCHN(TT), TCHN(DD-DT), TCHN(DT-TT) e TCHN(DD-DT- 


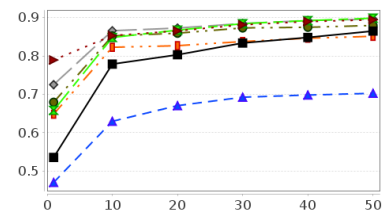

(a) Classic4

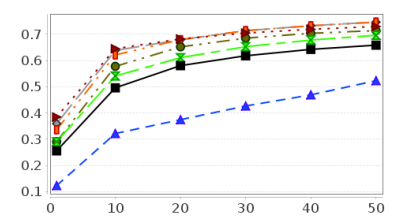

(e) Dmoz_Health_500

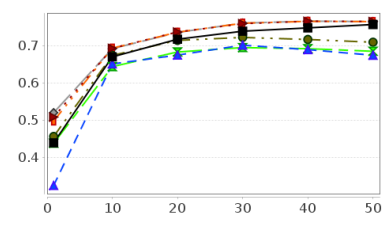

(i) FBIS

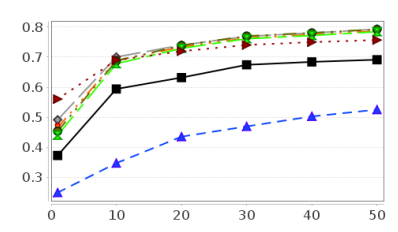

(m) La1s

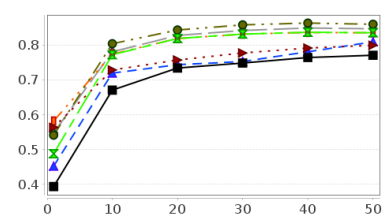

(q) Oh0

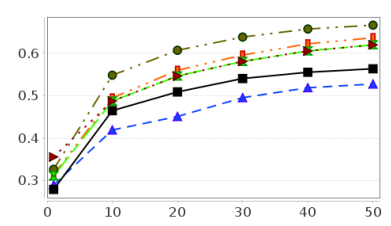

(u) Ohscal

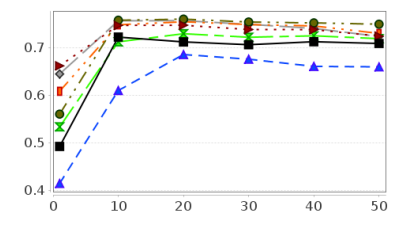

(b) CSTR

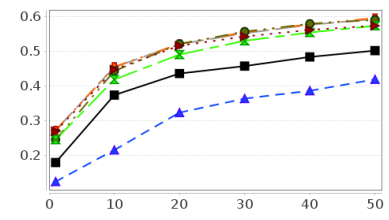

(f) Dmoz_Science_500

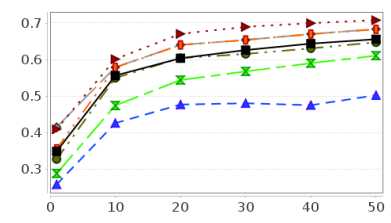

(j) Hitech

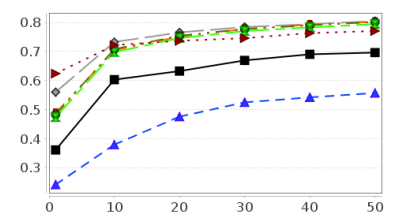

(n) La2s

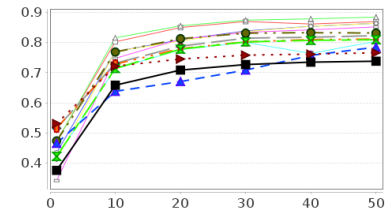

(r) Oh5

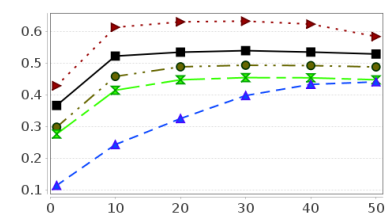

(v) Opinosis

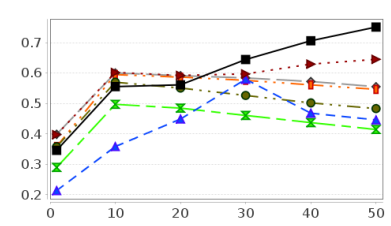

(y) Re1

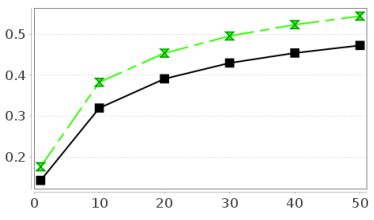

(c) Dmoz_Business_500

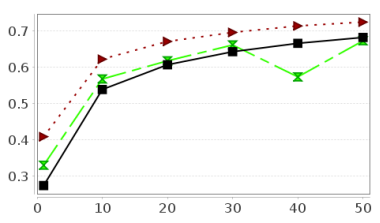

(g) Dmoz_Sports_500

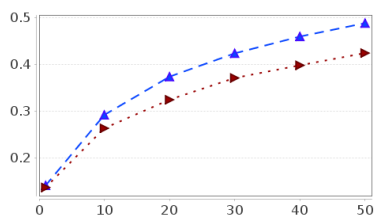

(k) Industry_Sector

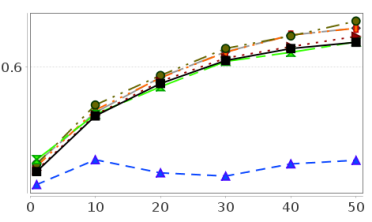

(o)

Multi_Domain_Sentiment

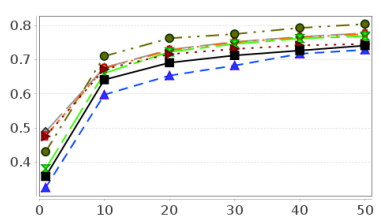

(s) Oh10

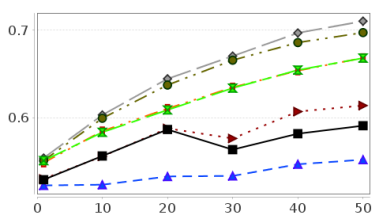

(w) Polarity

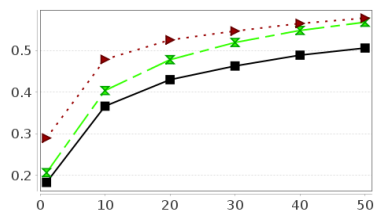

(d) Dmoz_Computers_500

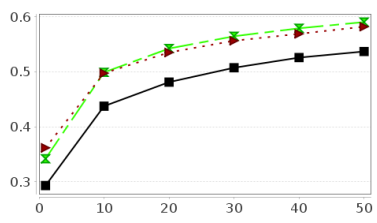

(h) Enron_Top_20

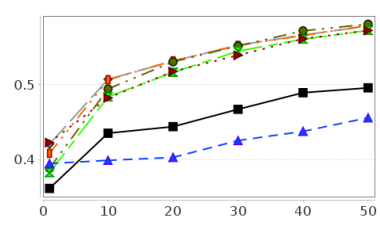

(1) IrishSentiment

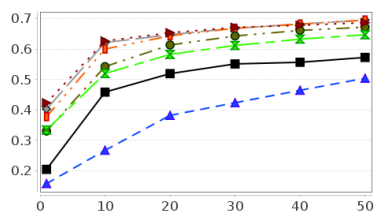

(p) NFS

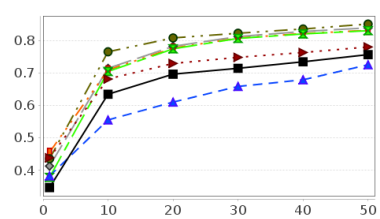

(t) Oh15

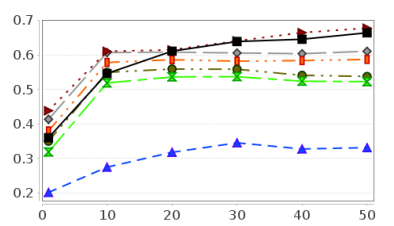

(x) $\operatorname{Re} 0$

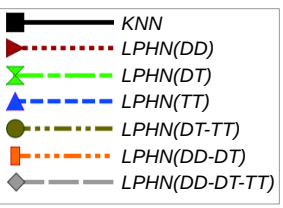

( $\mathrm{z}$ ) Legenda

Figura 4.19: Valores $F 1^{\text {Micro }}$ do $3^{\circ}$ grupo de experimentos (parte I).

TT). Isso permite comparar o impacto do uso de exemplos não rotulados na performance de classificação, por meio da comparação entre os algoritmos $I M H N^{\mathrm{R}}(\mathrm{DT})$ e $T C H N(\mathrm{DT})$, e também avaliar os impacto dos diferentes tipos de redes empregados no algoritmo TCHN. 


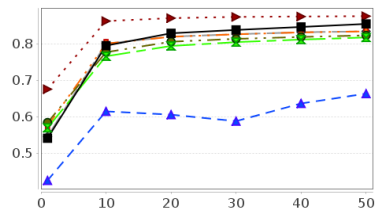

(a) $\operatorname{Re} 8$

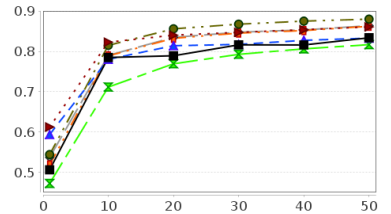

(b) Reviews

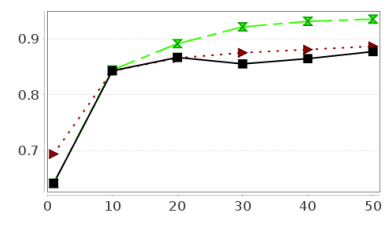

(c) SpamAssassin

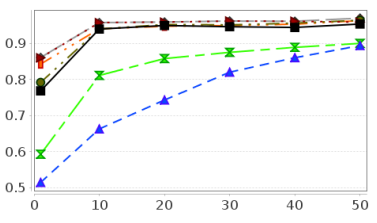

(d) SyskillWebert

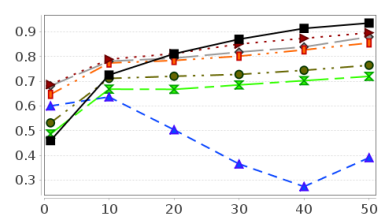

(e) $\operatorname{Tr} 11$

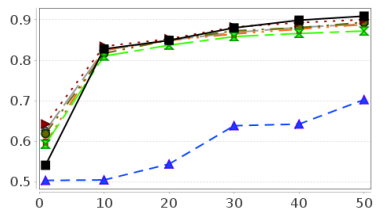

(i) $\operatorname{Tr} 31$

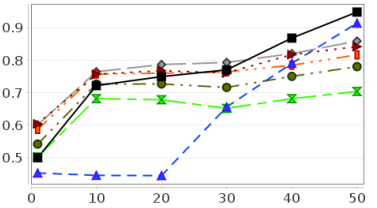

(f) $\operatorname{Tr} 12$

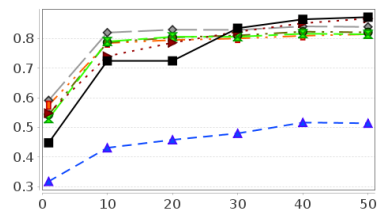

(j) $\operatorname{Tr} 41$

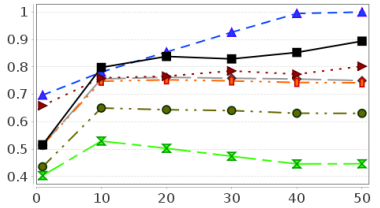

(g) $\operatorname{Tr} 21$

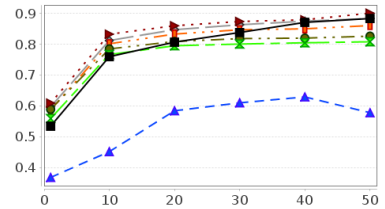

(k) $\operatorname{Tr} 45$

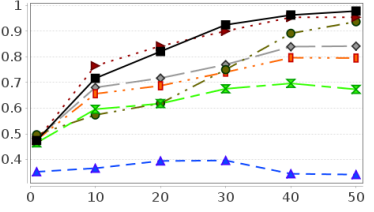

(h) $\operatorname{Tr} 23$

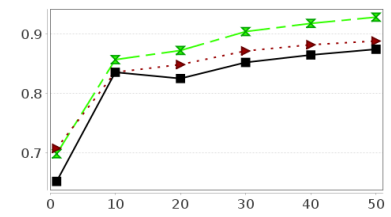

(1) Trec7_3000

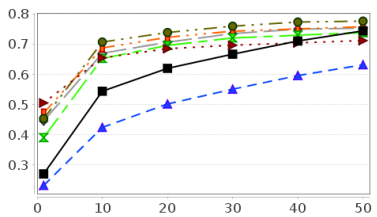

(m) Wap

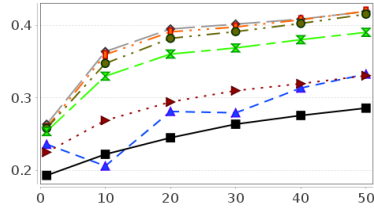

(n) WebKB

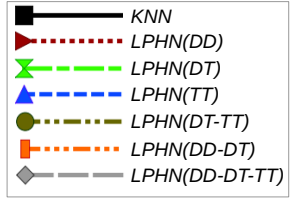

(o) Legenda

Figura 4.20: Valores $F 1^{\text {Micro }}$ do $3^{\circ}$ grupo de experimentos (parte II).

Tabela 4.6: Número de vitórias dos algoritmos indicados na linha em comparação com os algoritmos indicados na coluna para o terceiro grupo de experimentos considerando a medida $F 1^{\text {Micro }}$.
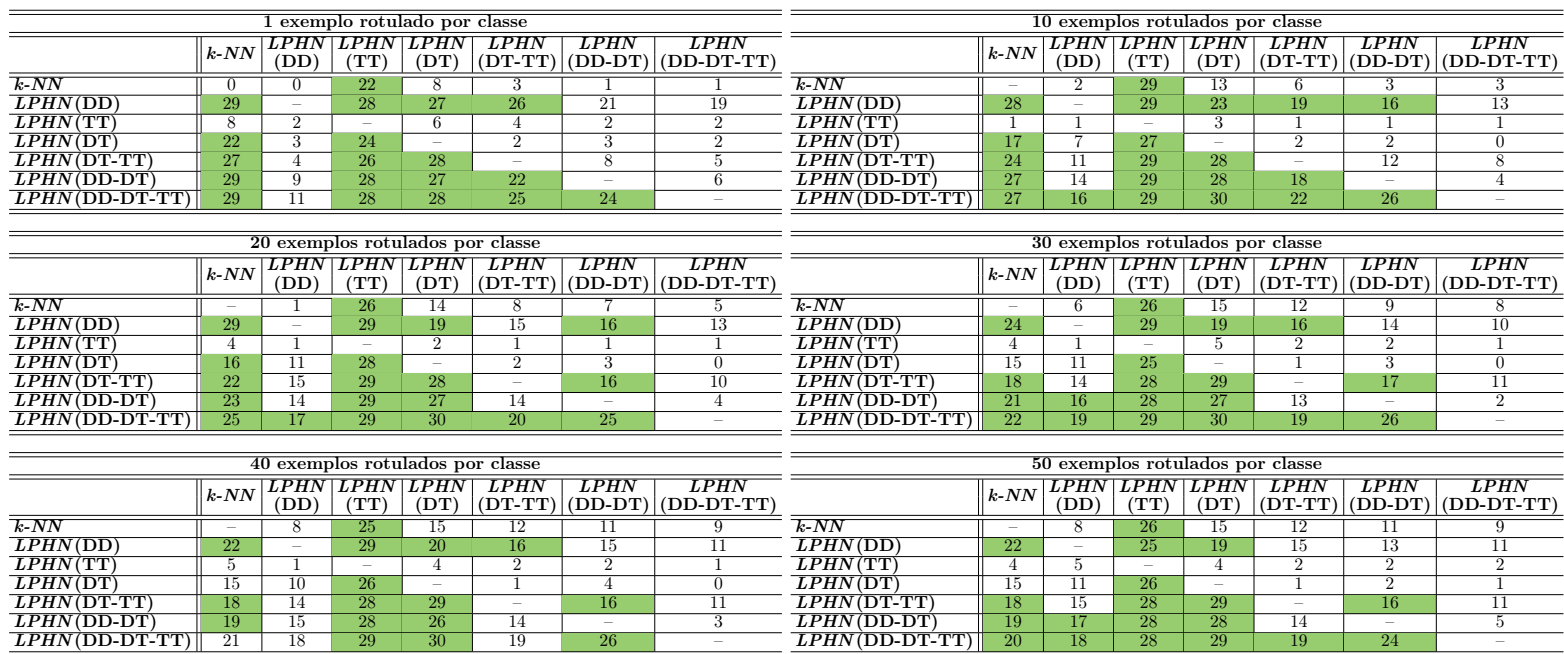

Nas Figuras 4.25 e 4.26 são apresentados os gráficos de performance de classificação considerando a medida $F 1^{\text {Micro }}$ e nas Figuras 4.27 e 4.28 são apresentados os resultados considerando a medida $F 1^{\text {Macro }}$ para o quarto grupo de experimentos considerado nesta avaliação experimental. Pode-se observar, que em geral, o algoritmo supervisionado $I M H N^{\mathrm{R}}(\mathrm{DT})$ foi superado pelo algoritmo $T C H N$ aplicado aos diferentes tipos de redes. 


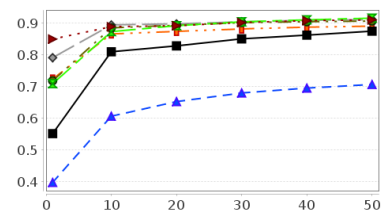

(a) Classic4

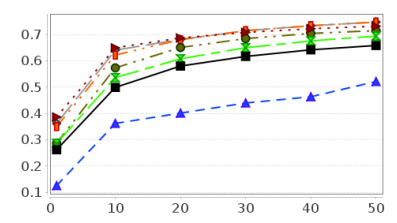

(e) Dmoz_Health_500

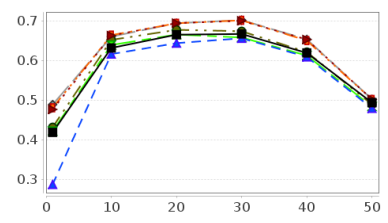

(i) FBIS

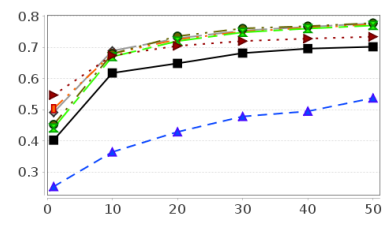

(m) La1s

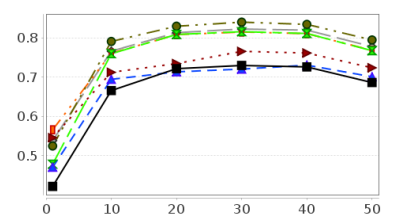

(q) Oh0

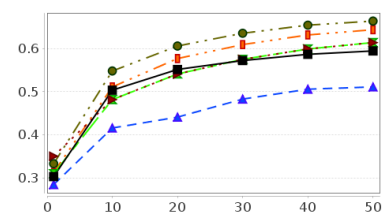

(u) Ohscal

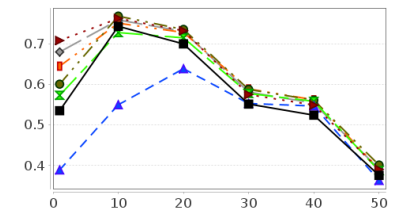

(b) CSTR

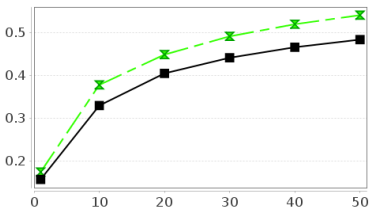

(c) Dmoz Business 500

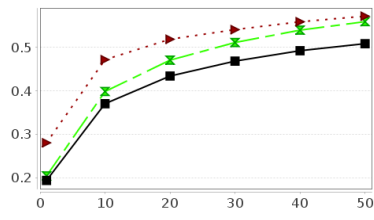

(d) Dmoz_Computers_500

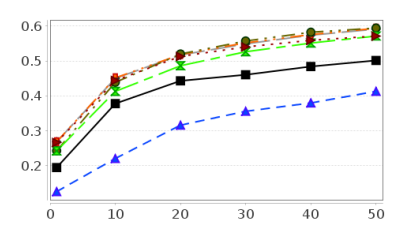

(f) Dmoz_Science_500

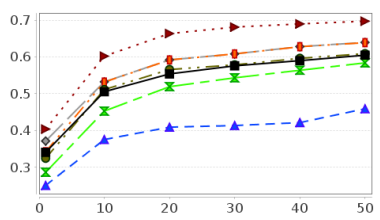

(j) Hitech

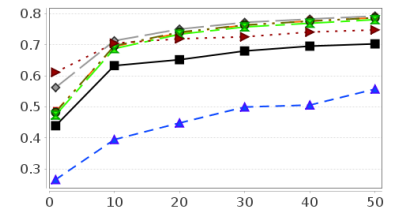

(n) La2s

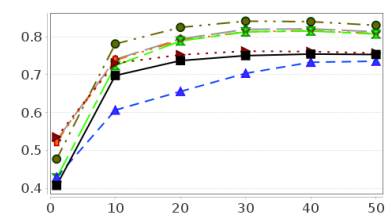

(r) Oh5

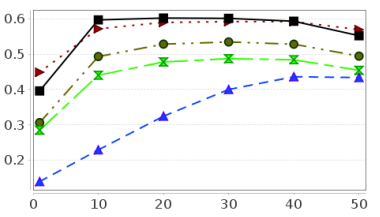

(v) Opinosis

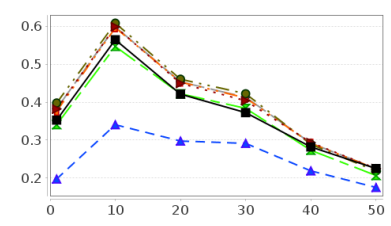

(y) Re1

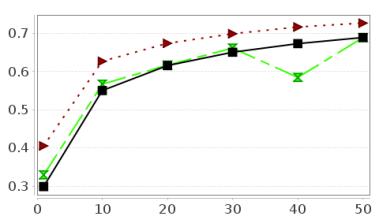

(g) Dmoz_Sports_500

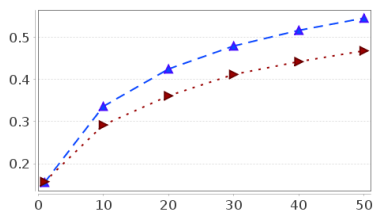

(k) Industry_Sector

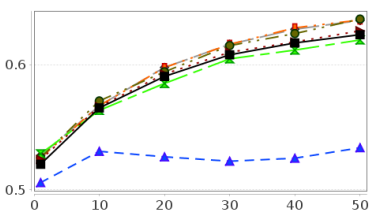

(o) Multi_Dom_Sentiment

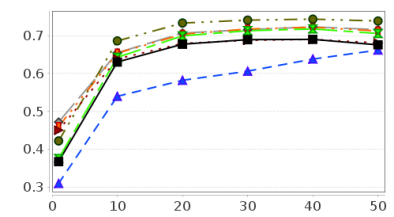

(s) Oh10

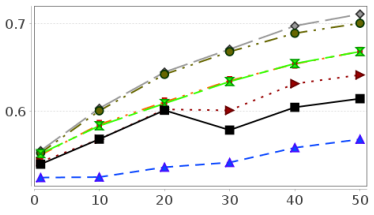

(w) Polarity

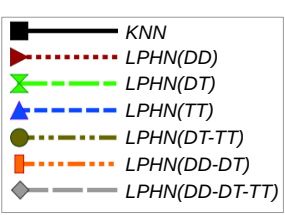

(z) Legenda

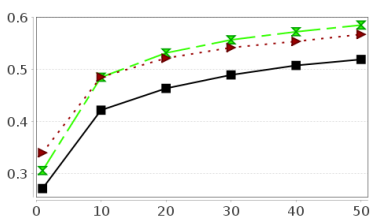

(h) Enron_Top_20

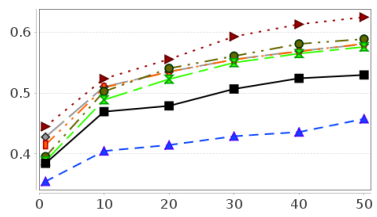

(1) IrishSentiment

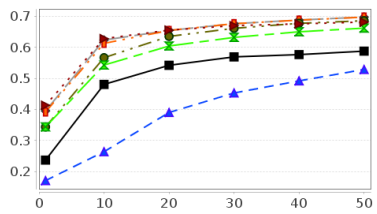

(p) NFS

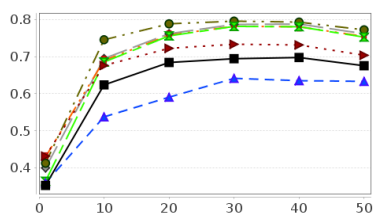

(t) Oh15

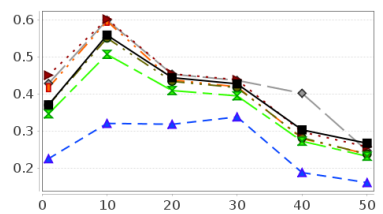

(x) $\operatorname{Re} 0$

Figura 4.21: Valores $F 1^{\text {Macro }}$ do $3^{\circ}$ grupo de experimentos (parte I).

Assim como nos demais algoritmos transdutivos baseados em redes, diferentes tipos de rede proveram diferentes performances de classificação. Porém, observa-se que para o algoritmo TCHN as rede DT-TT, em geral, obtiveram as maiores performances de classificação. 


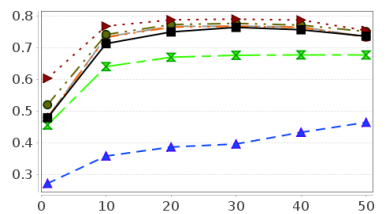

(a) $\operatorname{Re} 8$

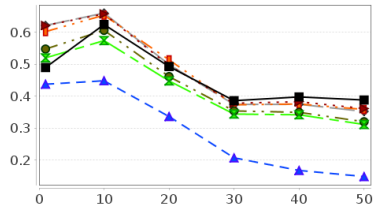

(e) $\operatorname{Tr} 11$

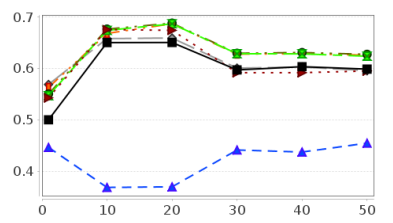

(i) $\operatorname{Tr} 31$

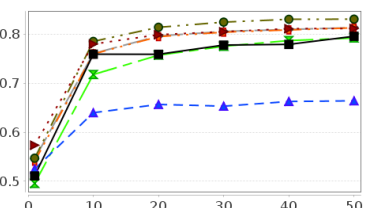

(b) Reviews

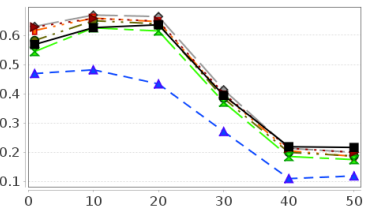

(f) $\operatorname{Tr} 12$

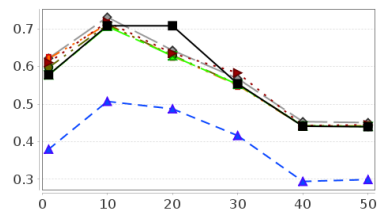

(j) $\operatorname{Tr} 41$

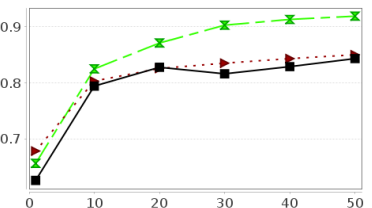

(c) SpamAssassin

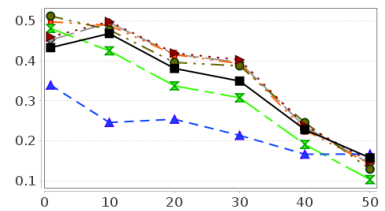

(g) $\operatorname{Tr} 21$

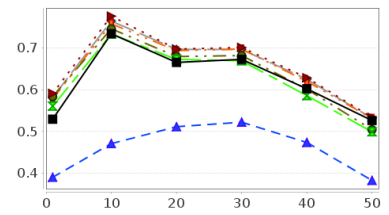

(k) $\operatorname{Tr} 45$

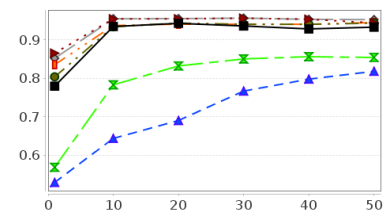

(d) SyskillWebert

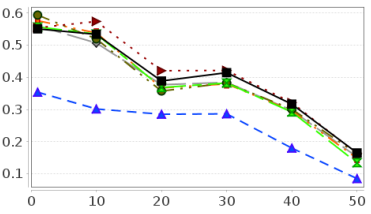

(h) $\operatorname{Tr} 23$

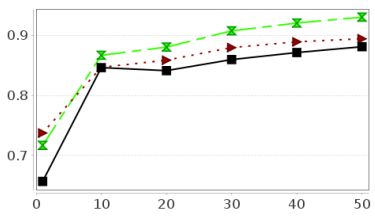

(l) Trec7_3000

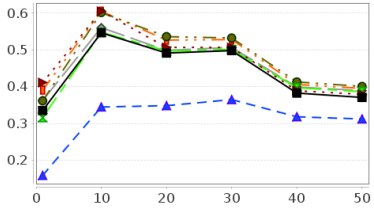

(m) Wap

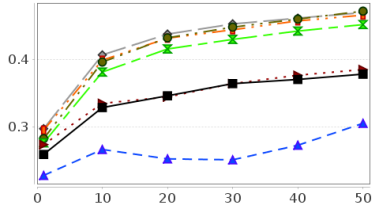

(n) WebKB

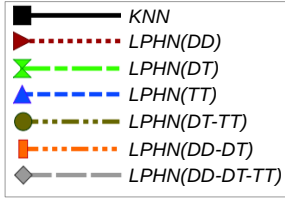

(o) Legenda

Figura 4.22: Valores $F 1^{\text {Macro }}$ do $3^{\circ}$ grupo de experimentos (parte II).

Tabela 4.7: Número de vitórias dos algoritmos indicados na linha em comparação com os algoritmos indicados na coluna para o terceiro grupo de experimentos considerando a medida F $1^{\text {Macro }}$.
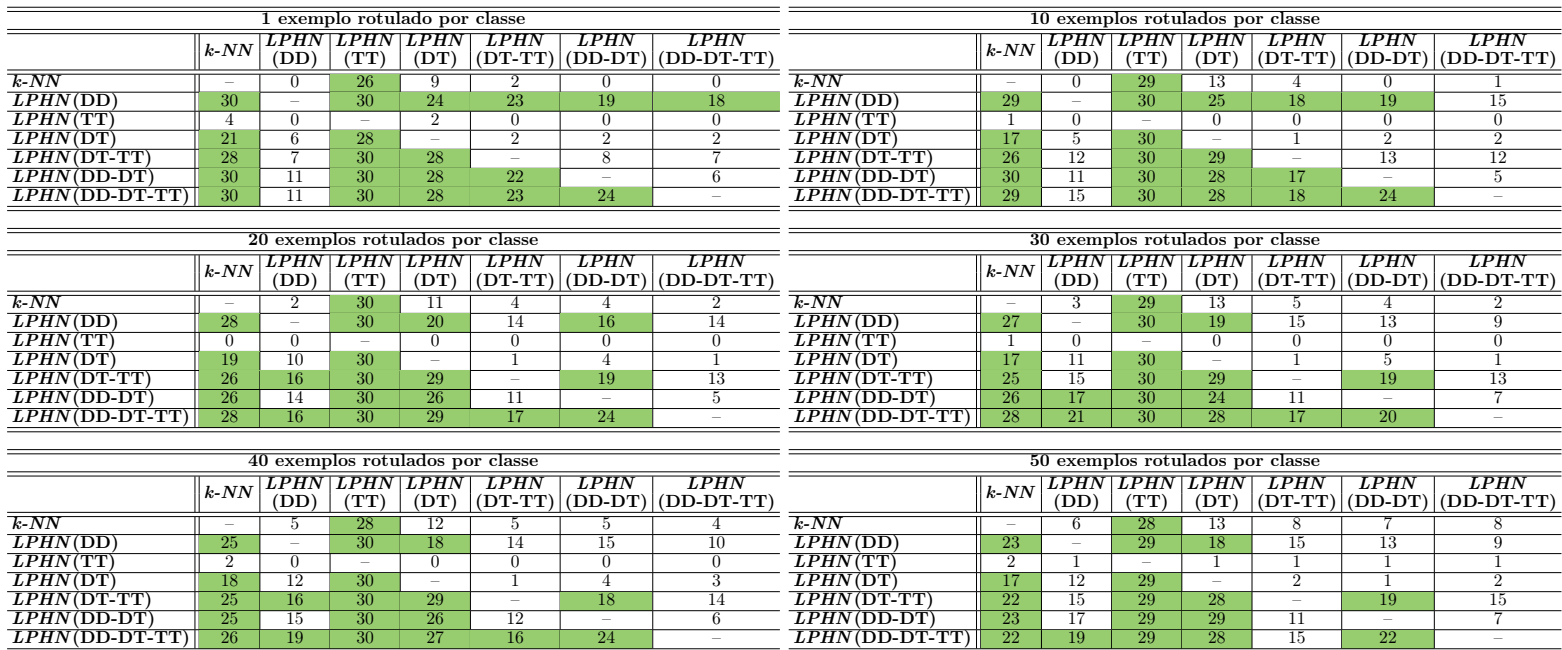

\begin{tabular}{|c|c|c|c|c|c|c|c|}
\hline \multicolumn{8}{|c|}{50 exemplos rotulados por classe } \\
\hline & $k-N N$ & $\begin{array}{l}\text { LPHN } \\
\text { (DD) }\end{array}$ & $\begin{array}{r}\begin{array}{l}L P H N \\
(\mathrm{TT})\end{array} \\
\end{array}$ & $\begin{array}{c}L P H N \\
\text { (DT) }\end{array}$ & 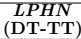 & $\begin{array}{l}\begin{array}{l}\text { LPHN } \\
\text { (DD-DT) }\end{array} \\
\end{array}$ & $\begin{array}{c}\text { LPHN } \\
\text { (DD-DT-TT) }\end{array}$ \\
\hline & & 6 & 28 & 13 & 8 & 77 & $8 \frac{8}{9}$ \\
\hline$L P$ & 23 & & 29 & 18 & 15 & 13 & 9 \\
\hline$L P$ & 2 & 1 & & 1 & 1 & 1 & 1 \\
\hline $\begin{array}{l}L P H N(\mathrm{D} \\
L P H N C \mathrm{D} \\
\end{array}$ & $\begin{array}{l}17 \\
22\end{array}$ & $\frac{12}{15}$ & 29 & 28 & 2 & $\begin{array}{c}1 \\
19\end{array}$ & $\frac{2}{15}$ \\
\hline LPHN(DD-I & 23 & 17 & 29 & 29 & 11 & & 7 \\
\hline LPHN (DD-DT-T & 22 & 19 & 29 & 28 & 15 & 22 & \\
\hline
\end{tabular}

Para elucidar a comparação das performances de classificação dos diferentes algoritmos no quarto grupo de experimentos, nas Tabelas 4.8 e 4.9 é apresentado o número de vitórias dos algoritmos considerando as medidas $F 1^{\text {Micro }}$ e $F 1^{\text {Macro }}$ respectivamente. Pode-

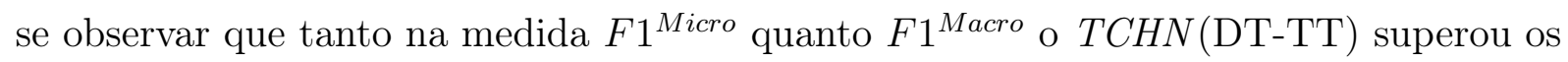
demais algoritmos utilizados nesse grupo de experimentos. Pode-se notar também que todos 


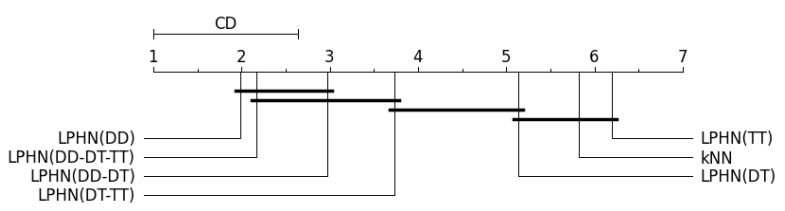

(a) 1 exemplo rotulado por classe.

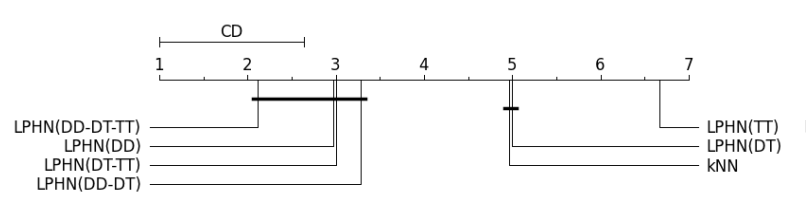

(c) 20 exemplos rotulados por classe.

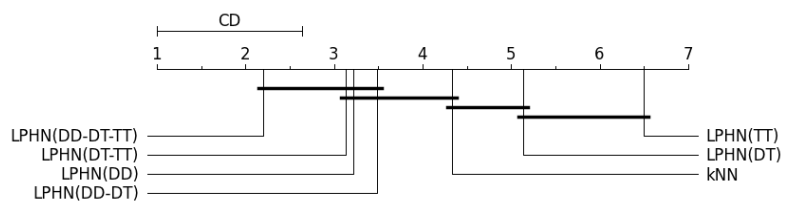

(e) 40 exemplos rotulados por classe.

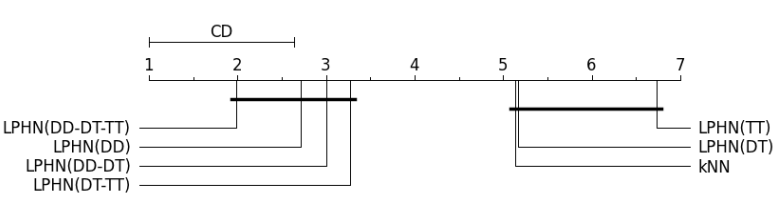

(b) 10 exemplos rotulados por classe.

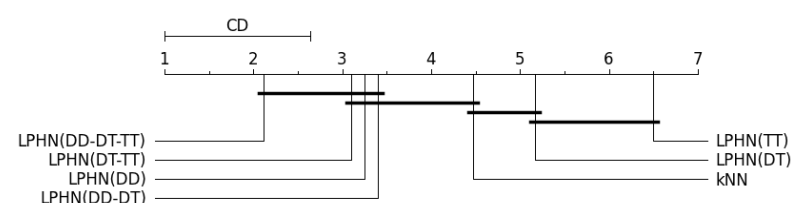

(d) 30 exemplos rotulados por classe.

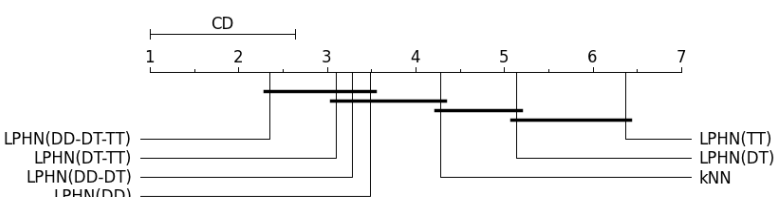

(f) 50 exemplos rotulados por classe.

Figura 4.23: Diagramas de diferença crítica para o terceiro grupo de experimentos considerando a medida $F 1^{\text {Micro. }}$.

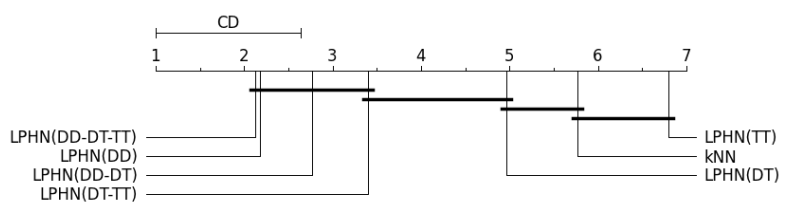

(a) 1 exemplo rotulado por classe.

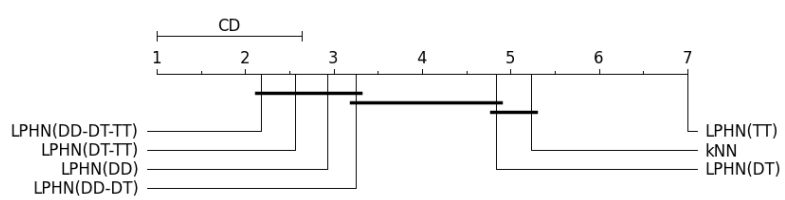

(c) 20 exemplos rotulados por classe.

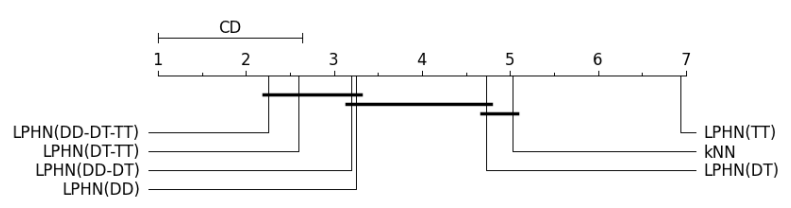

(e) 40 exemplos rotulados por classe.

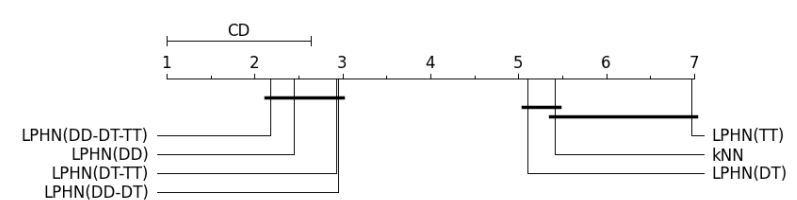

(b) 10 exemplos rotulados por classe.

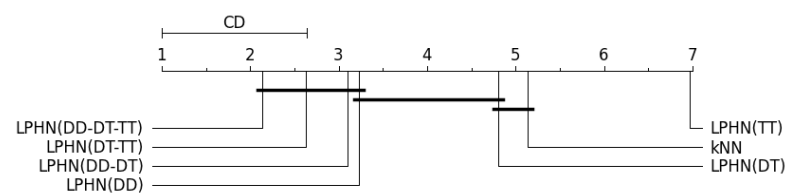

(d) 30 exemplos rotulados por classe.

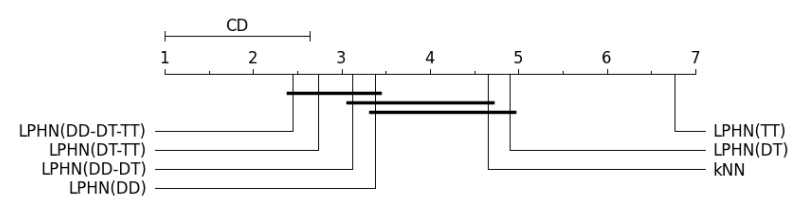

(f) 50 exemplos rotulados por classe.

Figura 4.24: Diagramas de diferença crítica para o terceiro grupo de experimentos considerando a medida $F 1^{\text {Macro }}$.

os algoritmos transdutivos superaram o $\operatorname{IMHN}^{\mathrm{R}}(\mathrm{DT})$ na maioria das coleções. Inclusive, no mesmo tipo de rede, o algoritmo $T C H N(\mathrm{DT})$ superou o algoritmo $I M H N^{\mathrm{R}}(\mathrm{DT})$ na grande maioria das coleções.

Nas Figuras 4.29 e 4.30 são apresentados os diagramas de diferença crítica considerando os resultados do quarto grupo de experimentos para as medidas $F 1^{\text {Micro }}$ e $F 1^{\text {Macro }}$ respectivamente. Pode-se observar que o TCHN(DT-TT) ocupou a primeira posição do ranking médio. Em geral, TCHN(DD-DT-TT) e TCHN(DD-DT) obtiveram a segunda e terceira 


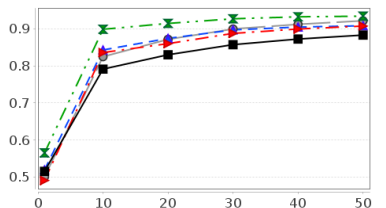

(a) Classic 4

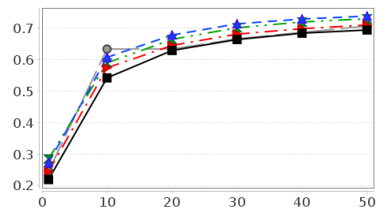

(e) Dmoz_Health_500

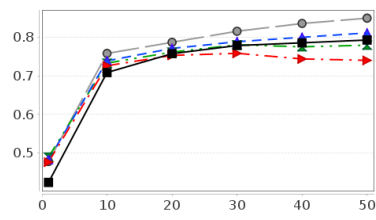

(i) FBIS

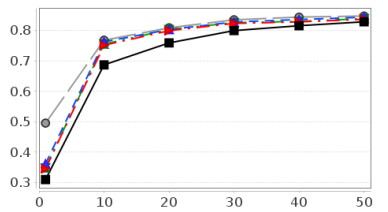

(m) La1s

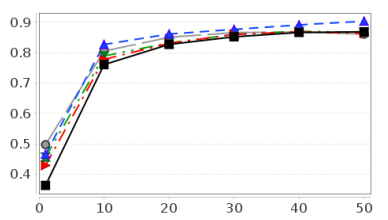

(q) Oh0

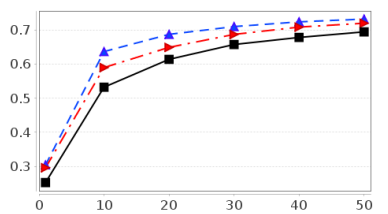

(u) Ohscal

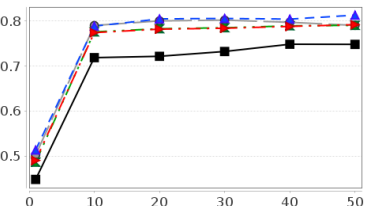

(b) CSTR

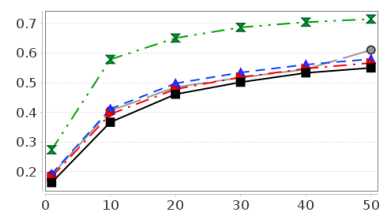

(f) Dmoz_Science_500

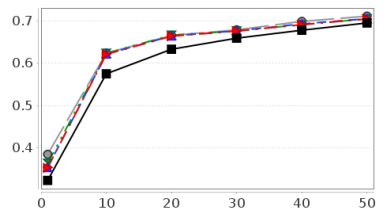

(j) Hitech

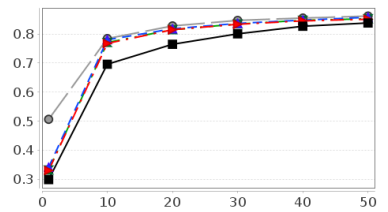

(n) La2s

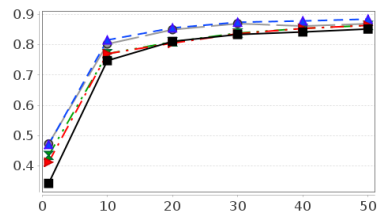

(r) Oh5

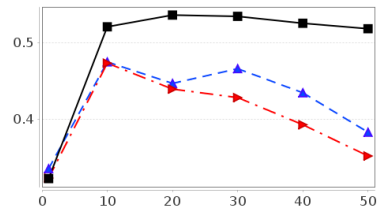

(v) Opinosis

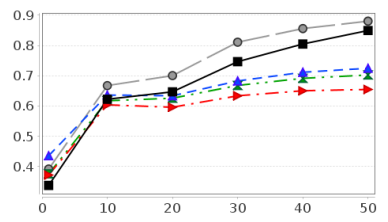

(y) Re1

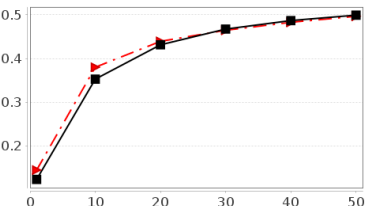

(c) Dmoz Business 500

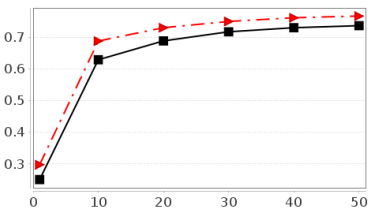

(g) Dmoz_Sports_500

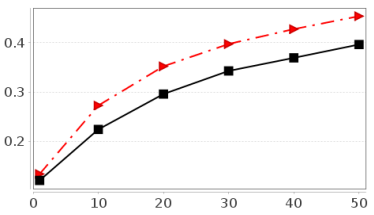

(k) Industry_Sector

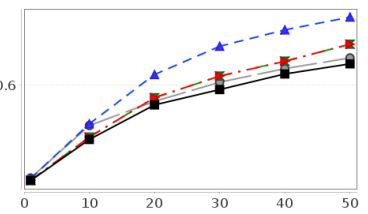

(o) Multi_Dom_Sentiment

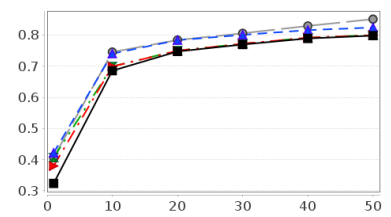

(s) Oh10

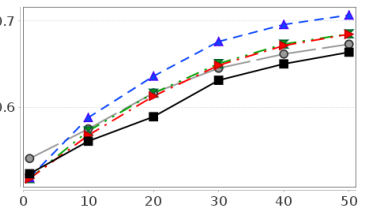

(w) Polarity

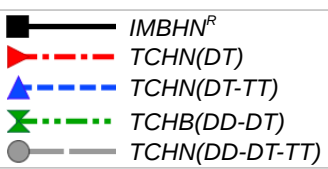

(z) Legenda

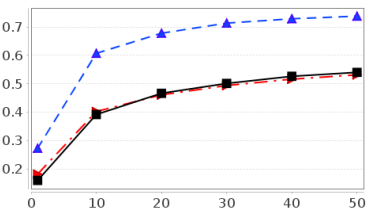

(d) Dmoz_Computers_500

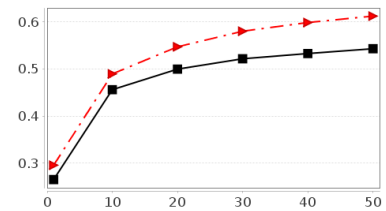

(h) Enron_Top_20

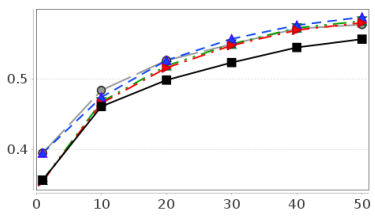

(l) IrishSentiment

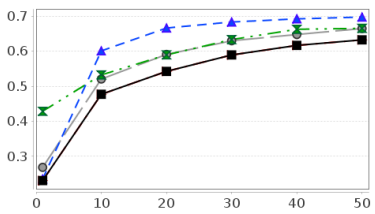

(p) NFS

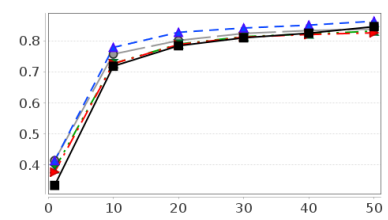

(t) Oh15

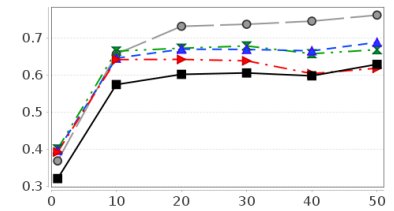

(x) $\mathrm{Re} 0$

Figura 4.25: Valores $F 1^{\text {Micro }}$ do $4^{\mathrm{o}}$ grupo de experimentos (parte I).

posições do ranking médio respectivamente. O TCHN(DT-TT) obteve melhores resultados com diferenças estatisticamente significantes para o $T C H N(\mathrm{DT})$ e o $I M H N^{\mathrm{R}}(\mathrm{DT})$ em todas as situações avaliadas. 


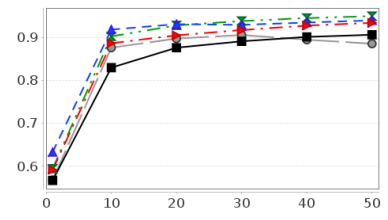

(a) $\operatorname{Re} 8$

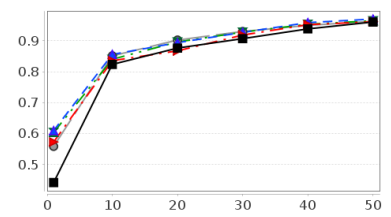

(e) $\operatorname{Tr} 11$

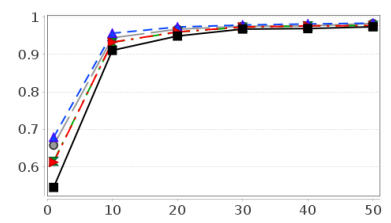

(i) $\operatorname{Tr} 31$

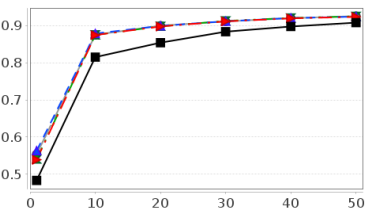

(b) Reviews

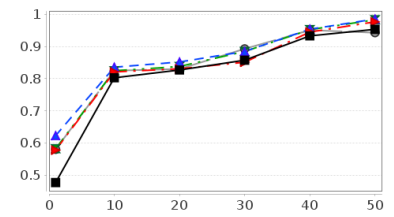

(f) $\operatorname{Tr} 12$

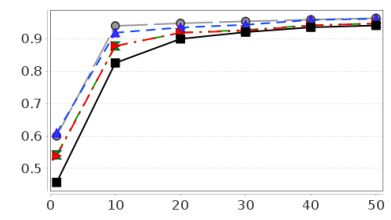

(j) $\operatorname{Tr} 41$

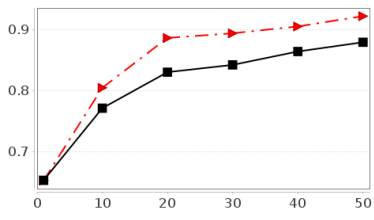

(c) SpamAssassin

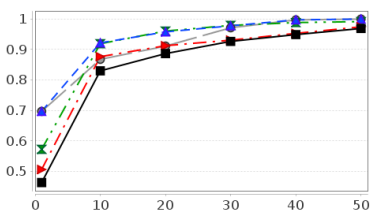

(g) $\operatorname{Tr} 21$

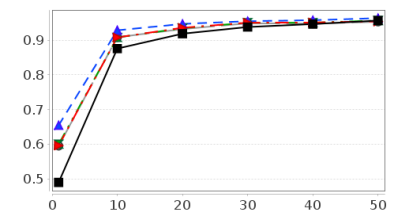

(k) $\operatorname{Tr} 45$

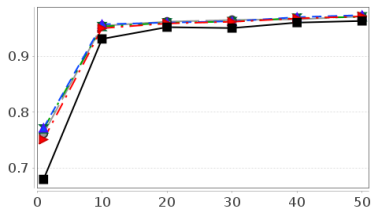

(d) SyskillWebert

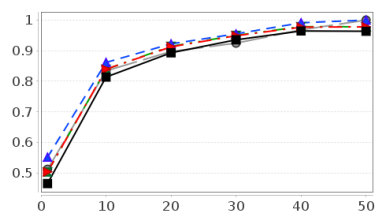

(h) $\operatorname{Tr} 23$

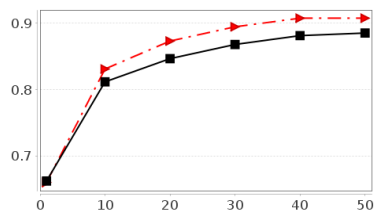

(l) Trec7_3000

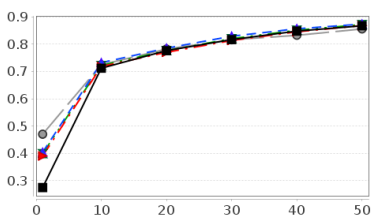

(m) Wap

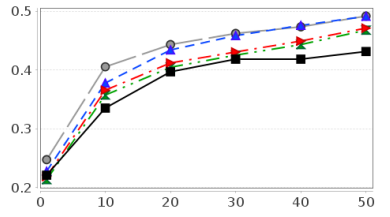

(n) WebKB

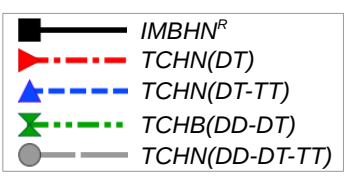

(o) Legenda

Figura 4.26: Valores $F 1^{\text {Micro }}$ do $4^{\mathrm{o}}$ grupo de experimentos (parte II).

Tabela 4.8: Número de vitórias dos algoritmos indicados na linha em comparação com os algoritmos indicados na coluna para o quarto grupo de experimentos considerando a medida $F 1^{\text {Micro }}$.

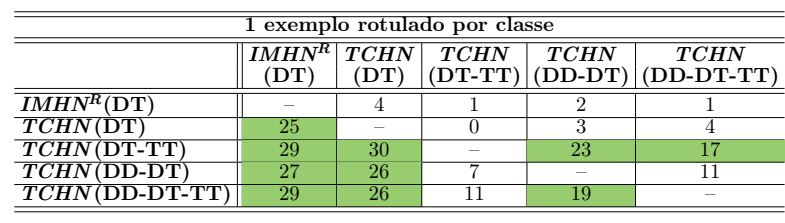

\begin{tabular}{|c|c|c|c|c|c|}
\hline \multicolumn{6}{|c|}{10 exemplos rotulados por classe } \\
\hline & $\begin{array}{c}\begin{array}{l}I M H N^{R} \\
(\mathrm{DT})\end{array} \\
\end{array}$ & $\begin{array}{c}T C H N \\
\text { (DT) }\end{array}$ & $\begin{array}{c}T C H N \\
\text { (DT-TT) }\end{array}$ & $\begin{array}{c}T C H N \\
\text { (DD-DT) }\end{array}$ & $\begin{array}{c}T C H N \\
\text { (DD-DT-TT) }\end{array}$ \\
\hline$\overline{I M H N^{R}(\mathrm{DT})}$ & - & 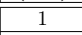 & 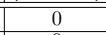 & 1 & 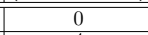 \\
\hline$T C H N(\mathrm{DT})$ & 28 & . & 0 & 3 & 4 \\
\hline TCHN(DT-TT) & 30 & 30 & - & 26 & 18 \\
\hline TCHN(DD-DT) & 29 & 24 & 4 & & 7 \\
\hline TCHN(DD-DT-TT) & 30 & 26 & 12 & 23 & - \\
\hline
\end{tabular}

\begin{tabular}{|c|c|c|c|c|c|}
\hline \multicolumn{6}{|c|}{20 exemplos rotulados por classe } \\
\hline & $\begin{array}{c}\begin{array}{l}I M H N^{K} \\
(\mathrm{DT})\end{array} \\
\end{array}$ & $\begin{array}{c}T C H N \\
\text { (DT) }\end{array}$ & $\begin{array}{c}\text { TCHN } \\
\text { (DT-TT) }\end{array}$ & $\begin{array}{c}T C H N \\
\text { (DD-DT) }\end{array}$ & $\begin{array}{c}T C H N \\
\text { (DD-DT-TT) }\end{array}$ \\
\hline$\overline{I M H N^{R}(\mathrm{DT})}$ & $=$ & 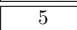 & 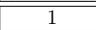 & 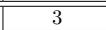 & 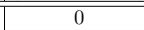 \\
\hline$T C H N(\mathrm{DT})$ & 24 & - & 0 & 5 & 7 \\
\hline TCHN $(\mathrm{DT}-\mathrm{TT})$ & 29 & 30 & - & 23 & 18 \\
\hline TCHN (DD-DT) & 27 & 25 & 6 & & 10 \\
\hline$T C H N(D D-D T-T T)$ & 30 & 23 & 12 & 20 & - \\
\hline \multicolumn{6}{|c|}{40 exemplos rotulados por classe } \\
\hline & $\begin{array}{c}I M H N^{K} \\
(\mathbf{D T})\end{array}$ & $\begin{array}{c}C C H N \\
\text { (DT) }\end{array}$ & $\begin{array}{c}T C H N \\
\text { (DT-TT) }\end{array}$ & $\begin{array}{c}T C H N \\
\text { (DD-DT) }\end{array}$ & $\begin{array}{c}T C H N \\
\text { (DD-DT-TT) }\end{array}$ \\
\hline$\overline{\overline{I M H N^{R}(\mathrm{DT})}}$ & $=$ & 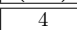 & $\overline{1} 1$ & 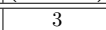 & 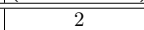 \\
\hline$T C H N(\mathrm{DT})$ & 25 & 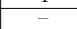 & 0 & 2 & 11 \\
\hline TCHN (DT-TT) & 29 & 30 & - & 26 & 20 \\
\hline TCHN(DD-DT) & 27 & 25 & 4 & - & 16 \\
\hline TCHN (DD-DT-TT) & 28 & 18 & 9 & 13 & 1 \\
\hline
\end{tabular}

\begin{tabular}{|c|c|c|c|c|c|}
\hline \multicolumn{6}{|c|}{30 exemplos rotulados por classe } \\
\hline & $\begin{array}{c}\begin{array}{l}I M H N^{R} \\
(\mathrm{DT})\end{array} \\
.\end{array}$ & $\begin{array}{c}\overline{\text { TCHN }} \\
\text { (DT) }\end{array}$ & $\begin{array}{c}\text { TCHN } \\
\text { (DT-TT) }\end{array}$ & $\begin{array}{c}T C H N \\
\text { (DD-DT) }\end{array}$ & $\begin{array}{c}T C H N \\
\text { (DD-DT-TT) }\end{array}$ \\
\hline$\overline{I M H H N^{R}(\mathrm{DT})}$ & 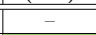 & 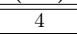 & 1 & 1 & 2 \\
\hline$T C H N(\mathrm{DT})$ & 25 & & 0 & 2 & 8 \\
\hline$T C H N(D T-T T)$ & 29 & 30 & - & 22 & 17 \\
\hline$T C H N(\mathrm{DD}-\mathrm{DT})$ & 29 & 23 & 7 & & 13 \\
\hline$T C H N(D D-D T-T T)$ & 28 & 22 & 13 & 17 & - \\
\hline
\end{tabular}

\begin{tabular}{|c|c|c|c|c|c|}
\hline \multicolumn{6}{|c|}{50 exemplos rotulados por classe } \\
\hline & $\begin{array}{c}I M H N^{R} \\
(\mathrm{DT})\end{array}$ & $\begin{array}{c}\text { TCHN } \\
\text { (DT) }\end{array}$ & $\begin{array}{c}T C H N \\
(\mathrm{DT}-\mathrm{TT})\end{array}$ & $\begin{array}{c}T C H N \\
\text { (DD-DT) }\end{array}$ & $\begin{array}{c}T C H N \\
\text { (DD-DT-TT) }\end{array}$ \\
\hline$\overline{I M H N^{R}(\mathrm{DT})}$ & - & 6 & 1 & 4 & 6 \\
\hline$T C H N(\mathrm{DT})$ & 23 & - & 0 & 3 & 10 \\
\hline$T C H N(D T-T T)$ & 29 & 30 & 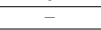 & 26 & 16 \\
\hline$T C H N(D D-D T)$ & 25 & 23 & 4 & & 13 \\
\hline$T C H N(\mathrm{DD}-\mathrm{DT}-\mathrm{TT})$ & 24 & 19 & 12 & 16 & - \\
\hline
\end{tabular}

No quinto grupo de experimentos, foram comparadas as melhores performances de classificação dos algoritmos transdutivos obtidas nos quatro grupos de experimentos anteriores, isto é, foram comparadas as melhores performances obtidas por algoritmos transdutivos baseados no modelo espaço-vetorial (MEV), as melhores performances do algoritmo GNetMine, as melhores performances do algoritmo $L P H N$ e as melhores performances do 

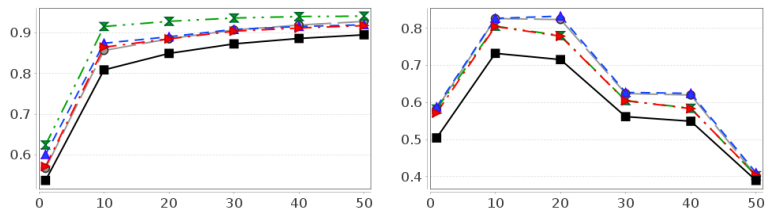

(a) Classic 4

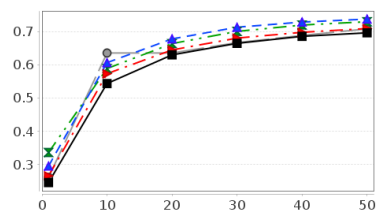

(e) Dmoz_Health_500

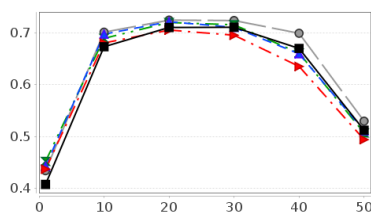

(i) FBIS

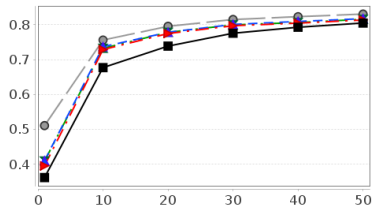

(m) La1s

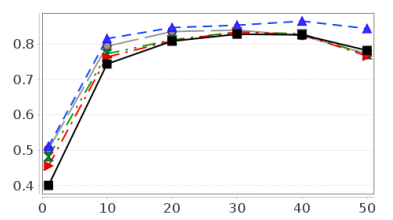

(q) $\mathrm{Oh0}$

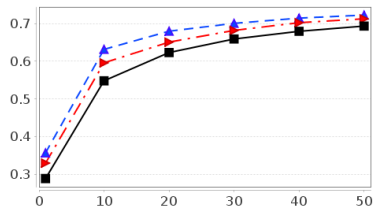

(u) Ohscal

(b) CSTR

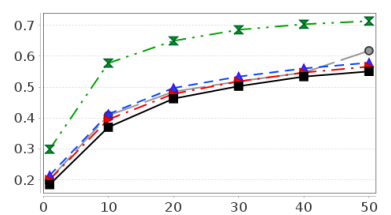

(f) Dmoz_Science_500

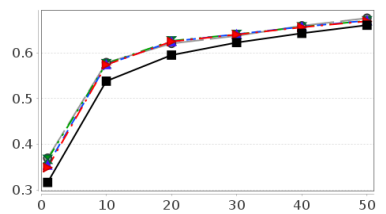

(j) Hitech

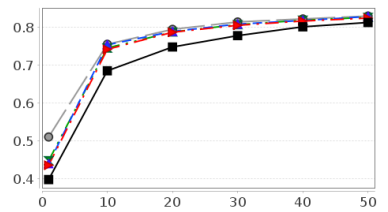

(n) La2s

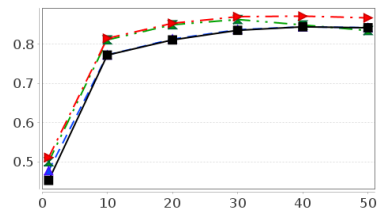

(r) Oh5

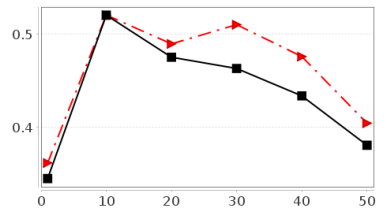

(v) Opinosis

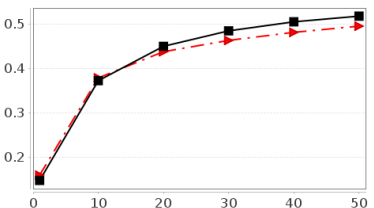

(c) Dmoz Business 500

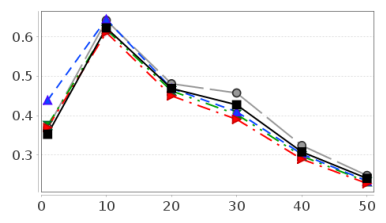

(y) Re1

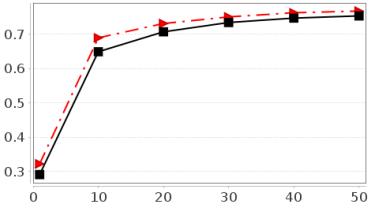

(g) Dmoz_Sports_500
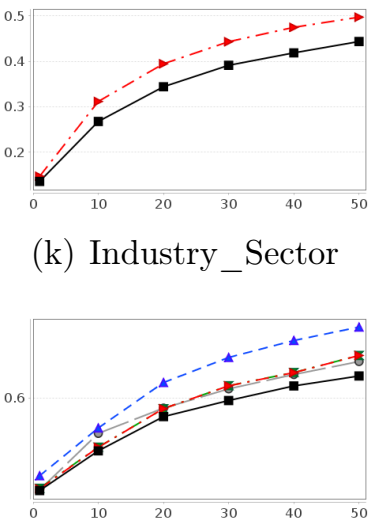

(o) Multi_Dom_Sentiment

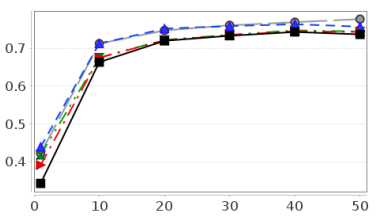

(s) Oh10

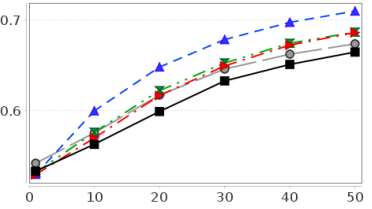

(w) Polarity

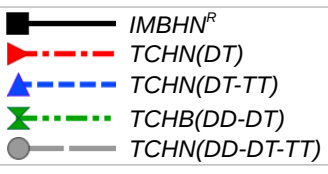

(z) Legenda (k) Industry_Sector

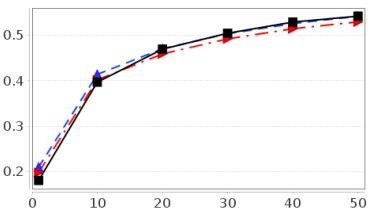

(d) Dmoz_Computers_500

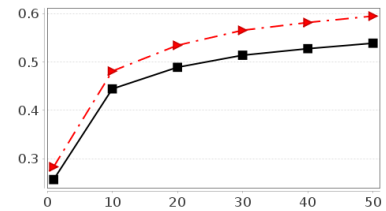

(h) Enron_Top_20

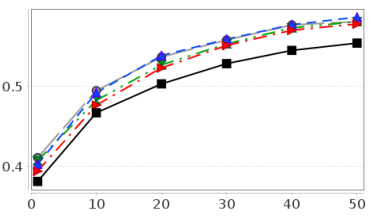

(l) IrishSentiment

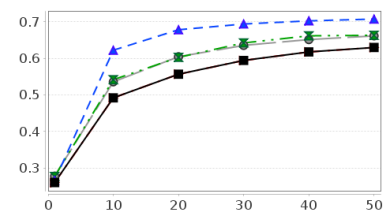

(p) NFS

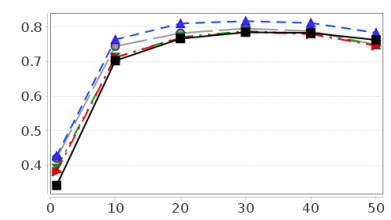

(t) Oh15

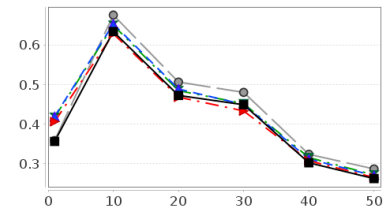

(x) $\operatorname{Re} 0$

Figura 4.27: Valores $F 1^{\text {Macro }}$ do $4^{\mathrm{o}}$ grupo de experimentos (parte I).

algoritmo TCHN. Nesse quinto grupo de experimentos o objetivo é analisar qual algoritmo obtém a maior performance na classificação transdutiva de textos. As performances dos algoritmos transdutivos também foram comparadas com as melhores performances dos 


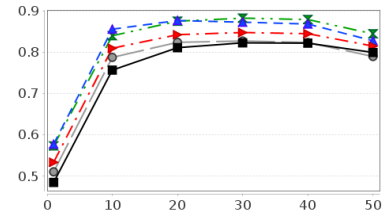

(a) $\operatorname{Re} 8$

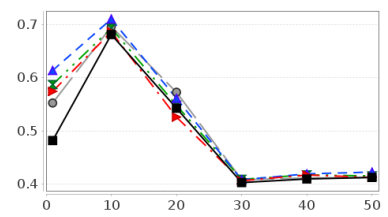

(e) $\operatorname{Tr} 11$

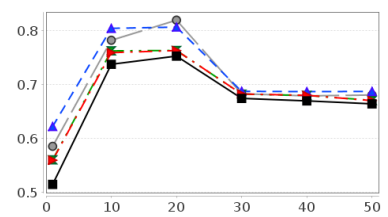

(i) $\operatorname{Tr} 31$

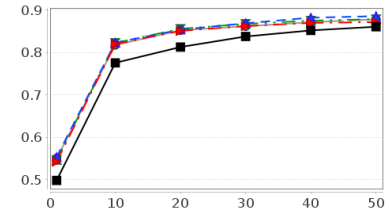

(b) Reviews

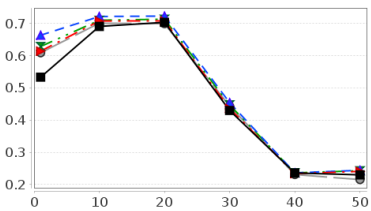

(f) $\operatorname{Tr} 12$

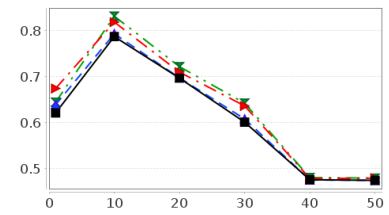

(j) $\operatorname{Tr} 41$

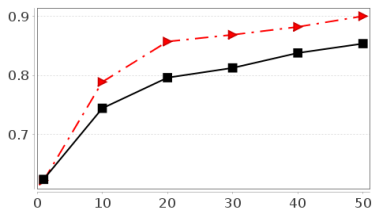

(c) SpamAssassin

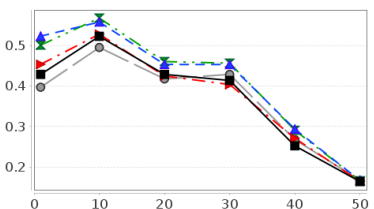

(g) $\operatorname{Tr} 21$

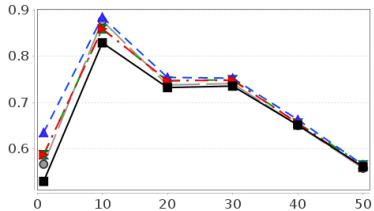

(k) $\operatorname{Tr} 45$

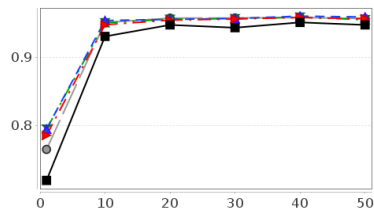

(d) SyskillWebert

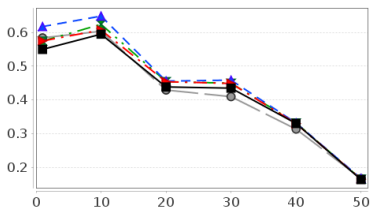

(h) $\operatorname{Tr} 23$

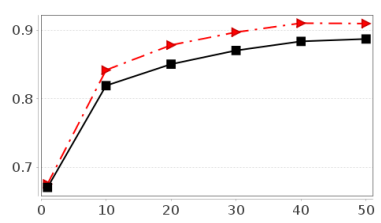

(l) Trec7_3000

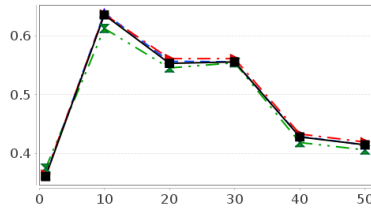

(m) Wap

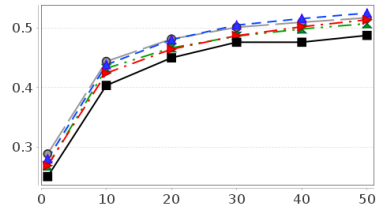

(n) WebKB

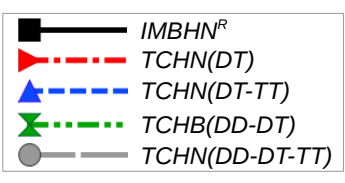

(o) Legenda

Figura 4.28: Valores $F 1^{\text {Macro }}$ do $4^{\circ}$ grupo de experimentos (parte II).

Tabela 4.9: Número de vitórias dos algoritmos indicados na linha em comparação com os algoritmos indicados na coluna para o quarto grupo de experimentos considerando a medida $F 1^{\text {Macro }}$.

\begin{tabular}{|c|c|c|c|c|c|}
\hline \multicolumn{6}{|c|}{1 1 exemplo rotulado por classe } \\
\hline & $\begin{array}{c}I M H N^{R} \\
(\mathrm{DT})\end{array}$ & $\begin{array}{c}T C H N \\
(\mathrm{DT})\end{array}$ & \begin{tabular}{|c|}
$T C H N$ \\
$(\mathrm{DT}-\mathrm{TT})$
\end{tabular} & $\begin{array}{c}T C H N \\
\text { (DD-DT) }\end{array}$ & $\begin{array}{c}T C H N \\
\text { (DD-DT-TT) } \\
\end{array}$ \\
\hline$\overline{I M H N^{R}(\mathrm{DT})}$ & - & 1 & 1 & 1 & 1 \\
\hline$T C H N(\mathrm{DT})$ & 28 & - & 0 & 2 & 12 \\
\hline$T C H N(\mathrm{DT}-\mathrm{TT})$ & 29 & 30 & - & 21 & 22 \\
\hline$T C H N(D D-D T)$ & 29 & 27 & 9 & & 13 \\
\hline$T C H N(\mathrm{DD}-\mathrm{DT}-\mathrm{TT})$ & 29 & 18 & 8 & 17 & 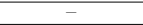 \\
\hline
\end{tabular}

\begin{tabular}{|c|c|c|c|c|c|}
\hline \multicolumn{6}{|c|}{10 exemplos rotulados por classe } \\
\hline & $\begin{array}{c}I M H N^{R} \\
(\mathrm{DT})\end{array}$ & $\begin{array}{c}T C H N \\
\text { (DT) }\end{array}$ & $\begin{array}{c}\text { TCHN } \\
\text { (DT-TT) }\end{array}$ & \begin{tabular}{|c}
$T C H N$ \\
$(\mathrm{DD}-\mathrm{DT})$
\end{tabular} & $\begin{array}{c}T C H N \\
\text { (DD-DT-TT) }\end{array}$ \\
\hline$\overline{I M H N^{R}(\mathrm{DT})}$ & - & $\overline{2}$ & $\overline{0}$ & 1 & 2 \\
\hline$T C H N(\mathrm{DT})$ & 27 & & 0 & 1 & 7 \\
\hline TCHN(DT-TT) & 30 & 30 & 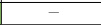 & 25 & 21 \\
\hline TCHN(DD-DT) & 29 & 29 & 5 & & 10 \\
\hline TCHN(DD-DT-TT) & 28 & 23 & 9 & 20 & - \\
\hline
\end{tabular}

\begin{tabular}{|c|c|c|c|c|c|}
\hline \multicolumn{6}{|c|}{20 exemplos rotulados por classe } \\
\hline & $\begin{array}{c}\begin{array}{c}I M H N^{R} \\
(\mathrm{DT})\end{array} \\
\end{array}$ & $\begin{array}{c}T C H N \\
\text { (DT) }\end{array}$ & $\begin{array}{c}T C H N \\
(\mathrm{DT}-\mathrm{TT})\end{array}$ & $\begin{array}{c}T C H N \\
\text { (DD-DT) }\end{array}$ & $\begin{array}{c}T C H N \\
\text { (DD-DT-TT) }\end{array}$ \\
\hline$\overline{I M H N^{R}(\mathrm{DT})}$ & ב- & 7 & 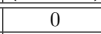 & 3 & 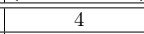 \\
\hline$T C H N(\mathrm{DT})$ & 22 & & 0 & 2 & 8 \\
\hline TCHN (DT-TT) & 30 & 29 & - & 24 & 20 \\
\hline TCHN(DD-DT) & 27 & 28 & 6 & & 12 \\
\hline$T C H N(\mathrm{DD}-\mathrm{DT}-\mathrm{TT})$ & 26 & 21 & 10 & 18 & - \\
\hline
\end{tabular}

\begin{tabular}{|c|c|c|c|c|c|}
\hline \multicolumn{6}{|c|}{30 exemplos rotulados por classe } \\
\hline & $\begin{array}{l}I M H N^{R} \\
(\mathrm{DT})\end{array}$ & $\begin{array}{c}\text { TCHN } \\
\text { (DT) }\end{array}$ & $\begin{array}{c}T C H N \\
\text { (DT-TT) }\end{array}$ & $\begin{array}{c}T C H N \\
\text { (DD-DT) }\end{array}$ & $\begin{array}{c}T C H N \\
\text { (DD-DT-TT) }\end{array}$ \\
\hline$\overline{I I M H N^{R}(\mathrm{DT})}$ & - & 6 & $\overline{2}$ & 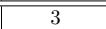 & $\overline{2}$ \\
\hline$T C H N(\mathrm{DT})$ & 23 & & 0 & 2 & 9 \\
\hline TCHN (DT-TT) & 28 & 30 & - & 23 & 21 \\
\hline$T C H N(\mathrm{I}$ & 27 & 28 & 7 & & 15 \\
\hline$T C H N(D D-D T-T T)$ & 28 & 21 & 9 & 15 & 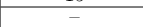 \\
\hline
\end{tabular}

\begin{tabular}{|c|c|c|c|c|c|}
\hline \multicolumn{6}{|c|}{ 40 exemplos rotulados por classe } \\
\hline & $\begin{array}{c}I M H N^{R} \\
(\mathrm{DT})\end{array}$ & $\begin{array}{c}\text { TCHN } \\
\text { (DT) }\end{array}$ & \begin{tabular}{|c} 
TCHN \\
(DT-TT)
\end{tabular} & $\begin{array}{c}T C H N \\
\text { (DD-DT) }\end{array}$ & $\begin{array}{c}T C H N \\
\text { (DD-DT-TT) }\end{array}$ \\
\hline$\overline{I M H N^{R}(\mathrm{DT})}$ & - & $\overline{c 6}$ & $\overline{\overline{2}}$ & 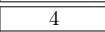 & 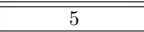 \\
\hline$T C H N(\mathrm{DT})$ & 23 & - & 0 & 3 & 14 \\
\hline TCHN (DT-TT) & 28 & 30 & & 22 & 21 \\
\hline TCHN(DD-DT) & 26 & 26 & 7 & & 17 \\
\hline$T C H N(D D-D T-T T)$ & 25 & 16 & 9 & 13 & 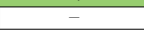 \\
\hline
\end{tabular}

\begin{tabular}{|c|c|c|c|c|c|}
\hline \multicolumn{6}{|c|}{$\overline{50}$ exemplos rotulados por classe } \\
\hline & $\begin{array}{c}I M H N^{R} \\
(\mathrm{DT})\end{array}$ & $\begin{array}{c}\text { TCHN } \\
\text { (DT) }\end{array}$ & \begin{tabular}{|c|}
$T C H N$ \\
(DT-TT)
\end{tabular} & $\begin{array}{c}T C H N \\
\text { (DD-DT) }\end{array}$ & $\begin{array}{c}T C H N \\
\text { (DD-DT-TT) } \\
\end{array}$ \\
\hline$\overline{I M H N^{R}(\mathrm{DT})}$ & 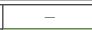 & 6 & 2 & 5 & 7 \\
\hline$T C H N(\mathrm{DT})$ & 23 & - & 0 & 4 & 9 \\
\hline$T C H N(\mathrm{DT}-\mathrm{TT})$ & 28 & 30 & 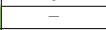 & 25 & 18 \\
\hline TCHN(DD-DT) & 25 & 23 & 5 & & 15 \\
\hline TCHN(DD-DT-TT) & 23 & 21 & 10 & 15 & - \\
\hline
\end{tabular}

algoritmos indutivos supervisionados utilizados nesta avaliação experimental (indicado nos gráficos de performance e tabelas de vitória por Ind. Sup.).

Nas Figuras 4.31 e 4.32 são apresentados os gráficos de performance de classificação considerando a medida $F 1^{\text {Micro }}$ e nas Figuras 4.33 e 4.34 são apresentados os resultados considerando a medida $F 1^{\text {Macro }}$ para o quinto grupo de experimentos considerados nesta 


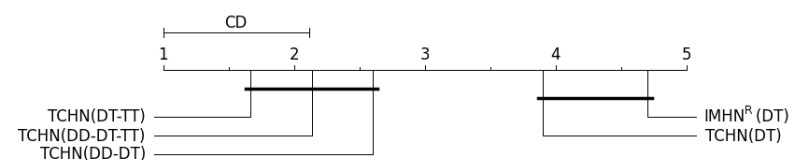

(a) 1 exemplo rotulado por classe.

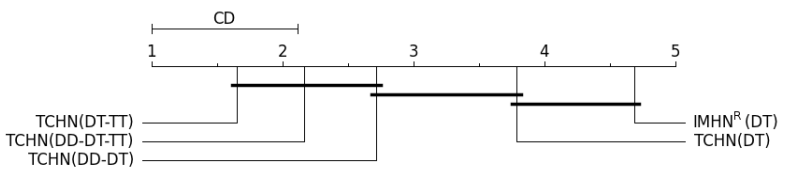

(c) 20 exemplos rotulados por classe.

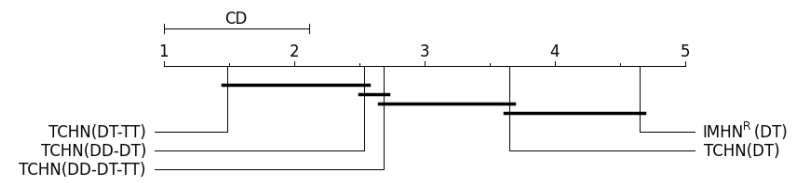

(e) 40 exemplos rotulados por classe.

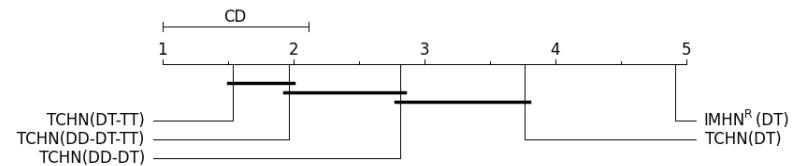

(b) 10 exemplos rotulados por classe.

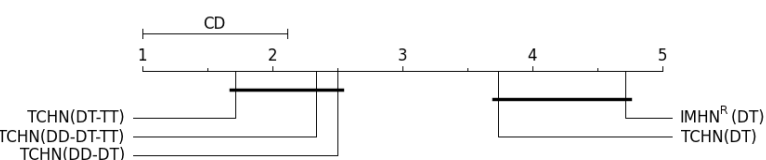

(d) 30 exemplos rotulados por classe.

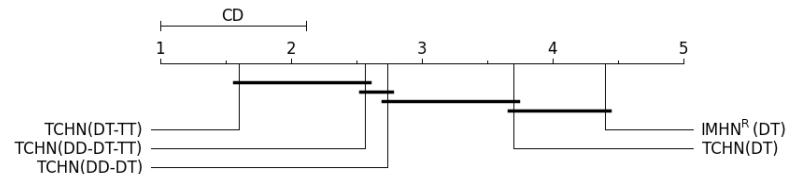

(f) 50 exemplos rotulados por classe.

Figura 4.29: Diagramas de diferença crítica para o quarto grupo de experimentos considerando a medida $F 1^{\text {Micro }}$.

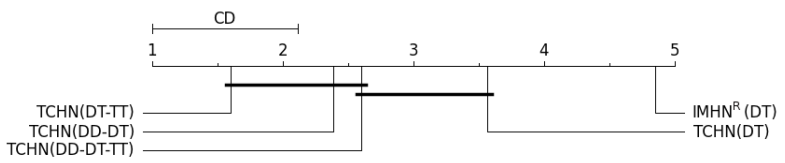

(a) 1 exemplo rotulado por classe.

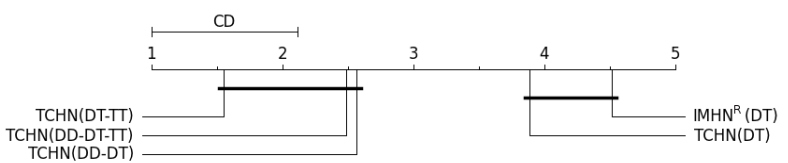

(c) 20 exemplos rotulados por classe.

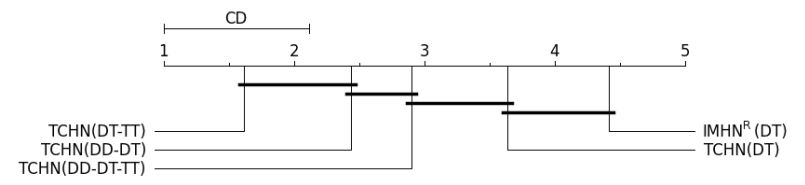

(e) 40 exemplos rotulados por classe.

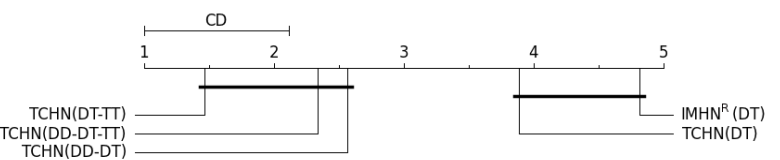

(b) 10 exemplos rotulados por classe.

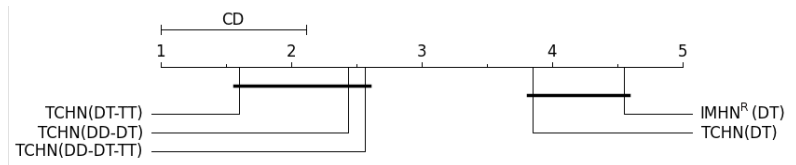

(d) 30 exemplos rotulados por classe.

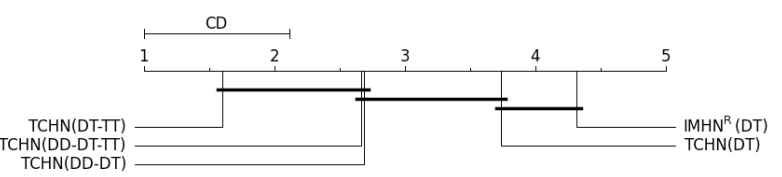

(f) 50 exemplos rotulados por classe.

Figura 4.30: Diagramas de diferença crítica para o quarto grupo de experimentos considerando a medida $F 1^{\text {Macro }}$.

avaliação experimental. Pode-se observar que, em geral, a performance de classificação dos algoritmos indutivos supervisionados foram superadas pela performance dos algoritmos transdutivos, principalmente os algoritmo GNetMine e TCHN.

Para elucidar a comparação das performances de classificação dos diferentes algoritmos no quinto grupo de experimentos, nas Tabelas 4.10 e 4.11 é apresentado o número de vitórias dos algoritmos considerando as medidas $F 1^{\text {Micro }}$ e $F 1^{\text {Macro }}$ respectivamente. Pode-se observar que os algoritmos indutivos supervisionados superaram os algoritmos transdutivos baseados no modelo espaço-vetorial e o algoritmo $T M$ para todas as quantidades de documentos rotulados utilizadas, e o algoritmo $L P H N$ a partir de 30 exemplos rotulados. 


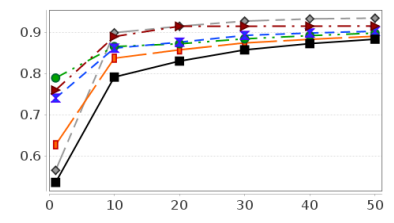

(a) Classic4

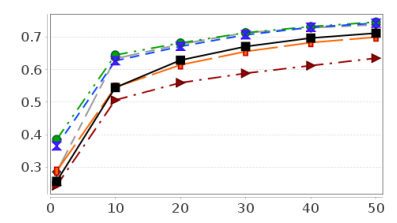

(e) Dmoz_Health_500

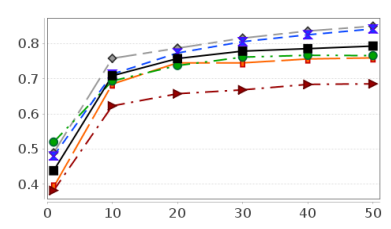

(i) FBIS

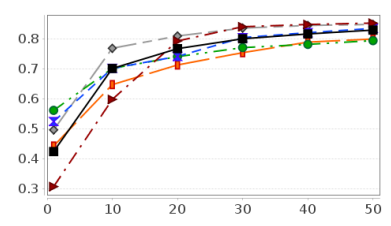

(m) La1s

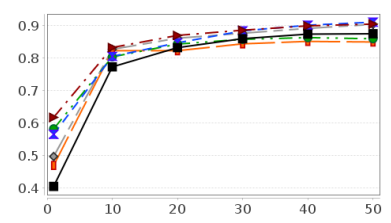

(q) Oh0

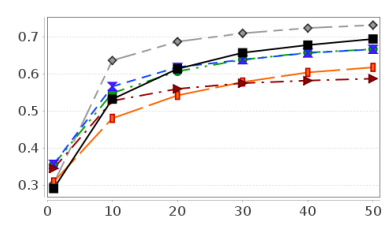

(u) Ohscal

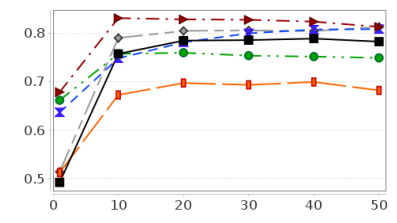

(b) CSTR

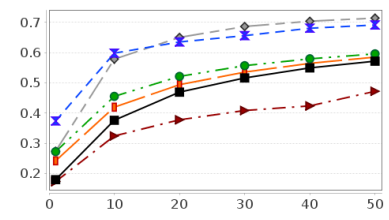

(f) Dmoz_Science_500

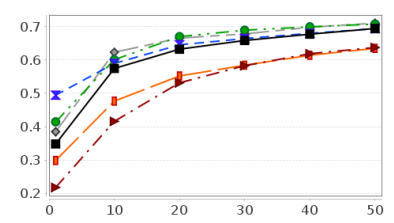

(j) Hitech

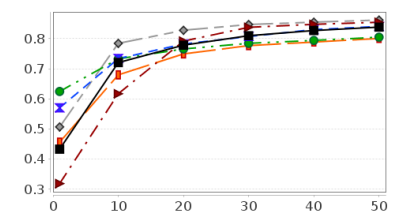

(n) La2s

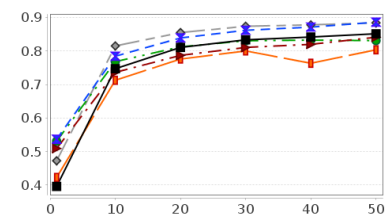

(r) Oh5

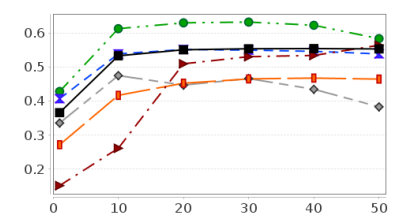

(v) Opinosis

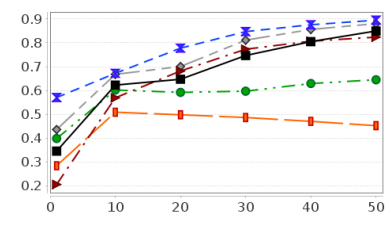

(y) Re1

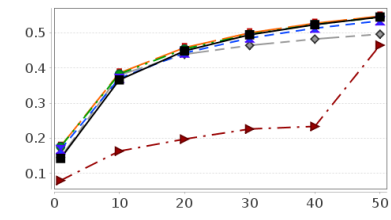

(c) Dmoz_Business_500

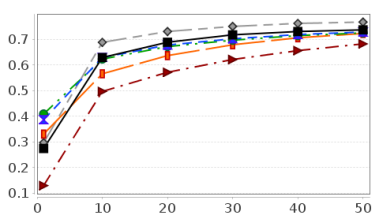

(g) Dmoz_Sports_500

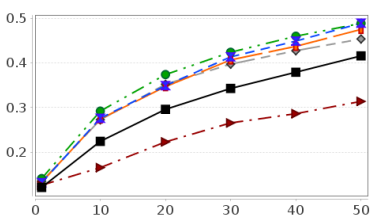

(k) Industry_Sector

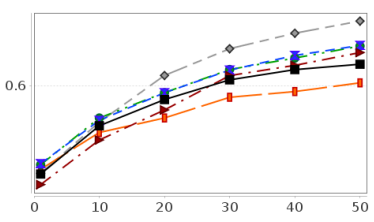

(o) Multi_Dom_Sentiment

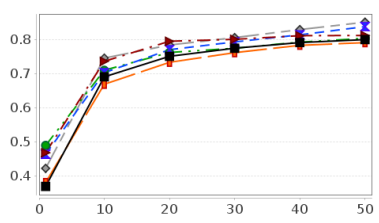

(s) Oh10

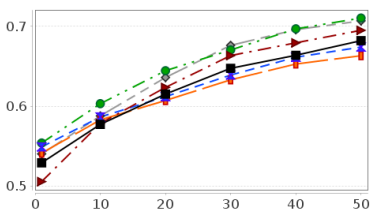

(w) Polarity

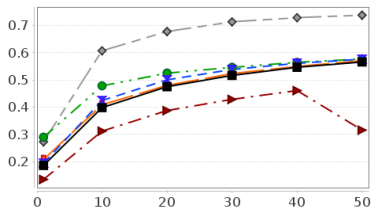

(d) Dmoz_Computers_500

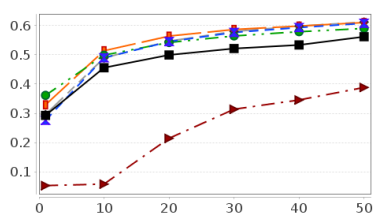

(h) Enron_Top_20

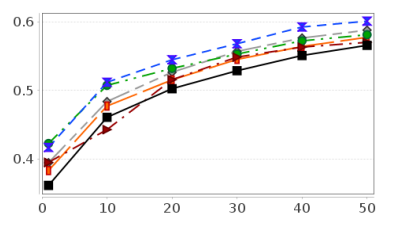

(1) IrishSentiment

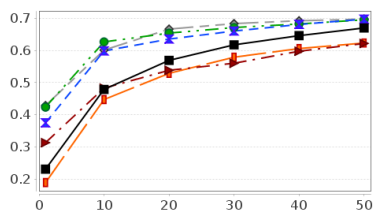

(p) NFS

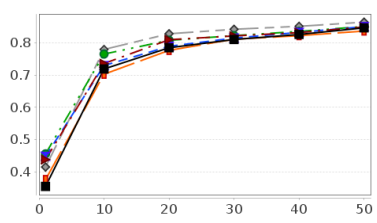

(t) Oh15

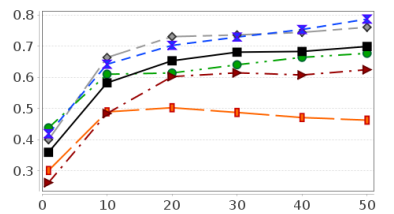

(x) $\operatorname{Re} 0$

Figura 4.31: Valores $F 1^{\text {Micro }}$ do $5^{\circ}$ grupo de experimentos (parte I).

Para 10 ou mais exemplos rotulados por classe, o algoritmo TCHN obteve a maior performance de classificação para a grande maioria das coleções. Pode-se observar também que o algoritmo $L P H N$, que é livre de parâmetros, superou os algoritmos transdutivos 


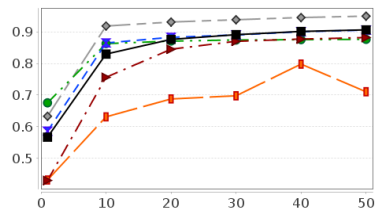

(a) $\operatorname{Re} 8$

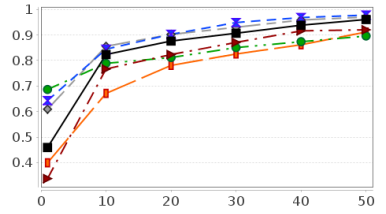

(e) $\operatorname{Tr} 11$

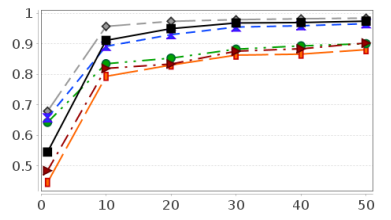

(i) $\operatorname{Tr} 31$

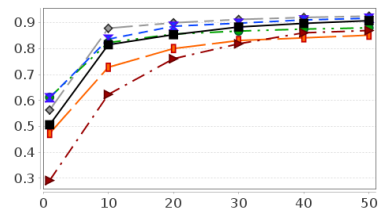

(b) Reviews

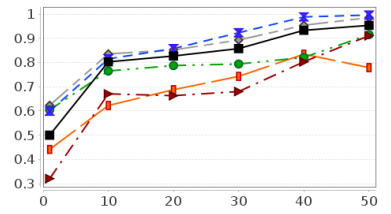

(f) $\operatorname{Tr} 12$

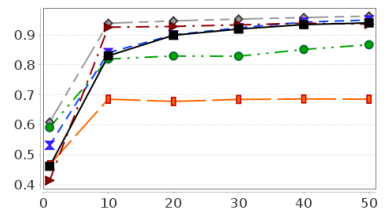

(j) $\operatorname{Tr} 41$

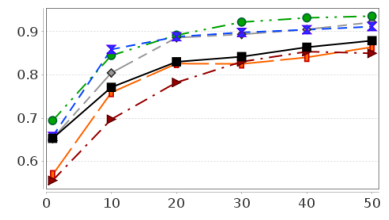

(c) SpamAssassin

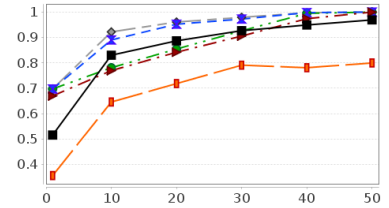

(g) $\operatorname{Tr} 21$

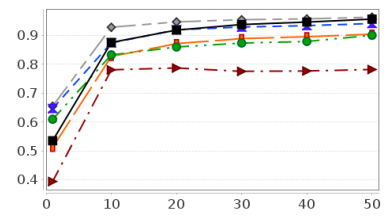

(k) $\operatorname{Tr} 45$

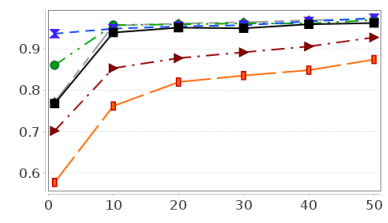

(d) SyskillWebert

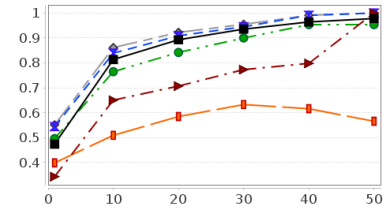

(h) $\operatorname{Tr} 23$

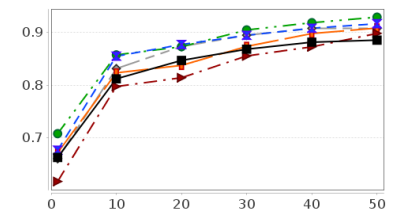

(1) Trec7_3000

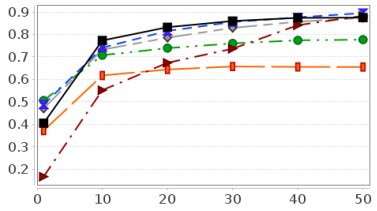

(m) Wap

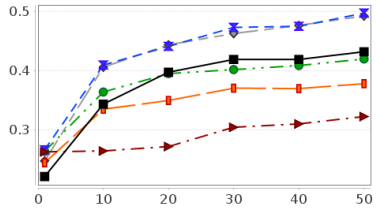

(n) WebKB

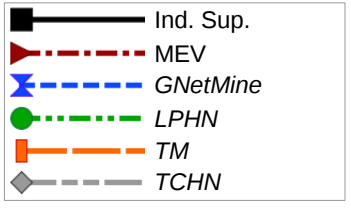

(o) Legenda

Figura 4.32: Valores $F 1^{\text {Micro }}$ do $5^{\circ}$ grupo de experimentos (parte II).

baseados no modelo espaço-vetorial mesmo considerando as maiores performances para diferentes valores de parâmetros desses algoritmos. Vale ressaltar que quando utilizado 1 exemplo rotulado por classe o algoritmo $L P H N$ obteve a maior performance de classificação para a maioria das coleções segundo a medida $F 1^{\text {Micro }}$.

Nas Figuras 4.35 e 4.36 são apresentados os diagramas de diferença crítica considerando os resultados do quinto grupo de experimentos para as medidas $F 1^{\text {Micro }}$ e $F 1^{\text {Macro }}$ respectivamente. Pode-se observar que para 1 exemplo rotulado por classe, os algoritmo LPHN, GNetMine e TCHN obtêm a primeira, segunda e terceira posições respectivamente no ranking médio. Não há diferenças estatisticamente significantes entre esses algoritmos mas há diferenças significantes desses algoritmos para os demais utilizados nesta avaliação. Para 10 ou mais exemplos rotulados, os algoritmo TCHN e GNetMine são sempre o primeiro e segundo respectivamente no ranking médio. Para as maiores quantidades de documentos rotulados utilizadas, em geral 30 ou mais exemplos, os algoritmos indutivos supervisionados obtiveram um ranking médio melhor que os algoritmos EM, MEV e LPHN.

Tanto para a medida $F 1^{\text {Micro }}$ quanto para a medida $F 1^{\text {Macro }}$, o algoritmo $T C H N$ apresentou melhores resultados com diferenças estatisticamente significantes em relação ao $T M, M E V, L P H N$ e os algoritmos indutivos supervisionados. Apenas não houve diferenças estatisticamente significantes do algoritmo $T C H N$ em relação ao algoritmo GNetMine. 


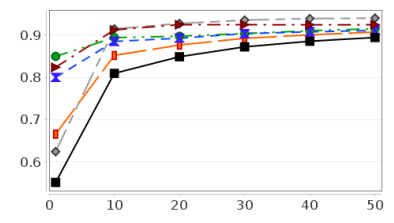

(a) Classic 4

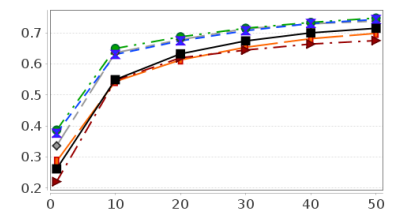

(e) Dmoz_Health_500

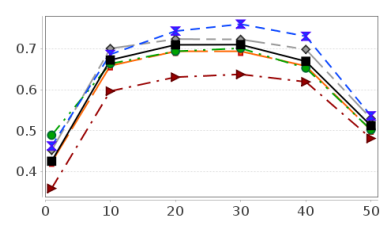

(i) FBIS

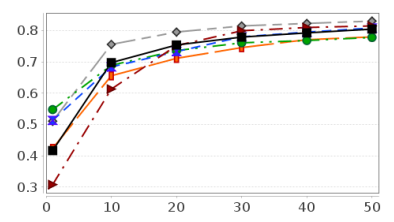

(m) La1s

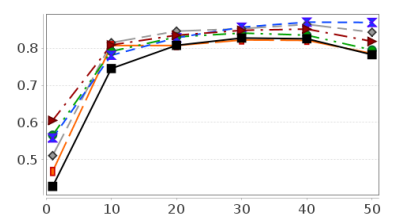

(q) Oh0

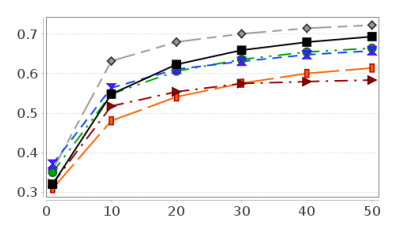

(u) Ohscal

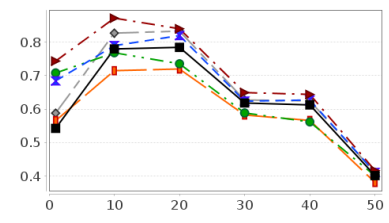

(b) CSTR

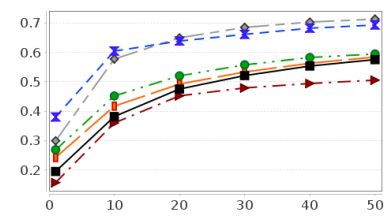

(f) Dmoz_Science_500

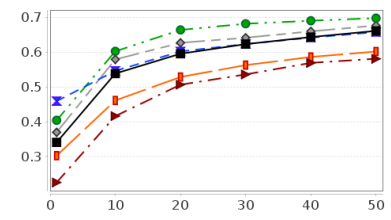

(j) Hitech

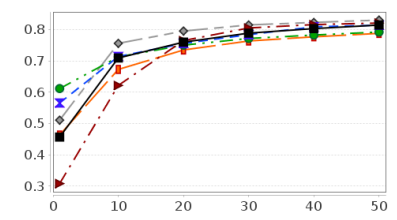

(n) La2s

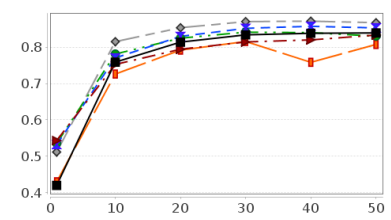

(r) Oh5

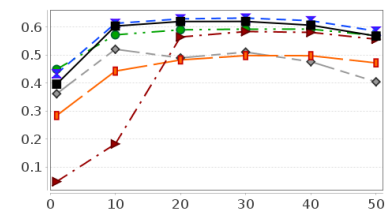

(v) Opinosis

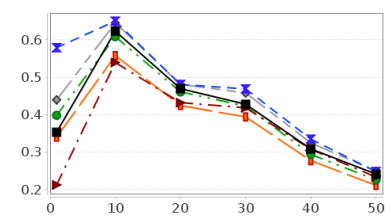

(y) $\operatorname{Re} 1$

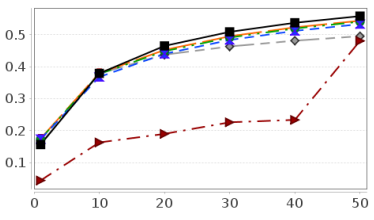

(c) Dmoz_Business_500

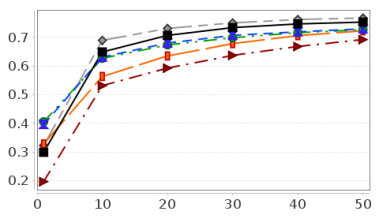

(g) Dmoz_Sports_500

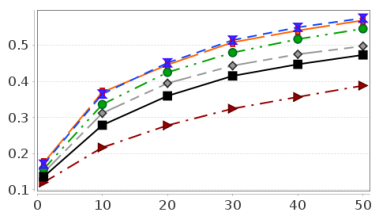

(k) Industry_Sector

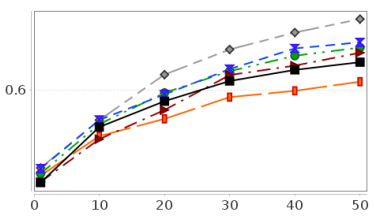

(o) Multi_Dom_Sentiment

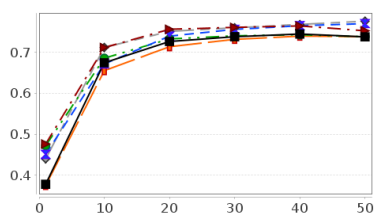

(s) Oh10

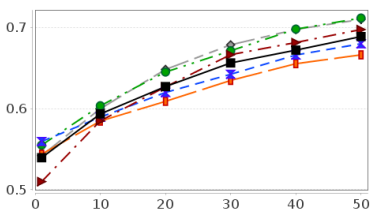

(w) Polarity

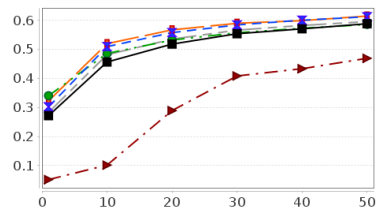

(h) Enron_Top_20

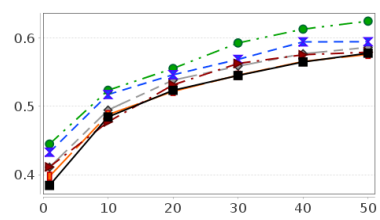

(1) IrishSentiment

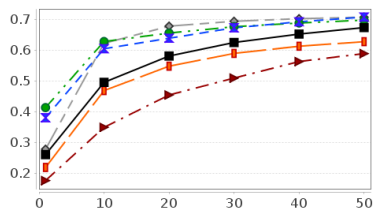

(p) NFS

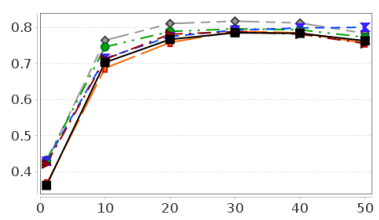

(t) Oh15

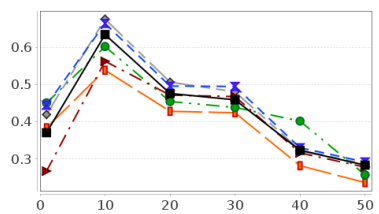

(x) $\operatorname{Re} 0$

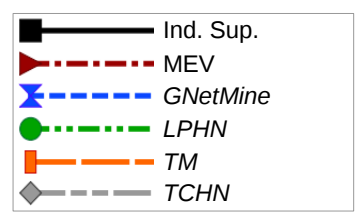

(z) Legenda

Figura 4.33: Valores $F 1^{\text {Macro }}$ do $5^{\circ}$ grupo de experimentos (parte I).

Porém, vale ressaltar que o algoritmo $T C H N$ possui um único parâmetro referente à taxa de correção de erro enquanto que para o algoritmo GNetMine é necessário definir os valores de importância para cada tipo de relação e o valor de $\alpha$. Os parâmetros utilizados 


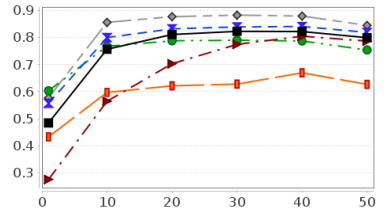

(a) $\operatorname{Re} 8$

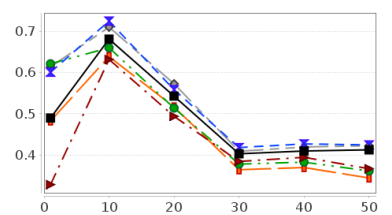

(e) $\operatorname{Tr} 11$

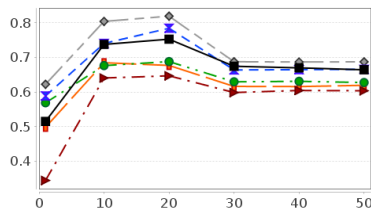

(i) $\operatorname{Tr} 31$

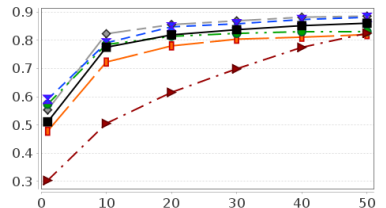

(b) Reviews

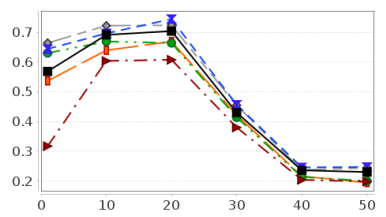

(f) $\operatorname{Tr} 12$

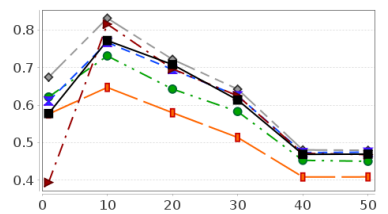

(j) $\operatorname{Tr} 41$

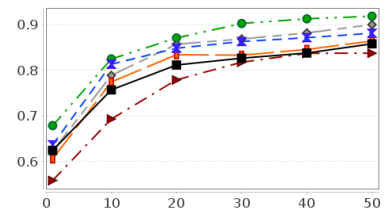

(c) SpamAssassin

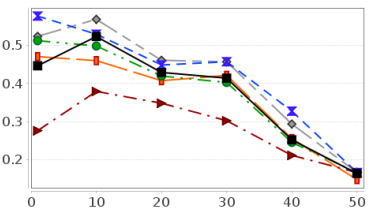

(g) $\operatorname{Tr} 21$

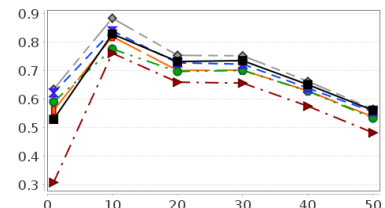

(k) $\operatorname{Tr} 45$

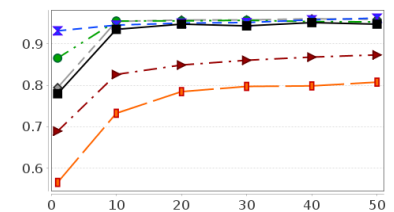

(d) SyskillWebert

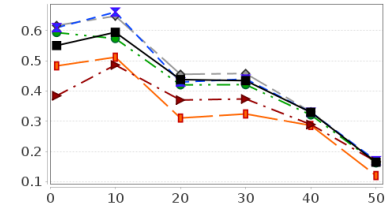

(h) $\operatorname{Tr} 23$

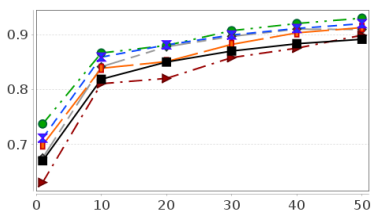

(l) Trec7_3000

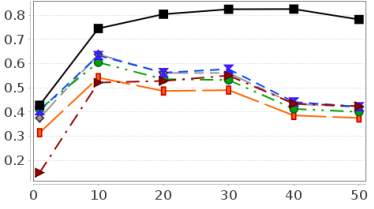

(m) Wap

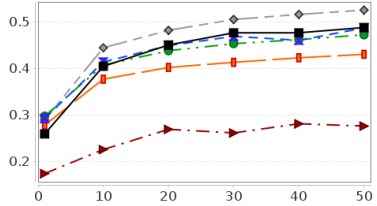

(n) WebKB

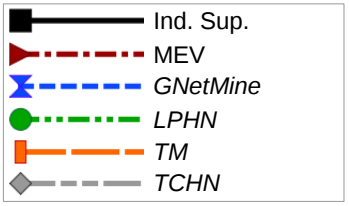

(o) Legenda

Figura 4.34: Valores $F 1^{\text {Macro }}$ do $5^{\circ}$ grupo de experimentos (parte II).

Tabela 4.10: Número de vitórias dos algoritmos indicados na linha em comparação com os algoritmos indicados na coluna para o quinto grupo de experimentos considerando a medida $F 1^{\text {Micro }}$.

\begin{tabular}{l||c|c|c|c|c|c}
\hline \hline \multicolumn{7}{c}{ 1 exemplo rotulado por classe } \\
\hline \hline & Ind. Sup & VSM & GNM & LPHN & TM & TCHN \\
\hline Ind. Sup & - & 20 & 0 & 0 & 15 & 0 \\
\hline VSM & 10 & - & 4 & 2 & 11 & 7 \\
\hline GNM & 30 & 26 & - & 10 & 29 & 20 \\
LPHN & 30 & 28 & 19 & - & 30 & 21 \\
TM & 15 & 19 & 1 & 0 & - & 4 \\
\hline TCHN & 30 & 23 & 9 & 8 & 26 & - \\
\hline \hline
\end{tabular}

\begin{tabular}{l||c|c|c|c|c|c}
\hline \hline \multicolumn{7}{c}{ 10 exemplos rotulados por classe } \\
\hline \hline & Ind. Sup & VSM & GNM & LPHN & TM & TCHN \\
\hline Ind. Sup & - & 22 & 4 & 10 & 24 & 1 \\
VSM & 8 & - & 6 & 5 & 16 & 2 \\
\hline GNM & 26 & 24 & - & 20 & 29 & 6 \\
LPHN & 19 & 25 & 10 & - & 29 & 6 \\
\hline TM & 6 & 14 & 1 & 1 & - & 0 \\
TCHN & 29 & 28 & 24 & 24 & 30 & - \\
\hline \hline
\end{tabular}

\begin{tabular}{l||c|c|c|c|c|c}
\hline \hline \multicolumn{7}{c}{ 20 exemplos rotulados por classe } \\
\hline \hline & Ind. Sup & VSM & GNM & LPHN & TM & TCHN \\
\hline Ind. Sup & - & 19 & 5 & 16 & 27 & 1 \\
\hline VSM & 11 & - & 9 & 10 & 22 & 3 \\
\hline GNM & 25 & 21 & - & 23 & 30 & 5 \\
\hline LPHN & 14 & 20 & 7 & - & 28 & 4 \\
\hline TM & 3 & 8 & 0 & 2 & - & 0 \\
\hline TCHN & 29 & 27 & 25 & 26 & 30 & - \\
\hline
\end{tabular}

\begin{tabular}{l||c|c|c|c|c|c}
\hline \hline \multicolumn{7}{c}{ 30 exemplos rotulados por classe } \\
\hline \hline & Ind. Sup & VSM & GNM & LPHN & TM & TCHN \\
\hline Ind. Sup & - & 18 & 6 & 19 & 26 & 1 \\
\hline VSM & 12 & - & 9 & 9 & 21 & 3 \\
\hline GNM & 24 & 21 & - & 23 & 30 & 7 \\
\hline LPHN & 10 & 21 & 7 & - & 29 & 2 \\
\hline TM & 4 & 9 & 0 & 1 & - & 0 \\
\hline TCHN & 29 & 27 & 23 & 28 & 30 & - \\
\hline \hline
\end{tabular}

\begin{tabular}{l||c|c|c|c|c|c}
\hline \hline \multicolumn{7}{c}{ 40 exemplos rotulados por classe } \\
\hline \hline & Ind. Sup & VSM & GNM & LPHN & TM & TCHN \\
\hline Ind. Sup & - & 17 & 4 & 18 & 27 & 1 \\
\hline VSM & 13 & - & 5 & 11 & 22 & 3 \\
\hline GNM & 26 & 25 & - & 25 & 30 & 10 \\
\hline LPHN & 12 & 19 & 5 & - & 27 & 3 \\
TM & 3 & 8 & 0 & 3 & - & 0 \\
TCHN & 29 & 27 & 19 & 27 & 30 & - \\
\hline \hline
\end{tabular}

\begin{tabular}{l||c|c|c|c|c|c}
\hline \hline \multicolumn{7}{c}{ 50 exemplos rotulados por classe } \\
\hline \hline & Ind. Sup & VSM & GNM & LPHN & TM & TCHN \\
\hline Ind. Sup & - & 17 & 5 & 18 & 27 & 1 \\
\hline VSM & 13 & - & 5 & 14 & 23 & 3 \\
\hline GNM & 25 & 23 & - & 25 & 30 & 11 \\
\hline LPHN & 12 & 15 & 4 & - & 27 & 2 \\
TM & 3 & 7 & 0 & 3 & - & 0 \\
TCHN & 29 & 24 & 17 & 27 & 30 & - \\
\hline \hline
\end{tabular}

para o algoritmo GNetMine neste capítulo geraram um total de 21 configurações contra 4 configurações do algoritmo $T C H N$. 
Tabela 4.11: Número de vitórias dos algoritmos indicados na linha em comparação com os algoritmos indicados na coluna para o quinto grupo de experimentos considerando a medida $F 1^{\text {Macro }}$.

\begin{tabular}{l||c|c|c|c|c|c}
\hline \hline \multicolumn{7}{|c}{ 1 exemplo rotulado por classe } \\
\hline \hline & Ind. Sup & VSM & GNM & LPHN & TM & TCHN \\
\hline Ind. Sup & - & 22 & 1 & 1 & 14 & 1 \\
\hline VSM & 8 & - & 5 & 4 & 8 & 6 \\
\hline GNM & 29 & 25 & - & 12 & 30 & 22 \\
\hline LPHN & 29 & 26 & 18 & - & 30 & 21 \\
\hline TM & 16 & 22 & 0 & 0 & - & 2 \\
\hline TCHN & 29 & 24 & 8 & 9 & 28 & - \\
\hline \hline
\end{tabular}

\begin{tabular}{l||c|c|c|c|c|c}
\hline \hline \multicolumn{7}{c}{ 10 exemplos rotulados por classe } \\
\hline \hline & Ind. Sup & VSM & GNM & LPHN & TM & TCHN \\
\hline Ind. Sup & - & 24 & 5 & 13 & 26 & 1 \\
\hline VSM & 6 & - & 5 & 5 & 11 & 1 \\
\hline GNM & 25 & 25 & - & 18 & 29 & 6 \\
LPHN & 17 & 25 & 12 & - & 27 & 6 \\
\hline TM & 4 & 19 & 1 & 3 & - & 0 \\
TCHN & 29 & 29 & 24 & 24 & 30 & - \\
\hline \hline
\end{tabular}

\begin{tabular}{l||c|c|c|c|c|c}
\hline \hline \multicolumn{7}{c}{ 20 exemplos rotulados por classe } \\
\hline \hline & Ind. Sup & VSM & GNM & LPHN & TM & TCHN \\
\hline Ind. Sup & - & 23 & 8 & 17 & 28 & 1 \\
\hline VSM & 7 & - & 9 & 8 & 19 & 2 \\
\hline GNM & 22 & 21 & - & 19 & 30 & 4 \\
\hline LPHN & 13 & 22 & 11 & - & 26 & 3 \\
TM & 2 & 11 & 0 & 4 & - & 0 \\
\hline TCHN & 29 & 28 & 26 & 27 & 30 & - \\
\hline \hline
\end{tabular}

\begin{tabular}{l|c|c|c|c|c|c|c}
\hline \hline \multicolumn{7}{c}{ 30 exemplos rotulados por classe } \\
\hline \hline & nd. Sup & VSM & GNM & LPHN & TM & TCHN \\
\hline Ind. Sup & - & 18 & 6 & 17 & 25 & 1 \\
\hline VSM & 12 & - & 6 & 10 & 17 & 3 \\
\hline GNM & 24 & 24 & - & 22 & 30 & 9 \\
\hline LPHN & 13 & 20 & 8 & - & 27 & 3 \\
\hline TM & 5 & 13 & 0 & 3 & - & 0 \\
\hline TCHN & 29 & 27 & 21 & 27 & 30 & - \\
\hline \hline
\end{tabular}

\begin{tabular}{l||c|c|c|c|c|c}
\hline \hline \multicolumn{7}{|c}{ 40 exemplos rotulados por classe } \\
\hline \hline & Ind. Sup & VSM & GNM & LPHN & TM & TCHN \\
\hline Ind. Sup & - & 20 & 6 & 17 & 25 & 1 \\
VSM & 10 & - & 5 & 11 & 18 & 2 \\
\hline GNM & 23 & 25 & - & 23 & 30 & 11 \\
\hline LPHN & 13 & 19 & 7 & - & 24 & 5 \\
\hline TM & 5 & 12 & 0 & 6 & - & 0 \\
TCHN & 29 & 28 & 19 & 25 & 30 & - \\
\hline \hline
\end{tabular}

\begin{tabular}{l||c|c|c|c|c|c}
\hline \hline \multicolumn{7}{c}{ 50 exemplos rotulados por classe } \\
\hline \hline & Ind. Sup & VSM & GNM & LPHN & TM & TCHN \\
\hline Ind. Sup & - & 19 & 6 & 17 & 26 & 1 \\
VSM & 11 & - & 6 & 14 & 21 & 2 \\
\hline GNM & 24 & 23 & - & 24 & 30 & 13 \\
\hline LPHN & 13 & 15 & 5 & - & 27 & 4 \\
TM & 4 & 9 & 0 & 2 & - & 0 \\
TCHN & 29 & 26 & 16 & 25 & 30 & - \\
\hline \hline
\end{tabular}

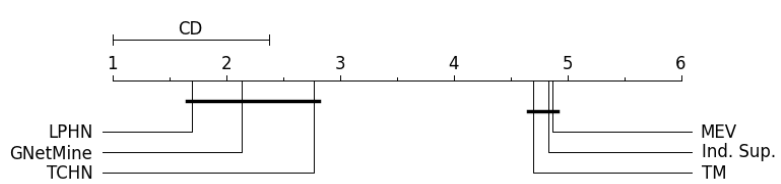

(a) 1 exemplo rotulado por classe.

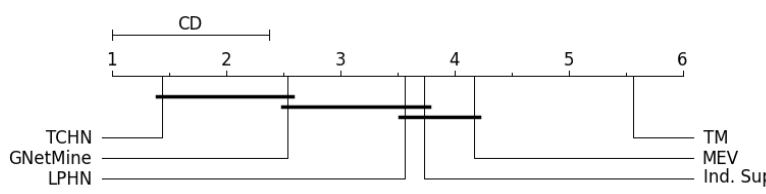

(c) 20 exemplos rotulados por classe.

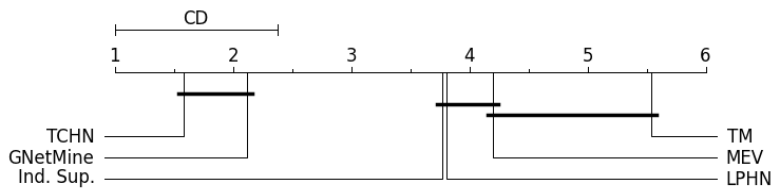

(e) 40 exemplos rotulados por classe.

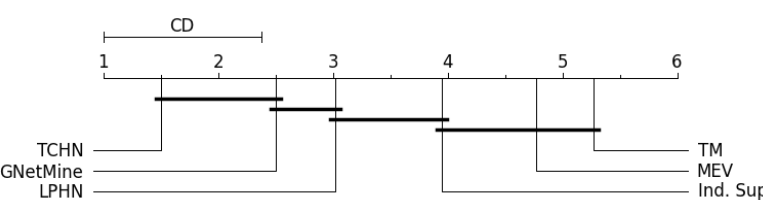

(b) 10 exemplos rotulados por classe.

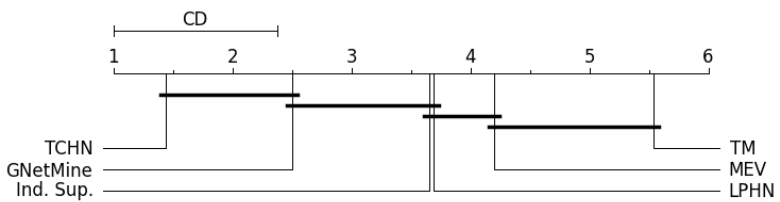

(d) 30 exemplos rotulados por classe.

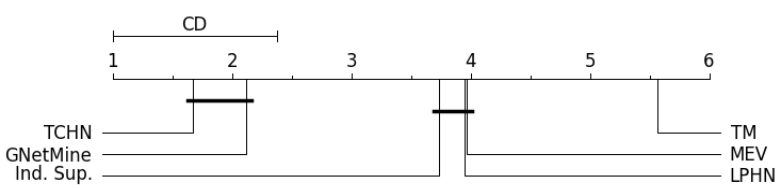

(f) 50 exemplos rotulados por classe.

Figura 4.35: Diagramas de diferença crítica para o quinto grupo de experimentos considerando a medida $F 1^{\text {Micro }}$. 


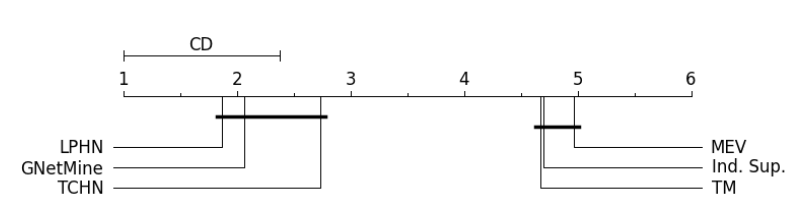

(a) 1 exemplo rotulado por classe.

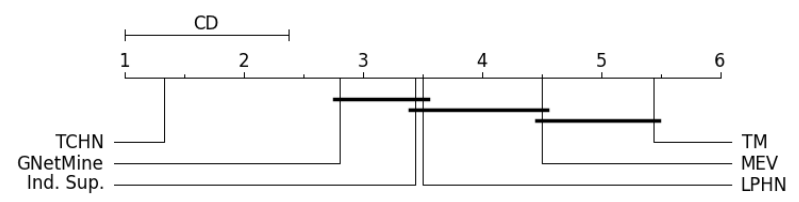

(c) 20 exemplos rotulados por classe.

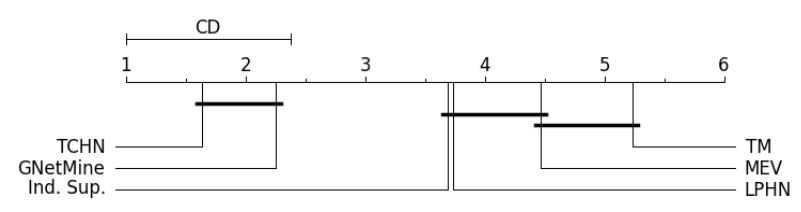

(e) 40 exemplos rotulados por classe.

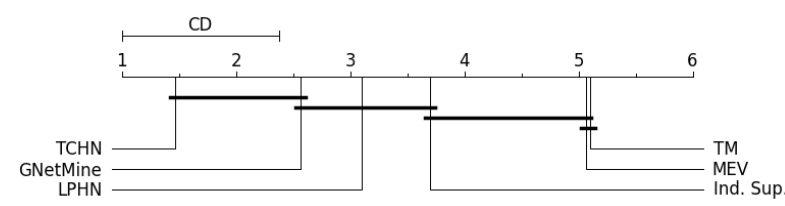

(b) 10 exemplos rotulados por classe.

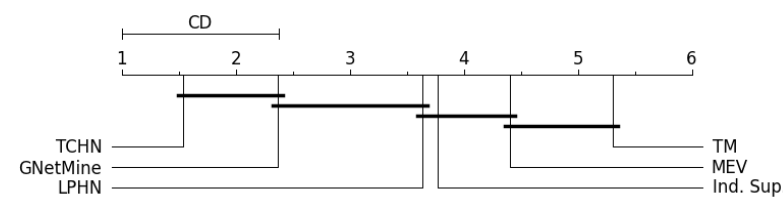

(d) 30 exemplos rotulados por classe.

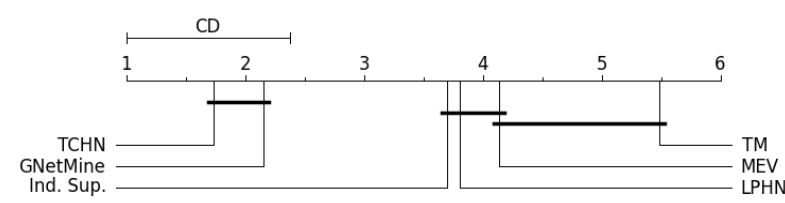

(f) 50 exemplos rotulados por classe.

Figura 4.36: Diagramas de diferença crítica para o quinto grupo de experimentos considerando a medida $F 1^{\text {Macro }}$. 


\subsection{Considerações Finais}

Neste capítulo foram apresentados algoritmos existentes baseados no modelo espaçovetorial bem como algoritmos baseados em redes para a tarefa de classificação transdutiva de textos. Também foram apresentadas neste capítulo três propostas para a classificação transdutiva de textos: (i) o algoritmo $L P H N$, que é um algoritmo livre de parâmetros e corresponde a uma versão para classificação em redes heterogêneas do tradicional algoritmo para classificação em redes homogêneas GFHF; (ii) o framework TCTN, que realiza a classificação transdutiva considerando uma rede modelada apenas por relações entre termos, uma vez que ainda não existia um algoritmo com essas características na literatura; e por fim (iii) o algoritmo $T C H N$, que alterna processos de otimização e propagação de rótulos para realizar a classificação transdutiva de textos.

O algoritmo $L P H N$ obteve melhores performances de classificação que os algoritmos transdutivos baseados no modelo espaço-vetorial e o algoritmo TM. O algoritmo LPHN também apresentou melhores resultados em relação aos algoritmos indutivos supervisionados quando consideradas as menores quantidades de documentos rotulados utilizadas na avaliação experimental. O algoritmo LPHN obteve, em geral, uma melhor performance de classificação que todos os algoritmos quando considerado um único exemplo rotulado por classe. Destaca-se o algoritmo $L P H N$ é interessante em situações em que há poucos exemplos rotulados, falta de condições de executar diversos testes com diferentes parâmetros, ou desconhecimento por parte do usuário a respeito de valores de parâmetros ou do funcionamento dos parâmetros nos algoritmos.

Com a proposta do framework TCTN, principalmente quando utilizado o algoritmo $L L G C$ para realizar a propagação das informações de classe entre os termos, foi demonstrado que é possível utilizar somente redes de termos para realizar a classificação transdutiva de textos. Em comparação com as redes compostas por relações simples, as performances de classificação utilizando as redes de termos foram melhores que usando as redes bipartidas e menores que as obtidas pelas redes de documentos.

Porém, vale ressaltar que o vocabulário é finito, e em geral, o número de documentos pode superar o número de termos para algumas coleções com um grande número de textos, fazendo com que a classificação baseada em rede de documentos apresente um tempo maior em relação à classificação baseada em rede de termos. Vale ressaltar também que é possível diminuir o número de objetos na rede de termos via técnicas de seleção de atributos (Seção 2.2.3), o que diminui o número de objetos da rede e consequentemente diminui o tempo de classificação. Neste caso, mesmo diminuindo o número de termos na rede é possível manter a performance de classificação, conforme apresentado em Rossi et al. (2015b).

Já o algoritmo TCHN demonstrou que a combinação de otimização e propagação de rótulos é útil na classificação transdutiva de textos. Também foi demonstrado que a utilização de documentos não rotulados influencia positivamente a indução das informações 
de classe dos termos, uma vez que a performance de classificação foi aumentada na presença dos mesmos. Vale ressaltar que o algoritmo TCHN obteve as maiores performances de classificação em relação aos algoritmos utilizados na avaliação experimental desse capítulo quando considerados 10 ou mais documentos rotulados por classe. Destaca-se que a utilização de 10 documentos rotulados apresentou o melhor custo benefício em relação a número de documentos rotulados e performance de classificação.

Para 10 ou mais exemplos rotulados por classe, o algoritmo TCHN obteve melhores resultados com diferenças estatisticamente significantes em relação aos demais algoritmos utilizados para comparação, exceto o algoritmo GNetMine. Porém, vale ressaltar que o algoritmo GNetMine possui um quantidade maior de parâmetros, que por sua vez causam uma variabilidade maior nas performances de classificação. Dado o fato de obter maiores performances de classificação e menor número de parâmetros, é aconselhável a utilização do algoritmo proposto $T C H N$ na classificação transdutiva de textos.

Com a avaliação experimental realizada neste capítulo também pôde-se verificar que de fato (i) as premissas por parte dos algoritmos transdutivos baseados no modelo espaçovetorial são frequentemente violadas na prática e consequentemente esses algoritmos apresentam performances de classificação inferiores aos demais algoritmos; (ii) a utilização de documentos não rotulados é benéfica para aumentar a performance de classificação desde que não haja premissas fortes a respeito da distribuição dos dados; (iii) os algoritmos transdutivos baseados em redes, em geral, obtém uma performance de classificação superior a de algoritmos transdutivos baseados no modelo espaço-vetorial; (iv) diferentes tipos de redes extraem diferentes padrões e que a combinação de diferentes relações, como documento-documento, documento-termo e termo-termo, é capaz de aumentar a performance de classificação.

Também pôde-se verificar na avaliação experimental realizada neste capítulo que, em geral, quanto mais tipos de objetos e tipos de relações na representação em rede, maior será a performance de classificação. Pôde-se observar na avaliação experimental que, em geral, as redes compostas pelas relações documento-documento, documento-termo e termo-termo, e as redes compostas pelas relações do tipo documento-termo e termo-termo proveram as maiores performances de classificação. Redes com relações simples propostas nesta tese, como as redes bipartidas e redes de termos, demostraram obter performances de classificação superiores tanto em relação a algoritmos transdutivos quanto algoritmos indutivos supervisionados baseados no modelo espaço-vetorial (Rossi et al., 2015a,b, 2014b).

Portanto, neste capítulo foram apresentados resultados que permitem o usuário dimensionar o uso da classificação transdutiva baseada em redes com sua capacidade computacional e tempo de processamento. Por exemplo, o usuário pode executar um algoritmo transdutivo em uma máquina com pouca memória utilizando redes de termos ou redes bipartidas, ou ainda executar a classificação transdutiva para uma grande quantidade de documentos onde seja inviável computar e utilizar redes de documento. Porém, mesmo com redes mais 
simples e classificações mais rápidas, é possível obter uma performance de classificação maior que quando utilizados algoritmos existentes. Caso o usuário possa despender de tempo e recursos computacionais maiores para realizar a classificação transdutiva, este pode optar por redes compostas por mais de um tipo de relação para obter maiores performances de classificação. 

CAPítulo

\section{Classificação de Textos por Meio de} Aprendizado Indutivo Semissupervisionado

\subsection{Considerações Iniciais}

O objetivo dos algoritmos de aprendizado indutivo semissupervisionado é induzir um modelo para a classificação de novos documentos. Diferente dos algoritmos de aprendizado indutivo supervisionado, nos algoritmos indutivos semissupervisionados são considerados tanto documentos rotulados quanto não rotulados para a indução do modelo de classificação. Dado a grande disponibilidade de dados não rotulados e a necessidade, em várias situações reais, de ter um modelo de classificação que rotule novos documentos, as pesquisas envolvendo aprendizado indutivo semissupervisionado também têm ganhado atenção nos últimos anos (Amini e Usunier, 2015; Subramanya e Talukdar, 2014; Zhu e Goldberg, 2009; Chapelle et al., 2006).

Algoritmos de aprendizado indutivo semissupervisionado podem ser considerados como uma combinação de algoritmos de aprendizado indutivo supervisionado com algoritmos de aprendizado transdutivo. Isso porque o processo de indução do modelo de classificação dos algoritmos semissupervisionados pode ser dividido em duas etapas: a primeira, que consiste em um processo de aprendizado transdutivo para definir os rótulos dos documentos de treinamento não rotulados, e a segunda, que consiste em extrair um modelo de classificação considerando os rótulos dos documentos previamente rotulados e os rótulos atribuídos aos documentos não rotulados pela classificação transdutiva. Na Figura 5.1 é apresentado um esquema ilustrativo sobre a classificação de textos utilizando aprendizado indutivo semissupervisionado.

Assim como no aprendizado transdutivo, os algoritmos indutivos semissupervisionados fazem uso dos exemplos não rotulados para melhorar a performance de classificação. Ao 


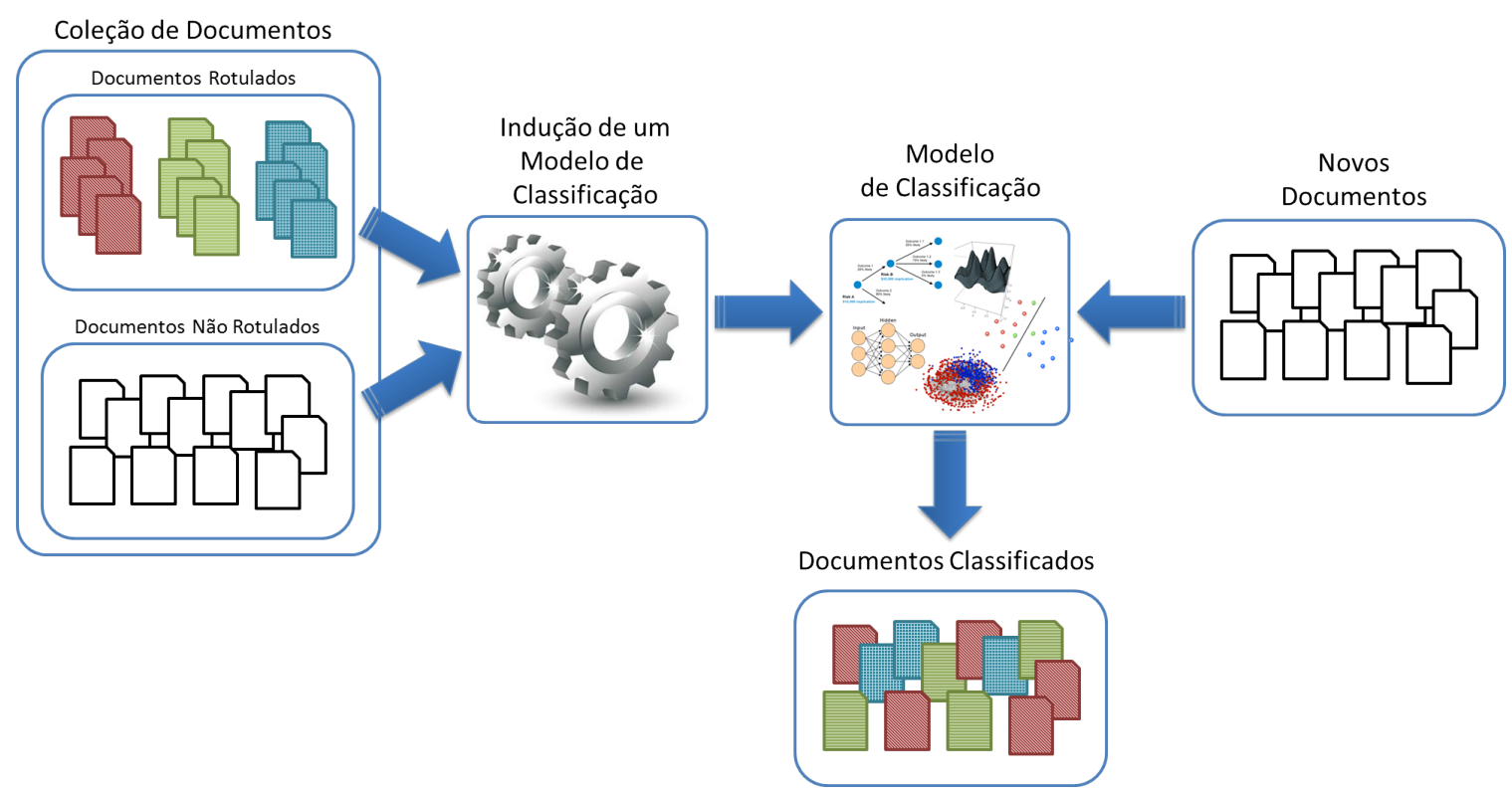

Figura 5.1: Esquema ilustrativo da classificação automática de textos por meio de aprendizado indutivo semissupervisionado.

considerar documentos não rotulados, diminui-se a quantidade necessária de exemplos rotulados por parte do usuário para alcançar performances de classificação satisfatórias, ou ainda, com uma mesma quantidade de exemplos rotulados, os algoritmos de aprendizado indutivo semissupervisionado podem superar a performance de classificação dos algoritmos de aprendizado indutivo supervisionado.

As aplicações da classificação de textos utilizando aprendizado indutivo supervisionado são as mesmas do aprendizado indutivo supervisionado, como filtragem de conteúdos (Bhattarai et al., 2009), classificação e resposta automática de e-mails (Koprinska et al., 2007; Scheffer, 2004), e mineração de opiniões (Matsuno et al., 2015; Tsur et al., 2010).

Assim como no aprendizado transdutivo, o objetivo do aprendizado indutivo semissupervisionado é induzir uma função $F: \mathcal{O}^{L+U} \rightarrow \mathcal{Y}^{L+U}$. Porém, no caso na indução semissupervisionada, a função $F$ será utilizada para classificar novos documentos.

Os algoritmos de aprendizado indutivo semissupervisionado baseados no modelo espaçovetorial apresentam as mesmas deficiências apresentadas no aprendizado transdutivo: as fortes premissas a respeito da distribuição dos dados degradam a performance de classificação. Já os algoritmos baseados em redes, assim também como no aprendizado transdutivo, em geral consideram redes composta apenas por relações do tipo documento-documento. Porém, foi demonstrado no Capítulo 4 que diferentes tipos de redes proveem diferentes performances de classificação e que a combinação de diferentes relações em uma única rede é benéfica para aumentar a performance de classificação. Como aprendizado indutivo semissupervisionado é baseado em uma etapa de transdução, esse tipo de modelagem também pode ajudar a melhorar a performance de classificação.

Além disso, as informações de classe dos termos demostraram ser úteis para a classificação de textos, conforme apresentado nos Capítulos 3 e 4. Porém, esse tipo de informação é desconsiderado pelas abordagens baseadas em redes encontradas na literatura. Dado isso, 
neste projeto de doutorado foi proposta uma abordagem para a indução de um modelo de classificação de maneira semissupervisionada, na qual são consideradas as redes propostas neste projeto de doutorado, e o modelo de classificação corresponde às informações de classe dos termos inferidas por meio de aprendizado transdutivo. Os resultados obtidos com a abordagem proposta demonstraram a viabilidade de extração de um modelo de classificação considerando as informações de classe dos termos da rede, uma vez que é possível obter, além de uma classificação mais rápida, as melhores performances de classificação.

O restante deste capítulo está divido da seguinte forma. Na Seção 5.2 são apresentados trabalhos relacionados sobre classificação indutiva semissupervisionada tanto considerando documentos representados no modelo espaço-vetorial quanto em redes. Na Seção 5.3 é apresentada a proposta para a classificação de textos por meio de aprendizado indutivo semissupervisionado considerando as redes propostas neste projeto de doutorado. $\mathrm{Na}$ Seção 5.4 são apresentados os resultados obtidos pelas abordagens existentes, tanto baseados no modelo espaço-vetorial quanto em redes, e pela abordagem proposta para classificação indutivo semissupervisionada de textos. Por fim, na Seção 5.4 são apresentadas as considerações finais sobre o conteúdo apresentado neste capítulo.

\subsection{Trabalhos Relacionados}

Como mencionado na seção anterior, a indução de um modelo de classificação de maneira semissupervisionado consiste de uma etapa de transdução e um etapa de extração de um modelo de classificação. A extração do modelo é feita considerando os rótulos dos documentos originalmente rotulados e os rótulos atribuídos aos documentos não rotulados durante o processo de transdução. Nas próximas seções são apresentados algoritmos de aprendizado indutivo semissupervisionados tanto baseados no modelo espaço vetorial quanto em redes.

\subsubsection{Aprendizado Indutivo Semissupervisionado no Modelo Espaço-Vetorial}

Os algoritmos transdutivos baseados no modelo espaço-vetorial também podem ser usados na indução semissupervisionada sem modificação alguma. Por exemplo, no caso da abordagem Self-Training (Yarowsky, 1995), o último modelo de classificação gerado durante o aprendizado transdutivo pode ser utilizado para classificar novos documentos. $\mathrm{O}$ mesmo vale para a abordagem Co-Trainig (Blum e Mitchell, 1998). No caso do algoritmo TSVM (Joachims, 1999), o hiperplano final obtido por meio de um processo de otimização considerando documentos rotulados e não rotulados pode ser utilizado para classificar novos exemplos. Já no caso do EM (Nigam et al., 2000), o modelo de misturas obtido ao final do processo de transdução podem ser utilizados para classificar novos documentos.

Assim como na transdução, outros algoritmos baseados no modelo espaço-vetorial também podem ser utilizados na indução semissupervisionada (Amini e Usunier, 2015; 
Zhu e Goldberg, 2009; Chapelle et al., 2006). Porém, observa-se na literatura um maior uso das abordagens e algoritmos apresentados acima.

\subsubsection{Aprendizado Indutivo Semissupervisionado em Redes}

De acordo com Zhu e Lafferty (2005), métodos de aprendizado semissupervisionado baseados em redes são inerentemente transdutivos. Também segundo Zhu e Lafferty (2005), quando um novo objeto é apresentado, não é claro o procedimento que deve ser realizado para classificar o novo objeto. Portanto, diferentes heurísticas para se extrair um modelo de classificação após realizado um processo de classificação aprendizado transdutivo na rede podem ser adotados.

As pesquisas sobre aprendizado indutivo supervisionado baseado em redes consideram apenas redes geradas considerando as similaridades entre as instâncias, que no contexto dessa tese correspondem às redes de documentos. Dada a rede de documentos, uma possibilidade para classificar um novo documento é incorporá-lo na rede, computando a similaridade entre o novo documento e os demais da rede, e utilizando uma das estratégias apresentada na Seção 2.3.2 para criar as relações entre os documentos. Em seguida é reexecutado o processo de classificação transdutiva. Dependendo do tamanho da coleção de documentos e da complexidade computacional do aprendizado transdutivo, este tipo de abordagem é inviável em situações reais devido ao alto tempo necessário para realizar a classificação de um novo objeto.

Outra possibilidade é "congelar" a rede após a transdução, ou seja, fixar os valores de informações de classe dos documentos obtidas ao final do aprendizado transdutivo, e dado um novo documento, incorporar esse novo documento na rede e realizar a propagação de rótulos. Em Delalleau et al. (2005) é apresentado um exemplo desse tipo de abordagem, na qual dado um novo documento $d_{i}$, suas informações de classe são definidas da seguinte forma:

$$
\mathbf{f}_{d_{i}}=\frac{\sum_{d_{j} \in \mathcal{D}} w_{d_{i}, d_{j}} \cdot \mathbf{f}_{d_{j}}}{\sum_{d_{j} \in \mathcal{D}} w_{d_{i}, d_{j}}} .
$$

Vale ressaltar que apesar do fato de não necessitar repetir o processo de aprendizado transdutivo na abordagem proposta em Delalleau et al. (2005), o cálculo da similaridade entre todos os documentos pode apresentar um alto tempo de reposta na classificação de novos documentos.

Em Zhu e Lafferty (2005) e Krishnapuram et al. (2005) são apresentadas abordagens que alternam a transdução em redes com a geração de modelos de misturas. Os modelos de misturas obtidos no final do processo de aprendizado são utilizados para classificar novos documentos. Vale ressaltar que de acordo com alguns trabalhos da literatura, como os apresentados em Cozman et al. (2003) e Rossi et al. (2015b), o aprendizado de modelos 
de misturas leva a um aumento na performance de classificação. Além disso, a combinação de transdução e geração de modelos de mistura é computacionalmente custosa (Bertini et al., 2011).

Em Belkin et al. (2006) é apresentado um framework de regulação de pode ser utilizando no aprendizado semissupervisionado. Esse framework consiste do acréscimo de mais dois termos regularizadores no framework de regularização apresentada no Equação 4.21. Entretanto, a adição de mais dois termos de regularização, que são ponderados pelos seus respectivos parâmetros, dificulta a utilização dessa abordagem em situações práticas devido à grande variabilidade dos resultados gerados pelas diversas combinações de valores parâmetros.

\subsection{Proposta para Classificação Classificação de Textos por Meio de Aprendizado Indutivo Semissupervisionado Baseado em Re- des}

As abordagens baseadas em redes existentes para aprendizado indutivo semissupervisionado, que consideram somente redes de documentos, demonstram ser custosas computacionalmente, seja na fase de indução do modelo de classificação ou na fase de classificação de novos documentos.

Outros tipos de redes são geradas mais rapidamente que as redes de documentos, caso das redes bipartidas, ou ainda executar um processo de aprendizado transdutivo mais rápido, caso das redes bipartidas ou redes de termos. Além disso, como demonstrado no Capítulo 4, considerar redes compostas por diferentes tipos de relações para realizar o aprendizado transdutivo aumenta a performance de classificação, sendo que esses tipos de redes não são utilizados nas abordagens existentes para aprendizado indutivo semissupervisionado. Outro ponto a ser ressaltado é que a utilização das informações de classe dos termos para definir as informações de classe dos documentos demonstrou obter performances de classificação satisfatórias. Porém, também não se observa o uso desse tipo de informação nas abordagens baseadas em redes encontradas na literatura.

Dado o alto custo computacional das abordagens existentes para indução do modelo ou para a classificação de novos documentos, a desconsideração de diferentes relações, e os indícios que as informações de classe dos termos são úteis na classificação de documentos, neste projeto de doutorado é proposto o "congelamento" das informações de classe dos termos obtidos por um processo de transdução e, dado um novo documento, este é conectado aos termos contidos no mesmo.

Ao incorporar o novo documento $d_{i}$ na rede, as informações de classe do mesmo são definidas por meio da propagação da informações de classe dos termos utilizando a seguinte equação: 


$$
\mathbf{f}_{d_{i}}=\frac{\sum_{t_{j} \in \mathcal{T}} w_{d_{i}, t_{j}} \cdot \mathbf{f}_{t_{j}}}{\sum_{t_{j} \in \mathcal{T}} w_{d_{i}, t_{j}}} .
$$

Vale ressaltar que a abordagem proposta neste projeto de doutorado para classificação gera um tempo de resposta menor em relação a abordagem proposta por Delalleau et al. (2005), uma vez que não é necessário calcular a similaridade entre todos os documentos para incorporar um novo documento na rede. Vale ressaltar também que a abordagem proposta permite a utilização das redes compostas por mais de um tipo de relação que também foram proposta neste projeto de doutorado e que demonstraram prover maiores performances de classificação na classificação de textos por meio de aprendizado transdutivo.

\subsection{Avaliação Experimental}

Nesta seção são apresentados os resultados da avaliação experimental para classificação de textos utilizando algoritmos de aprendizado indutivo semissupervisionado. Nesta avaliação foram comparados e analisados diferentes algoritmos de classificação baseados no modelo espaço-vetorial, baseados em redes existentes e os baseados em redes propostos. Também foi comparado e analisado o impacto de diferentes quantidades de exemplos rotulados e dos diferentes tipos de redes na performance de classificação. Todos os códigosfonte implementados e utilizados nesta avaliação bem como os resultados de todos os algoritmos e seus parâmetros estão disponíveis na pagina web http://sites. labic.icmc . usp.br/ragero/thesis/semi-supervised_inductive_learning/. Nas próximas seções são apresentados detalhes da configuração experimental, resultados e análises.

\subsubsection{Configuração Experimental}

As coleções de textos, as características das representações baseadas no modelo espaçovetorial e em redes, bem como as medidas de performance de classificação utilizadas nesta avaliação experimental são detalhadas nos Apêndices A e B respectivamente. Vale ressaltar que assim como na avaliação referente à classificação transdutiva, na avaliação realizada neste capítulo foram consideradas somente as representações bag-of-words para os algoritmos baseados no modelo espaço-vetorial, uma vez que os atributos dessa representação demonstraram ter um poder representativo satisfatório conforme apresentado no Capítulo 3. Vale ressaltar também que nesta avaliação experimental só foram consideradas redes compostas por relações simples, ou seja, redes composta por relações documento-documento, ou documento-termo ou termo-termo, uma vez que essas redes são suficientes para comprovar que a proposta para a indução semissupervisionada é viável para a classificação automática de textos. Porém, é realizada uma avaliação simples demonstrando que a combinação de relações também aumenta a performance de classificação 
utilizando aprendizado indutivo supervisionado.

Para obter os valores das medidas $F 1^{\text {Micro }}$ e $F 1^{\text {Macro }}$, primeiramente foi executado o procedimento 10-fold cross-validation. Em cada iteração desse procedimento, foi separada uma partição para testar a indução semissupervisionada, isto é, foi separada uma partição contendo documentos e teste, e 9 partições para induzir o modelo de classificação, isto é, partições contendo documentos que serão utilizados para o treinamento. Para cada conjunto de documentos de treinamento foram realizadas 10 execuções dos algoritmos de aprendizado indutivo semissupervisionado, na qual em cada execução foram selecionadas aleatoriamente $N$ documentos de cada classe como documentos rotulados, sendo $N=\{1,10,20,30,40,50\}$, e o restante dos documentos de treinamento foram considerados como documentos não rotulados na indução do modelo de classificação. Portanto, foram realizadas 100 execuções para se obter os valores das medidas $F 1^{\text {Micro }}$ e $F 1^{\text {Macro }}$, que correspondem à média dos valores das 100 execuções.

Para realizar a etapa transdutiva do aprendizado semissupervisionado foram utilizados algoritmos baseados no modelo espaço-vetorial, baseados em redes existentes e os baseados em redes propostos. Todos esses algoritmos foram descritos no Capítulo 4. Para os algoritmos baseados em redes de documento, foi considerada a proposta apresentada em Delalleau et al. (2005). Já para os algoritmos baseados em redes compostas por relações do tipo documento-termo ou termo-termo, foi considerada a abordagem proposta neste capítulo.

Os algoritmos semissupervisionados baseados no modelo-espaço vetorial utilizados nesta avaliação experimental são: Self-Training com o $M N B$ como algoritmo indutivo supervisionado (MNB-Se), EM e TSVM. Não foi considerada a abordagem Co-Training uma vez que esta apresentou resultados inferiores à abordagem Self-Training na avaliação experimental realizada no Capítulo 4.

A indução semissupervisionada baseada em redes foi realizada considerando os algoritmos TCHN, GNetMine, LPHN e TM. Os tipos de redes empregados nos algoritmos são especificados no frente dos nomes dos mesmos. Redes compostas por relações do tipo documento-documento serão denotadas por DD, redes compostas por relações termo-termo serão denotadas por TT e redes compostas por relações por relações documento-termo serão denotadas por DT. Por exemplo, o algoritmo TCHN aplicado a uma rede composta por relações documento-termo será denotado por $T C H N(\mathrm{DT})$. Vale ressaltar que foi descartado o algoritmo $\operatorname{LPHN}(\mathrm{TT})$ da avaliação experimento uma vez que este não apresentou performances de classificação satisfatórias no aprendizado transdutivo.

Também foram utilizados algoritmos indutivos supervisionados para comparar a diferença na performance de classificação ao considerar documentos rotulados e não rotulados em comparação com a utilização de somente documentos rotulados na indução semissupervisionada de um modelo de classificação. Neste caso, o modelo de classificação é induzido considerando somente os $N$ documentos rotulados do conjunto de treinamento. Os algoritmos indutivos supervisionados considerados nesta avaliação experimental são: 
$M N B, k-N N$ e $I M H N^{\mathrm{R}}(\mathrm{DT})$. O algoritmo $M N B$ foi considerado uma vez que esse algoritmo é utilizado como algoritmo indutivo nas abordagens Self-Training e é a base da abordagem $E M$. Além disso o algoritmo $M N B$ é um dos algoritmos indutivos supervisionados que apresenta a maior performance de classificação. O algoritmo $k-N N$ permite verificar se o uso de documentos não rotulados e das redes geradas considerando as similaridades entre os documentos são de fato úteis para melhorar a performance de classificação em comparação com a utilização da similaridade direta entre os documentos rotulados. Já o algoritmo $I M H N^{\mathrm{R}}(\mathrm{DT})$ permite avaliar o impacto na performance de classificação ao considerar documentos não rotulados ao ser comparado com o algoritmo TCHN(DT).

Devido ao grande número de execuções, 100 para cada algoritmo, para obter as medidas de performance de classificação dos algoritmos analisados, uma avaliação experimental considerando variação de parâmetros dos algoritmos ou dos parâmetros para gerar as redes de documento ou termos seria inviável. Assim, os algoritmos foram executados considerando os parâmetros dos algoritmos que proveram a maior performance de classificação para cada coleção ${ }^{1}$. No caso dos algoritmos baseados em rede, foi considerada a rede que proveu a melhor performance de classificação para uma determinada coleção.

\subsubsection{Resultados}

Nesta seção são apresentados os resultados obtidos considerando a configuração experimental apresentada na seção anterior. São exibidos três tipos de resultados para comparar e analisar as performances de classificação dos algoritmos utilizados nesta avaliação experimental: (i) gráficos de performance de classificação, (ii) tabela de vitórias e (iii) diagramas de diferença crítica.

Em cada gráfico de performance de classificação é exibido os valores da medida $F 1^{\text {Micro }}$ ou $F 1^{\text {Macro }}$ obtidos por um determinado algoritmo para um determinado número de documentos rotulados por classe. Nesses gráficos, o eixo horizontal corresponde ao número de exemplos rotulados por classe e o eixo vertical corresponde ao valor da performance de classificação. Os gráficos permitem uma comparação visual das performances de classificação obtidas pelos diferentes algoritmos e representações.

Em cada tabela de vitória é apresentado o número de vezes que um algoritmo (apresentado na linha) supera a performance de classificação de outro algoritmo (apresentado na coluna). Estão hachuradas (com a cor verde na versão colorida) as situações em que um algoritmo superou outro um maior número de vezes, isto é, quando a performance de classificação um algoritmo em relação ao outro foi maior em 16 ou mais das 34 coleções.

Cada diagrama de diferença crítica corresponde à uma ilustração gráfica do resultado do teste estatístico de Friedman $N \times N$ com pós-teste de Nemenyi e $95 \%$ de confiança. Esse é um teste não paramétrico, baseado em ranking e aconselhável para a análise

\footnotetext{
${ }^{1}$ Foi empiricamente verificado que um parâmetro que obtém uma melhor performance na classificação transdutiva, em geral, também provê uma melhor performance de classificação na classificação utilizando indução semissupervisionada.
} 
estatística dos resultados de múltiplos classificadores para múltiplas coleções (Trawinski et al., 2012; García et al., 2010; Demsar, 2006). Neste diagrama é exibido o ranking médio dos algoritmos e aqueles conectados por uma linha (diferença crítica) não apresentam diferenças estatisticamente significantes.

Devido à grande quantidade de algoritmos utilizados nesta avaliação experimental, foram criados 4 grupos de experimentos para melhor visualização, análise e compreensão dos resultados. No primeiro grupo de experimentos, foram comparados os algoritmos $M N B, M N B-S e, E M$ e TSVM. Os experimentos desse grupo visam comparar o impacto do uso de documentos não rotulados na performance de classificação considerando algoritmos baseados no modelo espaço-vetorial.

Nas Figuras 5.2 e 5.3 são apresentados os gráficos de performance de classificação considerando a medida $F 1^{\text {Micro }}$ e nas Figuras 5.4 e 5.5 são apresentados os gráficos de performance de classificação considerando a medida $F 1^{\text {Macro }}$ para o primeiro grupo de experimentos considerados nesta avaliação experimental. Pode-se observar que o algoritmo supervisionado $M N B$, em geral, obteve maior performance de classificação em relação aos algoritmos indutivos semissupervisionados baseados no modelo espaço-vetorial. Inclusive, para várias coleções houve diferenças significativa do $M N B$ para os algoritmos semissupervisionados.

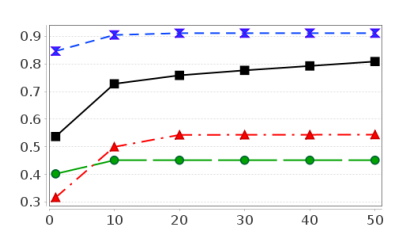

(a) Classic4

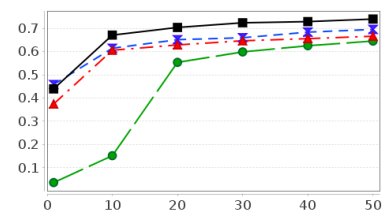

(e) FBIS

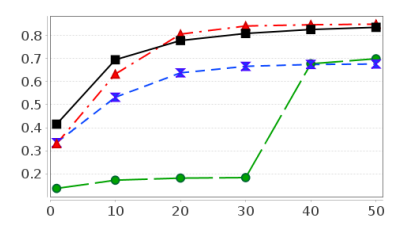

(i) La2s

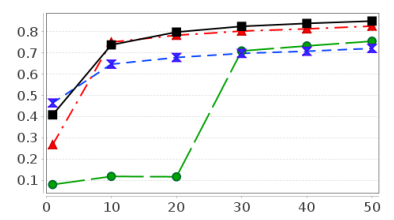

(m) Oh5

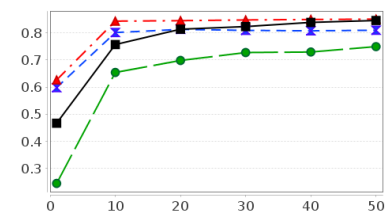

(b) CSTR

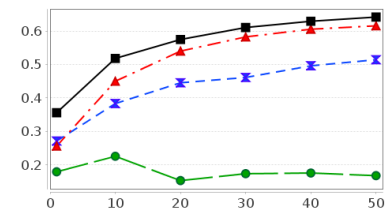

(f) Hitech

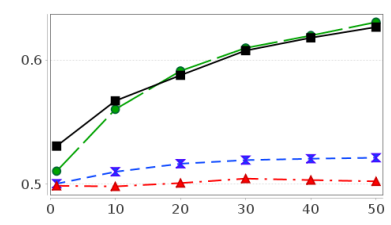

(j) Multi_Dom_Sentiment

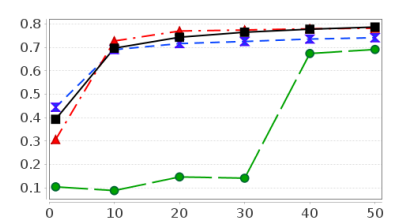

(n) Oh10

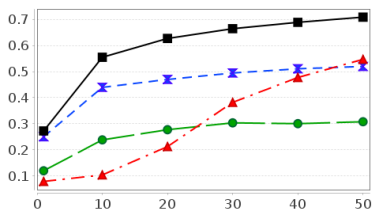

(c) Dmoz_Health_500

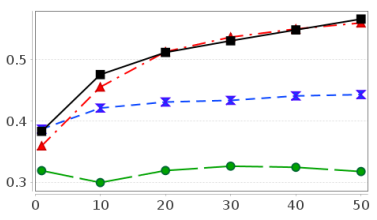

(g) IrishSentiment

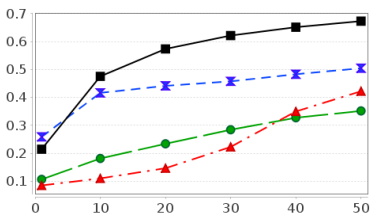

(k) NFS

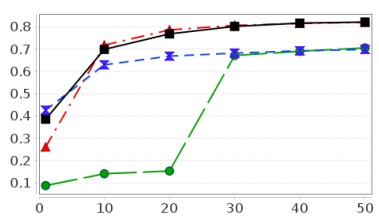

(o) Oh15

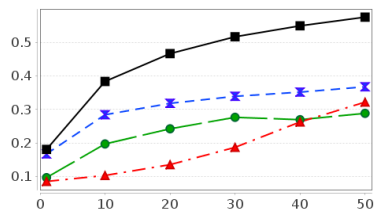

(d) Dmoz_Science_500

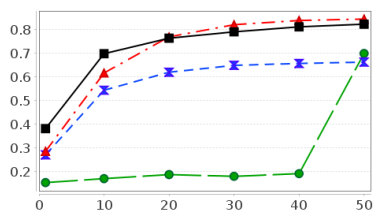

(h) La1s

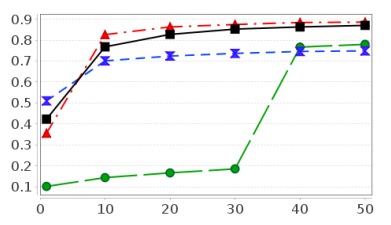

(l) $\mathrm{Oh} 0$

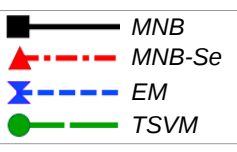

(p) Legenda

Figura 5.2: Valores $F 1^{\text {Micro }}$ do $1^{\mathrm{o}}$ grupo de experimentos (parte I). 


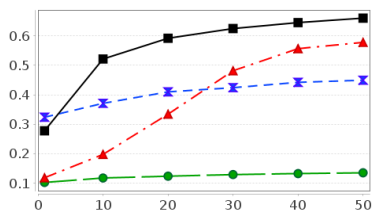

(a) Ohscal

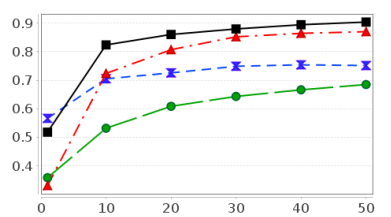

(e) $\operatorname{Re} 8$

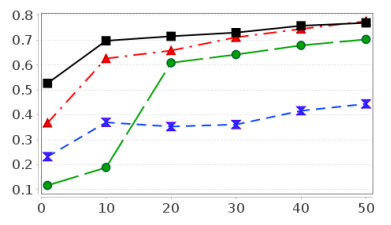

(i) $\operatorname{Tr} 12$

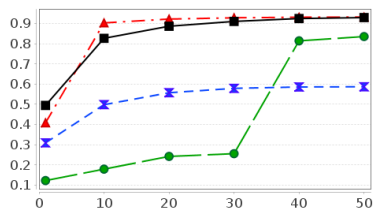

(m) $\operatorname{Tr} 41$

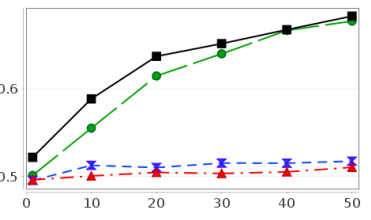

(b) Polarity

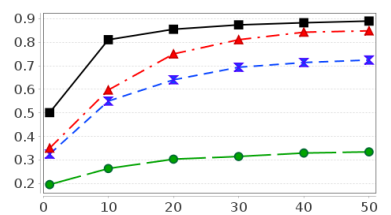

(f) Reviews

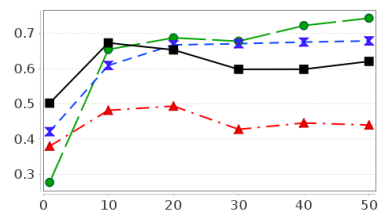

(j) $\operatorname{Tr} 21$

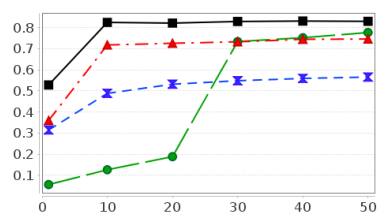

(n) $\operatorname{Tr} 45$

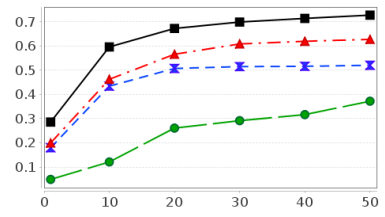

(c) $\operatorname{Re} 0$

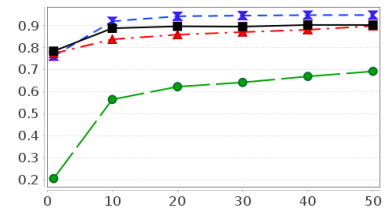

(g) SyskillWebert

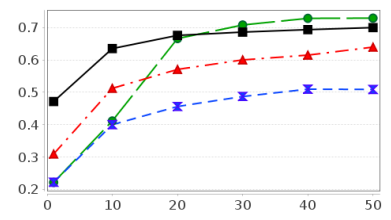

(k) $\operatorname{Tr} 23$

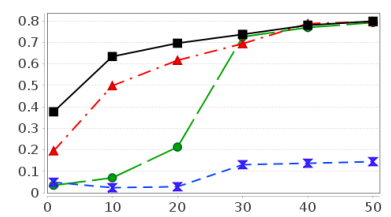

(o) Wap

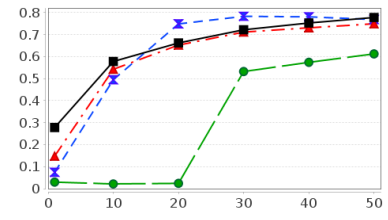

(d) Re1

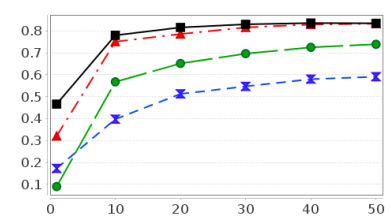

(h) $\operatorname{Tr} 11$

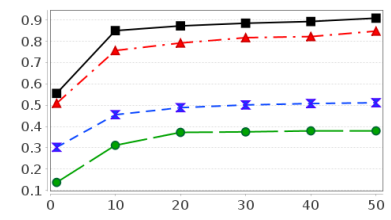

(l) $\operatorname{Tr} 31$

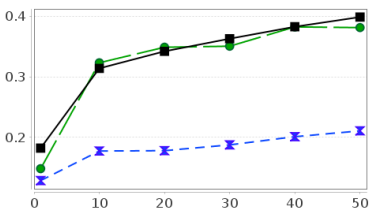

(p) WebKB

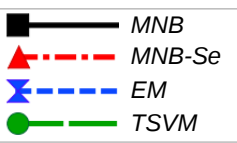

(q) Legenda

Figura 5.3: Valores $F 1^{\text {Micro }}$ do $1^{\circ}$ grupo de experimentos (parte II).

Para elucidar a comparação das performances de classificação dos diferentes algoritmos no primeiro grupo de experimentos, nas Tabelas 5.1 e 5.2 é apresentado o número de vitórias dos algoritmos considerando as medidas $F 1^{\text {Micro }}$ e $F 1^{\text {Macro }}$ respectivamente. Nestas tabelas pode-se comprovar que o $M N B$ de fato obtém a maior performance de relação em relação aos demais algoritmos utilizados no primeiro grupo na maioria das coleções. Em geral, o $M N B$-Se apresentou os melhores resultados dentre os algoritmos semissupervisionados baseados no modelo espaço-vetorial.

Nas Figuras 5.6 e 5.7 são apresentados os diagramas de diferença crítica considerando os resultados do primeiro grupo de experimentos para as medidas $F 1^{\text {Micro }}$ e $F 1^{\text {Macro }}$ respectivamente. Pode-se observar por esses diagramas que os algoritmos $M N B$ e $M N B-S e$ obtiveram a primeira e segunda posições respectivamente no ranking médio para a grande maioria das situações analisadas, sendo que o algoritmo $M N B$ apresentou diferenças estatisticamente significantes para o $T S V M$ em todas as situações analisadas, e para o $E M$ na grande maiorias das situações. 


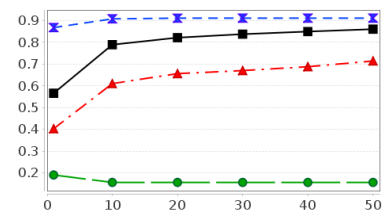

(a) Classic4

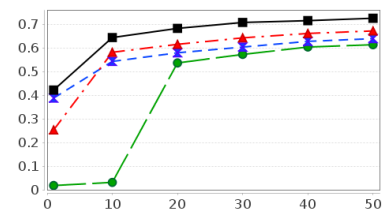

(e) FBIS

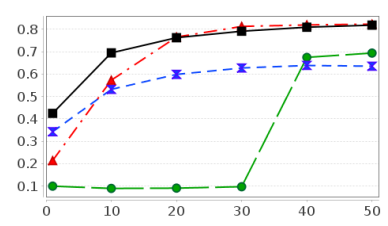

(i) La2s

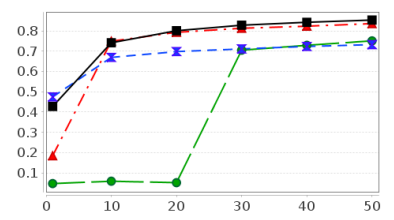

(m) Oh5

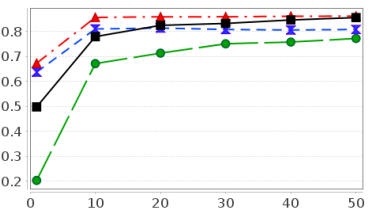

(b) CSTR

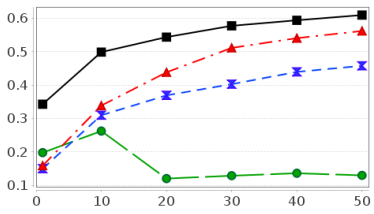

(f) Hitech

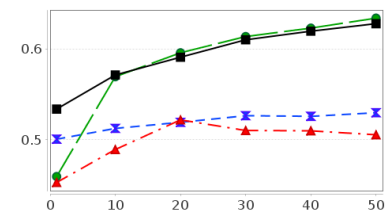

(j) Multi_Dom_Sentiment

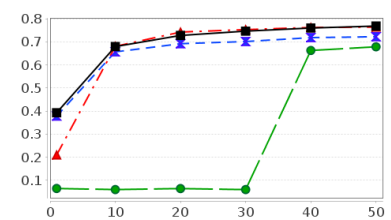

(n) Oh10

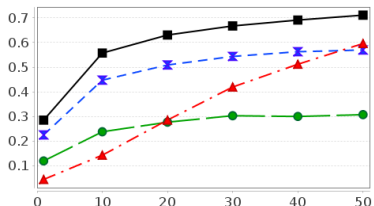

(c) Dmoz_Health_500

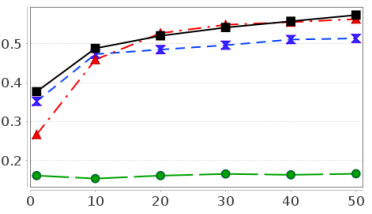

(g) IrishSentiment

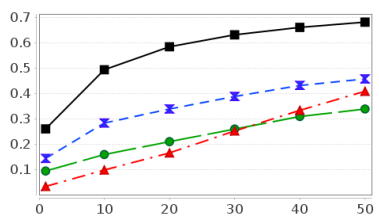

(k) NFS

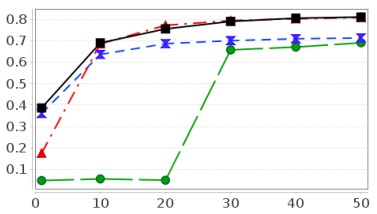

(o) Oh15

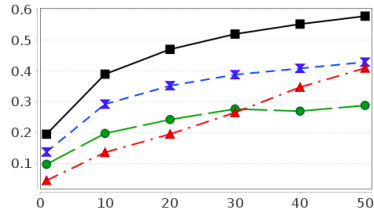

(d) Dmoz_Science_500

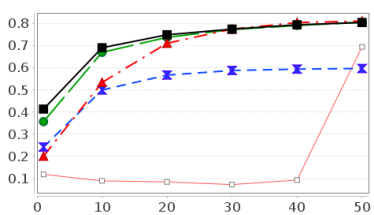

(h) La1s

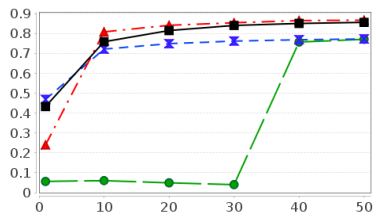

(l) $\mathrm{Oh} 0$

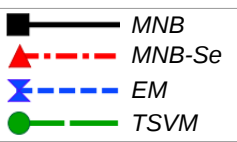

(p) Legenda

Figura 5.4: Valores $F 1^{\text {Macro }}$ do $1^{\circ}$ grupo de experimentos (parte I).

Tabela 5.1: Número de vitórias dos algoritmos indicados na linha em comparação com os algoritmos indicados na coluna para o primeiro grupo de experimentos considerando a medida $F 1^{\text {Micro }}$.

\begin{tabular}{|c|c|c|c|c|}
\hline \multicolumn{5}{|c|}{1 exemplo rotulado por classe } \\
\hline & $M N B$ & $M N B-S e$ & $E M$ & TSVM \\
\hline$M N B$ & & 29 & 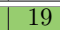 & 30 \\
\hline$M N B-S e$ & 1 & & 15 & 23 \\
\hline$E M$ & 11 & 15 & & 27 \\
\hline$T S V$ & 0 & 7 & 3 & \\
\hline
\end{tabular}

\begin{tabular}{l||c|c|c|c}
\hline \multicolumn{5}{c}{ 30 exemplos rotulados por classe } \\
\hline \hline & $\boldsymbol{M N B}$ & $\boldsymbol{M} \boldsymbol{B}-\boldsymbol{S e}$ & $\boldsymbol{E M}$ & $\boldsymbol{T S \boldsymbol { M }}$ \\
\hline \hline $\boldsymbol{M N B}$ & - & 22 & 26 & 27 \\
\hline $\boldsymbol{M N B}$ - $\boldsymbol{e}$ & 8 & - & 21 & 22 \\
\hline $\boldsymbol{E M}$ & 4 & 9 & - & 20 \\
\hline $\boldsymbol{T S} \boldsymbol{V} \boldsymbol{M}$ & 3 & 8 & 10 & - \\
\hline \hline
\end{tabular}

\begin{tabular}{|c|c|c|c|c|}
\hline \multicolumn{5}{|c|}{20 exemplos rotulados por classe } \\
\hline & $M N B$ & $M N B-S e$ & $E M$ & TSVN \\
\hline$M N$ & & 22 & 26 & 27 \\
\hline$M \Lambda$ & 0 & & 20 & 23 \\
\hline & 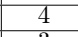 & 10 & & 22 \\
\hline & 3 & 7 & 8 & \\
\hline
\end{tabular}

\begin{tabular}{|c|c|c|c|c|}
\hline \multicolumn{5}{|c|}{40 exemplos rotulados por classe } \\
\hline & $M N B$ & $M N B-S e$ & $E M$ & TSVM \\
\hline$M N B$ & & 22 & 26 & 27 \\
\hline$M N B-S e$ & 8 & & 21 & 24 \\
\hline$E M$ & 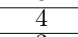 & 9 & & 17 \\
\hline$T S V M$ & 3 & 8 & 13 & \\
\hline
\end{tabular}

Tabela 5.2: Número de vitórias dos algoritmos indicados na linha em comparação com os algoritmos indicados na coluna para o primeiro grupo de experimentos considerando a medida $F 1^{\text {Macro }}$.

\begin{tabular}{l||c|c|c|c}
\hline \hline \multicolumn{5}{c}{ 1 exemplo rotulado por classe } \\
\hline \hline & MNB & MNB-Se & EM & TS $\boldsymbol{M}$ \\
\hline \hline $\boldsymbol{N} \boldsymbol{B}$ & - & 29 & 25 & 30 \\
\hline $\boldsymbol{M N} \boldsymbol{B}-\boldsymbol{S e}$ & 1 & - & 13 & 23 \\
\hline $\boldsymbol{E M}$ & 5 & 17 & - & 26 \\
\hline TSVM & 0 & 7 & 4 & - \\
\hline \hline
\end{tabular}

30 exemplos rotulados por classe \begin{tabular}{l||l|l|l|l|l|}
\hline & $M N B$ & $M N B-S e$ & $E M$ & $T S V M$ \\
\hline
\end{tabular}

\begin{tabular}{l||c|c|c|c}
\hline $\boldsymbol{M N \boldsymbol { B }}$ & - & 22 & 28 & 28 \\
\hline $\boldsymbol{M N \boldsymbol { B } - \boldsymbol { S e }}$ & 8 & - & 21 & 25 \\
\hline $\boldsymbol{E M}$ & 2 & 9 & - & 22 \\
\hline $\boldsymbol{T} \boldsymbol{S} \boldsymbol{V} \boldsymbol{M}$ & 2 & 5 & 8 & -
\end{tabular}

\begin{tabular}{l||c|c|c|c}
\hline \hline \multicolumn{5}{c}{ 10 exemplos rotulados por classe } \\
\hline \hline & $\boldsymbol{M N \boldsymbol { B }}$ & $\boldsymbol{M N \boldsymbol { N } - \boldsymbol { S e }}$ & $\boldsymbol{E M}$ & $\boldsymbol{T S \boldsymbol { M }}$ \\
\hline $\boldsymbol{M N \boldsymbol { B }}$ & - & 25 & 27 & 30 \\
\hline $\boldsymbol{M} \boldsymbol{\boldsymbol { B }}-\boldsymbol{S e}$ & 5 & - & 20 & 26 \\
\hline $\boldsymbol{E M}$ & 3 & 10 & - & 26 \\
\hline $\boldsymbol{T S} \boldsymbol{V} \boldsymbol{M}$ & 0 & 4 & 4 & - \\
\hline \hline
\end{tabular}

\begin{tabular}{c|c|c|c}
\hline 0 exemplos rotulados por classe \\
\hline \hline 40
\end{tabular}

\begin{tabular}{l||c|c|c|c}
\hline \hline & $\boldsymbol{M N B}$ & $\boldsymbol{M N B}$-Se & $\boldsymbol{E M}$ & $\boldsymbol{T S} \boldsymbol{V M}$ \\
\hline \hline $\boldsymbol{M N B}$ & - & 24 & 28 & 27 \\
\hline $\boldsymbol{M N B} \boldsymbol{S} \boldsymbol{e}$ & 6 & - & 24 & 26 \\
\hline $\boldsymbol{E M}$ & 2 & 6 & - & 19 \\
\hline $\boldsymbol{T} \boldsymbol{S} \boldsymbol{M} \boldsymbol{M}$ & 3 & 4 & 11 & -
\end{tabular}

\begin{tabular}{|c|c|c|c|c|}
\hline \multicolumn{5}{|c|}{20 exemplos rotulados por classe } \\
\hline & $\overline{M N B}$ & $M N B-S e$ & $E M$ & $T S V M$ \\
\hline$\overline{M N B}$ & - & 23 & 28 & 29 \\
\hline$M N B-S e$ & 7 & - & 22 & 27 \\
\hline$E M$ & 2 & 8 & - & 25 \\
\hline$T S V M$ & 1 & 3 & 5 & 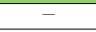 \\
\hline \multicolumn{5}{|c|}{50 exemplos rotulados por classe } \\
\hline & $M N B$ & $M N B-S e$ & $E M$ & $T S V M$ \\
\hline$\overline{M N B}$ & $\overline{-1}$ & 23 & 28 & 27 \\
\hline$M N B-S e$ & 6 & - & 26 & 26 \\
\hline$E M$ & 2 & 4 & - & 18 \\
\hline$T S V M$ & 3 & 4 & 12 & \\
\hline
\end{tabular}




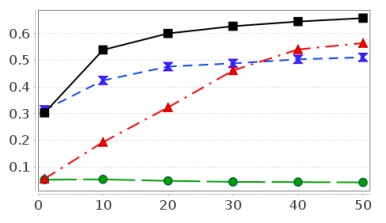

(a) Ohscal

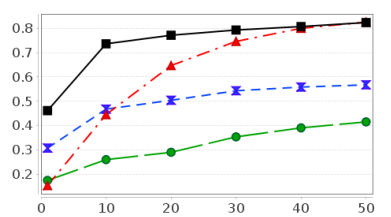

(e) Re8

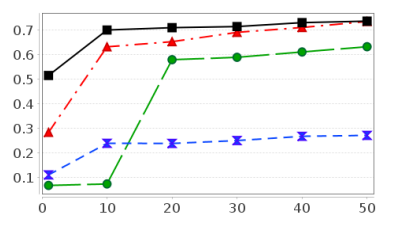

(i) $\operatorname{Tr} 12$

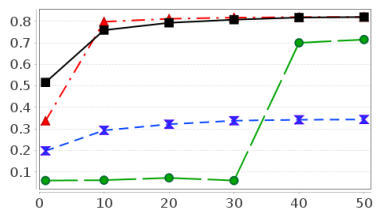

(m) $\operatorname{Tr} 41$

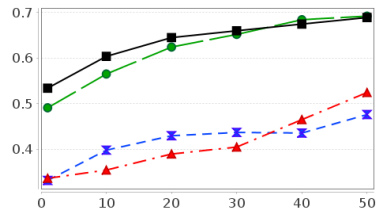

(b) Polarity

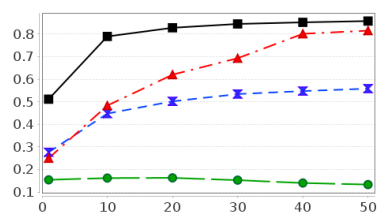

(f) Reviews

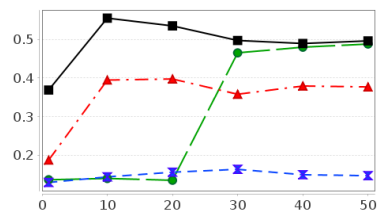

(j) $\operatorname{Tr} 21$

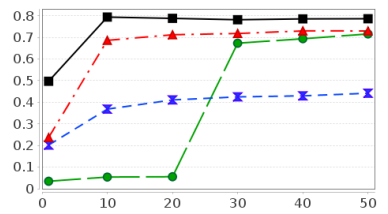

(n) $\operatorname{Tr} 45$

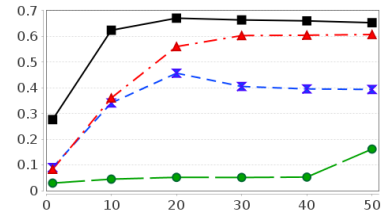

(c) $\mathrm{Re} 0$

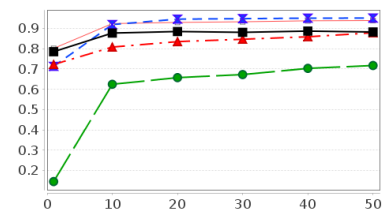

(g) SyskillWebert

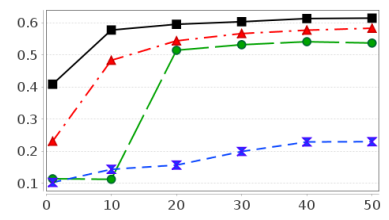

(k) $\operatorname{Tr} 23$

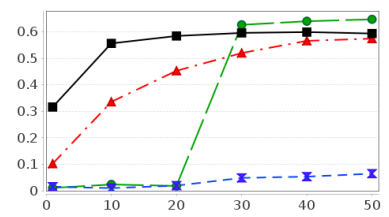

(o) Wap

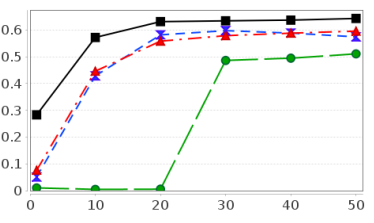

(d) Re1

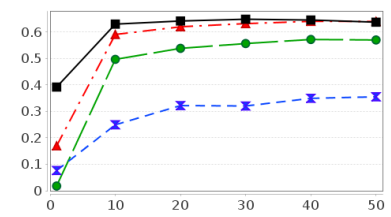

(h) $\operatorname{Tr} 11$

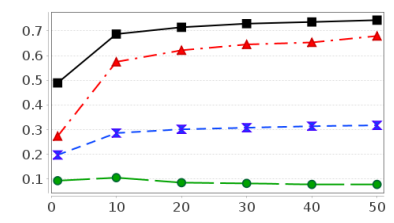

(l) $\operatorname{Tr} 31$

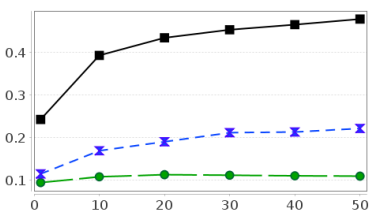

(p) WebKB

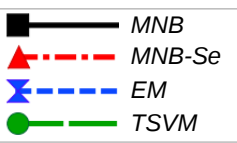

(q) Legenda

Figura 5.5: Valores $F 1^{\text {Macro }}$ do $1^{\circ}$ grupo de experimentos (parte II).

No segundo grupo de experimentos, foram comparados os algoritmos $k-N N$ com os algoritmos GNetMine(DD), GNetMine(DT), GNetMine(TT), $L P H N(\mathrm{DD})$ e $L P H N(\mathrm{DT})$. Isso permite comparar o impacto do uso de redes e exemplos não rotulados quando considerada a similaridade entre os documentos, no caso do algoritmo $k$ - $N N$ e os algoritmos baseados em redes com relações documento-documento, e também permite avaliar se a proposta de classificação considerando as informações de classe dos termos é capaz de superar as performances de classificação obtidas considerando redes de documentos.

Nas Figuras 5.8 e 5.9 são apresentados os gráficos de performance de classificação considerando a medida $F 1^{\text {Micro }}$ e nas Figuras 5.10 e 5.11 são apresentados os gráficos de performance de classificação considerando a medida $F 1^{\text {Macro }}$ para o segundo grupo de experimentos. Pode-se observar por esses gráficos que, em geral, o algoritmo GNetMine aplicados aos diferentes tipos de redes consideradas nesta avaliação superou o algoritmo supervisionado $k-N N$. Pode-se observar também que para algumas coleções o algoritmo $L P H N(\mathrm{DD})$ superou o algoritmo $k$-NN. Porém, na grande maioria das coleções, tanto o 

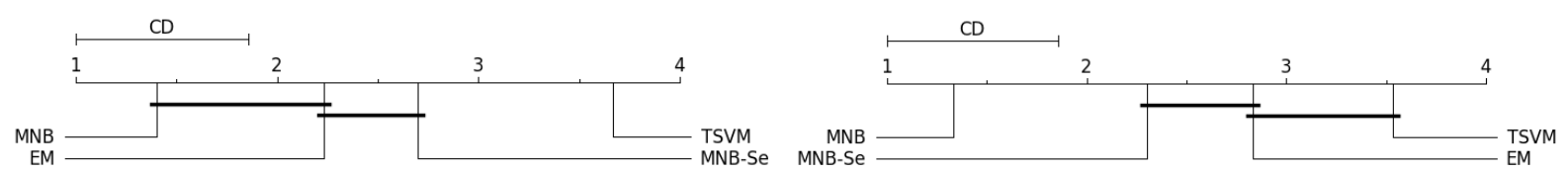

(a) 1 exemplo rotulado por classe.

(b) 10 exemplos rotulados por classe.
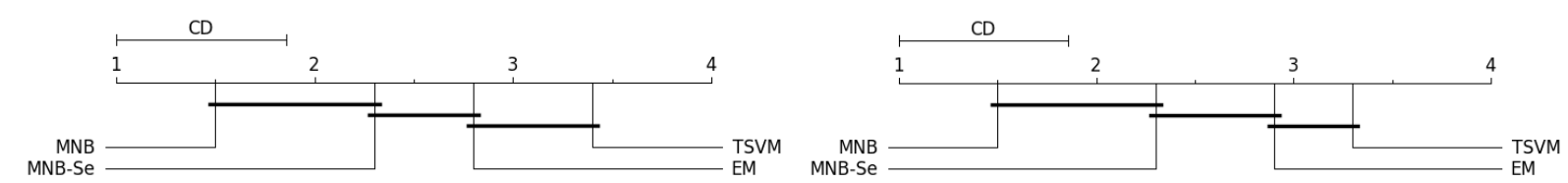

(c) 20 exemplos rotulados por classe.

(d) 30 exemplos rotulados por classe.
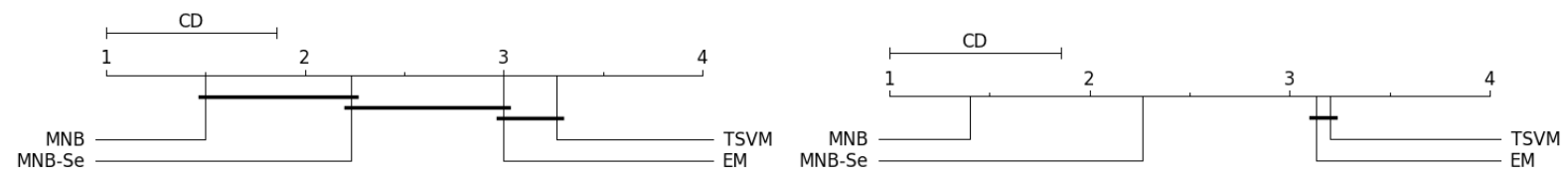

(e) 40 exemplos rotulados por classe.

(f) 50 exemplos rotulados por classe.

Figura 5.6: Diagramas de diferença crítica para o primeiro grupo de experimentos considerando a medida $F 1^{\text {Micro }}$.

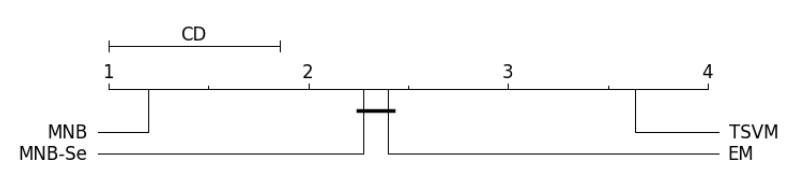

(a) 1 exemplo rotulado por classe.

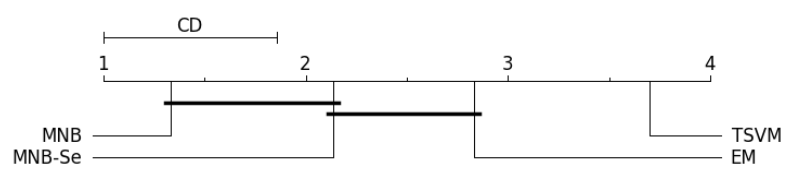

(c) 20 exemplos rotulados por classe.

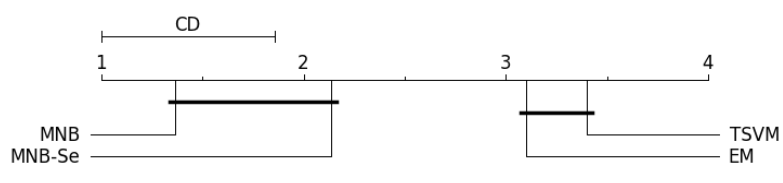

(e) 40 exemplos rotulados por classe.

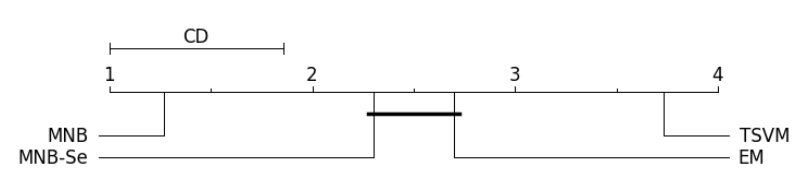

(b) 10 exemplos rotulados por classe.

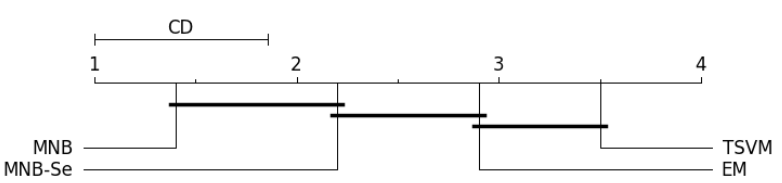

(d) 30 exemplos rotulados por classe.

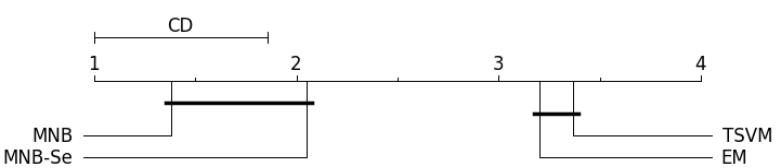

(f) 50 exemplos rotulados por classe.

Figura 5.7: Diagramas de diferença crítica para o primeiro grupo de experimentos considerando a medida F1 $1^{\text {Macro }}$.

$L P H N(\mathrm{DD})$ quanto o $L P H N(\mathrm{DT})$ apresentaram performances de classificação inferiores aos demais algoritmos.

Para elucidar a comparação das performances de classificação dos diferentes algoritmos no segundo grupo de experimentos, nas Tabelas 5.3 e 5.4 é apresentado o número de vitórias dos algoritmos considerando as medidas $F 1^{\text {Micro }}$ e $F 1^{\text {Macro }}$ respectivamente. Ao utilizar 10 ou mais documentos rotulados, a utilização do algoritmo GNetMine(DT), juntamente com a abordagem proposta, obteve maiores performances de classificação em relação ao algoritmo GNetMine(DD) na maioria das coleções ao considerar a medida $F 1^{\text {Macro }}$. Vale ressaltar que o algoritmo GNetMine(DT) apresenta um tempo de construção da rede e de 


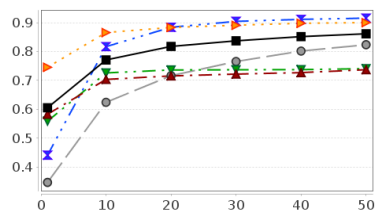

(a) Classic4

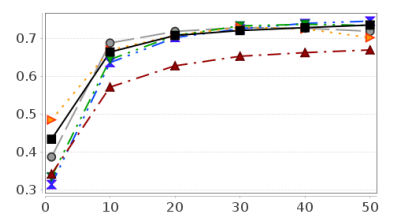

(e) FBIS

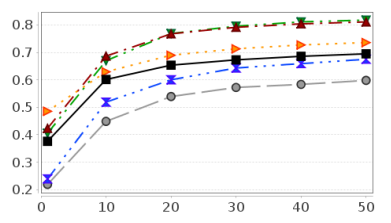

(i) La2s

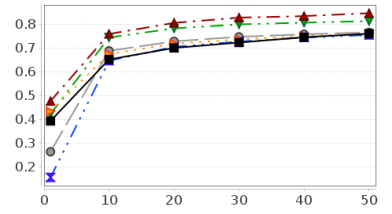

(m) Oh5

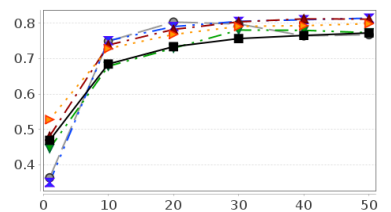

(b) CSTR

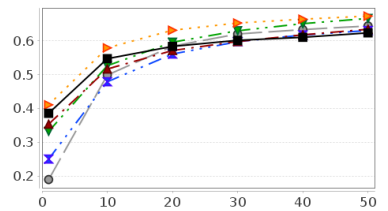

(f) Hitech

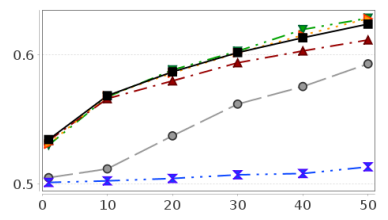

(j) Multi_Dom_Sentiment

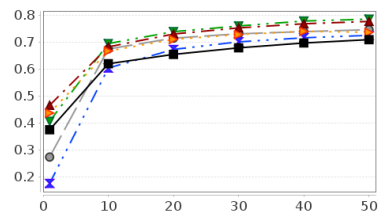

(n) Oh10

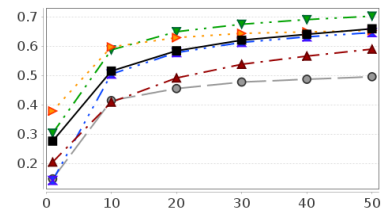

(c) Dmoz_Health_500

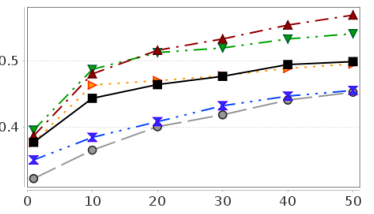

(g) IrishSentiment

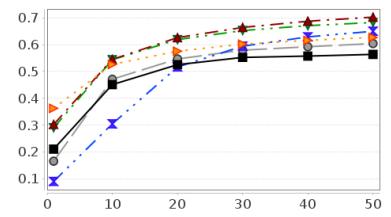

(k) NFS

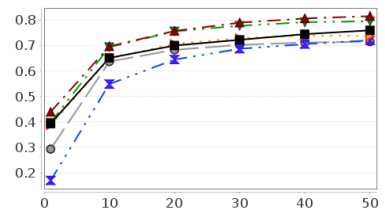

(o) Oh15

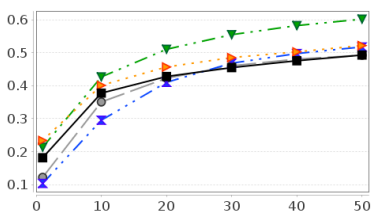

(d) Dmoz_Science_500

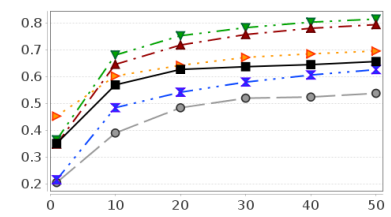

(h) La1s

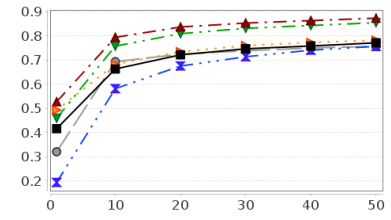

(l) $\mathrm{Oh} 0$

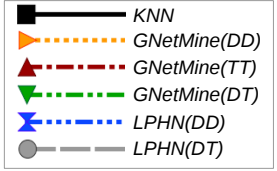

(p) Legenda

Figura 5.8: Valores $F 1^{\text {Micro }}$ do $2^{\circ}$ grupo de experimentos (parte I).

classificação de novos documentos menor que do algoritmo GNetMine(DD). Já a utilização do algoritmo $L P H N$ com os diferentes tipos de rede, em geral, não produziu melhores resultados que o algoritmo $k-N N$ e GNetMine.

Nas Figuras 5.12 e 5.13 são apresentados os diagramas de diferença crítica considerando os resultados do segundo grupo de experimentos para as medidas $F 1^{\text {Micro }}$ e $F 1^{\text {Macro }}$ respectivamente. Pode-se observar por esses diagramas que na grande maioria das situações o algoritmo GNetMine com os diferentes tipos de rede considerados obtiveram as primeiras posições no ranking. Para 10 ou mais exemplos rotulados, não houve diferenças estatisticamente significantes entre os algoritmos GNetMine(DD), GNetMine(DT) e GNetMine(TT).

Considerando a medida $F 1^{\text {Micro }}$, o GNetMine(DD) foi o primeiro no ranking médio quando utilizados de 1 a 30 documentos rotulados por classe, enquanto que o GNetMine(DT) obtém a primeiro posição no ranking médio quando utilizados 40 ou 50 documentos rotulados por classe. Considerado a medida $F 1^{\text {Macro }}$, o algoritmo GNetMine(DD) foi o primeiro colocado no ranking médio para 1 e 10 documentos rotulados por classe, enquanto que o GNetMine(DT) foi o primeiro no ranking para 20, 30 e 40 exemplos rotulados por classe e GNetMine(TT) para 50 documentos rotulados por classe. Portanto, GNetMine(DT) e GNetMine(TT) juntamente com a abordagem proposta são aconselháveis 


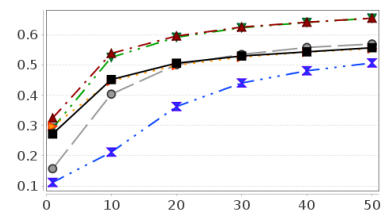

(a) Ohscal

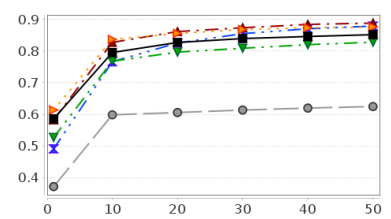

(e) $\operatorname{Re} 8$

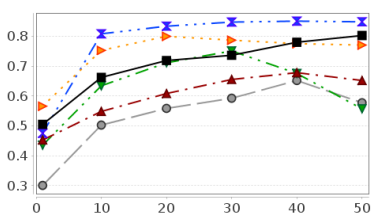

(i) $\operatorname{Tr} 12$

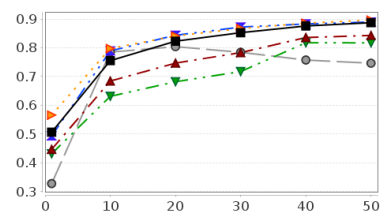

(m) $\operatorname{Tr} 41$

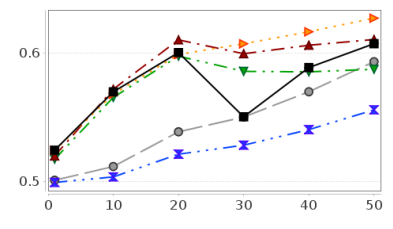

(b) Polarity

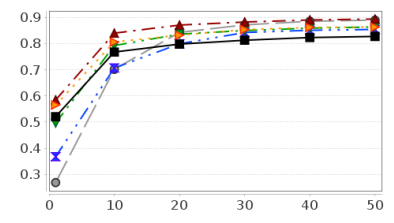

(f) Reviews

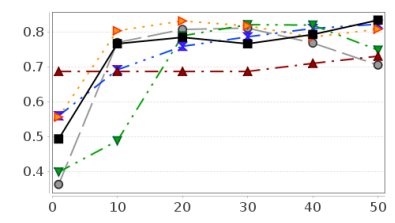

(j) $\operatorname{Tr} 21$

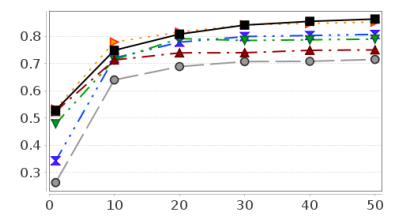

(n) $\operatorname{Tr} 45$

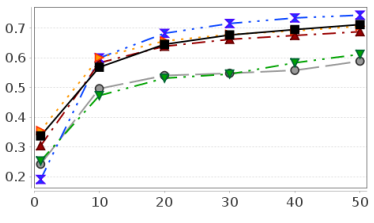

(c) $\operatorname{Re} 0$

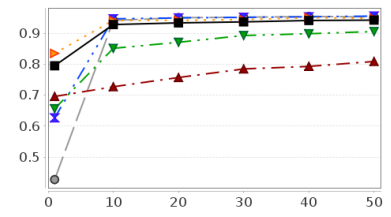

(g) SyskillWebert

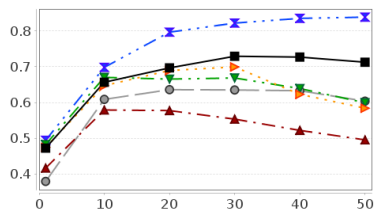

(k) $\operatorname{Tr} 23$

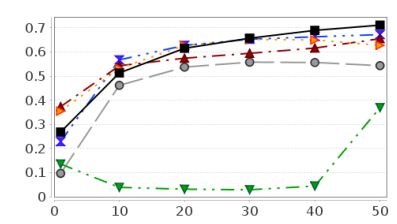

(o) Wap

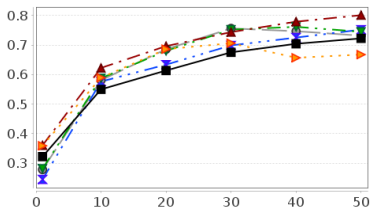

(d) Re1

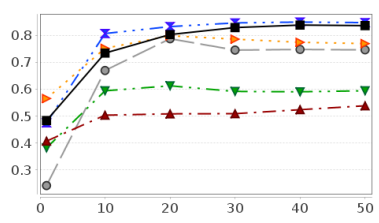

(h) $\operatorname{Tr} 11$

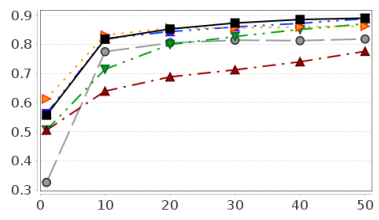

(1) $\operatorname{Tr} 31$

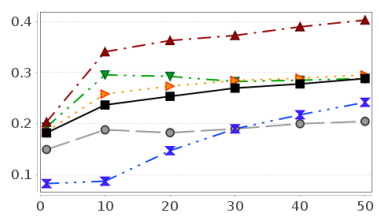

(p) WebKB

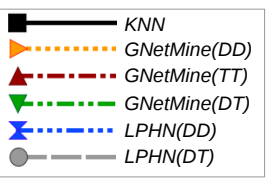

(q) Legenda

Figura 5.9: Valores $F 1^{\text {Micro }}$ do $2^{\circ}$ grupo de experimentos (parte II).

para indução semissupervisionada quando utilizado o algoritmo GNetMine, uma vez que ambos podem induzir uma modelo de classificação e classificar novos documentos mais rapidamente que o GNetMine(DD).

No terceiro grupo de experimentos foram comparados os algoritmos $I M H N^{\mathrm{R}}(\mathrm{DT})$, $T C H N(\mathrm{DT})$ e $T C H N(\mathrm{DT}-\mathrm{TT})$. Isso permite verificar se o uso de documentos não rotulados na indução de um modelo de classificação provê uma melhor performance de classificação para novos documentos, no caso da comparação entre os algoritmos TCHN(DT) e $I M H N^{\mathrm{R}}(\mathrm{DT})$. Além disso, também é analisado se o uso de redes compostas por mais de um tipo de relação também é capaz de aumentar a performance de classificação, no caso da comparação entre os algoritmos $T C H N(\mathrm{DT}-\mathrm{TT})$ e $T C H N(\mathrm{DT})$. Vale ressaltar que somente nesse grupo de experimentos foi utilizada uma rede composta por mais de um tipo de relação de forma a validar a hipótese de que redes compostas mais de um tipo de classificação proveem uma performance de classificar maior que as obtidas utilizando redes 


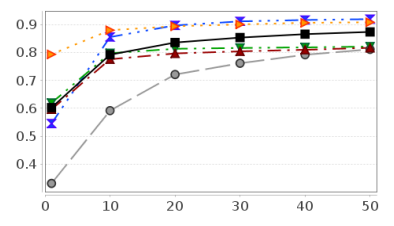

(a) Classic4

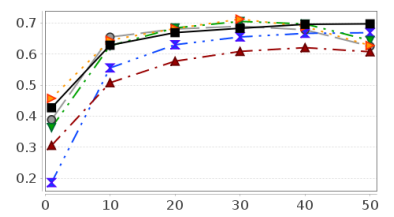

(e) FBIS

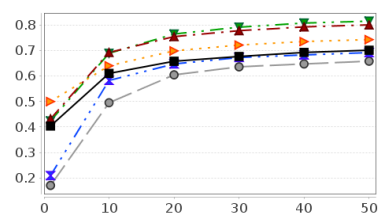

(i) La2s

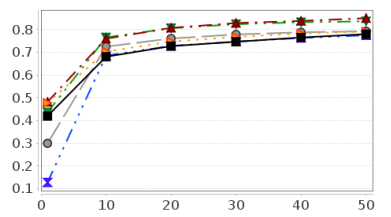

(m) Oh5

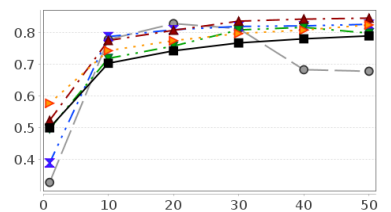

(b) CSTR

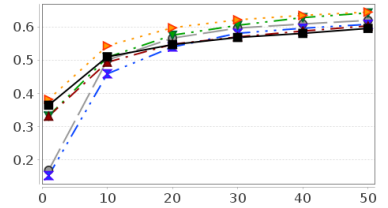

(f) Hitech

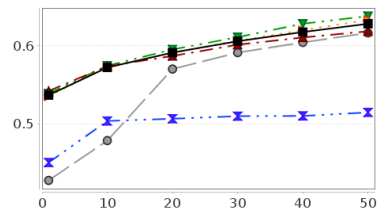

(j) Multi_Dom_Sentiment

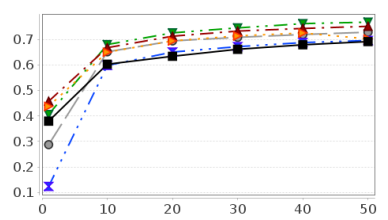

(n) Oh10

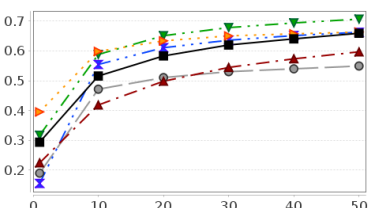

(c) Dmoz_Health_500

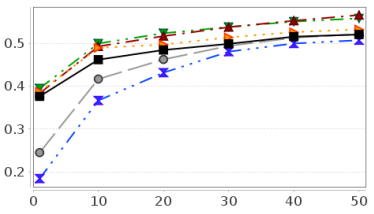

(g) IrishSentiment

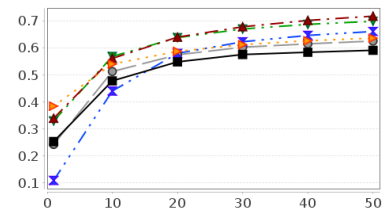

(k) NFS

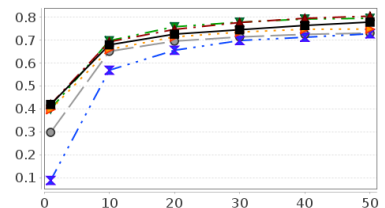

(o) Oh15

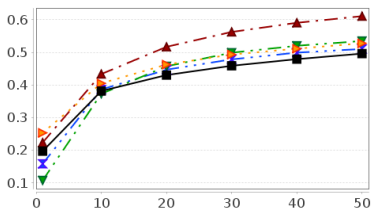

(d) Dmoz_Science_500

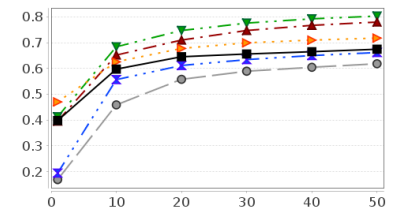

(h) La1s

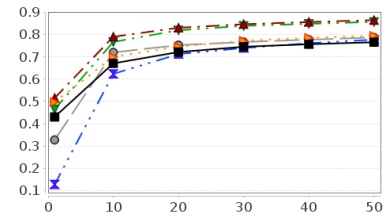

(l) $\mathrm{Oh} 0$

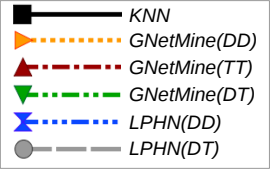

(p) Legenda

Figura 5.10: Valores $F 1^{\text {Macro }}$ do $2^{\circ}$ grupo de experimentos (parte I).

Tabela 5.3: Número de vitórias dos algoritmos indicados na linha em comparação com os algoritmos indicados na coluna para o segundo grupo de experimentos considerando a medida $F 1^{\text {Micro }}$.

\begin{tabular}{l||c|c|c|c|c|c}
\hline \hline \multicolumn{7}{c}{ 1 exemplo rotulado por classe } \\
\hline \hline & $\boldsymbol{k}-\boldsymbol{N N}$ & $\begin{array}{c}\text { GNM } \\
\text { (DD) }\end{array}$ & $\begin{array}{c}\text { GNM } \\
\text { (TT) }\end{array}$ & $\begin{array}{c}\text { GNM } \\
\text { DT }\end{array}$ & $\begin{array}{c}\boldsymbol{L P H N} \\
\text { (DD) }\end{array}$ & $\begin{array}{c}\boldsymbol{L P H N} \\
\text { (DT) }\end{array}$ \\
\hline $\boldsymbol{k - N \boldsymbol { N }}$ & - & 4 & 16 & 18 & 27 & 30 \\
\hline $\boldsymbol{G N M}$ (DD) & 26 & - & 18 & 26 & 28 & 30 \\
\hline $\boldsymbol{G N M}$ (TT) & 14 & 12 & - & 25 & 25 & 29 \\
\hline $\boldsymbol{G N M}$ (DT) & 12 & 4 & 5 & - & 23 & 29 \\
\hline $\boldsymbol{L P H N}$ (DD) & 3 & 2 & 5 & 7 & - & 16 \\
\hline $\boldsymbol{L P H N}$ (DT) & 0 & 0 & 1 & 1 & 14 & - \\
\hline
\end{tabular}

\begin{tabular}{|c|c|c|c|c|c|c|}
\hline \multicolumn{7}{|c|}{10 exemplos rotulados por classe } \\
\hline & $k-N N$ & $\begin{array}{l}G N M \\
\text { (DD) }\end{array}$ & $\begin{array}{c}G N M \\
(\mathrm{TT})\end{array}$ & $\begin{array}{c}G N M \\
\text { DT }\end{array}$ & $\begin{array}{c}L P H N \\
\text { (DD) }\end{array}$ & $\begin{array}{c}L P H N \\
\text { (DT) }\end{array}$ \\
\hline$k-N N$ & - & 4 & 13 & 16 & 19 & 20 \\
\hline GNM(DD) & 25 & - & 15 & 19 & 24 & 24 \\
\hline$G I$ & 17 & 15 & 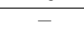 & 16 & 16 & 21 \\
\hline$G N M(\mathrm{DT})$ & 14 & 11 & 14 & 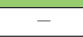 & 18 & 21 \\
\hline$L P H \Lambda$ & 11 & 6 & 14 & 12 & & 17 \\
\hline$L P H N(\mathrm{DT})$ & 10 & 5 & 9 & $y$ & 13 & \\
\hline
\end{tabular}

\begin{tabular}{l||c|c|c|c|c|c}
\hline \hline \multicolumn{7}{c}{ 20 exemplos rotulados por classe } \\
\hline \hline & $k-N \boldsymbol{N}$ & $\begin{array}{c}\text { GNM } \\
\text { (DD) }\end{array}$ & $\begin{array}{c}\text { GNM } \\
\text { (TT) }\end{array}$ & $\begin{array}{c}G N M \\
\text { DT }\end{array}$ & $\begin{array}{c}\boldsymbol{L P H N} \\
\text { (DD) }\end{array}$ & $\begin{array}{c}\boldsymbol{L P H N} \\
\text { (DT) }\end{array}$ \\
\hline$k-\boldsymbol{N} \boldsymbol{N}$ & - & 5 & 15 & 13 & 17 & 19 \\
\hline $\boldsymbol{G N M}$ (DD) & 25 & - & 15 & 17 & 22 & 23 \\
\hline $\boldsymbol{G N M}$ (TT) & 15 & 15 & - & 15 & 16 & 20 \\
\hline $\boldsymbol{G N M}$ (DT) & 16 & 13 & 15 & - & 19 & 19 \\
\hline $\boldsymbol{L P H N}$ (DD) & 13 & 8 & 14 & 11 & - & 14 \\
\hline $\boldsymbol{L P H N}$ (DT) & 11 & 7 & 10 & 11 & 16 & - \\
\hline \hline
\end{tabular}

\begin{tabular}{|c|c|c|c|c|c|c|}
\hline \multicolumn{7}{|c|}{30 exemplos rotulados por classe } \\
\hline & $k-N N$ & $\begin{array}{l}G N M \\
\text { (DD) }\end{array}$ & $\begin{array}{c}\text { GNM } \\
\text { (TT) }\end{array}$ & $\begin{array}{c}G N M \\
\text { DT }\end{array}$ & $\begin{array}{c}L P H N \\
\text { (DD) }\end{array}$ & $\begin{array}{c}P H N \\
\text { (DT) }\end{array}$ \\
\hline$\overline{k-N N}$ & - & $\overline{6} 6$ & 15 & 10 & 14 & 19 \\
\hline$G N M(\mathrm{DD})$ & 24 & - & 16 & 16 & 20 & 23 \\
\hline$G N M(\mathrm{TT})$ & 15 & 14 & - & 14 & 16 & 20 \\
\hline$G N M(\mathrm{DT})$ & 20 & 14 & 16 & - & 18 & 21 \\
\hline LPHN(DD) & 16 & 10 & 14 & 12 & - & 16 \\
\hline LPHN (DT) & 11 & 7 & 10 & 9 & 13 & - \\
\hline
\end{tabular}

\begin{tabular}{|c|c|c|c|c|c|c|}
\hline \multicolumn{7}{|c|}{40 exemplos rotulados por classe } \\
\hline & $k-N N$ & $\begin{array}{l}G N M \\
\text { (DD) }\end{array}$ & $\begin{array}{l}G N M \\
\text { (TT) }\end{array}$ & $\begin{array}{c}G N M \\
\text { DT }\end{array}$ & $\begin{array}{c}L P H N \\
\text { (DD) }\end{array}$ & $\begin{array}{c}L P H N \\
\text { (DT) }\end{array}$ \\
\hline$k-N N$ & & 13 & 14 & $\overline{12}$ & 14 & $\overline{22}$ \\
\hline$G N M(\mathrm{DD})$ & 17 & - & 16 & 15 & 17 & 23 \\
\hline GNM & 16 & 14 & & 16 & 17 & 22 \\
\hline GNM(1) & 18 & 15 & 14 & & 17 & 25 \\
\hline$L P H N$ & 16 & 13 & 13 & 13 & & 19 \\
\hline$L P H N(\mathrm{DT})$ & 8 & 7 & 8 & 5 & 11 & \\
\hline
\end{tabular}

\begin{tabular}{|c|c|c|c|c|c|c|}
\hline \multicolumn{7}{|c|}{50 exemplos rotulados por classe } \\
\hline & $k-N N$ & $\begin{array}{l}\text { GNM } \\
\text { (DD) }\end{array}$ & $\begin{array}{l}\text { GNM } \\
\text { (TT) }\end{array}$ & $\begin{array}{c}\text { GNM } \\
\text { DT }\end{array}$ & $\begin{array}{c}L P H N \\
\text { (DD) }\end{array}$ & $\begin{array}{c}L P H N \\
\text { (DT) }\end{array}$ \\
\hline$k-N N$ & - & 14 & 14 & 14 & 15 & 22 \\
\hline GNM(DD) & 16 & - & 15 & 14 & 16 & 22 \\
\hline$G N M(\mathrm{TT})$ & 16 & 15 & - & 15 & 16 & 23 \\
\hline$G N M(\mathrm{DT})$ & 15 & 16 & 15 & - & 15 & 22 \\
\hline$L P H N(\mathrm{DD})$ & 15 & 14 & 14 & 15 & - & 22 \\
\hline$L P H N(\mathrm{DT})$ & 8 & 8 & 7 & 8 & 7 & - \\
\hline
\end{tabular}

compostas por relações simples. 


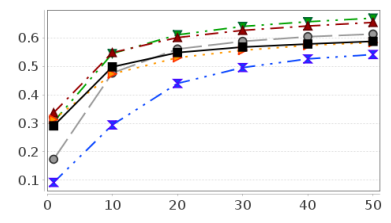

(a) Ohscal

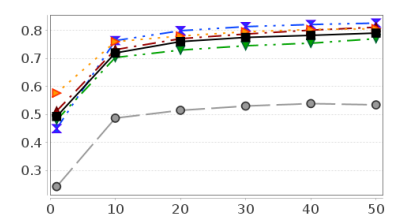

(e) $\operatorname{Re} 8$

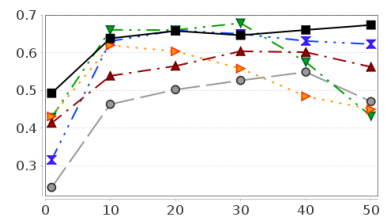

(i) $\operatorname{Tr} 12$

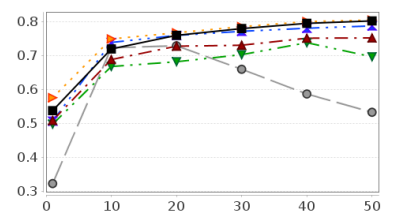

(m) $\operatorname{Tr} 41$

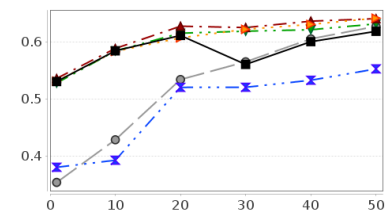

(b) Polarity

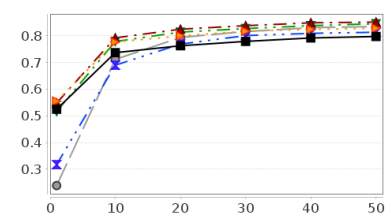

(f) Reviews

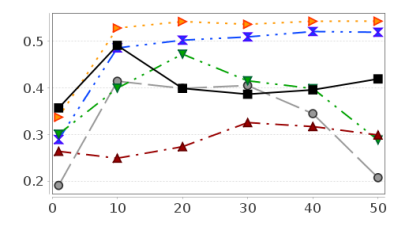

(j) $\operatorname{Tr} 21$

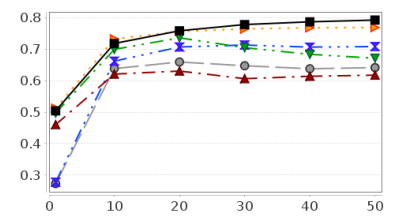

(n) $\operatorname{Tr} 45$

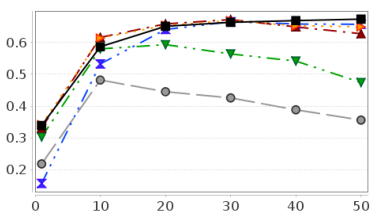

(c) $\operatorname{Re} 0$

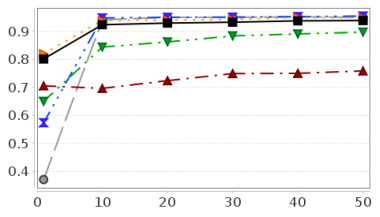

(g) SyskillWebert

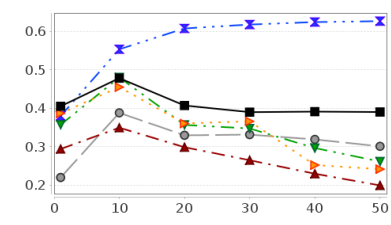

(k) $\operatorname{Tr} 23$

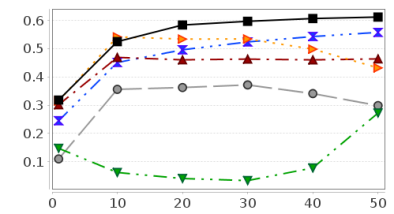

(o) Wap

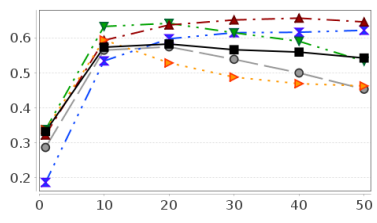

(d) Re1

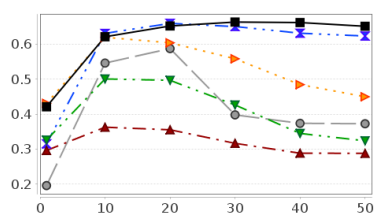

(h) $\operatorname{Tr} 11$

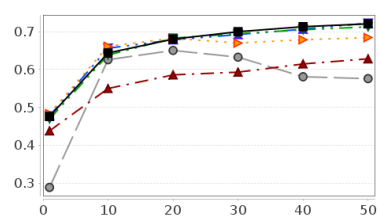

(1) $\operatorname{Tr} 31$

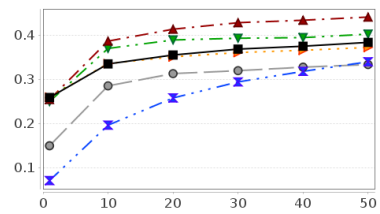

(p) WebKB

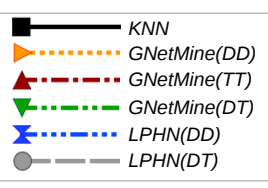

(q) Legenda

Figura 5.11: Valores $F 1^{\text {Macro }}$ do $2^{\circ}$ grupo de experimentos (parte II).

Nas Figuras 5.14 e 5.15 são apresentados os gráficos de performance de classificação considerando a medida $F 1^{\text {Micro }}$ e nas Figuras 5.16 e 5.17 são apresentados os gráficos de performance de classificação considerando a medida $F 1^{\text {Macro }}$ para o terceiro grupo de experimentos. Pode-se observar que, em geral, o algoritmo $I M H N^{\mathrm{R}}$ foi superado pelos algoritmos $T C H N(\mathrm{DT})$ e $T C H N(\mathrm{DT}-\mathrm{TT})$. Esses dois últimos apresentam performances de classificação parecidas. Entretanto, pode-se notar uma melhora na performance de classificação quando utilizadas redes DT-TT em relação as redes DT.

Para elucidar a comparação das performances de classificação dos diferentes algoritmos do terceiro grupo de experimentos, nas Tabelas 5.5 e 5.6 é apresentado o número de vitórias dos algoritmos considerando as medidas $F 1^{\text {Micro }}$ e $F 1^{\text {Macro }}$ respectivamente. Podese observar que, em geral, as redes DT-TT provêm maiores performance de classificação que as redes DT na indução semissupervisionado. Tanto o TCHN(DT-TT) quanto o $T C H N(\mathrm{DT})$ superaram o $I M H N^{\mathrm{R}}(\mathrm{DT})$. Exceção se dá apenas para a medida $F 1^{\text {Macro }}$ 
Tabela 5.4: Número de vitórias dos algoritmos indicados na linha em comparação com os algoritmos indicados na coluna para o segundo grupo de experimentos considerando a medida $F 1^{\text {Macro }}$.

\begin{tabular}{|c|c|c|c|c|c|c|}
\hline \multicolumn{7}{|c|}{1 exemplo rotulado por classe } \\
\hline & $k-N N$ & $\begin{array}{l}G N M \\
\text { (DD) }\end{array}$ & $\begin{array}{c}G N M \\
\text { (TT) }\end{array}$ & $\begin{array}{c}G N M \\
\text { DT }\end{array}$ & $\begin{array}{c}L P H N \\
\text { (DD) }\end{array}$ & $\begin{array}{c}L P H N \\
\text { (DT) }\end{array}$ \\
\hline$k-N N$ & - & 6 & 17 & 18 & 29 & 30 \\
\hline$G N M(\mathrm{DD})$ & 24 & - & 23 & 26 & 30 & 30 \\
\hline$G N M(\mathrm{TT})$ & 13 & 7 & - & 17 & 26 & 29 \\
\hline$G N M(\mathrm{DT})$ & 12 & 4 & 13 & - & 26 & 29 \\
\hline $\operatorname{LPHN}(\mathrm{DD})$ & 1 & 0 & 4 & 4 & - & 17 \\
\hline$L P H N(\mathrm{DT})$ & 0 & 0 & 1 & 1 & 13 & - \\
\hline
\end{tabular}

\begin{tabular}{|c|c|c|c|c|c|c|}
\hline \multicolumn{7}{|c|}{10 exemplos rotulados por classe } \\
\hline & $k-N N$ & $\begin{array}{l}\text { GNM } \\
\text { (DD) }\end{array}$ & $\begin{array}{c}\text { GNM } \\
(\mathrm{TT})\end{array}$ & $\begin{array}{c}G N M \\
\text { DT }\end{array}$ & $\begin{array}{c}P H N \\
\text { (DD) }\end{array}$ & $\begin{array}{c}\mathrm{LPHN} \\
\text { (DT) }\end{array}$ \\
\hline$k-N N$ & $\overline{-1}$ & 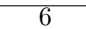 & 13 & 12 & 20 & 22 \\
\hline$G N M(\mathrm{DD})$ & 24 & - & 15 & 14 & 24 & 23 \\
\hline GNM (TT) & 17 & 15 & - & 11 & 17 & 19 \\
\hline$G N M(\mathrm{DT})$ & 18 & 16 & 19 & - & 20 & 23 \\
\hline LPHN(DD) & 10 & 6 & 13 & 10 & - & 17 \\
\hline LPHN(DT) & 8 & 7 & 11 & 7 & 13 & - \\
\hline
\end{tabular}

\begin{tabular}{|c|c|c|c|c|c|c|}
\hline \multicolumn{7}{|c|}{20 exemplos rotulados por classe } \\
\hline & $k-N N$ & $\begin{array}{l}G N M \\
\text { (DD) }\end{array}$ & $\begin{array}{c}G N M \\
(\mathrm{TT})\end{array}$ & $\begin{array}{c}G N M \\
\text { DT }\end{array}$ & $\begin{array}{c}\angle P H N \\
\text { (DD) }\end{array}$ & $\begin{array}{c}L P H N \\
\text { (DT) }\end{array}$ \\
\hline$\overline{k-N N}$ & - & 11 & 13 & 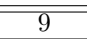 & 16 & 19 \\
\hline$G N M(\mathrm{DD})$ & 19 & - & 15 & 12 & 22 & 24 \\
\hline$G N M(\mathrm{TT})$ & 17 & 15 & - & 11 & 16 & 19 \\
\hline$G N M(\mathrm{DT})$ & 21 & 18 & 19 & - & 20 & 25 \\
\hline LPHN (DD) & 14 & 8 & 14 & 10 & - & 17 \\
\hline $\operatorname{LPHN}(\mathrm{DT})$ & 10 & 6 & 11 & 5 & 13 & - \\
\hline
\end{tabular}

\begin{tabular}{|c|c|c|c|c|c|c|}
\hline \multicolumn{7}{|c|}{30 exemplos rotulados por classe } \\
\hline & $k-N N$ & $\begin{array}{l}G N M \\
\text { (DD) }\end{array}$ & $\begin{array}{c}G N M \\
\text { (TT) }\end{array}$ & $\begin{array}{c}\text { GNM } \\
\text { DT }\end{array}$ & $\begin{array}{c}P H N \\
\text { (DD) }\end{array}$ & $\begin{array}{c}L P H N \\
\text { (DT) }\end{array}$ \\
\hline$k-N N$ & 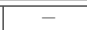 & 10 & 13 & 10 & 15 & 18 \\
\hline GNM(DD) & 20 & - & 14 & 13 & 20 & 25 \\
\hline GNM(TT) & 17 & 16 & - & 12 & 16 & 22 \\
\hline GNM(DT) & 20 & 17 & 18 & - & 18 & 27 \\
\hline LPHN(DD) & 15 & 10 & 14 & 12 & - & 18 \\
\hline LPHN(DT) & 12 & 5 & 8 & 3 & 12 & - \\
\hline
\end{tabular}

\begin{tabular}{|c|c|c|c|c|c|c|}
\hline \multicolumn{7}{|c|}{40 exemplos rotulados por classe } \\
\hline & $k-N N$ & $\begin{array}{l}\text { GNM } \\
\text { (DD) }\end{array}$ & $\begin{array}{c}G N M \\
\text { (TT) }\end{array}$ & $\begin{array}{c}G N M \\
\text { DT }\end{array}$ & $\begin{array}{c}L P H N \\
\text { (DD) }\end{array}$ & $\begin{array}{c}P P H N \\
\text { (DT) }\end{array}$ \\
\hline$k-N N$ & 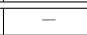 & 12 & 14 & 11 & 17 & 21 \\
\hline$G N M(\mathrm{DD})$ & 18 & - & 15 & 11 & 18 & 23 \\
\hline$G N M(\mathrm{TT})$ & 16 & 15 & - & 15 & 15 & 23 \\
\hline$G N M(\mathrm{DT})$ & 19 & 19 & 15 & - & 16 & 26 \\
\hline $\operatorname{LPHN}(\mathrm{DD})$ & 13 & 12 & 15 & 14 & - & 18 \\
\hline$L P H N(\mathrm{DT})$ & 9 & 7 & 7 & 4 & 12 & - \\
\hline
\end{tabular}

\begin{tabular}{|c|c|c|c|c|c|c|}
\hline \multicolumn{7}{|c|}{50 exemplos rotulados por classe } \\
\hline & $k-N N$ & $\begin{array}{l}G N M \\
\text { (DD) }\end{array}$ & $\begin{array}{l}\text { GNM } \\
\text { (TT) }\end{array}$ & $\begin{array}{c}\text { GNM } \\
\text { DT }\end{array}$ & $\begin{array}{c}\begin{array}{c}\text { LPHN } \\
\text { (DD) }\end{array} \\
\end{array}$ & $\begin{array}{c}P H N \\
\text { (DT) }\end{array}$ \\
\hline$k-N N$ & $\overline{-1}$ & 12 & 14 & 14 & 16 & 20 \\
\hline$G N M(\mathrm{DD})$ & 18 & - & 14 & 13 & 17 & 23 \\
\hline$G N M(\mathrm{TT})$ & 16 & 16 & - & 16 & 15 & 24 \\
\hline$G N M(\mathrm{DT})$ & 16 & 17 & 14 & - & 15 & 25 \\
\hline$L P H N(D D)$ & 14 & 13 & 15 & 15 & - & 20 \\
\hline$L P H N(\mathrm{DT})$ & 10 & 7 & 6 & 5 & 10 & - \\
\hline
\end{tabular}

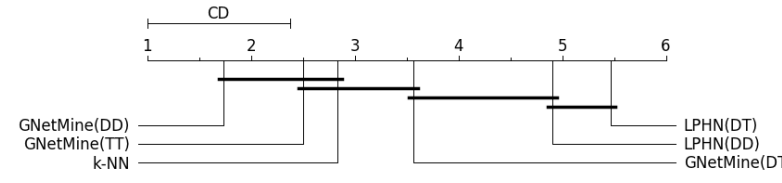

(a) 1 exemplo rotulado por classe.

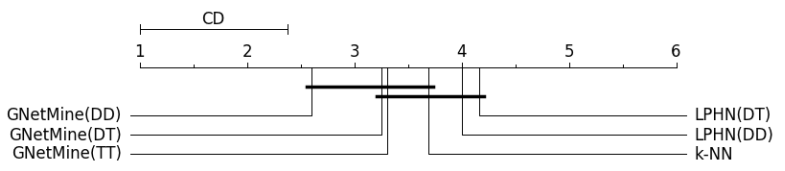

(c) 20 exemplos rotulados por classe.

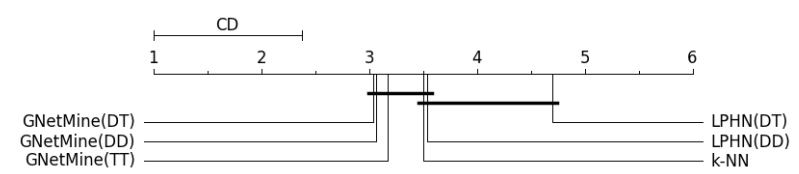

(e) 40 exemplos rotulados por classe.

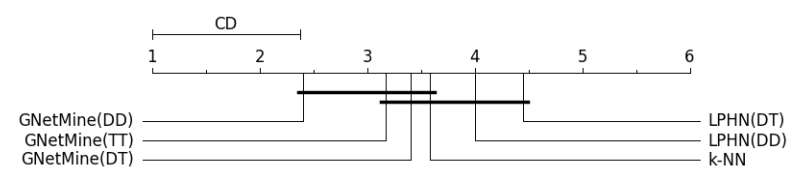

(b) 10 exemplos rotulados por classe.

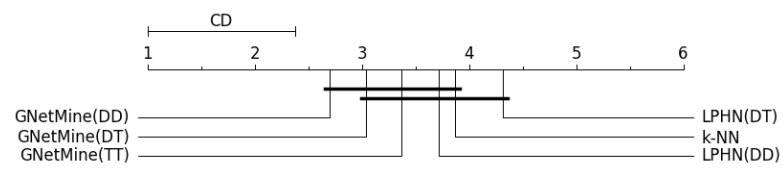

(d) 30 exemplos rotulados por classe.

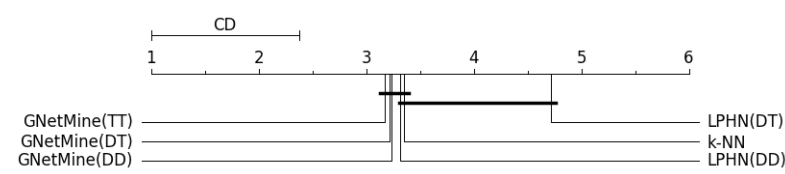

(f) 50 exemplos rotulados por classe.

Figura 5.12: Diagramas de diferença crítica para o segundo grupo de experimentos considerando a medida $F 1^{\text {Micro }}$.

quando utilizado um único exemplo rotulado por classe, na qual $I M H N^{\mathrm{R}}(\mathrm{DT})$ superou o $T C H N(\mathrm{DT}-\mathrm{TT})$ e $T C H N(\mathrm{DT})$, e o $T C H N(\mathrm{DT})$ superou o TCHN(DT-TT). Porém, vale ressaltar que a utilização de um único documento por classe provê uma performance de classificação muito inferior às performances obtidas utilizando 10 ou mais documentos rotulados por classe.

De acordo com as tabelas de vitória, pode-se comprovar que de fato a utilização de documentos não rotulados na indução de um modelo de classificação é capaz de melhorar a performance de classificação obtida pelo mesmo. Também pode-se observar que o uso de 


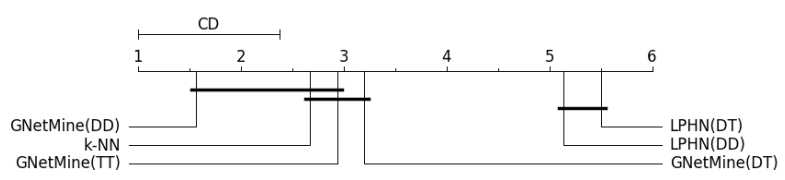

(a) 1 exemplo rotulado por classe.

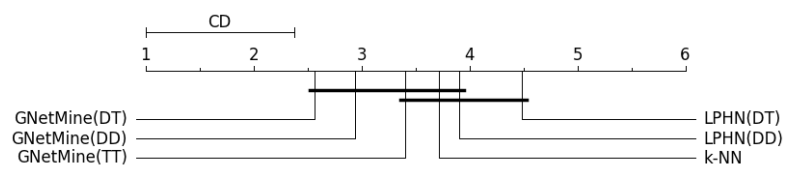

(c) 20 exemplos rotulados por classe.

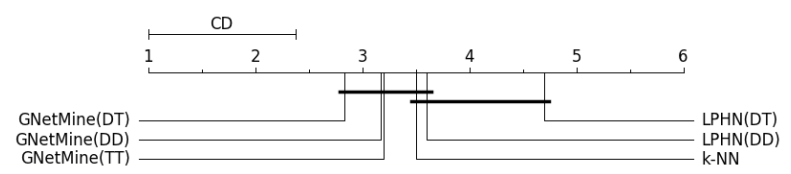

(e) 40 exemplos rotulados por classe.

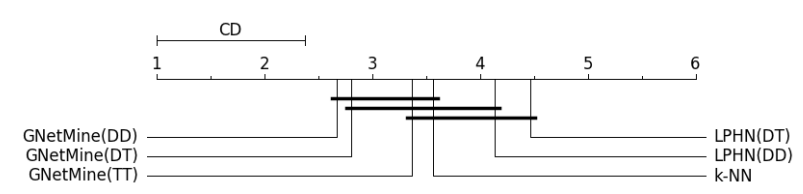

(b) 10 exemplos rotulados por classe.

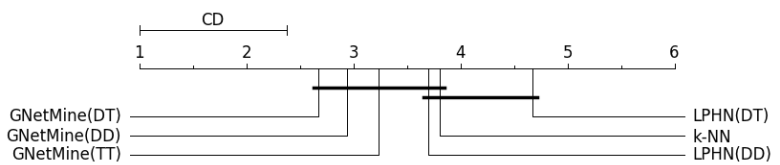

(d) 30 exemplos rotulados por classe.

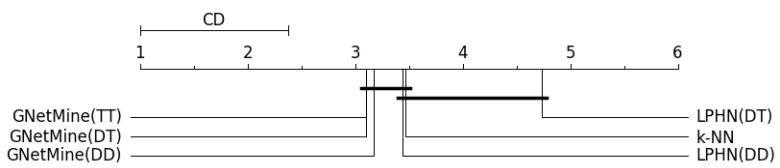

(f) 50 exemplos rotulados por classe.

Figura 5.13: Diagramas de diferença crítica para o segundo grupo de experimentos considerando a medida F1 $1^{\text {Macro }}$.

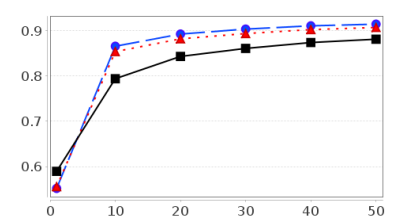

(a) Classic4

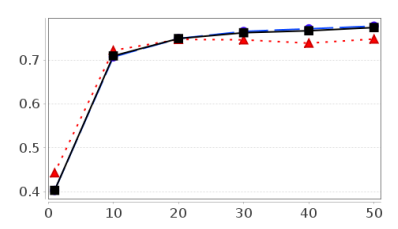

(e) FBIS

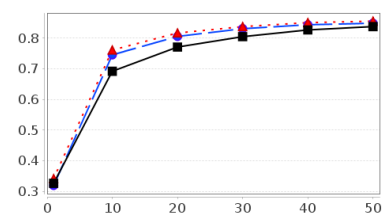

(i) La2s

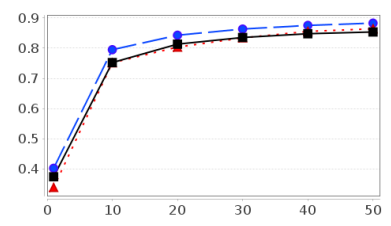

(m) Oh5

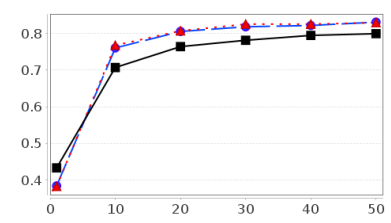

(b) CSTR

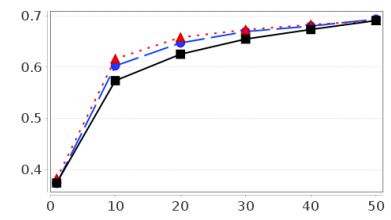

(f) Hitech

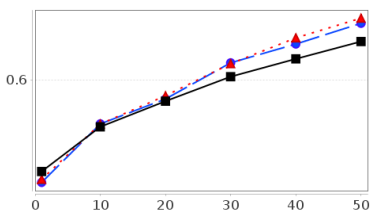

(j) Multi_Dom_Sentiment

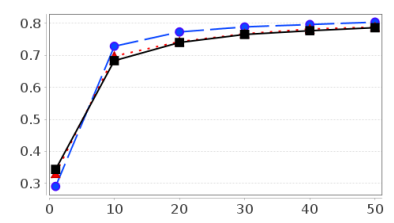

(n) Oh10

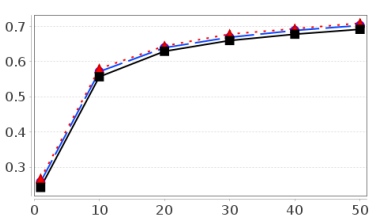

(c) Dmoz_Health_500

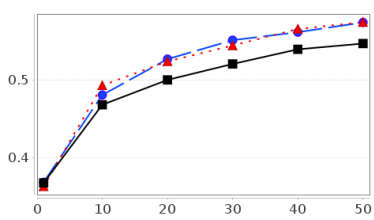

(g) IrishSentiment

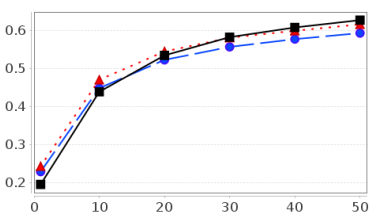

(k) NFS

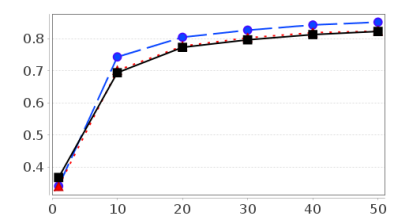

(o) Oh15

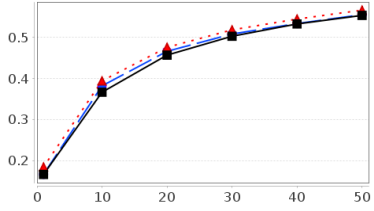

(d) Dmoz_Science_500

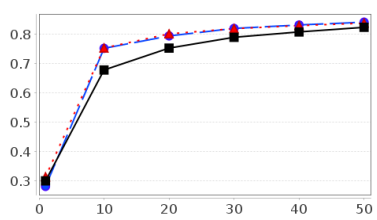

(h) La1s

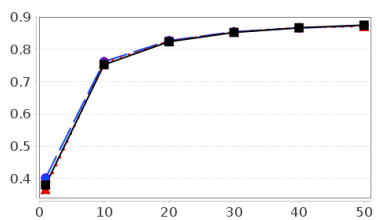

(l) $\mathrm{Oh} 0$

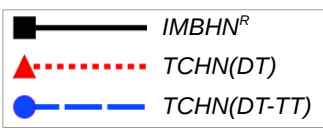

(p) Legenda

Figura 5.14: Valores $F 1^{\text {Micro }}$ do $3^{\circ}$ grupo de experimentos (parte I).

redes compostas por mais de um tipo de relação, no caso a rede DT-TT, proveu melhores performances de classificação em relação à utilização de redes compostas por relações simples, no caso a rede DT. Isso dá indícios que assim como no aprendizado transdutivo, 


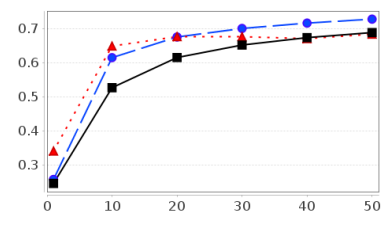

(a) Ohscal

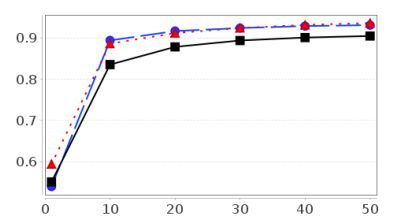

(e) $\operatorname{Re} 8$

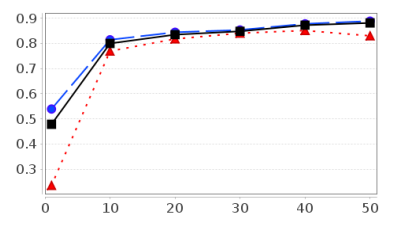

(i) $\operatorname{Tr} 12$

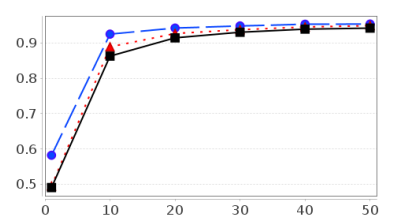

(m) $\operatorname{Tr} 41$

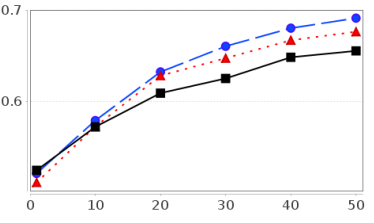

(b) Polarity

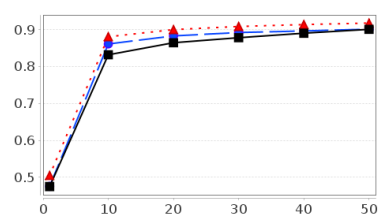

(f) Reviews

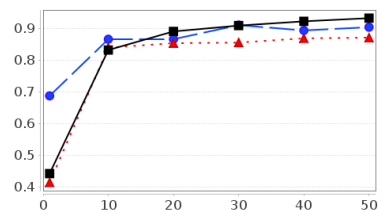

(j) $\operatorname{Tr} 21$

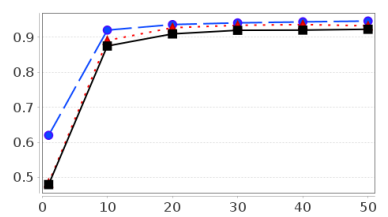

(n) $\operatorname{Tr} 45$

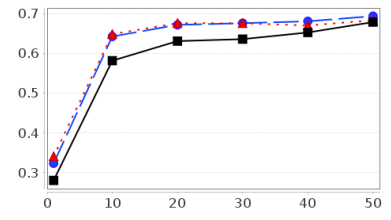

(c) $\mathrm{Re} 0$

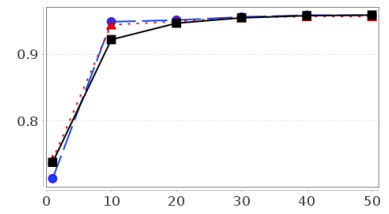

(g) SyskillWebert

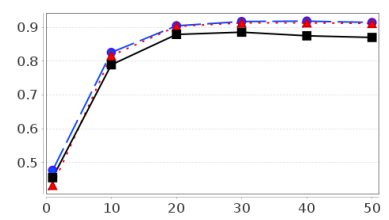

(k) $\operatorname{Tr} 23$

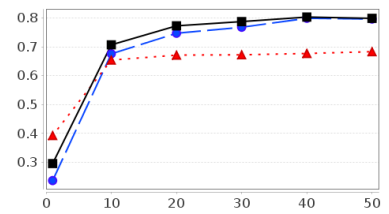

(o) Wap

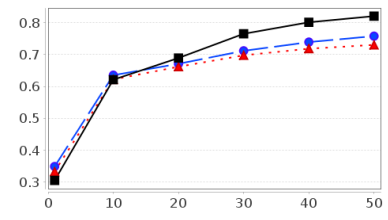

(d) Re1

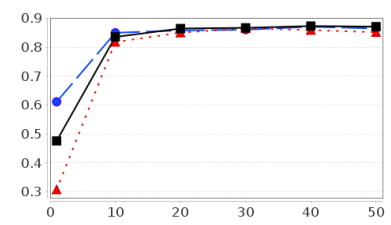

(h) $\operatorname{Tr} 11$

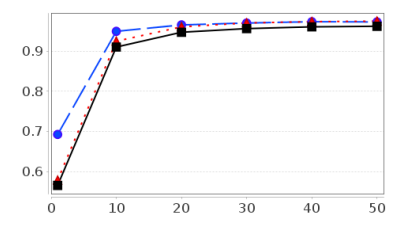

(1) $\operatorname{Tr} 31$

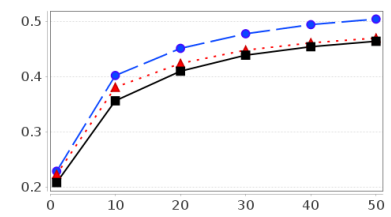

(p) WebKB

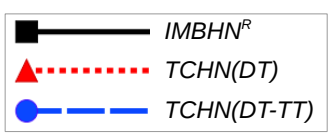

(q) Legenda

Figura 5.15: Valores $F 1^{\text {Micro }}$ do $3^{\circ}$ grupo de experimentos (parte II).

o uso de redes compostas por mais de um tipo de relação pode aumentar a performance de classificação de textos utilizando aprendizado indutivo semissupervisionado.

Tabela 5.5: Número de vitórias dos algoritmos indicados na linha em comparação com os algoritmos indicados na coluna para o terceiro grupo de experimentos considerando a medida $F 1^{\text {Micro }}$.

\begin{tabular}{|c|c|c|c|c|c|c|c|c|c|c|c|}
\hline \multicolumn{4}{|c|}{1 exemplo rotulado por classe } & \multicolumn{4}{|c|}{10 exemplos rotulados por classe } & \multicolumn{4}{|c|}{20 exemplos rotulados por classe } \\
\hline & $\begin{array}{c}I M H N^{R} \\
(\mathrm{DT})\end{array}$ & $\begin{array}{c}T C H N \\
\text { (DT) }\end{array}$ & $\begin{array}{c}T C H N \\
(\mathrm{DT}-\mathrm{TT})\end{array}$ & & $\begin{array}{c}I M H N^{R} \\
(\mathrm{DT})\end{array}$ & $\begin{array}{c}T C H N \\
\text { (DT) }\end{array}$ & $\begin{array}{c}T C H N \\
(\mathrm{DT}-\mathrm{TT})\end{array}$ & & $\begin{array}{c}I M H N^{R} \\
(\mathrm{DT})\end{array}$ & $\begin{array}{c}\text { TCHN } \\
\text { (DT) }\end{array}$ & $\begin{array}{c}T C H N \\
\text { (DT-TT) }\end{array}$ \\
\hline$\overline{I M H N^{R}(\mathrm{DT})}$ & - & 13 & 13 & $\overline{I M H N^{R}(\mathrm{DT})}$ & - & $\overline{4}$ & 2 & $\overline{I M H N^{R}(\mathrm{DT})}$ & - & 7 & 5 \\
\hline TCHN(DT) & 17 & - & 15 & $T C H N(\mathrm{DT})$ & 26 & - & 11 & $T C H N(\mathrm{DT})$ & 23 & - & 10 \\
\hline$T C H N(\mathrm{DT}-\mathrm{TT})$ & 17 & 15 & - & TCHN(DT-TT) & 28 & 19 & - & TCHN(DT-TT) & 24 & 20 & - \\
\hline \multicolumn{4}{|c|}{30 exemplos rotulados por classe } & \multicolumn{4}{|c|}{40 exemplos rotulados por classe } & \multicolumn{4}{|c|}{50 exemplos rotulados por classe } \\
\hline & $\begin{array}{c}I M H N^{R} \\
(\mathrm{DT})\end{array}$ & $\begin{array}{c}T C H N \\
(\mathrm{DT})\end{array}$ & $\begin{array}{c}T C H N \\
(\mathrm{DT}-\mathrm{TT})\end{array}$ & & $\begin{array}{c}I M H N^{R} \\
(\mathrm{DT})\end{array}$ & $\begin{array}{c}T C H N \\
\text { (DT) }\end{array}$ & $\begin{array}{c}T C H N \\
(\mathrm{DT}-\mathrm{TT})\end{array}$ & & $\begin{array}{c}I M H N^{R} \\
(\mathrm{DT})\end{array}$ & $\begin{array}{c}\text { TCHN } \\
\text { (DT) }\end{array}$ & $\begin{array}{c}T C H N \\
\text { (DT-TT) }\end{array}$ \\
\hline$I M H N^{R}(\mathrm{DT})$ & $2-$ & 8 & 4 & $\overline{I M H N^{R}(\mathrm{DT})}$ & $2-$ & 9 & 6 & $\overline{I M H N^{R}(\mathrm{DT})}$ & ב- & $\overline{10}$ & 7 \\
\hline$T C H N(\mathrm{DT})$ & 22 & - & 9 & $T C H N(\mathrm{DT})$ & 21 & - & 11 & $T C H N(\mathrm{DT})$ & 19 & - & 8 \\
\hline$T C H N(\mathrm{DT}-\mathrm{TT})$ & 26 & 21 & - & TCHN(DT-TT) & 24 & 19 & - & $T C H N(\mathrm{DT}-\mathrm{TT})$ & 23 & 22 & - \\
\hline
\end{tabular}

Nas Figuras 5.18 e 5.19 são apresentados os diagramas de diferença crítica considerando os resultados do terceiro grupo de experimentos para as medidas $F 1^{\text {Micro }}$ e $F 1^{\text {Macro }}$ respectivamente. Pode-se observar que TCHN(DT-TT) e TCHN(DT) sempre obtém a 


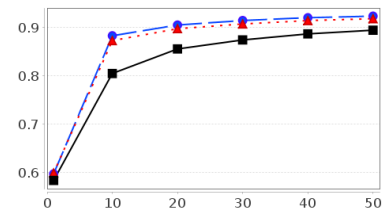

(a) Classic4

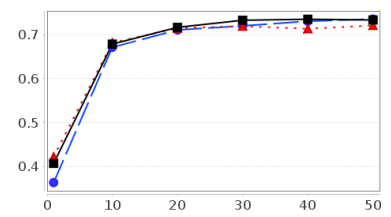

(e) FBIS

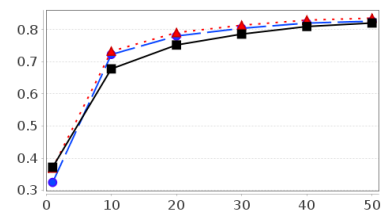

(i) La2s

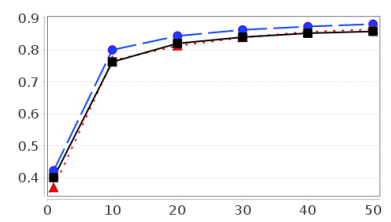

(m) Oh5

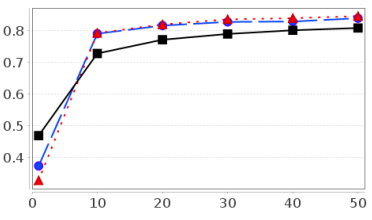

(b) CSTR

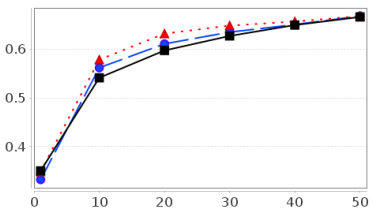

(f) Hitech

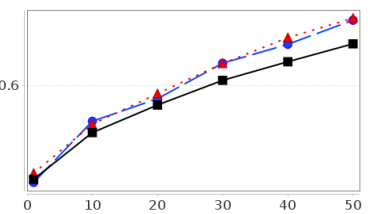

(j) Multi_Dom_Sentiment

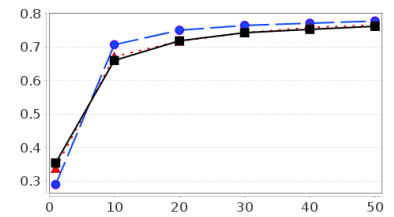

(n) Oh10

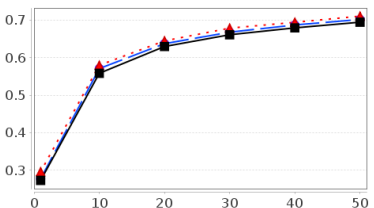

(c) Dmoz_Health_500

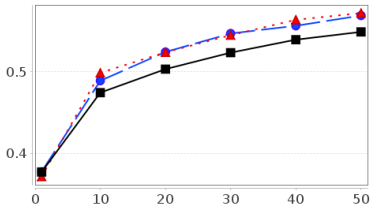

(g) IrishSentiment

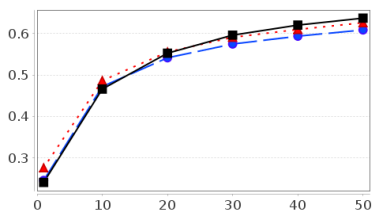

(k) NFS

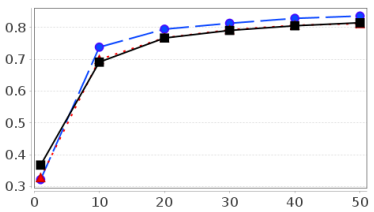

(o) Oh15

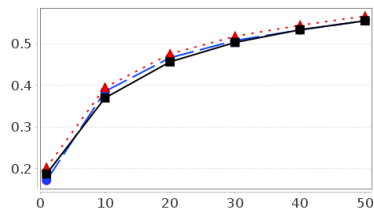

(d) Dmoz_Science_500

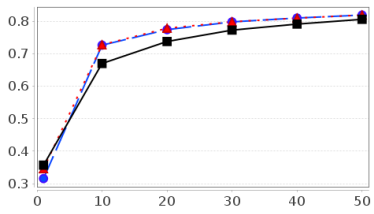

(h) La1s

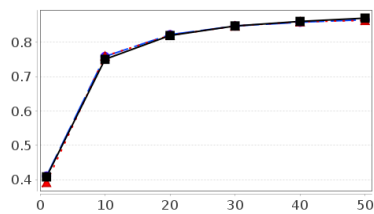

(l) $\mathrm{Oh} 0$

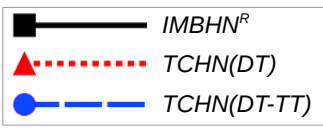

(p) Legenda

Figura 5.16: Valores $F 1^{\text {Macro }}$ do $3^{\circ}$ grupo de experimentos (parte I).

Tabela 5.6: Número de vitórias dos algoritmos indicados na linha em comparação com os algoritmos indicados na coluna para o terceiro grupo de experimentos considerando a medida $F 1^{\text {Macro }}$.

\begin{tabular}{l||c|c|c}
\hline \hline \multicolumn{4}{c}{ 1 exemplo rotulado por classe } \\
\hline \hline & $\begin{array}{c}\text { IMHN } \\
(\mathrm{DT})\end{array}$ & $\begin{array}{c}\boldsymbol{T C H N} \\
\text { (DT) }\end{array}$ & $\begin{array}{c}\text { TCHN } \\
(\mathrm{DT}-\mathrm{TT})\end{array}$ \\
\hline \hline $\boldsymbol{I M H N ^ { R } ( \mathrm { DT } )}$ & - & 17 & 15 \\
\hline $\boldsymbol{T C H N}(\mathrm{DT})$ & 13 & - & 20 \\
\hline $\boldsymbol{T C H N}$ (DT-TT) & 15 & 10 & - \\
\hline \hline
\end{tabular}

\begin{tabular}{|c|c|c|c|}
\hline \multicolumn{4}{|c|}{10 exemplos rotulados por classe } \\
\hline & $\begin{array}{c}I M H N^{R} \\
(\mathrm{DT})\end{array}$ & $\begin{array}{c}T C H N \\
\text { (DT) }\end{array}$ & $\begin{array}{c}\text { TCHN } \\
\text { (DT-TT) }\end{array}$ \\
\hline$I M H N^{R}(\mathrm{DT})$ & $\overline{-1}$ & 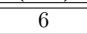 & 3 \\
\hline$T C H N(\mathrm{DT})$ & 24 & - & 12 \\
\hline$T C H N(\mathrm{DT}-\mathrm{TT})$ & 27 & 18 & 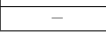 \\
\hline
\end{tabular}

\begin{tabular}{|c|c|c|c|}
\hline \multicolumn{4}{|c|}{20 exemplos rotulados por classe } \\
\hline & $\begin{array}{c}I M H N^{R} \\
(\mathrm{DT})\end{array}$ & $\begin{array}{c}\text { TCHN } \\
\text { (DT) }\end{array}$ & $\begin{array}{c}T C H N \\
\text { (DT-TT) }\end{array}$ \\
\hline$I M H N^{R}(\mathrm{DT})$ & - & $\overline{8}$ & 5 \\
\hline$T C H N(\mathrm{DT})$ & 22 & - & 11 \\
\hline$T C H N(\mathrm{DT}-\mathrm{TT})$ & 25 & 19 & - \\
\hline
\end{tabular}

\begin{tabular}{l||c|c|c}
\hline \hline \multicolumn{3}{c}{ 30 exemplos rotulados por classe } \\
\hline \hline & $\begin{array}{c}\text { IMHN } \\
\text { (DT) }\end{array}$ & $\begin{array}{c}\text { TCHN } \\
\text { (DT) }\end{array}$ & $\begin{array}{c}\text { TCHN } \\
\text { (DT-TT) }\end{array}$ \\
\hline \hline $\boldsymbol{I M H N ^ { \boldsymbol { R } } \text { (DT) }}$ & - & 10 & 6 \\
\hline $\boldsymbol{T C H N}$ (DT) & 20 & - & 10 \\
\hline $\boldsymbol{T C H N}$ (DT-TT) & 24 & 20 & - \\
\hline
\end{tabular}

40 exemplos rotulados por classe $\overline{50 \text { exemplos rotulados por classe }}$

\begin{tabular}{|c|c|c|c|c|c|c|c|}
\hline & $\begin{array}{c}M H N^{R} \\
(\mathrm{DT})\end{array}$ & $\begin{array}{c}C H N \\
\text { (DT) }\end{array}$ & $\begin{array}{c}T C H N \\
\text { (DT-TT) }\end{array}$ & & $\begin{array}{c}M M H N^{R} \\
\text { (DT) }\end{array}$ & $\begin{array}{c}T C H N \\
\text { (DT) }\end{array}$ & $\begin{array}{c}T C H N \\
(\text { DT-TT) }\end{array}$ \\
\hline$\overline{I M H N^{R}(\mathrm{DT})}$ & $=$ & $\overline{8} 8$ & $\overline{55}$ & $\overline{I M H N^{R}(\mathrm{DT})}$ & $=$ & 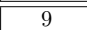 & 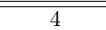 \\
\hline$T C H N(\mathrm{DT})$ & 22 & - & 12 & $T C H N(\mathrm{DT})$ & 21 & - & 12 \\
\hline$T C H N(\mathrm{DT}-\mathrm{TT})$ & 25 & 18 & - & $T C H N(\mathrm{DT}-\mathrm{TT})$ & 26 & 17 & - \\
\hline
\end{tabular}

primeira e segunda posições do ranking respectivamente quando utilizados 10 ou mais exemplos rotulados. O TCHN(DT-TT) apresentou melhores resultados com diferenças estatisticamente significantes para o $\operatorname{IMHN}^{\mathrm{R}}(\mathrm{DT})$ quando utilizados 10 ou mais exemplos rotulados. O TCHN(DT) também apresentou diferenças estatisticamente significantes em relação ao $I M H N^{\mathrm{R}}(\mathrm{DT})$ em várias situações analisadas.

No quarto grupo de experimentos, são comparadas as melhores performances de classificação obtidas (i) pelos algoritmos indutivos supervisionados $\left(M N B, k-N N\right.$ e $\left.I M H N^{\mathrm{R}}(\mathrm{DT})\right)$, (ii) pelos algoritmos semissupervisionados baseados no modelo espaço vetorial ( $M N B$ Se, EM e TSVM), (iii) pelos algoritmos GNetMine (GNetMine(DD), GNetMine(DT) e GNetMine(DT)), (iv) pelos algoritmos $L P H N(L P H N(\mathrm{DD})$ e $L P H N(\mathrm{DT}))$, (v) pelo 


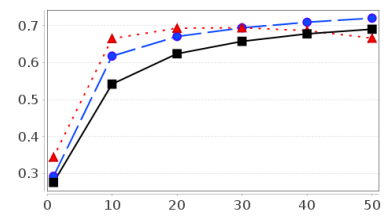

(a) Ohscal

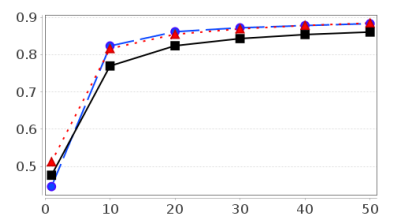

(e) $\operatorname{Re} 8$

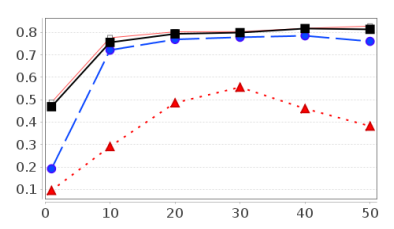

(i) $\operatorname{Tr} 12$

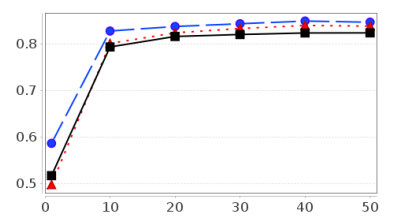

(m) $\operatorname{Tr} 41$

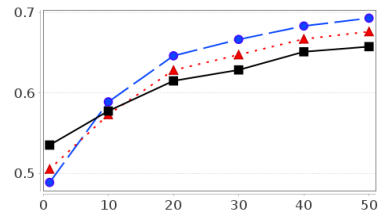

(b) Polarity

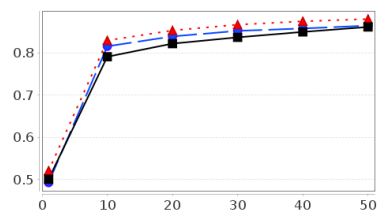

(f) Reviews

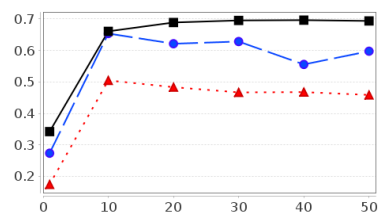

(j) $\operatorname{Tr} 21$

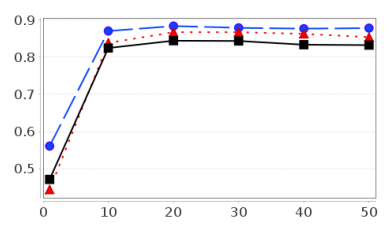

(n) $\operatorname{Tr} 45$

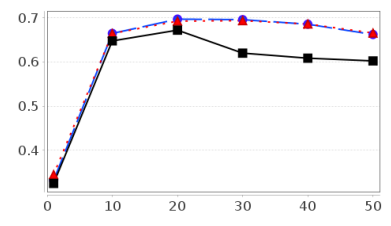

(c) $\operatorname{Re} 0$

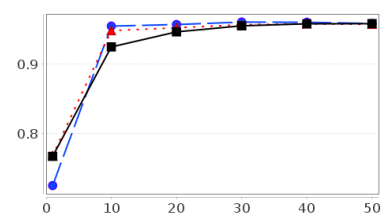

(g) SyskillWebert

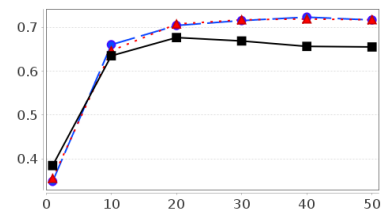

(k) $\operatorname{Tr} 23$

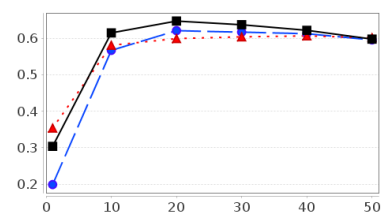

(o) Wap

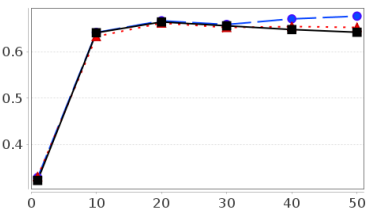

(d) Re1

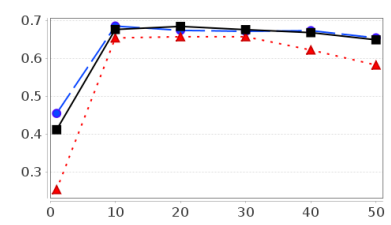

(h) $\operatorname{Tr} 11$

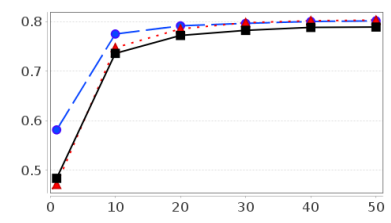

(l) $\operatorname{Tr} 31$

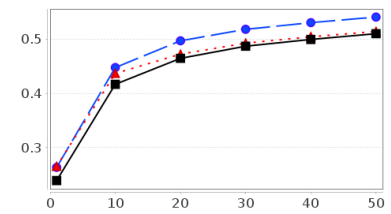

(p) WebKB

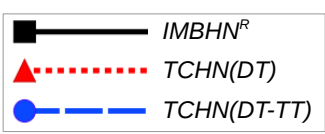

(q) Legenda

Figura 5.17: Valores $F 1^{\text {Macro }}$ do $3^{\circ}$ grupo de experimentos (parte II).

algoritmo $T M$ e (vi) pelo algoritmo $T C H N(\mathrm{DT})$. Vale ressaltar que foram desconsiderados os resultados do TCHN(DT-TT) uma vez que seria uma comparação injusta dado que os demais algoritmos baseados em redes foram aplicados a redes compostas por um único tipo de relação.

Nas Figuras 5.20 e 5.21 são apresentados os gráficos de performance de classificação considerando a medida $F 1^{\text {Micro }}$ e nas Figuras 5.23 e 5.23 são apresentados os gráficos de performance de classificação considerando a medida $F 1^{\text {Macro }}$ para o quarto grupo de experimentos. Pode-se observar que os melhores resultados dos algoritmos indutivos supervisionados são próximos aos melhores resultados dos algoritmos semissupervisionados. Destaca-se que, em geral, os algoritmos $T M$ e $L P H N$ apresentaram resultados inferiores em relação aos demais algoritmos.

Para elucidar a comparação das performances de classificação dos diferentes algoritmos do quarto grupo de experimentos, nas Tabelas 5.7 e 5.8 é apresentado o número de vitórias dos algoritmos considerando as medidas $F 1^{\text {Micro }}$ e $F 1^{\text {Macro }}$ respectivamente. Pode- 


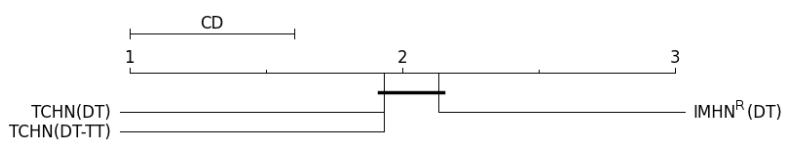

(a) 1 exemplo rotulado por classe.

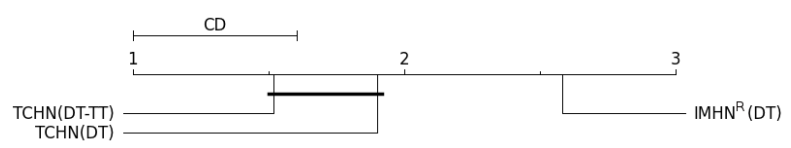

(c) 20 exemplos rotulados por classe.

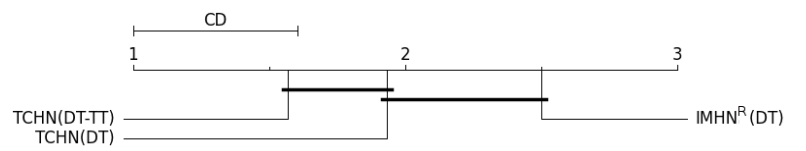

(e) 40 exemplos rotulados por classe.

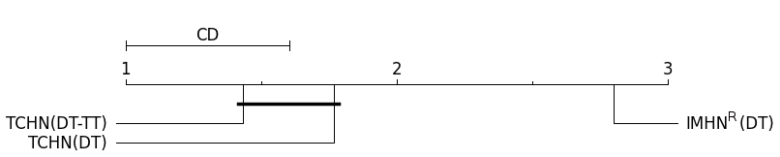

(b) 10 exemplos rotulados por classe.

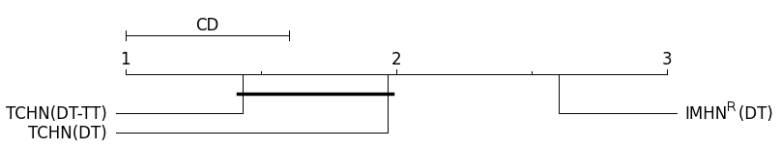

(d) 30 exemplos rotulados por classe.

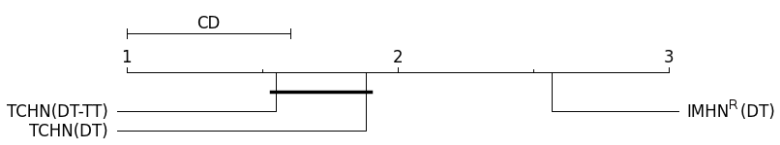

(f) 50 exemplos rotulados por classe.

Figura 5.18: Diagramas de diferença crítica para o terceiro grupo de experimentos considerando a medida $F 1^{\text {Micro }}$.

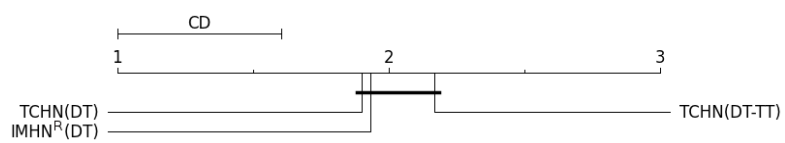

(a) 1 exemplo rotulado por classe.

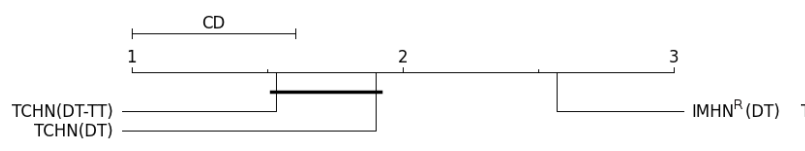

(c) 20 exemplos rotulados por classe.

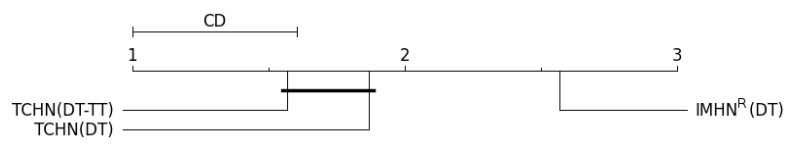

(e) 40 exemplos rotulados por classe.

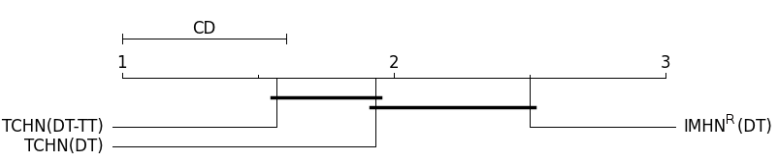

(b) 10 exemplos rotulados por classe.

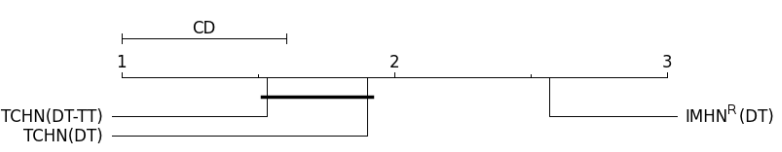

(d) 30 exemplos rotulados por classe.

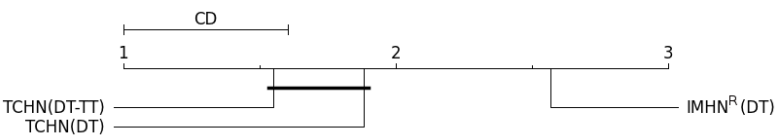

(f) 50 exemplos rotulados por classe.

Figura 5.19: Diagramas de diferença crítica para o terceiro grupo de experimentos considerando a medida $F 1^{\text {Macro }}$.

se observar que o algoritmo GNetMine obtém melhores performances em relação aos demais algoritmos quanto utilizado 1 documento rotulado por casse. De 10 a 40 exemplos rotulados por classe, o algoritmo TCHN obtém as maiores performances de classificação para maioria das coleções. Já ao utilizar 50 documentos rotulados por classe, os algoritmos indutivos supervisionados obtiveram maiores performances para a maioria das coleções em comparação com os demais algoritmos semissupervisionados.

Nas Figuras 5.24 e 5.25 são apresentados os diagramas de diferença crítica considerando os resultados do quarto grupo de experimentos para as medidas $F 1^{\text {Micro }}$ e $F 1^{\text {Macro }}$ respectivamente. Pose-se observar que tanto para a medida $F 1^{\text {Micro }}$ quanto para a medida $F 1^{\text {Macro }}$, o algoritmo GNetMine foi o primeiro colocado no ranking quando considerado 1 documento rotulado por classe. De 10 a 40 exemplos rotulados por classe, o algoritmo $T C H N$ obteve a primeira posição no ranking médio. Já ao utilizar 50 documentos rotulados 


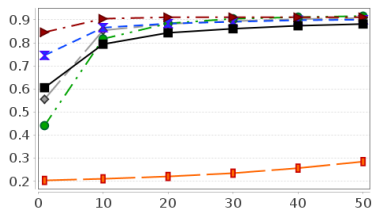

(a) Classic4

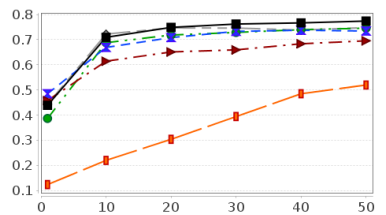

(e) FBIS

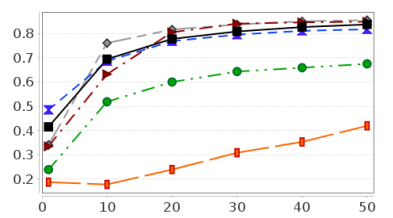

(i) $\mathrm{La} 2 \mathrm{~s}$

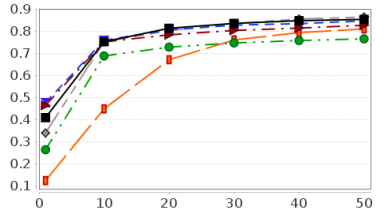

(m) Oh5

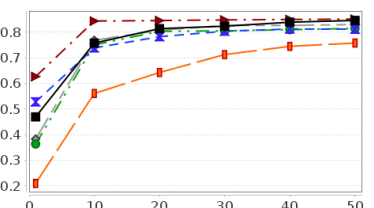

(b) CSTR

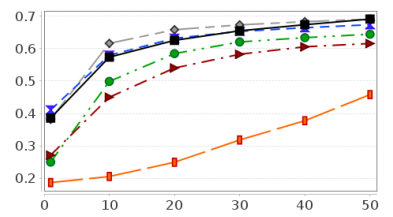

(f) Hitech

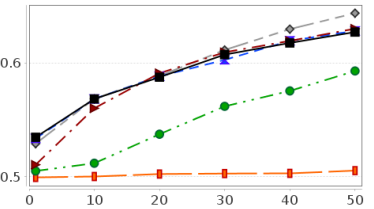

(j) Multi_Dom_Sentiment

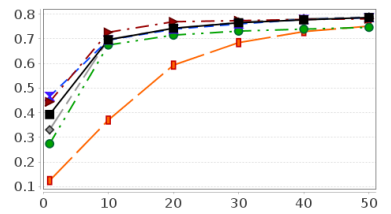

(n) Oh10

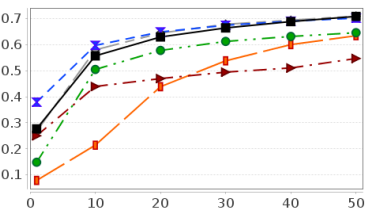

(c) Dmoz_Health_500

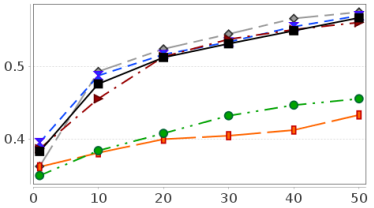

(g) IrishSentiment

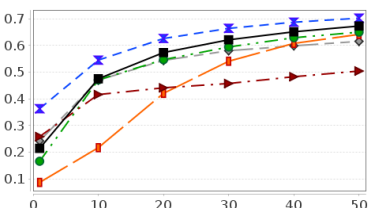

(k) NFS

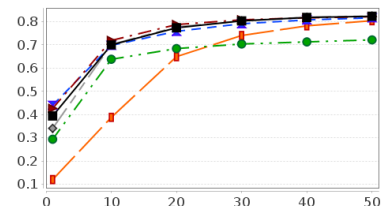

(o) Oh15

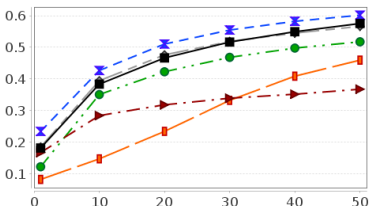

(d) Dmoz_Science_500

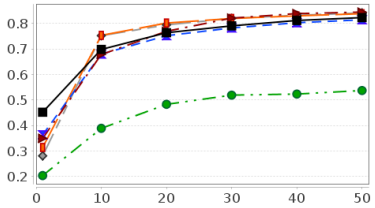

(h) La1s

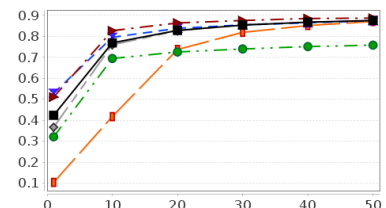

(l) $\mathrm{Oh0}$

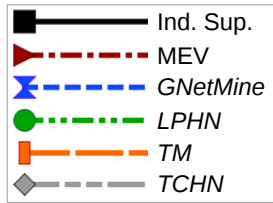

(p) Legenda

Figura 5.20: Valores $F 1^{\text {Micro }}$ do $4^{\mathrm{o}}$ grupo de experimentos (parte I).

Tabela 5.7: Número de vitórias dos algoritmos indicados na linha em comparação com os algoritmos indicados na coluna para o quarto grupo de experimentos considerando a medida $F 1^{\text {Micro. }}$.

\begin{tabular}{l||c|c|c|c|c|c}
\hline \hline \multicolumn{7}{c}{ 1 exemplo rotulado por classe } \\
\hline \hline & Ind. Sup. & MEV & GNetMine & LPHN & $\boldsymbol{T M}$ & $\boldsymbol{T C H N}$ \\
\hline Ind. Sup. & - & 20 & 5 & 28 & 30 & 21 \\
\hline MEV & 10 & - & 2 & 19 & 30 & 14 \\
\hline GNetMine & 25 & 28 & - & 29 & 30 & 27 \\
\hline $\boldsymbol{L P H N}$ & 2 & 11 & 1 & - & 28 & 4 \\
\hline $\boldsymbol{T M}$ & 0 & 0 & 0 & 2 & - & 1 \\
\hline TCHN & 9 & 16 & 3 & 26 & 29 & - \\
\hline \hline
\end{tabular}

\begin{tabular}{l||c|c|c|c|c|c}
\hline \hline \multicolumn{7}{c}{ 10 exemplos rotulados por classe } \\
\hline \hline & Ind. Sup. & MEV & GNetMine & LPHN & TM & TCHN \\
\hline Ind. Sup. & - & 24 & 16 & 26 & 29 & 7 \\
\hline MEV & 6 & - & 6 & 13 & 29 & 6 \\
\hline GNetMine & 13 & 24 & - & 23 & 29 & 6 \\
\hline LPHN & 4 & 17 & 7 & - & 28 & 3 \\
\hline TM & 1 & 1 & 1 & 2 & - & 1 \\
\hline TCHN & 23 & 24 & 24 & 27 & 29 & - \\
\hline \hline
\end{tabular}

\begin{tabular}{l||c|c|c|c|c|c}
\hline \hline \multicolumn{7}{c}{ 20 exemplos rotulados por classe } \\
\hline \hline & Ind. Sup. & MEV & GNetMine & LPHN & TM & TCHN \\
\hline Tnd. Sup. & - & 19 & 21 & 27 & 29 & 12 \\
\hline MEV & 11 & - & 12 & 14 & 28 & 7 \\
\hline GNetMine & 9 & 18 & - & 21 & 29 & 6 \\
\hline LPHN & 3 & 16 & 9 & - & 27 & 6 \\
\hline TM & 1 & 2 & 1 & 3 & - & 1 \\
\hline TCHN & 18 & 23 & 24 & 24 & 29 & - \\
\hline \hline
\end{tabular}

\begin{tabular}{l||c|c|c|c|c|c}
\hline \hline \multicolumn{7}{c}{ 30 exemplos rotulados por classe } \\
\hline \hline & Ind. Sup. & MEV & GNetMine & LPHN & TM & TCHN \\
\hline Ind. Sup. & - & 20 & 24 & 28 & 29 & 11 \\
\hline MEV & 10 & - & 16 & 15 & 27 & 9 \\
\hline GNetMine & 6 & 14 & - & 19 & 29 & 3 \\
\hline LPHN & 2 & 15 & 11 & - & 26 & 5 \\
\hline TM & 1 & 3 & 1 & 4 & - & 0 \\
\hline TCHN & 19 & 21 & 27 & 25 & 30 & - \\
\hline \hline
\end{tabular}

\begin{tabular}{l||c|c|c|c|c|c}
\hline \hline \multicolumn{7}{c}{ 40 exemplos rotulados por classe } \\
\hline \hline & Ind. Sup. & MEV & GNetMine & LPHN & TM & TCHN \\
\hline Tnd. Sup. & - & 22 & 23 & 28 & 29 & 12 \\
\hline MEV & 8 & - & 13 & 14 & 27 & 6 \\
\hline GNetMine & 7 & 17 & - & 21 & 29 & 3 \\
\hline LPHN & 2 & 16 & 9 & - & 26 & 5 \\
\hline TM & 1 & 3 & 1 & 4 & - & 2 \\
\hline TCHN & 18 & 24 & 27 & 25 & 28 & - \\
\hline \hline
\end{tabular}

\begin{tabular}{l||c|c|c|c|c|c}
\hline \hline \multicolumn{7}{c}{ 50 exemplos rotulados por classe } \\
\hline \hline & Ind. Sup. & MEV & GNetMine & LPHN & TM & TCHN \\
\hline Ind. Sup. & - & 24 & 26 & 28 & 29 & 13 \\
\hline MEV & 6 & - & 13 & 15 & 27 & 7 \\
\hline GNetMine & 4 & 17 & - & 19 & 29 & 4 \\
\hline LPHN & 2 & 15 & 11 & - & 25 & 5 \\
\hline TM & 1 & 3 & 1 & 5 & - & 2 \\
\hline TCHN & 16 & 23 & 26 & 25 & 28 & - \\
\hline
\end{tabular}

por classe, o algoritmos indutivos supervisionados obtiveram a primeira posição do ranking médio.

O algoritmo TCHN apresentou melhores resultados com diferenças estatisticamente significantes em relação aos algoritmos semissupervisionados baseados no modelo espaço- 


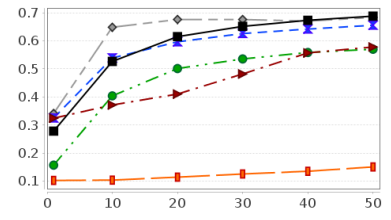

(a) Ohscal

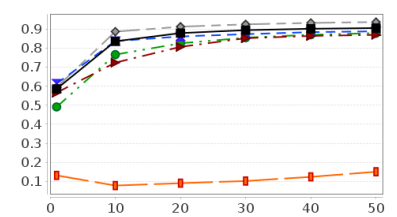

(e) $\operatorname{Re} 8$

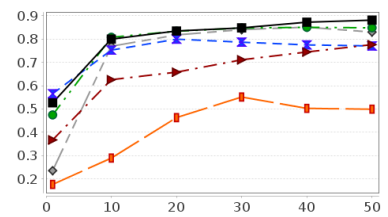

(i) $\operatorname{Tr} 12$

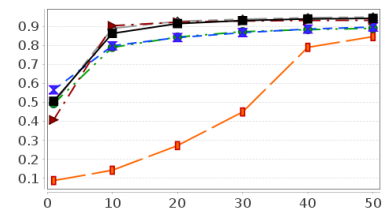

(m) $\operatorname{Tr} 41$

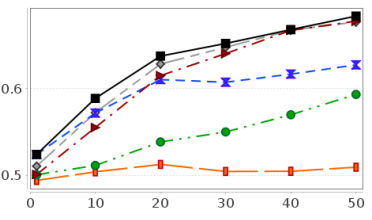

(b) Polarity

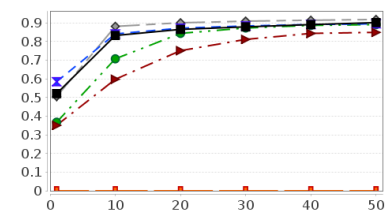

(f) Reviews

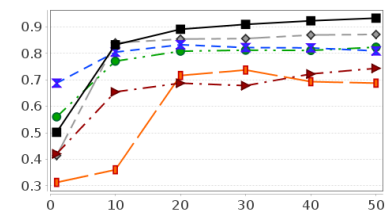

(j) $\operatorname{Tr} 21$

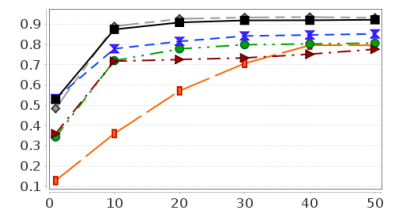

(n) $\operatorname{Tr} 45$

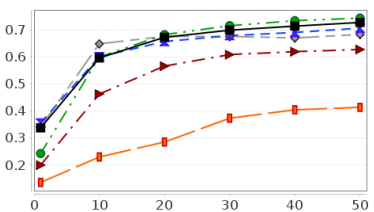

(c) $\operatorname{Re} 0$

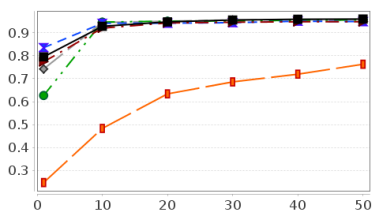

(g) SyskillWebert

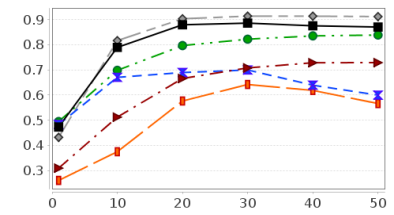

(k) $\operatorname{Tr} 23$

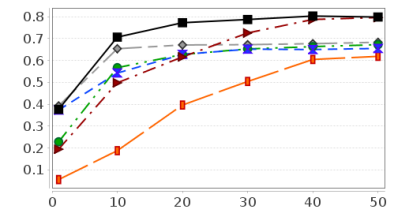

(o) Wap

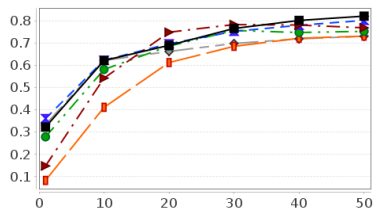

(d) Re1

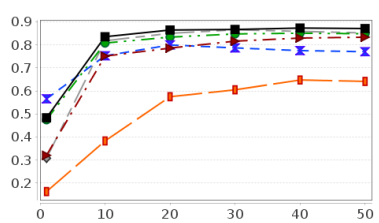

(h) $\operatorname{Tr} 11$

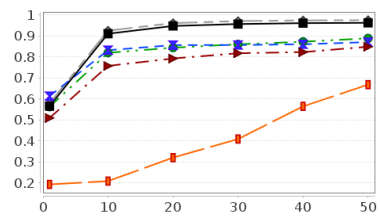

(1) $\operatorname{Tr} 31$

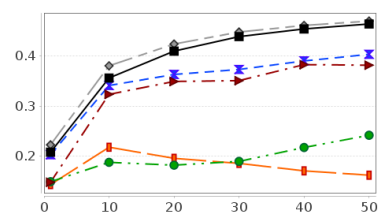

(p) WebKB

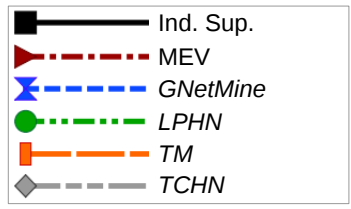

(q) Legenda

Figura 5.21: Valores $F 1^{\text {Micro }}$ do $4^{\mathrm{o}}$ grupo de experimentos (parte II).

vetorial, TM, GM e $L P H N$ para 10 ou mais exemplos rotulados. Pode-se observar também que o algoritmo $T C H N$ apresentou melhores resultados com diferenças estatisticamente significantes em relação ao algoritmo GNetMine para 20 ou mais exemplos rotulados. 


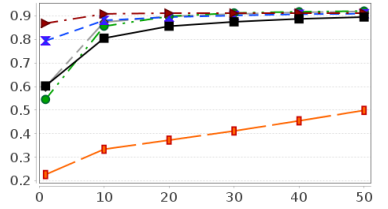

(a) Classic4

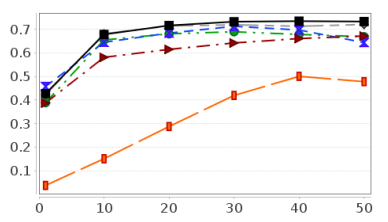

(e) FBIS

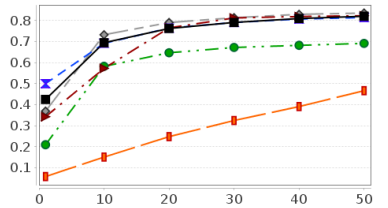

(i) La2s

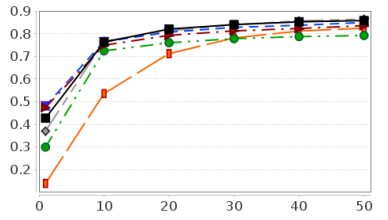

(m) Oh5

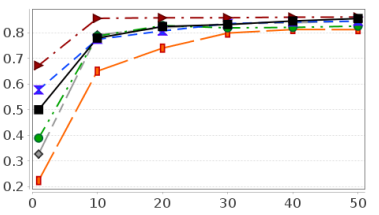

(b) CSTR

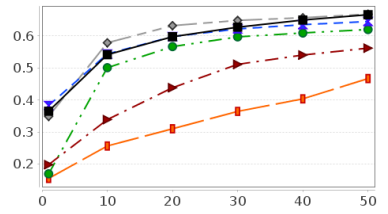

(f) Hitech

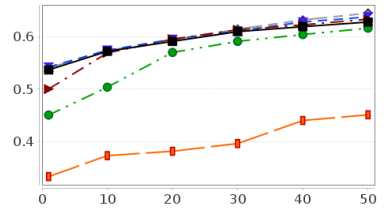

(j) Multi_Dom_Sentiment

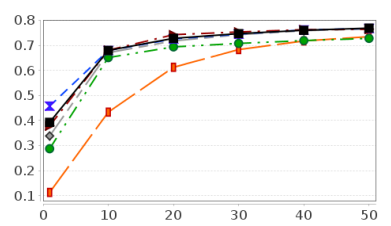

(n) Oh10

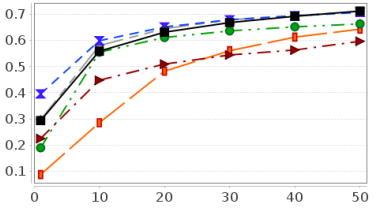

(c) Dmoz_Health_500

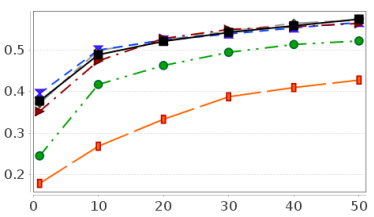

(g) IrishSentiment

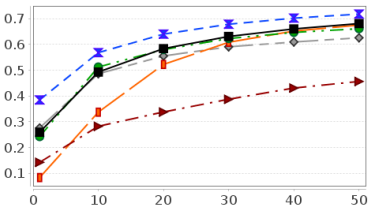

(k) NFS

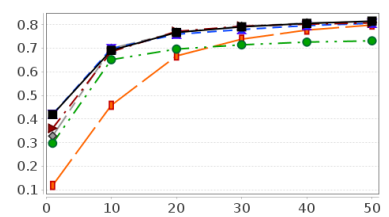

(o) Oh15

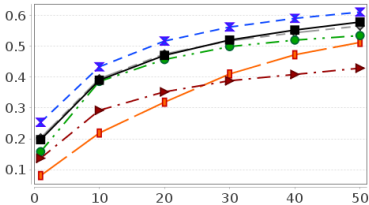

(d) Dmoz_Science_500

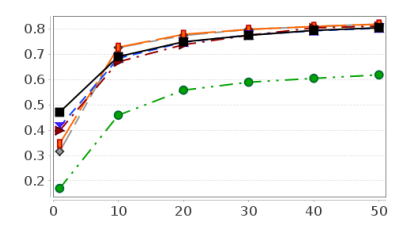

(h) La1s

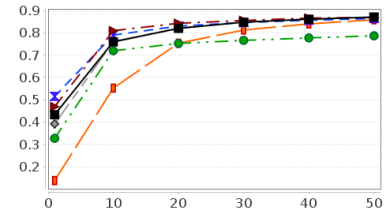

(l) Oh0

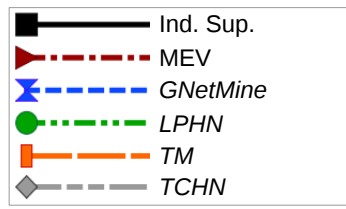

(p) Legenda

Figura 5.22: Valores $F 1^{\text {Macro }}$ do $4^{\mathrm{o}}$ grupo de experimentos (parte I).

Tabela 5.8: Número de vitórias dos algoritmos indicados na linha em comparação com os algoritmos indicados na coluna para o quarto grupo de experimentos considerando a medida $F 1^{\text {Macro }}$.

\begin{tabular}{l||c|c|c|c|c|c}
\hline \hline \multicolumn{7}{c}{ 1 exemplo rotulado por classe } \\
\hline \hline & Ind. Sup. & MEV & GNetMine & LPHN & TM & TCHN \\
\hline Ind. Sup. & - & 20 & 5 & 28 & 30 & 21 \\
\hline MEV & 10 & - & 2 & 19 & 30 & 14 \\
\hline GNetMine & 25 & 28 & - & 29 & 30 & 27 \\
\hline LPHN & 2 & 11 & 1 & - & 28 & 4 \\
\hline TM & 0 & 0 & 0 & 2 & - & 1 \\
\hline TCHN & 9 & 16 & 3 & 26 & 29 & - \\
\hline \hline
\end{tabular}

\begin{tabular}{l||c|c|c|c|c|c}
\hline \hline \multicolumn{7}{c}{ 10 exemplos rotulados por classe } \\
\hline \hline & Ind. Sup. & MEV & GNetMine & LPHN & TM & TCHN \\
\hline Ind. Sup. & - & 25 & 18 & 26 & 29 & 8 \\
\hline MEV & 5 & - & 6 & 13 & 27 & 4 \\
\hline GNetMine & 12 & 24 & - & 24 & 29 & 10 \\
\hline LPHN & 4 & 17 & 6 & - & 28 & 2 \\
\hline TM & 1 & 3 & 1 & 2 & - & 1 \\
\hline TCHN & 22 & 26 & 20 & 28 & 29 & - \\
\hline \hline
\end{tabular}

20 exemplos rotulados por classe

\begin{tabular}{l||c|c|c|c|c|c}
\hline \hline \multicolumn{7}{c}{ 20 exemplos rotulados por classe } \\
\hline \hline & Ind. Sup. & MEV & GNetMine & LPHN & TM & TCHN \\
\hline Ind. Sup. & - & 21 & 22 & 27 & 29 & 11 \\
\hline MEV & 8 & - & 12 & 13 & 27 & 7 \\
\hline GNetMine & 8 & 18 & - & 24 & 29 & 6 \\
\hline LPHN & 3 & 17 & 6 & - & 27 & 4 \\
\hline $\boldsymbol{T M}$ & 1 & 3 & 1 & 3 & - & 1 \\
\hline $\boldsymbol{T C H N}$ & 19 & 23 & 24 & 26 & 29 & - \\
\hline \hline
\end{tabular}

\begin{tabular}{l||c|c|c|c|c|c}
\hline \hline \multicolumn{7}{c}{ 30 exemplos rotulados por classe } \\
\hline \hline & Ind. Sup. & MEV & GNetMine & LPHN & TM & TCHN \\
\hline Ind. Sup. & - & 21 & 23 & 28 & 29 & 11 \\
\hline MEV & 9 & - & 15 & 14 & 26 & 8 \\
\hline GNetMine & 7 & 15 & - & 25 & 29 & 4 \\
\hline LPHN & 2 & 16 & 5 & - & 26 & 3 \\
\hline TM & 1 & 4 & 1 & 4 & - & 2 \\
\hline TCHN & 19 & 22 & 25 & 27 & 28 & - \\
\hline \hline
\end{tabular}

\begin{tabular}{l||c|c|c|c|c|c}
\hline \hline \multicolumn{7}{c}{ 40 exemplos rotulados por classe } \\
\hline \hline & Ind. Sup. & MEV & GNetMine & $\boldsymbol{L P H N}$ & $\boldsymbol{T M}$ & $\boldsymbol{T C H N}$ \\
\hline Tnd. Sup. & - & 21 & 24 & 29 & 29 & 11 \\
\hline MEV & 9 & - & 15 & 15 & 26 & 7 \\
\hline GNetMine & 6 & 15 & - & 21 & 29 & 5 \\
\hline LPHN & 1 & 15 & 9 & - & 25 & 4 \\
\hline TM & 1 & 4 & 1 & 5 & - & 1 \\
\hline TCHN & 19 & 23 & 25 & 26 & 29 & - \\
\hline
\end{tabular}

\begin{tabular}{l||c|c|c|c|c|c}
\hline \hline \multicolumn{7}{|c}{ 50 exemplos rotulados por classe } \\
\hline \hline & Ind. Sup. & MEV & GNetMine & LPHN & $\boldsymbol{T M}$ & $\boldsymbol{T C H N}$ \\
\hline Ind. Sup. & - & 23 & 26 & 29 & 29 & 16 \\
\hline MEV & 7 & - & 15 & 16 & 27 & 6 \\
\hline GNetMine & 4 & 15 & - & 20 & 28 & 5 \\
\hline LPHN & 1 & 14 & 10 & - & 24 & 4 \\
\hline TM & 1 & 3 & 2 & 6 & - & 1 \\
\hline TCHN & 14 & 24 & 25 & 26 & 28 & - \\
\hline \hline
\end{tabular}




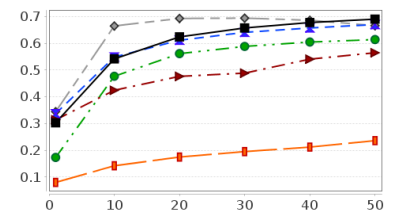

(a) Ohscal

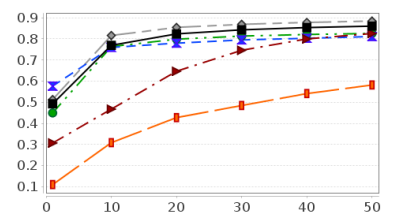

(e) $\operatorname{Re} 8$

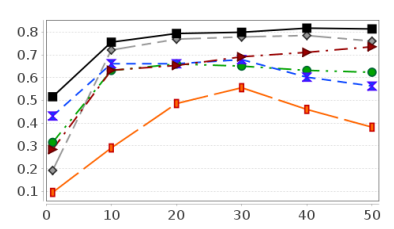

(i) $\operatorname{Tr} 12$

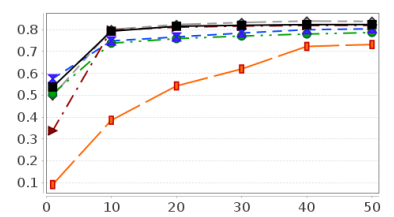

(m) $\operatorname{Tr} 41$

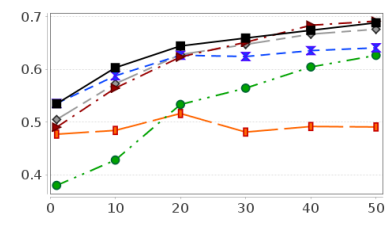

(b) Polarity

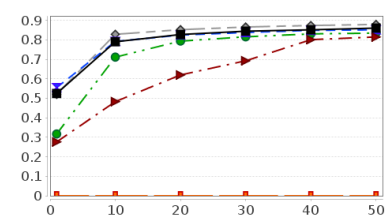

(f) Reviews

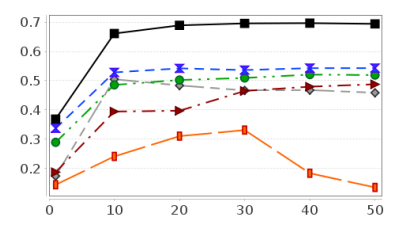

(j) $\operatorname{Tr} 21$

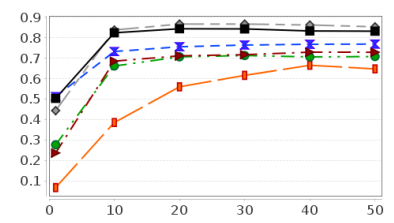

(n) $\operatorname{Tr} 45$

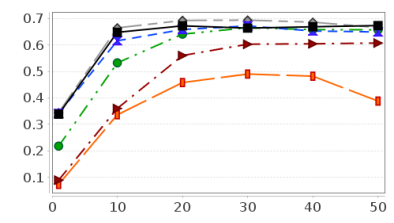

(c) $\operatorname{Re} 0$

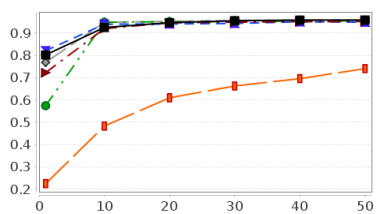

(g) SyskillWebert

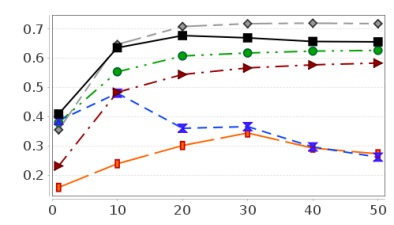

(k) $\operatorname{Tr} 23$

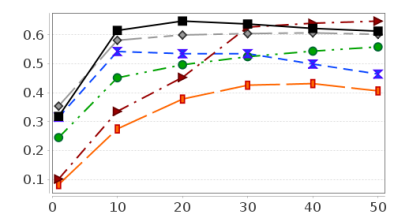

(o) Wap

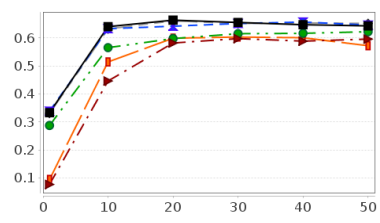

(d) Re1

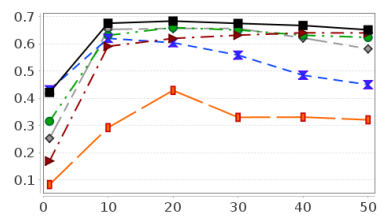

(h) $\operatorname{Tr} 11$

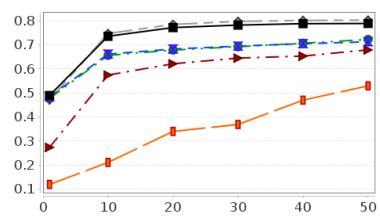

(1) $\operatorname{Tr} 31$

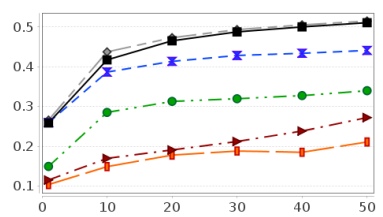

(p) WebKB

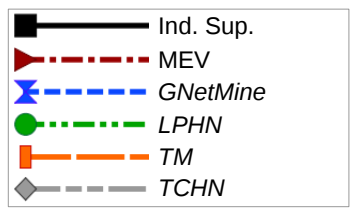

(q) Legenda

Figura 5.23: Valores $F 1^{\text {Macro }}$ do $4^{\circ}$ grupo de experimentos (parte II). 


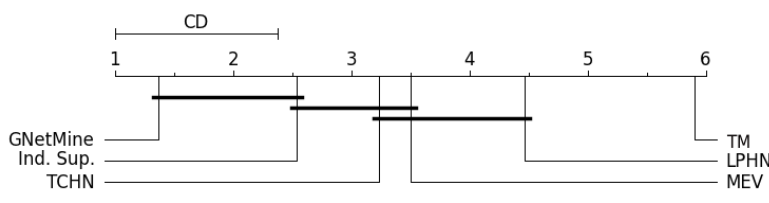

(a) 1 exemplo rotulado por classe.

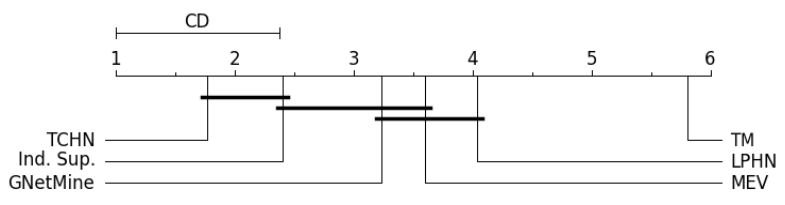

(c) 20 exemplos rotulados por classe.

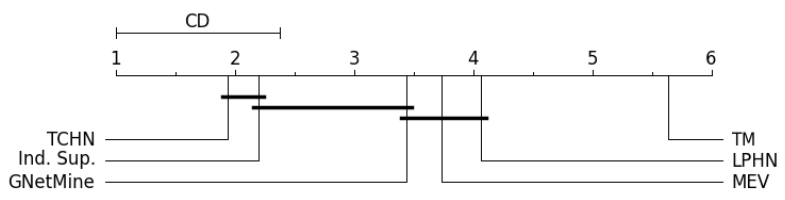

(e) 40 exemplos rotulados por classe.

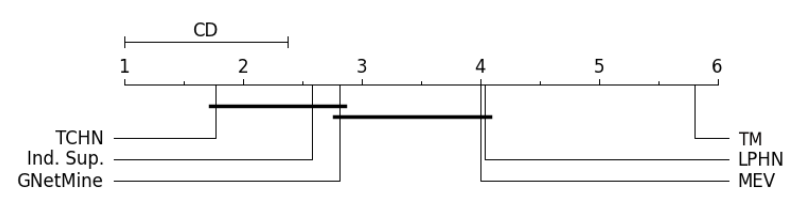

(b) 10 exemplos rotulados por classe.

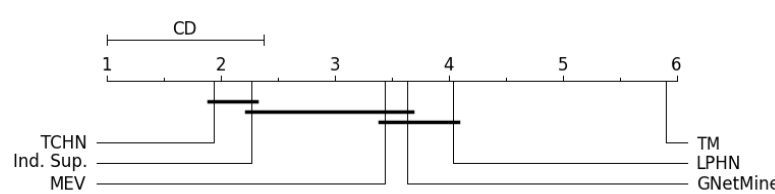

(d) 30 exemplos rotulados por classe.

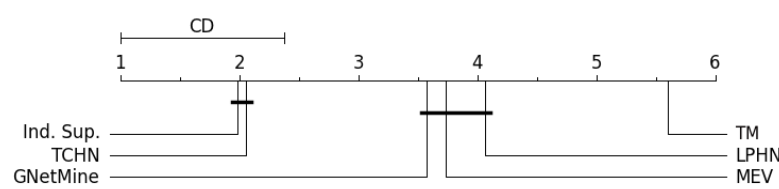

(f) 50 exemplos rotulados por classe.

Figura 5.24: Diagramas de diferença crítica para o quarto grupo de experimentos considerando a medida F1 $1^{\text {Micro }}$.

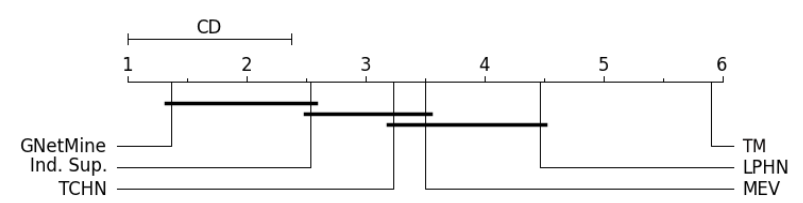

(a) 1 exemplo rotulado por classe.

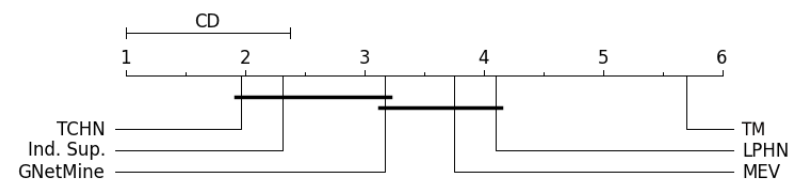

(c) 20 exemplos rotulados por classe.

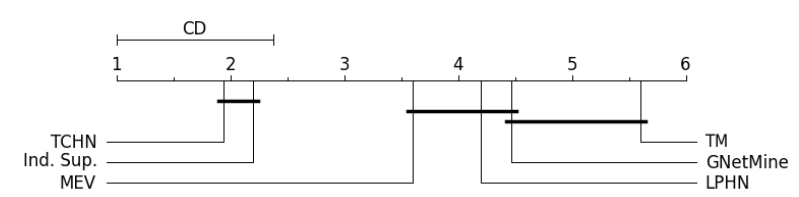

(e) 40 exemplos rotulados por classe.

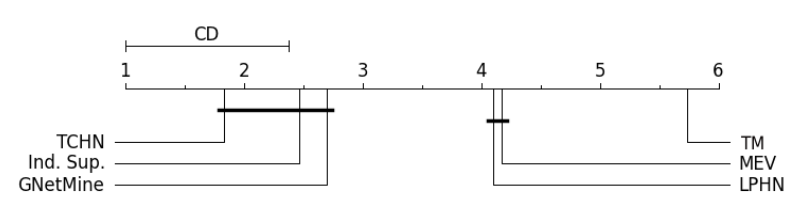

(b) 10 exemplos rotulados por classe.

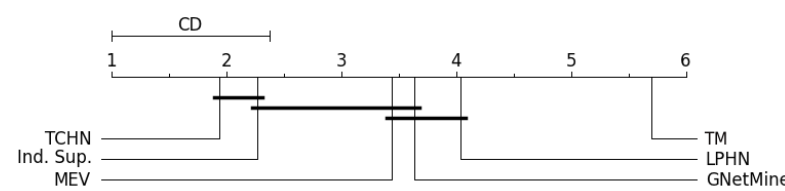

(d) 30 exemplos rotulados por classe.

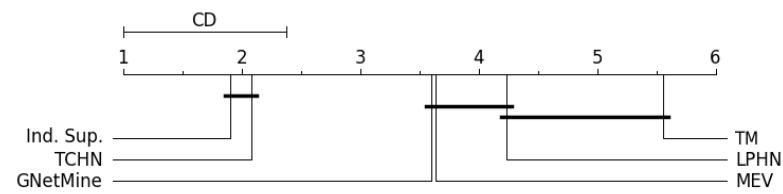

(f) 50 exemplos rotulados por classe.

Figura 5.25: Diagramas de diferença crítica para o quarto grupo de experimentos considerando a medida $F 1^{\text {Macro }}$. 


\subsection{Considerações Finais}

Neste capítulo foram apresentadas abordagens existentes para realizar a classificação automática de textos por meio de aprendizado indutivo semissupervisionado. Também foi apresentada a abordagem proposta para indução semissupervisionada, a qual é capaz de classificar rapidamente novos documentos utilizando as informações de classe dos termos inferidas por meio de um processo de aprendizado transdutivo.

Em geral, a abordagem proposta obteve resultados satisfatórios em relação às abordagens existentes para indução semissupervisionada, tanto baseadas em redes de documentos quanto baseadas no modelo espaço-vetorial. Vale ressaltar que a combinação da abordagem de indução proposta juntamente com o algoritmo $T C H N$, em geral, obteve as maiores performance de classificação. Inclusive, o algoritmo $T C H N$ em conjunto com a abordagem proposta apresentou melhores performance de classificação com diferenças estatisticamente significantes em relação aos algoritmos baseados no modelo espaço-vetorial na maioria das situações analisadas, isto é, na maioria dos diferentes números de exemplos de documentos rotulados e medidas de avaliação de performance de classificação.

Assim como apresentado no capítulo referente ao aprendizado transdutivo, a performance de classificação obtida pelos algoritmos de aprendizado indutivo semissupervisionado foram, em geral, inferiores a dos algoritmos de aprendizado indutivo supervisionado. Na avaliação experimental realizada neste capítulo, os algoritmos de aprendizado indutivo supervisionado superaram os demais algoritmo existentes para os diferentes tipos de redes utilizados, exceto o algoritmo proposto $T C H N$. Vale ressaltar que neste capítulo foi feita uma avaliação experimental apenas com redes compostas por relações simples com o intuito de demonstrar que é viável a utilização das informações de classe dos termos como modelo de classificação. Neste capítulo também foram observados indícios que a redes compostas por mais de um tipo de relação também são capazes de melhorar a performance de classificação no aprendizado indutivo semissupervisionado.

Portanto, de acordo com os resultados apresentados na avaliação experimental realizada neste capítulo, pôde-se observar que o aprendizado indutivo semissupervisionado baseado em redes também é útil para a classificação automática de texto e que com as redes compostas por mais de um tipo de relação propostas nesta tese também é possível obter as maiores performances de classificação. Além disso, a geração de respostas rápidas na classificação de novos documentos torna a utilização da abordagem proposta aconselhável em aplicações reais. 

CAPÍTULO 6

\section{Conclusões}

Neste capítulo são apresentadas as conclusões deste projeto de doutorado. Para tal, são retomadas as contribuições e inovações científicas alcançadas durante o desenvolvimento deste projeto referentes aos desafios científicos e objetivos definidos na introdução desta tese. Uma lista de artigos em periódicos, conferências e relatórios técnicos resultantes das contribuições e inovações científicas deste projeto de doutorado também é apresentada. Por fim, são apresentadas considerações sobre as limitações ocorridas no desenvolvimento deste projeto, bem como direções para trabalhos futuros.

\subsection{Contribuições e Inovações Científicas}

Neste projeto de doutorado foram desenvolvidos métodos para geração de representações de textos em redes as quais (i) permitem a representação de diferentes tipos de objetos e relações, (ii) são independentes de língua e domínio, e (iii) permitem uma classificação eficiente no que se refere ao tempo e performance de classificação. Além das representações, foram propostos e implementados algoritmos para realizar o aprendizado indutivo supervisionado, aprendizado transdutivo semissupervisionado e o aprendizado indutivo semissupervisionado considerando as redes propostas neste projeto. Também foram implementados métodos para geração de tipos de rede existentes e que foram consideradas relevantes para este projeto de doutorado, bem como algoritmos para realizar o aprendizado em tais tipos de rede. Destaca-se que foram realizadas extensas avaliações empíricas considerando algoritmos tradicionais, estado da arte e os algoritmos propostos neste projeto.

Quanto às inovações obtidas com o desenvolvimento deste projeto de doutorado, pode-se destacar as seguintes:

Proposta e desenvolvimento para geração de redes heterogêneas independen- 
tes de língua e domínio: as redes heterogêneas propostas nesta tese podem ser utilizadas para representar textos escritos em qualquer língua ou oriundos de qualquer domínio. Além disso, foram propostas desde redes com relações simples, que proveram performances de classificação satisfatórias, à redes compostas por mais de um tipo de relação, as quais proveram as maiores performances de classificação para os algoritmos baseados em redes.

Proposta e desenvolvimento para modelagem em redes eficientes, tanto para o aprendizado quanto para a classificação de textos: as redes heterogêneas propostas nesta tese proveram performances de classificação superiores a de algoritmos baseados no modelo espaço-vetorial ou de algoritmos baseados em redes existentes. No aprendizado indutivo, tanto supervisionado quanto semissupervisionado, a consideração de objetos do tipo termo na rede, permite rapidamente conectar um novo documento aos termos contidos no mesmo e propagar as informações de classe inferidas para os termos para definir o rótulo do novo documento. A classificação portanto tem custo linear em relação ao número de termos.

\section{Proposta e desenvolvimento de algoritmos de aprendizado de máquina ba-} seados nas redes propostas neste projeto de doutorado: foram propostos algoritmos de aprendizado supervisionado, algoritmos de aprendizado transdutivo semissupervisionado e algoritmos para realizar a indução semissupervisionada, todos utilizando como entrada as redes propostas nesta tese. Foi proposto e desenvolvido o algoritmo $I M H N$, que realiza o aprendizado do tipo indutivo supervisionado em redes compostas por relações documento-termo e/ou termo-termo e que demonstrou obter uma performance de classificação superior a de algoritmos baseados no modelo espaço-vetorial ou em redes. Também foi proposto e desenvolvido o framework $T C T N$, que realiza o aprendizado transdutivo em redes compostas por relações termo-termo e que permitiu demonstrar que as relações entre termos geradas por medidas de similaridade por sí só são úteis para a classificação de textos. Por fim, foram propostos e desenvolvidos os algoritmos $L P H N$ e $T C H N$, que realizam o aprendizado transdutivo em redes heterogêneas. O primeiro é livre de parâmetros e apresentou performances de classificação superiores a dos algoritmos baseados no modelo espaço-vetorial. Já o segundo apresentou as maiores performances para a classificação de transdutiva de textos. Além desses, a abordagem proposta para a indução semissupervisionada em redes, que consiste em utilizar as informações de classe dos termos inferidas por um processo de classificação transdutiva, apresentou uma classificação mais rápida e uma performance de classificação superior em relação às abordagens existentes, principalmente quando utilizando o algoritmo proposto TCHN para realizar o aprendizado transdutivo.

Aplicação dos algoritmos propostos e implementados neste projeto de doutorado em outros domínios de aplicação: os algoritmos de aprendizado semis- 
supervisionado desenvolvidos e implementados neste projeto de doutorado foram também aplicados em outras áreas além da classificação de textos, nas quais a realização da classificação automática por meio de aprendizado semissupervisionado não é difundida, como a extração de termos (Conrado et al., 2005), classificação de músicas (Silva et al., 2014) e identificação de aspectos (Matsuno et al., 2015). Os algoritmos de aprendizado transdutivos implementados neste trabalho também foram utilizados na identificação de regras de associação interessantes (de Padua et al., 2014).

Em decorrer das atividades desenvolvidas para atingir os objetivos deste projeto de doutorado e como consequência das propostas e desenvolvimentos apresentados acima, foram geradas também as seguintes contribuições científicas:

\section{Disponibilização para a comunidade científica de um repositório de coleções}

de textos: as 45 coleções de textos coletadas, pré-processadas, estruturadas, e que foram utilizadas nas avaliações experimentais nos Capítulos 3, 4 e 5 foram disponibilizadas à comunidade para que possam ser utilizadas em novos trabalhos nas mais diversas atividades envolvendo tanto classificação quanto agrupamento de textos. As descrições dessas coleções, os métodos de pré-processamento que foram utilizados para gerar representações estruturadas e as características dessas representações são apresentadas em Rossi et al. (2013). Também foram disponibilizados resultados de classificação e agrupamento obtidos por algoritmos tradicionais e estado da arte das respectivas áreas para evitar a reexecução de experimentos ao utilizar as coleções disponibilizadas.

\section{Disponibilização de códigos-fonte referente a pré-processamento e algoritmos} de aprendizado: todos os códigos-fonte desenvolvidos neste projeto de doutorado para realização do pré-processamento das coleções, geração das representações no modelo espaço-vetorial e em redes, dos algoritmos de aprendizado e das validações realizadas estão disponíveis para a comunidade na página web http://sites.labic . icmc.usp.br/ragero/thesis/text_categorization_tool/.

Geração de resultados de benchmarking: foram gerados resultados para diversas coleções de textos obtidos por diferentes algoritmos de aprendizado de máquina e diferentes parâmetros. A disponibilização desses resultados torna mais fácil o entendimento do comportamento dos algoritmos e de seus parâmetros, além de auxiliar na escolha dos algoritmos a serem utilizados em aplicações reais.

Padronização de notações e descrição de algoritmos: todos os algoritmos, mesmo dos diferentes tipos de aprendizado, foram descritos utilizando os mesmos conceitos e notações nesta tese. Isso permite facilmente tanto interpretar quanto perceber as diferenças entre os algoritmos. 


\subsection{Publicações}

As contribuições obtidas com o desenvolvimento desta tese de doutorado foram divulgadas por meio de publicações em periódicos (3), conferências (9), resumos referentes às colaborações em trabalhos de iniciação científica (3) e relatório técnico (1). Uma lista dessas publicações separadas por tipo de publicação e ordenadas pela data de publicação é apresentada a seguir:

\section{PERIÓDICOS}

1. Rossi, R. R.; Lopes, A. A.; Rezende, S. O. Optimization and label propagation in bipartite heterogeneous networks to improve transductive classification of texts (IN PRESS). Information Processing \& Management. Elsevier. (Qualis A2)

2. Rossi, R. G.; Lopes, A. A.; Faleiros, T. P.; Rezende, S. O. Inductive Model Generation for Text Classification Using a Bipartite Heterogeneous Network. Journal of Computer Science and Technology, v. 29, p. 361-375, 2014. (Qualis B2)

3. Rossi, R. G.; Marcacini, R. M., Rezende, S. O. Analysis of Domain Independent Statistical Keyword Extracion Methods for Incremental Clustering. Learning and Nonlinear Models, v. 12, p. 17-37, 2014. (Qualis B5)

\section{CONFERENCIAS}

1. Matsuno, I. P; Rossi, R. G.; Marcacini, R. M.; Rezende, S. O. Análise de sentimentos baseada em aspectos usando aprendizado semissupervisionado e redes heterogêneas bipartidas. Em: Symposium on Knowledge Discovery, Mining and Learning, 2015, p. 90-93. (Sem Qualis)

2. Rossi, R. G.; Rezende, S. O.; Lopes, A. A. Term Network Approach for Transductive Classification. Em: International Conference on Intelligent Text Processing and Computational Linguistics, 2015, p. 497-515. (Qualis B1)

3. Rossi, R. G.; Lopes, A. A.; Rezende, S. O. A parameter-free label propagation algorithm using bipartite heterogeneous networks for text classification. Em: ACM Symposium on Applied Computing, 2014, p. 79-84. (Qualis A1)

4. Drury, B.; Rossi, R. G.; Lopes, A. A. Identification of Brazilian Portuguese Causative Verbs through a Weighted Graph Classification Strategy. Em: International Conference on Computational Processing of Portuguese, 2014, p. 274-279. (Qualis B3)

5. Silva, D. F.; Rossi, R. G.; Rezende, S. O.; Batista, G. E. A. P. A. Music Classification by Transductive Learning Using Bipartite Heterogeneous Networks. Em: International Society for Music Information Retrieval Conference, 2014, p. 113-118. (Qualis A1) 
6. Domingues, M. A.; Cherman, E. A.; Nogueira, B. M.; Conrado, M. S.; Rossi, R. G.; Padua, R.; Marcacini, R. M.; Souza, V. M. A.; Batista, G. E. A. P. A. A comparative study of algorithms for recommending given names. Em: International Conference on Informatics $\&$ Applications, 2013, p. 66-71. (Sem Qualis)

7. Conrado, M. S.; Rossi, R. G.; Pardo, T. A. S.; Rezende, S. O. Applying transductive learning for automatic term extraction: The case of the ecology domain. Em: International Conference on Informatics \& Applications, 2013, p. 264-269. (Sem Qualis)

8. Rossi, R. G.; Marcacini, R. M.; Rezende, S. O. Analysis of Statistical Keyword Extraction Methods for Incremental Clustering. Em: Encontro Nacional de Inteligência Artificial e Computacional, 2013, p. 1-10. (Qualis B4)

9. Rossi, G. G.; Faleiros, T. P.; Rezende, S. O.; Lopes, A. A. Inductive Model Generation for Text Categorization using a Bipartite Heterogeneous Network. Em: IEEE International Conference on Data Mining, 2012, p. 1086-1081. (Qualis A1)

\section{RESUMOS}

1. Paravia, R. P. P.; Sinoara, R. A.; Rossi, G. R.; Rezende, S. O. Sistema para apoio à rotulação manual de textos utilizando aprendizado de máquina. Em: Simpósio Internacional de Iniciação Científica da Universidade de São Paulo, 2015.

2. Aires, C. M.; Rossi, R. G.; Rezende, S. O. Construção Semi-Supervisionada de Hierarquias de Tópicos. Em: Simpósio Internacional de Iniciação Científica da Universidade de São Paulo, 2014.

3. Albuquerque, D. L.; Santos, F. F.; Rossi, R. G.; Rezende, S. O. Organização de dados governamentais públicos baseada em hierarquias de tópicos. Em: Simpósio de Iniciação Científica da Universidade de São Paulo, 2012

\section{RELATÓRIO TÉCNICO}

1. Rossi, R. G.; Marcacini, R. M.; Rezende, S. O. Benchmarking Text Collections for Classification and Clustering Tasks. Relatório Técnico n 395, Instituto de Ciências Matemáticas e de Computação - Universidade de São Paulo, 2013.

Além das publicações apresentadas anteriormente, os seguintes trabalhos estão em fase de elaboração:

- Souza, V. M. A.; Rossi, R. G.; Rezende, S. O.; Batista, G. E. A. P. A. An Experimental Analysis of Active Learning Methods on Fully Unlabeled Sequential Data. Neurocomputing. (Qualis A2) 
- Rossi, R. G.; Lopes, A. A.; Rezende, S. O.; Inductive Model for Text Classification Using Generalized Relations in Heterogeneous Networks. Knowledge-Based Systems. Elsevier. (Qualis A2)

- Rossi, R. G.; Lopes, A. A.; Rezende, S. O.; Using Domain-Independent Heterogeneous Relations to Improve Transductive Classification of Texts. Information Sciences. Elsevier. (Qualis A1)

- Rossi, R. G.; Lopes, A. A.; Rezende, S. O.; Inductive Semi-Supervised Learning Based on Heterogeneous Networks for Text Classification. Information Processing 8 Management. Elsevier. (Qualis A2)

\subsection{Limitações e Trabalhos Futuros}

Durante o desenvolvimento deste projeto de doutorado, consideraram-se representações em redes compostas apenas por objetos do tipo documento e do tipo termo de forma a possibilitar a modelagem de qualquer coleção de textos. Entretanto, algumas coleções podem apresentar tipos de objetos específicos, como autores e conferências em artigos científicos, ou pacientes e médicos em coleções de laudos médicos. Portanto, uma direção futura é a construção de redes para coleções de domínios específicos, tendo como base as redes propostas nesta tese, e analisar o impacto desses tipos de objetos na performance de classificação.

Em relação aos algoritmos $I M H N$ ou $T C H N$, foi utilizado o método Least Mean Square para realizar a inferência das informações de classe, uma vez que esse algoritmo apresentou resultados satisfatórios quanto ao tempo de inferência e performance de classificação, conforme apresentado em Rossi et al. (2014a) e Rossi et al. (2015b). Entretanto, outros algoritmos podem ser utilizados para realizar tais inferências, como o Weighted Least Squares, Generalized Least Squares, dentre outros (Poularikas, 2014; Montgomery et al., 2012; Seber e Lee, 2012; Rousseeuw e Leroy, 1987).

Ainda referente ao algoritmo TCHN, que foi empregado tanto para realizar o aprendizado transdutivo quanto aprendizado indutivo semissupervisionado, não são alteradas as informações de classe dos documentos rotulados durante a classificação e não é ponderado o peso dos documentos não rotulados na inferências das informações de classe dos termos, conforme é realizado em outros algoritmos. Não foi feito esse tipo de consideração para manter um menor número de parâmetros no algoritmo TCHN. Mesmo assim, conforme apresentado nas avaliações experimentais dos Capítulos 4 e 5, o algoritmo TCHN apresentou uma performance de classificação superior a de outros algoritmos tradicionais e estado da arte. Porém, será futuramente explorado e analisado se a possibilidade de alterações das informações de classe dos documentos rotulados, bem como a diminuição do peso dado aos documentos não rotulados, podem aumentar a performance de classificação do algoritmo TCHN. 
Nas avaliações experimentais realizadas nos Capítulos 3, 4 e 5, foram apontados quais algoritmos apresentaram os melhores resultados em um caso geral, ou seja, considerando todas as coleções de textos de diferentes domínios e características. Buscou-se extrair correlações ou padrões de coocorrência entre características das coleções de textos apresentadas na Tabela A.1 com a performance de classificação dos algoritmos. Porém, não foram encontrados correlações ou padrões significativos para determinar qual algoritmo é melhor para cada coleção. Esse tipo de informação é potencialmente útil em situações práticas para determinar qual algoritmo é mais adequado para uma determinada coleção. Portanto, como trabalho futuro serão estudas e extraídas mais características para as coleções de textos visando determinar padrões de performance de classificação para os algoritmos. Também serão extraídas propriedades das representações em redes geradas para as coleções de textos e será verificado se existe correlação entre a performance de classificação e as propriedades das redes.

Pretende-se também estender e analisar todos os algoritmos propostos quanto os algoritmos implementados e utilizados nesta tese tanto para a classificação multi-rótulo (Yang et al., 2009; Katakis et al., 2008) quanto para a classificação hierárquica de textos (Bennett e Nguyen, 2009; Xue et al., 2008; Sun e Lim, 2001), tanto em um cenário de aprendizado supervisionado quanto semissupervisionado. Um ponto relevante e que será focado nos desenvolvimentos futuros é a execução dos algoritmos de aprendizado de máquina em situações onde não são informados exemplos de todas as classes. Para isso serão estudadas, implementadas e avaliadas técnicas de reconhecimento de conjuntos abertos, detecção de classes raras, aprendizado baseado em classes positivas e detecção de novidade (Aggarwal, 2014).

Os documentos rotulados para as avaliações realizadas nos cenários de aprendizado semissupervisionado (Capítulos 4 e 5) foram selecionados aleatoriamente. Porém, técnicas de aprendizado ativo podem ser utilizadas, em situações práticas, para apresentar documentos mais relevantes para rotulação por parte dos usuários e que proporcionem uma maior performance de classificação com um menor número de exemplos rotulados (Aggarwal, 2014; Settles, 2012; Yang et al., 2009; Zhu et al., 2003b). Como trabalho futuro, serão implementadas técnicas de aprendizado ativo e será analisado seu impacto na performance de classificação. 



\section{Referências Bibliográficas}

Aery, M. e Chakravarthy, S. (2005). Infosift: Adapting graph mining techniques for text classification. In Proceedings of the Florida Artificial Intelligence Research Society Conference, páginas 277-282. AAAI Press. Citado nas páginas xi, 6, 7, 39, 46, 49, 50, e 89.

Aggarwal, C. (2014). Data Classification: Algorithms and Applications. Chapman \& Hall/CRC Data Mining and Knowledge Discovery Series. Taylor \& Francis. Citado nas páginas 16, 17, 42 , e 231.

Aggarwal, C. C. e Li, N. (2011). On node classification in dynamic content-based networks. In Proceedings of the SIAM International Conference on Data Mining, páginas 355-366. SIAM / Omnipress. Citado nas páginas xi, 5, 6, 49, 50, e 60.

Aggarwal, C. C. e Wang, H. (2010). Managing and Mining Graph Data. Springer, $1^{\mathrm{a}}$ edição. Citado nas páginas 4, 16, e 35.

Aggarwal, C. C. e Zhai, C., editors (2012). Mining Text Data. Springer. Citado nas páginas 1, 3, $16,21,24,25,26,27,28,54,68,71,72,83,86$, e 100.

Aggarwal, C. C. e Zhao, P. (2013). Towards graphical models for text processing. Knowledge 83 Information Systems, 36(1):1-21. Citado nas páginas xi, 6, 16, 46, 47, 48, e 88.

Aggarwal, C. C., Zhao, Y., e Yu, P. S. (2012). On text clustering with side information. In Proceedings of the IEEE International Conference on Data Engineering, páginas 894-904. Citado na página 21.

Aggarwal, C. C., Zhao, Y., e Yu, P. S. (2014). On the use of side information for mining text data. IEEE Transactions on Knowledge and Data Engineering, 26(6):1415-1429. Citado na página 21.

Aghdam, M. H., Ghasem-Aghaee, N., e Basiri, M. E. (2009). Text feature selection using ant colony optimization. Expert Systems with Applications, 36(3):6843-6853. Citado na página 25.

Agirre, E. e Soroa, A. (2009). Personalizing pagerank for word sense disambiguation. In Proceedings of the Conference of the European Chapter of the Association for Computational Linguistics, páginas 33-41. ACL. Citado na página 39.

Ahonen-Myka, H., Heinonen, O., Klemettinen, M., e Verkamo, A. I. (1999). Finding co-occurring text phrases by combining sequence and frequent set discovery. In Proceedings of the Workshop on Text Mining: Foundations, Techniques and Applications, páginas 1-9. Citado na página 20.

Alexandrescu, A. e Kirchhoff, K. (2009). Graph-based learning for statistical machine translation. In Proceedings of the Annual Conference of the North American Chapter of the Association for Computational Linguistics, páginas 119-127. ACL. Citado na página 117. 
Altinçay, H. e Erenel, Z. (2010). Analytical evaluation of term weighting schemes for text categorization. Pattern Recognition Letters, 31(11):1310-1323. Citado na página 22.

Amancio, D. R. (2015). Probing the topological properties of complex networks modeling short written texts. Plos ONE, 10(2):1-17. Citado nas páginas 5, 6, 46, e 47.

Amancio, D. R., Altmann, E. G., Oliveira Jr, O. N., e Costa, L. F. (2011). Comparing intermittency and network measurements of words and their dependence on authorship. New Journal of Physics, 13(12):1-18. Citado na página 40.

Amancio, D. R., Antiqueira, L., Pardo, T. A., da F. Costa, L., Oliveira Jr, O. N., e Nunes, M. G. (2008). Complex networks analysis of manual and machine translations. International Journal of Modern Physics C, 19(04):583-598. Citado na página 39.

Amancio, D. R., jr., O. N. O., e da F. Costa, L. (2012a). Unveiling the relationship between complex networks metrics and word senses. Europhysics Letters, 98(1):18002. Citado na página 39.

Amancio, D. R., Oliveira Jr, O. N., e Costa, L. d. F. (2012b). On the use of topological features and hierarchical characterization for disambiguating names in collaborative networks. Europhysics Letters, 99(4):48002. Citado na página 39.

Amini, M. e Usunier, N. (2015). Learning with Partially Labeled and Interdependent Data. Springer. Citado nas páginas 195 e 197.

Androutsopoulos, I., Koutsias, J., Chandrinos, K., Paliouras, G., e Spyropoulos, C. (2000). An evaluation of naive bayesian anti-spam filtering. In Proceedings of the Workshop on Machine Learning in the New Information Age, páginas 9-17. Citado na página 69.

Angelova, R., Kasneci, G., e Weikum, G. (2012). Graffiti: graph-based classification in heterogeneous networks. World Wide Web, 15(2):139-170. Citado nas páginas 4, 36, e 133.

Angelova, R. e Weikum, G. (2006). Graph-based text classification: learn from your neighbors. In Proceedings of the Special Interest Group on Information Retrieval Conference, páginas 485-492. ACM. Citado nas páginas 6, 35, 39, 41, 126, 128, e 131.

Apache (2006). The apache spamassassin project. http://spamassassin.apache.org/ publiccorpus/. Último acesso em 6 de Novembro de 2013. Citado na página 266.

Apté, C., Damerau, F., e Weiss, S. M. (1994). Automated learning of decision rules for text categorization. ACM Transactions on Information Systems, 12(3):233-251. Citado na página 81.

Baccianella, S., Esuli, A., e Sebastiani, F. (2010). Sentiwordnet 3.0: An enhanced lexical resource for sentiment analysis and opinion mining. In Proceedings of the International Conference on Language Resources and Evaluation, páginas 2200-2204. ELRA. Citado na página 143.

Baeza-Yates, R. A. e Ribeiro-Neto, B. (1999). Modern Information Retrieval. Addison-Wesley Longman Publishing Co., Inc. Citado na página 117.

Barabási, A. L., Jeong, H., Néda, Z., Ravasz, E., Schubert, A., e Vicsek, T. (2002). Evolution of the social network of scientific collaborations. Physica A: Statistical Mechanics and its Applications, 311(3-4):590 - 614. Citado na página 31.

Beil, F., Ester, M., e Xu, X. (2002). Frequent term-based text clustering. In Proceedings of the International Conference on Knowledge Discovery and Data Mining, páginas 436-442. ACM. Citado na página 15. 
Bekkerman, R. e Allan, J. (2004). Using bigrams in text categorization. Relatório Técnico IR-408, Center of Intelligent Information Retrieval, UMass Amherst. Citado nas páginas 15 e 19.

Bekkerman, R., El-Yaniv, R., Tishby, N., e Winter, Y. (2001). On feature distributional clustering for text categorization. In Proceedings of the International Conference on Research and Development in Information Retrieval, páginas 146-153. ACM. Citado na página 16.

Belkin, M., Matveeva, I., e Niyogi, P. (2004). Regularization and semi-supervised learning on large graphs. In Proceedings of the Conference on Learning Theory, páginas 624-638. Citado na página 136.

Belkin, M., Niyogi, P., e Sindhwani, V. (2006). Manifold regularization: A geometric framework for learning from labeled and unlabeled examples. Journal of Machine Learning Research, 7:2399-2434. Citado nas páginas 6, 16, 41, 93, 126, 136, 199, e 271.

Benbrahim, H. e Bramer, M. (2009). Text and hypertext categorization. In Bramer, M., editor, Artificial Intelligence: An International Perspective, volume 5640 of Lecture Notes in Computer Science, páginas 11-38. Springer. Citado nas páginas 2, 26, 100, e 269.

Bennett, K. P. e Demiriz, A. (1998). Semi-supervised support vector machines. In Kearns, M. S., Solla, S. A., e Cohn, D. A., editors, Advances in Neural Systems, páginas 368-374, Cambridge, MA. MIT Press. Citado na página 125.

Bennett, P. N. e Nguyen, N. (2009). Refined experts: Improving classification in large taxonomies. In Proceedings of the International Conference on Research and Development in Information Retrieval, páginas 11-18. ACM. Citado na página 231.

Berlingerio, M., Coscia, M., Giannotti, F., Monreale, A., e Pedreschi, D. (2013). Multidimensional networks: foundations of structural analysis. World Wide Web, 16(5-6):567-593. Citado na página 33.

Berry, M. e Kogan, J. (2010). Text Mining: Applications and Theory. Wiley InterScience. Wiley. Citado na página 1.

Berry, M. W. (1992). Large-scale sparse singular value computations. International Journal of Supercomputer Applications, 6(1):13-49. Citado na página 27.

Berry, M. W. e Castellanos, M. (2008). Survey of Text Mining II: Clustering, Classification, and Retrieval. Springer, $1^{\mathrm{a}}$ edição. Citado na página 1.

Bertini, Jr., J. a. R., Zhao, L., Motta, R., e Lopes, A. A. L. (2011). A nonparametric classification method based on k-associated graphs. Information Sciences, 181(24):5435-5456. Citado nas páginas 6, 36, 44, 91, 102, e 199.

Berton, L. e Lopes, A. A. (2014). Graph construction based on labeled instances for semisupervised learning. In Proceedings of the International Conference on Pattern Recognition, páginas 2477-2482. Citado nas páginas 6 e 43.

Bhattarai, A., Rus, V., e Dasgupta, D. (2009). Characterizing comment spam in the blogosphere through content analysis. In Proceedings of the Symposium on Computational Intelligence in Cyber Security, páginas 37-44. Citado na página 196.

Bie, T. D. e Cristianini, N. (2003). Convex methods for transduction. In Thrun, S., Saul, L. K., e Schölkopf, B., editors, Advances in Neural Information Processing Systems. MIT Press. Citado na página 125 . 
Biemann, C. e Mehler, A. (2014). Text Mining: From Ontology Learning to Automated Text Processing Applications. Theory and Applications of Natural Language Processing. Springer. Citado na página 1.

Billsus, D. e Pazzani, M. J. (1999). A hybrid user model for news story classification. Springer. Citado na página 69.

Blanchard, J., Guillet, F., Gras, R., e Briand, H. (2005). Using information-theoretic measures to assess association rule interestingness. In Proceedings of the International Conference on Data Mining, páginas 66-73. Citado nas páginas xv, 55, 56, e 58.

Blanco, R. e Lioma, C. (2012). Graph-based term weighting for information retrieval. Information Retrieval, 15(1):54-92. Citado nas páginas 4, 29, e 39.

Blei, D. M., Ng, A. Y., e Jordan, M. I. (2003). Latent dirichlet allocation. Journal of Machine Learning Research, 3:993-1022. Citado nas páginas 4, 28, 29, e 271.

Blitzer, J., Dredze, M., e Pereira, F. (2009). Multi-domain sentiment dataset (version 2.0). http: //www.cs.jhu.edu// mdredze/datasets/sentiment/. Último acesso em 6 de Novembro de 2013. Citado na página 267.

Blum, A. e Chawla, S. (2001). Learning from labeled and unlabeled data using graph mincuts. In Proceedings of the International Conference on Machine Learning, páginas 19-26. Morgan Kaufmann. Citado nas páginas 126, 135, e 136.

Blum, A., Lafferty, J., Rwebangira, M. R., e Reddy, R. (2004). Semi-supervised learning using randomized mincuts. In Proceedings of the International Conference on Machine Learning, páginas 13-20. Citado nas páginas 136 e 137.

Blum, A. e Mitchell, T. (1998). Combining labeled and unlabeled data with co-training. In Proceedings of the Annual Conference on Computational Learning Theory, páginas 92-100. ACM. Citado nas páginas 119, 120, e 197.

Boiy, E., Hens, P., Deschacht, K., e Moens, M.-F. (2007). Automatic sentiment analysis in on-line text. In Proceedings of the International Conference on Electronic Publishing-, páginas 349-360. Citado na página 70.

Boley, D., Gini, M. L., Gross, R., Han, E.-H., Hastings, K., Karypis, G., Kumar, V., Mobasher, B., e Moore, J. (1999). Partitioning-based clustering for web document categorization. Decision Support Systems, 27(3):329-341. Citado na página 85.

Brefeld, U., Büscher, C., e Scheffer, T. (2005). Multi-view discriminative sequential learning. In Proceedings of the European Conference on Machine Learning, páginas 60-71. Springer. Citado na página 160.

Breve, F. A. (2010). Aprendizado de máquina em redes complexas. Tese de Doutorado, Instituto de Ciências Matemáticas e de Computação, Universidade de São Paulo. Citado na página 36.

Breve, F. A., Zhao, L., Quiles, M. G., Pedrycz, W., e Liu, J. (2012). Particle competition and cooperation in networks for semi-supervised learning. IEEE Transactions on Knowledge and Data Engineering, 24(9):1686-1698. Citado nas páginas 3, 4, 16, 136, e 138.

Brighton, H. e Mellish, C. (1999). On the consistency of information filters for lazy learning algorithms. In Proceedings of the European Conference on the Principles of Data Mining and Knowledge Discovery, páginas 283-288. Springer Verlag. Citado na página 87. 
Bródka, P., Filipowski, T., e Kazienko, P. (2011). An introduction to community detection in multi-layered social network. Information Systems, E-learning, and Knowledge Management Research, 1:185-190. Citado na página 33.

Bunke, H. e Shearer, K. (1998). A graph distance metric based on the maximal common subgraph. Pattern Recognitoin Letters, 19(3-4):255-259. Citado nas páginas 45 e 88.

Cai, D., Mei, Q., Han, J., e Zhai, C. (2008). Modeling hidden topics on document manifold. In Proceedings of the ACM Conference on Information and Knowledge Management, páginas 911-920. ACM. Citado na página 35.

Cai, D., Wang, X., e He, X. (2009). Probabilistic dyadic data analysis with local and global consistency. In Danyluk, A. P., Bottou, L., e Littman, M. L., editors, Proceedings of the Internation Conference on Machine Learning, volume 382, páginas 105-112. ACM. Citado nas páginas 39 e 40.

Camps-Valls, G., Marsheva, T. V. B., e Zhou, D. (2007). Semi-supervised graph-based hyperspectral image classification. IEEE Transactions on Geoscience and Remote Sensing, 45(10):3044-3054. Citado na página 134.

Caropreso, M. F., Matwin, S., e Sebastiani, F. (2001). A learner-independent evaluation of the usefulness of statistical phrases for automated text categorization. Text databases 86 document management: theory \& practice, páginas 78-102. Citado nas páginas 15 e 20.

Caruana, R. e Niculescu-Mizil, A. (2006). An empirical comparison of supervised learning algorithms. In Proceedings of the International Conference on Machine Learning, páginas 161-168. ACM. Citado na página 101.

Carvalho, V. R. e Cohen, W. W. (2006). Improving "email speech acts" analysis via n-gram selection. In Proceedings of the Workshop on Analyzing Conversations in Text and Speech, páginas 35-41. ACL. Citado nas páginas 15 e 20.

Chakrabarti, S., Dom, B., e Indyk, P. (1998). Enhanced hypertext categorization using hyperlinks. SIGMOD Record, 27(2):307-318. Citado nas páginas 39, 41, 125, 127, 128, 129, e 131.

Chakrabarti, S., Dom, B. E., Agrawal, R., e Raghavan, P. (1997). Using taxonomy, discriminants, and signatures for navigating in text databases. In Jarke, M., Carey, M. J., Dittrich, K. R., Lochovsky, F. H., Loucopoulos, P., e Jeusfeld, M. A., editors, Proceedings of the International Conference on Very Large Data Bases, páginas 446-455. Morgan Kaufmann Publishers. Citado na página 69.

Chakraborti, S., Mukras, R., Lothian, R., Wiratunga, N., Watt, S., e Harper, D. (2007). Supervised latent semantic indexing using adaptive sprinkling. In Proceedings of the International Joint Conference on Artifical Intelligence, páginas 1582-1587. Morgan Kaufmann Publishers Inc. Citado na página 29.

Chakravarthy, S., Venkatachalam, A., Telang, A., e Aery, M. (2014). Infosift: A novel, miningbased framework for document classification. Proceedings of the International Journal of Next Generation Computing, 5(2):1-10. Citado na página 89.

Chapelle, O., Schölkopf, B., e Zien, A., editors (2006). Semi-Supervised Learning. MIT Press. Citado nas páginas 3, 116, 118, 125, 135, 195, e 198.

Chapman, W. W., Christensen, L. M., Wagner, M. M., Haug, P. J., Ivanov, O., Dowling, J. N., e Olszewski, R. T. (2005). Classifying free-text triage chief complaints into syndromic categories with natural language processing. Artificial Intelligence in Medicine, 33(1):31-40. Citado na página 70 . 
Chen, R. C. e Hsieh, C. H. (2006a). Web page classification based on a support vector machine using a weighted vote schema. Expert Systems with Applications, 31(2):427-435. Citado na página 3.

Chen, R. C. e Hsieh, C. H. (2006b). Web page classification based on a support vector machine using a weighted vote schema. Expert Systems with Applications, 31(2):427-435. Citado na página 69.

Cheng, H., Yan, X., Han, J., e Hsu, C.-W. (2007). Discriminative frequent pattern analysis for effective classification. In Chirkova, R., Dogac, A., Özsu, M. T., e Sellis, T. K., editors, Internation Conference Data Engineering, páginas 716-725. IEEE. Citado na página 55.

Chisholm, E. e Kolda, T. G. (1999). New term weighting formulas for the vector space method in information retrieval. Oak Ridge National Laboratory, US. Citado na página 22.

Ciaccia, P., Patella, M., e Zezula, P. (1997). M-tree: An efficient access method for similarity search in metric spaces. In Proceedings of the International Conference on Very Large Data Bases, páginas 426-435. Morgan Kaufmann Publishers Inc. Citado na página 87.

CMU Text Learning Group (1998). The 4 universities data set. http://www.cs.cmu.edu/afs/cs . cmu.edu/project/theo-20/www/data/. Último acesso em 6 de Novembro de 2013. Citado na página 268.

Cohen, W. W. (1995). Fast effective rule induction. In Proceedings of the International Conference on Machine Learning, páginas 115-123. Citado nas páginas 79 e 80.

Cohen, W. W. (2009). Enron email dataset. http://www.cs.cmu.edu/〜enron/. Último acesso em 19 de Julho de 2013. Citado na página 266.

Cohen, W. W. e Singer, Y. (1999). Context-sensitive learning methods for text categorization. ACM Transactions on Information Systems, 17(2):141-173. Citado nas páginas 79, 81, e 101.

Collins, M. e Singer, Y. (1999). Unsupervised models for named entity classification. In Proceedings of the Joint Conference on Empirical Methods in Natural Language Processing and Very Large Corpora, páginas 100-110. Citado na página 119.

Conrado, M. S. (2009). O efeito do uso de diferentes formas de extração de termos na compreensibilidade e representatividade dos termos em coleções textuais na língua portuguesa. Dissertação de mestrado, ICMC-USP, São Carlos - SP. Citado na página 269.

Conrado, M. S., Gutiérrez, V. A. L., e Rezende, S. O. (2012). Evaluation of normalization techniques in text classification for portuguese. In Proceedings of the International Conference on Computational Science and Its Applications, páginas 618-630. Springer-Verlag. Citado na página 21.

Conrado, M. S., Rossi, R. G., Pardo, T. A. S., e Rezende, S. O. (2005). Applying transductive learning for automatic term extraction: the case of the ecology domain. In Proceedings of the International Conference on Informatics $\&$ Applications, páginas 264-269. IEEE. Citado nas páginas $12,65,117$, e 227.

Cook, D. J. e Holder, L. B. (2000). Graph-based data mining. IEEE Intelligent Systems, 15:32-41. Citado na página 90.

Cormack, G. V. e Lynam, T. R. (2007). 2007 trec public spam corpus. http://plg. uwaterloo.ca/ gvcormac/treccorpus07/. Último acesso em 6 de Novembro de 2013. Citado na página 266. 
Coussement, K. e den Poel, D. V. (2008). Improving customer complaint management by automatic email classification using linguistic style features as predictors. Decision Support Systems, 44(4):870-882. Citado nas páginas 3 e 69.

Cozman, F., Cohen, I., e Cirelo, M. (2003). Semi-supervised learning of mixture models. In Proceedings of the International Conference on Machine Learning. Citado nas páginas 118 e 198.

Cubranic, D. e Murphy, G. C. (2004). Automatic bug triage using text categorization. In Proceedings of the International Conference on Software Engineering and Knowledge Engineering, páginas 92-97. Citado nas páginas 3 e 70.

Culp, M. e Michailidis, G. (2008). An iterative algorithm for extending learners to a semisupervised setting. Journal of Computational \& Graphical Statistics, 17(3):545-571. Citado nas páginas 3 e 119 .

Dang, E. K. F., Luk, R. W. P., e Allan, J. (2014). Beyond bag-of-words: Bigram-enhanced context-dependent term weights. Journal of the Association for Information Science and Technology, 65(6):1134-1148. Citado nas páginas 4 e 20.

Danon, L., Guilera, A. D., Duch, J., e Arenas, A. (2005). Comparing community structure identification. Journal of Statistical Mechanics: Theory and Experiment, 2005(9):P09008. Citado na página 36.

Dasgupta, S. e Ng, V. (2009). Mine the easy, classify the hard: A semi-supervised approach to automatic sentiment classification. In Proceedings of the Joint Conference of the Annual Meeting of the Association for Computational Linguistics, páginas 701-709. ACL. Citado na página 117.

Data Mining Research (2010). Classic3 and classic4 datasets. http://www. dataminingresearch. com/index.php/2010/09/classic3-classic4-datasets/. Último acesso em 19 de Julho de 2013. Citado na página 267.

de Padua, R., Rezende, S. O., e de Carvalho, V. O. (2014). Post-processing association rules using networks and transductive learning. In Proceedings of the International Conference on Machine Learning and Applications, páginas 318-323. Citado nas páginas 12, 117, e 227.

de Sousa, C. A. R., Rezende, S. O., e Batista, G. E. A. P. A. (2013). Influence of graph construction on semi-supervised learning. In Proceedings of the European Conference Machine Learning and Knowledge Discovery in Databases, páginas 160-175. Citado na página 136.

Debole, F. e Sebastiani, F. (2003). Supervised term weighting for automated text categorization. In Proceedings of the ACM Symposium on Applied Computing, páginas 784-788. ACM. Citado na página 22.

Deerwester, S. C., Dumais, S. T., Landauer, T. K., Furnas, G. W., e Harshman, R. A. (1990). Indexing by latent semantic analysis. Journal of the Association for Information Science and Technology, 41(6):391-407. Citado na página 27.

Del-Vecchio, R., Vinagre, C., e Stevanović, D. (2007). Introdução à Teoria Espectral de Grafos com Aplicações. Notas em Matemática Aplicada. Sociedade Brasileira de Matemática Aplicada e Computacional. Citado na página 38.

Delalleau, O., Bengio, Y., e Le Roux, N. (2005). Efficient non-parametric function induction in semi-supervised learning. In Proceedings of the International Workshop on Artificial Intelligence and Statistics, páginas 96-103. Citado nas páginas 134, 198, 200, e 201. 
Delany, S. J., Buckley, M., e Greene, D. (2012). Review: SMS spam filtering: methods and data. Expert Systems with Applications, 39(10):9899-9908. Citado na página 70.

Demiriz, A., Bennett, K., e Embrechts, M. J. (1999). Semi-supervised clustering using genetic algorithms. In Proceedings of the Artificial Neural Networks in Engineering Conference, páginas 809-814. ASME Press. Citado na página 125.

Dempster, A. P., Laird, N. M., e Rubin, D. B. (1977). Maximum likelihood from incomplete data via the EM algorithm. Journal of the Royal Statistical Society: Series B, 39. Citado nas páginas 28 e 121.

Demsar, J. (2006). Statistical comparisons of classifiers over multiple data sets. Journal of Machine Learning Research, 7:1-30. Citado nas páginas 105, 163, 203, e 265.

Deng, H., Han, J., Zhao, B., Yu, Y., e Lin, C. X. (2011). Probabilistic topic models with biased propagation on heterogeneous information networks. In Proceedings of the ACM International Conference on Knowledge Discovery and Data Mining, páginas 1271-1279. ACM. Citado nas páginas 39 e 41.

Deng, Z.-H., Luo, K.-H., e Yu, H.-L. (2014). A study of supervised term weighting scheme for sentiment analysis. Expert Systems with Applications, 41(7):3506-3513. Citado na página 22.

Dhillon, I., Kogan, J., e Nicholas, C. (2003). Feature selection and document clustering. In Berry, M. W., editor, Survey of Text Mining, páginas 73-100. Springer. Citado na página 24.

Dhillon, I. S. (2001). Co-clustering documents and words using bipartite spectral graph partitioning. In Proceedings of the International Conference on Knowledge Discovery and Data Mining, páginas 269-274. ACM. Citado nas páginas 33 e 39.

Diederich, J., Kindermann, J., Leopold, E., e Paass, G. (2003). Authorship attribution with support vector machines. Applied Intelligence, 19(1-2):109-123. Citado na página 70.

Dietterich, T. G. (2000). Ensemble methods in machine learning. In Proceedings of the International Workshop on Multiple Classifier Systems, páginas 1-15. Springer-Verlag. Citado na página 52.

Dinakar, K., Jones, B., Havasi, C., Lieberman, H., e Picard, R. W. (2012). Common sense reasoning for detection, prevention, and mitigation of cyberbullying. ACM Transactions on Interactive Intelligent Systems, 2(3):1-30. Citado na página 70.

Dinakar, K., Reichart, R., e Lieberman, H. (2011). Modeling the detection of textual cyberbullying. In The Social Mobile Web, volume WS-11-02 of AAAI Workshops. AAAI. Citado na página 70.

Ding, C. H. Q., He, X., Zha, H., Gu, M., e Simon, H. D. (2001). A min-max cut algorithm for graph partitioning and data clustering. In Proceedings of the International Conference on Data Mining, páginas 107-114. IEEE. Citado na página 36.

do Prado, H. A. e Ferneda, E., editors (2008). Emerging Technologies of Text Mining: Techniques and Applications. Information Science Reference. Citado na página 16.

Dongarra, J. J., Bunch, J. R., Moler, C. B., e Stewart, G. W. (1979). LINPACK users' guide, volume 8. SIAM. Citado na página 75.

Dorow, B. e Widdows, D. (2003). Discovering corpus-specific word senses. In Proceedings of the Conference on European Chapter of the Association for Computational Linguistics, páginas 79-82. ACL. Citado na página 39.

Draszawka, K. e Szymanski, J. (2013). Thresholding strategies for large scale multi-label text classifier. In Proceedings of the International Conference on Human System Interaction, páginas 350-355. IEEE. Citado na página 62. 
Druck, G., Mann, G., e McCallum, A. (2008). Learning from labeled features using generalized expectation criteria. In Proceedings of the International Conference on Research and Development in Information Retrieval, páginas 595-602. ACM. Citado na página 118.

Drucker, H., Wu, D., e Vapnik, V. (1999). Support vector machines for spam categorization. IEEE Transactions on Neural Networks, 10(5):1048-1054. Citado na página 69.

Drury, B., Rossi, R. G., e de Andrade Lopes, A. (2014). Identification of brazilian portuguese causative verbs through a weighted graph classification strategy. In International Conference on Computational Processing of the Portuguese Language, páginas 274-279. Citado nas páginas 12 e 65.

Dumais, S., Platt, J., Heckerman, D., e Sahami, M. (1998). Inductive learning algorithms and representations for text categorization. In Proceedings of the International Conference on Information and Knowledge Management, páginas 148-155. ACM. Citado nas páginas 2, 67, 68,71 , e 101.

Dumais, S. T. e Chen, H. (2000). Hierarchical classification of web ontent. In Proceedings of the International Conference on Research and Development in Information Retrieval, páginas 256-263. Citado na página 69.

Dupont, S. e Ravet, T. (2013). Improved audio classification using a novel non-linear dimensionality reduction ensemble approach. In Proceedings of the International Society of Music Information Retrieval, páginas 287-292. Citado na página 117.

Durant, K. T. e Smith, M. D. (2006). Predicting the political sentiment of web log posts using supervised machine learning techniques coupled with feature selection. In Proceedings of the International Workshop on Knowledge Discovery on the Web, páginas 187-206. Citado na página 70.

Elworthy, D. (1994). Does baum-welch re-estimation help taggers? In Proceedings of the Conference on Applied Natural Language Processing, páginas 53-58. ACL. Citado na página 118.

Erenel, Z. e Altinçay, H. (2012). Nonlinear transformation of term frequencies for term weighting in text categorization. Engineering Applications of Artificial Intelligence, 25(7):1505-1514. Citado na página 22.

Erkan, G. e Radev, D. R. (2004). LexRank: Graph-based lexical centrality as salience in text summarization. Artificial Intelligence Research, 22:457-479. Citado na página 39.

Escudero, G., Màrquez, L., e Rigau, G. (2000). Boosting applied to word sense disambiguation. In Proceedings of the European Conference on Machine Learning, páginas 129-141. Springer-Verlag. Citado na página 70.

Esuli, A. e Sebastiani, F. (2010). Machines that learn how to code open-ended survey data. International Journal of Market Research, 52(6):775-800. Citado na página 70.

Eyheramendy, S., Lewis, D. D., e Madigan, D. (2003). On the naive bayes model for text categorization. In International Workshop on Artificial Intelligence and Statistics, páginas 3-6. Citado na página 73.

Fagan, J. (1989). The effectiveness of a nonsyntactic approach to automatic phrase indexing for document retrieval. Journal of the American Society for Information Science, 40(2):115-132. Citado na página 19.

Feldman, R. e Sanger, J. (2006). The Text Mining Handbook: Advanced Approaches in Analyzing Unstructured Data. Cambridge University Press. Citado nas páginas 1, 16, 22, 68, 71, 73, 87, 100, 101, e 269. 
Ferreira, R., de Freitas, F. L. G., de Souza Cabral, L., Lins, R. D., Lima, R., de Franca Pereira e Silva, G., Simske, S. J., e Favaro, L. (2013). A four dimension graph model for automatic text summarization. In Proceedings of the Web Intelligence Congress, páginas 389-396. IEEE. Citado nas páginas 16 e 39.

Figueiredo, F., Rocha, L., Couto, T., Salles, T., Gonçalves, M. A., e Meira Jr., W. (2011). Word co-occurrence features for text classification. Information Systems, 36(5):843-858. Citado nas páginas 54 e 55.

Forman, G. (2003). An extensive empirical study of feature selection metrics for text classification. Journal of Machine Learning Research, 3:1289-1305. Citado na página 25.

Forman, G. (2006). 19MclassTextWc dataset, http://sourceforge.net/projects/weka/files/ datasets/text-datasets/19MclassTextWc.zip/download. Último acesso em 26 de julho de 2015. Citado nas páginas 266, 267, e 268.

Frank, E. e Witten, I. H. (1998). Generating accurate rule sets without global optimization. In Proceedings of the International Conference on Machine Learning, páginas 144-151. Morgan Kaufmann Publishers Inc. Citado na página 81.

Fritscher, E. (2011). Propriedades espectrais de um grafo. Dissertação de Mestrado, Instituto de Matemática, Universidade Federal do Rio Grande do Sul. Citado na página 38.

Fuchs, C., Boersma, K., Albrechtslund, A., e Sandoval, M. (2013). Internet and Surveillance: The Challenges of Web 2.0 and Social Media. Routledge Studies in Science, Technology and Society. Taylor \& Francis. Citado na página 1.

Fung, B. C. M., Wang, K., e Ester, M. (2003). Hierarchical document clustering using frequent itemsets. In Proceedings of the SIAM International Conference on Data Mining, páginas 59-70. Citado nas páginas 15, 54, e 55 .

Fung, G. P. C., Yu, J. X., e Lam, W. (2002). News sensitive stock trend prediction. In Advances in Knowledge Discovery and Data Mining, páginas 481-493. Springer. Citado na página 70.

Fürnkranz, J. e Widmer, G. (1994). Incremental reduced error pruning. In Proceedings of the International Conference on Machine Learning, páginas 70-77. Citado nas páginas 20 e 81.

Fürnkranz, J. (1998). A study using n-gram features for text categorization. Relatório Técnico OEFAI-TR-98-30, Austrian Research Institute for Artificial Intelligence. Citado na página 55.

Gaines, B. R. e Compton, P. (1995). Induction of ripple-down rules applied to modeling large databases. Journal of Intelligent Information Systems, 5(3):211-228. Citado na página 81.

Gamon, M. (2006). Graph-based text representation for novelty detection. In Proceedings of the Workshop on Graph Based Methods for Natural Language Processing, páginas 17-24. ACL. Citado na página 40.

Gao, B., Liu, T.-Y., e Ma, W.-Y. (2006). Star-structured high-order heterogeneous data coclustering based on consistent information theory. In Proceedings of the International Conference on Data Mining, páginas 880-884. IEEE. Citado na página 34.

Gao, B., Liu, T.-Y., Zheng, X., Cheng, Q., e Ma, W.-Y. (2005). Consistent bipartite graph co-partitioning for star-structured high-order heterogeneous data co-clustering. In Proceedings of the International Conference on Knowledge Discovery and Data Mining, páginas 41-50. ACM. Citado nas páginas 5, 30, 34, e 36. 
Gao, Y., Wang, M., Ji, R., Zha, Z.-J., e Shen, J. (2012). k-partite graph reinforcement and its application in multimedia information retrieval. Information Sciences, 194:224-239. Citado nas páginas 34 e 135 .

García, S., Fernández, A., Luengo, J., e Herrera, F. (2010). Advanced nonparametric tests for multiple comparisons in the design of experiments in computational intelligence and data mining: Experimental analysis of power. Information Sciences, 180(10):2044-2064. Citado nas páginas 105, 163, e 203.

Gee, K. R. e Cook, D. J. (2005). Text classification using graph-encoded linguistic elements. In Proceedings of the Florida Artificial Intelligence Research Society Conference, páginas 487-492. AAAI Press. Citado nas páginas 16 e 39.

Geman, S. e Geman, D. (1984). Stochastic relaxation, gibbs distributions and the bayesian restoration of images. IEEE Transactions on Pattern Analysis and Machine Intelligence, PAMI-6(6):721-741. Citado na página 130.

Geng, L. e Hamilton, H. J. (2006). Interestingness measures for data mining: A survey. Computing Surveys, 38(3):9. Citado nas páginas xv, 55, 56, 57, e 58.

Genkin, A., Lewis, D. D., e Madigan, D. (2007). Large-scale bayesian logistic regression for text categorization. Technometrics, 49:291-304(14). Citado nas páginas 73 e 101.

Getoor, L. e Diehl, C. P. (2005). Link mining: a survey. SIGKDD Explorations, 7(2):3-12. Citado nas páginas 5 e 16.

Getoor, L. e Taskar, B. (2007). Introduction to Statistical Relational Learning (Adaptive Computation and Machine Learning). The MIT Press. Citado na página 127.

Gidó, G. (2003). Using news articles to predict stock price movements. Relatório técnico, Department of Computer Science and Engineering, University of California. Citado na página 70 .

Giorgetti, D. e Sebastiani, F. (2003). Automating survey coding by multiclass text categorization techniques. Journal of the American Society for Information Science and Technology, 54(14):1269-1277. Citado na página 70.

Girolami, M. e Kabán, A. (2003). On an equivalence between PLSI and LDA. In Proceedings of the International Conference on Research and Development in Informaion Retrieval, páginas 433-434. ACM. Citado na página 29.

Goldberg, A. B. e Zhu, X. (2006). Seeing stars when there aren't many stars: Graph-based semi-supervised learning for sentiment categorization. In Proceedings of the First Workshop on Graph Based Methods for Natural Language Processing, páginas 45-52. ACL. Citado nas páginas 117 e 134.

Griffiths, T. L. e Steyvers, M. (2004). Finding scientific topics. In: Proceedings of the National Academy of Sciences of the United States of America, 101(Suppl. 1):5228-5235. Citado na página 29.

Group, M. L. (2009). Irish economic sentiment dataset. http://mlg.ucd.ie/sentiment. Último acesso em 12 de Julho de 2012. Citado na página 267.

Guan, J. e Zhou, S. (2002). Pruning training corpus to speedup text classification. In Hameurlain, A., Cicchetti, R., e Traunmüller, R., editors, Proceedings of the Database and Expert Systems Applications, volume 2453 of Lecture Notes in Computer Science, páginas 831-840. Springer. Citado na página 87. 
Guo, Z., Zhu, S., Chi, Y., Zhang, Z., e Gong, Y. (2010). Unsupervised learning from linked documents. In Proceedings of the International Conference on Pattern Recognition, páginas 730-733. IEEE. Citado na página 15.

Gupta, V. e Lehal, G. (2009). A survey of text mining techniques and applications. Journal of Emerging Technologies in Web Intelligence, 1(1):60 - 76. Citado na página 1.

Haffari, G. e Sarkar, A. (2007). Analysis of semi-supervised learning with the yarowsky algorithm. In Proceedings of the Twenty-Third Conference on Uncertainty in Artificial Intelligence, páginas 159-166. Citado na página 119.

Hall, M. A. (1999). Correlation-based feature selection for machine learning. Tese de Doutorado, The University of Waikato. Citado na página 23.

Han, E., Karypis, G., e Kumar, V. (2001). Text categorization using weight adjusted k-nearest neighbor classification. In Pacific-Asia Conference on Knowledge Discovery and Data Mining, páginas 53-65. Springer. Citado nas páginas 78 e 86.

Han, E.-H., Boley, D., Gini, M., Gross, R., Hastings, K., Karypis, G., Kumar, V., Mobasher, B., e Moore, J. (1998). Webace: a web agent for document categorization and exploration. In Proceedings of the International Conference on Autonomous Agents, páginas 408-415. ACM. Citado na página 268.

Han, E.-H. e Karypis, G. (2000). Centroid-based document classification: Analysis and experimental results. In Proceedings of the European Conference Principles of Data Mining and Knowledge Discovery, páginas 242-231. Springer. Citado nas páginas 85, 86, e 268.

Han, J. (2012). Mining heterogeneous information networks: the next frontier. In Proceedings of the International Conference on Knowledge Discovery and Data Mining, páginas 2-3. ACM. Citado na página 4.

Han, J. e Kamber, M. (2011). Data mining: concepts and techniques. The Morgan Kaufmann Series in Data Management Systems. Elsevier. Citado na página 78.

Hassan, S., Mihalcea, R., e Banea, C. (2007). Random-walk term weighting for improved text classification. In International Conference on Semantic Computing, páginas 242-249. IEEE. Citado nas páginas 39 e 47.

Hayes, P. J., Anderson, P. M., Nirenburg, I. B., e Schmandt, L. M. (1990). TCS: A shell for content-based text categorization. In Proceedings of the Conference on Artificial Intelligence Applications, páginas 320-326. IEEE. Citado na página 7.

Hayes, P. J. e Weinstein, S. P. (1991). Construe/tis: A system for content-based indexing of a database of news stories. In Proceedings of the Conference on Innovative Applications of Artificial Intelligence, páginas 49-64. AAAI Press. Citado na página 67.

Hensman, S. (2004). Construction of conceptual graph representation of texts. In Proceedings of the Student Research Workshop at HLT-NAACL 2004, páginas 49-54. ACL. Citado na página 16.

Hersh, W., Buckley, C., Leone, T. J., e Hickam, D. (1994). Ohsumed: an interactive retrieval evaluation and new large test collection for research. In Proceedings of the Annual International Conference on Research and Development in Information Retrieval, páginas 192-201. SpringerVerlag New York, Inc. Citado na página 266.

Hofmann, T. (1999). Probabilistic latent semantic indexing. In Proceedings of the International Conference on Research and Development in Information Retrieval, páginas 50-57. ACM. Citado nas páginas 4 e 28. 
Huang, Z., Chung, W., Ong, T.-H., e Chen, H. (2002). A graph-based recommender system for digital library. In Proceedings of the ACM/IEEE-CS Joint Conference on Digital Libraries, páginas 65-73. ACM. Citado na página 39.

Jacobs, N. (2002). Co-term network analysis as a means of describing the information landscapes of knowledge communities across sectors. Journal of Documentation, 58(5):548-562. Citado nas páginas 6,40 , e 56 .

Jebara, T., Wang, J., e Chang, S.-F. (2009). Graph construction and b-matching for semisupervised learning. In Proceedings of the Annual International Conference on Machine Learning, páginas 441-448. ACM. Citado na página 43.

Jensen, D., Neville, J., e Gallagher, B. (2004). Why collective inference improves relational classification. In Proceedings of the International Conference on Knowledge Discovery and Data Mining, páginas 593-598. ACM. Citado na página 125.

Ji, M., Sun, Y., Danilevsky, M., Han, J., e Gao, J. (2010). Graph regularized transductive classification on heterogeneous information networks. In Proceedings of the European Conference on Machine Learning and Knowledge Discovery in Databases, páginas 570-586. Springer-Verlag. Citado nas páginas 5, 6, 16, 30, 36, 39, 41, 50, 93, 98, 135, 140, e 154.

Jiang, C., Coenen, F., Sanderson, R., e Zito, M. (2010). Text classification using graph miningbased feature extraction. Knowledge-Based Systems, 23(4):302-308. Citado nas páginas xi, 5, $16,46,47$, e 88 .

Joachims, T. (1998). Text categorization with suport vector machines: Learning with many relevant features. In Proceedings of the European Conference on Machine Learning, páginas 137-142. Springer-Verlag. Citado nas páginas 53, 75, 125, e 269.

Joachims, T. (1999). Transductive inference for text classification using support vector machines. In Proceedings of the International Conference on Machine Learning, páginas 200-209. Morgan Kaufmann Publishers Inc. Citado nas páginas 21, 119, 123, 160, 197, e 269.

Joachims, T. (2003). Transductive learning via spectral graph partitioning. In Proceedings of the International Conference on Machine Learning, páginas 290-297. Citado nas páginas 117, 126, e 136.

Joachims, T. (2006). Semi supervised Learning, capítulo 6 - Transductive Support Vector Machine. MIT Press, $1^{\mathrm{a}}$ edição. Citado nas páginas 116 e 124.

Jockers, M. L. e Witten, D. M. (2010). A comparative study of machine learning methods for authorship attribution. Literary and Linguistic Computing, 25(2):215-223. Citado na página 70 .

Johnson, D. E., Oles, F. J., 0001, T. Z., e Götz, T. (2002). A decision-tree-based symbolic rule induction system for text categorization. IBM Systems Journal, 41(3):428-437. Citado na página 81.

Jolliffe, I. (2002). Principal Component Analysis. Springer Series in Statistics. Springer. Citado na página 27.

Jones, R. (2005). Learning to Extract Entities from Labeled and Unlabeled Text. Tese de Doutorado, Carnegie Mellon University. Citado nas páginas 117 e 119.

Jurek, A., Bi, Y., Wu, S., e Nugent, C. D. (2014). A survey of commonly used ensemble-based classification techniques. Knowledge Engineering Review, 29(5):551-581. Citado na página 52. 
Kalt, T. (1998). A new probabilistic model of text classification and retrieval title2:. Relatório técnico, University of Massachusetts. Citado na página 73.

Kang, U., Akoglu, L., e Chau, D. H. (2014). Big graph mining for the web and social media: algorithms, anomaly detection, and applications. In Proceedings of the International Conference on Web Search and Data Mining, páginas 677-678. Citado na página 35.

Karypis, G. (2006). Cluto - software for clustering high-dimensional datasets. http://glaros . dtc.umn.edu/gkhome/cluto/cluto/download. Último acesso em 6 de Novembro de 2013. Citado nas páginas 266 e 267.

Katakis, I., Tsoumakas, G., e Vlahavas, I. (2008). Multilabel text classification for automated tag suggestion. In Proceedings of the European Conference on Machine Learning and Principles and Practice of Knowledge Discovery in Databases - Discovery Challenge, páginas 1-9. Citado na página 231.

Kim, S., Pantel, P., Duan, L., e Gaffney, S. (2009). Improving web page classification by labelpropagation over click graphs. In Proceedings of the ACM Conference on Information and Knowledge Management, páginas 1077-1086. Citado nas páginas 6, 35, 39, e 42.

Kim, S.-B., Han, K.-S., Rim, H.-C., e Myaeng, S. H. (2006). Some effective techniques for naive bayes text classification. IEEE Transactions on Knowledge and Data Engineering, 18(11):1457 -1466. Citado na página 72 .

Kleinberg, J. M. (1999). Authoritative sources in a hyperlinked environment. Journal of the ACM, 46(5):604-632. Citado nas páginas 39 e 40.

Koller, D. e Sahami, M. (1997). Hierarchically classifying documents using very few words. In Proceedings of the International Conference on Machine Learning, páginas 170-178. Morgan Kaufmann. Citado na página 69.

Konstas, I., Stathopoulos, V., e Jose, J. M. (2009). On social networks and collaborative recommendation. In Proceedings of the International Conference on Research and Development in Information Retrieval, páginas 195-202. ACM. Citado na página 39.

Koprinska, I., Poon, J., Clark, J., e Chan, J. (2007). Learning to classify e-mail. Information Sciences, 177(10):2167-2187. Citado na página 196.

Koussounadis, A., Redfern, O., e Jones, D. T. (2009). Improving classification in protein structure databases using text mining. BMC Bioinformatics, 10. Citado na página 70.

Krishnapuram, B., Williams, D., Xue, Y., Hartemink, A., Carin, L., e Figueiredo, M. (2005). On Semi-Supervised classification. In Advances in Neural Information Processing Systems, páginas 721-728. MIT Press. Citado na página 198.

Krogel, M. e Scheffer, T. (2004). Multi-relational learning, text mining, and semi-supervised learning for functional genomics. Machine Learning, 57(1-2):61-81. Citado na página 117.

Kuechler, W. L. (2007). Business applications of unstructured text. Communications of the ACM, 50(10):86-93. Citado na página 1.

Lacoste-Julien, S., Sha, F., e Jordan, M. I. (2009). Disclda: Discriminative learning for dimensionality reduction and classification. In Koller, D., Schuurmans, D., Bengio, Y., e Bottou, L., editors, Advances in Neural Information Processing Systems, páginas 897-904. Curran Associates, Inc. Citado na página 29. 
Lam, W. e Ho, C. Y. (1998). Using a generalized instance set for automatic text categorization. In Proceedings of the International Conference on Research and Development in Information Retrieval, páginas 81-89. ACM. Citado na página 85.

Lan, M., Tan, C.-L., e Low, H.-B. (2006). Proposing a new term weighting scheme for text categorization. In Proceedings of the National Conference on Artificial Intelligence, páginas 763-768. AAAI Press. Citado na página 22.

Lan, M., Tan, C.-L., Low, H.-B., e Sung, S.-Y. (2005). A comprehensive comparative study on term weighting schemes for text categorization with support vector machines. In Proceedings of the International Conference on World Wide Web - Special Interest Tracks and Posters, páginas 1032-1033. ACM. Citado na página 22.

Lan, M., Tan, C. L., Su, J., e Lu, Y. (2009). Supervised and traditional term weighting methods for automatic text categorization. IEEE Transactions on Pattern Analysis and Machine Intelligence, 31(4):721-735. Citado na página 22.

Lang, K. (1995). Newsweeder: Learning to filter netnews. In Proceedings of the International Machine Learning Conference, páginas 331-339. Citado na página 69.

Larkey, L. S. (1998). Automatic essay grading using text categorization techniques. In Proceedings of the International Conference on Research and Development in Information Retrieval, páginas 90-95. ACM. Citado na página 70.

Lee, J. H. (1995). Combining multiple evidence from different properties of weighting schemes. In Proceedings of the International Conference on Research and Development in Information Retrieval, páginas 180-188. ACM. Citado na página 22.

Levin, A., Lischinski, D., e Weiss, Y. (2004). Colorization using optimization. ACM Transactions on Graphics, 23(3):689-694. Citado na página 134.

Lewis, D. D. (2004). Reuters-21578. http://www.daviddlewis.com/resources/ testcollections/reuters21578/. Último acesso em 6 de Novembro de 2013. Citado na página 267.

Lewis, D. D. (2005). The LYRL2004 distribution of the RCV1-v2 text categorization test collection, http://www.ai.mit.edu/projects/jmlr/papers/volume5/lewis04a/lyrl2004_ rcv1v2_README.htm. Último acesso em 6 de Novembro de 2014. Citado na página 267.

Lewis, D. D. e Gale, W. A. (1994). A sequential algorithm for training text classifiers. In Proceedings of the International Conference on Research and Development in Information Retrieval, páginas 3-12. Springer-Verlag. Citado na página 73.

Li, F. e Yang, Y. (2003). A loss function analysis for classification methods in text categorization. In Proceedings of the International Conference on Machine Learning, páginas 472-479. AAAI Press. Citado na página 75.

Liao, Y. e Vemuri, V. R. (2002). Use of k-nearest neighbor classifier for intrusion detection. Computers ES Security, 21(5):439-448. Citado na página 70.

Liu, B., Hsu, W., e Ma, Y. (1998). Integrating classification and association rule mining. In Proceedings of the International Conference on Knowledge Discovery and Data Mining, páginas 80-86. AAAI Press. Citado nas páginas 54 e 81.

Liu, B. e Zhang, L. (2012). A survey of opinion mining and sentiment analysis. In Aggarwal, C. C. e Zhai, C., editors, Mining Text Data, páginas 415-463. Springer. Citado nas páginas 3 e 70. 
Liu, J., Chen, Y., Xie, J., Gao, X., e Gao, W. (2009a). Semi-supervised learning of caricature pattern from manifold regularization. In Proceedings of the International Multimedia Modeling Conference, volume 5371 of Lecture Notes in Computer Science, páginas 413-424. Springer. Citado nas páginas 126 e 134.

Liu, J., Wang, J., e Wang, C. (2008). A text network representation model. In Proceedings of the International Conference on Fuzzy Systems and Knowledge Discovery, páginas 150-154. Citado nas páginas 20, 39, 40, 47, e 88.

Liu, L., Kang, J., Yu, J., e Wang, Z. (2005a). A comparative study on unsupervised feature selection methods for text clustering. In Proceedings of the IEEE International Conference on Natural Language Processing and Knowledge Engineering, páginas 597-601. IEEE. Citado nas páginas 23 e 24 .

Liu, N., Zhang, B., Yan, J., Chen, Z., Liu, W., Bai, F., e Chien, L. (2005b). Text representation: From vector to tensor. In Proceedings of the International Conference on Data Mining, páginas 725-728. IEEE. Citado na página 15.

Liu, T., Liu, S., Chen, Z., e Ma, W.-Y. (2003). An evaluation on feature selection for text clustering. In Fawcett, T. e Mishra, N., editors, Proceedings of the International Conference on Machine Learning, páginas 488-495. AAAI Press. Citado na página 24.

Liu, W. e Chang, S.-F. (2009). Robust multi-class transductive learning with graphs. In Proceedings of the IEEE Computer Society Conference on Computer Vision and Pattern Recognition, páginas 381-388. Citado nas páginas 135 e 136.

Liu, X. e Murata, T. (2011). Detecting communities in k-partite k-uniform (hyper)networks. Journal of Computer Science and Technology, 26:778-791. Citado na página 34.

Liu, Y., Loh, H. T., e Sun, A. (2009b). Imbalanced text classification: A term weighting approach. Expert Systems with Applications, 36(1):690-701. Citado na página 22.

Lodhi, H., Saunders, C., Shawe-Taylor, J., Cristianini, N., e Watkins, C. (2002). Text classification using string kernels. Journal of Machine Learning Research, 2:419-444. Citado na página 15.

Long, B., Wu, X., Zhang, Z., e Yu, P. S. (2006). Unsupervised learning on k-partite graphs. In Proceedings of the International Conference on Knowledge Discovery and Data Mining, páginas 317-326. ACM. Citado na página 34.

Long, B., Zhang, Z., e Yu, P. S. (2010). A general framework for relation graph clustering. Knowledge Information Systems, 24(3):393-413. Citado nas páginas 5 e 36.

Lopes, A. A., Bertini, J. R., Motta, R., e Zhao, L. (2009). Classification based on the optimal k-associated network. In Proceedings of the International Conference on Complex Sciences, páginas 1167-1177. Citado nas páginas 44 e 91.

Lopes, A. A., Pinho, R., Paulovich, F. V., e Minghim, R. (2007). Visual text mining using association rules. Computers $\&$ Graphics, 31(3):316-326. Citado na página 54.

Lu, Q. e Getoor, L. (2003). Link-based classification. In Proceedings of the International Conference on Machine Learning, páginas 496-503. AAAI Press. Citado nas páginas 4, 16, 39, 41, 127, 128, 129, 130, e 131.

Lu, X. (1990). Document retrieval: A structural approach. Information Processing \& Management, 26(2):209-218. Citado na página 39.

Luhn, H. P. (1958). The automatic creation of literature abstracts. Journal of Research and Development - IBM, 2(2):159-165. Citado na página 23. 
Lü, L. e Zhou, T. (2011). Link prediction in complex networks: A survey. Physica A, 390(6):11501170. Citado na página 36.

Maas, A. L., Daly, R. E., Pham, P. T., Huang, D., Ng, A. Y., e Potts, C. (2011). Learning word vectors for sentiment analysis. In Proceedings of the Annual Meeting of the Association for Computational Linguistics: Human Language Technologies, páginas 142-150. ACL. Citado na página 22.

Macskassy, S. e Provost, F. (2003). A simple relational classifier. In Proceedings of the Workshop on Multi-Relational Data Mining in Conference on Knowledge, Discovery, and Data Mining, páginas 64-76. Citado na página 126.

Macskassy, S. A. (2007). Improving learning in networked data by combining explicit and mined links. In Proceedings of the Association for the Advancement of Artificial Intelligence Conference, páginas 590-595. AAAI Press. Citado na página 35.

Macskassy, S. A. e Provost, F. (2007). Classification in networked data: A toolkit and a univariate case study. Journal of Machine Learning Research, 8:935-983. Citado nas páginas 39, 125, 126, 127, 128, 130, 131, e 134 .

Magnani, M. e Rossi, L. (2013). Pareto distance for multi-layer network analysis. In Proceedings of the International Conference on Social Computing, páginas 249-256. Citado na página 33.

Mak, H., Koprinska, I., e Poon, J. (2003). Intimate: A web-based movie recommender using text categorization. In Proceedings of the Web Intelligence Conferece, páginas 602-605. IEEE. Citado na página 70.

Malioutov, I. e Barzilay, R. (2006). Minimum cut model for spoken lecture segmentation. In Proceedings of the International Conference on Computational Linguistics and the Annual Meeting of the Association for Computational Linguistics, páginas 25-32. ACL. Citado na página 39.

Mandic, D. P. (2004). A generalized normalized gradient descent algorithm. IEEE Signal Processing Letters, 11(2):115-118. Citado na página 96.

Manning, C., Raghavan, P., e Schütze, H. (2008). An Introduction to Information Retrieval. Cambridge University Press. Citado nas páginas 1, 2, 22, 42, 67, 68, 69, 72, 87, e 284.

Marcacini, R. M. e Rezende, S. O. (2010). Incremental construction of topic hierarchies using hierarchical term clustering. In Proceedings of the International Conference on Software Engineering and Knowledge Engineering, páginas 553-558. Citado nas páginas 32, 35, 39, 40, 55 , e 69 .

Markov, A., Last, M., e Kandel, A. (2006). Fast categorization of web documents represented by graphs. In Proceedings of the International Workshop on Knowledge Discovery on the Web, páginas 56-71. Citado nas páginas 5, 7, 46, e 88.

Mathworks, T. e NIST, F. f. (1999). Singularvaluedecomposition.class, http://weka. sourceforge.net/doc.dev/weka/core/matrix/SingularValueDecomposition.html. Último acesso em 13 de Novembro de 2014. Citado na página 75.

Matsuno, I. P., Rossi, R. G., Marcacini, R. M., e Rezende, S. O. (2015). Análise de sentimentos baseada em aspectos usando aprendizado semissupervisionado em redes heterogêneas (in press). In Proceedings of the Symposium on Knowledge Discovery, Mining and Learning, páginas 90-93. Citado nas páginas 12, 65, 117, 146, 196, e 227. 
Matsuo, Y., Ohsawa, Y., e Ishizuka, M. (2001). Keyworld: Extracting keywords from a document as a small world. In International Conference on Discovery Science, páginas 271-281. Citado nas páginas 39 e 55 .

Mcauliffe, J. D. e Blei, D. M. (2008). Supervised topic models. In Platt, J., Koller, D., Singer, Y., e Roweis, S., editors, Advances in Neural Information Processing Systems, páginas 121-128. Curran Associates, Inc. Citado na página 29.

McCallum, A. e Nigam, K. (1998). A comparison of event models for naive bayes text classification. In Proceedings of the AAAI Workshop on Learning for Text Categorization, páginas 41-48. AAAI Press. Citado nas páginas 72 e 73.

McClosky, D., Charniak, E., e Johnson, M. (2006). Effective self-training for parsing. In Proceedings of the North American Chapter of the Association of Computational Linguistics, páginas 152-159. ACL. Citado nas páginas 117 e 119.

Mei, Q., Cai, D., Zhang, D., e Zhai, C. (2008a). Topic modeling with network regularization. In Proceedings of the International Conference on World Wide Web, páginas 101-110. ACM. Citado na página 39.

Mei, Q., Zhang, D., e Zhai, C. (2008b). A general optimization framework for smoothing language models on graph structures. In Proceedings of the International Conference on Research and Development in Information Retrieval, páginas 611-618. ACM. Citado na página 134.

Melville, P., Gryc, W., e Lawrence, R. D. (2009). Sentiment analysis of blogs by combining lexical knowledge with text classification. In Proceedings of the International Conference on Knowledge Discovery and Data Mining, páginas 1275-1284. ACM. Citado nas páginas 3 e 70.

Menczer, F. (2004). Lexical and semantic clustering by web links. Journal of the American Society for Information Science and Technology, 55(14):1261-1269. Citado na página 35.

Merris, R. (1994). Laplacian matrices of graphs: a survey. Linear algebra and its applications, 197:143-176. Citado na página 38.

Metzler, D. e Croft, W. B. (2005). Analysis of statistical question classification for fact-based questions. Information Retrieval, 8(3):481-504. Citado na página 70.

Mhamdi, F., Rakotomalala, R., e Elloumi, M. (2006). A compromise between n-gram length and classifier characteristics for protein classification. International Journal of Computer Science and Network Security, 6(4):82-87. Citado na página 70.

Mihalcea, R. (2004). Co-training and self-training for word sense disambiguation. In Hwee, editor, Proceedings of the Conference on Computational Natural Language Learning, páginas 33-40. ACL. Citado nas páginas 117 e 119.

Mihalcea, R. e Radev, D. (2011). Graph-based natural language processing and information retrieval. Cambridge University Press. Citado nas páginas 16, 30, 35, 39, e 40.

Mihalcea, R. e Tarau, P. (2004). TextRank: Bringing order into texts. In Proceedings of the Conference on Empirical Methods in Natural Language Processing, página 404-411. Citado nas páginas 39, 40, 54, 55, 90, e 102.

Mihalcea, R. e Tarau, P. (2005). A language independent algorithm for single and multiple document summarization, UNT digital library, http://digital.library.unt.edu/ark: /67531/metadc30965/. Último acesso em 26 de julho de 2015. Citado na página 39. 
Miller, G. A., Beckwith, R., Fellbaum, C., Gross, D., e Miller, K. J. (1990). Introduction to WordNet: an on-line lexical database. International Journal of Lexicography, 3(4):235-244. Citado na página 39.

Miller, K. T., Griffiths, T. L., e Jordan, M. I. (2009). Nonparametric latent feature models for link prediction. In Bengio, Y., Schuurmans, D., Lafferty, J. D., Williams, C. K. I., e Culotta, A., editors, Advances in Neural Information Processing Systems, páginas 1276-1284. Curran Associates, Inc. Citado na página 36.

Mishra, M., Huan, J., Bleik, S., e Song, M. (2012). Biomedical text categorization with concept graph representations using a controlled vocabulary. In Proceedings of the International Workshop on Data Mining in Bioinformatics, páginas 26-32. ACM. Citado nas páginas xi, 5, $16,39,45,46$, e 89.

Missaoui, R. e Sarr, I. (2015). Social Network Analysis - Community Detection and Evolution. Lecture Notes in Social Networks. Springer. Citado na página 35.

Mitchell, T. M. (1997). Machine Learning. McGraw-Hill., $1^{\mathrm{a}}$ edição. Citado na página 73.

Mitra, M., Buckley, C., Singhal, A., e Cardie, C. (1997). An analysis of statistical and syntactic phrases. In Proceedings of the International Conference on Computer-Assisted Information Retrieval, páginas 200-217. Citado na página 19.

Modha, D. S. e Spangler, W. S. (2000). Clustering hypertext with applications to web searching. In Proceedings of the Conference on Hypertext and Hypermedia, páginas 143-152. ACM. Citado nas páginas 21 e 35 .

Montgomery, D., Peck, E., e Vining, G. (2012). Introduction to Linear Regression Analysis. Wiley Series in Probability and Statistics. Wiley. Citado na página 230.

Monz, C. e Dorr, B. J. (2005). Iterative translation disambiguation for cross-language information retrieval. In Baeza-Yates, R. A., Ziviani, N., Marchionini, G., Moffat, A., e Tait, J., editors, Proceedings of the International Conference on Research and Development in Information Retrieval, páginas 520-527. ACM. Citado na página 39.

Mooney, R. J. (1996). Comparative experiments on disambiguating word senses: An illustration of the role of bias in machine learning. In Proceedings of the Conference on Empirical Methods in Natural Language Processing, páginas 82-91, Philadelphia, PA. Citado na página 70.

Mooney, R. J., Bennett, P. N., e Roy, L. (1998). Book recommending using text categorization with extracted information. In Proceedings Workshop on Recommender Systems, páginas 70-74, Madison, WI. AAAI. Citado na página 70.

Mooney, R. J. e Roy, L. (2000). Content-based book recommending using learning for text categorization. In Proceedings of the ACM Conference on Digital Libraries, páginas 195-204. ACM. Citado na página 70.

Nalini, K. e Sheela, L. J. (2014). A survey on datamining in cyber bullying. International Journal on Recent and Innovation Trends in Computing and Communication, 2(7):1865-1869. Citado na página 70.

Nam, J., Herrera, J., Slaney, M., e Smith, J. O. (2012). Learning sparse feature representations for music annotation and retrieval. In Gouyon, F., Herrera, P., Martins, L. G., e Müller, M., editors, Proceedings of the International Society for Music Information Retrieval Conference, páginas 565-570. Citado na página 70.

Nedjah, N., de Macedo Mourelle, L., Kacprzyk, J., Frana, F. M. G., e de Souza, A. F. (2008). Intelligent Text Categorization and Clustering. Springer, $1^{\mathrm{a}}$ edição. Citado na página 1. 
Nelson, D. L., McKinney, V. M., e Janczura, G. A. (1999). Interpreting the influence of implicitly activated memories on recall and recognition. Psychological Review, 105:299. Citado na página 39 .

Netscape (2013). Dmoz - open directory project. http://www.dmoz.org/. Último acesso em 19 de Julho de 2013. Citado na página 268.

Neville, J. e Jensen, D. (2000). Iterative classification in relational data. In Proceedings of the Workshop on Learning Statistical Models from Relational Data, páginas 13-20. AAAI Press. Citado na página 131.

Newman, M. (2010). Networks: An Introduction. Oxford University Press, Inc. Citado nas páginas $4,16,30,33,35,36,37,38$, e 59 .

Ng, V. (2009). Graph-cut-based anaphoricity determination for coreference resolution. In Proceedings Annual Conference of the North American Chapter of the Association for Computational Linguistics, páginas 575-583. ACL. Citado nas páginas 35 e 39.

Ni, B., Yan, S., e Kassim, A. A. (2012). Learning a propagable graph for semisupervised learning: Classification and regression. IEEE Transactions on Knowledge and Data Engineering, 24(1):114-126. Citado na página 36.

Nigam, K. (2000). The industry sector dataset. http://www.cs.cmu.edu/ TextLearning/ sector-data.tar.gz. Último acesso em 12 de Julho de 2012. Citado na página 268.

Nigam, K. e Ghani, R. (2000). Analyzing the effectiveness and applicability of co-training. In Proceedings of the International Conference on Information and Knowledge Management, páginas 86-93. ACM. Citado nas páginas 121 e 160.

Nigam, K., McCallum, A. K., Thrun, S., e Mitchell, T. (2000). Text classification from labeled and unlabeled documents using EM. Machine Learning, 39(2-3):103-134. Citado nas páginas $72,73,121,122,123,154,160$, e 197.

Niu, Z.-Y., Ji, D.-H., e Tan, C. L. (2005). Word sense disambiguation using label propagation based semi-supervised learning. In Proceedings of the Annual Meeting on Association for Computational Linguistics, páginas 395-402. ACL. Citado na página 134.

Nogueira, B. M. (2009). Avaliação de métodos não supervisionados de seleção de atributos para mineração de textos. Dissertação de Mestrado, Instituto de Ciências Matemáticas e de Computação, Universidade de São Paulo. Citado na página 23.

Nogueira, B. M., Moura, M. F., Conrado, M. S., Rossi, R. G., Marcacini, R. M., e Rezende, S. O. (2008). Winning some of the document preprocessing challenges in a text mining process. In Anais do Workshop em Algoritmos e Aplicações de Mineração de Dados, páginas 10-18. SBC. Citado nas páginas 20, 23, e 24.

Oh, H., Myaeng, S., e Lee, M. (2000). A practical hypertext categorization method using links and incrementally available class information. In Proceedings of the Special Interest Group on Information Retrieval Conference, páginas 264-271. ACM. Citado nas páginas 39, 41, 125, 127,128 , e 131.

Ohsawa, Y., Benson, N. E., e Yachida, M. (1998). Keygraph: Automatic indexing by co-occurrence graph based on building construction metaphor. In Proceedings of the Advances in Digital Libraries Conference, páginas 12-. IEEE. Citado nas páginas 39 e 40.

O'Reilly, T. (2009). What is Web 2.0. O'Reilly radar report. O'Reilly. Citado na página 1. 
Ozaki, K., Shimbo, M., Komachi, M., e Matsumoto, Y. (2011). Using the mutual k-nearest neighbor graphs for semi-supervised classification of natural language data. In Proceedings of the Conference on Computational Natural Language Learning, páginas 154-162. ACL. Citado nas páginas 43 e 271 .

Page, L., Brin, S., Motwani, R., e Winograd, T. (1999a). The PageRank citation ranking: Bringing order to the web. Technical Report 1999-66, Stanford University. Citado nas páginas 39 e 40.

Page, L., Brin, S., Motwani, R., e Winograd, T. (1999b). The PageRank citation ranking: Bringing order to the web. Technical Report 1999-66, Stanford University. Citado nas páginas 90 e 133.

Palshikar, G. K. (2007). Keyword extraction from a single document using centrality measures. In Proceedings of the International Conference on Pattern Recognition and Machine Intelligence, páginas 503-510. Springer. Citado nas páginas 6, 35, 39, 40, 54, e 55.

Pang, B. e Lee, L. (2004). Movie review data. http://www.cs.cornell.edu/People/pabo/ movie-review-data/. Último acesso em 6 de Novembro de 2013. Citado na página 268.

Pang, S. (2010). CSMINING group - the Re8 of Reuters-21578 data set. Último acesso em 10 de Março de 2014. Citado na página 267.

Pazzani, M. (1998). Syskill and webert web page ratings data set. http://archive.ics.uci.edu/ $\mathrm{ml} /$ datasets/Syskill+and+Webert+Web+Page+Ratings. Último acesso em 6 de Novembro de 2013. Citado na página 268.

Pendar, N. (2007). Toward spotting the pedophile telling victim from predator in text chats. In Proceedings of the International Conference on Semantic Computing, páginas 235-241. Citado na página 70.

Phan, X.-H., Nguyen, L.-M., e Horiguchi, S. (2008). Learning to classify short and sparse text \& web with hidden topics from large-scale data collections. In Proceedings of the International Conference on World Wide Web, páginas 91-100. ACM. Citado na página 271.

Porter, M. F. (1980). An algorithm for suffix stripping. Readings in Information Retrieval, 14(3):130-137. Citado nas páginas 155 e 269.

Poularikas, A. (2014). Adaptive Filtering: Fundamentals of Least Mean Squares with MATLABß. CRC Press. Citado na página 230.

Provost, J. (1999). Naive Bayes vs. rule-learning in classification of email. Relatório Técnico AI-TR-99-284, University of Texas at Austin. Citado na página 69.

Qi, G.-J., Aggarwal, C. C., e Huang, T. S. (2012). Community detection with edge content in social media networks. In Proceedings of the IEEE International Conference on Data Engineering, páginas 534-545. IEEE. Citado na página 32.

Quan, X., Wenyin, L., e Qiu, B. (2011). Term weighting schemes for question categorization. IEEE Transactions on Pattern Analysis and Machine Intelligence, 33(5):1009-1021. Citado na página 22.

Quinlan, J. R. (1986). Induction of decision trees. Machine Learning, 1(1):81-106. Citado na página 83.

Quinlan, J. R. (1993). C4.5: Programs for Machine Learning. Morgan Kaufmann. Citado nas páginas 83, 84, e 101. 
Quinlan, J. R. (1995). MDL and categorical theories (continued). In Proceedings of the International Conference on Machine Learning, páginas 464-470. Morgan Kaufmann. Citado na página 80 .

Rakotomalala, R. e Mhamdi, F. (2008). Handbook of research on text and web mining technologies, volume 1, capítulo 8 - Using the Text Categorization Framework for Protein Classification, páginas 128-140. IGI Publishing, $1^{\mathrm{a}}$ edição. Citado na página 70.

Ramage, D., Hall, D., Nallapati, R., e Manning, C. D. (2009). Labeled LDA: A supervised topic model for credit attribution in multi-labeled corpora. In Proceedings of the Conference on Empirical Methods in Natural Language Processing, páginas 248-256. ACL. Citado na página 29.

Rawat, S., Gulati, V., Pujari, A. K., e Vemuri, V. R. (2006). Intrusion detection using text processing techniques with a binary-weighted cosine metric. Journal of Information Assurance and Security, 1(1):43-50. Citado na página 70.

Reed, J. W., Jiao, Y., Potok, T. E., Klump, B. A., Elmore, M. T., e Hurson, A. R. (2006). TF-ICF: A new term weighting scheme for clustering dynamic data streams. In Proceedings of the International Conference on Machine Learning and Applications, páginas 258-263. IEEE. Citado na página 22.

Ren, F. e Sohrab, M. G. (2013). Class-indexing-based term weighting for automatic text classification. Information Sciences, 236:109-125. Citado na página 22.

Rennie, J. (2008). 20 newsgroup dataset. http://qwone.com/ jason/20Newsgroups/. Último acesso em 18 de Julho de 2013. Citado na página 266.

Riloff, E., Wiebe, J., e Wilson, T. (2003). Learning subjective nouns using extraction pattern bootstrapping. In Proceedings of the Conference on Natural Language Learning, páginas 25-32. ACL. Citado nas páginas 117 e 119.

Rocchio, J. J. (1971). Relevance feedback in information retrieval. In Salton, G., editor, The Smart retrieval system - experiments in automatic document processing, páginas 313-323. Englewood Cliffs, NJ: Prentice-Hall. Citado na página 85.

Rodriguez, M. A. e Shinavier, J. (2010). Exposing multi-relational networks to single-relational network analysis algorithms. Journal of Infometrics, abs/0806.2274:29-41. Citado na página 33.

Roget, P. (1966). Roget's thesaurus of english words and phrases. Penguin Reference Books. P Shalom Pubns. Citado na página 39.

Rohban, M. H. e Rabiee, H. R. (2012). Supervised neighborhood graph construction for semisupervised classification. Pattern Recogniton, 45(4):1363-1372. Citado na página 43.

Rossi, R., de Paulo Faleiros, T., de Andrade Lopes, A., e Rezende, S. (2012). Inductive model generation for text categorization using a bipartite heterogeneous network. In Proceedings of the International Conference on Data Mining, páginas 1086-1091. IEEE. Citado nas páginas $8,33,97$, e 160 .

Rossi, R. G., de Andrade Lopes, A., de Paulo Faleiros, T., e Rezende, S. O. (2014a). Inductive model generation for text classification using a bipartite heterogeneous network. Journal of Computer Science and Technology, 3(29):361-375. Citado nas páginas 8, 23, 97, 230, e 270.

Rossi, R. G., de Andrade Lopes, A., e Rezende, S. O. (2015a). Optimization and label propagation in bipartite heterogeneous networks to improve transductive classification of texts (in press). Information Processing 85 Management. Citado nas páginas 9, 16, 152, e 192. 
Rossi, R. G., Lopes, A. A., e Rezende, S. O. (2014b). A parameter-free label propagation algorithm using bipartite heterogeneous networks for text classification. In Proceedings of the Symposium on Applied Computing, páginas 79-84. ACM. Citado nas páginas 9, 16, 33, 115, 146, e 192.

Rossi, R. G., Marcacini, R. M., e Rezende, S. O. (2013). Benchmarking text collections for classification and clustering tasks. Relatório Técnico 395, Institute of Mathematics and Computer Sciences, University of Sao Paulo. Citado nas páginas 11, 155, 227, 266, e 270.

Rossi, R. G. e Rezende, S. O. (2011a). Building a topic hierarchy using the bag-of-related-words representation. In Symposium on Document Engineering. ACM. Citado nas páginas 20, 54, e 55 .

Rossi, R. G. e Rezende, S. O. (2011b). Generating features from textual documents through association rules. In Anais do Encontro Nacional de Inteligência Artificial. SBC. Citado nas páginas 20 e 55 .

Rossi, R. G., Rezende, S. O., e de Andrade Lopes, A. (2015b). Term network approach for transductive classification. In International Conference on Intelligent Text Processing and Computational Linguistics, páginas 497-515. Citado nas páginas 10, 16, 135, 142, 191, 192, 198, e 230.

Rousseeuw, P. J. e Leroy, A. M. (1987). Robust regression and outlier detection. John Wiley \& Sons, Inc. Citado na página 230.

Ráez, A. M. e López, L. A. U. (2006). Selection strategies for multi-label text categorization. In Proceedings of the International Conference on Advances in Natural Language Processing, volume 4139 of Lecture Notes in Computer Science, páginas 585-592. Springer. Citado na página 62.

Saberi, A., Vahidi, M., e Bidgoli, B. M. (2007). Learn to detect phishing scams using learning and ensemble methods. In Proceedings of the International Conferences on Web Intelligence and Intelligent Agent Technology - Workshops, páginas 311-314. IEEE. Citado na página 69.

Salton, G. (1989). Automatic text processing: the transformation, analysis, and retrieval of information by computer. Addison-Wesley series in computer science. Addison-Wesley. Citado nas páginas 3 e 87.

Salton, G., Singhal, A., Mitra, M., e Buckley, C. (1997). Automatic text structuring and summarization. Information Processing \& Management, 33(2):193-207. Citado nas páginas 35,39 , e 40.

Samei, B., Estiagh, M., Keshtkar, F., e Hashemi, S. (2014). Multi-document summarization using graph-based iterative ranking algorithms and information theoretical distortion measures. In Proceedings of the International Florida Artificial Intelligence Research Society Conference, páginas 214-218. Citado na página 39.

Sarkar, A. (2001). Applying co-training methods to statistical parsing. In Proceedings of the North American Chapter of the Association for Computational Linguistics on Language Technologies, páginas 1-8. ACL. Citado na página 119.

Scheffer, T. (2004). Email answering assistance by semi-supervised text classification. Intelligent Data Analysis, 8(5):481-493. Citado na página 196.

Schenker, A., Last, M., Bunke, H., e Kandel, A. (2003). Classification of web documents using a graph model. In Proceedings of the International Conference on Document Analysis and Recognition, páginas 240-244. IEEE. Citado nas páginas xi, 5, 7, 39, 45, 46, 87, e 88. 
Schneider, K.-M. (2005). Techniques for improving the performance of Naive Bayes for text classification. In Proceedings of the Conference onIntelligentTextProcessing andComputationalLinguistics, volume 3406, páginas 682-693. Springer. Citado nas páginas 20, 26, e 271.

Sebastiani, F. (2002). Machine learning in automated text categorization. ACM Computing Surveys, 34(1):1-47. Citado nas páginas 1, 2, 3, 67, 68, 71, 101, e 284.

Seber, G. e Lee, A. (2012). Linear Regression Analysis. Wiley Series in Probability and Statistics. Wiley. Citado na página 230.

Sen, P., Namata, G. M., Bilgic, M., Getoor, L., Gallagher, B., e Eliassi-Rad, T. (2008). Collective classification in network data. AI Magazine, 29(3):93-106. Citado na página 130.

Settles, B. (2012). Active Learning. Synthesis Lectures on Artificial Intelligence and Machine Learning. Morgan \& Claypool Publishers. Citado na página 231.

Shalev-Shwartz, S. e Ben-David, S. (2014). Understanding machine learning: from theory to algorithms. Cambridge University Press. Citado na página 17.

Sharm, G. (2008). Finding patterns in semantic graph formalisms. Tese de Doutorado, Free University of Bozen-Bolzano. Citado na página 5.

Sharma, A., Pujari, A. K., e Paliwal, K. K. (2007). Intrusion detection using text processing techniques with a kernel based similarity measure. Computers \&S Security, 26(7-8):488-495. Citado na página 70.

Shelly, G. e Frydenberg, M. (2009). Web 2.0: concepts and applications. Shelly Cashman. Texere Publishing Limited. Citado na página 1.

Shi, J. e Malik, J. (2000). Normalized cuts and image segmentation. IEEE Transactions on Pattern Analysis and Machine Intelligence, 22(8):888-905. Citado na página 136.

Silva, D. F., Rossi, R. G., Rezende, S. O., e Batista, G. E. D. A. P. A. (2014). Music classification by transductive learning using bipartite heterogeneous networks. In Proceedings of the International Society for Music Information Retrieval Conference, páginas 113-118. Citado nas páginas 12, $16,65,117,146$, e 227.

Silva, T. C. e Zhao, L. (2012). Stochastic competitive learning in complex networks. IEEE Neural Networks and Learning Systems, 23(3):385-398. Citado na página 16.

Sindhwani, V. e Melville, P. (2008). Document-word co-regularization for semi-supervised sentiment analysis. In Proceedings of the International Conference on Data Mining, páginas 1025-1030. IEEE. Citado na página 117.

Sindhwani, V., Niyogi, P., e Belkin, M. (2005). Beyond the point cloud: From transductive to semi-supervised learning. In Proceedings of the International Conference on Machine Learning, páginas 824-831. ACM. Citado na página 93.

Singhal, P. e Bansal, A. (2013). Improved textual cyberbullying detection using data mining. International Journal of Information and Computation Technology, 3(6):569-576. Citado nas páginas 3 e 70.

Sinoara, R. A., Sundermann, C. V., Marcacini, R. M., Domingues, M. A., e Rezende, S. O. (2014). Named entities as privileged information for hierarchical text clustering. In Proceedings of the International Database Engineering \& Applications Symposium, páginas 57-66. ACM. Citado na página 21. 
Soares, M. M., Corso, G., e Lucena, L. S. (2005). The network of syllables in portuguese. Physica A: Statistical Mechanics and its Applications, 355(2-4):678-684. Citado na página 40.

Soares, M. V. B., Prati, R. C., e Monard, M. C. (2008). PreTexT II: Descrição da reestruturação da ferramenta de pré-processamento de textos. Relatório Técnico 333, Instituto de Ciência Mátemáticas e de Computação - USP. Citado na página 269.

Søgaard, A. (2013). Semi-supervised learning and domain adaptation in natural language processing. Synthesis Lectures on Human Language Technologies. Morgan \& Claypool Publishers. Citado na página 3.

Sokolova, M. e Lapalme, G. (2009). A systematic analysis of performance measures for classification tasks. Information Processing \& Management, 45(4):427-437. Citado nas páginas 3 e 284.

Sole, R. V., Corominas, B., Valverde, S., e Steels, L. (2005). Language networks: their structure, function and evolution. Trends in Cognitive Sciences, páginas 1-10. Citado na página 39.

Solé, R. V., Corominas-Murtra, B., Valverde, S., e Steels, L. (2010). Language networks: their structure, function, and evolution. Complexity, 15(6):20-26. Citado na página 16.

Solorio, T., Pérez-Coutiño, M., Montes-y Gémez, M., Villaseñor Pineda, L., e López-López, A. (2004). A language independent method for question classification. In Proceedings of the International Conference on Computational Linguistics, páginas 1374-1380. ACL. Citado na página 70.

Song, M. e Wu, Y.-F. B. (2008). Handbook of research on text and web mining technologies. IGI Publishing. Citado na página 285.

Sra, S., Nowozin, S., e Wright, S. (2012). Optimization for Machine Learning. Neural information processing series. MIT Press. Citado na página 17.

Steedman, M., Osborne, M., Sarkar, A., Clark, S., Hwa, R., Hockenmaier, J., Ruhlen, P., Baker, S., e Crim, J. (2003). Bootstrapping statistical parsers from small datasets. In Proceedings of the European Chapter of the Association for Computational Linguistics, páginas 331-338. ACL. Citado nas páginas 117 e 119.

Steyvers, M. e Tenenbaum, J. B. (2005). The large-scale structure of semantic networks: Statistical analyses and a model of semantic growth. Cognitive Science, 29:41-78. Citado nas páginas 5 e 39 .

Su, L., Yeh, C., Liu, J., Wang, J., e Yang, Y. (2014). A systematic evaluation of the bagof-frames representation for music information retrieval. IEEE Transaction on Multimedia, 16(5):1188-1200. Citado na página 70.

Subramanya, A. e Bilmes, J. (2008). Soft-supervised learning for text classification. In Proceedings of the Conference on Empirical Methods in Natural Language Processing, páginas 1090-1099. ACL. Citado nas páginas 6, 39, 40, e 41.

Subramanya, A. e Talukdar, P. (2014). Graph-based semi-supervised learning. Synthesis Lectures on Artificial Intelligence and Machine Learning. Morgan \& Claypool Publishers. Citado nas páginas 3 e 195.

Sun, A. e Lim, E.-P. (2001). Hierarchical text classification and evaluation. In Proceedings of the International Conference on Data Mining, páginas 521-528. Citado na página 231.

Sun, A., Lim, E.-P., e Ng, W.-K. (2002). Web classification using support vector machine. In Proceedings of the International Workshop on Web Information and Data Management, páginas 96-99. ACM. Citado na página 69. 
Sun, J.-T., Chen, Z., Zeng, H.-J., Lu, Y.-C., Shi, C.-Y., e Ma, W.-Y. (2004). Supervised latent semantic indexing for document categorization. In Proceedings of the Fourth IEEE International Conference on Data Mining, página 535-538. IEEE Computer Society. Citado na página 29.

Sun, Y. e Han, J. (2012). Mining Heterogeneous Information Networks: Principles and Methodologies. Synthesis Lectures on Data Mining and Knowledge Discovery. Morgan \& Claypool Publishers. Citado nas páginas 4, 16, 30, e 35.

Sun, Y. e Han, J. (2013). Mining heterogeneous information networks: a structural analysis approach. ACM SIGKDD Exploration Newsletter, 14(2):20-28. Citado nas páginas 30 e 35.

Sun, Y., Han, J., Zhao, P., Yin, Z., Cheng, H., e Wu, T. (2009a). Rankclus: integrating clustering with ranking for heterogeneous information network analysis. In Proceedings of the International Conference on Extending Database Technology, páginas 565-576. ACM. Citado nas páginas 5, 30,33 , e 36 .

Sun, Y., Tang, J., Han, J., Gupta, M., e Zhao, B. (2010). Community evolution detection in dynamic heterogeneous information networks. In Proceedings of the Workshop on Mining and Learning with Graphs, páginas 137-146. ACM. Citado na página 30.

Sun, Y., Yu, Y., e Han, J. (2009b). Ranking-based clustering of heterogeneous information networks with star network schema. In Proceedings of the International Conference on Knowledge Discovery and Data Mining, páginas 797-806. ACM. Citado nas páginas 34 e 135.

Szummer, M. e Jaakkola, T. (2002). Partially labeled classification with markov random walks. In Advances in Neural Information Processing Systems, volume 14, páginas 945-952. MIT Press. Citado na página 138.

Tan, C., Lee, L., Tang, J., Jiang, L., Zhou, M., e Li, P. (2011). User-level sentiment analysis incorporating social networks. In Proceedings of the ACM International Conference on Knowledge Discovery and Data Mining, páginas 1397-1405. ACM. Citado na página 117.

Tan, C.-M., Wang, Y.-F., e Lee, C.-D. (2002a). The use of bigrams to enhance text categorization. Information Processing and Management, 38(4):529-546. Citado na página 15.

Tan, P.-N., Kumar, V., e Srivastava, J. (2002b). Selecting the right interestingness measure for association patterns. In Proceedings of the International Conference on Knowledge Discovery and Data Mining, páginas 32-41. ACM. Citado nas páginas xv, 55, 56, 57, e 58.

Tan, P.-N., Steinbach, M., e Kumar, V. (2005). Introduction to Data Mining. Addison-Wesley. Citado nas páginas 18, 26, 42, 64, 76, 78, 83, 87, e 100.

Tang, L., Liu, H., Zhang, J., e Nazeri, Z. (2008). Community evolution in dynamic multi-mode networks. In Proceedings of the ACM International Conference on Knowledge Discovery and Data Mining, páginas 677-685. ACM. Citado na página 33.

Tesar, R., Strnad, V., Jezek, K., e Poesio, M. (2006). Extending the single words-based document model: a comparison of bigrams and 2-itemsets. In Proceedings of the Symposium on Document Engineering, páginas 138-146. Citado nas páginas 15 e 20.

Ting, I.-H., Hong, T.-P., e Wang, L. S.-L. (2011). Social Network Mining, Analysis and Research Trends: Techniques and Applications. IGI Global, 1st ${ }^{\mathrm{a}}$ edição. Citado na página 35.

Tomita, J., Nakawatase, H., e Ishii, M. (2004). Graph-based text database for knowledge discovery. In Proceedings of the International Conference on World Wide Web, páginas 454-455. Citado nas páginas 39 e 55 . 
Tong, S. e Koller, D. (2002). Support vector machine active learning with applications to text classification. Journal of Machine Learning Research, 2:45-66. Citado na página 119.

Trawinski, B., Smetek, M., Telec, Z., e Lasota, T. (2012). Nonparametric statistical analysis for multiple comparison of machine learning regression algorithms. Applied Mathematics and Computer Science, 22(4):867-881. Citado nas páginas 105, 163, e 203.

TREC (2013). Text REtrieval Conference data. http://trec.nist.gov/data.html. Último acesso em 6 de Novembro de 2013. Citado nas páginas 266, 267, e 268.

Tsai, M.-F., Tzeng, C.-W., e Chen, A. L. P. (2012). Discovering leaders from social network by action cascade. In Yoneki, E., Frey, D., e Brown, I., editors, Proceedings of the Workshop on Social Network Systems, páginas 1-2. ACM. Citado na página 35.

Tseng, Y.-H., Ho, Z.-P., Yang, K.-S., e Chen, C.-C. (2012). Mining term networks from text collections for crime investigation. Expert Systems with Applications, 39(11):10082-10090. Citado nas páginas 6, 35, 39, 40, 56, e 58 .

Tsur, O., Davidov, D., e Rappoport, A. (2010). Semi-supervised recognition of sarcastic sentences in online product reviews. In Cohen, W. W. e Gosling, S., editors, Proceedings of the International Conference on Web and Social Media, páginas 107-116. The AAAI Press. Citado na página 196.

Turner, V., Gantz, J. F., Reinsel, D., e Minton, S. (2014). The digital universe of opportunities: Rich data and the increasing value of the internet of things. External Publication of IDC (Analyse the Future) Information and Data, páginas 1-10. Citado na página 1.

Ueffing, N., Haffari, G., e Sarkar, A. (2007). Transductive learning for statistical machine translation. In Proceedings of the International Conference on Computational Linguistics, páginas 25-32. ACL. Citado na página 117.

Ur-Rahman, N. e Harding, J. A. (2012). Textual data mining for industrial knowledge management and text classification: A business oriented approach. Expert Systems with Applications, 39(5):4729-4739. Citado na página 1.

Uysal, A. K. e Gunal, S. (2014). The impact of preprocessing on text classification. Information Processing \& Management, 50(1):104-112. Citado nas páginas 20, 21, e 270.

Valejo, A., Valverde-Rebaza, J. C., e de Andrade Lopes, A. (2014). A multilevel approach for overlapping community detection. In Proceedings of the Brazilian Conference on Intelligent Systems, páginas 390-395. Citado na página 36.

Valin, J.-M. e Collings, I. B. (2007). Interference-Normalized least mean square algorithm. IEEE Signal Processing Letters, 14(12):988-991. Citado na página 96.

Valverde-Rebaza, J. C. e de Andrade Lopes, A. (2013). Exploiting behaviors of communities of twitter users for link prediction. Social Network Analysis and Mining, 3(4):1063-1074. Citado na página 36.

Vapnik, V. N. (1998). Statistical learning theory. Wiley, $1^{\mathrm{a}}$ edição. Citado nas páginas 75 e 123.

Vapnik, V. N. e Sterin, A. (1977). On structural risk minimization or overall risk in a problem of pattern recognition. Automation and Remote Control, 10(3):1495-1503. Citado na página 125.

Vargas, R. N. P., Moura, M. F., Speranza, E. A., Rodriguez, E., e Rezende, S. O. (2012). The SpatialCIM methodology for spatial document coverage disambiguation and the entity recognition process aided by linguistic techniques. In Geospatial Information and Documents Workshop, alocado em Pacifc-Asia Conference on Knowledge Ddiscovery and Data Mining, páginas 1-12. Citado na página 21. 
Wan, M., Ouyang, Y., Kaplan, L., e Han, J. (2015). Graph regularized meta-path based transductive regression in heterogeneous information network. In Proceedings of the SIAM International Conference on Data Mining, páginas 918-926. SIAM. Citado na página 36.

Wan, X., Yang, J., e Xiao, J. (2007). Towards an iterative reinforcement approach for simultaneous document summarization and keyword extraction. In Proceedings of the Annual Meeting of the Association for Computational Linguistics, páginas 552-559. ACM. Citado nas páginas 33 e 39 .

Wang, C., Danilevsky, M., Liu, J., Desai, N., Ji, H., e Han, J. (2013). Constructing topical hierarchies in heterogeneous information networks. In Proceedings of the IEEE International Conference on Data Mining, páginas 767-776. Citado nas páginas 39 e 41.

Wang, H., Yan, S., Huang, T. S., Liu, J., e Tang, X. (2007). Transductive regression piloted by inter-manifold relations. In Proceedings of the Internation Conference on Machine Learning, volume 227, páginas 967-974. Citado na página 36.

Wang, J., Zeng, H.-J., Chen, Z., Lu, H., Tao, L., e Ma, W.-Y. (2003). ReCoM: reinforcement clustering of multi-type interrelated data objects. In Proceedings of the International Conference on Research and Development in Information Retrieval, páginas 274-281. ACM. Citado na página 33.

Wang, W., Do, D. B., e Lin, X. (2005). Term graph model for text classification. In Proceedings of the International Conference on Advanced Data Mining and Applications, páginas 19-30. Springer. Citado nas páginas 35, 47, 55, 58, 90, e 91.

Wang, Y., Dai, W., e Yuan, Y. (2008). Website browsing aid: A navigation graph-based recommendation system. Decision Support Systems, 45(3):387-400. Citado na página 39.

Wang, Z., Tu, L., Guo, Z., Yang, L. T., e Huang, B. (2014). Analysis of user behaviors by mining large network data sets. Future Generation Computer Systems, 37:429-437. Citado na página 35 .

Weiss, S., Indurkhya, N., e Zhang, T. (2015). Fundamentals of Predictive Text Mining. Texts in Computer Science. Springer, $2^{\mathrm{a}}$ edição. Citado na página 1.

Weiss, S. M., Indurkhya, N., e Zhang, T. (2012). Fundamentals of Predictive Text Mining. Springer. Citado nas páginas 3, 68, 69, 70, e 100.

Weng, S. e Liu, C. (2004). Using text classification and multiple concepts to answer e-mails. Expert Systems with Applications, 26(4):529-543. Citado na página 69.

Weninger, T., Bisk, Y., e Han, J. (2012). Document-topic hierarchies from document graphs. In Proceedings of the ACM International Conference on Information and Knowledge Management, páginas 635-644. ACM. Citado na página 39.

Widrow, B. e Hoff, M. E. (1960). Adaptive switching circuits. In Institute of Radio Engineers, Western Electronic Show and Convention, Convention Record, Part 4, páginas 96-104. Citado nas páginas 95 e 150 .

Wiener, A. W. E. (1995). A neural network approach to topic spotting. In Proceedings of Symposium on Document Analysis and Information Retrieval, páginas 317-332. Citado na página 29.

Willett, P. (2006). The porter stemming algorithm: then and now. Program, 40(3):219-223. Citado na página 269. 
Wilson, A. T. e Chew, P. A. (2010). Term weighting schemes for latent dirichlet allocation. In Proceedings of the Annual Conference of the North American Chapter of the Association for Computational Linguistics, páginas 465-473. ACL. Citado na página 271.

Witten, I. H. e Frank, E. (2005). Data Mining: Practical machine learning tools and techniques. Morgan Kaufmann, $2^{\mathrm{a}}$ edição. Citado nas páginas 23, 101, e 270.

Wu, X., Kumar, V., Ross Quinlan, J., Ghosh, J., Yang, Q., Motoda, H., McLachlan, G. J., Ng, A., Liu, B., Yu, P. S., Zhou, Z.-H., Steinbach, M., Hand, D. J., e Steinberg, D. (2007). Top 10 algorithms in data mining. Knowledge and Information Systems, 14(1):1-37. Citado nas páginas 83 e 86 .

Xia, X., Lo, D., Qiu, W., Wang, X., e Zhou, B. (2014). Automated configuration bug report prediction using text mining. In Proocedings of the Computer Software and Applications Conference, páginas 107-116. IEEE. Citado nas páginas 3 e 70.

Xu, W., Liu, X., e Gong, Y. (2003). Document clustering based on non-negative matrix factorization. In Proceedings of the International Conference on Research and Development in Informaion Retrieval, páginas 267-273. ACM. Citado na página 28.

Xu, X., Yuruk, N., Feng, Z., e Schweiger, T. A. J. (2007). SCAN: a structural clustering algorithm for networks. In Proceedings of the International Conference on Knowledge Discovery and Data Mining, páginas 824-833. ACM. Citado na página 36.

$\mathrm{Xu}$, Z. e King, I. (2015). Introduction to semi-supervised learning. Chapman \& Hall/CRC Machine Learning \& Pattern Recognition. CRC Press. Citado na página 3.

Xue, G.-R., Shen, D., Yang, Q., Zeng, H.-J., Chen, Z., Yu, Y., Xi, W., e Ma, W.-Y. (2004). IRC: An iterative reinforcement categorization algorithm for interrelated web objects. In Proceedings of the International Conference on Data Mining, páginas 273-280. IEEE. Citado nas páginas 16, 33, 36, 130, e 132 .

Xue, G.-R., Xing, D., Yang, Q., e Yu, Y. (2008). Deep classification in large-scale text hierarchies. In Proceedings of the Annual International Conference on Research and Development in Information Retrieval, páginas 619-626. ACM. Citado na página 231.

Yang, B., Sun, J.-T., Wang, T., e Chen, Z. (2009). Effective multi-label active learning for text classification. In Proceedings of the International Conference on Knowledge Discovery and Data Mining, páginas 917-926. ACM. Citado na página 231.

Yang, L., Ji, D., Zhou, G., Nie, Y., e Xiao, G. (2006). Document re-ranking using cluster validation and label propagation. In Proceedings of the ACM International Conference on Information and Knowledge Management, páginas 690-697. ACM. Citado nas páginas 39 e 40.

Yang, Y. e Chute, C. G. (1992). A linear least squares fit mapping method for information retrieval from natural language texts. In Proceedings of the Conference on Computational Linguistics, páginas 447-453. ACL. Citado na página 74.

Yang, Y. e Chute, C. G. (1994). An example-based mapping method for text categorization and retrieval. ACM Transaction on Information Systems, 12(3):252-277. Citado na página 74.

Yang, Y. e Liu, X. (1999). A re-examination of text categorization methods. In Proceedings of the International Conference on Research and Development in Information Retrieval, páginas 42-49. ACM. Citado nas páginas 71, 101, e 285.

Yang, Y. e Pedersen, J. O. (1997). A comparative study on feature selection in text categorization. In Proceedings of the International Conference on Machine Learning, páginas 412-420. Morgan Kaufmann Publishers Inc. Citado nas páginas 25, 269, e 270. 
Yang, Y., Slattery, S., e Ghani, R. (2002). A study of approaches to hypertext categorization. Journal of Intelligent Information Systems, 18(2-3):219-241. Citado na página 69.

Yang, Z., Zhang, L., Yan, J., e Li, Z. (2003). Using association features to enhance the performance of Naïve Bayes text classifier. In Proceedings of the International Conference on Computational Intelligence and Multimedia Applications, páginas 336-341. IEEE. Citado nas páginas 15 e 20.

Yarowsky, D. (1995). Unsupervised word sense disambiguation rivaling supervised methods. In Proceedings of the Annual Meeting on Association for Computational Linguistics, páginas 189-196. ACL. Citado nas páginas 119 e 197.

Yeh, C.-C. M. e Yang, Y.-H. (2012). Supervised dictionary learning for music genre classification. In Proceedings of the International Conference on Multimedia Retrieval, páginas 55:1-55:8. ACM. Citado na página 70.

Yianilos, P. N. (1993). Data structures and algorithms for nearest neighbor search in general metric spaces. In Proceedings of the ACM-SIAM Symposium on Discrete Algorithms, páginas 311-321. Society for Industrial and Applied Mathematics. Citado na página 87.

Yin, D., Xue, Z., Hong, L., Davison, B. D., e Kontostathis, A. (2009a). Detection of harassment on web 2.0. In Proceedings of the Content Analysis in the WEB 2.0, páginas 1-7. Citado nas páginas 3 e 70 .

Yin, Z., Li, R., Mei, Q., e Han, J. (2009b). Exploring social tagging graph for web object classification. In Proceedings of the International Conference on Knowledge Discovery and Data Mining, páginas 957-966. Citado nas páginas 16, 36, 135, 139, e 140.

Yoon, Y. e Lee, G. G. (2008). Text categorization based on boosting association rules. In Proceedings of the IEEE International Conference on Semantic Computing, páginas 136-143. Citado na página 81.

Yu, H., Han, J., e Chang, K. C.-C. (2002). PEBL: positive example based learning for web page classification using SVM. In Proceedings of the International Conference on Knowledge Discovery and Data Mining, páginas 239-248. ACM. Citado na página 69.

Yu, L. e Liu, H. (2004). Efficient feature selection via analysis of relevance and redundancy. Journal of Machine Learning Research, 5:1205 - 1224. Citado na página 19.

Yu, P. S., Han, J., e Faloutsos, C. (2010). Link mining: models, algorithms, and applications. Springer, $1^{\mathrm{a}}$ edição. Citado na página 35.

Zamir, O. e Etzioni, O. (1998). Web document clustering: A feasibility demonstration. In Proceedings of the International Conference on Research and Development in Information Retrieval, páginas 46-54. ACM. Citado na página 15.

Zha, H. (2002). Generic summarization and keyphrase extraction using mutual reinforcement principle and sentence clustering. In Proceedings of the International Conference on Research and Development in Information Retrieval, páginas 113-120. ACM. Citado nas páginas 33 e 39 .

Zha, H., He, X., Ding, C., Simon, H., e Gu, M. (2001). Bipartite graph partitioning and data clustering. In Proceedings of the International Conference on Information and Knowledge Management, páginas 25-32. ACM. Citado nas páginas 33 e 39.

Zhai, Y., Hsu, A., e Halgamuge, S. K. (2007). Combining news and technical indicators in daily stock price trends prediction. In Advances in Neural Networks, páginas 1087-1096. Springer. Citado na página 70. 
Zhai, Z., Liu, B., Xu, H., e Jia, P. (2010). Grouping product features using semi-supervised learning with soft-constraints. In Proceedings of the International Conference on Computational Linguistics, páginas 1272-1280. ACL. Citado na página 117.

Zhang, D. e Lee, W. S. (2003). Question classification using support vector machines. In Proceedings of the International Conference on Research and Development in Informaion Retrieval, páginas 26-32. ACM. Citado nas páginas 20 e 70.

Zhang, J. e Yang, Y. (2003). Robustness of regularized linear classification methods in text categorization. In Proceedings of the International Conference on Research and Development in Information Retrieval, páginas 190-197. ACM. Citado na página 15.

Zhang, T. e J. Oles, F. (2001). Text categorization based on regularized linear classification methods. Information Retrieval, 4(1):5-31. Citado na página 75.

Zhang, W., Yoshida, T., Tang, X., e Wang, Q. (2010). Text clustering using frequent itemsets. Knowledge-Based Systems, 23(5):379-388. Citado na página 55.

Zhang, X. e Zhu, X. (2007). A new type of feature - loose n-gram feature in text categorization. In Proceedings of the Iberian Conference on Pattern Recognition and Image Analysis, páginas 378-385. Springer. Citado nas páginas 15 e 20.

Zheng, R., Qin, Y., Huang, Z., e Chen, H. (2003). Authorship analysis in cybercrime investigation. In Proceedings of the Conference on Intelligence and Security Informatics, páginas 59-73. Springer-Verlag. Citado na página 70.

Zhou, D., Bousquet, O., Lal, T. N., Weston, J., e Schölkopf, B. (2004). Learning with local and global consistency. In Advances in Neural Information Processing Systems, volume 16, páginas 321-328. Citado nas páginas 6, 41, 93, 126, 135, 138, e 271.

Zhou, Y., Cheng, H., e Yu, J. X. (2009). Graph clustering based on structural/attribute similarities. Very Large Data Bases Endowmen, 2(1):718-729. Citado na página 125.

Zhou, Z. e Li, M. (2005). Tri-training: Exploiting unlabeled data using three classifiers. IEEE Transactions on Knowledge and Data Engineering, 17(11):1529-1541. Citado na página 121.

Zhu, X. (2005a). Semi-supervised learning literature survey. Relatório Técnico 1530, Computer Sciences, University of Wisconsin-Madison. Citado na página 134.

Zhu, X. (2005b). Semi-supervised learning with graphs. Tese de Doutorado, Carnegie Mellon University. Citado nas páginas 42, 137, e 272.

Zhu, X., Ghahramani, Z., e Lafferty, J. (2003a). Semi-supervised learning using gaussian fields and harmonic functions. In Proceedings of the International Conference on Machine Learning, páginas 912-919. AAAI Press. Citado nas páginas 6, 41, 126, 135, 137, 138, 144, e 271.

Zhu, X. e Goldberg, A. B. (2009). Introduction to semi-supervised learning. Morgan and Claypool Publishers. Citado nas páginas xii, 3, 76, 118, 119, 120, 124, 125, 135, 136, 137, 195, 198, e 271 .

Zhu, X. e Lafferty, J. (2005). Harmonic mixtures: combining mixture models and graph-based methods for inductive and scalable semi-supervised learning. In Proceedings of the International Conference on Machine learning, páginas 1052-1059. ACM. Citado na página 198.

Zhu, X., Lafferty, J., e Ghahramani, Z. (2003b). Combining active learning and semi-supervised learning using gaussian fields and harmonic functions. In Proceedings of the Workshop on The Continuum from Labeled to Unlabeled Data in Machine Learning and Data Mining, páginas 58-65. Citado na página 231. 



\title{
APÊNDICE
}

\section{Coleções de Textos e Características das Representações Utilizadas nas Avaliações}

\author{
Experimentais
}

A grande maioria dos trabalhos, envolvendo propostas de algoritmos de aprendizado de máquina, métodos de pré-processamento ou representações de coleções de textos, realizam uma avaliação experimental utilizando poucas coleções de textos, geralmente duas ou três coleções. Com esse pequeno número de textos é difícil afirmar que um algoritmo ou método de pré-processamento apresenta melhores resultados que outros utilizados na comparação. Também não é possível realizar uma análise estatística para determinar se a diferença de performance de classificação obtida por diferentes algoritmos ou métodos é estatisticamente significante (Demsar, 2006).

Para avaliar tanto as representações em redes bem como dos algoritmos de aprendizado de máquina baseados em redes propostos nesta tese, foram coletadas, estruturadas, extraídas características e disponibilizadas 45 coleções de documentos textuais. Nas próximas seções serão apresentadas as descrições das coleções de textos, o pré-processamento utilizado para gerar as representações estruturadas, e as características das representações tanto baseadas no modelo espaço-vetorial quanto baseadas em redes.

\section{A.1 Descrição das coleções de texto}

As coleções textuais coletadas são de diferentes domínios e a maioria delas já foi utilizada em outros trabalhos da literatura. Os domínios das coleções utilizadas nas avaliações experimentais dessa tese são: e-mails (EM), documentos médicos (DM), notícias (NO), documentos científicos (DC), análise de sentimentos (AS), documentos da Text 
Retrieval Conference (TREC) e páginas web (PW). A seguir é apresentada uma breve descrição das coleções textuais utilizadas nas avaliações experimentais apresentadas nesta tese $^{12}$ :

\section{E-mails}

20 Newsgroups: coleção composta por mensagens de 20 grupos da Usenet (Rennie, 2008).

Enron-Top-20: coleção derivada do Enron Dataset (Cohen, 2009), a qual é compostas por e-mails organizados em pastas de 150 usuário da Enron Corporation. Foram agrupados os e-mails de pastas cujos rótulos apresentavam o mesmo radical, como federal_legis e federal_legislation. Pastas genéricas, as quais poderiam conter e-mails de diferentes categorias, como contact, sent, inbox, e-mail, attachments e miscellaneous, foram removidas. Após o agrupamento e remoção de pastas, foram selecionadas somente as 20 pastas com maior número de e-mails. SpamAssassin: coleção para testar sistemas de filtro de spam (Apache, 2006). Esta coleção é composta por documentos com os rótulos spam e ham.

Trec7-3000: coleção compostas por e-mails rotulados como spam e ham (Cormack e Lynam, 2007). Foram selecionados 3000 e-mails com o rótulo spam e 3000 com o rótulo ham do conjunto de e-mails original.

\section{Documentos Médicos}

Oh0, Oh5, Oh10, Oh15, Ohscal: coleções que correspondem a subconjuntos da coleção OHSUMED (Forman, 2006; Hersh et al., 1994).

Ohsumed-400: coleção também derivada da coleção OHSUMED. A coleção Ohsumed400 é composta por resumos médicos sobre 23 doenças. Foram selecionados 400 documentos de cada categoria.

Pubmed-Cancer: coleção composta por resumos de artigos médicos sobre 12 tipos de câncer (cólon, pulmão, seios, endométrio, leucemia, pâncreas, próstata, bexiga, tireoide, linfoma não-Hodgkin, rim, melanoma) extraídos da coleção Pubmed ${ }^{3}$.

\section{Notícias}

Foreign Broadcast Information Service (FBIS): coleção composta por notícias coletadas em diversos pontos do mundo (Forman, 2006). A coleção FBIS corresponde a uma subcoleção da coleção TREC (TREC, 2013).

Hitech: composta por notícias sobre computadores, aparelhos eletrônicos, medicina, pesquisa e tecnologia coletadas do jornal San Jose Mercury ${ }^{4}$ (Karypis, 2006). Esta coleção faz parte da coleção TREC (TREC, 2013).

\footnotetext{
${ }^{1}$ Maiores detalhes sobre essas coleções são apresentados em Rossi et al. (2013)

${ }^{2} \mathrm{~A}$ coleções que não possuem referência bibliográfica foram coletadas pelo autor desta tese.

${ }^{3}$ http://www.ncbi.nlm.nih.gov/pubmed

${ }^{4}$ http://www.mercurynews.com/
} 
La1, La2: coleções compostas por notícias do jornal Los Angeles Times e correspondem a subcoleções da coleção TREC-5 (Forman, 2006; TREC, 2013).

New3s: coleção composta por notícias do jornal San Jose Mercury. Corresponde a uma subcoleção das coleções TREC-5, TREC-6 e TREC-7 (Forman, 2006; TREC, 2013).

Reuters Corpus Volume 1 - v2 - Top Four Categories (RCV1 Top-4): notícias extraídas do jornal Reuters ${ }^{5}$ (Lewis, 2005). Foram consideradas apenas as 4 principais categorias da hierarquia de categorias (economics, government/social, corporate/industrial, equity market) e apenas notícias que pertenciam a uma única categoria.

Re0, Re1 e Re8: Re0 e Re1 (Forman, 2006), e Re8 (Pang, 2010) são compostas por artigos da coleção Reuters-21578 (Lewis, 2004).

Reviews: composta por notícias do jornal San Jose Mercury. As noticias são sobre comida, cinema, música, radio e restaurantes (Karypis, 2006).

\section{Documentos Científicos}

Association for Computing Machinery (ACM): composta por anais de conferências disponíveis na $A C M$ Digital Library ${ }^{6}$. Os anais pertencem a 40 conferências de diferentes áreas da Ciência de Computação.

Classic4: composta pela junção das coleções CACM (títulos e resumos de artigos do periódico Communications of the $A C M$ ), CISI (artigos de recuperação de informação), CRANFIELD (artigos da área de aeronáutica) e MEDLINE (artigos médicos) (Data Mining Research, 2010).

Computer Science Technical Reports (CSTR): coleção composta por resumos de relatórios técnicos publicados no Department of Computer Science da University of Rochester ${ }^{7}$ no período de 1991 a 2007. Os documentos são das áreas de processamento de linguagem natual, robótica, sistemas e teoria.

National Science Foundation (NFS): coleção composta por resumos de artigos financiados pela National Science Foundation ${ }^{8}$ entre 1999 e 2003.

\section{Análise de Sentimentos}

Irish Sentiment: composta por artigos rotulados por usuários como positivo, negativo e irrelevante (Group, 2009). Os artigos foram extraídos das fontes irlandesas RTE News, The Irish Times e Irish Independent.

Multi Domaim Sentiment: contém revisões positivas e negativas sobre diferentes produtos da Amazon ${ }^{9}$ (Blitzer et al., 2009).

Opinosis: contém opiniões de usuário de diferentes tópicos, como "Performance

\footnotetext{
${ }^{5}$ http: //www.reuters.com/

${ }^{6}$ http://dl.acm.org/

${ }^{7}$ http://www.cs.rochester.edu/trs/

${ }^{8}$ www.nsf .gov

${ }^{9}$ http: //www . amazon.com/
} 
do Honda Accord 2008" or "Atributos do Windows 7". As fontes das revisões são: (i) Tripadvisor ${ }^{10}$ para tópicos referentes à hotéis; (ii) Edmunds.com ${ }^{11}$ para tópicos referentes à carros; (iii) Amazon.com ${ }^{12}$ para à produtos eletrônicos.

Review Polarity: composta por 1000 revisões positivas e 1000 revisões negativas sobre filmes (Pang e Lee, 2004).

\section{Web Pages}

Dmoz-Business-500, Dmoz-Computers-500, Dmoz-Health-500, Dmoz-Science-500, Dmoz-Sports-500: composta por páginas web extraídas do portal DMOZ - Open Directory Project (Netscape, 2013) das subcategorias das categorias Business, Computers, Health, Science e Sports respectivamente. Foram selecionadas 500 páginas de cada subcategoria.

Industry Sector: composta por páginas web de companhias de vários setores econômicos (Nigam, 2000).

Syskill \& Webert: composta por páginas web sobre bandas, ovelhas, cabras e biomedicina (Pazzani, 1998).

WebACE Project (WAP): composta por páginas web coletadas pelo projeto WebACE (Han et al., 1998; Forman, 2006). As páginas pertencem às categorias do diretório do $Y_{a h o o}{ }^{13}$.

World Wide Knowledge Base (WebKB): composta por páginas web de departamentos de computação de varias universidades coletadas pelo CMU Text Learning Group $^{14}$ em 1997 (CMU Text Learning Group, 1998).

\section{Documentos TREC}

Tr11, Tr31, Tr41, Tr45: subcoleções extraídas das coleções TREC-5, TREC-6 e TREC-7 (Forman, 2006; TREC, 2013). Os documentos são rotulados com as strings de consultas para as quais foram considerados relevantes.

\section{A.2 Geração e Características das Representações no Modelo Espa- ço-Vetorial}

Algumas das coleções coletadas para este projeto de doutorado já se encontravam pré-processadas e representadas no modelo espaço-vetorial. É o caso das coleções FBIS, La1s, La2s, New3s, Oh0, Oh5, Oh10, Oh15, Ohscal, Re0, Re1, Tr11, Tr12, Tr21, Tr23, Tr31, Tr41, Tr45, WAP que pertencem ao conjunto 19MclassTextWc (Forman, 2006). Porém, os passos para geração dessas representações são semelhantes aos utilizados na geração das representações das demais coleções (Han e Karypis, 2000).

\footnotetext{
${ }^{10}$ http: //www.tripadvisor.com/

${ }^{11}$ http: //www. edmunds.com/

${ }^{12} \mathrm{http} / / \mathrm{www}$. amazon.com

${ }^{13}$ http://dir.yahoo.com/

${ }^{14}$ http://www.cs. cmu.edu/afs/cs.cmu.edu/project/theo-4/text-learning/www/index.html
} 
Para as demais coleções, palavras simples foram consideradas como termos, foram removidas as stopwords, as palavras foram radicalizadas, foram removidas tags HTML e cabeçalhos de e-mails, e apenas foram considerados termos com $d f \geq 2$.

Palavras simples foram consideradas como termos uma vez que apresentam um bom custo-benefício entre dimensionalidade e performance de classificação, conforme apresentado no Capítulo 2. Além disso, esse tipo de representação (bag-of-words) vem sendo amplamente utilizado na literatura sobre classificação automática de textos e também permite o emprego de algoritmos de extração de tópicos para agrupar termos semanticamente relacionados e consequentemente gerar uma representação mais compacta.

As stopwords foram removidas considerando como base as listas fornecidas na ferramenta PreText (Soares et al., 2008). Essa ferramenta possui uma lista satisfatória de proposições, artigos, verbos e numerais. Neste projeto foram adicionadas à stoplist da ferramenta PreText stopwords referente ao domínio de artigos científicos como lemma, proof, theorem, symposium, figure, conference e proceedings.

As palavras foram radicalizadas utilizando o algoritmo de Porter (Porter, 1980). Segundo Conrado (2009); Willett (2006), o algoritmo de Porter é simples e muito eficiente para a radicalização de termos. Além disso, de acordo com Joachims (1999), a simplificação de termos geradas pela radicalização gera uma representação mais compacta sem perder muita informação.

As tags HTML aparecem em todas as páginas independentemente da categoria. Portanto, sua remoção tem impacto apenas no número de atributos e não na performance de classificação. Cabeçalhos de e-mail, como remente, ou data de envio também foram removidos uma vez que um mesmo usuário para enviar e-mails sobre diferentes assuntos assim como e-mails sobre diferentes assuntos podem ser enviados na mesma data. Optou-se apenas manter atributos que ocorressem em ao menos dois documentos da coleção de documentos, uma vez que um atributo que ocorra em um único documento não é útil para extrair um padrão e dificilmente será utilizado ou terá influência na classificação de novos exemplos. Além disso, optou-se por não utilizar cortes agressivos utilizando a medida $d f$ uma vez que termos com baixa $d f$ podem ser discriminativos (Yang e Pedersen, 1997) e o corte de muito atributos pode levar a perda de informação (Benbrahim e Bramer, 2009; Joachims, 1998). Além disso, algoritmos de aprendizado de máquina para classificação de textos deve ser eficientes a atributos ruidosos (Feldman e Sanger, 2006).

Optou-se também por não utilizar métodos de seleção de atributos supervisionados pois (i) isso pode introduzir novos problemas, como escolher métodos e número de atributos; (ii) a maioria dos métodos de seleção de atributos eficientes computacionalmente não levam em consideração conjunto de atributos para a análise, fazendo com que possam ser selecionados atributos redundantes e diminuindo o poder discriminativo da representação; (iii) métodos de seleção de atributos supervisionados não apresentariam resultados satisfatório considerando poucos exemplos rotulados, caso das avaliações apresentadas nos Capítulos 4 e 5; e (iv) o corte por $D F$ provê performances de classificação tão boas quanto quanto GI 
ou $\chi^{2}$, além de possuir um custo computacional menor (Yang e Pedersen, 1997).

A medida utilizada para definir o peso dos termos nos documentos foi a $t f$. Esse tipo de medida é mais simples e apresentam bons resultados em comparação com outras medidas mais complexas tanto supervisionadas quanto não supervisionadas. Em Rossi et al. (2014a) é apresentada uma comparação da performance de classificação utilizando $t f$ e outra tradicional medida, $t f-i d f$, na performance de classificação de textos para diferentes coleções e algoritmos de aprendizado de máquina indutivos supervisionados. Observou-se que o uso da medida $t f-i d f$ apresentou uma performance de classificação inferior em relação a medida $t f$ para a maioria das coleções. Isso se deve ao fato que a medida $t f-i d f$ tem maior impacto em algoritmos baseados em distância quando aplicados em coleções com presença de termos como artigos, preposições e verbos, ou outras palavras que deveriam ser consideradas stopwords. Neste caso, seria necessário diminuir o peso desses tipos de termos nas representações das coleções para terem pouco impacto no cálculo das similaridades entre os documentos. Porém, dada uma boa stoplist, este tipo de medida não tem grande impacto na performance de classificação de textos (Uysal e Gunal, 2014; Rossi et al., 2014a). Vale ressaltar que as representações bag-of-words considerando a $t f$ como peso dos termos pode ser diretamente utilizada para gerar as representações em redes bipartidas, uma vez que os pesos das relações nestas redes consideram as frequências dos termos nos documentos.

Na Tabela A.1 são apresentadas as características das representações bag-of-words geradas após aplicar as técnicas de pré-processamento de textos apresentadas anteriormente ${ }^{15}$. Como características das coleções foram consideradas o domínio da coleção (Dom.), o número de documentos $(|\mathcal{D}|)$, número de termos $(|\mathcal{T}|)$, número médio de termos por documento $(|\overline{\mathcal{T}}|)$, número de classes $(|\mathcal{C}|)$, o desvio padrão considerando as porcentagens das classes $(\sigma(\mathcal{C}))$ para medir o nível de balanceamento de classes da coleção, a porcentagem da classe majoritária.

Pode-se observar pela Tabela A.1 que as coleções com suas respectivas representações bag-of-words possuem diferentes características além do domínio. O número de documentos dessas coleções varia de 204 a 685071, o número de termos de 1726 a 153458, o número médio de termos de 6.65 a 720.30, o número de classes de 2 a 51, desvio padrão da porcentagem das classes de 0 a 34.45 e a porcentagem da classe majoritária de 2.70 a 74.36 . As representações bag-of-words das coleções estão disponíveis em formato ARFF (Witten e Frank, 2005) na página web http://sites.labic.icmc.usp.br/text_collections/. Em Rossi et al. (2013) também foram extraídas outras características das coleções além de também estarem disponibilizados resultados obtidos por algoritmos tradicionais de classificação e agrupamento de textos de forma a servir como base para futuras pesquisas ou ainda evitar a reexecução de experimentos por parte da comunidade científica.

Também foi considerada a representação de relações entre termos no modelo espaço-

\footnotetext{
${ }^{15}$ Em http://sites.labic.icmc.usp.br/ragero/thesis/text_categorization_tool/ está disponível uma ferramenta computacional que implementa todos as técnicas de pré-processamento descritas nesta seção.
} 
vetorial. Para tal, foi utilizada a técnica $L D A$, que por meio da extração de tópicos considerando uma representação bag-of-words, produz uma matriz documento-tópico, na qual o tópico corresponde a grupos de palavras semanticamente relacionadas (usualmente palavras com mesmo significado ou palavras coocorrentes). Optou-se por utilizar tópicos para representar relações entre termos uma vez que esse tipo de técnica apresenta maior sucesso do que as técnicas utilizando frases sintáticas ou estatísticas (Schneider, 2005). Além disso, a técnica $L D A$ foi utilizada uma vez que esta é uma das técnicas que vem apresentando melhores resultados e vantagens em relação a outros algoritmos de extração de tópicos, como velocidade, menor número de parâmetros para estimar, e soluções determinísticas (Wilson e Chew, 2010; Blei et al., 2003). As representações baseadas em tópicos foram geradas utilizando a ferramenta Mallet ${ }^{16}$. Essa ferramenta inclui implementações rápidas e escaláveis do método Gibbs Sampling para obter os parâmetros do LDA. Existe também a opção de estimar os parâmetros $\alpha$ e $\beta$ automaticamente.

Foram geradas representações documento-tópico contendo 50, 100, 150 e 200 tópicos (Phan et al., 2008). As maioria das características apresentadas na Tabela A.1 se mantém nas representações documento-tópico. Exceção se dá pelo número de termos, que agora corresponde ao número de tópicos, e ao número médio de termos, que não faz sentido nesse tipo de representação uma vez que as matrizes documento-tópico não são esparsas. As matrizes documento-tópico utilizadas nesta tese estão disponíveis em formato ARFF na página web http://sites.labic.icmc.usp.br/text_collections/topics_LDA/.

\section{A.3 Geração e Características das Representações em Redes}

As representações em redes utilizadas neste projeto de doutorado foram extraídas a partir das representações bag-of-words apresentadas na seção anterior. Nesta seção apresentados os detalhes referentes à geração das redes apresentadas na Seção 2.3.2 e 2.3.3. Essas redes são compostas por um único tipo de relação que pode ser documento-documento, termo-termo ou documento-termo, ou ainda pela combinação dessas relações. Serão apresentadas características das redes contendo um único tipo de relação. Em redes compostas por mais de um tipo de relação, basta apenas combinar as características das relações individuais. As características apresentadas referem-se ao número de objetos e o número médio de conexões, os quais definem a complexidade computacional dos algoritmos. Vale ressaltar que não foram executados experimentos considerando representações em redes para todas as coleções de textos por questões de tempo e consumo de memória, e assim não foram extraídas características para essas coleções.

Para gerar relações do tipo documento-documento, foram consideradas as abordagem Exp e $M-k N N$ (Seção 2.3.2). Essas duas abordagens são comumente usadas em algoritmos de aprendizado de máquina semissupervisionados (Ozaki et al., 2011; Zhu e Goldberg, 2009; Belkin et al., 2006; Zhou et al., 2004; Zhu et al., 2003a). A rede Exp tende a gerar

\footnotetext{
${ }^{16}$ http://mallet.cs.umass.edu/
} 
um grande número de relações entre objetos. Já a rede $M-k N N$ tende a gerar um número menor de relações entre os objetos, além de explorar a questão da mutualidade entre os vizinhos. Portanto, esse dois tipos de redes são contrastantes.

$\mathrm{Na}$ abordagem Exp foram considerados $\sigma=\{0,05 ; 0,20 ; 0,35 ; 0,50\}$. Como os valores da medida de similaridade Cosseno varia entre 0 e 1 , valores de $\sigma$ acima de 1 teriam pouco impacto na definição do peso das relações. Além disso, quanto maior o valor de $\sigma$, menor a diferença entre o valor da similaridade Cosseno e o valor retornado pela função Gaussiana. Foram selecionados 4 valores com intervalos fixos entre eles que empiricamente obtiveram as melhores performances de classificação.

Já na abordagem $M-k N N$, foram considerados $k=\{7,17,37,57\}$. Não foram considerados valores maiores de $k$ uma vez que o objetivo da rede $M k-N N$ é gerar uma rede esparsa para apenas manter as relações mais importantes e ser processada mais rapidamente que as redes não esparsas. Ao aumentar o valor de $k$, menor será a esparsidade da rede, maior será o tempo de processamento, e mais similar será uma rede $M k-N N$ de uma rede Exp. Além disso, segundo Zhu (2005b), as redes $k \mathrm{NN}$ com pequeno valor de $k$ empiricamente produzem performances de classificação satisfatórias.

Na Tabela A.2 são apresentadas as características das redes compostas por relações documento-documento. Vale ressaltar que o número médio de relações é o mesmo nas redes Exp, uma vez que os valores de $\sigma$ alteram apenas o peso das relações. Vale ressaltar também que o número de vizinhos é na rede $M k-N N$ foi sempre menor que $k$, mostrando que dificilmente todos os vizinhos mais próximos dos objetos da rede são mútuos.

$\mathrm{Na}$ geração das relações do tipo termo-termo, foram consideradas as medidas de similaridade Suporte, Informação Mútua, Kappa, Q de Yule e Piatetsky-Shapiro. Também foram consideradas as abordagens Threshold $(\epsilon)$ e TopK $(\kappa)$ para gerar as relações bom base nas medidas de similaridade (Seção 2.3.3). Na abordagem TopK foram considerados $\kappa \in\{7,17,37,57\}$. Os limiares utilizados na abordagem Threshold foram definido considerando a seguinte equação:

$$
\text { threshold }=\epsilon \cdot\left(\Omega_{\max }-\Omega_{\min }\right)+\Omega_{\min }
$$

na qual $\Omega_{\min }$ é o valor de similaridade mínima entre todos os termos, $\Omega_{\max }$ é a similaridade máxima entre dois termos, e foram utilizados valores de $\epsilon \in\{0.00,0.25,0.50,0.75\}$. Com isso, o intervalo de valores de similaridade é dividido em quatro intervalos equidistantes, considerando portanto todas as relações entre termos, e 25\%, 50\% e 75\% das relações mais significativas. As características das redes compostas por relações term-term utilizando as diferentes estratégias de conexão utilizando as medidas Suporte, Informação Mútua, Kappa, Q de Yule e Shapiro são apresentadas respectivamente nas Tabelas A.3, A.4, A.5, A. 6 e A.7.

Vale ressaltar que diferentemente do que ocorre na abordagem $M k-N N$ ao gerar relações do tipo documento-documento, na abordagem TopK o número de relações entre os objetos pode ser maior que $\kappa$. Isso se deve ao fato de que as medidas de similaridades entre os 
termos são baseadas nas ocorrências e coocorrências dos termos, e não na frequência. Com isso, um termo pode apresentar o mesmo valor de similaridade para $z$ outros termos, com $z \geq \kappa$. Neste caso, optou-se por extrapolar o número de conexões em relação à $\kappa$ para considerar todas as relações que apresentem o mesmo valor de similaridade e não ter que descartar conexões igualmente importantes aleatoriamente.

Por fim, na Tabela A.8 são apresentadas as características das redes compostas por relações documento-termo. Vale ressaltar que como mencionado na Seção 2.3.3, não é necessário definir parâmetros para a geração deste tipo de relação. 
Tabela A.1: Características das representações bag-of-words das coleções utilizadas neste projeto de doutorado.

\begin{tabular}{|c|c|c|c|c|c|c|c|}
\hline Coleção & Dom. & $|\mathcal{D}|$ & $|\mathcal{T}|$ & $\overline{|\bar{T}|}$ & $|\mathcal{C}|$ & $\sigma(\mathcal{C})$ & $\max (\mathcal{C})$ \\
\hline $20 \mathrm{ng}$ & $\overline{\mathrm{EM}}$ & 18808 & 45434 & 76.47 & 20 & 0.52 & 5.31 \\
\hline $\mathrm{ACM}$ & CD & 3493 & 60768 & 720.30 & 40 & 0.37 & 3.03 \\
\hline Classic4 & CD & 7095 & 7749 & 35.28 & 4 & 1.94 & 45.16 \\
\hline CSTR & $\mathrm{CD}$ & 299 & 1726 & 54.27 & 4 & 18.89 & 42.81 \\
\hline Dmoz-Business-500 & $\overline{\mathrm{PW}}$ & 18500 & 8303 & 11.93 & 37 & 0.00 & 2.70 \\
\hline Dmoz-Computers-500 & $\overline{\mathrm{PW}}$ & 9500 & 5011 & 10.83 & 19 & 0.00 & 5.26 \\
\hline Dmoz-Health-500 & PW & 6500 & 4217 & 12.40 & 13 & 0.00 & 7.69 \\
\hline Dmoz-Science-500 & $\overline{\mathrm{PW}}$ & 6000 & 4821 & 11.52 & 12 & 0.00 & 9.63 \\
\hline Dmoz-Sports-500 & PW & 13500 & 5682 & 11.87 & 27 & 0.00 & 3.70 \\
\hline Enron-Top-20 & EM & 13199 & 18194 & 50.69 & 20 & 2.37 & 9.63 \\
\hline FBIS & $\mathrm{NO}$ & 2463 & 2001 & 159.24 & 17 & 5.66 & 26.54 \\
\hline Hitech & NO & 2301 & 12942 & 141.93 & 6 & 8.25 & 26.21 \\
\hline Industry-Sector & PW & 8817 & 21490 & 88.49 & 12 & 7.37 & 11.24 \\
\hline Irish_Sentiment & $\mathrm{AS}$ & 1660 & 8659 & 112.65 & 3 & 6.83 & 39.46 \\
\hline La1s & $\mathrm{NO}$ & 3204 & 13196 & 144.64 & 6 & 8.22 & 29.43 \\
\hline La2s & $\mathrm{NO}$ & 3075 & 12433 & 144.83 & 6 & 8.59 & 29.43 \\
\hline Multi_Domaim_Sentiment & $\mathrm{NO}$ & 8000 & 13360 & 42.36 & 2 & 0.00 & 50.00 \\
\hline New3s & $\mathrm{NO}$ & 9558 & 26833 & 234.53 & 44 & 1.32 & 7.28 \\
\hline NFS & $\mathrm{DC}$ & 10524 & 3888 & 6.65 & 16 & 3.82 & 13.39 \\
\hline Oh0 & $\overline{\mathrm{DM}}$ & 1003 & 3183 & 52.50 & 10 & 5.33 & 19.34 \\
\hline Oh10 & $\overline{\mathrm{DM}}$ & 1050 & 3239 & 55.64 & 10 & 4.25 & 15.71 \\
\hline Oh15 & $\mathrm{DM}$ & 913 & 3101 & 59.30 & 10 & 4.27 & 17.20 \\
\hline Oh5 & DM & 918 & 3013 & 54.43 & 10 & 3.72 & 16.23 \\
\hline Ohscal & $\overline{\mathrm{DM}}$ & 11162 & 11466 & 60.39 & 10 & 2.66 & 14.52 \\
\hline Ohsumed-400 & $\mathrm{DM}$ & 9200 & 13512 & 55.15 & 12 & 0.00 & 4.35 \\
\hline Opinosis & $\mathrm{AS}$ & 6457 & 2693 & 7.56 & 51 & 1.42 & 8.18 \\
\hline Pubmed-Cancer & $\overline{\mathrm{DM}}$ & 76876 & 14425 & 98.73 & 12 & 9.22 & 27.07 \\
\hline RCV1 Top-4 & $\mathrm{NO}$ & 685071 & 153458 & 74.61 & 4 & 14.46 & 43.63 \\
\hline $\mathrm{Re} 0$ & $\mathrm{NO}$ & 1504 & 2887 & 51.73 & 13 & 11.56 & 40.43 \\
\hline Re1 & $\mathrm{NO}$ & 1657 & 3759 & 52.70 & 25 & 5.54 & 22.39 \\
\hline Re8 & $\mathrm{NO}$ & 7674 & 8901 & 35.31 & 8 & 18.24 & 51.12 \\
\hline Review Polarity & $\mathrm{AS}$ & 2000 & 15698 & 205.06 & 2 & 0.00 & 50.00 \\
\hline Reviews & NO & 4069 & 22927 & 183.10 & 5 & 12.80 & 34.11 \\
\hline SpamAssassin & EM & 9348 & 97851 & 108.02 & 2 & 34.45 & 74.36 \\
\hline Syskill \& Webert & $\overline{\mathrm{PW}}$ & 334 & 4340 & 93.16 & 4 & 10.75 & 41.02 \\
\hline $\operatorname{Tr} 11$ & TREC & 414 & 6430 & 281.66 & 9 & 9.80 & 31.88 \\
\hline $\operatorname{Tr} 12$ & TREC & 313 & 5805 & 273.60 & 8 & 7.98 & 29.71 \\
\hline $\operatorname{Tr} 21$ & TREC & 336 & 7903 & 469.86 & 6 & 25.88 & 68.75 \\
\hline $\operatorname{Tr} 23$ & TREC & 204 & 5833 & 385.29 & 6 & 15.58 & 44.61 \\
\hline Tr31 & TREC & 927 & 10129 & 268.50 & 7 & 13.37 & 37.97 \\
\hline $\operatorname{Tr} 41$ & TREC & 878 & 7455 & 195.33 & 10 & 9.13 & 27.68 \\
\hline $\operatorname{Tr} 45$ & TREC & 690 & 8262 & 280.58 & 10 & 6.69 & 23.19 \\
\hline Trec7-3000 & EM & 6000 & 100464 & 244.08 & 2 & 0.00 & 50.00 \\
\hline WAP & $\overline{\mathrm{PW}}$ & 1560 & 8461 & 141.33 & 20 & 5.20 & 21.86 \\
\hline WebKB & PW & 8282 & 22892 & 89.78 & 7 & 15.19 & 45.45 \\
\hline
\end{tabular}


Tabela A.2: Número de objetos do tipo documento e número médio de relações do tipo documento-documento para as abordagens $\operatorname{Exp}$ e $M k-N N$.

\begin{tabular}{|c|c|c|c|c|c|c|}
\hline Coleção & $|\mathcal{D}|$ & $\sigma=\{\mathbf{0}, \mathbf{0 5} ; \mathbf{0}, \mathbf{2 0} ; \mathbf{0}, \mathbf{3 5} ; \mathbf{0}, \mathbf{5 0}\}$ & $\mathrm{k}=7$ & $\mathrm{k}=17$ & $\mathrm{k}=\mathbf{3 7}$ & $\mathrm{k}=\mathbf{5 7}$ \\
\hline $20 \mathrm{ng}$ & 18827 & 18827,0000 & 3,6845 & 8,4284 & 18,4853 & 29,1108 \\
\hline $\mathrm{ACM}$ & 3493 & 3491,8259 & 3,4446 & 8,7088 & 20,4128 & 32,4603 \\
\hline Classic4 & 13500 & 5779,5810 & 2,9898 & 7,0470 & 16,2721 & 25,9397 \\
\hline CSTR & 299 & 280,6020 & 4,2542 & 10,6555 & 24,2207 & 38,8361 \\
\hline Dmoz-Business-500 & 18500 & 5153,3901 & 2,9071 & 6,9470 & 16,1851 & 25,9208 \\
\hline Dmoz-Computers-500 & 9500 & 2183,9122 & 2,9221 & 7,1145 & 16,8423 & 27,2107 \\
\hline Dmoz-Health-500 & 6500 & 2357,6563 & 3,0440 & 7,5431 & 17,7326 & 28,7542 \\
\hline Dmoz-Science-500 & 6000 & 1155,1937 & 3,2273 & 8,0440 & 18,8767 & 30,3773 \\
\hline Dmoz-Sports-500 & 13500 & 5779,5810 & 2,9898 & 7,0470 & 16,2721 & 25,9397 \\
\hline Enron-Top-20 & 13199 & 7576,2473 & 3,3139 & 7,3715 & 16,2140 & 25,4671 \\
\hline FBIS & 24630 & 2461,5526 & 3,4397 & 8,5067 & 20,5538 & 33,4576 \\
\hline Hitech & 2301 & 2238,4172 & 3,3751 & 7,9426 & 17,6801 & 28,0130 \\
\hline Industry-Sector & 8817 & 7175,4826 & 3,7788 & 7,5082 & 14,8568 & 22,2892 \\
\hline Irish_Sentiment & 1660 & 1623,1145 & 3,3494 & 8,3060 & 19,1422 & 30,6928 \\
\hline La1s & 3204 & 3198,8901 & 3,2484 & 7,0762 & 15,0936 & 23,6305 \\
\hline La2s & 3075 & 3069,8862 & 3,3652 & 7,5558 & 15,9883 & 24,9054 \\
\hline Multi_Domaim_Sentiment & 8000 & 5292,8100 & 2,4570 & 5,1495 & 11,9162 & 19,4082 \\
\hline New3s & 9558 & 9499,5198 & 3,3388 & 7,9837 & 18,7782 & 30,4419 \\
\hline NFS & 10524 & 886,0226 & 3,3694 & 8,2425 & 18,8120 & 29,6230 \\
\hline Oh0 & 1003 & 889,2562 & 3,2841 & 7,8923 & 18,2532 & 29,6570 \\
\hline Oh10 & 1050 & 971,3029 & 3,4933 & 8,8514 & 20,9238 & 33,9829 \\
\hline Oh15 & 913 & 858,7667 & 3,0712 & 7,0887 & 16,6002 & 27,3122 \\
\hline Oh5 & 918 & 834,8235 & 3,3312 & 8,4379 & 19,8540 & 31,9891 \\
\hline Ohscal & 11162 & 10238,2317 & 2,8495 & 6,3342 & 13,7628 & 21,3702 \\
\hline Ohsumed-400 & 9200 & 8360,4474 & 3,1607 & 6,9709 & 15,0252 & 23,2283 \\
\hline Opinosis & 6457 & 1111,5146 & 2,7579 & 6,6687 & 16,3711 & 26,9717 \\
\hline Pubmed-Cancer & - & - & - & - & - & - \\
\hline RCV1 Top-4 & - & - & - & - & - & - \\
\hline Re0 & 1504 & 1291,2939 & 3,4548 & 8,0771 & 18,3152 & 30,1117 \\
\hline Re1 & 1657 & 1354,3754 & 3,7477 & 9,1285 & 20,4249 & 31,6427 \\
\hline Re8 & 7674 & 7007,6271 & 2,9356 & 6,4251 & 14,0162 & 22,0696 \\
\hline Review Polarity & 2000 & 1998,7110 & 2,4440 & 3,5420 & 6,0610 & 9,4460 \\
\hline Reviews & 4069 & 3954,4468 & 3,0686 & 6,7024 & 14,7599 & 23,9789 \\
\hline SpamAssassin & 9348 & 8997,5807 & 3,4356 & 7,2330 & 15,1795 & 23,8631 \\
\hline Syskill \& Webert & 334 & 277,3353 & 3,0539 & 7,7246 & 22,3234 & 41,1976 \\
\hline Tr11 & 414 & 414,0000 & 3,7343 & 9,4493 & 22,4686 & 36,1304 \\
\hline Tr12 & 313 & 313,0000 & 3,6166 & 8,9329 & 20,1342 & 30,9585 \\
\hline Tr21 & 336 & 336,0000 & 3,2619 & 7,9524 & 19,5179 & 32,0952 \\
\hline $\operatorname{Tr} 23$ & 204 & 204,0000 & 3,5686 & 9,9118 & 23,7059 & 37,8922 \\
\hline Tr31 & 927 & 927,0000 & 3,6181 & 8,6990 & 20,2783 & 32,6775 \\
\hline $\operatorname{Tr} 41$ & 878 & 878,0000 & 3,7084 & 9,3781 & 20,3918 & 31,3599 \\
\hline $\operatorname{Tr} 45$ & 690 & 688,9449 & 3,5681 & 8,8638 & 21,0841 & 32,9130 \\
\hline Trec7-3000 & 6000 & 4726,4287 & 4,0897 & 9,4250 & 20,8487 & 31,6457 \\
\hline WAP & 1560 & 1559,0000 & 3,5833 & 7,7282 & 15,8974 & 23,2795 \\
\hline WebKB & 8282 & 7333,9657 & 2,6407 & 5,3016 & 11,2980 & 17,6264 \\
\hline
\end{tabular}


Tabela A.3: Número de objetos do tipo termo e número de objetos do tipo termo-termo para as abordagens Threshold e TopK utilizando a medida de similaridade Suporte.

\begin{tabular}{|c|c|c|c|c|c|c|c|c|c|}
\hline Coleção & $|\mathcal{T}|$ & $\overline{\epsilon \epsilon=\mathbf{0 . 0}}$ & $\epsilon=\mathbf{0 . 2 5}$ & $\epsilon=\mathbf{0 . 5 0}$ & $\epsilon=\mathbf{0 . 7 5}$ & $\overline{\mathrm{k}=7}$ & $\mathrm{k}=17$ & $\mathrm{k}=\mathbf{3 7}$ & $\mathrm{k}=57$ \\
\hline$\overline{20 \mathrm{ng}}$ & 45433 & 1807,5697 & 0,0011 & 0,0002 & 0,0001 & 339,3072 & 494,9246 & 672,3855 & 7795,0812 \\
\hline $\mathrm{ACM}$ & 60767 & 4140,3117 & 3,3732 & 0,4976 & 0,0474 & 510,3798 & 719,7238 & 953,1248 & 1096,8665 \\
\hline Classic4 & 7748 & 551,0597 & 0,2176 & 0,0209 & 0,0021 & 86,9517 & 152,6503 & 222,1531 & 257,9504 \\
\hline CSTR & 1725 & 321,0012 & 0,7613 & 0,0800 & 0,0127 & $\begin{array}{l}108,6008 \\
\end{array}$ & 167,3546 & 180,2764 & 180,5533 \\
\hline Dmoz-Business-500 & 8302 & 151,7615 & 0,0205 & 0,0039 & 0,0010 & 32,8957 & 54,6510 & 71,7891 & 79,8390 \\
\hline Dmoz-Computers-500 & 5010 & 122,5013 & 0,0515 & 0,0084 & 0,0012 & 31,2836 & 51,0447 & 65,3269 & 69,5406 \\
\hline Dmoz-Health-500 & 4216 & 119,6666 & 0,0360 & 0,0047 & 0,0009 & 32,6865 & 52,1669 & 64,3609 & 69,6026 \\
\hline Dmoz-Science-500 & 4820 & 113,9137 & 0,0353 & 0,0041 & 0,0017 & 39,4256 & 58,5103 & 68,5542 & 69,2699 \\
\hline Dmoz-Sports-500 & 5681 & 118,2643 & 0,0222 & 0,0046 & 0,0011 & 26,7666 & 40,7110 & 51,6084 & 59,0178 \\
\hline Enron-Top-20 & 18193 & 2312,0011 & 0,1416 & 0,0089 & 0,0021 & 403,7102 & 604,6386 & 826,2408 & 972,3834 \\
\hline FBIS & 2000 & 1796,6087 & 1,2364 & 0,0610 & 0,0100 & 21,5977 & 94,7976 & 244,0550 & 359,3368 \\
\hline Hitech & 12941 & 1650,0366 & 0,3418 & 0,0165 & 0,0006 & 244,4338 & 442,4799 & 658,1468 & 768,3108 \\
\hline Industry-Sector & 21489 & 1986,1162 & 0,1089 & 0,0096 & 0,0013 & 288,0371 & 466,1289 & 651,9483 & 771,5951 \\
\hline Irish Sentiment & 8658 & 1136,8225 & 0,0889 & 0,0049 & 0,0007 & 181,4637 & 331,8268 & 486,8979 & 572,4242 \\
\hline La1s & 13195 & 2425,2711 & 0,0150 & 0,0035 & 0,0009 & 224,5844 & 479,3378 & 765,8058 & 939,4501 \\
\hline La2s & 12432 & 2375,3791 & 0,0161 & 0,0037 & 0,0010 & 211,6335 & 468,7777 & 752,5254 & 924,1560 \\
\hline Multi Domaim Sentiment & 13359 & 905,0720 & 0,0320 & 0,0034 & 0,0009 & 164,1096 & 293,0684 & 425,7272 & 480,2760 \\
\hline New3s & 26832 & 5815,1019 & 0,1634 & 0,0075 & 0,0010 & 1478,1801 & 2006,8258 & 2348,9655 & 2519,5563 \\
\hline NFS & 3887 & 66,1312 & 0,0005 & 0,0005 & 0,0005 & 24,2094 & 33,4450 & 36,0275 & 36,1952 \\
\hline Oh0 & 3183 & 487,6808 & 0,1301 & 0,0101 & 0,0013 & 123,2557 & 215,9428 & 270,7983 & 276,2369 \\
\hline Oh10 & 3238 & 514,0012 & 0,2563 & 0,0185 & 0,0043 & 122,5437 & 224,8923 & 286,7471 & 299,8052 \\
\hline Oh15 & 3100 & 528,4979 & 0,3476 & 0,0445 & 0,0097 & 118,4599 & 214,0090 & 273,3837 & 285,9381 \\
\hline Oh5 & 3012 & 491,7405 & 0,2549 & 0,0186 & 0,0033 & 121,4876 & 205,3657 & 259,5752 & 265,3024 \\
\hline Ohscal & 11465 & 963,8547 & 0,0604 & 0,0052 & 0,0005 & 105,5981 & 195,4249 & 299,6514 & 369,4266 \\
\hline Ohsumed-400 & - & - & - & - & - & - & - & . & - \\
\hline Opinosis & 2692 & 87,3435 & 0,0349 & 0,0119 & 0045 & 28,5897 & 41,7527 & 46,0063 & 46,7423 \\
\hline Pubmed-Cancer & - & - & - & - & - & - & - & - & - \\
\hline$\overline{R C V 1 \text { Top-4 }}$ & - & - & - & - & - & - & - & - & - \\
\hline$\overline{\mathrm{Re} 0}$ & 2886 & 779,1874 & 0,3381 & 0,0208 & 0,0035 & \begin{tabular}{|l|}
112,2691 \\
\end{tabular} & 237,3561 & 367,2335 & 416,5133 \\
\hline Re1 & 3758 & 698,9923 & 0,4916 & 0,0442 & 0,0059 & 115,9194 & 228,8827 & 322,1681 & 345,3381 \\
\hline Re8 & 8900 & 566,5795 & 0,0173 & 0,0034 & 0,0007 & 83,3087 & 151,9423 & 221,8643 & 257,0189 \\
\hline Review Polarity & 15697 & 2000,8847 & 0,0943 & 0,0070 & 0,0006 & \begin{tabular}{|l|}
246,7379 \\
\end{tabular} & 474,5950 & 742,1270 & 906,4104 \\
\hline Reviews & 22926 & 2439,9969 & 474 & 0,0122 & 0,0012 & 270,4620 & 511,3256 & 794,7742 & 967,6744 \\
\hline SpamAssassin & 97850 & 571,7040 & 0,0580 & 0,0029 & 0,0003 & 63,3707 & 119,8063 & 186,2197 & 226,7312 \\
\hline Syskill Webert & 4339 & 931,1000 & 0,3779 & 0,0253 & 0,0009 & 356,2159 & 530,3272 & 590,6876 & 595,5562 \\
\hline Tr11 & 6429 & 3955,3471 & 0,3260 & 0,0258 & 0,0065 & 545,7236 & 1039,9820 & 1525,0589 & 1739,2705 \\
\hline Tr12 & 5804 & 3427,1318 & 0,3394 & 0,0314 & 0,0072 & 582,5046 & 1135,8405 & 1624,0954 & 1770,9376 \\
\hline Tr21 & 7902 & 5757,4972 & 1,8725 & 0,0630 & 0,0048 & \begin{tabular}{|l|}
610,4880 \\
\end{tabular} & 1331,0511 & 1961,3826 & 2256,6723 \\
\hline $\operatorname{Tr} 23$ & 5832 & 4851,8687 & 0,4159 & 0,0319 & 0,0038 & 827,3235 & 1819,0756 & 2494,4785 & 2578,7122 \\
\hline Tr31 & 10128 & 4716,7245 & 0,1027 & 0,0065 & 0,0004 & \begin{tabular}{|l|}
482,5211 \\
\end{tabular} & 1046,7558 & 1615,5971 & 1940,1516 \\
\hline $\operatorname{Tr} 41$ & 7454 & 2756,4791 & 0,1197 & 0,0097 & 0,0008 & \begin{tabular}{|l|}
367,2994 \\
\end{tabular} & \begin{tabular}{|l|}
716,6779 \\
\end{tabular} & 1087,7989 & 1271,5390 \\
\hline Tr45 & 8261 & \begin{tabular}{|l}
4018,9768 \\
\end{tabular} & 0,2927 & 0,0194 & 0,0027 & \begin{tabular}{|l|}
533,1325 \\
\end{tabular} & \begin{tabular}{|l|}
1030,6928 \\
\end{tabular} & \begin{tabular}{|l|}
1630,1305 \\
\end{tabular} & 1965,9745 \\
\hline Trec7 3000 & 100463 & 5577,6077 & $0.0051:$ & 0,0003 & 0,0002: & 2252,7850 & 2729,0638 & 3290,7504 & 3372,1281 \\
\hline WAP & 8460 & 1371,8532 & 0,1279 & 0,0596 & 0,0496 & \begin{tabular}{|l}
173,5947 \\
\end{tabular} & 362,8474 & 540,7754 & 614,9866 \\
\hline WebKB & 22891 & 2341,2688 & 0,0195 & 0,0023 & 0,0004 & 412,5385 & 655,8669 & 890,1634 & 1030,5527 \\
\hline
\end{tabular}


Tabela A.4: Número de objetos do tipo termo e número de objetos do tipo termo-termo para as abordagens Threshold e TopK utilizando a medida de similaridade Informação Mútua.

\begin{tabular}{|c|c|c|c|c|c|c|c|c|c|}
\hline Coleção & $|\mathcal{T}|$ & $\epsilon=\mathbf{0 . 0}$ & $\epsilon=\mathbf{0 . 2 5}$ & $\epsilon=\mathbf{0 . 5 0}$ & $\epsilon=\mathbf{0 . 7 5}$ & $\overline{\mathrm{k}=7}$ & $\mathrm{k}=17$ & $\bar{k}=37$ & $\mathrm{k}=57$ \\
\hline$\overline{20 \mathrm{ng}}$ & 45433 & 1807,5697 & 0,0002 & 20,0001 & 0,0001 & 7,8365 & 17,1301 & 33,5041 & 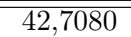 \\
\hline $\mathrm{ACM}$ & 60767 & 4140,3117 & 0,0049 & 0,0013 & 0,0002 & 2,0790 & 3,7411 & 7,7627 & 11,8390 \\
\hline Classic4 & 7748 & 551,0597 & 0,0070 & 0,0008 & 0,0003 & 1,4224 & 2,3615 & 4,6055 & 6,9862 \\
\hline CSTR & 1725 & 321,0012 & 1,0568 & 0,0417 & 0,0058 & 2,9519 & 7,6512 & 19,0429 & 29,3088 \\
\hline Dmoz-Business-500 & 8302 & 151,7615 & 0,0108 & 0,0014 & 0,0005 & 1,2133 & 1,6129 & 2,4751 & 3,3063 \\
\hline Dmoz-Computers-500 & 5010 & 122,5013 & 0,0036 & 0,0008 & 0,0008 & 1,3251 & 1,8396 & 2,9212 & 3,9234 \\
\hline Dmoz-Health-500 & 4216 & 119,6666 & 0,0237 & 0,0028 & 0,0009 & 1,2288 & 1,5653 & 2,3604 & 3,1501 \\
\hline Dmoz-Science-500 & 4820 & 113,9137 & 0,0228 & 0,0012 & 0,0004 & 1,2956 & 1,8758 & 2,7805 & 3,5005 \\
\hline$\overline{\text { Dmoz-Sports-500 }}$ & 5681 & 118,2643 & 0,0042 & 0,0011 & 0,0004 & 1,2283 & 1,7191 & 2,6964 & 3,6457 \\
\hline Enron-Top-20 & 18193 & 2312,0011 & 0,0095 & 0,0022 & 0,0013 & 10,9300 & 13,5328 & 17,7894 & 20,6804 \\
\hline FBIS & 2000 & 1796,6087 & 0,0900 & 0,0150 & 0,0090 & 1,0015 & 1,0320 & 1,2199 & 1,5177 \\
\hline Hitech & 12941 & 1650,0366 & 0,0059 & 0,0009 & 0,0005 & 1,7349 & 3,4113 & 8,0491 & 14,1260 \\
\hline Industry-Sector & 21489 & 1986,1162 & 0,0008 & 0,0001 & 0,0001 & 4,2279 & 6,3236 & 10,1977 & 13,6267 \\
\hline Irish_Sentiment & 8658 & 1136,8225 & 0,0120 & 0,0016 & 0,0005 & 1,6401 & 3,2898 & 8,1243 & 13,6319 \\
\hline La1s & 13195 & 2425,2711 & 0,0021 & 0,0005 & 0,0005 & 1,3453 & 2,4153 & 6,1640 & 11,3321 \\
\hline La2s & 12432 & 2375,3791 & 0,0021 & 0,0005 & 0,0005 & 1,1849 & 1,9839 & 5,0725 & 9,9369 \\
\hline Multi_Dom & 13359 & 905,0720 & 0,0015 & 0,0003 & 0,0001 & 1,8262 & 3,7749 & 8,0100 & 12,3901 \\
\hline New3s & 26832 & 5815,1019 & 0,0051 & 0,0010 & 0,0002 & 1,1450 & 1,3196 & 2,6976 & 4,8201 \\
\hline NFS & 3887 & 66.1312 & 0,0005 & 0,0005 & 0,0005 & 1,1173 & 1,3930 & 1,9866 & 2,4519 \\
\hline$\overline{\text { Oh0 }}$ & 3183 & 487,6808 & 0,0408 & 0,0088 & 0,0013 & 1,7229 & 3,9874 & 10,3676 & 17,3987 \\
\hline Oh10 & 3238 & 514,0012 & 0,0494 & 0,0025 & 0,0006 & 1,5128 & 2,9781 & 7,0627 & 12,0250 \\
\hline Oh15 & 3100 & 528,4979 & 0,0187 & 0,0006 & 0,0006 & 1,5779 & 3,6346 & 9,9668 & 16,8455 \\
\hline Oh5 & 3012 & 491,7405 & 0,2363 & 0,0325 & 0,0073 & 2,0724 & 5,0651 & 13,3120 & 22,3024 \\
\hline Ohscal & 11465 & 963,8549 & 0,0237 & 0,0028 & 0,0012 & 1,0836 & 1,3984 & 2,4869 & 3,8825 \\
\hline Ohsumed-400 & - & - & - & - & - & - & - & - & - \\
\hline Opinosis & 2692 & 87,3435 & 0,0111 & 0,0037 & 0,0015 & 1,2213 & 1,7118 & 2,7542 & 3,5496 \\
\hline Pubmed-Cancer & - & - & - & - & - & - & - & - & - \\
\hline$\overline{R C V 1 ~ T o p-4}$ & - & - & - & - & - & - & - & - & - \\
\hline $\mathrm{Re} 0$ & 2886 & 779,1874 & 0,1198 & 0,0208 & 0,0021 & 1,2778 & 2,1725 & 4,9882 & 9,0287 \\
\hline$\overline{R e 1}$ & 3758 & 698,9923 & 0,0638 & 0,0074 & 0,0027 & 1,3770 & 2,6675 & 7,0162 & 12,7526 \\
\hline$\overline{\operatorname{Re} 8}$ & 8900 & 566,5795 & 0,0063 & 0,0016 & 0,0004 & 1,2368 & 1,7635 & 3,2465 & 4,9885 \\
\hline Review Polarity & 15697 & 2000,8847 & 0,0312 & 0,0025 & 0,0004 & 1,4945 & 3,0516 & 8,1082 & 14,3470 \\
\hline$\overline{\text { Reviews }}$ & 22926 & 2439,9969 & 0,0688 & 0,0041 & 0,0004 & 1,3713 & 2,4833 & 5,9703 & 10,5088 \\
\hline SpamAssassin & 97850 & 571,7040 & 0,0161 & 0,0010 & 0,0001 & 0,3213 & 0,5818 & 1,3989 & 2,4623 \\
\hline Syskill Webert & 4339 & 931,1000 & 0,0442 & 0,0088 & 0,0018 & 11,7035 & 26,3664 & 58,5138 & 89,9541 \\
\hline Tr11 & 6429 & 3955,3471 & 0,0320 & 0,0040 & 0,0022 & 3,4843 & 8,6737 & 25,0947 & 46,9082 \\
\hline Tr12 & 5804 & 3427,1318 & 0,0296 & 0,0041 & 0,0014 & 6,5654 & 14,1159 & 37,5905 & 65,4560 \\
\hline Tr21 & 7902 & 5757,4972 & 0,3047 & 0,0218 & 0,0084 & 2,9870 & 5,9943 & 17,6768 & 33,3532 \\
\hline$\overline{T r} 23$ & 5832 & 4851,8687 & 38,1450 & 0,0192 & 0,0062 & 4,3595 & 6,5659 & 23,0067 & 58,3151 \\
\hline Tr31 & 10128 & 4716,7245 & 0,0334 & 0,0061 & 0,0006 & 3,2230 & 4,4328 & 11,4884 & 22,1607 \\
\hline$\overline{T r} 41$ & 7454 & 2756,4791 & 0,0673 & 0,0199 & 0,0070 & 2,8207 & 5,7882 & 15,8773 & 30,3150 \\
\hline $\operatorname{Tr} 45$ & 8261 & 4018,9768 & 0,0448 & 0,0140 & 0,0046 & 1,8222 & 4,7669 & 15,3000 & 29,9776 \\
\hline Trec7_3000 & 100463 & 5577,6077 & 0,0072 & 0,0004 & 0,0001 & 1032,1034 & 1204,8738 & 1372,2752 & 1453,9826 \\
\hline WAP & 8460 & 1371,8532 & 0,0045 & 0,0007 & 0,0005 & 11,7834 & 13,5686 & 19,8290 & 27,8581 \\
\hline WebKB & 22891 & 2341,2688 & 0,0031 & 0,0018 & 0,0004 & 1,7672 & 3,7281 & 11,2140 & 20,6567 \\
\hline
\end{tabular}


Tabela A.5: Número de objetos do tipo termo e número de objetos do tipo termo-termo para as abordagens Threshold e TopK utilizando a medida de similaridade Kappa.

\begin{tabular}{|c|c|c|c|c|c|c|c|c|c|}
\hline Coleção & $|\mathcal{T}|$ & $\epsilon=\mathbf{0 . 0}$ & $\epsilon=\mathbf{0 . 2 5}$ & $\epsilon=\mathbf{0 . 5 0}$ & $\epsilon=\mathbf{0 . 7 5}$ & $\mathrm{k}=7$ & $\mathrm{k}=17$ & $\mathrm{k}=37$ & $\mathrm{k}=57$ \\
\hline$\overline{\overline{20 n g}}$ & 445433 & 1807,5697 & $\overline{189,1778}$ & $\overline{56,1477}$ & $\overline{111,0947}$ & $\overline{177,6090}$ & 31,1293 & $\overline{444,2748}$ & $\overline{50,4781}$ \\
\hline $\mathrm{ACM}$ & 60767 & 4140,3117 & 793,2177 & 32,1061 & 1,3626 & 4,5346 & 7,1407 & 13,5875 & 19,8455 \\
\hline Classic4 & 7748 & 551,0597 & 25,0546 & 1,0401 & 0,0679 & 1,6988 & 3,0467 & 5,8608 & 8,6562 \\
\hline CSTR & 1725 & 321,0012 & 111,9282 & 7,0313 & 0,5180 & 3,7868 & 9,7654 & 22,1530 & 33,0771 \\
\hline Dmoz-Business-500 & 8302 & 151,7615 & 5,2150 & 0,3148 & 0,0258 & 1,2622 & 1,7230 & 2,6418 & 3,4837 \\
\hline Dmoz-Computers-500 & 5010 & 122,5013 & 2,6601 & 0,3357 & 0,0367 & 1,3941 & 2,0255 & 3,2203 & 4,4197 \\
\hline Dmoz-Health-500 & 4216 & 119,6666 & 4,0123 & 0,4330 & 0,0427 & 1,2239 & 1,4838 & 2,0749 & 2,7410 \\
\hline$\overline{\text { Dmoz-Science-500 }}$ & 4820 & 113,9137 & 4,0357 & 0,4704 & 0,0407 & 1,3842 & 1,9056 & 2,8195 & 3,4922 \\
\hline Dmoz-Sports-500 & 5681 & 118,2643 & 5,0500 & 0,3449 & 0,0563 & 1,3317 & 1,9020 & 3,1778 & 4,3113 \\
\hline Enron-Top-20 & 18193 & 2312,0011 & 369,7701 & 93,6160 & 32,1901 & 11,7050 & 16,6848 & 26,6146 & 34,3765 \\
\hline FBIS & 2000 & 1796,6087 & 1796,6027 & 875,7061 & 0,2579 & 1,0005 & 1,0090 & 1,0795 & 1,2074 \\
\hline Hitech & 12941 & 1650,0366 & 540,7461 & 8,2357 & 0,3248 & 2,7963 & 5,4691 & 13,3153 & 21,7277 \\
\hline Industry-Sector & 21489 & 1986,1162 & 72,5643 & 13,8383 & 3,5285 & 5,4750 & 8,5057 & 12,9523 & 16,2425 \\
\hline Irish_Sentiment & 8658 & 1136,8225 & 117,2493 & 7,4032 & 0,2615 & 2,5436 & 5,2764 & 11,6010 & 17,9805 \\
\hline La1s & 13195 & 2425,2711 & 2425,0059 & 5,3806 & 0,2305 & 2,3794 & 5,4160 & 12,7481 & 21,0859 \\
\hline La2s & 12432 & 2375,3791 & 2375,2623 & 8,2204 & 0,1317 & 1,6875 & 3,5142 & 9,7117 & 17,3999 \\
\hline Multi_Domaim_Sentiment & 13359 & 905,0720 & 35,7295 & 2,3743 & 0,3183 & 2,9921 & 6,0121 & 11,5041 & 16,3615 \\
\hline New3s & 26832 & 5815,1019 & 5815,0916 & 72,3757 & 7,5269 & 1,2968 & 1,0537 & 1,1955 & 1,4764 \\
\hline NFS & 3887 & 66,1312 & 1,8657 & 0,3230 & 0,0885 & 1,1301 & 1,4200 & 2,0329 & 2,5792 \\
\hline Oh0 & 3183 & 487,6808 & 31,3874 & 0,6466 & 0,0415 & 2,1769 & 5,2180 & 12,3761 & 19,4345 \\
\hline Oh10 & 3238 & 514,0012 & 50,6107 & 0,5940 & 0,0475 & 1,6780 & 3,1395 & 6,5520 & 10,3853 \\
\hline Oh15 & 3100 & 528,4979 & 372,1483 & 1,1093 & 0,0484 & 1,8736 & 4,6904 & 11,9016 & 19,0310 \\
\hline Oh5 & 3012 & 491,7405 & 77,4995 & 0,7388 & 0,0418 & 2,7985 & 6,9857 & 16,4109 & 25,6193 \\
\hline Ohscal & 11465 & 963,8549 & 14,9834 & 0,2674 & 0,0413 & 1,1543 & 1,5893 & 2,7261 & 4,1872 \\
\hline Ohsumed-400 & - & - & - & - & - & 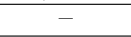 & - & - & - \\
\hline Opinosis & 2692 & 87,3435 & 5,2648 & 0,6937 & 0,1916 & 1,2603 & 1,7360 & 2,6937 & 3,5499 \\
\hline Pubmed-Cancer & - & - & - & - & - & - & - & - & - \\
\hline RCV1 Top-4 & - & - & - & - & - & - & - & - & - \\
\hline Re0 & 2886 & \begin{tabular}{|l|}
779,1874 \\
\end{tabular} & 150,0769 & 2,8355 & 0,1614 & 1,6256 & 2,9425 & 6,1063 & 9,8060 \\
\hline Re1 & 3758 & 698,9923 & 98,1011 & 1,8787 & 0,2187 & 1,8377 & 4,0684 & 9,7635 & 15,8984 \\
\hline Re8 & 8900 & 566,5795 & 464,6168 & 3,3697 & 0,4492 & 1,4334 & 2,3705 & 4,3250 & 6,2107 \\
\hline Review_Polarity & 15697 & 2000,8847 & 44,9554 & 2,6826 & 0,3067 & 2,2717 & 5,0752 & 12,5045 & 20,3324 \\
\hline Reviews & 22926 & 2439,9969 & 522,9492 & 7,2264 & 0,3306 & 2,1822 & 4,7128 & 11,1148 & 17,9948 \\
\hline SpamAssassin & 97850 & 571,7040 & 122,5297 & 1,6932 & 0,0775 & 0,5113 & 1,1042 & 2,6042 & 4,2163 \\
\hline Syskill_Webert & 4339 & 931,1000 & 826,9392 & 72,1498 & 5,7046 & 19,4583 & 42,0219 & 78,3251 & 105,7048 \\
\hline Tr11 & 6429 & 3955,3471 & 3955,3431 & 3041,9462 & 30,3863 & 8,1890 & 32,4465 & 97,9523 & 157,5574 \\
\hline Tr12 & 5804 & 3427,1318 & 3427,1287 & 2461,6565 & 55,7233 & 16,1218 & 40,4022 & 98,6303 & 153,7137 \\
\hline Tr21 & 7902 & 5757,4972 & 5757,4615 & 5524,7466 & 80,3404 & 4,7758 & 18,4427 & 72,6338 & 132,8292 \\
\hline Tr23 & 5832 & 4851,8687 & 4851,0046 & 2818,2637 & 145,7446 & 6,3424 & 35,0081 & 171,7631 & 312,0465 \\
\hline Tr31 & 10128 & 4716,7245 & 4716,7142 & 2745,6156 & 31,9220 & 4,8780 & 17,1944 & 53,8818 & 92,8533 \\
\hline $\operatorname{Tr} 41$ & 7454 & 2756,4791 & 2756,4571 & 1459,0444 & 1,5705 & 5,6362 & 17,4547 & 46,4376 & 75,7422 \\
\hline Tr45 & 8261 & 4018,9768 & 4018,9257 & 1030,6110 & 10,1995 & 4,8367 & 21,7603 & 65,8618 & 108,7605 \\
\hline Trec7_3000 & 100463 & 5577,6077 & 4672,7780 & 2100,7955 & 1408,4957 & 1033,4751 & 1253,6577 & 1451,3733 & 1589,2538 \\
\hline WAP & 8460 & 1371,8532 & 1371,8525 & \begin{tabular}{|l|}
152,4189 \\
\end{tabular} & 1,8530 & 2,9006 & 6,7587 & 17,0403 & 29,6099 \\
\hline WebKB & \begin{tabular}{|l|}
22891 \\
\end{tabular} & 2341,2688 & 256,9482 & 17,1530 & 0,7068 & 3,7095 & 9,0906 & 29,3976 & 48,9868 \\
\hline
\end{tabular}


Tabela A.6: Número de objetos do tipo termo e número de objetos do tipo termo-termo para as abordagens Threshold e TopK utilizando a medida de similaridade Q de Yule.

\begin{tabular}{|c|c|c|c|c|c|c|c|c|c|}
\hline Coleção & $\overline{|\mathcal{T}|}$ & $\overline{\bar{t} \epsilon=\mathbf{0 . 0}}$ & $\epsilon=0.25$ & $\overline{\epsilon \epsilon=\mathbf{0 . 5 0}}$ & $\epsilon=\mathbf{0 . 7 5}$ & $\overline{k=7}$ & $\overline{\mathrm{k}=17}$ & $\overline{\mathrm{k}=37}$ & $\overline{\mathrm{k}=57}$ \\
\hline$\overline{20 n g}$ & 45433 & 1807,5697 & $\mid 1803,8693$ & 1749,5917 & 1480,2515 & 48,9400 & 59,3157 & 64,6619 & 66,1788 \\
\hline$\overline{\mathrm{ACM}}$ & 60767 & 4140,3117 & 4049,6465 & 3358,5692 & 2055,4004 & 89,6229 & 106,1477 & 131,7849 & 153,4293 \\
\hline Classic4 & 7748 & 551,0597 & 546,1616 & 498,3058 & 341,6454 & 2,6130 & 4,9424 & 9,1243 & 12,9459 \\
\hline CSTR & 1725 & 321,0012 & 316,8076 & 277,4844 & 178,2028 & 6,4090 & 13,7202 & 26,0898 & 35,8436 \\
\hline Dmoz-Business-500 & 8302 & 151,7615 & 149,6175 & 135,0786 & 102,5420 & 1,6328 & 2,3655 & 3,4095 & 4,2660 \\
\hline Dmoz-Computers-500 & 5010 & 122,5013 & 120,6997 & 109,5294 & 84,0327 & 1,7737 & 2,6883 & 4,1521 & 5,2093 \\
\hline Dmoz-Health-500 & 4216 & 119,6666 & 117,7078 & 106,5369 & 81,1283 & 1,3704 & 1,6884 & 2,2848 & 2,6950 \\
\hline Dmoz-Science-500 & 4820 & 113,9137 & 112,7621 & 105,2823 & 84,3962 & 1,4549 & 1,9280 & 2,5561 & 3,0180 \\
\hline Dmoz-Sports-500 & 5681 & 118,2643 & 115,2714 & 102,8578 & 77,2415 & 1,6536 & 2,5257 & 3,9534 & 5,0264 \\
\hline Enron-Top-20 & 18193 & 2312,0011 & 2309,5073 & 2291,3448 & 2189,0826 & 203,9580 & 211,8052 & 228,0047 & 244,2865 \\
\hline FBIS & 2000 & 1796,6087 & 1746,6087 & 1469,6072 & 694,2579 & 1,0060 & 1,0175 & 1,1054 & 1,2534 \\
\hline Hitech & 12941 & 1650,0366 & 1637,2505 & 1459,0198 & 915,0400 & 7,1708 & 12,4925 & 24,2116 & 35,9396 \\
\hline Industry-Sector & 21489 & 1986,1162 & 1983,2911 & 1931,2111 & 1613,9509 & 14,4757 & 17,4140 & 21,2367 & 23,9119 \\
\hline Irish_Sentiment & 8658 & 1136,8225 & 1127,4420 & 998,3448 & 629,0687 & 4,6759 & 8,8605 & 18,0055 & 26,8023 \\
\hline La1s & 13195 & 2425,2711 & 2417,4924 & 2267,9460 & 1490,1641 & 5,1269 & 9,5604 & 19,8522 & 30,2049 \\
\hline La2s & 12432 & 2375,3791 & 2365,7135 & 2197,7790 & 1406,6098 & 4,4977 & 7,1853 & 14,5927 & 23,3209 \\
\hline Multi_Domaim_Sentiment & 13359 & 905,0720 & 902,8964 & 866,4271 & 680,4829 & 5,9290 & 9,6174 & 15,8144 & 20,8777 \\
\hline New3s & 26832 & 5815,1019 & 5798,8691 & 5614,5721 & 4559,1025 & 9,0701 & 9,8321 & 11,6029 & 13,3254 \\
\hline NFS & 3887 & 66,1312 & 65,4455 & 61,4779 & 51,0905 & 1,3436 & 1,6700 & 2,2310 & 2,6211 \\
\hline Oh0 & 3183 & 487,6808 & 481,4860 & 421,7474 & 268,3676 & 2,5649 & 6,2463 & 13,8992 & 20,9742 \\
\hline Oh10 & 3238 & 514,0012 & 506,3322 & 434,1451 & 265,9784 & 2,1019 & 4,5304 & 9,5952 & 13,9966 \\
\hline Oh15 & 3100 & 528,4979 & 521,9665 & 451,3789 & 273,7298 & 2,1193 & 5,7340 & 14,0135 & 21,5111 \\
\hline Oh5 & 3012 & 491,7405 & 484,7222 & 419,4909 & 258,6684 & 4,0763 & 9,9708 & 22,0219 & 31,9715 \\
\hline Ohscal & 11465 & 963,8549 & 944,4087 & 785,9702 & 459,0870 & 1,3471 & 2,0693 & 3,8598 & 5,8131 \\
\hline Ohsumed-400 & - & - & - & - & - & - & - & - & - \\
\hline Opinosis & 2692 & 87,3435 & 86,5600 & 81,8076 & 67,6079 & 2,0787 & 2,5952 & 3,4534 & 4,1136 \\
\hline Pubmed-Cancer & - & - & - & - & - & - & - & - & - \\
\hline RCV1 Top-4 & - & - & - & - & - & - & - & - & - \\
\hline Re0 & 2886 & 779,1874 & 773,3273 & 719,9591 & 506,6360 & 1,8393 & 3,3793 & 6,6536 & 9,8580 \\
\hline Re1 & 3758 & 698,9923 & 693,6685 & 633,5238 & 423,7973 & 2,4453 & 6,4568 & 15,2596 & 23,6268 \\
\hline Re8 & 8900 & 566,5795 & 562,5496 & 539,2547 & 435,4538 & 4,5976 & 7,3846 & 12,5170 & 16,8237 \\
\hline Review_Polarity & 15697 & 2000,8847 & 1979,6263 & 1671,7016 & 949,5500 & 3,8954 & 6,9889 & 14,8279 & 22,7830 \\
\hline Reviews & 22926 & 2439,9969 & 2414,8031 & 2154,9851 & 1371,4611 & 3,8215 & 7,8949 & 17,6677 & 27,4992 \\
\hline SpamAssassin & 97850 & 571,7040 & 565,8010 & 504,9243 & 321,3405 & 0,8954 & 1,8498 & 4,1396 & 6,4432 \\
\hline Syskill_Webert & 4339 & 931,1000 & 929,4576 & 908,1387 & 782,8535 & 45,7530 & 75,3272 & 112,7283 & 138,1244 \\
\hline $\operatorname{Tr} 11$ & 6429 & 3955,3471 & 3949,7002 & 3901,2547 & 3478,7695 & 12,4201 & 50,4835 & 118,8630 & 181,5073 \\
\hline $\operatorname{Tr} 12$ & 5804 & 3427,1318 & 3422,3611 & 3367,8522 & 2935,9869 & 49,7051 & 98,5945 & 185,3402 & 259,9099 \\
\hline $\operatorname{Tr} 21$ & 7902 & 5757,4972 & 5746,7298 & 5691,5480 & 5211,3754 & 11,3252 & 32,3977 & 88,1839 & 146,1535 \\
\hline $\operatorname{Tr} 23$ & 5832 & 4851,8687 & 4841,6136 & 4809,2553 & 4572,4612 & 131,5522 & 209,8688 & 374,4442 & 519,3557 \\
\hline Tr31 & 10128 & 4716,7245 & 4705,9876 & 4602,7211 & 4033,7658 & 8,7155 & 27,7128 & 73,8579 & 122,6928 \\
\hline $\operatorname{Tr} 41$ & 7454 & 2756,4791 & 2744,9698 & 2607,9345 & 1895,1772 & 9,9054 & 31,5180 & 78,0251 & 122,0071 \\
\hline $\operatorname{Tr} 45$ & 8261 & 4018,9768 & 4007,9511 & 3891,7323 & 3183,4725 & 12,8345 & 39,2665 & 99,5626 & 157,0490 \\
\hline Trec7_3000 & 100463 & 5577,6077 & 5570,2659 & 5526,8335 & $5372,4984-$ & 1768,1390 & 1844,5226 & 1962,9361 & 2044,6621 \\
\hline WAP & 8460 & 1371,8532 & 1359,5225 & 1217,8724 & 782,6262 & 14,4063 & 20,6356 & 33,7331 & 46,0760 \\
\hline WebKB & 22891 & 2341,2688 & 2338,7097 & 2290,1081 & 1986,9209 & 12,6315 & 18,8123 & 41,4116 & 61,9232 \\
\hline
\end{tabular}


Tabela A.7: Número de objetos do tipo termo e número de objetos do tipo termo-termo para as abordagens Threshold e TopK utilizando a medida de similaridade Piatetsky-Shapiro.

\begin{tabular}{|c|c|c|c|c|c|c|c|c|c|}
\hline Coleção & $|\mathcal{T}|$ & $\epsilon=\mathbf{0 . 0}$ & $\epsilon=\mathbf{0 . 2 5}$ & $\epsilon=\mathbf{0 . 5 0}$ & $\epsilon=\mathbf{0 . 7 5}$ & $\mathrm{k}=7$ & $\mathrm{k}=17$ & $\mathrm{k}=\mathbf{3 7}$ & $\mathrm{k}=57$ \\
\hline $20 \mathrm{ng}$ & 45433 & 1807,5697 & 0,0007 & 0,0001 & $\begin{array}{ll}0,0000 \\
\end{array}$ & 6,6848 & 20,8280 & 51,8189 & $\begin{array}{l}74,9770 \\
\end{array}$ \\
\hline $\mathrm{ACM}$ & 60767 & 4140,3117 & 4139,1711 & 0,0224 & 0,0012 & 1,2963 & 2,2273 & 5,9867 & 11,6007 \\
\hline Classic4 & 7748 & 551,0597 & 551,0471 & 0,2279 & 0,0044 & 1,2991 & 3,0764 & 10,0005 & 19,8171 \\
\hline CSTR & 1725 & 321,0012 & 313,6906 & 0,3453 & 0,0081 & 2,1275 & 9,0400 & 33,3679 & 59,5359 \\
\hline Dmoz-Business-500 & 8302 & 151,7615 & 151,7608 & 151,7278 & 0,0053 & 1,4836 & 4,3495 & 11,5429 & 17,2182 \\
\hline Dmoz-Computers-500 & 5010 & 122,5013 & 0,1389 & 0,0048 & 0,0012 & 1,5570 & 4,5586 & 12,0245 & 18,3119 \\
\hline Dmoz-Health-500 & 4216 & 119,6666 & 119,2331 & 0,0541 & 0,0057 & 1,7380 & 5,3557 & 13,8395 & 20,1304 \\
\hline Dmoz-Science-500 & 4820 & 113,9137 & 1,6967 & 0,0087 & 0,0008 & 1,7436 & 5,7069 & 14,6679 & 21,8218 \\
\hline Dmoz-Sports-500 & 5681 & 118,2643 & 0,0954 & 0,0046 & 0,0007 & 1,5016 & 4,4565 & 11,6522 & 17,0824 \\
\hline Enron-Top-20 & 18193 & 2312,0011 & 35,2590 & 0,0147 & 0,0031 & 4,0005 & 11,6602 & 24,7172 & 40,2567 \\
\hline FBIS & 2000 & 1796,6087 & 1796,6027 & 1790,1049 & 0,0380 & 1,2114 & 2,2594 & 5,7536 & 10,4888 \\
\hline Hitech & 12941 & 1650,0366 & 1650,0079 & 0,0671 & 0,0009 & 1,4947 & 3,9557 & 13,7930 & 27,3749 \\
\hline Industry-Sector & 21489 & 1986,1162 & 0,0627 & 0,0007 & 0,0001 & 2,5755 & 7,5601 & 16,7245 & 27,0357 \\
\hline Irish_Sentiment & 8658 & 1136,8225 & 1136,5827 & 0,0571 & 0,0012 & 1,4319 & 4,0654 & 14,1029 & 28,0574 \\
\hline La1s & 13195 & 2425,2711 & 2425,2667 & 0,0388 & 0,0009 & 1,5224 & 3,1441 & 10,6095 & 23,3634 \\
\hline La2s & 12432 & 2375,3791 & 2375,3754 & 0,0470 & 0,0010 & 1,2657 & 2,6323 & 9,9597 & 22,7104 \\
\hline Multi_Domaim_Sentiment & 13359 & 905,0720 & 0,2689 & 0,0007 & 0,0001 & 1,3860 & 3,5144 & 11,7296 & 23,6619 \\
\hline New3s & 26832 & 5815,1019 & 5815,0978 & 0,2497 & 0,0013 & 9,7620 & 31,9871 & 73,8761 & 113,2249 \\
\hline NFS & 3887 & 66,1312 & 0,0005 & 0,0005 & 0,0005 & 1,9280 & 5,2760 & 10,6073 & 14,6211 \\
\hline Oh0 & 3183 & 487,6808 & 486,0013 & 0,0641 & 0,0019 & 1,7345 & 5,6830 & 20,4251 & 41,3610 \\
\hline Oh10 & 3238 & 514,0012 & 513,8617 & 0,1698 & 0,0031 & 1,8314 & 5,7027 & 19,2847 & 37,6311 \\
\hline Oh15 & 3100 & 528,4979 & 528,4908 & 9,9413 & 0,0297 & 1,6201 & 5,5879 & 19,7498 & 39,5540 \\
\hline Oh5 & 3012 & 491,7405 & 491,7345 & 20,9207 & 0,0531 & 1,7660 & 5,9250 & 21,6074 & 43,5184 \\
\hline Ohscal & 11465 & 963,8549 & 963,8493 & 0,2609 & 0,0021 & 1,2546 & 2,5519 & 7,2623 & 13,6406 \\
\hline Ohsumed-400 & - & - & - & - & - & - & - & - & - \\
\hline Opinosis & 2692 & 87,3435 & 87,2908 & 0,0149 & 0,0052 & 1,9035 & 5,5693 & 12,6476 & 18,0371 \\
\hline Pubmed-Cancer & - & - & - & - & - & - & - & - & - \\
\hline RCV1 Top-4 & - & - & - & - & - & - & - & - & - \\
\hline $\operatorname{Re} 0$ & 2886 & 779,1874 & 778,9983 & 0,3055 & 0,0097 & 1,4087 & 3,5670 & 11,5449 & 22,8334 \\
\hline Re1 & 3758 & 698,9923 & 698,9561 & 0,3650 & 0,0080 & 1,6566 & 4,5478 & 14,5994 & 28,6906 \\
\hline $\operatorname{Re} 8$ & 8900 & 566,5795 & 566,4435 & 0,0103 & 0,0018 & 1,4726 & 3,4161 & 9,9981 & 18,4520 \\
\hline Review Polarity & 15697 & 2000,8847 & 4,0066 & 0,0050 & 0,0003 & 1,2353 & 2,8102 & 10,1577 & 21,1171 \\
\hline Reviews & 222926 & 2439,9969 & 2439,8895 & 0,1690 & 0,0014 & 1,2231 & 2,6119 & 8,4541 & 17,7776 \\
\hline SpamAssassin & 97850 & 571,7040 & 571,6788 & 0,0396 & 0,0003 & 0,2866 & 0,6120 & 1,9808 & 4,1654 \\
\hline Syskill \& Webert & 4339 & 931,1000 & \begin{tabular}{|l|}
930,8894 \\
\end{tabular} & 0,4258 & 0,0124 & 8,1809 & 30,2380 & 84,2438 & 140,8060 \\
\hline Tr11 & 6429 & 3955,3471 & 3955,3437 & 3951,9076 & 0,0230 & 6,2722 & 23,4760 & 62,4757 & 90,5196 \\
\hline $\operatorname{Tr} 12$ & 5804 & 3427,1318 & 3427,1294 & 3426,1209 & 0,0389 & 5,2634 & 20,8727 & 47,4360 & 73,0090 \\
\hline $\operatorname{Tr} 21$ & 7902 & 5757,4972 & 5757,4625 & 3919,3003 & 0,0944 & 5,8914 & 19,5636 & 53,9679 & 78,6427 \\
\hline $\operatorname{Tr} 23$ & 5832 & 4851,8687 & 4851,4133 & 563,4212 & 0,0295 & 3,2090 & 7,2757 & 19,2241 & 43,0463 \\
\hline Tr31 & 10128 & 4716,7245 & 4716,7160 & 83,2659 & 0,0107 & 3,4280 & 10,5455 & 34,2903 & 60,1310 \\
\hline $\operatorname{Tr} 41$ & 7454 & 2756,4791 & 2756,4614 & 329,8109 & 0,0413 & 5,3693 & 16,4605 & 43,3590 & 69,9842 \\
\hline $\operatorname{Tr} 45$ & 8261 & 4018,9768 & 4018,9523 & 88,8775 & 0,0242 & 2,4241 & 10,9127 & 35,1140 & 61,8316 \\
\hline Trec7_3000 & 100463 & 5577,6077 & 151,9095 & 0,0029 & 0,0002 & 1160,4247 & 1260,6692 & 1403,4413 & 1490,6881 \\
\hline WAP & 8460 & 1371,8532 & 1371,8527 & 1371,8459 & 0,0262 & 8,6203 & \begin{tabular}{|l|}
11,3223 \\
\end{tabular} & 22,2386 & 37,9900 \\
\hline WebKB & 22891 & 2341,2688 & 0,4205 & 0,0037 & 0,0024 & 2,1759 & 7,1699 & 23,5953 & 42,4756 \\
\hline
\end{tabular}


Tabela A.8: Número de objetos do tipo documento, número de objetos do tipo termo e número médio de relações do tipo documento-termo.

\begin{tabular}{|c|c|c|c|}
\hline Coleção & $|\mathcal{D}|$ & $|\mathcal{T}|$ & $\overline{|\bar{R}|}$ \\
\hline $20 \mathrm{ng}$ & 18828 & 245433 & 776,39 \\
\hline $\mathrm{ACM}$ & 3493 & 60767 & 720,31 \\
\hline Classic4 & 7095 & 7748 & 35,28 \\
\hline CSTR & 299 & 1725 & 54,31 \\
\hline Dmoz-Business-500 & 18500 & 8302 & 11,92 \\
\hline Dmoz-Computers-500 & 9500 & 5010 & 10,83 \\
\hline Dmoz-Health-500 & 6500 & 4216 & 12,39 \\
\hline Dmoz-Science-500 & 6000 & 4820 & 11,52 \\
\hline Dmoz-Sports-500 & 13500 & 5681 & 11,87 \\
\hline Enron-Top-20 & 13199 & 18193 & 50,69 \\
\hline FBIS & 2463 & 2000 & 159,71 \\
\hline Hitech & 2301 & 12941 & 141,93 \\
\hline Industry-Sector & 8817 & 21489 & 88,48 \\
\hline Irish_Sentiment & 1660 & 8658 & 112,64 \\
\hline La1s & 3204 & 13195 & 144,64 \\
\hline La2s & 3075 & 12432 & 144,82 \\
\hline Multi_Domaim_Sentiment & 8000 & 13359 & 42,36 \\
\hline New3s & 9558 & 26832 & 234,53 \\
\hline NFS & 10524 & 3887 & 6,55 \\
\hline Oh0 & 1003 & 3182 & 52,51 \\
\hline Oh10 & 1050 & 3238 & 55,64 \\
\hline Oh15 & 913 & 3100 & 59,30 \\
\hline Oh5 & 918 & 3012 & 54,43 \\
\hline Ohscal & 11162 & 11465 & 60,41 \\
\hline Ohsumed-400 & 9200 & 13511 & 55,14 \\
\hline Opinosis & 6457 & 2692 & 7,55 \\
\hline Pubmed-Cancer & 65991 & 28328 & 71,20 \\
\hline RCV1 Top-4 & 685071 & 153457 & 74,61 \\
\hline Re0 & 1504 & 2886 & 51,73 \\
\hline Re1 & 1657 & 3758 & 52,70 \\
\hline $\operatorname{Re} 8$ & 7674 & 8900 & 35,31 \\
\hline Review Polarity & 2000 & 15697 & 205,06 \\
\hline Reviews & 4069 & 22926 & 183,14 \\
\hline SpamAssassin & 9348 & 97850 & 108,01 \\
\hline Syskill \& Webert & 334 & 4339 & 93,16 \\
\hline $\operatorname{Tr} 11$ & 414 & 6429 & 281,67 \\
\hline $\operatorname{Tr} 12$ & 313 & 5804 & 273,61 \\
\hline $\operatorname{Tr} 21$ & 336 & 7902 & 469,86 \\
\hline $\operatorname{Tr} 23$ & 204 & 5832 & 385.33 \\
\hline Tr31 & 927 & 10128 & 268,50 \\
\hline $\operatorname{Tr} 41$ & 878 & 7454 & 195,34 \\
\hline $\operatorname{Tr} 45$ & 690 & 8261 & 280,58 \\
\hline Trec7-3000 & 6000 & 100463 & 244,08 \\
\hline WAP & 1560 & 8460 & 141,33 \\
\hline WebKB & 8282 & 22891 & 89,78 \\
\hline
\end{tabular}





\section{APENNDICE}

\section{Critérios de Avaliação de Performance de Classificação}

A performance de classificação pode ser estimada utilizando um conjunto de documentos denominados documentos de teste. No caso da classificação indutiva, tanto supervisionada quanto semissupervisionada, o conjunto de documentos de teste corresponde a um conjunto de documentos rotulados que não foram utilizados no processo de indução de um modelo de classificação. Já no caso da transdução, os documentos de teste são considerados como documentos não rotulados no processo de aprendizado. Em ambos os casos, são ocultados os rótulos dos documentos de teste, estes são submetidos aos classificadores e no final do processo de classificação, os rótulos atribuídos pelo classificador são comparados com os rótulos reais dos documentos de teste para estimar a performance de classificação.

Para comparar os resultados das avaliações experimentais realizadas nos Capítulos 3, 4 e 5, foi utilizada a medida $F 1$ para avaliar a performance de classificação dos algoritmos. Essa medida corresponde à uma média harmônica simples das medidas Precisão e Revocação, ou seja,

$$
F 1=2 * \frac{\text { Precisão } * \text { Revocação }}{\text { Precisãa }+ \text { Revocação }} .
$$

Nesta tese, tanto a Precisão quanto a Revocação foram calculadas considerando o cenário de avaliação multiclasse, isto é, a coleção de documentos é composta por duas ou mais classes e cada documento é rotulado com uma única classe. Para tal, é preciso calcular as medidas Precisão e Revocação para cada classe $c_{i} \in \mathcal{C}$. A Precisão e Revocação para uma classe $c_{i}$ são dadas respectivamente por

$$
\operatorname{Precis}_{\tilde{a} o_{c_{i}}}=\frac{V P_{c_{i}}}{V P_{c_{i}}+F P_{c_{i}}}
$$




$$
\operatorname{Revocação~}_{c_{i}}=\frac{V P_{c_{i}}}{V P_{c_{i}}+F N_{c_{i}}},
$$

na qual $V P_{c_{i}}$ (verdadeiros positivos) representa o número de documentos de teste que foram corretamente atribuídos à classe $c_{i}, F P_{c_{i}}$ (falsos positivos) representa o número de documentos de teste de uma classe $c_{j}\left(c_{j} \neq c_{i}\right)$ mas atribuídos à classe $c_{i}$, e $F N_{c_{i}}$ (falsos negativos) representa o número de documentos de teste da classe $c_{i}$ mas rotulados com uma classe $c_{j}\left(c_{j} \neq c_{i}\right)$. A Precisão retorna a porcentagem de documentos corretamente rotulados pelo classificador como $c_{i}$ em relação a todos os documentos de teste que foram rotulados pelo classificador como $c_{i}$, enquanto que a Revocação retorna a porcentagem de documentos corretamente rotulados pelo classificador como $c_{i}$ em relação a todos os documentos de teste que pertencem a classe $c_{i}$.

A Precisão e Revocação são complementares uma à outra. Por exemplo, considere 100 documentos de uma classe $c_{i}$ e 100 documentos da classe $c_{j}$. Se um classificador atribuir corretamente apenas um único exemplo a classe $c_{i}$, têm-se Precisão ${ }_{c_{i}}=1 \mathrm{e}$ Revocação $=0,01$. Por outro lado, se um classificador atribuir todos os exemplos de teste à uma única classe $c_{i}$, têm-se Revocaçã $o_{c_{i}}=1$ e Precisão $=0.5$.

Existem basicamente duas estratégias para sumarizar os resultados da Precisão e Revocação para todas as classes da coleção: Micro-Averaging e Macro-Averaging. Na estratégia Micro-Averaging é calculada a soma dos termos individuais de cada uma das medidas. Portanto, os valores de Precisão e Revocação de acordo com a estratégia MicroAveraging são dados por (Sokolova e Lapalme, 2009; Manning et al., 2008; Sebastiani, 2002):

$$
\operatorname{Precis} \tilde{a} O^{\text {Micro }}=\frac{\sum_{c_{i} \in \mathcal{C}} V P_{c_{i}}}{\sum_{c_{i} \in \mathcal{C}}\left(V P_{c_{i}}+F P_{c_{i}}\right)},
$$

$\mathrm{e}$

$$
\text { Revocaçãao }{ }^{\text {Micro }}=\frac{\sum_{c_{i} \in \mathcal{C}} V P_{c_{i}}}{\sum_{c_{i} \in \mathcal{C}}\left(V P_{c_{i}}+F N_{c_{i}}\right)} .
$$

Na estratégia Macro-Averaging é calculada a média dos valores de Precisão e Revocação considerando todas as classes da coleção. Portanto, a Precisão e a Revocação utilizando a estratégia Macro-Averaging são dadas por:

$$
\text { Precisão }{ }^{\text {Macro }}=\frac{\sum_{c_{i} \in \mathcal{C}} \text { Precisão }_{c_{i}}}{|\mathcal{C}|}
$$

e

$$
\text { Revocação }{ }^{\text {Macro }}=\frac{\sum_{c_{i} \in \mathcal{C}} \operatorname{Revocação~}_{c_{i}}}{|\mathcal{C}|}
$$

Na estratégia Micro-Averaging é dado o mesmo peso para cada documento e essa 
estratégia pode ser considera como uma média por documentos. Portanto, os valores obtidos por essa estratégia são dominados pelos valores de $V P_{c_{i}}$ das classes majoritárias, ou seja, classificadores que rotulem corretamente mais documentos das classes majoritárias apresentarão melhor performance de classificação segundo a estratégia Micro-Averaging. Por outro lado, na estratégia Macro-Averaging é dado o mesmo peso para cada categoria e essa estratégia pode ser considerada uma média das categorias. Portanto, nessa estratégia é enfatizada a correta classificação dos exemplos de classes minoritárias Yang e Liu (1999).

As estratégias Micro-Averaging e Macro-Averaging resultam em diferentes valores para Precisão e Revocação e são complementares uma à outra (Song e Wu, 2008). A medida $F^{1}$ calculada considerando os valores de Precisão e Revocação obtidos pela estratégia Micro-Averaging será denotada por $F 1^{\text {Micro }}$ e quando considerada a estratégia Macro-Averaging será denotada por $F 1^{\text {Macro }}$. 